71 


\section{LIBRARY}

STATE TEACHERB COLLHGK

SANTA BAREARA. CALIFORNIA 5558 





\title{
GRAY'S BOTANICAL TEXT-BOOK
}

\author{
Volume I.
}

8TRUCTURAL BOTANY. 


\title{
GRAY'S BOTANICAL TEXT-BOOK
}

\author{
Covsists or
}

Doz. I. Structural Botant. By Asa Gray.

II. Physrological Botant. By George L. Goodale.

III. Introduction to Cryptogamic Botany, both Structural and Systematic. By William G. FARLOW. (In preparation.)

IV. Sketch of the Natural Orders of Phanogamous Plasts; their Special Morphology, Useful Products, \&c. (In preparation.) 
GRAY'S BOTANICAL TEXT-BOOK.

(SIXTH EDITION.)

VoL. I.

\section{STRUCTURAL BOTANY,}

OR

ORGANOGRAPHY ON THE BASIS OF

MORPHOLOGY.

TO WHICH IS ADDED THE PRINCIPLES OF

TAXONOMY AND PHYTOGRAPHY,

AND

A Blossary of Batanical Terms.

BY

ASA GRAY, LL.D., ETC., FISHER PROFESSOR " OF NATURAL HISTORY (BOTANY) II HARVARD UNIVERSITY.

NEW YORK • : • CINCINNATI •:• CHICAGO

AMERICAN BOOK COMPANY 


\section{GRAY'S BOTANICAL SERIES}

Gray's How Plants Grow

Gray's How Plants Behave

Gray's Lessons in Botany

Gray's Field, Forest, and Garden Botany

(Flora only)

Gray's School and Field Book of Botany

(Lessons and Flora)

Gray's Manual of Botany. (Flora only)

Gray's Lessons and Manual of Botany

Gray's Botanical Text-Book

I. Gray's Structural Botany

II. Goodale's Physiological Botany

Coulter's Manual of Botany of the Rocky Mountains

Gray and Coulter's Text-Book of Western Botany

Copyright, 1879, by ASA GrAY

Copyright, 1907, by

President and Fellows of Harvard College

GRAY'S STRUCTURAL BOTANY

W. P. 13 


\section{PREF A CE.}

THE first edition of this treatise was published in the year 1842 , the fifth in 1857. Each edition has been in good part rewritten, - the present one entirely so, - and the compass of the work is now extended. More elementary works than this, such as the author's First Lessons in Botany (which contains all that is necessary to the practical study of systematic Phænogamous Botany by means of Manuals and local Floras), are best adapted to the needs of the young beginner, and of those who do not intend to study Botany comprehensively and thoroughly. The present treatise is intended to serve as a text-book for the higher and completer instruction. To secure the requisite fulness of treatment of the whole range of subjects, it has been decided to divide the work into distinct volumes, each a treatise by itself, which may be independently used, while the whole will compose a comprehensive botanical course. This volume, on the Structural and Morphological Botany of Phænogamous Plants, properly comes first. It should thoroughly equip a botanist for the scientific prosecution of Systematic Botany, and furnish needful preparation to those who proceed to the study of Vegetable Physiology and Anatomy, and to the wide and varied department of Cryptogamic Botany. 
The preparation of the volume upon Physiological Botany (Vegetable Histology and Physiology) is assigned to the author's colleague, Professor Goodale.

The Introduction to Cryptogamous Botany, both structural and systematic, is assigned to his colleague, Professor FARLOW.

A fourth volume, a sketch of the Natural Orders of Phænogamous Plants, and of their special Morphology, Classification, Distribution, Products, \&c., will be needed to complete the series: this the present author may rather hope than expect himself to draw up.

ASA GRAY.

Herbaridu of Hartard Univirgity,

Chubridge April 10, 1879.

The numerals in parentheses, which are here and there introdnced into sentences or appended to them, are references to the numbered pars. graphs in which the topic is treated or the term explained. 


\section{CONTENTS.}

introduction. The Departments of the Science $\ldots$ Page

CHAPTER L. OUTLINES OF THE GENERAL MORPHOLOGY OF PHANOGAMOUS PLANTS . . . . . . . 5

CHAPTER II. MORPHOLOGY AND DEVELOPMENT OF THE EMBRYO AND SEEDLING . . . . . . . 9

The Embryo, its Nature, Structure, and Parts . . . . . . 9

Development of the Dicotyledonous Embryo in Maple . . . 10

In Ipomøea, or Morning Glory, \&c., with Albuminous Seeds . 13

In Embryos with thickened Cotyledons . . . . . . . 16

As of Almond, Beech, Bean, \&c. . . . . . . . . . . . 17

With Hypogæous Germination and no Elongation of Caulicle 19

In Megarrhiza, \&c., with concreted Petioles to the Cotyledons 21

In Ipomœa leptophylla with foliaceous and long-petioled Cotyledons and no elongation of Caulicle . . . . . . 22

In Pumpkin, \&c., with no Primary Root . . . . . . . . 22

The Polycotyledonous Embryo . . . . . . . . . . . 23

The Monocotyledonous Embryo of Iris, Onion, Cereal Grains 24

Pseudo-monocotyledonous and Acotyledonons Embryo . . . 26

Dicotyledonous and Monocotyledonous Plants . . . . . 27

CHAPTER III. MORPHOLOGY AND STRUCTURE OF THE ORGANS OF THE PLANT IN VEGETATION • . 27

Section I. Of the Root . . . . . . . . . . . 27

Nature, Growth, and Composition . . . . . . . 28

Root-hairs . . . . . . . . . . 29

Kinds of Roots . . . . . . . . . . . 29

Duration; Annuals . . . . . . . . . 30

Biennials . . . . . . . . . . . . 31

Perennials. . . . . . . . . 32

Aerial Roots . . . . . . . . . . . 33

Epiphytes or Air-plants . . . . . . . . . . . . . 35

Parasitic Plants, Green and Colored . . . . . . . 36 
Szcriox II. Or Buds . . . . . . . . . 40

Scaly Buds and Bud-scales . . . . . . . . . 40

Naked, Subpetiolar, and Fleshy Buds . . . . . . 41

Bud-propagation . . . . . . . . . . . 43

Normal, Accessory, and Adventitious Buds . . . . . . 44

Sxction III. Of the SteM . . . . . . . . 45

81. General Characteristics and Growth . . . . 45

Development and Structure . . . . . . . 46

Ramification, Branches . . . . . . . . . . 47

Excurrent and Deliquescent Stems . . . . . . . 48

Definite and Indefinite Annual Growth . . . . . . 49

52. Forms of Stem and Branches . . . . . . 50

Herbs, Shrubs, Trees, Culm, Caudex, Scape . . . . 50

Climbing Stems, Twining or otherwise . . . . . . 51

Leaf-climbers, Tendril-climbers, and Root-climbers . . . 52

Suckers, Stolons, Offsets, Runners . . . . . . . 53

Tendrils formed of Stems . . . . . . . . . 54

Sympodial and Monopodial Stems . . . . . . . 55

Spines or Thorns and Subterranean Stems . . . . . 56

Rhizoma or Rootstock . . . . . . . . . 57

Tuber, Tubercles . . . . . . . . . . . . 59

Corm or Solid Bulb . . . . . . . . . . 61

Bulb, Bulblets . . . . . . . . . . . . . . 62

Condensed Aerial Stems . . . . . . . . 64

Stems serving for Foliage, Phyllocladia, Cladophylla . . 65

Frondose Stems . . . . . . . . . . 66

83. InTERnAL STRUCTURE . . . . . . . . 67

Anatomical Elements. . . . . . . . . 68

Endogenous Structure . . . . . . . . 70

Exogenous Structure; its Beginning . . . . . . 73

First Year's Growth . . . . . . . . . . . 74

Pith, Layer of Wood, \&c. . . . . . . . . . . 75

Bark, its Parts and Structure . . . . . . . . 76

Annual Increase in Diameter . . . . . . . 78

Demarcation of Annual Layers . . . . . . . . 79

Sap-wood and Heart-wood . . . . . . . . . 80

Growth and Duration of Bark . . . . . . . 81

Living Parts of a Tree or Shrub, Longevity . . . . . 83

The Plant composite . . . . . . . . . 84

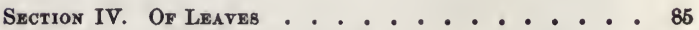

81. Their Nature and Office . . . . . . 85

Parts of a Leaf . . . . . . . . . . . 85

Duration, Defoliation, Normal Position . . . . . 86 
82. Their Structure and Forms as Folinge . . . . 87

Internal Structure or Anatomy . . . . . . . 87

Parenchyma-cells . . . . . . . . . . . . 88

Epidermis, Stomata or Breathing-pores . . . . . 89

Framework, Venation . . . . . . . . . 90

Parallel-veined or Nerved Leaves . . . . . . . . 91

Reticulated or Netted-veined Leaves . . . . . . . 92

Pinnately or Feather-veined and Palmately or Radiately

Veined ...... . . . . . . . 93

Forms as to Outline . . . . . . . . . . . 94

Forms as to Extremity . . . . . . . . . . . . . . 98

Forms as to Margin or Special Outline and Dentation . . . 97

Lobation or Segmentation . . . . . . . . . . . 98

Number and Arrangement of Parts . . . . . . . . . 99

Compound Leaves, Pinnate and Palmate or Digitate, \&c. . . 100

Petiole or Leafstalk _. . . . . . . . . . 104

Stipules, Ligule, Stipels . . . . . . . . . . 105

Leaves in unusual Modifications . . . . . . . . 106

Such as Inæquilateral, Connate, Perfoliate . . . . . . 107

Vertical and Equitant . . . . . . . . . 108

Without distinction of Parts . . . . . . . . 109

Stipules serving for Blade . . . . . . . . . . 109

Phyllodia, or Petioles serving for Blade . . . . . 110

\$ 3. Leates serving Special Offices ....... 110

Utilizing Animal Matter . . . . . . . . 110

Ascidia or Pitchers . . . . . . . . . 111

Sensitive Fly-traps . . . . . . . . . 113

Leaves for Storage . . . . . . . . . 115

Bulb-scales and Bud-scales . . . . . . . . 116

CHAPTER IV. PHYLLOTAXY, OR LEAF-ARRANGEMENT • 119

Section I. Distribution of Leaves on the Stem . . . 119

Phyllotaxy either Verticillate or Alternate, Cyclical or Spiral 119

Verticillate or Cyclical Arrangement . . . . . . . 120

Alternate or Spiral Arrangement . . . . . . . . 121

Its Modes and Laws . . . . . . . . . . . . . 122

Relation of Whorls to Spirals . . . . . . . . 129

Hypothesis of the Origin of Both . . . . . . 130

Fascicled Leaves . . . . . . . . . . 131

Section II. Disposition of Leates in the Bud . . . 132

Vernation and Festivation; the Modes . . . . . 132

Direction, Dextrorse and Sinistrorse . . . . . 140 
Bracts and Bractlets and their Modifications . . . . . 141

Peduncles, Pedicels, Rhachis, Receptacle . . . . . . . 143

Position of Flower-buds, Kinds of Inflorescence . . . . . 144

Indeterminate, Indefinite, or Botryose . . . . . . 146

Raceme, Corymb, Umbel . . . . . . . . . 146

Head or Capitulum . . . . . . . . . . . . . . 147

Syconium or Hypanthodium . . . . . . . . . . 148

Spike, Spadix, Ament or Catkin . . . . . . . . 149

Panicle and other Compound Forms . . . . . . 150

Determinate or Cymose . . . . . . . . . . 151

Cyme, Glomerule, \&c . . . . . . . . . . 152

Botryoidal Forms of Cymose Type . . . . . . . . 153

Sympodial Forms . . . . . . . . . . . . . . 154

Scorpioid and Helicoid, the Pleiochasium, Dichasium, and

Monochasium . . . . . . . . . 155

Bostryx, Cincinnns, Rhipidium, Drepanium, \&c. . . . . . 156

Mixed Inflorescence . . . . . . . . . . 158

Thyrsus, Verticillaster, \&c. . . . . . . . . . 159

Relations of Bract, Bractlet, and Flower . . . . . . 160

Anterior and Posterior, or Inferior and Superior . . . . 160

Median and Transverse . . . . . . . . 160

Position of Bractlets . . . . . . . . . . . 161

Tabular View of Inflorescence . . . . . . . 162

CHAPTER VI. THE FLOWER . . . . . . . 163

Section I. Its Nature, Parts, and Metamorphy . . . 163

Floral Envelopes, Perianth, or Perigone . . . . . . 164

The Parts, Calyx and Corolla . . . . . . . . . 165

Androcium, Stamens . . . . . . . . . . 165

Gynœcium, Pistils . . . . . . . . . . . 166

Torus or Receptacle of the Flower . . . . . . . . 167

Metamorphosis . . . . . . . . . 167

Unity of Type illustrated by Position and Transitions . . . 169

Teratological Transitions and Changes . . . . . 170

Section II. Floral Stmmetry . . . . . . . . . . 174

Symmetrical, Regular, and Complete Flower . . . . . 175

Numerical Ground-plan . . . . . . . . . 176

Pattern Flowers . . . . . . . . . . . 176

Diplostemonous Type. . . . . . . . . . 177

Szction III. Variods Modifications of the Flowhr . • 179

8 1. Enumeration of the Kinds . . . . . . . 179

8 2. Regular Union of Similar Parts . . . . 180

Coalescence or Cohesion . . . . . . . . 180 
8. Uxion of Dissimilar or Successive Parts . . . 181

Adnation or Connation . . . . . . . . . . 182

Hypogynous, Perigynous, Epigynous . . . . . . . 183

84. Irrag dlarity of Similar Parts . . . . . . 184

85. Disappearance or Obliteration of Parts . . . 187

Abortion or Suppression of Parts of a Circle . . . . . 187

Abortion or Suppression of whole Circles. . . . . . . 190

Terms therewith connected . . . . . . . . . 191

Suppressed Perianth . . . . . . . . . . . . 191

Suppressed Androcium or Gynœcium . . . . . . . 193

Along with suppressed Perianth . . . . . . . . . 194

Neutral Flowers. . . . . . . . . . . 195

§ 6. Interroption of normal Alternation . . . . . 195

Anteposition or Superposition . . . . . . . . . 195

In Appearance only . . . . . . . . . . . . . 196

Superposition by Spirals . . . . . . . . . . 196

Anteposition with Isostemony and Diplostemony . . . . 197

With Obdiplostemony . . . . . . . . . . . 198

§ 7. Increased Number of Parts . . . . . . . . 200

Regular Multiplication . . . . . . . . . . 200

Parapetalous Multiplication . . . . . . . . 201

Chorisis or Deduplication . . . . . . . . . . 202

§ 8. OUTGROWTHS . . . . . . . . . . . . . 209

Their relation to Chorisis: Trichomes . . . . . . 209

Corona or Crown . . . . . . . . . . . 210

Ligule . . . . . . . . . . . . . . . 211

89. Forms of the Tords or Receptache . . . . . . 211

Stipe, Thecaphore, Gynophore, Carpophore, \&c. . . . . . 212

Disk . . . . . . . . . . . . . . . . 213

Hypanthium . . . . . . . . . . . . 214

Section IV. Adaptations of the Flower to the Act of

Fertilization . . . . . . . . . . . 215

§ 1. IN General . . . . . . . . . . . . . 215

Close and Cross Fertilization, or Autogamy and Allogamy . 216

8 2. Adaptations for Allogamy or Intercrossing • • 216

Wind-fertilizable or Anemophilous Flowers . . . . . . 217

Insect-fertilizable or Entomophilous Flowers . . . . . . 218

Irregularity as related to Allogamy . . . . . . . 219 
Dichogamy, either Proterandrous or Proterogynous . . . . 219

Proterogyny . . . . . . . . . . . 219

Proterandry . . . . . . . . . . . 220

Particular Adaptations in Papilionaceous Flowers . . . 225

In Kalmia-blossoms, Iris, \&c. . . . . . . . . . . 229

Transportation of Pollinia . . . . . . . . . 230

In Orchidaceæ and Asclepiadaceæ . . . . . . . . 231

Heterogonous Dimorphism and Trimorphism . . . . . 234

83. Adaptations for Close Ferthlzation . . . . 240

Cleistogamy . . . . . . . . . . . . 241

Section V. The Periakth, or the Calyx and Corolia in

PARTICULAR . . . . . . . . . . . 243

Perianth as to Duration, Numerical Terms, Union, \&c. . . . 243

Parts of Petals and of Gamophyllous Perianth . . . . . 245

Forms of Corolla and Calyx . . . . . . . . . 246

Section VI. The Andegcium, or Stamens in particular - 249

The Stamen as a whole; Numerical Terms . . . . . . 249

The Filament and the Anther; their Modifications . . . 251

Pollen . . . . . . . . . . . . 256

Pollen-tubes . . . . . . . . . . . 258

Section VII. The Pistils, or Gracecrom . . . . . 259

\$1. In Angrosperms . . . . . . . . . . . 259

Carpel or Carpophyll . . . . . . . . . . . . . 260

Ventral and Dorsal Sutures; Placenta . . . . . . 261

Simple or Apocarpous Pistils . . . . . . . . . . 262

Compound or Syncarpous Pistil . . . . . . . . 263

With two or more Cells and Axile Placentæ; Partitions . . 264

With one Cell and Parietal Placentæ . . . . . . . 265

With one Cell and Free Central Placenta . . . . . . 266

Anomalous Placentation. . . . . . . . . 267

8 2. In Grmosperms . . . . . . . . . . 268

Structure in Gnetaceæ . . . . . . . . 269

Structure in Coniferæ . . . . . . . . . 270

In the Yew Family . . . . . . . . . 271

In the Pine Tribe, \&c. . . . . . . . . . . 272

In the Cypress Tribe . . . . . . . . . . 273

Structure in Cycadaceæ . . . . . . . . . . 274

Section VIII. The Ovule . . . . . . . . 276

Its Structure and Position . . . . . . . . . . . 277

Its Forms, Orthotropous, Campylotropous, Amphitropous,

Anatropous . . . . . . . . . . 278

Origin and Morphological Nature of the Ovule. . . . . 282

Origination of the Embryo . . . . . . . . . 283 
Section I. Its Structure, Transformations, and DehisCENCE. . . . . . . . . . . . . . 285

Pericarp, its Alterations, Accessions, and Transformations . 287 Dehiscence . . . . . . . . . . . 288

Section II. The Kinds of Fruit . . . . . . . . 291

Simple Fruits . . . . . . . . . . . . 291

Dehiscent Fruits, Follicle, Legume, Capsule, Pyxis, Silique 292 Indehiscent Dry Fruits, Samara, Akene, Utricle, Caryopsis,

Nut, \&c. . . . . . . . . . . . . . . . . 294

Fleshy Fruits, Drupe, Pome, Pepo, Berry, \&c. . . . . . . 297

Aggregate Fruits . . . . . . . . . . . 299

Accessory or Anthocarpous Fruits . . . . . . . 300

Multiple or Collective Fruits, Syconium, Strobile, \&c. . . . 301

Table of Simple Fruits . . . . . . . . . 304

CHAPTER VIII. THE SEED ........... 305

Its Stalk, Coats, and Appendages . . . . . . 308

Aril or Arillus . . . . . . . . . . . . . 308

Nucleus or Kernel, Albumen . . . . . . . . . 309

The Embryo, its Parts and Positions . . . . . . . . 311

The Cotyledons as to Adjustment and Number . . . . . . 313

CHAPTER IX. TAXONOMY . . . . . . . . . 315

Section I. The Prinoiples of Chassimication in Natural

History . . . . . . . . . . . . 315

Individuals . . . . . . . . . . . 315

Species . . . . . . . . . . . . . 317

Varieties, Races, \&c. . . . . . . . . . . . . 318

Cross-breeds and Hybrids . . . . . . . . . 321

Genera . . . . . . . . . . . . 323

Orders, Classes, Tribes, \&c. . . . . . . . . . . . 325

Sequence of the Grades . . . . . . . . . . 327

Nature and Meaning of Affinity . . . . . . . . . 327

Theory of Descent and Natural Selection . . . . . 328

Szction II. Botanical Chassification . . . . . . 331

Ante-Linnæan Classifications . . . . . . . . 332

Linnæan Classification . . . . . . . . . . 333

Sexual Artificial System . . . . . . . . . 334

Natural System . . . . . . . . . . 338

As presented by Jussieu . . . . . . . . . . 339

Some of its Modiflcations . . . . . . . . 840 
CHAPTER X. PHYTOGRAPHY . . . . . . . 345

Section I. Nomenclature . . . . . . . . 345

Names of Plants, Binomial Nomenclature . . . . . 346

Rules for naming Plants . . . . . . . . . . 347

Names of Genera . . . . . . . . . . . 348

Names of Species, Varieties, \&c. . . . . . . . 350

The Fixation, Precision, and Citation of Names : . . . 352

Subgeneric Names . . . . . . . . . . . 358

Tribal and Ordinal Names . . . . . . . . . 357

Names of Cohorts, Classes, \&c. . . . . . . 358

Szction II. Glossology or Terminology . . . . . 359

Section III. Description. . . . . . . . . . 361

Characters . . . . . . . . . . 361

Punctuation . . . . . . . . . . . 364

Synonomy . . . . . . . . . . . . . 365

Iconography . . . . . . . . . . . 366

Habitat and Station, \&c. : . . . . . . . . 366

Etymology of Names . . . . . . . . . . . 368

Accentuation, Abbreviations . . . . . . . . 367

Signs . . . . . . . . . . . . . . 368

Floras, Monographs, \&c. . . . . . . . . . . 369

Section IV. Specimens, Directions for their Examina-

tion, Pregervation, \&c. . . . . . . . . . . . 370

Implements of Investigation . . . . . . . . 370

Diagrams . . . . . . . . . . . . . . 371

Herborizing . . . . . . . . . . . 371

Drying Specimens . . . . . . . . . . 375

Poisoning Specimens . . . . . . . . . . . 379

The Herbarium . . . . . . . . . . . 380

ABBREVIATIONS . . . . . . . . . 385

SIGNS . . . . . . . . . . . . . 391

GLOSSARY OF BOTANICAL TERMS, WITH INDEX • • 393 


\title{
STRUCTURAL BOTANY
}

\author{
ON
}

\section{THE BASIS OF MORPHOLOGY.}

\section{INTRODUCTION.}

1. The two Biological Sciences, ${ }^{1}$ considered as parts of Natural History, are Zoology and Botany. The latter is the natural history of the Vegetable Kingdom. It embraces every scientific inquiry that can be made respecting plants, their nature, their kinds, the laws which govern them, and the part they play in the general economy of the world.

2. We cannot distinguish the vegetable from the animal kingdom by any complete and precise definition. Although ordinary observation of their usual representatives may discern little that is common to the two, yet there are many simple forms of life which hardly rise high enough in the scale of being to rank distinctively either as plant or animal ; there are undoubted plants possessing faculties which are generally deemed characteristic of animals; and some plants of the highest grade share in these endowments. But in general there is a marked contrast between animal and vegetable life, and in the part which animals and plants respectively play in nature.

3. Plants only are nourished upon mineral matter, upon earth and air. It is their peculiar office to appropriate mineral materials and to organize them into a structure in which life is manifested, - into a structure which is therefore called organic. So the material fitted for such structure, and of which the bodies

1 Biology, the science of life, or rather of living things, in its earlier use was equivalent to physiology : recently, it has come to denote the natural history of plants and animals, i. e. of the two organic kingdoms, including both their physiology and descriptive natural history. 
of plants and animals are composed, is called organic matter. Animals appropriate and live upon this, but have not the power of producing it. So the vegetable kingdom stands between the mineral and the animal; and its function is to convert materials of the one into food for the other. Although plants alone are capable of building up living structure out of mineral materials, and are the sole producers of the organic matter which is essential to animal life, and although animals consume that which plants produce, yet plants also consume organic matter, more or less, acting in this respect like animals in all their operations, except in the grand and peculiar one by which they assimilate mineral matter. Most plants of the higher grades assimilate largely and consume little, except in special operations. Some, on the contrary, are mainly consumers, and feed upon formed organic matter, living in this respect after the manner of animals. The living substance of plants and animals is essentially the same.

4. Botany deals with plants : 1. As individuals, and in respect to their structure and functions. 2. In their kinds, and as respects their classification, nomenclature, \&c. Accordingly, the most comprehensive division of the science is into PhysioLOGICAL or BIOLOGICAL BotaNy (using these terms in their widest sense) and Systematic Botany. But as Physiology and Biology, in the restricted sense, relate only to functions or actions and their consequences, the first department naturally divides into two, viz. Structural Botany and Physiology.

5. Structural Botany comprehends all inquiries into the structure, the parts, and the organic composition of vegetables. This is termed Organography, when it considers the organs or obvious parts of which plants are made up, and MorpHoLogr, when the study proceeds on the idea of type. The term Organogeny has been applied to the study of the nascent organs and their development; Рнyтotomy, or Vegetable Anatomx, to that of the minute structure of vegetables as revealed by the microscope, $i$. e. to the composition of the organs themselves. But, since anatomy in the animal kingdom includes the consideration of general as well as of minute structure, and indeed answers to organography, the minute anatomy of both kingdoms takes the special name of Histologr. The study of functions, or of the living being (animal or plant) in action, is the province of Physiology.

6. Systematic Botany, or the study of plants in their kinds and in regard to their relationships, comprises TAXONOMY, or the principles of classification, as.derived from the facts and ideas 
upon which species, genera, \&c., rest; Classification or the System of Plants, the actual arrangement of known plants in systematic order according to their relationships ; Phyrography, the rules and methods of describing plants ; and NoMENCLATURE, the methods and rules adopted for the formation of botanical names. Glossology or Terminology ${ }^{1}$ is a necessary part of Phytography or Descriptive Botany, and hardly less so of Structural Botany : it relates to the application of distinctive terms or names to the several organs or parts of plants, and to their numberless modifications of form, \&c. This requires a copious vocabulary of well-defined technical terms, by the use of which the botanist is able to describe the objects of his study with a precision and brevity not otherwise attainable. It will be convenient to exemplify the principal terms along with the modifications of conformation which they designate; and also, for greater fulness and facility of reference, to append to this volume an alphabetical summary of them, or Vocabulary of Botanical Terms. ${ }^{2}$

7. The present volume is mainly devoted to Morphological Botany; that is, to Structural Botany on the basis of morphology. This department cannot be properly dealt with apart from considerable reference to intimate structure, development, and function, the subject-matter of vegetable histology and physiology. But these will here be treated only in the most general or incidental and elementary way, and only so far as is necessary to the understanding of the morphology of the stem, leaves, \&c. The whole discussion of the histology and physiology of plants is relegated to a following volume and to another hand.

8. The most comprehensive and important division of the vegetable kingdom is into plants of the higher and of the lower series or grade, i.e. into Phenogamous (or Phanerogamous) or Flowering, and Cryptogamous or Flowerless Plants. The first are all manifestly of one type, and therefore have a consistent and simple morphology. The second differ among themselves almost as widely as they do from the higher series; and

I Grossology is the better word, but Terminology, although a hybrid of Latin and Greek, is in common use.

2 What is called Geographical Botany is the study of plants in respect to their natural distribution at the present time over the earth's surface, and the causes of it. Fossil Botaxy (Vegetable Palæontology) relates to the plants of former ages, as more or less made known in their fossil remains. Medical Botany, Agricultural Botany, and the like, are applications of Botany to medicine, agriculture, \&c. 
their morphology is more special and difficult. Wherefore it is better to treat them separately and subsequently. This will be done in a third part, by an associate devoted to Cryptogamic Botany.

9. Thus the field is here left clear for the Structural Botany of Phænogamous or Flowering Plants, with which the study of the science should naturally begin. In theory it may seem proper to commence with the simplest plants and the most elementary structures; but that is to put the difficult and recondite before the plain and obvious. The type or plan of the vegetable kingdom, upon which morphological botany is grounded, is fully exemplified only in the higher grade of plants, is manifest to simple observation, and should be clearly apprehended at the outset. 


\section{CHAPTER I.}

\section{OUTLINES OF THE GENERAL MORPHOLOGY OF PHANOGAMOUS PLANTS.}

10. Morphology, the doctrine of forms, as the name denotes, is used in natural history in nearly the same sense as the older term Comparative Anatomy. If it were concerned merely with the description and classification of shapes and modifications, it would amount to little more than glossology and organography. But it deals with these from a peculiar point of view, and under the idea of unity of plan or type. ${ }^{1}$

11. As all vertebrate animals are constructed upon one type (or ground plan), which culminates or has its archetype in man, so all plants of the higher grade (8) are strictly of one type; the different kinds being patterns or repetitions of it, with variations. The vegetable kingdom, however, does not culminate in an archetype or highest representative. As respects the organs of vegetation, the higher classes of cryptogamous plants exhibit this same type; but it is only in the most general or in a recondite sense that this can be said of their organs of reproduction, and of the less differentiated structure of the lowest classes. Wherefore cryptogamous plants are left out of the present view, to be treated apart.

12. Viewed morphologically and as to its component organs, a plant is seen to consist of an axis or stem, which sends off roots into the soil, and bears lateral appendages, commonly as leaves, but which may be very unlike leaves in whole appearance

1 The term Morphology was introduced into science by Gœthe, at least as early as the year 1817 (Zur Naturwissenschaft überhaupt, besonders zur Morphologie, Stuttgart und Tübingen, 1817-24). On page 9 of the first volume, he is understood to have suggested this word for the purpose and in the sense now adopted in botany and zoology. It essentially replaces an earlier and somewhat misleading word, Metamorphosis. (304.)

Apparently the first botanist to adopt the term was Auguste de St. Hilaire, in his "Leçons de Botanique, comprenant principalement la Morphologie Végétale, etc., Paris, 1841. The term seems not to have been taken up, in zoology, by Etienne Geoffroy Saint-Hilaire, the antagonist of Cuvier (who was of a wholly different family from that of the botanist), although the same idea was denoted by his phrase "unity of organic composition." 
and function. These appendages, whatever their form or use, accord with leaves in mode of origin, position, and arrangement on the axis or stem. Their most general and ordinary form is the familiar one of foliage; hence the name of leaves has been by botanists extended in a generic way from the green expansions which constitute foliage to other forms under which such appendages occur. The proper morphological expression is, that the latter are homologous with leaves, or are the homologues of leaves. ${ }^{1}$

13. Leaves are borne upon the stem at definite places, which are termed Nodes. A node may bear a single leaf or a greater number. When it bears two, they occupy opposite sides of the stem. When three, four, or more, they divide the circumference of the stem equally, forming a circle, technically a WhorL, or in Latin form a Verticil. When only two, the pair evidently answers to the simplest kind of whorl. So that leaves are either single on the nodes, in which case they are alternate, that is, come one after another on the stem; or in whorls (whorled, verticillate), in the commoner case of a single pair being called opposite. The bare space between two successive nodes is an INTERNode. This is longer or shorter, according to the amount of longitudinal growth, which thus spaces the leaves, or whorls of leaves, in most various degrees, either widely when the internodes are elongated, or slightly when they remain very short. The plant, therefore (roots excepted), is made up of a series of similar parts, $i . e$. of portions of stem, definitely bearing leaves, each portion developed from the apex of the preceding one. This constitutes a simple-stemmed plant.

14. Branching is the production of new stems from the older or parent stem. These normally appear in the Axils of leaves, that is, in the upper angle which the leaf forms with the stem, from which they grow much as the primary stem grew from the seed. The primary stem, connected with the ground, produces roots which develop downwardly into the soil, from which they draw sustenance. Branches, when developed above ground,

I A common designation for all these appendages being desirable, a good

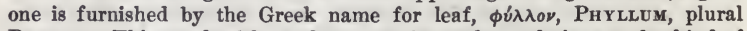
Phylla. This, used with prefixes, may be made to designate the kind of leaves in many cases, - as, prophylla, cataphylla, hypsophylla.

Recent German botanists use the word Phyllome in this sense. It is a rather convenient and well-sounding word; but phylloma is the exact Greek equivalent of our word foliage, and therefore not very well chosen as a common term for leaves which are not foliage as well as those which are. Nor will this word, like phyllum, readily take prefixes, as above, or the adjec. tive form, as it readily does in prophyllous, hypsophyllous, gamophyllous, \&c. 
being in organic connection with their parent stem, do not usually produce roots; but when placed in equally favorable conditions for it, $i$. e. on or in the soil, they may strike root as freely as does the original stem.

15. An incipient stem or branch, with its rudimentary leaves, is a BUD. The normal situation of a bud is in the axil of a leaf (axillary), the development giving rise to branches; or else at the apex of an axis (terminal), where there can be only one, the development of which continues that axis. ${ }^{1}$

16. As branches are repetitions and in one sense progeny of the stem which bears them, so the serial similar parts or leafbearing portions of a simple stem are repetitions, or in a like sense progeny, each of the preceding one from which it grew. The simple-stemmed plant is made up of a series of such growths, each from the summit of its predecessor; the branched plant, of additional series, laterally developed, from axillary buds. These ultimate similar parts into which a plant may thus be analyzed, and which are endowed with or may produce all the fundamental organs of vegetation, were by Gaudichaud called Prrross. But phyton, being the common Greek name for plant, was not a happily chosen appellation for plantelements, or homologous plant-units. A better term for them is Phytómera (qúzov, plant, $\mu \varepsilon$ és, part), equivalent to plant-parts, - the structures which, produced in a series, make up a plant of the higher grade. In English, the singular may be shortened to PнÝ́Tомer.

17. This theoretical conception of the organic composition of the plant is practically important to the correct understanding of morphological botany. The diagram, Fig. 1, serves to represent the organic elements, or phytomera, in a simple case, such as that of a growing plant of Indian Corn, or other Grass. Here

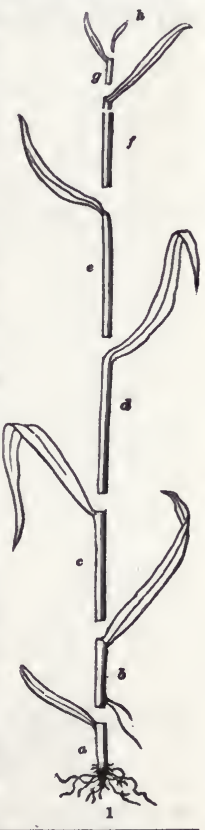

1 Bifurcation by the division of a terminal bnd into two, as in Acrogenous Cryptogams, is supposed by some to occur, even normally, in some Phænogams, especially in certain forms of inflorescence; but this has never been convincingly made out.

FIG. 1. Diagram of a simple-stemmed plant, exhibiting the similar parts, or phytomera, $a$ to $h$, of which it is composed. 
the leaves are alternate; in other words, each phytomer is single-leaved; while in the subsequent illustrations of plants developed from the seed, at least the earliest phytomera are two-leaved.

18. The plan thus exhibited in the leafy stem begins in the embryo, or initial plant in the seed, and is carried on into the flower, in which the normal development of the axis finally ends. One plan prevails throughout. To illustrate it, the morphology and growth of the embryo, of the plant developed for vegetation and the general purposes of its individual existence, and lastly of the flower, through which sexual reproduction takes place, may be successively treated in this order. 


\section{CHAPTER II.}

\section{MORPHOLOGY AND DEVELOPMENT OF THE EMBRYO AND SEEDLING.}

19. The Embryo is the initial plant, originated in the seed. ${ }^{1}$ In some seeds it is so simple and rudimentary as to have no visible distinction of parts : in others, these parts may have assumed forms which disguise their proper character. But every well-developed embryo essentially consists of a nascent axis, or stem, bearing at one end a nascent leaf or leaves, or what answers to these, while from the other and naked end a root is normally to be produced. This stem is the primitive internode of the plant: its leaf or pair of leaves is that of the first node. The plant therefore begins as a single phytomer. Some embryos are no more than this, even when they have completed their proper germination: others have taken a further development in the seed itself, and exhibit the rudiments of one or more following phytomera. The embryo of the Maple is an example of the first kind; and, being large enough for handling and for the display of all its parts to the naked eye, and the character of these parts being manifest even in the seed, it is a good subject with which to commence this study. And for this the SugarMaple is one of the best of the Maples. Its embryo (seen in Fig. 2 in the coiled condition which it occupies in the seed, and in Fig. 3 and Fig. 4 uncoiling and be-

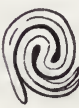

2

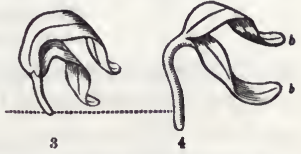

3 ginning to grow) is an initial stem, bearing a pair of leaves, and nothing more. These parts take the technical names of

1 Normally a seed contains a single embryo. Polyembry, the formation of two or more embryos, occurs occasionaliy as a kind of superfotation in some seeds. In those of the cultivated Orange it is most common, and an evident monstrosity. In Coniferm and Loranthace», two or three embryos, of equai size and perfection, are not rarely produced.

FIG. 2. Embryo of Sugar Maple, in vertical section, as colled in the seed, merely somewhat loosened. 8. Embryo of same, just beginning to unfold in germination. 4. Same more advanced : $a$. its stem or caulicle; $b b$. its two leaves or cotyledons. 
20. Canlicle or Radicle, and Cotyledons. The name of radicle was early applied to the axis of the embryo below the cotyledons, on the supposition that it was the actual beginning of the root. But its structure and mode of growth show it is not root (24, $44,78)$, but a body of the exact nature of stem, from the naked end of which the root is developed. Wherefore Caulicle (Lat. cauliculus, diminutive of caulis, stem) is

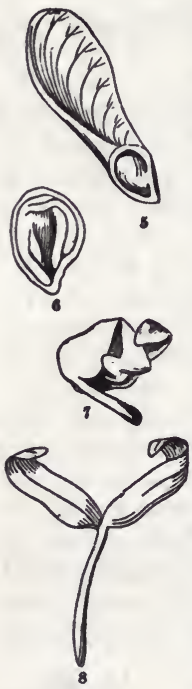
the appropriate name; and it would be generally adopted, were it not that the older term is so incorporated into the language of systematic botany (in which fixity and uniformity are of the utmost importance) that it is not easily displaced. It may be continued in descriptive botany on this account, but in morphology it is apt to mislead; and the name of caulicle, suggestive of the true nature of the organ, is preferable. ${ }^{1}$ The more fanciful name of Cotylédons was very early applied to what are now recognized as answering to the leaves of the embryo : it has the negative merit of suggesting no misleading analogy. ${ }^{2}$

21. Development of the Dicotyledonons Embryo, $i . e$. the two-leaved embryo. This, in the Red Maple (Figs. 5-8), usually germinates in summer, shortly after the fruits of the season have matured and fallen to the ground. It differs from that of Sugar Maple in the crumpling instead of coiling of the cotyledons in the seed. Referring the whole physiology of germination to that part of the work which treats of Vegetable Physiology, the development of the embryo into the seedling may here be described, taking that of a Maple for a convenient type or pattern, with which other forms

1 Linnæus called it Rostellum, a name which, being etymologically meaningless in this connection, is not misleading. The French botanists named it Tigelle, diminutive of tige, stem: but some (like Mirbel) applied the term to the developing axis above the cotyledons; others, to the early axis both above and below them. The name Radicula originated with Gaertner.

2 The name Cotyledon, which was adopted by Linnæus, is a Greek word for a cup-shaped hollow or cavity, also for a plant with thickish and saucershaped leaves. It was primarily applied to the thickened "lobes" of the embryo, the foliaceous nature of which was not recognized.

FIG. 5. One of the twin winged fruits of Red Maple (Acer rubrum), with body divided, to show the seed. 6. Seed extracted and divided, to show the embryo within. 7. Embryo partlo unfolded. 8. Embryo in early stage of germinative. 
may afterward be compared. The first growth is seen in the elongation of the radicle or caulicle, and its assumption, as far as possible, of a vertical position, and the production of a root from the naked end. As it emerges from the seed in consequence of this elongation, the root-end of the caulicle points downward into the soil, the caulicle bending, if need be, to assume this position; and the nascent root, partaking of this disposition, grows in a downward direction. Hence the root has been called the Descending Axis of the plant. While this avoids, the opposite or budding end (as it may be termed) seeks the light, and when free takes an upward direction. The result of this, and of the elongation of the caulicle, is to carry the budding end out of the soil and into the air, where the growing cotyledons unfold or expand and become the first leaves, or Seed-leaves. This initial stem and its continuation therefore constitutes the Ascending Axis. If the budding end happen to lie pointing downward and the root-end upward in the ground when germination begins, both will curve quite round, as they grow, to assume their appropriate directions. If obstacles intervene, each will take as nearly as possible its wonted direction, through an instinctive tendency and action, which insures that each part of the plant shall be developed in its fit medium, - the root in the dark and moist earth, the stem and leaves in the light and air.

22. The plantlet, thus established, has now all the essential Organs of Vegetation, as they are called, $i$. e. root, stem, and leaves. Its subsequent development, so far as vegetation (apart from proper reproduction) is concerned, consists in the addition of more of these, until the whole herb, shrub, or tree is built up.

23. In Maples (as in the Morning Glory, Fig. 16, and many others) the embryo in the seed, and until after the full development of its cotyledons or seed-leaves, shows no rudiments of the subsequent growth. The embryo grows into the plantlet wholly by the appropriation of prepared nourishing matter which was provided by

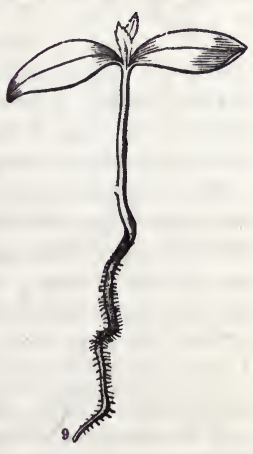
the mother-plant and stored in the seed, - in the case of the Maple, wholly in the embryo itself, mainly in its cotyledons.

FIG. 9. Maple embryo developed into plantlet of one phytomer, and producing rudiments of the second: the lower portion covered with root-hairs is the root; the naked portion above is the caulicle. 
After this is consumed and in good part converted into structure, the plantlet must by the action of its root and leaves imbibe

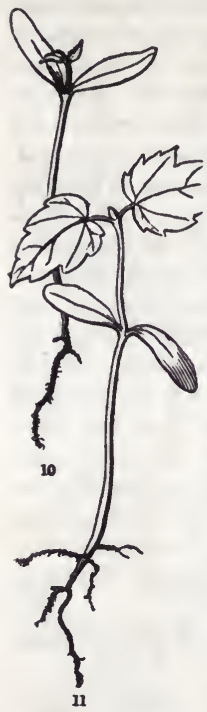
from the soil and air appropriate materials, and assimilate them into nourishing matter needful for further growth. Only then does the rudiment of new structure appear, in the form of a growing point, or bud, at the node or apex of the primitive stemlet, between the two seedleaves. In this case it soon shows itself as a second pair of leaves, at first resting on the node (Fig. 9), next as somewhat upraised by the development of the second internode (Fig. 10, summit), and finally both this internode and the pair of leaves complete their growth (Fig. 11). Then the terminal bud which crowns the second node develops in the same way the third pair of leaves and their supporting internode or joint of stem (Fig. 12); and so on.

24. The root and the stem grow not only in opposite directions, but in a different mode. The primordial stem, pre-existing in the seed (though at first it may be extremely short) grows throughout its whole length, but most in its upper part, so that it may become a stemlet two or three inches long. But, soon attaining its full growth as to length, the stem is carried upwards by the subsequent joints or portions, similarly developed and elongated, one after the other. Not that each portion necessarily waits until the growth of its predecessor is complete, - though this occurs at first in seedling Maples and other embryos unprovided with much store of food,-yet the development follows this course and order of succession. The root, on the contrary, cannot be said to pre-exist in the seed, or at most it may be said to exist potentially in tissue of the caulicle from which a root or roots normally originate. ${ }^{1}$ It is formed

1 Yet from nothing which is special to this part of the embryo, nor to the embryo at all. The primary root is developed from subjacent tissue of the tip of the caulicle, just as it is sometimes developed from along the sides, and as secondary roots are from all or most stems under favoring conditions. This complete similarity, and the fact of what is called the "endogenous" origin of roots (i.e. their springing from subjacent rather than superficial tissue) appear fully to warrant the statement in the text above.

FIG. 10. Maple plantlet with second internode developing. 11. Same with second internode and pair of leaves complete, and bud of the third apparent. 
in the process of germination, and originates in tissue just back of that which covers the root-end of the caulicle, and which, being carried forward by the subjacent formation (to which it becomes a sort of cap or sheath), is called the Root-cap. As the primary root thus began by a new and local growth at the extremity of pre-existing stem, so it goes on to grow in length wholly or mainly by a continuation of this formation, the new at the end of the old. That is, the root elongates by continual minute increment of its apex or near it, the formed parts very soon ceasing to lengthen. This is in marked distinction from stem, which grows by successive individualized portions; and these portions (internodes), at first very short, attain or are capable of attaining a considerable and sometimes very great, but definitely terminable length, by interstitial growth throughout. Moreover, roots are naked, not producing as they grow either leaves or any organs homologous with leaves. They commonly branch or divide, but

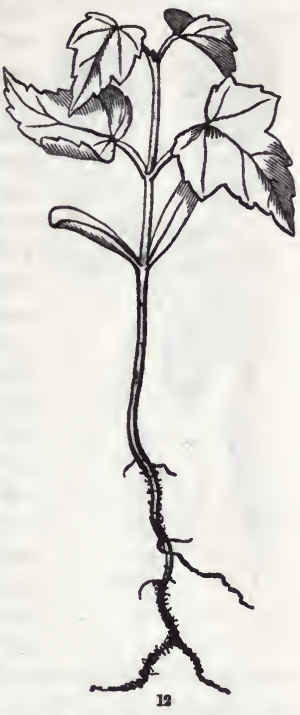
in a vague manner; and their new parts bear what are called Root-hairs, which greatly increase the absorbing surface; otherwise they are destitute of appendages or organs.

25. With the Maple embryo, here taken as a type, that of Morning Glory, Ipomuea purpurea, or any of its kin, may next be compared. The cotyledons are different in shape, being as broad as long, and notched both at base and apex. They lie in contact in Fig. 14, and are very thin, leaf-like, and green while contained in the seed. Their thinness is shown in Fig. 13, where a section of the crumpled and folded embryo, as it lies in the seed, exactly divides them (passing through the terminal and basal notches) and also the caulicle, which here is thicker than both. The germination is similar to that of the Maple; and like that (as Fig. 16 shows), and for the same reason, no bud or rudiment of the further growth pre-exists in the embryo or

FIG. 12. Red Maple seedling, with three joints of stem and pairs of leaves developed, the first being the cotyledons. 
appears in the young plantlet, until that has established itself and had time to elaborate proper material therefor. This con-

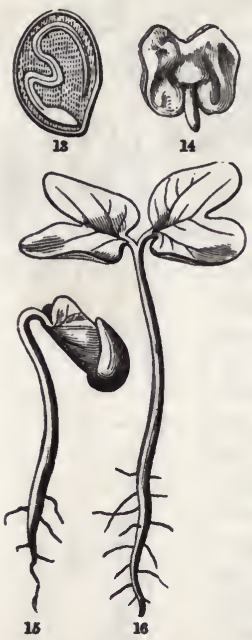
dition is correlated with thin foliaceous cotyledons, holding no store of nourishment. Here they do not contain sufficient material for the development of the initial stem and root. The maternal provision for this is here stored up in the seed around but not within the embryo. This nourishing deposit, seen in the section (Fig. 13) filling the whole space between the seed-coats and the thin embryo, was named by the early botanists and vegetable anatomists the AlBuMEN of the seed. ${ }^{1}$ This substance, softened in germination and by chemical changes rendered soluble, is gradually absorbed by the cotyledons as material for their growth and that of the developing primary stem and root.

26. Seeds in this regard are accordingly distinguished into albuminous and exalbuminous, those supplied with and those destitute of albumen. The difference inheres neither in the character nor in the amount of the maternal provision for the development of the embryo-plant, but merely in the storage. In exalbuminous seeds the nourishment supplied for this purpose is taken into the embryo itself, mostly into the cotyledons, during the growth and before the maturity of the seed. In albuminous seeds this same material is deposited around or at least external to the embryo.

27. The amount of this deposit is, in the main, inversely pro-

1 Grew appears to have first applied this name, and Gaertner to have introduced it into systematic botany, where it remains in use, although Jussieu replaced it by the term Perisperm, and Richard by Endosperm, neither of them much better etymologically than the old word Albumen. But it must be kept in mind that it was intended to liken the "albumen" of the seed with the albumen or white of an egg as a body or mass, and not as a chemical substance; the embryo being fancifully conceived to be analogous to the yolk of the egg, the surrounding substance of this kind not unnaturally took the name of the white, viz. albumen.

FIG. 13. Section of seed of common Morning Glory, Ipomces purpurea, dividing the contained embryo through the centre. 14. Embryo of same, detached and straightened. 15. Embryo in germination; the cotyledons only partly detached from the coat of the seed. 16. Same, later and more developed, the cotyledons unfolded and outopread as the first pair of leares. 
portional to the size and strength of the embryo, or the degree of its development in the seed. A comparison of the various illustrations sufficiently shows this. Figures 17 to 24 exhibit, in a few common seeds, somewhat of this relation, and also of the position and shape assumed in some instances. The upper rank of figures represents sections of seeds; the embryo left in white ; the albumen as a dotted surface.
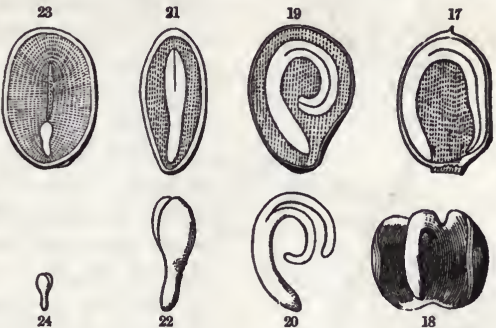

The lower rank shows the embryos detached. That of Mirabilis has very broad and thin cotyledons, a caulicle of equal length, and the whole curved round the albumen which thus occupies the centre of the seed. That of Potato is coiled in the midst of the albumen, is slender; the cotyledons narrowed down to semi-cylindrical bodies, not leaf-like in appearance, and the two together not thicker than the caulicle. In Barberry the embryo is straight, in the axis of the albumen, which it almost equals in length; the cotyledons considerably broader than the caulicle, but short and thickish. That of the Peony is similar, but very much smaller, occupying a small space at one end of the albumen, and seemingly without distinction of parts, but under the microscope and with some manipulation the broader end is found to be divided, that is, to consist of two minute cotyledons. The embryo of a Crowfoot is similar, but still more minute and the parts hardly to be distinguished; and in some minute embryos there is no apparent distinction of parts until they develop in germination.

28. The study of the formation of the embryo in the seed teaches that all embryos begin with a still more simple, minute, and homogeneous structure; and these comparisons suffice to show that all such differences are referable to different degrees and somewhat different modes of the development of the embryo while yet in the seed. It also appears that the size and shape

FIG. 17. Section of seed and contained embryo of Mirabilis (Four-o-clock), 18. Embryo detached entire.

FIG. 19. Section of a Potato-seed. 20. Embryo detached entire.

FIG. 21. Section of Barberry-seed. 22. Embryo detached entire.

FIG. 23. Section of Peony-seed. 24. Embryo detached entire. 
of an organ do not indicate its nature, either in the embryo or in subsequent growth. But in all the cases yet mentioned the

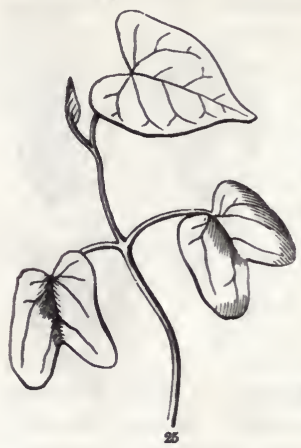

cotyledons actually demonstrate their nature by developing in germination in a foliaceous manner and becoming the first leaves of the seedling. Nor is this nature much disguised by the fact that they differ greatly in form in different species, and that the seedleaves, or developed cotyledons, differ much in shape and often in texture from the succeeding leaves. (See Fig. $11,12,25, \& c$.

29. To complete the comparison between the seedling Morning Glory and that of the Maple, it is to be noted that here, while the cotyledons or seed-leaves are two, the following internode bears only one leaf (Fig. 25), as also will the just developing third internode; and this continues throughout up to the blossom: that is, the leaves subsequent to the cotyledons are not opposite as in the Maple, but alternate. (13.)

30 . All the preceding illustrations are from embryos which previous to germination have developed nothing beyond the cotyledons. In the following, a rudiment of further growth,

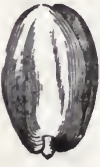

26

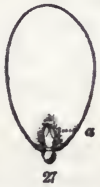

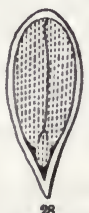

88
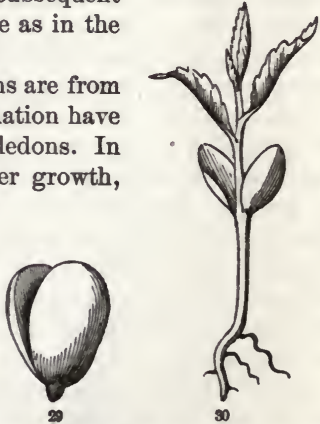

or a primary terminal bud, is visible in the seed. It is most manifest in large and strong embryos with thick or fleshy cotyle-

FIG. 25. Further development of Morning Glory, Fig. 16, the root cut away, the internode above the cotyledons and its leaf completed, the next internode and its leaf sppearing.

FIG. 26. Embryo (kernel) of the Almond. 27. Same, with one cotyledon removed, to show the plumule, $a$.

FIG. 28. Section of an Apple-seed, magnified, cutting throngh the thickness of the cotyledons. 29. Embryo of the same, extracted entire, the cotyledons a little separated.

FIG. 30. Germination of the Cherry, showing the thick cotyledons little altered, and the plumule developing the earllust real foliage. 
dons, $i . e$. cotyledons well charged with nourishing matter. The early vegetable physiologists gave to it the name of Plomole (Lat. plumula, a little plume). The name was suggested by its appearance in such an embryo as that of the bean (Phaseolus), in which it evidently consists of a rudimentary pair of leaves, while in the pea and the acorn it is a rudimentary stem, the leaves of which appear only later, when germination has considerably advanced. In any case, the plumule is the bud of the ascending axis already discernible in the seed. Fig. 27, $a$, shows it in the almond, one cotyledon being removed. Fig. 28 shows it in the section of a similar although much smaller embryo, that of an apple-seed, enlarged to nearly the size of the other. It is equally visible in the cherry, the bean, and the beechnut. The embryo in all these cases constitutes the whole kernel of the seed. For the nourishment, which in all the foregoing illustrations except the first (i.e. in Fig. 13, 17-23), is deposited around or exterior to the embryo, is in these stored within it.

31. The development of these embryos in germination proceeds in the normal manner, but with two correlated peculiarities. First, by the

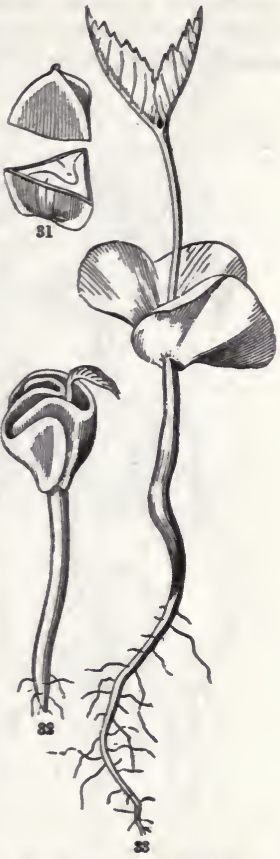
lengthening of the radicle more or less, their thick cotyledons are usually raised to or above the surface of the soil; they expand, assume the green color needful to foliage; but they imperfectly or in a small degree perform the function of green leaves. Their main office is to supply the other growing parts with the prepared nourishment which they abundantly contain. Then, being thus copiously nourished, the root below and the ready-formed plumule above grow rapidly and strongly, having accumulated capital to draw upon; and the leaves of the

FIG. 31. Beechnut cut across, flled by the fleshy embryo; the thick cotyledons partly enfolding each other. 32. Embryo of the same in early germination 33. 8ame more advanced; the plumule, whlch is just emerging in the preceding, here developed Into a long Internode anil a pair of leaves. 
latter are practically the earliest efficient foliage of the plantlet. Thus, as in the germinating Cherry-seed (Fig. 30), three or four internodes of stem, with their leaves, may be produced before these leaves themselves are sufficiently developed to make any sensible contribution to this growth. And in the Beech and Bean,
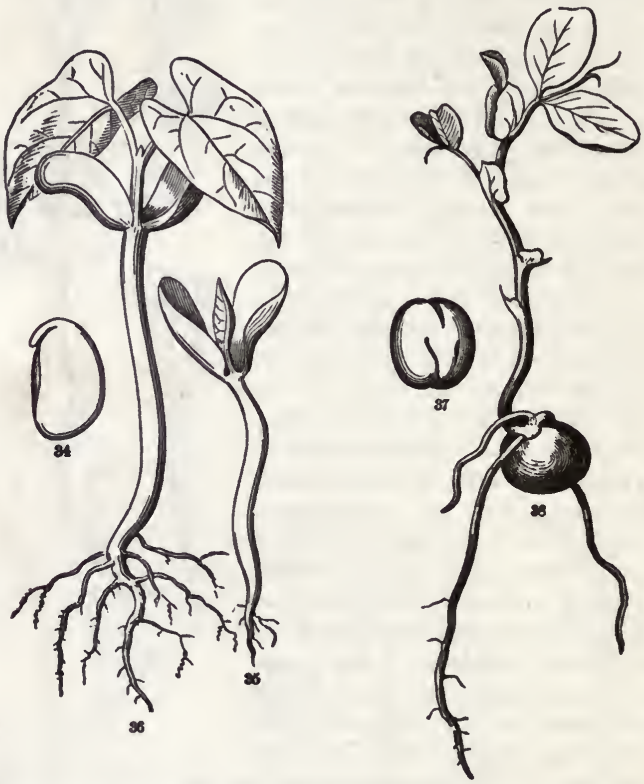

the leaves of the plumule come forward almost before the root has attached the plantlet to the soil. (Fig. 32, 35.) Between such cases and that of Maple and the like there are all degrees. There are also familiar cases in which the storage of nourishment in the cotyledons is carried to a maximum, with results which gravely affect the development.

FIG. 34. The embryo (the whole kernel) of the Bean. 35. Same early in germination; the thlck cotyledons expanding and showing the plumnle. 36. Same, more advanced in germination; the plumule developed into an internode of stem bearing a pair of leaves.

FIG. 37. Embryo of Pea, i. e. a pea minus the seed-coat. 38. Advanced germination of the same. 
32. Thus, in the Pea, near relative of the Bean, the embryo (Fig. 37), which is the whole kernel of the seed, has the cotyledons so gorged with this nutritive store that they are hemispherical; and the acorn of the Oak (Fig. 39), near relative of the Beech, is in similar case. These extremely obese cotyledons have not only lost all likeness to leaves, but all power of fulfilling the office of foliage, which is apparently no disadvantage; for when two different duties are performed by the same organ, it rarely performs both equally well. Here they become mere receptacles of prepared food; the nature and office of which is the same as of the albumen, or nutritive deposit exterior to the embryo in what are called albuminous seeds. (25-27.) The difference is in the place rather than in the character of the deposit. The plumule in such cases is always apparent before germination; and it develops even with more vigor than in the preceding cases. It usually rises as a stout stem of several internodes lengthening almost simultaneously, or at least the upper strongly developing long before the lower have finished their growth; and the latter are practically leafless, bearing only small and scale-like and useless rudiments of leaves. This is correlated with the peculiarity that the caulicle does not lengthen in germination, or it lengthens very slightly; the cotyledons remain within the coats of the seed; and if this were

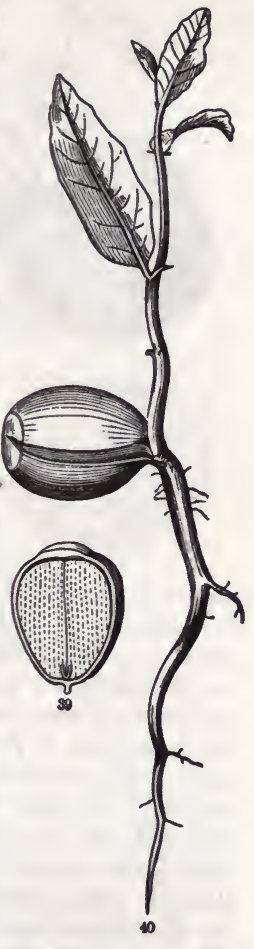
buried beneath the surface of the ground, there it remains. The abortion of the earliest leaves of the plumule is in correlation with this hypogroous ( $i$. e. underground) situation of the cotyledons throughout the germination. The slight elongation of the caulicle serves merely to protrude its root-end from the coats of the seed in a downward direction, and from this a strong root usually is formed.

FIG. 39. Section of an acorn, flled by the embryo. 40. Advanced germination $\alpha$ the same. 
33. In some Oaks, notably in our Live Oak (Quercus virens), and less so in the Horsechestnut, the two cotyledons coalesce or

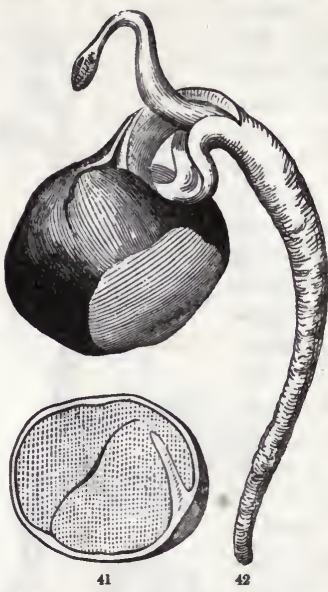
cohere by their contiguous faces. In some of these cases of hypogæous germination, the short caulicle and plumule are extricated from the enclosing coats or husk by the development of short stalks (petioles, 157) to the fleshy cotyledons ; as is seen in Fig. 42 , and in most germinating acorns. These petioles are not visible in the seed, but are the first development in germination.

34. There are some curious cases in which, while the caulicle remains short and subterranean, the cotyledons are raised out of ground in germination by the formation of far longer stalks (petioles) than those of the Horsechestnut. A singularly disguised instance of this kind is seen in Megarrhiza, a genus of Cucurbitaceous plants of California and Oregon, remarkable for their huge root. The large seed has very thick and fleshy cotyledons, and a very short and straight caulicle. In germination, the whole seed is elevated, seemingly in the manner of the bean, upon a stout stem. One waits for a long time expecting to see the cotyledons throw off the bursting husk and expand, or else to put forth the plumule from between their bases. But at length the plumule makes its appearance from an unexpected place, coming separately out of the soil. Removing this, the state of things represented in Fig. 43 is presented,-that of the plumule seemingly originating from the base, instead of the apex, of an elongated caulicle! But on examination of the cleft from which this proceeds, by making a section of the stem above (showing that it is hollow), and finally by separating the cotyledons and gently tearing apart the two short stalks by which they are united to their stem-like support, it is found that the latter may be divided into two (as shown in Fig. 44), even down to the cleft below. This explains the anomaly. The real caulicle has re-

FIG. 41. Section of a Horsechestnut or Buckeye seed, through the very thick cotyledons and the incurved caulicle. 42. Seed in germination, showing the petioles to the cotyledons, \&c. 
mained short and subterranean, and is confluent with the upper part of the thickening root: the seeming caulicle, which raised the cotyledons above the soil, consists of the petioles of these combined into a tubular stem-like body, no evident trace of which is visible in the seed, although in germination it attains the length of two or three inches : in age it is readily separable into the two leaf-stalks or petioles of which it is composed: the plumule is thus seen to be wholly normal, originating from between the cotyledons. All the extensive growth so far, and until the proper foliage-leaves of the continuation of the plumule are developed and begin their action, is from nutritive material stored in the thickened cotyledons, a considerable part of which was transferred to the already enlarging root, before a remaining portion was used in building up the strong plumule. The economy of this elevation of cotyledons which never open, and of the lengthened distance through which the nutritive matter has to be carried, is not apparent. But it is the family habit in Cucurbitaceæ to bring up the cotyledons that they may develop as leaves (as in the Pumpkin, Fig. 47): here this elevation is brought
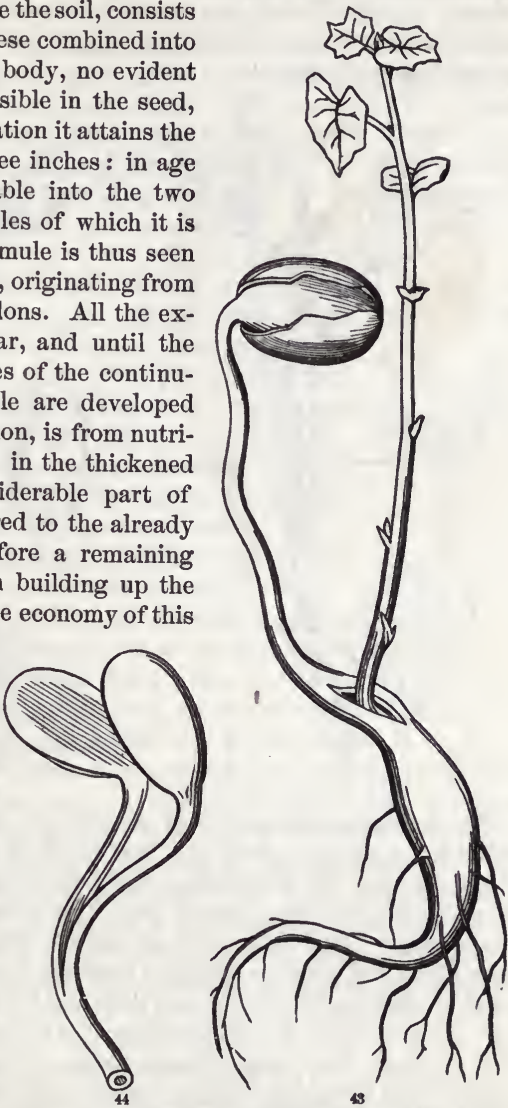
about in a different way, but without securing the useful end. ${ }^{1}$

1 It may be inferred that Megarrhiza is a descendant of some Cucurbitacea with thinner cotyledons, which in germination developed into long-stalked leaves, in the manner described in the next following paragraphs.

FIG. 43, 44. Peculiar germination of Megarrhiza Californica; explained above. 
35. This same anomaly, as to the development of long stalks to the cotyledons and their union into a stem-like body, occurs in various species of Larkspur (notably in the Californian Delphinium nudicaule); but in these the cotyledons develop into a pair of efficient green leaves.
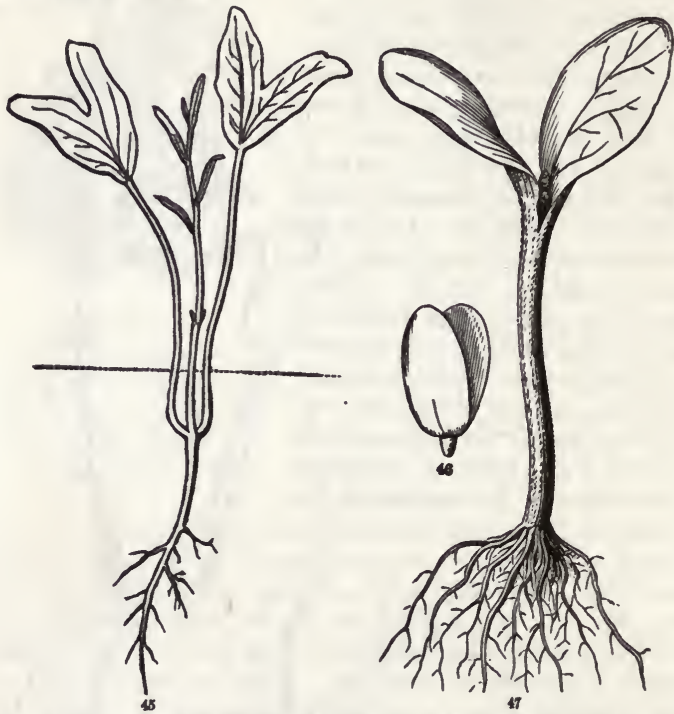

36. A similar elongation of petioles of the cotyledons, but without any union, occurs in a species of Morning Glory of the plains beyond the Mississippi (Ipomœa leptophylla); the leaflike cotyledons coming up on their long stalks separately from the ground (Fig. 45); the developed plumule rising some time afterward between them. Compare this with the ordinary species $(25$, Fig. 15, 16, 25), and note that the difference is merely that the caulicle in the common Morning Glory elongates and the petioles of the cotyledons remain short.

37. In all instances thus far a single primary root so regularly develops from the lower end of the axis of the embryo (variously named radicle or caulicle), and forms such a direct downward

FIG. 45. Germination of Ipomcea leptophylla; the caulicle not developing, the plumule and the petioled cotyledons rise from underground. Dotted line marks the level of the soil.

FIG. 46. Embryo of a Pumpkin, the cotyledons separated. 47. Same germinated; a cluster of roets from the base of caulicle. 
prolongation of it, that it was called the descending axis; and the body from which it originates was named the radicle, on the supposition that it was itself the nascent root. But, as already explained, the so-called radicle grows in the manner of stem (24), and is morphologically that initial internode the node of which bears the first leaves or cotyledons. (20.) Let it now be noted that this descending axis or single primary root is far from universal. In Pumpkin, Squash, Echinocystis, and the like, the strong caulicle sends out directly from its root-end a cluster of roots or rootlets, of equal strength; $i$. e., it strikes root in nearly the manner that a cutting does. (Fig. 47.)

38. The Polycotyledonous Embryo is one having a whorl of more than two seed-leaves. The dicotyledonous embryo being a whorl of the very simplest kind, that is, with the members reduced to two, the polycotyledonous may be regarded as a variation of it. In all but one group of plants it is simply a variation, of casual occurrence, or even a monstrosity, in which three or rarely four cotyledons appear instead of two. In Pines (Fig. 48, 49), however, and in most but not all Coniferæ, a whorl of from 3 to 10 cotyledons is the normal structure, varying according to the species, but of almost uniform number in each. In germination these are brought out of the soil by the elongation of the caulicle, and when the husk of the seed is thrown off they expand into a circle of needle-shaped leaves. In the Pine

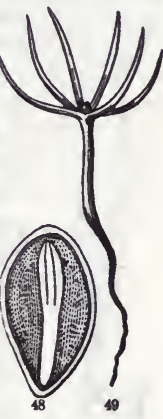
tribe, all the subsequent leaves are alternate (spiral) in arrangement, with some disguises. In the Cypress tribe, the cotyledons are fewer (not more than four, and more commonly only two), and the subsequent leaves also are in whorls of two to four; $i$. e., are either opposite or verticillate. From the occasional union at base of the cotyledons of a polycotyledonous embryo in pairs or groups, and from a study of their early development, Duchartre $^{1}$ plausibly maintains that such cotyledons really consist of a single pair, parted into divisions or lobes. The ordinary interpretation, however, is equally tenable.

39. The Monocotyledonous Embryo, although theoretically the simplest, is practically a more difficult study. It has a single cotyledon (as the name denotes); also a single leaf to each node

1 Ann. Sci. Nat. ser. 3, x. 207. This view, which originated with Jussieu, is adopted by Parlatore in DC. Prodr. xvi.

FIG. 48. Section of a seed of a Pine, with its embryo of several cotyledons. 49. Early seedling Pine, with its stemlet, displaying its six seed-leaves. 
of the plumule; that is, the leaves of the embryo are alternate. But the caulicle is usually very short, and there is no external
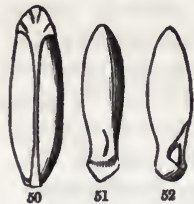
mark by which its limits may be distinguished from the cotyledon, until germination has begun. For a type of it, the embryo of some aquatic or marsh plants may be taken, where it forms the whole kernel of the seed (Fig. 50-53), and the structure can be made out antecedent to germination. It is understood by supposing that the cotyledon, which forms its principal bulk (the caulicle being only the

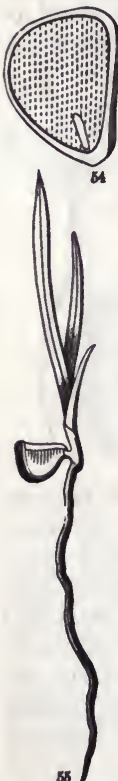
very short thickish base), is convolute around a short plumule, and the margins concreted, except a minute longitudinal chink at base, out of which the growing plumule protrudes in germination. The embryo of Iris may be similar in structure, but no distinction of parts is visible. It is very small in proportion to the size of the seed, the kernel being mostly albumen, - a supply of food, from which the germinating embryo draws the materials of its growth. When this takes place, either the cotyledon or the whole embryo lengthens, its lower part is pushed out of the seed, a root forms at the free end of the excessively short caulicle, and the plumule develops from the other in a series of one-leaved nodes, the internodes of which remain so short that the leaves continue in close contact, the bases of the older successively enclosing the inner and younger. (Fig. 55.) Here, therefore, the cotyledon mainly remains in the seed, and the seed remains underground (hypogæous).

40. It is somewhat different in the Onion, which has a similar embryo, except that it is longer, and the cotyledon is curved in the albumen of the seed. The first steps are the same as in Iris; but as soon as a root is formed and embedded in the soil, the cotyledon lengthens vastly more, into a long and filiform green leaf, which, taking an erect position,

IIG. 50. Seed of Triglochin palustre; the rhaphe, leading to the strong chalaza at the summit, turned towards the eye. 51. The embryo detached from the seed-coats, showing the longitudinal chink at the base of the cotyledon; the short part below is the radicle. 52. Same, with the chink tnrned laterally, and half the cotyledon cut away, bringing to view the plumule concealed within. 53. A cross-section through the plumula, more magnified.

FIG. 54. Section of seed of Iris, enlarged, showing the emall and apparently simple embryo at the base of the albumen. 55. Germinating seed and seedling of the same, of natural size. 
carries up the light seed far above the surface of the ground, the tip only remaining in the albumen of the seed until that is exhausted, when the tip perishes and the emptied husk falls away. About this time the plumule shoots forth from one side of the subterranean base of this cotyledonar leaf, in the form of a second and similar filiform leaf, to be followed by a third, and so on. The sheathing bases of these succeeding leaves become the coats of the Onion-bulb. The internodes remain undeveloped until the plant is ready to blossom. Very similar is the germination of a date-seed, except that the protruding cotyledon does not lengthen so much, nor does it elevate the heavy seed. Instead of the seed being carried up, the lower end of the embryo, contain-
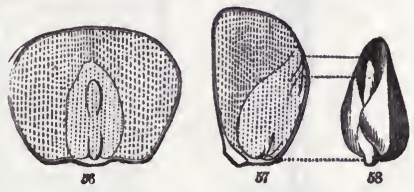
ing the plumule, is pushed down more or less into the loose soil, from which in time the developing plumule emerges.

41. The embryo of Grasses, especially of those which yield the cereal grains, is more complex, owing mainly to the great development of the plumule and the manner in which its rudimentary leaves successively enclose each other. That of Maize or Indian Corn, one of the largest, is most convenient
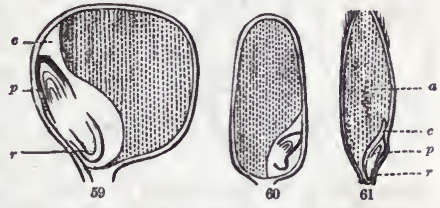

for study. (Fig. 56-59.) The floury part of the seed, which makes most of its bulk, is the albumen, largely composed of starch. The embryo is exterior to this, applied to one of its flat sides, and reaching from the thinner edge to or above the middle in the common variety of corn here represented. The form of the embryo is best shown, detached entire, in Fig. 58 : its structure appears in the sections. The outer part is the cotyledon, which incompletely enwraps the plumule : it adheres closely to the albumen by the whole back, and remains unchanged in germination: its function is to absorb nutritive

FIG. 56. Section, flatwise, of a grain of Indian Corn, dividing the albumen and the embryo. 57. Similar section at right angles to the first. 58. A detached embryo: corresponding parts of Fig. 57 and 58 indicated by dotted lines.

FIG. 59. Vertical section of Indian Corn across the thickness of the grain, dividing the embryo throngh the centre and displaying its parts: $c$, cotyledon; $p$. plumule; $r$, the radicle or canlicle.

FIG. 60. Similar section of grain of rice. 61. Same of an oat-grain; the parts as in Fig. 59. 
matter furnished by the albumen, and to transmit it to the growing plumule. The plumule consists of a succession of

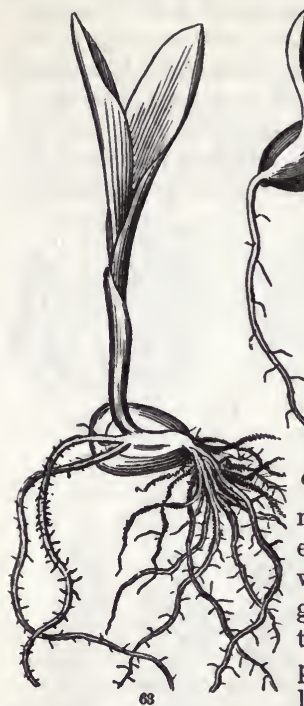
rudimentary leaves, sheathing and enclosing one another, on the summit of a very short axis, which is mainly the caulicle, otherwise called radicle. This is completely enclosed by a basal portion of the cotyledon and of the outermost leaf of the plumule, which form a peculiar sheath for it, named the Coleorhiza, ${ }^{1}$ i. e. root-sheath : consequently the first root or roots have to break through this covering. As in the Oak and Pea (32), the very first or outermost leaves of the plumule develop imperfectly and not into efficient foliage. The one in Fig. 62, which encloses the rest in the early growth, is left behind as a mere sheath to the base of the following and more perfect leaves: it is the same as the lowest in Fig. 63. The leaves are first developed : the internodes lengthen later, and the lowest lengthen very little. Not rarely the first root starts singly from the tip of the caulicle (Fig. 62, just as in Fig. 55) ; but others of equal strength follow from any part of the caulicle, and soon from the nodes above; and no tap-root is ever formed.

42. A Pseudo-monocotyledonous embryo occasionally occurs; that is, one of the dicotyledonous type, of which one cotyledon is wanting through abortion. This occurs in Abronia, a genus related to Mirabilis, and bearing an embryo very similar to that represented in Fig. 17, 18, except that one cotyledon is absent. The anomaly of an acotyledonous embryo occurs in Dodder, a plant of the dicotyledonous type, but with both cotyledons

1 This, the Coleorhize of Mirbel, should not be confounded (as by some it has been) with the "root-cap," or tissue which ordinary roots (whether primary or secondary) break through in their development or carry on their apex.

FIG. 62. Early germination of Indian Corn. 63. More advanced germination of same: roots produced from portion of stem above the cotyledon as well as below. 
actually wanting, - a correlation with its parasitic mode of life. (64, Fig. 78.)

43. The dicotyledonous and the monocotyledonous character of the embryo is correlated with profound differences in the whole ulterior development, as revealed in the structure of the stem, leaves, and flower; which differences mark the two great divisions of Phænogamous plants, viz. Dicotrledones or Dicotyledonous Plants, and Monocotyledones or Monocotyledonous Plants, - names introduced into classification by Ray, and adopted by A. L. Jussieu, in his Genera Plantarum.

\section{CHAPTER III.}

MORPHOLOGY AND STRUCTURE OF THE ORGANS OF THE PLANT IN VEGETATION.

\section{Section I. Of the Root.}

44. The Root, which has been called the descending axis, is that portion of the body of the plant which grows downward, ordinarily fixing the vegetable to the soil, and absorbing from it materials which the plant may elaborate into nourishment. As already stated (24), the root grows in length, by continuous additions of new fabric to its lower extremity, elongating from that part only or chiefly; so that the tip of a growing root always consists of the most newly formed and active tissue. It normally begins, in germination, at the root-end of the caulicle, or so called radicle. But roots soon proceed, or may proceed, from other parts of the stem, when this is favorably situated for their production. The root does not grow from its naked apex, but from a stratum immediately behind it: consequently its blunt

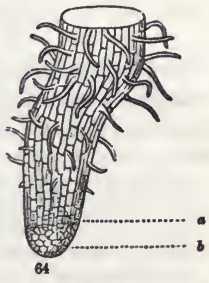
or obtusely conical advancing tip consists of older, firmer, and in part effete tissue. The tip of all secondary roots and rootlets

FIG. 64. Magnified tip of root of a seedling Maple (such as in Fig. 9), sufficiently enlarged to indicate the cellular structure: $a$. the portion where growth is taking place; $b$. the older and firmer tip. 
is similarly capped or protected. ${ }^{1}$ But the so-called root-cap is seldom so distinct or separable as to deserve a particular name.

45. Nature of Growth, Cells. The development and growth of the root, as of other organs, results from the development, growth, and increase in number of certain minute parts, of which the plant is built up. These component parts are so much alike, at least in an early stage, and are so obviously formed all on one type, that they take one common name, that of Cells. These are the histological elements of plants, $i$. e. the units of minute anatomical structure. While, in the morphology of the plant's obvious organs, analysis brings us to the phytomer (16) as the individual element which by a kind of propagation produces its like in a second phytomer, remaining however in connection with the first, thus building up the general structure, so, in an analogous way, each of the obvious parts - each stalk or blade or rootlet - is microscopically determined to be composed of these ultimate organic units, generally called cells.

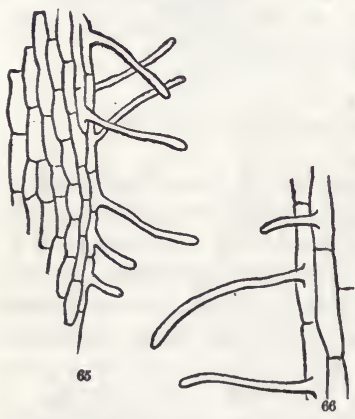

The cell (cellula, by the French conveniently termed cellule) is the living vegetable unit, in the same sense that the brick is the unit of a brick edifice. To make this analogy fairly complete, the bricks should be imagined to have a firm exterior or shell, and a soft or at length hollow interior, also to be living when incorporated into the structure, and finally to be produced in the forming structure by a kind of propagation. The production or increase in number of these cells by development from previous ones, and their successive increase in size up to maturity, are what constitutes vegetable growth. ${ }^{2}$ The inspection through a

1 The notion that the tip of the root consists of delicate forming or newly formed tissue, or bears some organ or structure of this nature (a "Spongiole"), has hardly yet been eliminated from the text-books and popular writings. It had no proper foundation in fact.

In Lemna, and in some other aquatics, and also in some aerial roots, this older tissue often separates into a real root-cap, free at base, like an inverted calyptra.

2 This, as to the structure, is the subject of Histology; as to processes or actions, the subject of Physiology; both to be treated in a separate volume.

FIG. 65, 66. Portions of surface of Fig. 64, more magnified, clearly displaying the superficial cellular structure and the long processes from some of the cells, called root hairs, which abound on the upper part of Fig. 64. 
simple microscope of a slender young root, and of thin slices of it immersed in water, may serve to give a general though crude idea of the vegetable cellular structure, sufficient for the present purpose. Roots are naked; that is, they bear no other organs. When they send off branches, these originate from the main root just as roots originate from the stem; and in both cases without much predetermined order. The ultimate and very slender branches are sometimes called root-fibrils; but these are only delicate ramifications of the root. Like any other part of the plant, however, roots may produce hairs or such like growths from the surface, which are wholly distinct from branches. (383.)

46. Root-hairs. Roots absorb water, \&c., from the soil by imbibition through the surface ; that is, through the walls of the cells, which are in a certain sense permeable to fluids, more readily when young and tender, less so when older and firmer. Roots, therefore, absorb most by their fresh tips and adjacent parts; and these are continually renewed in growth and extended further into the soil. As the active surface of a plant above ground is enormously incrcased by the spread of foliage, so in a less degree is the absorbing surface of young roots increased by the production of root-hairs. (Fig. 64, upper part, and more magnified in Fig. 65, 66.) These are attenuated outgrowths of some part of the superficial cells into capillary tubes (only one from each cell), closed at the tip, but the calibre at base continuous with the cavity of the cell; into which, therefore, whatever is imbibed through the thin wall may freely pass. These appear (as Fig. 64 shows) at a certain distance behind the root-tip. Further back the older or effete root-hairs die away as the cells which bear them thicken into a firmer epidermis.

47. To the general statement that roots give birth to no other organs, there is this abnormal, but by no means unusual exception, that of producing buds, and therefore of sending up leafy branches. Although not naturally furnished with buds in the manner of the stem, yet many roots have the power of originating them under certain circumstances, and some produce them habitually. Thus Apple-trees and Poplars send up shoots from the ground, especially when the superficial roots are wounded. And the roots of Maclura or Osage Orange so readily originate buds that the tree is commonly propagated by root-cuttings.

48. Kinds of Roots. The root, commonly single, which originates from the embryo itself, is called the Primary Root. (37.) Roots which originate from other and later parts of the stem, or elsewhere, are distinguished as SEcondary Roots. But the 
latter are as normal as the primary root; that is, to stems so situated that they can produce them. Most creeping plants emit them freely, usually from the nodes; and so do most branches, not too old, when bent to the ground and covered with earth, thus securing the requisite moisture and darkness. Separate pieces of young stems (cuttings) can commonly be made to strike root. Upon this faculty of stems to originate roots depends all propagation by division, by laying or layering, by cuttings, \&c. It is mainly annuals and common trees that naturally depend on the primary root; and most of these can be made to produce secondary roots. Even leaves and leaf-stalks of some plants may be made to strike root and be used as cuttings. (77.)

49. Duration. By differences in respect to this, either the root or the plant, as the case may be, is distinguished into Annual, Biennial, or Perennial, according to whether life is continued for a single year or season, for two, or for a greater number. The difference is not in all cases absolute or even well marked.

50. Annuals are plants which, springing from the seed, flower and seed the same year or season, and die at or before its close. They produce fibrous roots, either directly from the embryo and succeeding joints of stem (as in Grasses, Fig. 63), or from a persistent primary or tap-root, more or less thickened into a trunk or divided into branches. The products of vegetation in all such herbs are not stored in subterranean or other reservoirs, but are expended directly in new vegetative growth, in the production of blossom, and finally in the maturation of fruit and seed. This completed, the exhausted and not at all replenished individual perishes.

51. But some annuals may have their existence prolonged by not allowing them to blossom or seed. Others, with prostrate stem or branches, may from these produce secondary roots, which, forming new connections with the soil, enable the newer growth to survive when the older parts with the original root have perished. And many herbs, naturally annuals, are continued from year to year through such propagation from the branches, used as layers or cuttings. Moreover, certain plants (such as Ricinus or Castor-oil Plant), which are perennial or even arborescent in warm climates to which they belong, become annuals in temperate climates, early perishing by autumnal cold.

52. The annuals of cool climates, where growth completely ceases in winter, germinate in spring, mature, and die in or before autumn. But, in climates with comparatively warm and rainy winter and rainless summer, many germinate in autumn, vegetato 
through the winter, flower and seed in spring, and perish in early summer. These may be termed Winter Annuals.

53. Biennials are plants which, springing from the seed and vegetating in one season, live through the interruption of winter, and blossom, fructify, and perish in the next growing season; their life being thus divided into two stages, the first of vegetation, the second of fructification. In typical biennials, nearly the whole work of vegetation is accomplished in the first stage, with the result of accumulation of a stock of nutritive matter, to be expended in the second stage in the production of blossom and seed. This accumulation is usually stored in the root or in the base of a very short stem in connection with the root. The root of a biennial accordingly enlarges and becomes fleshy, or obese, as this matter accumulates. At the close of the growing season, - the leaves perishing and the stem having remained very short (with undeveloped internodes), - the root, crowned with the bud or buds, contains the main result of the summer's work, as provision for the next year's development and the completion of the cycle. This development, being thus amply provided for, is undertaken in spring with great vigor ; blossom, fruit, and seed are rapidly produced; and the stock being consumed, but not at all replenished, the cells of the great root are now empty and effete, and the individual perishes. The Beet, Turnip, Parsnip, and Carrot are familiar examples of biennials, with the store of nourishment in the root. ${ }^{1}$

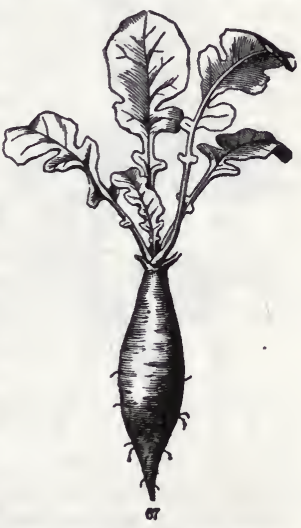
The Kohl-rabi is a biennial with this deposit in the stem: the Cabbage, partly in the stem, partly in the head of leaves.

1 In these the caulicle enlarges with the root, so that the npper and bud-bearing end is stem.

Tap-roots of this kind are said, in descriptive botany, to be

Fusiform or Spindle-shaped, when broader in the middle and tapering towards both ends, as in the common Kadish (Fig. 67);

Conical, when tapering regularly from base to tip, as in carrots, \&c. ;

Napiform, i. e. Turnip-shaped, when the thickened part is wider than high, \&c.

Fascicled Roots are those which form in clusters; these may be slender or thickened. When much thickened, either irregularly or not of the abore shapes, they are said to be tuberous.

FIG. 67. Radish : a fusiform tap-root. 
54. But some plants, such as the Radish, which when they spring from seed in autumn are true biennials, will when raised in spring pass on directly to the flowering stage in summer, or when sown after the warm season begins will often run through their course as annuals. Then there are various biennials which thicken the root very little and hold their leaves through the winter. Between these and winter annuals no clear demarcation can be drawn. As respects annual and biennial duration, the terms may for the most part be applied indiscriminately to the plant or to the root. We may say either that the plant is a biennial, or that its root is biennial.

55. Perennials are plants which live and blossom or fructify year after year. They may or they may not have perennial

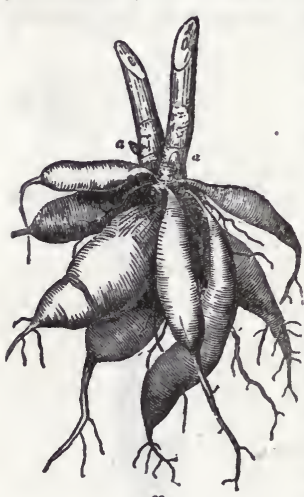
roots. In trees and shrubs, also in herbs with growth from year to year from a strong tap-root, the root is naturally perennial. But in most perennials with only fibrous roots, these are produced anew from time to time or from year to year. Also, while some such roots remain fibrous and serve only for absorption, others may thicken in the manner of the ordinary biennial root and serve a similar use, $i$. e. become reservoirs of elaborated nourishment. The Dahlia (Fig. 68) and the Peony afford good examples of this. Sweet potato is another instance. ${ }^{1}$ Most such roots have only a biennial duration : they are produced in one growing season; they yield their store to form or aid the growth of the next. When perennials store up nutritive matter underground, the deposit is more commonly made in a subterranean portion of the stem, in tubers, corms, bulbs, \&c. (See 115-122.)

56. The distinction between annuals and biennials is at times so difficult, and the particular in which they agree so manifest, - namely, that of blossoming only once, then dying, as it were by exhaustion, - that it was proposed by DeCandolle to unite

1 It is only by the readiness of this root to produce adventitious buds, especially from its upper part, that it has been mistaken for a tuber, such as the common potato.

FIG. 68. Fascicled and tuberous or fusiform (secondary) roots of Dahlis: $a, a$. buds on bese of the stem. 
the two under the common appellation of Monocarpic plants, Planta monocarpica, taken in the sense of only once-fruiting plants; and to designate perennials by the corresponding term of PoLYCARPIC, Planta polycarpica, literally many-fruited, taken in the sense of many-times fruiting. ${ }^{1}$

57. But the distinction even here is no more absolute than that between annuals and biennials. For example, it is not quite clear whether the Cardinal Flower and related species of Lobelia should be ranked as annuals, biennials, or perennials. The plants may blossom and seed toward the end of the season in which they came from seed; or, germinated in autumn, the small seedlings may survive the winter; but whenever fructified the fibrous-rooted mother plant dies throughout; yet usually not before it has established, and perhaps detached from the base, small offsets to blossom the next season; and so on. Then Houseleeks (Sempervivum) and such-like fibrous-rooted succulent plants multiply freely by offsets which are truly perennial in the sense that they live and grow for a few or several years; but when at length a flowering stem is sent up producing blossom and seed, that plant dies as completely and in the same manner as any biennial, only the generation of offsets surviving. The same is true of the Century plant (Agave Americana, wrongly denominated American Aloe), which vegetates in the manner of the accumulating stage of a biennial, except that this continues for several or very many years, while the flowering stage, when it arrives, is precipitated and terminated in a single season.

58. Although the stem usually sends forth roots only when covered by or resting on the soil, which affords congenial darkness and moisture, yet these are in some cases produced in the open air. Roots may likewise subserve other and more special uses than the absorption of crude or the storing of elaborated nourishment.

59. Aerial Roots is a general name for those which are produced in the open air. One class of these may serve the office of ordinary roots, by descending to the ground and becoming established in the soil. This occurs, on a small scale, in the stems of Indian Corn; the lower nodes emitting roots which grow to the length of several inches before they reach the ground

1 These terms or some equivalents have a convenience in descriptive botany. But those employed by DeCandolle are not happily chosen, as has of ten been said. Monotocous (bearing progeny once) and Polytocous (bearing many times) would be more appropriate. 
into which they penetrate. More remarkable cases abound in those tropical regions where the sultry air, saturated with moisture for a large part of the year, favors the utmost luxuriance of vegetation. In the Palm-like Pandanus or Screw-Pine ${ }^{1}$ (Fig. $69)$, very strong roots, emitted in the open air from the trunk,

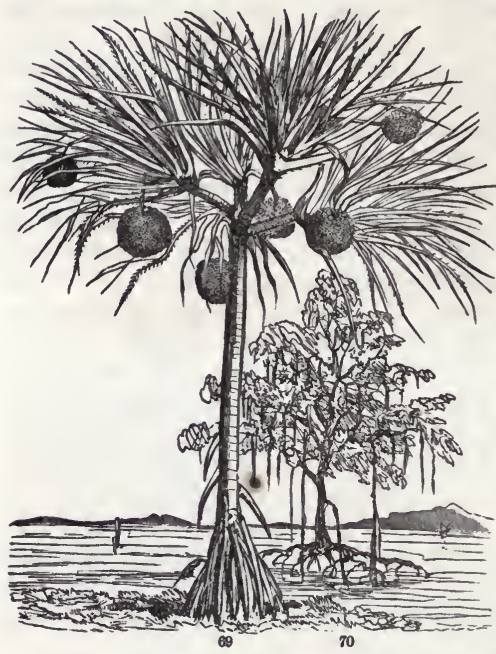

and soon reaching the soil, give the appearance of a tree partially raised out of the ground. The famous Banyan-tree of India (Fig. 71) is a still more striking illustration; for the aerial roots strike from the horizontal branches of the tree, often at a great height, at first swinging free in the air, but finally reaching and establishing themselves in the ground, where they increase in diameter and form accessory trunks, surrounding the original bole and supporting the wide-spread canopy of branches and foliage. Very similar is the economy of the Mangrove (Fig. 70), which forms impenetrable thickets on low and muddy sea-shores in the tropics throughout most parts of the world, extending even to the coast of Florida and Louisiana. Here aerial roots spring not only from the main trunk, as in the Pandanus, but also from the branchlets, as in the Banyan. Even the radicle of the embryo starts into growth, protrudes, and attains considerable length while the fruit is still attached to the branch.

$59^{a}$. Aerial Rootlets for elimbing are familiar in the Ivy of the Old World (Hedera), Trumpet-Creeper (Tecoma radicans), and our Poison Ivy (Rhus Toxicodendron); by the adhesion of

1 So named, not from any resemblance to a Pine-tree, but from a likeness of the foliage to that of a Pine-Apple.

FIG. 69. Pandanus, or Screw-Pine; and in the background, 70, a Mangrove-tree (Rhizophora Mangle). 
which the stems, as they grow, ascend walls and the trunks of trees with facility. In Rhus a superabundance of these rootlets is produced, thickly covering all sides of the stem.

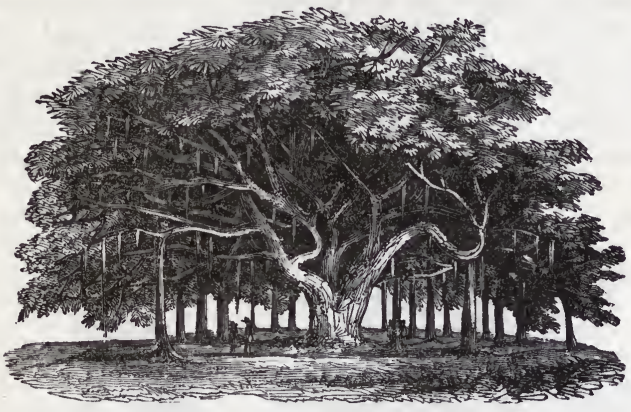

71

60. Epiphytes or Air-Plants also have roots which are throughout life unconnected with the ground. Epiphytes, or Epiphytic plants, as the name denotes, are such as grow upon other plants without taking nourishment from them. Deriving this from the air alone, they are called Air-plants. This name might be extended to the same or other kinds of plants attaching themselves to bare walls, rocks, and the like, and unconnected with the soil, though such would not technically be epiphytes. Very many Lichens, Mosses, and other plants of the lower grade, and not a few phænogamous plants, are in this case. The greater part of the phænogamous Epiphytes pertain to two monocotyledonous orders, the Orchis family and that to which the PineApple belongs, viz. the Bromeliaceæ. Their thread-like or cord-like simple roots either adhere to the bark of the supporting tree, securing the plant in its position, or some hang loose in the air. Of these, Orchids, i.e. plants of the Orchis family, are the most showy and numerous, and of the greatest variety of forms, especially of their blossoms, which are often bizarre and fantastic. They belong, naturally, to climates which are both warm and humid; they are highly prized in hot-house cultivation; and, along with the hardy and terrestrial portion of the order, they are peculiarly interesting to the botanist on account of the singular and exquisite adaptation of their flowers in relation to insects which visit them. In some the blossoms curiously 
resemble butterflies or other insects; as, for example, Oncidium Papilio, Fig. 72. Epiphytic orchids are indigenous to the United States only from Georgia to Texas, and only in huisble forms, in company with species of Tillandsia, representing Bromeliaceous epiphytes. The commonest of the latter tribe, and of most northern range, is the T. usneoides, the so-called Long Moss, which, pendent in long and tangled gray clusters or festoons from the branches of the Live-Oak or Long-leaved Pine, gives such a peculiar and sombre aspect to the forests of the warmer portions of our Southern States.

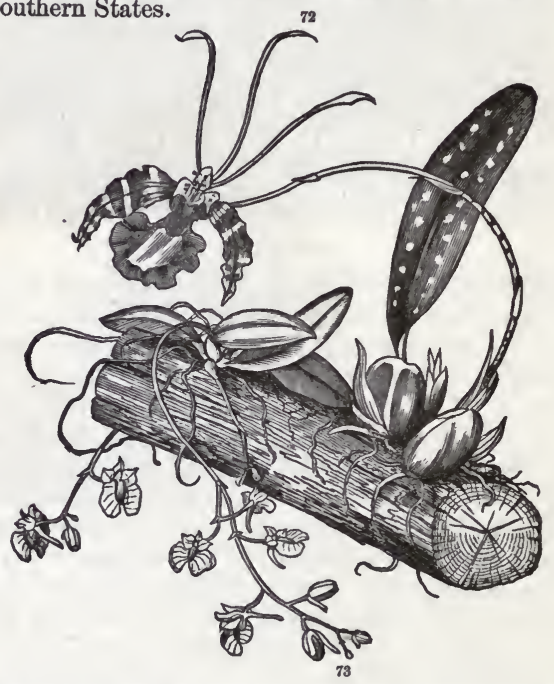

61. Parasitic Plants have the peculiarity that their roots, or what answer to roots, not only fix themselves to other plants, but draw therefrom their nourishment, at least in part. Among cryptogamous plants very many Fungi are parasitic upon or within living plants or animals. But only phænogamous parasites are here under consideration. These may be divided into two classes; those with and those without green foliage.

62. Green Parasites may be either wholly or partially parasitic; that is, they may draw all their support from a foster plant, or

FIG. 72. Oncidium Papilio, and, 73, Comparettia roses; two showy epiphytes of the Orchis family; showing the mode in which these Air-plants grow. 
they may be likewise rooted in the soil, and receive from it materials of their food. Having green foliage, they are capable of elaborating such food, whether taken directly from the soil or from the crude sap of the foster plant. The Mistletoes (Viscum and its allies) are the principal examples of complete green parasitic plants. Seeds dropped by birds on the boughs of trees germinate there; the root-end of the caulicle points thither instead of towards the earth; the root, or what would be such, penetrates the bark and incorporates itself with the sap-wood so perfectly that the junction of parasite with foster trunk is like that of branch with parent trunk. The parasite is probably fed by both elaborated and crude sap, that is, both by what the foster tree has assimilated and what it has merely taken from the soil and air: the former it can at once incorporate; the latter it has first to assimilate in its own green leaves. Sometimes one Mistleto is parasitic upon another of the same or of a different species.

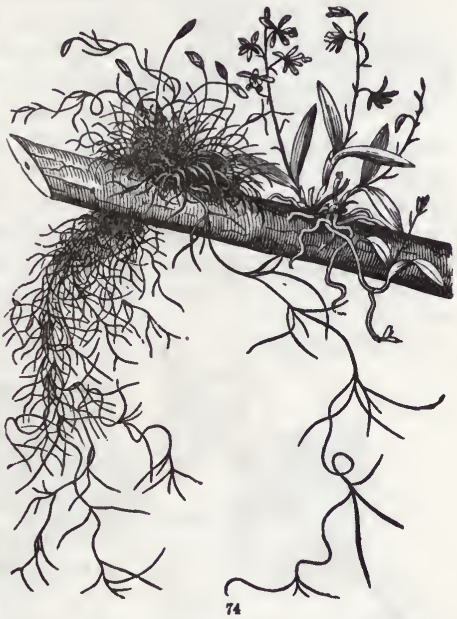

63. Partially parasitic plants (mostly green) may be either woody and arborescent or herbaceous. The species of Clusia in tropical

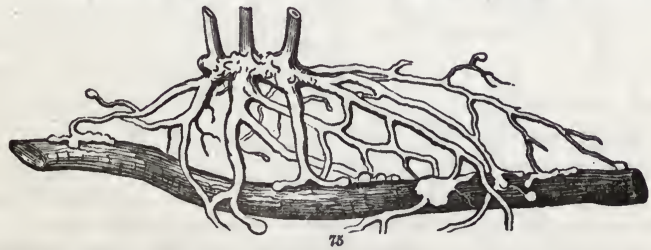

FIG. 74. Native eplphytes of Georgia, \&c. : the erect one at the right an Orchid, Epidendrum conopseum; the hanging one Tillandsia nsneoldes, called Long Moss.

FIG. 75. Roots of Gerardia flava : some of the rootlets attaching themselves para sitically to the root of a Blueberry. (From a drawing by Mr. J. Stauffer.) 
America (called Cursed Fig) are examples of the former. They form trees, send down aerial roots in the manner of the Banyan; but, while some roots seek the ground, some may attach themselves to other trees parasitically, and draw from them a portion of their support. The parasitism of certain herbaceous plants with green foliage is clandestine, the connection being underground and therefore long unsuspected. This occurs in species

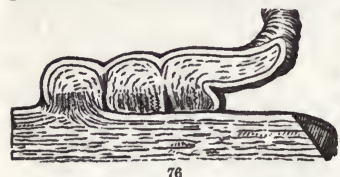
of Gerardia (at least of the section Dasystoma) and other plants of the same family, the uncultivability of which is thereby explained. Also in Comandra and in their relatives the Thesiums of the Old World, belonging to a natural order (the Santalaceæ) which has much affinity with the entirely parasitic order (Loranthaceæ) to which the Mistleto belongs.

64. Pale or Colored Parasites, such as Beech-Drops, Pine-Sap, \&c., are those which are destitute of green herbage, and are

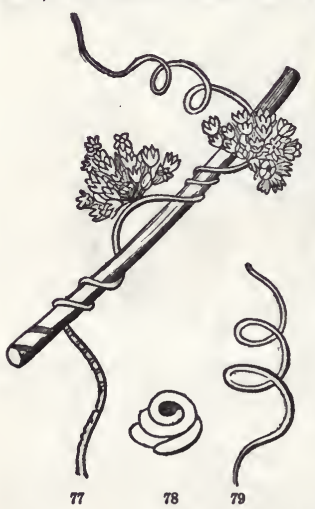
usually of a white, tawny, or reddish hue; in fact, of any color except green. These strike their roots, or sucker-shaped discs, into the bark, mostly that of the root, of other plants, and thence draw their food from the sap already elaborated. They have accordingly no occasion for digestive organs of their own, $i$. e. for green foliage. The Dodder (Fig. 77) is a common plant of this kind which is parasitic above ground. Its seeds germinate in the earth, but form no proper root: when the slender twining stem reaches the surrounding herbage, it forms suckers, which attach themselves firmly to the surface of the supporting plant, penetrate its epidermis, and feed upon its juices; while the original root and base of the stem perish, and the plant has no longer any connection with the soil. Thus stealing its nour-

FIG. 76. Section of one of the attached rootlets of Gerardia, showing the union.

FIG. 77. The common Dodder of the Northern States (Cuscuta Gronovii), of the natural size, parasitic upon the stem of an herb: the uncolled portion at the lower end shows the mode of its attachment. 78. The coiled embryo taken from the seed, consisting of naked caulicle and plnmnle; moderately magnified. 79. The same in germination, elongating into a thread-like leafless stem. 
ishment ready prepared, it requires no proper digestive organs of its own, and, consequently, does not produce leaves. This economy is foreshadowed in the embryo of the Dodder, which is a naked thread spirally coiled in the seed (Fig. 78, 79), and presenting no vestige of cotyledons or seed-leaves. A species of Dodder infests and greatly injures flax in Europe, and sometimes makes its appearance in our own flax-fields, having been introduced with the imported seed. Such parasites do not live upon all plants indiscriminately, but only upon those whose elaborate juices furnish a propitious nourishment. ${ }^{1}$ Some of them are restricted, or nearly so, to a particular species; others show little preference, or are found indifferently upon several species of different families. Their seeds, in some cases, it is said, will germinate only when in contact with the stem or root of the species upon which they are destined to live. Having no need of herbage, such plants may be reduced to a stalk bearing a single flower or a cluster of flowers, or even to a single blossom developed from a bud directly parasitic on the bark of the foster plant. Of this kind are the several species of Pilostyles (parasitic flowers on the shoots of Leguminous plants) in Tropical America, one species of which was discovered by Dr. Thurber

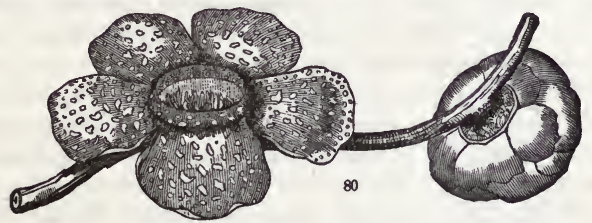

near the southern borders of New Mexico. Its flowers are small, only about a quarter of an inch in diameter. The most wonderful plant of this kind is that vegetable Titan, the Rafflesia Arnoldi of Sumatra (Fig. 80) which grows upon the stem of a kind of a Cissus or Vitis. It is a parasitic flower, measuring nine feet in circumference, and weighing fifteen pounds! Its color is light orange, mottled with yellowish-white.

1 Monotropa or Indian Pipe (and perhaps some related plants), although probably parasitic on living roots in early growth, appears to live afterwards in the manner of the larger Fungi, upon leaf-mould and decaying herbage. Its mode of life should be investigated.

FIG. 80. Rafflesia Arnoldi; an expanded flower, and a bud, directly parasitic on the stem of a vine: reduced to the scale of half an inch to a foot. 


\section{Section II. Of Buds.}

65. Buds are the germs of stems: they are axes with their appendages in an early state. LEAF-BUds (GEMms) are those devoted to vegetation, and the parts, or some of them, develop as leaves. MIXED BUDs contain both foliage and flower or flowers. Flower-buds (Alabastra) are unexpanded blossoms. These are considered in another chapter.

66. The conspicuous portion of an ordinary bud, or that which first develops, usually consists of leaves, or scales the homologues of leaves; the axis itself being very short and undeveloped. If this remains comparatively short, the leaves as developed are crowded in a rosette, as in a Houseleek (Fig. 91 ${ }^{b}$ ), a Barberry and the Larch: when the internodes lengthen, the leaves are interspaced upon the axis.

67. The cotyledons and plumule of the embryo are, morphologically, the first bud, on the summit of the initial stem, the caulicle. This in germination and subsequent growth develops into a leafy stem, in the manner already described. Normally this stem has the capacity of growing on in this way from the apex or growing point, which is always potentially a bud, the apical or terminal bud (15). Sometimes it is merely potential, and there is no external structure visible until the new growth begins, or the bud is said to be latent.

68. But commonly, in plants that live from year to year, growth is divided into seasons or stages, with intervals of repose. In such cases, especially in trees and shrubs, instead of a continuous succession of foliage, the period of interruption is apt to be marked by the production of scales (Bud-scales, Perula, etc.) or dry teguments, which serve to protect the tender rudiments or growing point within during the season of rest. This being the winter-season in cold climates, Linnæus gave to such bud-coverings the common name of Hibernaculum. From the usually squamose (scale-like) character of this covering, such buds take the name of

69. Scaly Buds. Large and strong ones of this kind, such as those of Horsechestnut, Magnolia, Hickory, Lilac, \&c., may be taken as the type of bud. The scales serve to protect the tender parts within against injury from moisture and from sudden changes in temperature during the dormant or earliest growing state. To ward off moisture more effectually, they are sometimes coated with a waxy, resinous, or balsamic exudation, as is conspicuous on the scales of the Horsechestnut, Balsam-Poplar or Balm of Gilead, and Balsam-Fir. To guard against sudden 
changes of temperature, they are often lined, or the rudimentary leaves within invested with non-conducting down or wool.

70. Nature of Bud-scales. That they answer to leaves is made manifest by a consideration of their situation and arrangement, which are the same as of the proper leaves of the species; and by the gradual transitions from the former to the latter in many plants. In the Turions, or subterranean budding shoots of numerous perennial herbs, and in the unfolding buds of the Lilac and Sweet Buckeye (Asculus parviflora), every gradation may be traced between bud-scales and foliage, showing that no line of distinction can be drawn between them, but that the two are essentially of the same nature, are different modifications of the same organ. In the Lilac they may be regarded as the blade of the leaf, modified and depauperate; in the Buckeye (Fig. 233), and therefore in Horsechestnut, as the base of leaf-stalks; in Magnolia (Fig. 81, 82), in the Tulip-tree, and in the Beech, they are evidently stipules. They must therefore be referred to in the section on the morphology of leaves. (227.)

71. Naked Buds, \&c., of shrubs and trees, even in climates with severe winter, are not unknown, that is, buds unprotected by special scales or other coverings. For example, the latest pair of leaves of the season in Viburnum nudum, V. lantanoides (Hobblebush), and the like, remain in a nascent state over winter without covering, and expand into the first foliage in the spring.

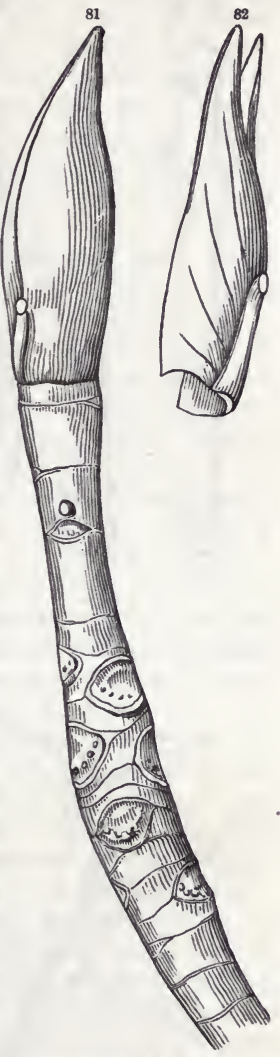
Yet V. Opulus (Snowball, \&c.), another species of the same genus and inhabiting the same region, has well-formed scaly

FIG. 81. Branch of Magnolia Umbrella, of the natural size, crowned with the terminal bud; and below exhibiting the large rounded leaf-scars, as well as the rings or annular scars left by the fall of the bud-scales of the previous season. 82. A detacbed scale from a similar bnd; Its thickened axis is the base of a leaf-stalk; the membranous sides consist of the pair of stipules united with it. 
leaf-buds. In other hardy shrubs and trees, the buds, equally

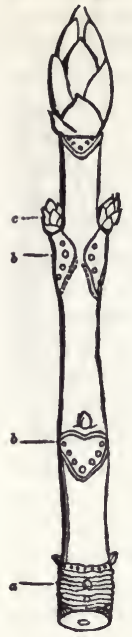

85

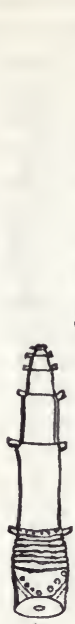

84

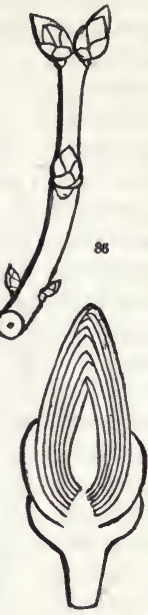

83 or almost destitute of scales, are minute, hidden in or under the bark, or otherwise inconspicuous until vernal growth commences. Philadelphus and Taxodium are of this kind.

72. Subpetiolar Buds. Some leaf-buds are singularly covered in their early state and through the summer, as in the Locust (Robinia), Honey-Locust Fig. 96 (where they remain very undeveloped), in Yellow Wood (Cladrastis), and more conspicuously in the Plane-tree (Platanus, Fig. 87) : here they are all formed under the base of the protecting leaf-stalk, which in Plane-tree forms a sheath or inverted cup, very like a candle-extinguisher, fitted to and concealing the conical bud until autumn, when by the fall of the leaves these buds are exposed.

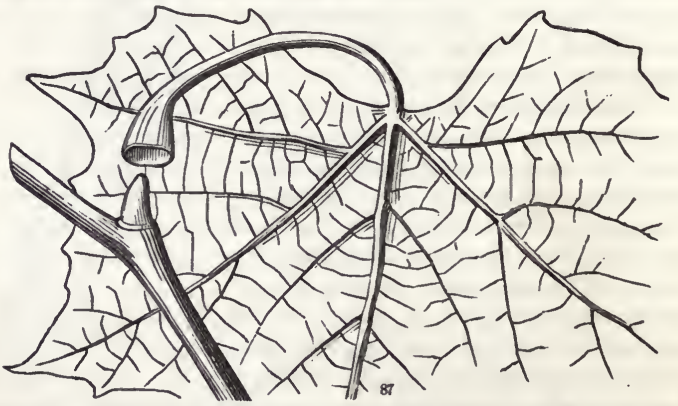

FIG. 83. Dlagram of vertical section of a strong bud, such as of Horsechestnut. 84. The axis of the same developing, the elongation beginning with the lowest internode, soon followed by the others in succession. 85. A year's growth of Horsechestnut, crowned with a terminal bud: $a$, ecars left by the bud-scales of the previous year: $b$, scars left by the fallen leaf-stalks: $c$, axillary buds.

FIG. 86. Branch and buds (all axiliary) of the Lilac.

FIG. 87. Leaf-bud under the petiole of the Plane-tree. 
73. Fleshy Buds. Bulbs are peculiar buds of certain herbaceous plants, with fleshy scales, and often of a more permanent character. Their nature and economy may most conveniently be illustrated under subsequent sections. Usually bulbs are subterranean or partly so. But small bulbs (Bulblets, 123) regularly appear in the axil of nearly all the leaves of certain common Lilies, being obviously ordinary axillary buds, under certain modifications. They become detached at maturity, fall to the ground, produce roots, and grow as independent plants; and their fleshy scales are storehouses of nourishment for the early support of this independent growth.

74. Bud-propagation is a normal mode of reproduction in cases like the above, the spontaneously detached bulblets or buds establishing themselves as progeny. In several species of Allium (Onions and Leeks), such bulblets usurp the place of flower-buds, making the analogy seem closer. Stems or branches which habitually root in the soil, or along its surface, equally propagate or divide into new individuals, becoming distinct by the perishing of the older connecting parts, or by breaking away from them. Propagation by cuttings is an acceleration or extension of this same natural operation. . The cutting is a portion of stem bearing one or more buds, which, through the faculty of the stem to strike root, is made to grow independently. In grafting, such a cutting, and in budding a bud only, with a small portion of wood and bark, is transferred to the stem of another plant of the same or of some related species, and made to grow there, uniting its wood and bark with those of the stock, and so becoming a limb or branch, in place of striking root into the soil and becoming a separate plant. The horticultural advantage of bud-propagation is, that the offsets or new individuals share in all the peculiarities of the parent as completely as if still branches of that tree. In propagation by seed, the special peculiarities or excellencies of individuals or varieties may not, and in some measure probably will not, be reproduced.

75. Normal or Regular Buds, as to position, are either terminal or axillary, as already stated. (15.) They are single, that is, one bud normally occupies the apex of a stem or branch, and appears, or usually may appear, in the axil of (or upper angle formed with the stem by) any well-developed leaf. In these positions, buds are so usual, or so capable of appearing, that they are commonly regarded as potential when not actually present. The potentiality may be manifested by the actual development of these buds in shrubs or trees after the lapse of years. (84.) The terminal leaf-bud is to continue the axis it 
surmounts : axillary and any other lateral leaf-buds are to become branches. But even of buds which actually appear a large proportion do not grow. When a terminal bud is formed (as Fig. $81,85,91$ ), this is commonly the strongest, or among the stronger. But in many cases it habitually or commonly fails to appear. In the Elm (with leaves and therefore buds alternate), the bud axillary to the last leaf of the season takes its place. In the common Lilac, a pair of buds, which were in the axils of the uppermost of the (opposite) leaves, seem to replace the terminal bud, which seldom develops. (Fig. 86.) When all the regular buds make their appearance, and the leaves are opposite, the stem will be crowned with the terminal bud, having an axillary bud on each side of it. (Fig. 88.)

76. Accessory Buds. These are, as it were, multiplications of the regular axillary bud, giving rise to two, three, or more, instead
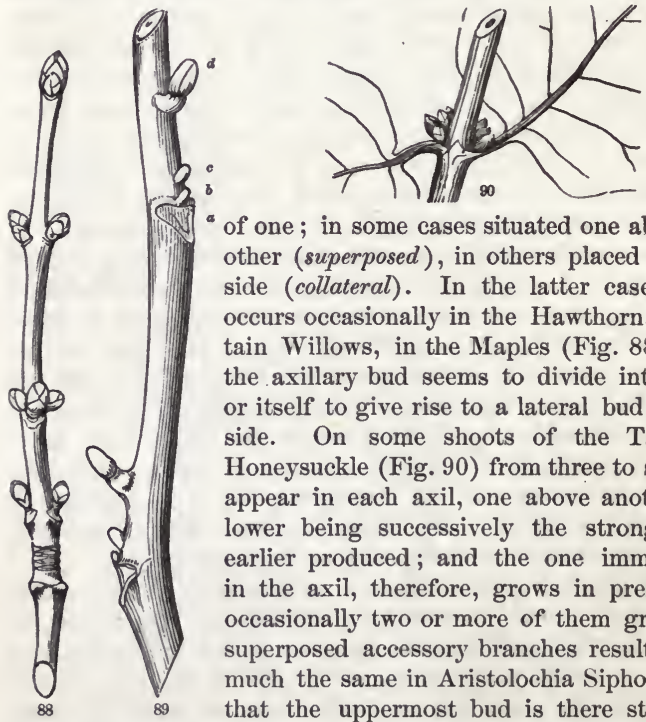

of one; in some cases situated one above an. other (superposed), in others placed side by side (collateral). In the latter case, which occurs occasionally in the Hawthorn, in certain Willows, in the Maples (Fig. 88), \&c., the axillary bud seems to divide into three, or itself to give rise to a lateral bud on each side. On some shoots of the Tartarean Honeysuckle (Fig. 90) from three to six buds appear in each axil, one above another, the lower being successively the stronger and earlier produced; and the one immediately in the axil, therefore, grows in preference: occasionally two or more of them grow, and superposed accessory branches result. It is much the same in Aristolochia Sipho, except that the uppermost bud is there strongest.

FIG. 88. Branch of Red Maple, at the midlle bearing triple axillary buds, placed side by side.

FIG. 89. Plece of a branch of the Butternut, with accessory buds placed one above another: $a$, the leaf scar: $b$, proper axillary bud : $c, d$, accessory buds.

FIG. 90. Part of a branch of Tartarean Honeysuckle, with crowded accessory buds superposed in the axil of each leaf. 
So it is in the Butternut (Fig. 89), where the true axillary bud is minute and usually remains latent, while the accessory ones are considerably remote, and the uppermost, which is much the strongest, is far out of the axil: this usually develops, and gives rise to an extra-axillary branch.

77. Adventitious Buds are such as are abnormal and irregular, being produced without order and from any part of the stem, or even from roots. The latter, like the internodes of a stem, although normally destitute of buds, do produce them notwithstanding in certain cases, especially when wounded, and in some plants (such as Blackberries) so freely that gardeners propagate them by root-cuttings. The stems share this tendency; and buds are apt to break out on the sides of trunks, especially when wounded or pollarded, or to spring from new tissues produced on cut surfaces, especially where the bark and wood join. Even leaves may develop adventitious buds, and then be used for propagation. In Bryophyllum, such buds, followed by rootlets, are freely produced on the margins of the blade or of its leaflets. In Begonia, a leaf, used as a cutting, will root from the base of the petiole stuck in the soil, and produce buds on the blade, at the junction with the petiole, or elsewhere.

\section{Section III. Of the Stem.}

\section{§ 1. General Characteristics and Growth.}

78. The Stem is the ascending axis, or that portion of the trunk which in the embryo grows in an opposite direction from the root, seeking the light, and exposing itself as much as possible to the air. All phænogamous plants possess stems. ${ }^{1}$ In those which, in botanical descriptions, are said to be acaulescent, or stemless, it is either very short, or concealed beneath the ground. Although the stem always takes an ascending direction at the commencement of its growth, it does not uniformly retain it; but sometimes trails along the surface of the ground, or burrows beneath it, sending up branches, flower-stalks, or leaves into the air. The common idea, that all the subterranean portion of a plant belongs to the root. is incorrect. Equally incorrect is the common expression that plants spring from the root. Roots spring from the stem, not the stem from the root. $(21,24,37,44$.

1 There are, however, reduced forms in which there is no distinction of axis and foliage; but most of these are clearly leafless rather than stemless, and not even in Lemna and Wolffia can the stem be said to be wanting. 
79. While the root normally gives birth to no other organs, but itself performs those functions which pertain to the relations of the vegetable with the soil, - binding it to the earth and absorbing nourishing materials from it, - the aerial functions of vegetation are chiefly carried on, not so much by the stem itself as by a distinct set of organs which it bears, namely, the leaves. Hence, the production of leaves is one of the characteristics of the stem. These are produced only at certain definite and symmetrically arranged points, called nodes. $(13,23$.

80. Development and Structure. In a bud or undeveloped stem, the nodes are in contact or close proximity. In the development, growth in length takes place in such manner as to carry these apart more or less, according to the degree of elongation, that is, the internodes (13) elongate. The order of development is from below upward, the lowest internode first lengthening, the others in regular succession. Each completes its growth, with more or less rapidity, although the length attained varies greatly in different stems, in different parts of the same stem, and under different conditions. Unlike the root, in which the elongation of formed parts is very soon finished and therefore only the tip is perceptibly growing, internodes go on growing throughout, and several formed internodes may be growing simultaneously, thus producing elongation throughout a considerable extent of stem and with considerable rapidity. But each internode grows independently. Some parts of an internode may lengthen faster or continue in growth longer than others; this is usually the upper portion, at least in long internodes and when every part is equally exposed to light.

81. The development of a stem from a bud is wholly like that from the embryo, and has already been described in Chap. II. It exhibits similar variations as to rapidity and vigor, dependent upon the constitution of the bud, - which, like the plumule in the seed or seedling, may be either latent or much developed before growth begins, - also upon the amount of nourishment provided. Strong buds commonly have their parts, or some of them, ready formed in miniature, and a store of elaborated nourishment in the parent stem to draw upon. Those well-developed buds which in many of our shrubs and trees crown the apex or occupy the axils of stem and branches early in the preceding summer (as in Magnolia, Fig. 81, Horsechestnut, Fig. 85, and Hickory, Fig. 91) often exhibit the whole plan and amount of the next year's growth; the nodes, the leaves they bear, and sometimes the blossoms being already formed, and only requiring the elongation of the internodes for their full expansion. As 
the bud is well supplied with nourishment in spring by the stem on which it rests, its axis elongates rapidly ; and although the growth commences with the lowest internode, yet the second, third, and fourth internodes may begin to lengthen long before the first has attained its full growth. Such very strong buds are usually terminal ; but sometimes, as in Lilac (Fig. 86), they are the uppermost axillary, which take the place of a suppressed or abortive terminal bud.

82. Such woody stems, developed from a strong bud, and terminated at the close of the season's growth by a similar bud, may be continued from year to year in an unbroken series. A set of narrow rings on the bark (Fig. $85 a$ ) commonly marks the limit of each year's growth. These are the scars left by the fall of the scales of the bud; and these, in the Horsechestnut, and in other trees with large scaly buds, may be traced back on the stem for a series of years, growing fainter with age, until they are at length obliterated by the action of the weather and the distention caused by the increase

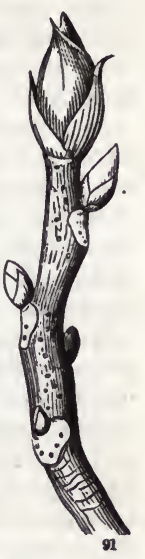
of the stem in diameter. The same is the case with the more conspicuous Leaf-scars, or marks on the bark left by the separation of the leaf-stalk, which are for a long time conspicuous on the shoots of the Horsechestnut (Fig. 85 b), the Magnolia (Fig. 81), and Hickory, Fig. 91.

83. Ramifleation. Branches (14-16) are secondary stems developed from a primary one, or tertiary ones from these, and so on. Ultimate or small ramifications of latest order are sometimes called Branchlets. The terminal bud continues the stem or axis which bears it. Lateral buds give rise to branches. ${ }^{1}$ As the normal lateral buds are axillary (75), so are normal branches. The symmetry or arrangement of branches, being that of the buds from which they are developed, is fixed by and follows that of the leaves. When the leaves are alternate, the

1 Dichotomy or forking, the division of an apex into two, although of common occurrence in the lower cryptogamous plants, occurs so rarely and exceptionally, if at all, in phænogamous plants that it may here be left out of view.

In phænogamous plants only the ramification of axes should take the name of branches. That is, roots and stems branch; and the term may without confusion be extended to hairs and all Trichomes (383) when compound, but not to leaves and their modifications.

FIG. 91. End of a Hickory branch (Carya alba) with a strong terminal and smaller axdllary buds. 
branches will be alternate; when the leaves are opposite, and the buds develop regularly, the branches will be opposite, \&c. This holds in fact sufficiently to determine and exemplify the plan of ramification ; but, if entirely carried out, there would be as many branches as leaves. This could rarely if ever be, even in primary ramification.

84. Non-development of Buds. Some of the buds are latent or merely potential, that is, do not make their appearance : of those which do appear only a part actually grow into branches; and of these some are apt to perish at an early stage. In our trees, most of the lateral buds generally remain dormant for the first season : they appear in the axils of the leaves early in summer, but do not grow into branches until the following spring; and even then only a part of them grow. Sometimes the failure occurs without appreciable order; but it often is nearly uniform in each species. Thus, when the leaves are opposite, there are usually three buds at the apex of a branch ; namely, the terminal, and one in the axil of each leaf; but it seldom happens that all three develop at the same time. Sometimes the terminal bud continues the branch, the two lateral generally remaining latent, as in the Horsechestnut (Fig. 85); sometimes the terminal one fails, and the lateral ones grow, when the stem annually becomes two-forked, as in the Lilac, Fig. 86. The undeveloped buds do not necessarily perish, but are ready to be called into action in case the others are checked. When the stronger buds are destroyed, some that would else remain dormant develop in their stead, incited by the abundance of nourishment, which the former would have monopolized. In this manner our trees are soon reclothed with verdure, after their tender foliage and branches have been killed by a late vernal frost, or consumed by insects. And buds which have remained latent for several years occasionally shoot forth into branches from the sides of old stems, especially in certain trees.

85. Most branches springing from old trunks, however, as in Willows and Poplars, especially when wounded or pollarded, originate from adventitious buds (77), which occur without order. So also when accessory buds (76) develop into branches, normal symmetry is more or less disturbed, as by contiguous shoots standing directly over each other in Tartarean Honeysuckle, or by a branch far out of the axil in Walnuts (Fig. 89) and Honey-Locust, Fig. 96 .

86. Excurrent and Deliquescent Stems. Sometimes the primary axis is prolonged without interruption, even through the whole life of a tree (unless accidentally destroyed), by the continued 
evolution of a terminal bud, or by some upper strong bud which equally becomes a leader, - forming an undivided main trunk, from which lateral branches proceed; as in most Fir-trees. Such a trunk is said to be excurrent. In other cases, the main stem is arrested, sooner or later, either by flowering, by the failure of the terminal shoot, or by the more vigorous development of some of the lateral buds ; and thus the trunk is dissolved into branches, or is deliquescent, as in the White Elm and most of our deciduous-leaved trees. The first naturally gives rise to conical or spire-shaped trees; the second, to rounded or spreading forms. As stems extend upward and evolve new branches, those near the base, being overshadowed, are apt to perish, and thus the trunk becomes naked below. This strikingly occurs in the excurrent trunks of Firs and Pines, grown in forest, which seem to have been branchless to a great height. But the knots in the centre of the wood are the bases of branches, which have long since perished, and have been covered with a great number of annual layers of wood, forming the clear stuff of the trunk.

87. Deflnite and Indefinite Annual Growth of Branches. In many of our trees and shrubs, especially those with scaly buds, the whole year's growth (except on certain vigorous shoots) is either already laid down rudimentally in the bud, or else is early formed, and the development is completed long before the end of summer; when the shoot is crowned with a vigorous terminal bud, as in the Horsechestnut (Fig. 85) and Magnolia (Fig. 81), or with the uppermost axillary buds, as in the Lilac (Fig. 86) and Elm. Such definite shoots do not die down at all the following winter, but grow on directly, the next spring, from these terminal or upper buds, which are generally more vigorous than those lower down. In other cases, on the contrary, the branches grow onward indefinitely, until arrested by the cold of autumn : the buds at or near their summit are consequently young and unmatured, or at least the lower and older axillary buds are more vigorous, and alone develop into branches the next spring ; the later-formed upper portion most commonly perishing from the apex downward for a certain length in the winter. The Rose and Raspberry, and among trees the Sumac and HoneyLocust, are good illustrations of this sort; and so are most perennial herbs, their stems dying down to or beneath the surface of the ground, where the persistent base is charged with vigorous buds, well protected by the ground, for the next year's vegetation.

88. Many of the details and applications of ramification, of most importance in morphology and descriptive botany, relate 
to anthotaxy or inflorescence (Chap. V.), which has its own terminology. But some of its terms may be conveniently employed in the description of ramification unconnected with flowering.

\section{§2. Forms of Stems aNd Branches.}

89. On the size and duration of the stem the oldest and most obvious division of plants is founded, namely, into Herbs, Shrubs, and Trees.

90. Herbs are plants in which the stem does not become woody and persistent, but dies annually or after flowering, down to the ground at least. The difference between annual, biennial, and perennial herbs has already been pointed out in the chapter on the root (50-57), and the gradations between them indicated. Herbs pass into shrubs and shrubs into trees through every gradation. The following definitions are therefore only general :-

91. Undershrubs, or Suffruticose plants, are woody plants of humble stature, their stems rising little above the surface. If less decidedly woody, they are termed Suffrutescent.

92. Shrubs are woody plants, with stems branched from or near the ground, and less than five times the height of a man. A shrub which approaches a tree in size, or imitates it in aspect, is said to be Arborescent.

93. Trees are woody plants with single trunks, which attain at least four or five times the human stature. Yet the name of tree is not to be denied to a woody plant having a single and stout trunk of less altitude; and those which grow in a bushy manner, sending up a cluster of stems from the ground to the height of thirty feet or more, may still be called shrubs.

94. The erect position, elevation above the soil, and self-support, are normal conditions of the stem, but are far from universal. And certain kinds of stem or branches are sufficiently peculiar to have received substantive names : other equally peculiar forms have no special names. There are, moreover, certain organs (such as spines and tendrils) which are commonly homologous (12) with stems, but not always. Two kinds of erect stems have special names in descriptive botany.

95. Culm is a name applied to the peculiar closed-jointed stem of Grasses and Sedges, whether herbaceous, as in most Grasses, or woody or arborescent, as in the Bamboo.

96. Candex is the name technically applied to the trunk of Palms (Fig. 126), Tree-Ferns, and the like, consisting of a commonly simple column, the surface beset with scales, - the 
bases of former leaf-stalks, - or marked by scars, left by their fall. This name was used by botanists anterior to Linnæus for any tree-trunk, but is now used for the peculiar stems abovementioned; also for the persistent base of a stem, otherwise annual, which throws up fresh herbaceous stems or stalks from year to year. Such short and enduring stems, being usually near the ground or under it, were commonly mistaken for roots. The old English name of Stock is sometimes used in botanical description for all short and enduring stems of this sort, whether rising somewhat above or concealed beneath the surface of the soil.

97. A Scape is a stem or branch which rises from beneath or near the surface of the ground and bears flowers, but no proper foliage. It therefore belongs to inflorescence. (265.) Scapes usually spring from some one of the subterranean forms of stem.

98. Of stems which do not stand upright in the air there are various modifications and gradations.

99. Scandent or Climbing Stems are those which rise by attaching themselves to some extraneous support. This is effected in various ways; in some by the action of the stem itself, in others by that of organs which it bears. ${ }^{1}$

100. Voluble or Twining Stems, or Twiners, are those which ascend by coiling round a support, which must accordingly be comparatively slender, or at least not too large. Some ascend by coiling "with the sun" (that is, from right to left of the observer viewing the coil from the outside ${ }^{2}$ ), as the Hop ; more,

1 See Darwin, The Movements and Habits of Climbing Plants, London and New York, 1875. Also the earlier paper on the subject in Journal of the Linnean Society, ix. 1865.

Note that in North America climbing plants in general are in popular language called Vines (e. g. Hop-Vine, Grape-Vine, Squash-Vine, \&c.), a name which properly belongs to Vitis only.

2 Dextrorse and Sinistrorse, $\mathbf{i}$. e. to the right or to the left, are almost indispensable terms, but there is an ambiguity and discrepancy in their use. Darwin (in Climbing Plants, above referred to) seeks to avoid this by usually employing the terms "with the sun," and "against the sun," phrases which would be unmanageable in terminology. The writer (in Amer. Jour. Sci. ser. 3, xiii. 391) suggested Eutropic for the former, Antitropic for the latter, to be used in case it is preferred to evade rather than to encounter the ambiguity. Probably the terms dextrorse and sinistrorse, or right and left, will continue in use, as most natural and convenient. Now, in the first place, it should be understood that a plant, or at least a plant's axis, having no front and back, can have no right and left of its own. These relations of direction must refer to the right and left of an observer. All depends, accordingly, upon the position which the viewing observer is supposed to occupy when he predicates the direction of the turns of a helix or of the overlapping of the parts of a bud. Linnæus supposed the observer to view the 
by coiling in the opposite direction, as the Bean (Phaseolus), the woody Aristolochia Sipho, the Morning Glory (Fig. 91 ${ }^{a}$ ) and other Convolvu-
laceæ. The Dod-
der, a leafless par-
asitic plant of the
latter family, not only gains support by coiling
on the stems of other plants, but by attachment,
through the development of sucker-like discs,
along the whole contiguous surface. (Fig. 77.)
The various actions through which plants climb,
and the attendant phenomena, are physiological,
and will be treated in the second part of this
Text Book. The most complete and satisfac-
tory discussion of the subject, of a readable sort,
is that of Darwin's volume, referred to in a
preceding note.

101. Leaf-Climbers are those in which support is gained by the action, not of the stem itself, but of the leaves it bears ; in most by the coiling or clasping of petioles, as in Clematis, Maurandia, Tropæolum, and Solanum jasminoides (Fig. 235) ; in some by the incurvation of leaf-blades or portions of them, as in Adlumia ; or by an extension of the midrib into a hook or short tendril, as in Gloriosa ; or by the transformation of some of the blades of a compound leaf into hooks or tendrils, as in Cobæa and the Pea.

102. Tendril-Climbers (Fig. 92-95) are those in which the prehension is by a tendril, a slender filiform body, either simple or branched, specially adapted to the purpose, and capable of coiling, either to secure a hold, or to draw the stem up to the

coil or circle from the inside; Mohl, Palm, Braun, and the DeCandolles adopt this, and the latter insist on it. Such authority should be decisive, if common usage and popular sense went along with it. But some of the botanists following Linnæus adopted the reverse view; and to the present writer, as to Bentham and Hooker, Darwin, Eichler, and in part G. Henslow, it was 80 natural to view the coil from the outside that we without concert adopted this position and mode of expression. A right-hand coil, or one turning to the right, with us, is one the turns of which pass from the left to right of a bystander who confronts the coil. It is in this sense that a common screw is called a right-handed screw, and that the right bank of a river is that to the right of the person who follows the course of the stream. So natural is this, that even on a map or plate, which has face and back, and therefore a right and left of its own, the figures occupying its right or left portions are understood to be those which are toward the right or the left hand of the observer who stands before it.

FIG. 91. Dextrorsely twining stem of Morning Glory, Ipomces purpurea. 
support. In certain tendrils the attachment to the support is by a sucker-like disc at the apex, as in the Virginia Creeper or Ampelopsis, Fig. 94 .

103. Root-Climbers are those in which the stems produce aerial rootlets $\left(59^{a}\right)$, which fix themselves to a supporting surface along which the stem creeps or ascends. In this way Trumpet Creeper (Tecoma radicans), Ivy, and Poison Ivy (Rhus Toxicodendron) climb extensively.

104. Stems or branches which neither climb nor stand upright may have their direction or habit of growth expressed by certain adjective terms; such as

Ascending or Assurgent, when they rise obliquely upward;

Reclining, when from an ascending or erect base the upper part recurves and trails;

Decumbent, when trailing along the ground, but with apex assurgent;

Procumbent or Prostrate, when lying at length upon the ground;

Repent or Creeping, when growing prostrate on the ground and rooting as they grow. Also applied to similar stems growing under, as well as upon the surface of the soil, as in CouchGrass and Mint, Fig. 99.

105. A Sucker (Surculus) is an ascending stem rising from a subterranean creeping base. The Rose and Raspberry multiply freely by suckers. Such plants are easiest to propagate "by division."

106. A Stolon is a prostrate or reclined branch which strikes root at the tip, and then develops an ascending growth, which becomes an independent plant.

107. An Offset is a short stolon or a short sucker. Houseleek (Fig. $91^{b}$ ) offers a familiar example. By offsets, some herbs, otherwise annuals, are continued from year to year in a vegetative progeny (Lobelia cardinalis, \&c.), and perennials may thus establish colonies around a parent individual.

108. A Runner (Flagellum) is a filiform or very slender

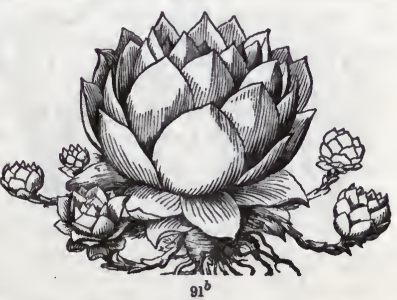
stolon, naked and tendril-like except at tip, where it roots, develops a bud, and so a new plant. The Strawberry furnishes the most familiar example. 
109. The two following are organs which may be of axial nature, or may not. This may ordinarily be determined by posi-

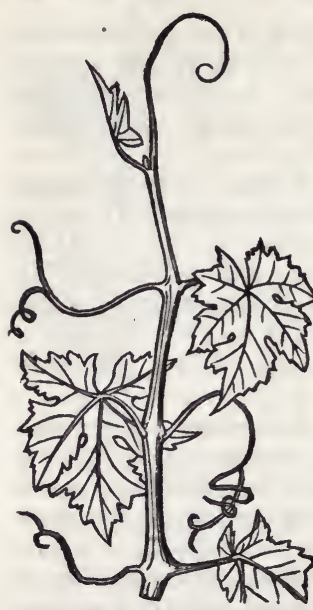
tion. Any direct continuation of stem or branch must be of axial nature, that is, of the nature of stem ; and the same is true of whatever primarily develops in the axil of a leaf. Conversely, whatever subtends a lateral axis or branch may be taken for a leaf or foliar production, being in the place of such.

110. A Tendril, a thread-shaped and leafless body, capable of coiling spirally, and used for climbing (102), is homologous with stem in Grapevines (Fig. 92) ; for the uppermost tendril is seen to be a direct continuation of the stem. The small bud which appears in the axil of the uppermost leaf will in its growth produce another internode and leaf, or some species more than one, but will terminate in a similar tendril: the present terminal tendril will have then become lateral and opposite the leaf, like the three in the lower part of

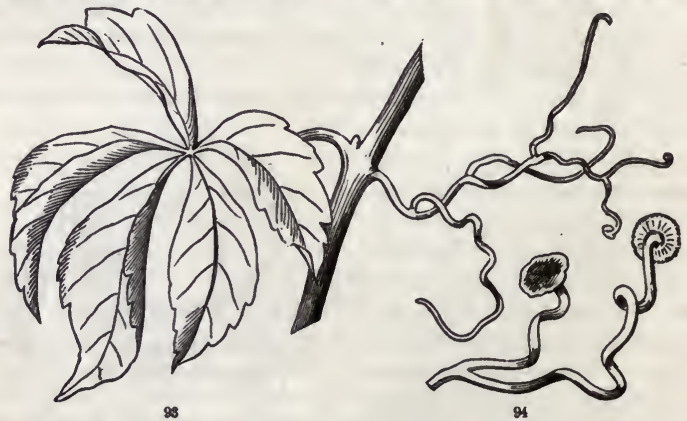

FIG. 92. End of a shoot of the Grape-vine, with young tendrils: a sympodial stem. (See note.)

FIG. 93. A portion of a stem of Ampelopsis quinquefolia, or Virginia Creeper, with

- leaf and a tendril.

FIG. 94. Ends of the latter, enlarged, showing the expanded tips or disce by which they cling. 
the figure. ${ }^{1}$ The tendrils of Virginia Creeper (Fig. 93) are of the same nature and position. But, instead of laying hold by a coiling of the tip, when it has reached any solid surface, such as a wall or tree-trunk, the tip expands into an adhesive disc, which forms a secure attachment. (Fig. 94.) In a related plant, Vitis (Cissus) tricuspidata of Japan, these disks terminate the branches of very short tendrils: consequently the shoots as they grow are at once applied closely and secured firmly to the surface of the support, - an admirable adaptation for climbing walls and trunks.

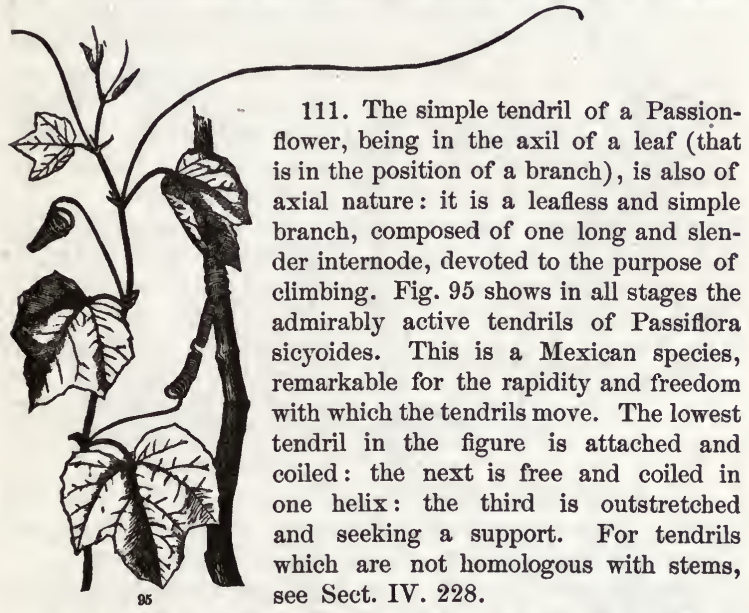

112. A Spine or Thorn (Fig. 96, 97) is usually a branch or the termination of a stem or branch, indurated, leafless, and attenuated to a point. The nature of spines is manifest in the Hawthorn (Fig. 97), not only by their position in the axil of a leaf, but often by producing imperfect leaves and buds. And in the Sloe, Pear, \&c., many of the stinted branches become spinose or spinescent at the apex, tapering off gradually into a rigid and leafless point, thus exhibiting every gradation between a spine and an ordinary branch. These spinose branches are less

1 This forms what is called a Sympodium or Sympodial stem, which is morphologically made up of a series of superposed branches. (See Chapter V. 281,282 .) In contradistinction, a stem formed by the continued development of a terminal bud is Monopodial or a Monopodium. Fig. 95 is an example.

FIG. 95. Leafy shoot of Passiflora sicyoides, of Mexico, with fixed and coiled, free aud full grown, and forming tendrils. 
liable to appear on the cultivated tree, when duly cared for, such branches being thrown mostly into more vigorous growth. In

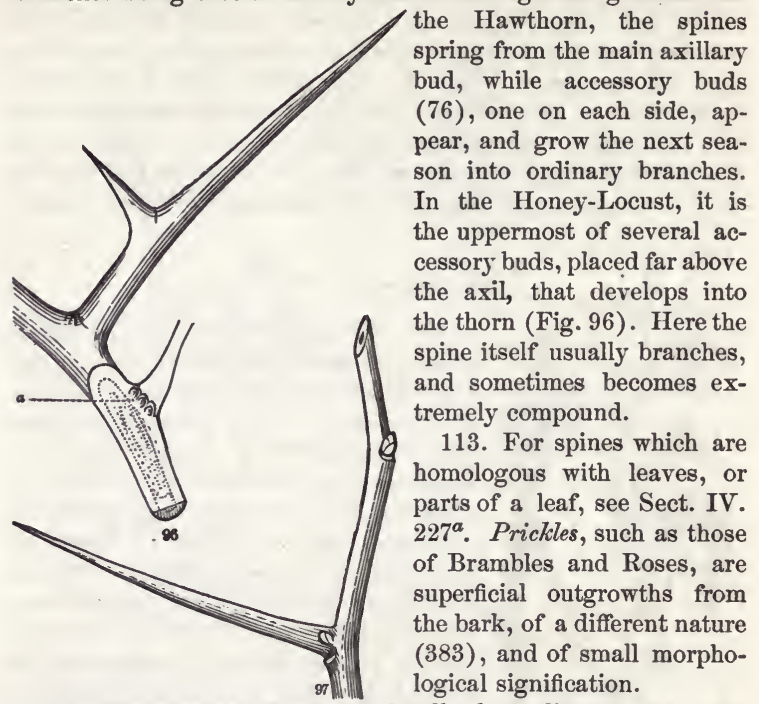

114. Subterranean Stems are hardly less diverse than the aerial. They are classed as Rhizomes, Tubers, Corms, and BuLBs, the forms passing one into another by gradations.

115. Rhizoma (Rhizome, or in English Rootstock) is a general name for any horizonal or oblique perennial stem, which lies on the ground or is buried beneath its surface. It sends off roots of a fibrous or slender sort wherever it rests on or is covered by the soil, and usually produces from its apex some kind of aerial stem, either leafy or as a flower-stalk (scape, 97), which rises into the air and light. Before morphology was understood, rootstocks were called creeping roots, scaly roots, \&c. Some are slender, such as those of Mints (Fig. 99), of most Sedges (Fig. 98), and of Couch-Grass. Their cauline nature is evident from their structure and appearance; their nodes and internodes are well marked, the former bearing leaves reduced to

FIG. 96. Branching thorn of the Honey-Locust (Gleditschia), an indurated brancb developed from an accessory bud produced above the axil. $a$. Three buds under the base of the leaf-stalk, brought to view in a section of the stem and leaf-stalk below.

FIG 97. Thorn of the Cockspur Thorn, developed from the central of three axillary buds; one of the lateral buds is seen at its base. 
scales, and the advancing apex rises at length into an ordinary stem, while the opposite and older end gradually dies away. A

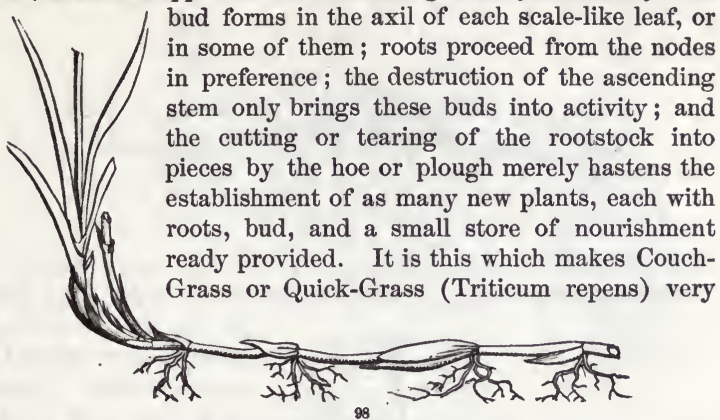

troublesome to the agriculturist; and the Nut-Grass (Cyperus rotundus, var. Hydra) of the Southern Atlantic States is even

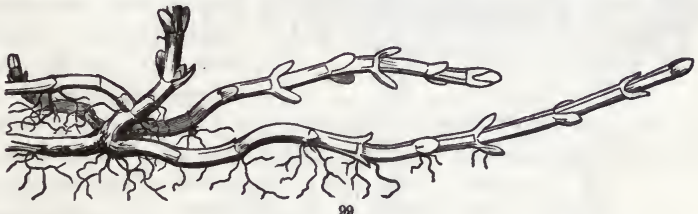

99

more so, portions of its rootstock being tuberiferous, $i . e$. enlarged into a tuber which contains a supply of concentrated nourishment to feed the growth.

116. Thickened rootstocks are common; nourishing matter, elaborated in the leaves above, being accumulated in them, just as it is in thickened roots, and for the same pur-

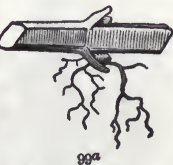
pose. (53-55.) Such are the so-called roots of Sweet-Flag, of Ginger, of Iris or Flower-de-Luce (Fig. 216), of Bloodroot, of Solomon's Seal (Fig. 100), \&c. These grow after the manner of ordinary stems, advancing from year to year by the annual development of a bud at the apex, and emitting roots from the under side or the whole surface. Thus established, the older

FIG. 98. Slender rhizoma of Carex arenaria, of Europe, which binds shifting sands of the sea-shore.

FIG. 99. Rootstocks, or creeping subterranean branches, of the Peppermint.

FIG. 99a. A plece of the rootstock of the Peppermint, eniarged, with its node or joint, and two axillary buds ready to grow. 
portions die and decay as corresponding additions are made to the opposite growing extremity. Each year's growth is often

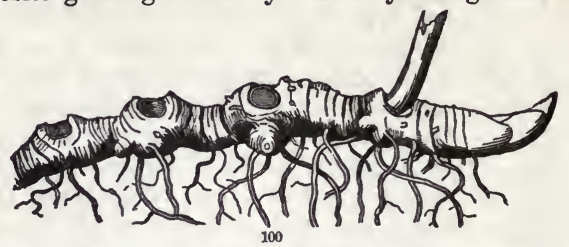

marked conspicuously, sometimes by a strong contraction where the interruption took place, as in certain species of Iris (Fig. 216);

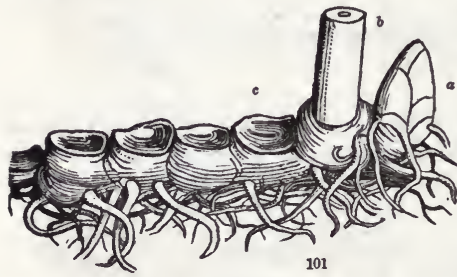
or by the circular impressed scar (likened to the impression of a seal) in Solomon's Seal ; this being the place where the annual aerial stem, bearing the vegetation, separated in autumn from the perennial rhizoma. The numerous slender lines encircling the rootstock are the scars left after the decay of the scale-like leaves or bud-scales, such as are seen at

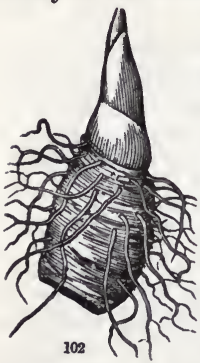
the young and growing end of the rootstock. The rootstock of Diphylleia, of the Alleghany Mountains (Fig. 101), is similar; but the yearly growths are so exceedingly short that they become vertical, the bud of each year is close to the stalk of the year preceding, and the scars marking previous growths are in contact. ${ }^{1}$ Trillium makes a short and mostly vertical rootstock, which, when it remains simple and dies away promptly below (as in Fig. 102), comes nearly within the definition of a corm. But in several

1 The rootstock in Polygonatum and Diphylleia is a sympodium $(110$, note $)$, the terminal bud developing yearly the growth above ground and perishing

FIG. 100. Rootstock of Polygonatum or Solomon's Seal, with the terminal bud, the base of the stalk of the season, and three scars from which the latter has separated in as many former years.

FIG. 101. Rhizoma of Diphyllela cymosa, showing six years' growth, and a bud for the seventh: $a$, the bud: $b$, base of the stalk of the current year: $c$, scar left by the decay of the annual stalk of the year before; and beyond are the scars of previous years.

FIG. 102. Shoot and young rootstock of Trillium erectum, with only terminal bud. 
species, and in older individuals, it is longer, often oblique, and branching, and bears the scars from which the annual aerial growths have separated. ${ }^{1}$ Nymphæa odorata, the sweet-scented white Water Lily, grows by very long, stout, and simple rootstocks. In $\mathrm{N}$. tuberosa the sides of the rootstock produce short lateral branches or tubers.

117. A Tuber may be morphologically char'acterized as a short thickened rhizoma on a slender base, or a rootstock some portion of which-mostly a terminal portion and involving several nodes - is thickened by the deposition of nourishing matter. A potato and a Jerusalem artichoke are typical examples (Fig. 104-107) ; and the difference between

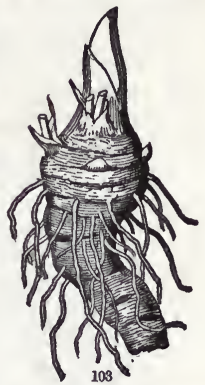
these subterranean branches and the roots which they may bear is very obvious. Their eyes are axillary buds ; the leaves which subtend them are plainly discernible, in the form of short and closely appressed scales. In the attempt, occasionally seen, to form axillary tubers aboveground by the Potato-plant, the leafy nature of the scales is evidenced. (Fig. 105.) By heaping the soil around the stems, the number of tuberiferous branches may be in10405 creased. The number of nodes and internodes involved in a tuber may be many or few. There is one instance of what may

in autumn, to be renewed by an axillary bud, which makes its subterranean growth and the rudiments of the aerial in early summer.

1 This rhizoma is a monopodium, being continued year by year by the terminal bud, and the aerial stem or stems sent up in spring, bearing the whorl of leaves and blossom, are axillary branches.

FIG. 103. An older and longer one of the same species, showing branches, scars left by former leaf- and flower-bearing stems: also at tip (stripped of the covering scales), the bases of two such stems of the season, and the terminal bud between them, for the continuation of the growth of the rootstock, \&c., the next season.

FIG. 104. Base of stem of Helianthus tuberosus, or Jerusalem Artichoke, developed from a tuber, and producing a second generation of tubers.

FIG. 105. Monstrosity of a Potato-plant, with an axillary bnd developing into something between a bulblet and a tuber; the scales represented by obvious leaves. (From the Gardeners' Chronicle.) 
be called a Monomerous tuber, namely in Nelumbium luteum (Fig. $108^{a}$ ), where it consists of a single thickened internode of

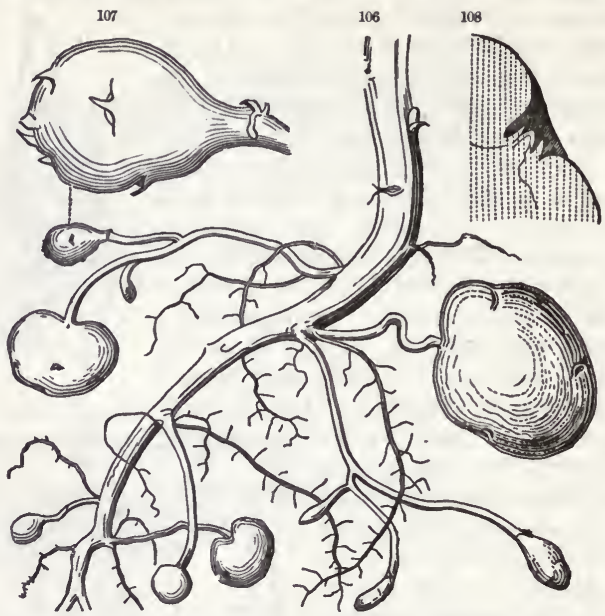

an aquatic runner, which is accordingly quite destitute of scales or buds. The growth proceeding from this simple tuber is

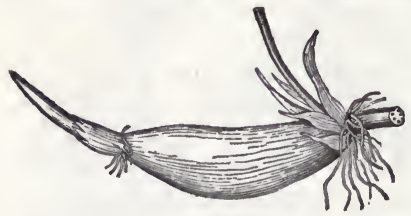

$108^{a}$ necessarily from a bud of the node at its apex, whence also a cluster of roots is produced. Of a somewhat similar nature are the concatenate tubers of Apios tuberosa (several of which are strung as it were upon a long filiform axis), the tubers not unfrequently being monomerous, although the larger ones are not so.

$117^{a}$. Tubercles, as they may be termed, are of a mixed or ambiguous character between tubers and tuberous roots. A good example of the latter is afforded by Dahlia-roots. (Fig. 68.) They yield their nourishing substance to growing buds on the stem above, but do not themselves normally produce even

FIG. 106. Forming potatoes in various stages. 107. One of the younger ones enlarged. 108. Section of a small portion passing through an eye, or bud, more enlarged.

FIG. 108a, A monomerous (i. e. one-membered) tuber of Nelumbium Inteum, formed of a single internode. 
adventitious buds. Sweet potatoes (55), although equally roots, do produce adventitious buds, especially from near the upper end. The somewhat similar tubercles or tumefied roots of certain Orchises and other plants of the same tribe, ${ }^{1}$ definite in number and shape, and sometimes imitating a corm, are charged with a bud at the upper end, near their origin. Apparently, the origin is a bud from the base of the parent stem, which bud directly forms a tumefied short root from its very base. ${ }^{2}$

118. A Corm (Cormus) is to be compared on the one hand with a short rootstock or tuber, on the other with a bulb. It is a subterranean fleshy stem, of rounded or depressed figure and solid texture. Some of its buds grow into new corms, and these, upon the death of or separation from the parent, become new individuals: some develop above ground the vegetation and the blossoms of the season. A good type of corm is that of Cyclamen (Fig. 109), in which the very base of the. seedling stem grows fleshy, and widens from year to year, but hardly at all lengthens, and so becomes far broader than high, or depressed. As the main bulk belongs to the

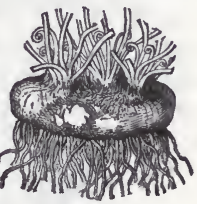

100 first internode, or caulicle, the buds from which the yearly growths of leaves and flower-stalks spring are at the centre of the summit or upper surface, the roots from the lower, and the sides seldom produce any buds. The corm of Indian Turnip (Arisæma triphyllum, Fig. 110) is somewhat similar, but it sends up a single stout stem, and the roots spring from around the base of this. These are completely naked corms.

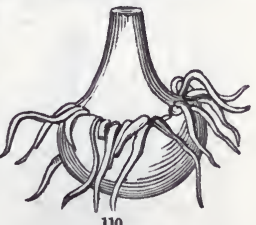

119. But in Crocus (Fig. 111, 112), Colchicum (Fig. 117), Gladiolus, and the like, the sheathing bases of one or two leaves enclose the corm with a membranous-scaly coat, giving it exactly the appearance externally of a coated bulb. Such have been not inappropriately named solid bulbs. In common parlance, they will doubtless continue to be called bulbs, and even in popular

1 Not, however, such as those of Aplectrum, Tipularia, etc., which are genuine corms or tubers.

2 Irmisch, Beitr. Biol. \& Morphol. Orchid. 1853, flde Duchartre, Elém. Bot. 278 . 
botanical descriptions. In fact, while they differ from naked corms in having some investment, they differ from true bulbs only in the greater size of the solid axis and the fewness of
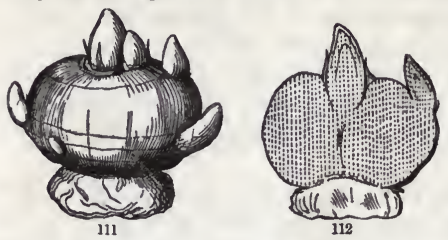

the investing scales; the stem or solid body making the greater part of the corm, but a very small part of a proper bulb. There are, moreover, all gradations between the two.

120. A Bulb, as compared with a corm, may be said to be an exceedingly abbreviated stem, reduced to a flat plate, from the lower face of which roots are produced, from the upper face, leaves in the form of scales; these scales being either reduced and thickened leaves or the thickened bases of ordinary leaves. Compared with buds (73), it is a very fleshy bud, usually large and subterranean, the axis of which never elongates. It is a

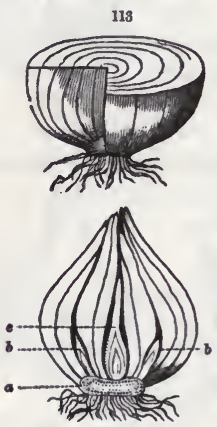

114

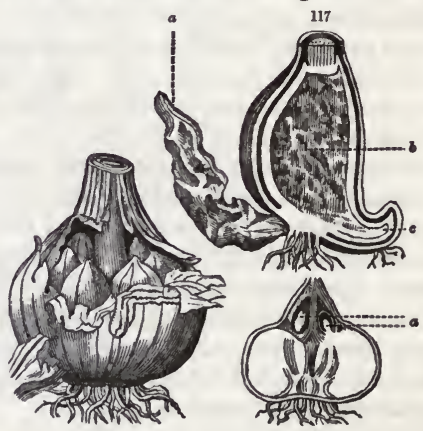

116

provision for future growth, the stored nourishment of which is deposited in the leaves, or the homologues of leaves, instead of in the stem.

FIG. 111. Corm of Crocus, the few thin enveloplng scales removed, showing their scars, whlch mark the nodes, the shrivelled vestige of the last year's corm at the base, and buds developing into new ones on various parts of its surface. 112. Vertical section of a simllar corm, with a terminal and one lateral bud.

FIG. 118. Section of a tunicated bulb of the Onion.

FIG. 114. Vertical section of the bulb of the Tullp, showing its stem or terminal bud $(c)$ and two axillary buds $(b, b)$.

FIG. 115. Bulb of a Garlle, with a crop of young bulbs.

FIG. 116. Vertical section of the corm of a Crocus: $a$. new buds.

FIG. 117. Vertical section of the corm of Colchicnm (b), with the withered corm of the preceding (a), and the forming one (c) for the ensuing year. 
121. A Tunicated or Coated Bulb (Fig. 113-115) is one in which the scales are broad and completely enwrapping, forming concentric coatings. These are thickish when fresh, but thin when exhausted and dry, as in the Onion, Garlic, and Tulip.

122. A Scaly Bulb has the bulb-scales comparatively narrow, thick, and small, imbricated, but not severally enwrapping each other. That of the Lily is the most familiar and characteristic example. (Fig. 118, 119.)

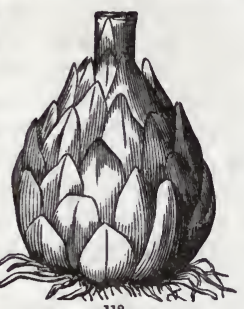

118

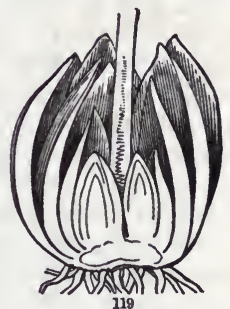

119

123. Bulblets are small aerial bulbs, or buds with fleshy scales, which arise in the axils of the leaves of several plants, such as the common Lilium bulbiferum and L. tigrinum, the Tiger Lilies of the gardens (Fig. 120). Here they appear during the summer as axillary buds : they are at length detached, and falling to the ground strike root, and grow as independent plants. In the common Onion, and in many other species of Allium, similar bulblets take the place of flower-buds in the

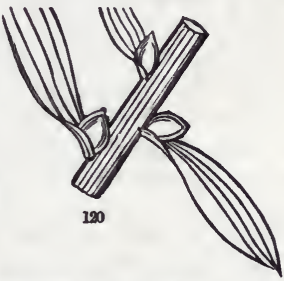
umbel. Bulblets plainly show the identity of bulbs with buds.

124. All these extraordinary, no less than the ordinary, forms of the stem, grow and branch, or multiply, by the development of terminal and axillary buds. This is perfectly evident in the rhizoma and tuber, and is equally the case in the corm and bulb. The stem of the bulb is usually reduced to a mere plate (Fig. $114 a$ ), which produces roots from its lower surface, and leaves or scales from the upper. Besides the terminal bud $(c)$, which usually forms the flower-stem, lateral buds $(b, b)$ are produced in the axils of the leaves or scales. One or more of these may develop as flowering stems the next season, and thus the same bulb survive and blossom from year to year; or these axillary buds may themselves become bulbs, feeding on the parent bulb, which in this way is often consumed by its own offspring, as in

FIG. 118. Scaly bulb of Canada Lily, Lilium Canadense, after flowering. 119. Vertical section of same, showing two new young bulbs within.

EIG. 120. Bulblets in the axil of the cauline leaves of THger Lily. 
the Garlic (Fig. 115); or, finally separating from the living parent, just as the bulblets of the Tiger Lily fall from the stem, they may form so many independent individuals. So the corm of the Crocus (Fig. 111, 112) produces one or more new ones, which feed upon and exhaust it, and take its place; and the next season the shrivelled remains of the old corm may be found underneath the new. The corm of Colchicum (Fig. 117) produces a new bud on one side at the base, and is consumed by it in the course of the season; the new one, after flowering by its terminal bud, is in turn consumed by its own offspring; and so on. The figure represents at one view, $a$, the dead and shrivelled corm of the year preceding; $b$, that of the present season (in a vertical section); and, $c$, the nascent bud for the growth of the ensuing year.

125. Condensed Stems, homologous with corms, tubers, \&c., and similar in mode of growth, but above ground, and multiplying in the same ways, are not uncommon. The Cactus family is mainly composed of such forms, of flat- or round-jointed Prickly Pears (Opuntia), fluted or angled columns (Cereus), and globular Melon-Cactus, Mamillaria, and Echinocactus. The latter types, which completely imitate corms, are the most consolidated forms of vegetation. While ordinary plants are constructed on the plan of great expansion of surface, these present the least possible amount of surface in proportion to their bulk, their permanent spherical figure being that which exposes the smallest portion of their substance to the air. Such plants are evidently adapted to very dry regions; and in such only are they naturally found. Similarly, bulbous and corm-bearing plants, and the like, are a form of vegetation which in the growing season may in the foliage expand a large surface to the air and light, while during the period of rest the living vegetable is reduced to a globular or other form of the least surface; and this is protected by its outer coats of dead and dry scales, as well as by its subterranean situation; - thus exhibiting another and very similar' adaptation to a season of drought. And such plants mainly belong to countries (such as Southern Africa, and the interior of Oregon and California) which have a long hot season, during which little or no rain falls, when, their stalks and foliage above and their roots beneath being early cut off by drought, the plants rest securely in the corm-like forms to which they are reduced, and retain their moisture with great tenacity until the rainy season returns. Then they shoot forth leaves and flowers with wonderful rapidity, and what was perhaps a desert of arid sand becomes green with foliage and gay with blossoms, almost in a day. 
126. Stems serving the purpose of foliage, Phyllocladia. Most of these condensed and permanent stems are illustrations of this, their green rind doing duty for leaves, which are either absent, or transient, or reduced to spines or other organs not effective as foliage. In the flat and broad-jointed species of Opuntia, and still more in Phyllocactus and Epiphyllum, the forms assumed give a considerable surface of green rind, which well answers the purpose of leaves. Flattened stems or branches of the same sort and economy not seldom occur in other than fleshy or succulent plants (such as the Cactuses); sometimes accompanied by a certain number of real foliage-leaves, but these more or less transient, as in Bossiæa and Carmichælia among Leguminous shrubs, and Muhlenbeckia platyclada, now in common cultivation (Fig. 121); sometimes with all the leaves reduced to small and functionless scales, as in the Xylophylla (i.e. woodenleaved) section of Phyllanthus, and in Phyllocladus (New Zealand and Tasmanian trees of the Yew family). In all these, the cauline nature is manifest by the continuous or proliferous growth, by the marked nodes and internodes, and often by the bearing of flowers.

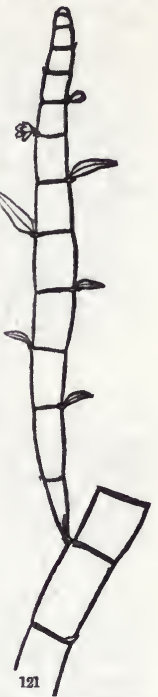

127. Cladophylla (literally, branch-leaves) are more ambiguous in character. The most familiar examples are found in the peculiar foliage of Ruscus, Myrsiphyllum, Asparagus, and in some other genera of the same family. In these the primary or proper leaves of the shoots are little scales, one to each node, and quite functionless. From the axil of each is immediately produced a body answering in all respects to the blade of a leaf, both in appearance and in office. They also accord with leaves in being expanded horizontally, although they take a twist which brings them more or less into a vertical position, in the manner of phyllodia (that is, of leaf-stalks assuming the form and office of leaf-blades, 217); wherefore they may be regarded as the first and only leaf of an axillary branch with the internode under the leaf wholly undeveloped and no further growth ever taking place. But, on the other hand, their anatomical structure is said to be that of stems rather than of leaves. Moreover, 
the cladophyll of Ruscus (called Butcher's Broom in England, Fig. 123) not only becomes firm, hard, and spiny-tipped, but

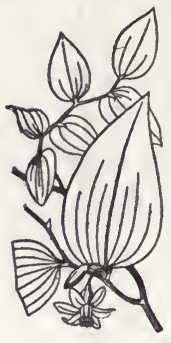

122

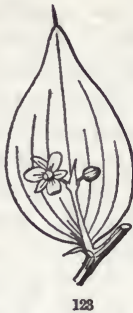

it exhibits the character of a branch by bearing flowers on the middle of one face, in the axil of a little bract. Under this view such a cladophyll would seem to be a flattened branch of two internodes, or else of one internode with a flower-stalk adnate to it. In Myrsiphyllum (a South African climber, commonly cultivated under the erroneous name of Smilax, Fig. 122), the cladophyll is wholly leaf-like in appearance

as well as in function, and it never bears either scale-leaf or blossom; but the flowers are on slender stalks from buds out of the same axil. (See Dickson in Trans. Bot. Soc. Edinb. xvi., and Van Tieghem, Bull. Bot. Soc. France, xxxi., for a discussion of the nature of cladophylla.)

128. To all such leaves or imitations of leaves, Bischoff has given the name Phyllocladia, sing. Phyllocladium. To those definitely restricted to one internode, and which so closely counterfeit leaves, Kunth gave the name of Cladodia, sing. Cladodium. The best common name for all productions which

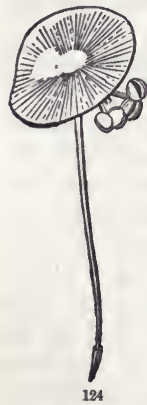
imitate leaves would have been that of phyllodium (meaning simply a leaf-like body); but that term was first applied and is restricted to the case of a petiole imitating the blade of a leaf. The name Phyllocladium (meaning a leaf-like branch) may properly be retained for the whole series of leaf-like bodies here described. But for those of. the preceding paragraph, which are so peculiarly leaf-like, Kunth's name of Cladodium (i.e. a branch-like body) is false in meaning, and may be replaced by that of Cladophyllum (i.e. leafbranch), or in shorter English Cladophrll.

129. Frondose Stems. Finally, in some few phænogamous plants, the whole vegetation is reduced to a simple leaf-like expansion, as in Duckweed (Lemna),

FIG. 122. Myrsiphyllum, with cladophylls serving for follage; the true leaves consisting of minute and very inconspicuous scales subtending the former.

FIG. 123. A single cladophyll of Ruscus aculeatus in the axil of a scale-leaf, bearing another scale-leaf on the middle of its face, and flowers in the axil of this.

FIG. 124. Lemna minor, a common Duckweed, whole plant in flower, magnifed. 
Fig. 124. Here is no differentiation whatever into stem and foliage; but the expanded floating body which serves for both must be counted as stem developed horizontally into a flat plate, for it produces a root from the under surface and a flower from the edge. This simplification is common in some orders of Cryptogamous plants ; and such a body, which answers both for stem and foliage, is termed a Frond, from the Latin frons, which means either leaf or leafy bough. In some species of Lemna the frond is thickened or plano-convex : in Wolffia, the simplest and smallest of phænogamous plants, it is a globular green mass, seldom much larger than the head of a pin, wholly destitute of root, propagated by proliferous budding from one side, and from within the top producing a flower or pair of flowers.

\section{§3. Internal Structure.}

130. The investigation of the intimate structure of the stem, as of the other organs, belongs to vegetable anatomy or histology (treated in Part II.) ; but the general outlines of structure, so far as is requisite to the explanation of what is visible to the naked eye, should be here explained.

131. The stems of phænogamous plants anatomically consist of two general elements, the cellular and the woody ; the former exemplified in the commoner stems by the pith and outer bark, the latter by the wood. Both are equally composed of cells, or origi-

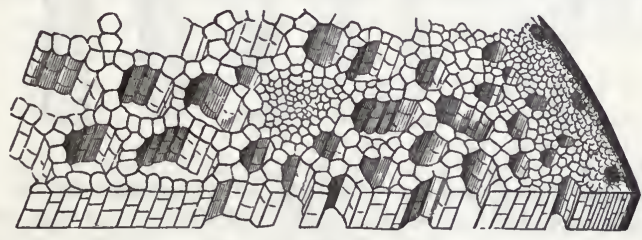

$124^{a}$

nate as such ; but those which form the woody system of the stem mainly undergo, at a very early period, transformation into tubes, some of which are of such small calibre that their common name of fibres is not inappropriate; others, of larger size or ampler calibre, take the name of ducts or vessels. The latter are almost

FIG. 124a. A magnified slice of a portion of the flower-stalk of Richardia Ethiopica (the so-called Calla Lily), transverse with some longitudinal view: mainly parenchyma, the cells built ap so as to leave comparatively large vacancles (intercellular spaces or air-passages); near the centre a cross-section of a fibro-vascular bundle, and next the margin or rind some finer ones. 
always associated with the wood-cells, so that they are in a general way taken together as constituting the wood, or woody tissue, and as forming what is more definitely termed fibro-vascular tissue or, when distinguishable into threads, fibro-vascular bundles. These run lengthwise through the stem, sometimes as such separate threads, sometimes confluent into a compact structure. The softer or at least the non-fibrous portions, formed of comparatively
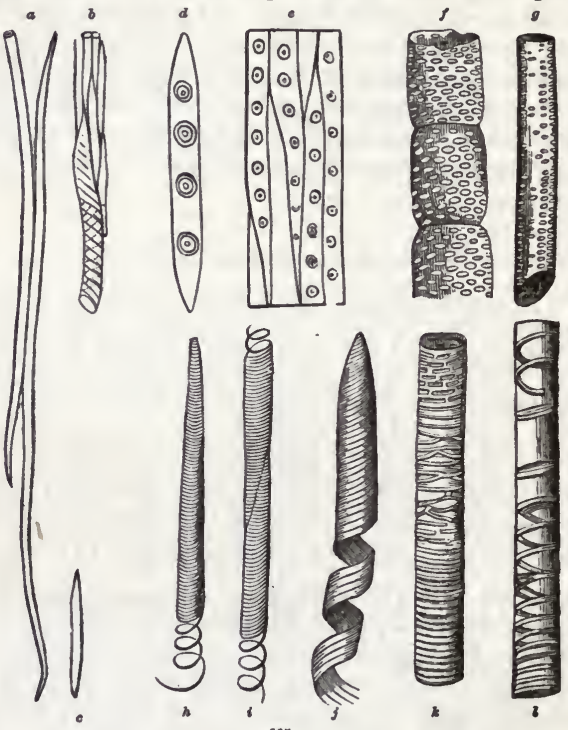

short and commonly thin-walled cells, form cellular tissue. Its ordinary form (of roundish, cubical, or polyhedral and thin-walled cells) is called parenchyma. This abounds in herbaceous stems or herbaceous parts : in trees and shrubs, woody tissue largely prevails; in most herbs, it forms a notable portion ; in some (especially

FIG. 125. Fibro-vascular elements. a. Bast-cells (long wood-cells) of fibrous bark of Linden or Bass-wood. b. Some wood-cells and (below) a dnct, and c. a detached wood-cell of the wood of same tree, equally magnified with $a$. $d$. A detached woodcell from a shaving of White Pine, showing the peculiar disk-like markings. e. Portion of same shaving. $f$. Portion of a dotted duct from the Vine, evidently made up of a series of short cells. g. Part of a smaller dotted duct, showing no appearance of such composition. $h, i$. Spiral ducts or vessels, of the ordinary kind. $j$. Spiral duct of Banana. $k$. Duct from Celery, the thread within spiral or annular below, retlculated above, and higher passing into the state of dotted duct. $l$. Duct from Impatiens, with the open opiral paseing into rings at the middle. All magnified somewhat equally. 
in certain aquatic herbs), it is reduced to a few threads or vessels, generally delicate, and sometimes obscure. The accompanying anatomical illustrations (Fig. $124^{a}, 125$, with their explanations) will give a general idea of the nature of the anatomical elements of the stem.

132. In the forming state, the whole stem is parenchyma; but an early differentiation takes place, converting certain portions into woody or fibro-vascular tissue. This is arranged in two ways, giving rise to two kinds of stem in phænogamous plants, which have been termed the Endogenous and the Exogenous, ${ }^{1}$ meaning inside and outside growers.

133. The two plans of stem are usually manifested in external conformation as well as internal structure, and are correlated with important differences in embryo, foliage, and flower. ${ }^{9}$ Palms, Lilies, Rushes, and Grasses are examples of the endogenous class; the ordinary trees and shrubs, especially those of cool climates, and a large part of the herbs, are of the exogenous class. In an exogenous stem, the wood occupies annual concentric layers, one of each year's growth; the centre is occupied by a pith, composed of parenchyma only, the circumference by a separable bark; so that a cross-section presents a series of rings or circles of wood, or in the first year one ring, surrounding the pith and surrounded by the bark. An endogenous stem has the wood in distinct threads or fibro-vascular bundles, traversing the cellular system or parenchyma with little or no obvious order, and presenting

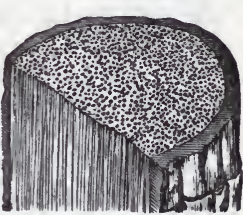

128 on the cross-section the divided ends of these bundles in the form of dots; these usually (but not always) diffused over

1 Terms introduced by DeCandolle, following the ideas of Desfontaines, and which have played an important part in structural and systematic botany ever since DeCandolle adopted these names as those of the two primary divisions of phænogamous plants, Exogenae and Erdogence. But it has long been seen that the name of the second kind is not appropriate; and the older and better (though longer) names of Jussieu, Monocotyledones and Dicotyledones, are reverted to. Yet the Candollean names are still much employed, with due explanation, to designate the two kinds of structure of the stem.

2 Yet with some more or less valid exceptions, as when the annual stem of Podophyllum and the rhizoma of Ny mphæa, among dicotyledonous plants, imitate the endogenous structure; or where the pith of an evidently exogenous stem, as in the Piperacex, has scattered woody bundles in an endogenous fashion; or where monocotyledonous plants have all their woody bundles in a definite circle, as in Luzula, Croomia, \&c.

FIQ. 126. Section of a small Palm-stem, in two directions. 
the whole section, or when few in number of somewhat definite position or arrangement. The ordinary appearance of such a stem, both on the longitudinal and the cross-section, is shown in Fig. 126 ; it may also be examined in the Cane or Rattan, the Bamboo, and in the annual stalk of Indian Corn or of Asparagus. The appearance of ordinary wood is very familiar.

135. The newer woody bundles of an endogenous stem are variously intermingled with the old. When DeCandolle gave the name, it was supposed, from Desfontaines's researches, that the older bundles occupied, or came at length to occupy, the circumference of the trunk, while only new ones were formed in the centre; and that increase in diameter, when it took place at all, resulted from the gradual growth and distention of the whole. Hence the contrasting name of endogenous, or inside growing, and for such plants the name of Endogenous Plants, or Endogens. Our actual knowledge of the structure and growth of these stems, as will be seen, cannot be harmonized with this view in any way which gives to the name endogenous an appropriate signification. The name continues as a counterpart to the more correct one of exogenous, and as a survival of former ideas.

136. The Endogenous Structure (so called) of the stem is correlated with a monocotyledonous embryo (39), usually with a ternary arrangement in the flower (322), and commonly with parallel-veined leaves. (173.) Endogens, although they have many herbaceous and a few somewhat woody representatives in cool temperate climes, mostly attain their full variety of features and rise to noble arborescent forms under a tropical sun. Yet Palms - the arboreous type of the class - do extend as far north in this country as the coast of North Carolina (the natural limit of the Palmetto, Fig. $126^{a}$ ); while in Europe the Date and the Chamærops thrive in the warmest parts of the European shore of the Mediterranean. The manner of their growth gives them a striking appearance; their trunks being unbranched cylindrical columns, rising to the height of from thirty to onc hundred and fifty feet, and crowned at the summit with a simple cluster of peculiar foliage. Palms generally grow from the terminal bud alone, and perish if this bud be destroyed; they grow slowly, and bear their foliage in a cluster at the summit of the trunk, which consequently forms a simple cylindrical column. But in some instances two or more buds develop, and the stem branches, rarely and accidentally in ordinary species, regularly in the Doum Palm of Upper Egypt, and in the Pandanus, or Screw-Pine (Fig. 69), which belongs to a family allied to Palms : in such cases the branches are cylindrical. But when lateral 
buds are freely developed (as in the Asparagus), or the leaves are scattered along the stem or branches by the full development of internodes (as in the Bamboo, Maize, \&c.), they gradually taper upward in the manner of most exogenous stems.

137. This kind of stem comprises several subordinate types as to internal structure, which to be well understood must be studied histologically, under the microscope. ${ }^{1}$ To one of these, by no means the simplest, belongs the ordinary palmstem, the anatomy of which was made classical by Mohl, and has been supplemented by Nægeli. In this a large part of the bundles, or all of the more

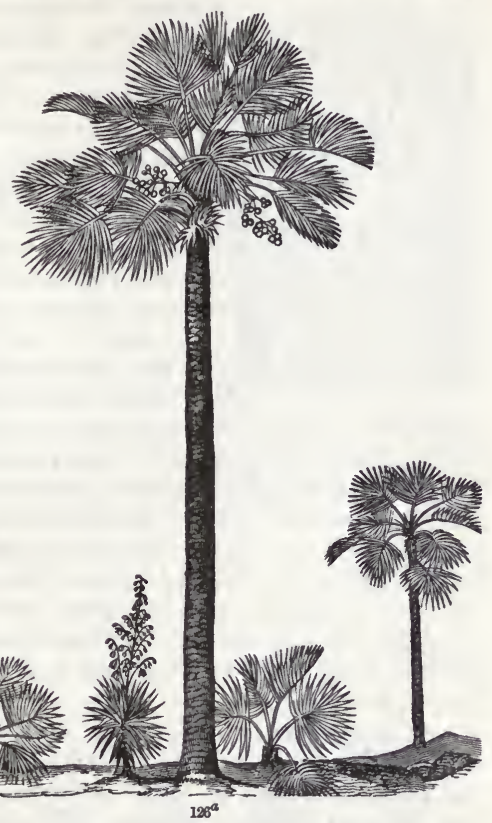

conspicuous kind, starting from the base of the leaf to which they respectively belong, curve inward more or less strongly toward the centre of the stem, and thence gradually outward as they descend until they reach the rind, in which the attenuated lower extremity mostly terminates. Consequently, the bundles from different heights cross in their course, somewhat

1 For the best and most accessible memoir on the subject, of recent date, see Guillaud, Recherches sur l'Anatomie comparée et le Développement des Tissus de la Tige dans les Monocotylédones, published in Ann. Sci. Nat. ser. 6, v. 1-176, 1877. Six types of the stem of Monocotyledons are here recognized by anatomical characters and modes of growth, one of them having four modifications.

FIG. 126a. Sabal Palmetts in various stages; also the Yucca aloifolia or Spanish Bayonet. 
as shown in Fig. 127. It is partly owing to this connection of these fibres with the rind that the latter is not separable from

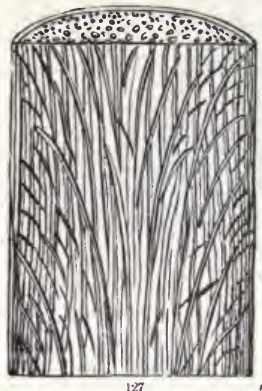
the stem. In some Palms, and in Grasses, there is no marked distinction between the wood and rind, or no proper rind at all. In others, such as the Palmetto (Fig. 126), there is a marked rind or false bark, which receives independent fibro-vascular bundles from the leaf-stalks, and is traversed by them in parallel lines. In Grass-stems, and others with long internodes and closed nodes, the fibro-vascular bundles all run approximately straight and parallel through the internodes, but are intricate and anastomosed in the nodes. The whole centre of the internodes, when not hollow or before it becomes so, is occupied by a true pith, like that of an Exogen, and in some cases equally destitute of fibro-vascular bundles, but often with scattered ones, after the manner of certain Exogens anomalous in this respect, such as Nyctaginaceæ and some Araliaceæ. Endogenous stems of simpler structure, as in herbaceous Liliaceæ, Commelynaceæ, $\& c .$, have a distinct cortical portion (at least in the root-stock or portion of stem properly eomparable with palm-trunks and the like); but this is mostly destitute of fibro-vascular bundles. Most of them have two kinds of vascular bundles, one of which not rarely occupies an exact circle in the line of division between the cortical and medullary portion (between bark and pith), and the other is within this circle, either of very few and scattered bundles, as in Convallaria majalis, or numerous and scattered, as in Uvularia and the leafy stems of Tradescantia Virginica; or these bundles are few and arranged nearly in an inner circle close around the centre. Finally, Luzula and Croomia have only one kind of bundles, answering to the outer ones of Convallaria; in other words, the woody system forms a simple circle, dividing a purely cellular medullary from a similar cortical portion, thus closely imitating an herbaceous exogenous stem of the same age.

138. An annual endogenous stem increases in diameter by general growth until it attains its limit. Ligneous and enduring stems increase similarly up to a certain period. Then the rind

FIG. 127. Diagrammatic view of the curved course of the flbro-vascular bundles in a palm-trunk. 
sooner or later ceases to distend or adapt itself to further increase in diameter, and there is no interior provision for indefinite increase in the greater number of woody endogenous trunks. But in Dracæna (Dragon-trees), in the arborescent Yuccas, and the like, the zone intermediate between the cortical and interior region, which is for a time active in many Endogens, here grows continuously and indefinitely. Such trunks increase in diameter throughout life; they may attain a very great age (as some Dragon-trees have done); and they imitate exogenous trunks to a considerable extent in mode of growth.

139. The wood of an endogenous woody stem is hardest and most compact at the circumference; in palm-stems commonly it is largely mixed with parenchyma or pith at the centre, even in old trunks.

140. The Exogenons Structure, that of ordinary wood, is characterized by the formation of a distinct zone of wood between a central cellular medullary portion (pith) and an outer chiefly cellular portion (bark), traversed by plates from the pith (medullary rays), and by increasing from the outer surface of this zone between wood and bark, the increase in enduring stems consisting of definite concentric annual layers.

141. Its Beginning, at the earliest growth of the embryo, is in the appearance of a few ducts (Fig. 125, $f-l$ ), at definite points in the common parenchyma of the initial stem (four equidistant ones in the Sugar Maple); each is soon surrounded by incipient

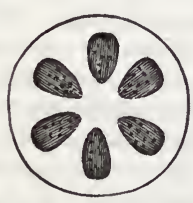

128

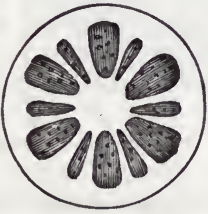

129

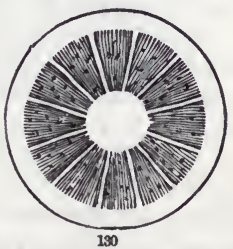

130

proper wood-cells (Fig. 125, $b, c$ ), together forming a fibro-vascular bundle or thread. Additional ones are intercalated as the second and third internodes develop, and so a column (in crosssection a ring) of wood is produced, always so arranged as to

FIG. 128. Diagram of a cross-section of a forming seedling stem, showing the manner in which the young wood is arranged in the cellular system.

FIG. 129. The same at a later period, the woody bundles increased so as nearly to fill the circle.

FIG. 130. The same at the close of the season, where the wood has formed a complete circle, interrupted only by the medullary rays, which radiate from the pith to the bark. 
surround a purely cellular central part (the pith), while surrounded by a cellular external rind, the bark, or outer bark. The diagrams (Fig. 128-130) rudely show some stages in the formation of the zone of wood. The fibro-vascular bundles originate in the bases of the leaves, and develop outward into the forming leaves as well as downward into the forming stem.

142. First Year's Growth. The wood, even in a herbaceous or annual stem, at the completion of the first year's growth,

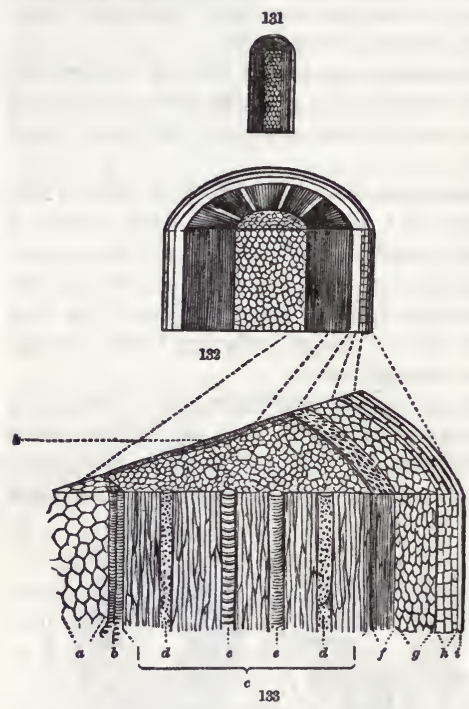
forms a zone or tube, enclosing the pith. But it is traversed by plates (in cross-section lines) of parenchyma, or cel Iular tissue of the same nature as the pith, which radiate from that to the bark, and thus divide the wood into wedges. These lines, forming what is called the silver-grain in wood, are the MEDULLARY RaYs. They represent the cellular system of the wood itself, or untransformed parenchyma. Being pressed by the woody wedges, their cells aro laterally flattened. In some stems, the medullary rays, or many of them, are comparatively broad and conspicuous; in others, thin and inconspicuous or irregular. The growth of the woody wedges is soon complete, except at the outer portion, next the bark: here they usually continue to grow through the season; that, is the wood grows externally. The general ana-

FIG. 131. Longitudinal and transverse section of a stem of the Soft Maple (Acer dasycarpnm), at the close of the first year's growth; of the natural size.

FIG. 132. Portion of the same, magnified, showing the cellular pith, surrounded by the wood, and that by the bark.

FIG. 133. More magnified slice of the same, reaching from the bark to the pith: $a$. part of the pith; $b$. vessels of the medullary sheath; $c$. the wood; $d, d$. dotted ducts in the wood; $e, e$. annular ducts; $f$. the liber, or inner fibrous bark; $g$. the cellular envelope, or green bark; $h$. the corky envelope; $i$. the skin or epidermis; $k$. one of the medullary rays, seen on the transverse section. 
tomical structure of a woody exogenous stem of a year old is displayed in the Fig. 131-133. Viewing the parts particularly, and in order from centre to circumference, there is, -

1st. The Pith or Medulla, consisting entirely of soft and rather large thin-walled cells, ${ }^{1}$ gorged with sap or other nourishing matter during the growing state, becoming light, dry, and empty when effete.

2nd. The Layer of Wood, traversed by the medullary rays. In Pines and other Coniferæ, the wood is of uniform structure, being wholly composed of a woody tissue with peculiar markings (Fig. $125, d, e):$ in other wood, ducts of one or more sorts occur; the most conspicuous being what are termed dotted ducts. These are so large as to be evident to the naked eye in many ordinary kinds of wood, especially where they are accumulated in the inner portion of the layer, as in the Chestnut and Oak. In the Maple, Plane, \&c., they are rather equably scattered through the annual layer, and are too small to be seen by the naked eye. Next the pith, $i$. e. in the very earliest formed part of the wood, some spiral ducts are uniformly found, and this is the only part of the exogenous stem in which these ordinarily occur. They may be detected by breaking a woody twig in two, after dividing the bark and most of the wood by a circular incision, and then pulling the ends gently asunder, when their spirally coiled fibres are readily drawn out as gossamer threads. As these spiral ducts form a circle immediately surrounding the pith, they have collectively been termed the medullary sheath, but they hardly deserve a special name. The vertical section in Fig. 133 divides one of the woody wedges, and shows no medullary ray ; but there is one at the posterior edge of the transverse section. But, in the much more diagramatic Fig. 134, the section is made so as to show the surface of one of these plates, or medullary rays, passing horizontally across it, connecting the pith $(p)$ with the bark $(b)$. These medullary rays form the silver-grain (as it is termed), which is so conspicuous in the Maple, Oak, \&c., and which gives the glimmering lustre to many kinds of wood when cut in this direction. A section made as a tangent to the circumference, and therefore perpendicular to the medullary rays, brings their ends to view, as in Fig. 135, much as they appear on the surface of a piece of wood from which the bark is stripped. They are here seen to be composed of parenchyma, and to represent the horizon-

1 In rare instances, a few fibro-vascular threads are found dispersed through the pith, presenting a somewhat remarkable anomaly. This occurs in Aralia racemosa, and more strikingly in Mirabilis and other Nyctaginaceæ, and in Piperaceæ. (133. foot-note.) 
tal system of the wood, or the woof, into which the vertical woody fibre, \&c., or warp, is interwoven. The inspection of a piece of oak or maple wood at once shows the pertinency of this illustration.

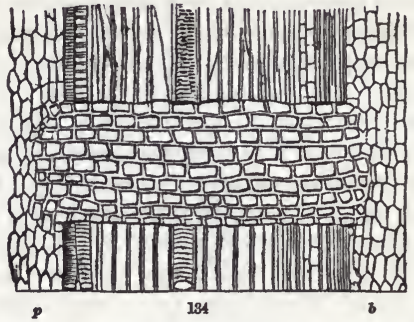

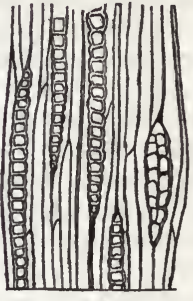

135

3rd. The Bark or rind. This at first consisted of simple parenchyma, like that of the pith, except for the green color developed in it, the same as that which gives verdancy to foliage. This green matter is formed in the cells of all such parts when exposed to light, consists of green grains of somewhat complex chemical composition, has important functions to perform in assimilation (i.e. in the conversion of the plant's crude food into vegetable matter), and is named ChLorophrLL, $i$. e. leaf-green. The completed bark, when all its parts are apparent, as especially in most trees and shrubs, is composed of three strata, of which the green bark, the most conspicuous in the young shoot, is the middle layer, therefore named the Mesophloum. This is soon covered, and the green color obscured, by a superficial stratum of cells, generally of some shade of ash-color or brown, occasionally of brighter tints, which gives to the twigs of trees and shrubs the hue characteristic of each species, the CoRKY Envelope or layer, or Epiphladu. The latter name denotes its external position; the former, that it is the layer which, when much developed, forms the cork of Cork-Oak and those corky expansions which are so conspicuous on the twigs of the Sweet Gum (Liquidambar), and on some of our Elms (Ulmus alata and racemosa). It also forms the paper-like exfoliating layers of Birch-bark. It is composed of laterally flattened parenchymatous cells, much like those of the EpIDERMIs (Fig. 133, $i$ ), which directly overlies it, and forms the skin or surface of the

IIG. 134. Vertical section through the wood of a branch of the Maple, a year old, so as to show one of the medullary rays, passing transversely from the pith $(p)$ to the bark $(b)$ : magnified. But a section can seldom be made so as to show one unbroken plate stretching across the wood, as in this instance.

FIG. 135. A vertical section across the ends of the medullary rays: magnified. 
stem, and of the whole plant. Lastly, the inner bark, accordingly named ENDOPHLCUM, takes the special name of LiBER, and is the most important portion of the bark in the stems of trees and shrubs. Complete and well-developed liber, like that of Linden or Basswood, contains two peculiar kinds of cells in

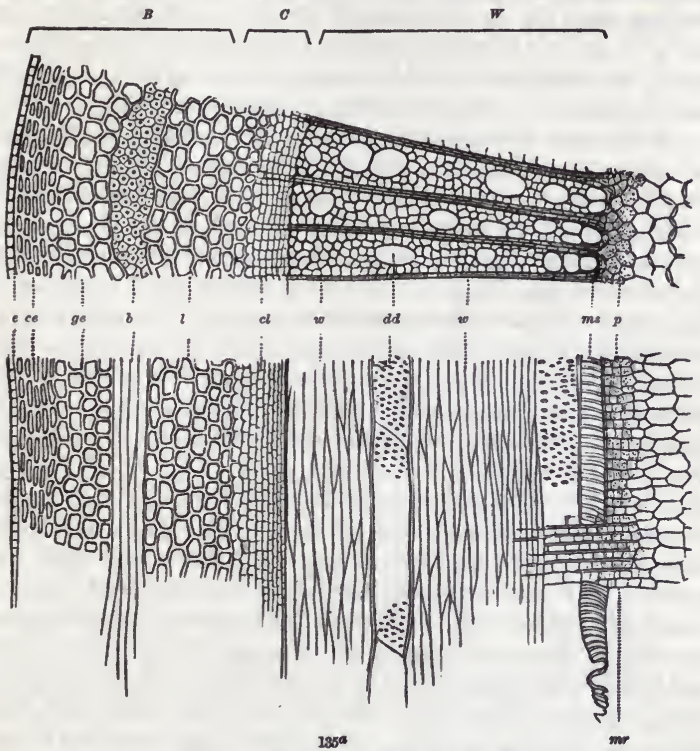

addition to common parenchyma, both of the fibrous or vascular class : viz., 1. Cribriform or Sieve-Cells, a sort of ducts the walls of which have open slits, through which they communicate with each other; 2. BAST or BAST-CELLS, the fibre-like cells which give to the kinds of inner bark that largely contain them

FIG. 135 . Portion of a transverse section (above), and a corresponding vertical section (below), magnified, reaching from the pith $(p)$ to the epldermis $(e)$ of a stem of Negundo, a year old : $B$. the bark; $W$. the wood; and $C$. the camblum-layer, as found in February. The parts referred to by small letters are: $p$. a portion of the pith: $m r$. small portion of a medullary ray where it runs into the pith; fonr complete medvllary rays as seen on a transverse section, appear in the npper figure, running from pith to bark : ms. medullary sheath, a circle of spiral unrollable ducts, one seen lengthwise with uncolling extremity in the lower flgure: $w$, $w$. woody tissne: $d d$. one of the dotted ducts interspersed in the wood: $c l$. cambium-layer or zone of new growth of wood and inner bark : $l-b$. liber or inner bark, the inner portion of which is bere cellular, the outer $(b)$ composed of slender and thick-walled bast-cells or true liber-cells: ge. green envelope or inner cellular bark: ce. corky envelope or outer celiular bark: e. epidermis. 
their strength and toughness. They are like wood-cells except in their greater length and flexibility, and in the thickness of their walls, which greatly exceeds the calibre. This is the material which gives to the bast or inner bark of Basswood, \&c., the strength and pliability that adapts it for cordage and for making mats : it is the material of linen, and the like textile fibres. (For a view of the whole composition and structure of a woody stem at the close of the first year's growth, and immediately before that of the second year begins, see Fig. 135 ${ }^{\mathrm{a}}$.)

143. Annual Increase in Diameter. An herbaceous stem does not essentially differ from a woody one of the same age, except that the wood forms a less compact or thinner zone; and the whole perishes, at least down to the ground, at the close of the season. But a woody stem makes provision for continuing its growth from year to year. As the layer of wood continues to increase in thickness throughout the season, by the multiplication of cells on its outer surface, between it and the bark, and when growth ceases this process of cell-multiplication is merely suspended, so there is always a zone of delicate young cells interposed between the wood and the bark. This is called the Cambium, or, better, the Cambiom-layer. It is charged with organizable matter, which is particularly abundant and mucilaginous in spring when growth recommences. This mucilaginous matter was named Cambium by the older botanists: they supposed - as is still popularly thought - that the bark, then so readily separable, really separated from the wood in spring, that a quantity of rich mucilaginous sap was poured out between them and became organized into a tissue, the inner part becoming new wood, the outer, new bark. But delicate slices show that there is then no more interruption of the wood and inner bark than at any other season. The bark, indeed, is then very readily detached from the wood, because the cambium-layer is gorged with sap; but such separation is effected by the rending of a delicate forming tissue. And if some of this apparent mucilage be scraped off from the surface of the wood, and examined under a good microscope, it will be seen to be a thin stratum of young wood-cells, with the ends of medullary rays here and there interspersed. The inner portion of the cambium-layer is therefore nascent wood, and the outer is nascent bark. As the cells of this layer multiply, the greater number lengthen vertically into woody tissue: some are transformed into ducts; and others, remaining as parenchyma, continue the medullary rays or commence new ones. In this way, a second layer of wood is formed the second season over the whole surface of the former layer 
between it and the bark; and this is continuous with the woody layer of the new roots below and of the leafy shoots of the season above. Each succeeding year another layer is added to the wood in the same manner, coincident with the growth in length by the development of the buds. A cross-section of an exogenous stem, therefore, exhibits the wood disposed in concentric rings between the bark and the pith; the oldest lying next the latter, and the youngest occupying the circumference. Each layer being the product of a single year's growth, the age of an exogenous tree may, in general, be correctly ascertained by counting the rings in a cross-section of the trunk. ${ }^{1}$

144. Demarcation of the Annual Layers results from two or more causes, separate or combined. In oak and chestnut wood, and the like, the layers are strongly defined by reason of the accumulation of the large dotted ducts (here of extreme size and in great abundance) in the inner portion of each layer, where their open mouths on the cross-section are conspicuous to the naked eye, making a strong contrast between the inner porous and the exterior solid part of the successive layers. In maple and beech wood, however, the ducts are smaller, and are dispersed throughout the whole breadth of the layer; and in coniferous wood, viz. that of Pine, Cypress, \&c., there are no ducts at all, but only a aniform woody tissue of a peculiar sort. In all these, the demarcation between two layers is owing to the greater fineness of the wood-cells formed at the close of the season, viz. those at the outer border of the layer, while the next layer begins, in its

1 The annual layers are most distinct in trees of temperate climates like ours, where there is a prolonged period of total repose, from the winter's cold, followed by a vigorous resumption of vegetation in spring. In tropical trees, they are rarely so well defined; but even in these there is generally a more or less marked annual suspension of vegetation, occurring, however, in the dry and hotter, rather than in the cooler season. There are numerous cases, moreover, in which the wood forms a uniform stratum, whatever be the age of the trunk, as in the arborescent species of Cactus; or where the layers are few and by no means corresponding with the age of the trunk, as in the Cycas.

In many woody climbing or twining stems, such as those of Clematis, Aristolochia Sipho, and Menispermum Canadense, the annual layers are rather obscurely marked, while the medullary rays are unusually broad; and the wood, therefore, forms a series of separable wedges disposed in a circle around the pith. In the stem of Bignonia capreolata, the annual rings, after the first four or five, are interrupted in four places, and here as many broad plates of cellular tissue, belonging properly to the bark, are interposed, passing at right angles to each other from the circumference towards the centre, so that the transverse section of the wood nearly resembles a Maltese cross. But these are exceptional cases, which scarcely require notice in a general view. 
vigorous vernal growth, with much larger cells, thus marking an abrupt transition from one layer to the next. Besides being finer, the later wood-cells of the season are commonly flattened antero-posteriorly, probably by growing under greater pressure.

145. Each layer of wood, once formed, remains essentially unchanged in position and dimensions. But, in trunks of considerable age, the older layers undergo more or less change in color, density, perviousness to moisture, \&c.

146. Sap-wood (Alburnum). In the plantlet and in the developing bud, the sap ascends through the whole tissue, of whatever sort: at first through the parenchyma, for there is then no other tissue; and the transmission is continued through it, especially through its central portion, or the pith, in the growing apex of the stem throughout. But, in the older parts below, the pith, soon drained of sap, becomes filled with air in its place, and thenceforth it bears no part in the plant's nourishment. As soon as wood-cells and ducts are formed, they take an active part in the conveyance of sap, for which their tubular and capillary character is especially adapted. But, the ducts in older parts, except when gorged with sap, contain air alone; and in woody trunks the sap continues to rise year after year to the places where growth is going on, mainly through the proper woody tissue of the wood. In this transmission, the new layers are most active ; and these are in direct communication with the new roots on the one hand and with the buds or shoots and leaves of the season on the other. So, by the formation of new annual layers outside of them, the older ones are each year removed a step farther from the region of growth; or rather the growing stratum, which connects the fresh rootlets that imbibe with the foliage that elaborates the sap, is each year removed farther from them. The latter, therefore, after a few years, cease to convey sap, as they have long before ceased to take part in any vital operations. The cells of the older layers, also, usually come to have thicker walls and smaller calibre than those of the newer. Thus arises a distinction - sometimes obscurely marked, sometimes abrupt and conspicuous - into sap-wood and heart-roood. The former is the popular name given to the outer and newer layers of softer, more open, and bibulous wood. The early physiologists named it alburnum from its white or pale color. Being more or less sappy, or containing soluble organic matter, and readily imbibing moisture, this part of the wood is liable to decay, and it is therefore discarded from timber used for construction.

147. Heart-wood (or Duramen, so called from its greater hardness or durability) is the older and mature portion of the wood. 
In all trees which have the distinction between the sap-wood and heart-wood well marked, the latter acquires a deeper color, and that peculiar to the species, such as the dark brown of the Black Walnut, the blacker color of the Ebony, the purplish-red of Red Cedar, and the bright yellow of the Barberry. These colors are owing to special vegetable products, or sometimes to alterations resulting from age. In the Red Cedar, the deep color belongs chiefly to the medullary rays. In many of the softer woods, there is little change in color of the heart-wood, except from incipient decay, as in the White Pine, Poplar, Tulip-tree, \&c. The heart-wood is no longer in any sense a living part: it may perish, as it frequently does, without affecting the life or health of the tree.

148. The Growth and Duration of the Bark, also the differences in structure, are much more various than of the wood. Moreover, the bark is necessarily subject to grave alterations with advancing age, on account of its external position; to distention from the constantly increasing diameter of the stem within, and to abrasion and decay from the influence of the elements without. It is never entire, therefore, on the trunks of large trees; but the dead exterior parts, no longer able to enlarge with the enlarging wood, are gradually fissured and torn, and crack off in strips or pieces, or disappear by slow decay. So that the bark of old trunks bears only a small proportion in thickness to the wood, even when it makes an equal amount of annual growth.

149. The three parts of the bark (142), for the most part readily distinguishable in the bark of young shoots, grow independently, each by the addition of new cells to its inner face, so long as it grows at all. The green layer commonly doe's not increase after the first year; the opaque corky layer soon excludes it from the light ; and it gradually perishes, never to be renewed. The corky layer usually increases for a few years only, by the formation of new tabular cells : occasionally it takes a remarkable development, forming the substance called Cork, as in the Cork Uak, and the thin and parchment-like layers of the White and Paper Birches.

150. The liber, or inner bark, continues its growth throughout the life of the exogenous tree, by an annual addition from the cambium-layer applied to its inner surface. Sometimes this growth is plainly distinguishable into layers, corresponding with or more numerous than the annual layers of the wood: often, there is scarcely any trace of such layers to be discerned. In composition and appearance, the liber varies greatly in different plants, especially in trees and shrubs. That of Basswood or 
Linden, and of other plants with a similar fibrous bark, may be taken as best representing the liber. Here it consists of alternate strata of fibrous bast, and of the peculiar liber-cells called sieve-cells, in which nourishing matter is especially contained and elaborated. While the latter, or their equivalents, occur and play an important part in all inner bark, the bast-cells are altogether wanting in the bark of some plants, and are not produced after the first year in many others. The latter is the case in Negundo, where abundant bast-cells, like those of Basswood, compose the exterior portion of the first year's liber, but none whatever are formed in the subsequent layers. In Beeches and Birches, also, a few bast-cells are produced the first year, but none afterwards. In Maples, a few are formed in succeeding years. In the Pear, bast-cells are annually formed, but in very small quantity, compared with the parenchymatous part of the liber. In Pines, at least in White Pines, the bark is nearly as homogeneous as the wood, the whole liber, except what answers to the medullary rays, consisting of one kind of cells, resembling those of bast or of wood in form, but agreeing with the proper liber-cells in their structure and markings.

151. The bark on old stems is constantly decaying or falling away from the surface, without any injury to the tree; just as the heart-wood within may equally decay without harm, except by mechanically impairing the strength of the trunk. There are great differences as to the time and manner in which the older bark of different shrubs and trees is thrown off. Some have their trunks invested with the liber of many years' growth, although only the innermost layers are alive; in others, it scales off much earlier. On the stems of the common Honeysuckle, of the Nine-Bark (Spiræa opulifolia), and of Grape-vines (except Vitis vulpina), the liber lives only one season, and is detached the following year, hanging loose in papery layers in the former species, and in fibrous shreds in the latter.

152. While the newer layers of the wood abound in crude sap. which they convey to the leaves, those of the inner bark abound in elaborated sap, which they receive from the leaves and convey to the cambium-layer or zone of growth. The proper juices and peculiar products of plants are accordingly found in the foliage and the bark, especially in the latter. In the bark, therefore (either of the stem or of the root), medicinal and other principles are usually to be sought, rather than in the wood. Nevertheless, as the wood is kept in connection with the bark by the medullary rays, many products which probably originate in the former are deposited in the wood. 
153. The Living Parts of a tree or shrub, of the exogenous kind, are obviously only these: 1st, The summit of the stem and branches, with the buds which continue them upwards and annually develop the foliage. $2 \mathrm{~d}$, The fresh roots and rootlets annually developed at the opposite extremity. 3d. The newest strata of wood and bark, and especially the interposed cambiumlayer, which, annually renewed, maintain a living communication between the rootlets on the one hand and the buds and foliage on the other, however distant they at length may be. These are all that is concerned in the life and growth of the tree; and these are annually renewed. The branches of each year's growth are, therefore, kept in fresh communication, by means of the newer layers of wood, with the fresh rootlets, which are alone active in absorbing the crude food of the plant from the soil. The fluid they absorb is thus conveyed directly to the branches of the season, which develop leaves to digest it. And the sap they receive, having been elaborated and converted into organic nourishing matter, is partly expended in the upward growth of new branches, and partly in the formation of a new layer of wood, reaching from the highest leaves to the remotest rootlets.

154. Longevity of trees. As the exogenous tree, therefore, annually renews its buds and leaves, its wood, bark, and roots, - every thing, indeed, that is concerned in its life and growth, there seems to be no necessary cause, inherent in the tree itself, why it may not live indefinitely. Some trees are known to have lived for one and two thousand years, and some are possibly older. ${ }^{1}$ Equally long may survive such endogenous trees as the Dragon tree (Dracæna), which have provision for indefinite increase in diameter (138), and for the production of branches. The famous Dragon tree of Orotava, in Teneriffe, now destroyed by hurricanes and other accidents, had probably reached the age of more than two thousand years.

155. On the other hand, increase in height, spread of branches and length of root, and extension of the surface over which the annual layer is spread, are attended with inevitable disadvantage, which must in time terminate the existence of the tree in a way quite analogous to the death of aged individual animals, which is not directly from old age, but from casualties or attacks to

1 The subject of the longevity of trees has been discussed by DeCandolle, in the "Bibliothèque Universelle" of Geneva, for May, 1831, and in the second volume of his "Physiologie Végétale;" more recently, by Alphonse DeCandolle in the "Bibliotheque Universelle;" and in this country by myself in the "North American Review," for July, 1844. For an account of the huge Red. woods (Sequoias) of California, see Whitney's Yosemite Book. 
which the aged are either increasingly incident or less able to resist. A tree like the Banyan (59, Fig. 71), which by aerial roots continues to form new trunks for the support and sustenance of the spreading branches, and thus ever advances into new soil, has a truly indefinite existence; but, then, it becomes a forest, or is to be likened to a colony propagated and indefinitely increased by suckers, offsets, or other subterranean shoots. So the question of the secular continuation of the individual plant becomes merged in that of continuation of the race, - at least of a bud-propagated race, - the answer to which is wholly in the domain of conjecture. ${ }^{1}$ However this may be, it is evident that a vegetable of the higher grade is not justly to be compared with an animal of higher grade; that individuality is incompletely realized in the vegetable kingdom ${ }^{2}$ that rather

156. The Plant is a Composite Being, or Community, lasting, in the case of a tree, through an indefinite and often immense number of generations. These are successively produced, enjoy a term of existence, and perish in their turn. Life passes onward continually from the older to the newer parts, and death follows, with equal step, at a narrow interval. No portion of the tree is now living that was alive a few years ago; the leaves die annually and are cast off, while the internodes or joints of stem that bore them, as to their wood at least, buried deep in the trunk under the wood of succeeding generations, are converted into lifeless heart-wood, or perchance decayed, and the bark that belonged to them is thrown off from the surface. It is the aggregate, the blended mass alone, that long survives. Plants of single cells, and of a definite form, alone exhibit complete individuality; and their existence is extremely brief. The more complex vegetable of a higher grade is not to be compared with the animal of the highest organization, where the offspring always separates from the parent, and the individual is simple and indivisible. But it is truly similar to the branching or arborescent coral, or to other compound animals of the lowest grade, where successive generations, though capable of living independently and sometimes separating spontaneously, yet are usually developed in connection, blended in a general body, and nourished more or less in common. Thus, the coral structure is built up by the combined labors of a vast number of individuals, - by the successive labors of many generations. The surface or the recent shoots only are alive; beneath are only the dead remains

1 See Darwiniana, xii. 338-355.

2 As, perhaps, was first explicitly stated by Engelmann, in his inaugural essay, De Antholysi Prodromus, Introduction, \& 4. 
of ancestral generations. As in a genealogical tree, only the later ramifications are among the living. The tree differs from the coral structure in that, as it ordinarily imbibes its nourishment mainly from the soil through its roots, it makes a downward growth also, and, by constant renewal of fresh tissues, maintains the communication between the two growing extremities, the buds and the rootlets. Otherwise, the analogy of the two, as to individuality, is well-nigh complete.

\section{Section IV. Of Leaves.}

\section{§1. Their Nature and Office.}

157. Leaf (Lat. Folium, in Greek form Phyllum), as a botanical term, has on the one hand a comprehensive, on the other a restricted sense. In its commonest sense, as used in descriptive botany, it denotes the green blade only. Yet it is perfectly understood that the footstalk is a part of the leaf, and therefore that the phrase "leaves cordate," or the like, is a short way of saying that the blade of the leaf is cordate or heart-shaped. Moreover, two appendages, one on each side of the base of the footstalk, when there is any, are of so common occurrence that they are ranked as a proper part of the organ. So that, to the botanist, a typical leaf consists of three parts: 1, BLADE or Lamina ; 2, Foot-stalk or Leaf-stalk, technically Petiole; 3, A pair of Stipules. (Fig. 142.)

158. The blade, being the most important part of an ordinary leaf, may naturally be spoken of as the whole. Petiole and stipules are indeed subsidiary when present, and are not rarely wanting. Yet sometimes they usurp the whole function of foliage, and sometimes there is no such distinction of parts.

159. Physiologically, leaves are green expansions borne by the stem, outspread in the air and light, in which assimilation (3) and the processes connected with it are carried on. Vegetable assimilation, - the most essential function of plants, being the conversion of inorganic into organic matter, - takes place in all ordinary vegetation only in green parts, and in these when exposed to the light of the sun. And foliage is an adaptation for largely increasing the green surface. But stems, when green, take part in this office in proportion to the amount of surface, sometimes monopolize it, and in various cases increase their means of doing so by assuming leaf-like forms. (126-129.) Leaves, especially in such cases, may lose this function, appear only as useless vestiges, or may be subservient to various wholly 
different uses. Form and function, therefore, are not sure indications of the true nature of organs.

160. Morphologically, and in the most comprehensive sense, leaves are special lateral outgrowths from the stem, definitely and symmetrically arranged upon it; in ordinary vegetation and in the most general form constituting the assimilating apparatus (or foliage), but also occurring in other forms and subserving various uses. Sometimes these uses are combined with or subsidiary to the general function of foliage; sometimes the leaf is adapted to special uses only. So the botanist - recognizing the essential identity of organs, whatever their form, which appear in the position and conform to the arrangement of leaves discerns the leaf in the cotyledons of a bean or acorn, the scale of a lily-bulb or the coat of an onion, the scale of a winter bud, and the petal of a blossom. Therefore, while expanded green leaves (which may be tautologically termed foliage-leaves) are taken as the proper type, the common name of leaves, in the lack of any available generic word, is in morphological language extended to these special forms whenever it becomes needful to express their phylline or foliar nature.

161. In the morphological view, all the plant's organs excepting roots (and excepting mere superficial productions, such as hairs, prickles, \&c.), belong either to stem or to leaves, are either cauline or phylline in nature. To the latter belong all the primary outgrowths from nodes, all lateral productions which are not axillary. ${ }^{1}$ Whatever is produced in the axil of a leaf is cauline, and when developed is a branch.

162. The Duration of Leaves is transient, compared with that of the stem. They may be fugacious, when they fall off soon after their appearance; deciduous, when they last only for a single season; and persistent, when they remain through the cold season, or other interval during which vegetation is interrupted, and until after the appearance of new leaves, so that the stem is never leafless, as in Evergreens. In many evergreens, the leaves have only an annual duration; the old leaves falling soon after those of the ensuing season are expanded, or, if they remain longer, ceasing to bear any active part in the economy of the vegetable, and soon losing their vitality altogether. In Pines and Firs, however, although there is an annual fall of leaves either in autumn or spring, yet these were the produce of some

1 There are cases in which this rule is of difficult application, or is seemingly violated, sometimes by the suppression of the subtending leaf, as in the inflorescence of Cruciferæ, rarely in other ways, to be explained in the proper places. 
season earlier than the last; and the branches are continually clothed with the foliage of from two to five, or even ten or more successive years. On the other hand, it is seldom that all the leaves of an herb endure through the whole growing season, the earlier foliage near the base of the stem perishing while fresh leaves are still appearing above. In our deciduous trees and shrubs, however, the leaves of the season are mostly developed within a short period, and they all perish in autumn nearly simultaneously.

163. Leaves soon complete their growth, and have no power of further increase. Being organs for transpiration, a very large part of the water imbibed by the roots is given out by the foliage, leaving dissolved earthy matters behind. Assimilation can take place only in fresh and vitally active tissue. It is incident to all this that leaves should be of only transient duration, at least in their active condition.

164. Defoliation. The leaves of most Dicotyledons and some Monocotyledons separate from the stem and fall by means of an articulation at the junction with the stem, which begins to form early in the season and is completed at the close. There is a kind of disintegration of a transverse layer of cells, which cuts off the petiole by a regular line, and leaves a clean scar, such as is seen in Fig. 81, 85, 91. Some leaves, notably those of Palms, Yucca, and other endogens, die and wither on the stem, or wear away without falling.

165. In temperate climates, defoliation mostly takes place at the approach of winter. In warmer climates having only winter rain, this occurs in the hot and dry season.

166. Normal Direction or Position. The leaf-blade is expanded horizontally, that is, has an upper and an under surface. When erect, the upper surface faces the axis which bears it. To this, there are many seeming but no real exceptions; that is, none which are not explicable as deviations or changes from the normal condition. (213-217.)

\section{§ 2. Their Structure and Forms as Organs of Assmilation or Vegetation, i. e. as Foliage.}

167. The Internal Structure or Anatomy of the leaf needs here to be examined so far as respects its obvious parts and their general composition. The leaf, like the stem, is composed of two elements (131), the cellular and the woody. The cellular portion is the green pulp or parenchyma, and in this the work of assimilation is carried on. The woody is the fibrous frame- 
work, the separate parts or ramifications of which form what are variously called the ribs, - a sufficiently proper term, - nerves or veins. The latter names may suggest false analogies; but they are of the commonest use in descriptive botany. That of veins, and of its diminutive, veinlets, for the smaller ramifications, is not amiss; for the fibrous framework not only gives firmness and support to the softer cellular apparatus, $i$. e. forms ribs, but serves in the leaf, as it does in the stem, for the more rapid conveyance and distribution of the sap. The subdivisions continue beyond the limits of unassisted vision, until the fibro-vascular bundles are reduced to attenuated fibres ramified through the parenchyma. In leafstalks, the woody bundles are parallel, not ramified, and arranged in various ways; in Exogens usually so as to form in cross-section an arc or an incomplete or complete ring. In leaves serving as foliage or organs of assimilation, the blade is the important part, and this only is here regarded.

168. The characteristic contents of these cells of parenchyma are grains of chlorophyll $\left(142^{8}\right)$, literally leaf-green, to which the green color of foliage is wholly owing, and which may be regarded as the most important of all vegetable products; because it is in them (or in this green matter, whatever its form, 189) that all ordinary assimilation takes place. As it acts only under the influence of light, the expanded leaf-blade may be viewed as an arrangement for exposing the largest practicable amount of this green matter - the essential element of vegetation - to the light and air.

169. The Parenchyma-cells, constituting the green pulp, are

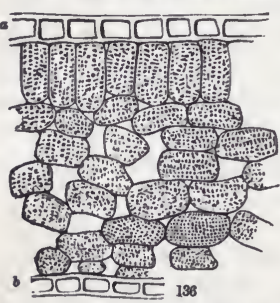
themselves arranged in accordance with this adaptation. The upper stratum is mostly of oblong cells, compactly arranged in one or more layers, their longer diameter perpendicular to the surface. The stratum next the lower surface of the leaf consists of loosely arranged cells, with longer diameter usually parallel to the plane of the leaf, often irregular in form, and so disposed as to leave intervening sinuous air-spaces freely permeating all

FIG. 136. A magnified section through the thickness of a leaf of Illicium Floridanum, showing the Irregular spaces or passages between the cells, which are small in the upper layer of the green pulp, the cells of which (placed vertically) are well compacted, so as to leave only minute vacuities at their rounded ends; but the spaces are large and copfous in the rest of the leaf, where the cells are very loosely arranged: also the epidermis or skin of the npper $(a)$ and of the lower surface of the leaf $(b)$, composed of perfectly combined and thick-walled empty cells. 
that part of the leaf. (Fig. 136, 137.) Hence in good part the deeper green hue of the upper, and the paler of the lower face of leaves.

170. Epidermis. The whole surface of leaves, as of young stems, is invested with a translucent membrane, composed of one or sometimes two or three layers of empty and ratherthick-walled cells. This is the skin or epidermis, which is so readily separable from the succulent tissue of such leaves as those of Stonecrop and other species of Sedum. It is of a single layer in the Illicium (Fig. 136) and Lily (Fig. 137); of as many as three in the firm leaf of the Oleander; is generally

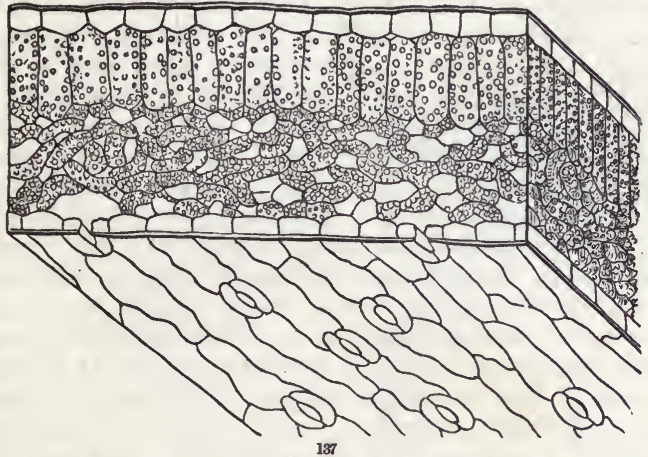

hard and thick in such coriaceous leaves as those of Pittosporum and Laurustinus, which thereby the better endure the dry air of rooms in winter.

171. Stomata or Breathing-pores. ${ }^{1}$ The epidermis forms a continuous protective investment of the leaf except where certain organized openings occur, the stomata. They are formed by a transformation of some of the cells of the epidermis ; and consist usually of a pair of cells (called guardian-cells), with an opening between them, which communicates with an air-chamber within, and thence with the irregular intercellular spaces which permeate the interior of the leaf. Through the stomata, when open, free interchange may take place between the external air and that

1 The technical name has been anglicized stomates, singular stomate, which has no advantage over the proper Greek, sing. stoma, pl. stomata.

FIG. 137. A magnifled section through the thickness of a minute piece of the leat of the White Lily of the gardens, showing also a portion of the under side with some breathing-pores, stomata. 
within the leaf, and thus transpiration be much facilitated. When closed, this interchange will be interrupted or impeded.

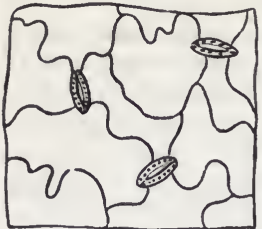

188 The mechanism of stomata is somewhat recondite, and will be illustrated in the anatomical and physiological volume of this series.

172. It is only when leaves assume a vertical or edgewise position that the stomata are in equal numbers on both faces of a leaf. Ordinarily, they occupy or most abound on the lower face, which is turned away from the sun; but in certain coniferous trees the reverse of this is true. In the Water Lilies (Nymphæa, Nuphar),

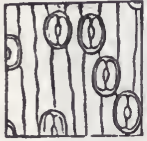

189

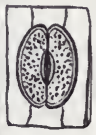

140

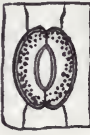

141 and other leaves which float upon the water, the stomata all belong to the upper surface. Leaves which live under water, where there can be no evaporation, are destitute, not only of stomata, but usually of a distinct epidermis also. The number of the stomata varies from 800 to about 170,000 on the square inch of surface in different leaves. In the Apple, there are said to be about 24,000 to the square inch (which is under the average number, as given in a table of 36 species by Lindley) ; so that each leaf of that tree would present about 100,000 of these orifices. The leaf of Dragon Arum is said to have 8,000 stomata to a square inch of the upper surface, and twice that number in the same space of the lower. That of the Coltsfoot has 12,000 stomata to a square inch of the lower epidermis, and only 1,200 in the upper. That of the White Lily has from 20,000 to 60,000 to the square inch on the lower surface, and perhaps 3,000 on the upper; and they are so remarkably large that they may be discerned by a simple lens of an inch focus.

172. Venation, the veining of leaves, \&c., relates to the mode in which the woody tissue, in the form of ribs, veins, \&c., is distributed in the cellular. There are two principal modes, the parallel-veined and the reticulated or netted-veined. The former is especially characteristic of plants with endogenous stem and monocotyledonous embryo, and also of gymnospermous trees,

FIG. 138. A highly magnified piece of the epidermis of the Garden Balsam, with three stomata (after Brongniart).

FIG. 139. Magnified view of the 10,000th part of a square inch of the epidermis of the lower surface of the leaf of the White Lily, with Its stomata. 140. A single stoma, more magnifed. 141. Another stoma, widely open. 
which have exogenous stems and at least dicotyledonous embryos. The latter prevails in ordinary plants with exogenous stem and dicotyledonous embryo.

173. Parallel-veined or Nerved leaves (of which Fig. 143 is an illustration) have a framework of simple ribs (called by the earlier botanists nerves, a name still used in descriptions), which run from the base to tip, or sometimes from a central strong rib to margin of the leaf, in a generally parallel and undivided way, and sending off or connected by minute veinlets only. Grasses,
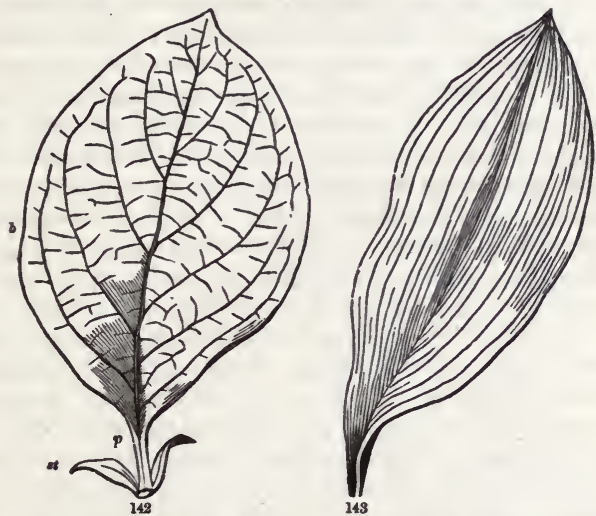

Lily of the Valley, and the like, illustrate the commoner mode in which the threads of wood run from base to apex. The Banana and Canna are familiar illustrations of a mode not uncommon in tropical or subtropical endogens, in which the threads or "nerves" run from a central rib (midrib) to the margin. Parallel-veined leaves are generally entire, or at least their margins not toothed or indented. The principal exception to this occurs when the ribs or the stronger ones are few in number and radiately divergent, as in the flabelliform leaves of Fanpalms, a peculiar modification of the parallel-veined type. Between leaves with nerves wholly of basal origin, and those with nerves all springing from a midrib, there are various gradations, and also in respect to curving. But parallel-veined or nerved leaves may be classified into

FIG. 142. A leaf of the Quince, of the netted-veined or reticulated sort, with blade $(b)$, petiole or leaf-stalk $(p)$, and stipules $(s t)$.

FIG. 143. Parallel-veined leaf of the Llly of the Valley, Convallaris majalis. 
Basal-nerved, that is, with the nerves all springing from the base of the leaf, and

Costal-nerved, springing from a midrib or costa. Either may be Rectinerved, the nerves running straight from origin to apex or margin of the leaf, as the case may be ;

Curvinerved, when curving in their course, as in the leaves of Funkia and in Canna ;

Flabellinerved, where straight nerves and ribs radiate from the apex of the petiole, as in Fan-palms and the Gingko tree.

174. In typical parallel-veined leaves, all reticulation is confined to minute and straight cross-veinlets : in many, these are coarser, branching, and reticulated ; in some, as in Smilax and Dioscorea, only the primary ribs or strongest nerves are on the parallel-veined plan; the space between being filled with reticulations of various strength; thus passing by gradations into

175. Reticulated or Netted-veined leaves. In most of these, from one to several primary portions of the framework are particularly robust, and give origin to much more slender ramifications, these to other still smaller ones, and so on. The strong primary portions are RIBS (cost $\Theta$ ); the leading ramifications, Verns (vena) ; the smaller and the ultimate subdivisions, VeINLETs (venula). All or some of the veins and veinlets are said to anastomose, $i$. e. variously to connect with those from other trunks or ribs, apparently in the manner of the veins and arteries of animals, forming meshes. But, as there is no opening of calibre of one into another, the word is etymologically rather misleading. More properly, it is said that the veins or veinlets form reticulations or net-work. A primary division of reticulated leaves, and incleed of nerved leaves also, into two classes, is founded upon the number of primary ribs.

176. There may be only a single primary rib; this traversing the blade from base to tip through its centre or axis (as in Fig. 142, 152-156) is called the MIDRIB. There may be others, generally few (one, two, three, or rarely four), rising from the apex of the petiole on each side of the midrib, running somewhat parallel with it or more or less diverging from it: these are lateral ribs. Among parallel-veined leaves, the Banana, Canna, \&c., have a single rib, from which the veins (in the older nomenclature here called nerves) all proceed. Most Lilies and the like have several approximately parallel ribs, but the midrib predominant: in other cases, the midrib is no stronger than the others. In Fan-palms, the ribs are radiately divergent, giving a fan-shaped or rounded outline to the blade. In reticulated leaves, in which the veins all spring from the ribs, the two 
classes into which they divide are the pinnately veined and the palmately veined.

177. Pinnately or Feather-veined (or Penninerved) leaves are accordingly those of which the veins and their subdivisions are side branches of a single central rib (midrib), which traverses the blade from base to apex; the veins thus being disposed in the manner of the plume on the shaft of a feather, (Fig. 142, 152 , \&c.) Sometimes these continue straight and undiminished from midrib to margins (straight-veined, as in Beech and Chestnut, Fig. 152), sending off only small lateral veinlets; sometimes they ramify in their course into secondary or tertiary veins, and these into veinlets. Pinnate venation in reticulated leaves naturally belongs to leaves which are decidedly longer than wide.

178. Some of the primary veins, commonly among the lower, may be stronger than the rest, and thus take on the character of ribs, or by gradations pass into such. The leaf of the common annual Sunflower (Fig. 155) becomes in this way triple-ribbed or tripli-nerved. The appearance of a second pair of such strength ened veins makes the venation quintupli-ribbed or quintupli-nerved.

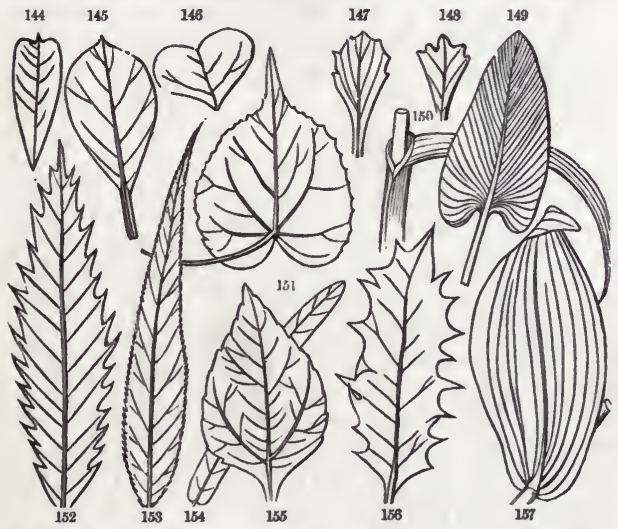

Through the approximation of such strong veins to the base of the blade, this venation may pass into the

179. Palmately, Digitately, or Radiately Veined (or Palmunerved) class, of which leaves of common Maples and the Vine are familiar examples. (Also Fig. 158-160, \&c.) In these

FIG. 144-157. Various forms of simple leaves, explained in the text and in the Glossary. 
there are three, five, seven, or sometimes more ribs of equal strength, the central being the midrib, and each with its system of veins which ramify and form meshes in the interspaces. Here the whole woody portion of the leaf divides equally into a number of parts upon leaving the petiole or entering the blade. The ribs there commonly diverge more or less in a palmate or digitate manner (i. e. like outspread fingers of the hand, or the claws of a bird, or like radii of more or less of a circle) : so, in the correlation of outline and venation, this class of veining goes with

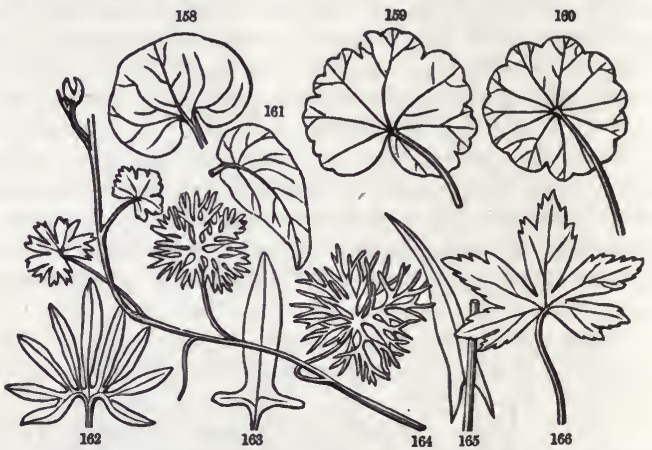

roundish circumscription. This is not so true, however, in a special case, viz., where the ribs, however divergent below, curve forward and all run to the apex of the blade, thus imitating the parallel-veined system, as in Rhexia and generally in the family of which that genus is the single northern representative. ${ }^{1}$

180. Forms as to Ontline, \&c. DeCandolle conceived the shape of leaves (both the general circumscription and the special configuration) to depend on the distribution of the ribs and veins, and quantity of the parenchyma in which these were outspread, - a too mechanical view, and not conformable to the history of development. This proves that the framework is adapted to the parenchyma, which grows and shapes the organ in its own way, rather than the parenchyma to it. It were better to say that the

1 In Linnæan terminology, palmate and digitate referred to particular outline only, and were separately used to denote extent of division, - palmate, not divided down to the petiole, digitate, when divided, like the claws of a bird, quite down the base. DeCandolle generalized the use of the former term, and ever since the two have been used interchangeably.

ITE. 158-166. Yarious forms of simple, chiefly palmately veined leaves. 
two elements of the structure are correlated. Descriptive terms applied to leaves are equally applicable to all expanded organs or parts, and indeed to all outlines. Some leading forms are here enumerated; and all are defined in the Glossary.

181. As to general Circumscription, proceeding from narrower to broader shapes, and then to those with either narrowed or notched base, leaf-blades are

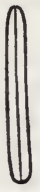

167

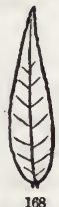

168
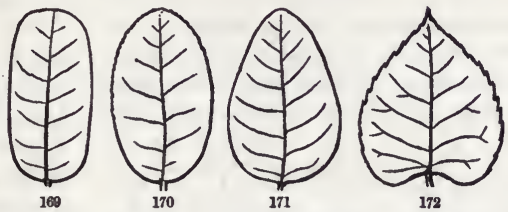

Linear, when narrow, several times longer than wide, and of about the same breadth throughout. (Fig. 167.)

Lanceolate, or Lance-shaped, when several times longer than wide, and tapering upwards (Fig. 153, 168), or tapering both upward and downward.

Oblong, when nearly twice or thrice as long as broad. (Fig. 169.)

Elliptical, oblong with a flowing outline, the two ends alike in width. (Fig. 170.)

Oval, the same as broadly elliptical, or elliptical with the breadth considerably more than half the length.

Ovate, when the outline is like a section of a hen's-egg lengthwise, the broader end being downward. (Fig. 171, 155.)

Orbicular, or Rotund, circular in outline, or nearly so. (Fig. 160.)

Obovate, inversely ovate, or ovate with the narrower end toward the base, the broader upward. (Fig. 175, 145.)
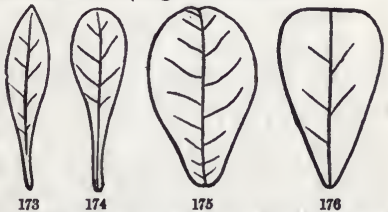

Cuneate, or Cuneiform, that is, Wedge-shaped, broad above and tapering by straight lines to an acute base. (Fig. 176, 148.)

Spatulate, rounded above, long and narrow below, like a spatula. (Fig. 174, 147.)

Oblanceolate, inverted lance-shaped, $i$. $e$. such a lanceolate leaf as that of Fig. 168, but with the more tapering end at base, as in Fig. 173. To those who restrict the term lanceolate to the sense of a narrow leaf tapering equally in both directions, the 
term oblanceolate is superfluous. The following terms designate leaves with a notched instead of narrowed base.

Cordate, or Heart-shaped, when a leaf of an ovate form, or something like it, has the outline of its rounded base turned in (forming a notch or sinus) where the stalk is attached, as in Fig. 172, 151. Also Fig. 149, Pontederia, a leaf of the parallelveined class.

Reniform, or Kidney-shaped, like the last, only rounder and broader than long. (Fig. 158.)

Auriculate, or Eared, having a pair of small and blunt projections, or ears, at the base, as in Magnolia Fraseri, Fig. 178.

Sagittate, or Arrow-shaped, where such ears are acute and turned

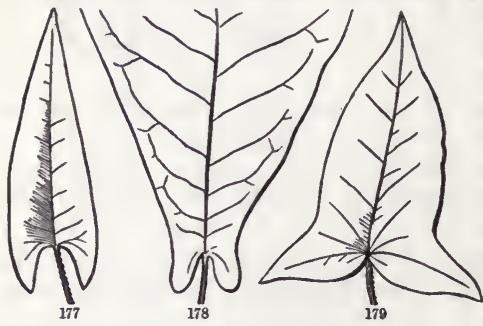

downwards, while the main body of the blade tapers upwards to a point, as in the common species of Sagittaria or Arrow-head, and in the Arrowleaved Polygonum. (Fig. 165, 177.)

Hastate, or Halberdshaped, when such lobes at the base point outwards, giving the leaf the shape of the halberd of the olden time, as in Polygonum arifolium (Fig. 179) and Sorrel, Fig. 163.

182. Peltate or Shield-shaped leaves are those in which a blade of rounded or sometimes of other shape is attached to the petiole by some part of the lower surface, instead of the basal margin: those of Water-shield or Brasenia, of Nelumbium, and of Hydrocotyle umbellata are marked examples. The anomaly is morphologically explained by a comparison with deeply cordate or reniform leaves having a narrow sinus, such as those of Nymphæa or Water Lily, and by supposing a union of the approximated edges of the sinus. Fig. 159 and 160, from two species of Hydrocotyle, one with open and the other with closed sinus obliterated by the union, illustrate this.

183. As to Extremity, whether base or apex, there are severa] descriptive terms, expressive of the principal modifications ; such as

Acuminate, tapering, either gradually or abruptly, into a narrow more or less prolonged termination. (Fig. 180.) 
Acute, ending in an acute angle, without special tapering, as in Fig. 181.

Obtuse, ending with a blunt or roundish extremity, Fig. 182.

Truncate, with termination as if cut off by a straight transverse line, as in Fig. 183.

Retuse, with an obtuse extremity slightly depressed or re-entering, as in Fig. 184.

Emarginate, with a more decided terminal notch, Fig. 185.

Obcordate, inversely heart-shaped, $i$. e. like cordate, but the broader end and its strong notch at apex instead of base, Fig. 186. This and the following terms are applicable to apex only.

Mucronate, abruptly tipped with a small and short point, like a projection of the midrib, as in Fig. 188.

Cuspidate, tipped with a sharp and rigid point, as in Fig. 187.

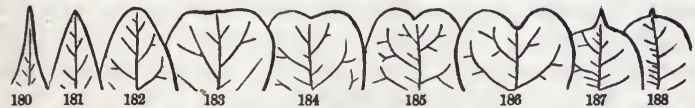

184. As to Margin or special Outline, the terminology proceeds upon the convenient supposition of a blade with quite entire margin, but subject to incisions, which give rise to notches or clefts, if we regard the sinuses ; or to teeth, lobes, segments, \&c., if we regard the salient portions between the sinuses. The ribs, or the stronger veins, \&c., commonly terminate in the teeth or lobes ; but in Cicuta maculata, and in a few other cases, they run to the notches.

185. Dentation relates to mere marginal incision, not extending deeply into the blade. The blade is said to be

Entire, ${ }^{1}$ when the margin is completely filled out to an even line, as in Fig. 173-179.

Serrate, when with small and sharp teeth directed forward, like the teeth of a saw, as in Fig. 189.

Serrulate is the

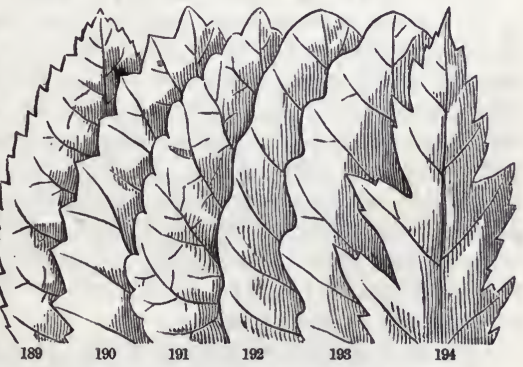
diminutive of serrate, and is equivalent to minutely serrate.

1 Integerrimus-a-um, or quite entire, is the term in Latin terminology. Inte ger means undivided or not lobed.

FIG. 180-188. Terminations of leaves.

FIG. 189-194. Dentation of pinnately reined leaves. 
Dentate, or Toothed, a general term for toothing, specially applied to the case of salient teeth which are not directed forward or towards the apex of the blade, Fig. 190.

Crenate, or Scalloped, the same as dentate or serrate, but with teeth much rounded, Fig. 191.

Repand, or Undulate, when the margin is a wavy line, bending slightly inward and outward, Fig. 192.

Sinuate, when this wavy line is stronger or distinctly sinuous, as in Fig. 193.

Incised, when cut by sharp and irregular incisions more or less deeply, Fig. 194. This is intermediate between dentation and

186. Lobation or Segmentation. When the blade is more deeply penetrated by incisions from the margin, that is, when the spaces between the ribs or principal veins are not filled to near the general outline, it is said to be lobed, cleft, parted, or divided, according to the degree of separation; and the portions are called lobes, segments, divisions, \&c. The most general name for such parts of any simple blade is that of lobes. More particularly a leaf-blade, or other body, is said to be

Lobed, when the division extends not more than half way down. and either the sinuses or the lobes are rounded;

Cleft, when the division is half way down or more, and the lobes or sinuses narrow or acute;

Parted, when the divisions reach almost, but not quite, to the base or the midrib;

Divided, when they sever the blade into distinct parts, which makes the leaf compound. (193.)

187. LOBE is the common name of one of the parts of a simple blade, especially when there is only one order of incision. But when there are more, as when a leaf is divided or parted and these primary lobes again lobed or cleft, the lobes of first order are commonly called SEgments (sometimes divisions or partitions), and the parts of these, Lobes. Or the lobes may be designated as primary, secondary, tertiary, \&c. Ultimate portions or small lobes may be called Lobules or Lobelets. Also the portions of a quite divided blade take the name of Leaflets. By proper selection of terms, the degree of division or lobing may thus be expressed in a single word.

188. As to Number of parts, this may be tersely expressed by combination with the adjective term applicable to the degree; as, Two-lobed, Three-lobed, Five-lobed, Many-lobed, \&c. ; or Two-Fivecleft, Many-cleft, \&c., in Latin form Bifid, Trifid, Multifid, \&c. ; Two-five-parted, \&c., according to the number of divisions which extend almost to the base or axis; Two-Five-divided (in 
Latin form Bisected, Trisected, \&c.), when there are two or three or more complete divisions of the blade.

189. As to Arrangement of parts, this may be simply and best expressed by taking into account the nature of the venation or the distribution of the ribs, \&c., which controls or is co-ordinated with the disposition of the lobes. Pinnately veined leaves, when lobed, must needs have the incisions directed to the midrib; palmately-veined or radiated, to the apex of the petiole. The lobes or divisions of the first will be pinnately, of the second

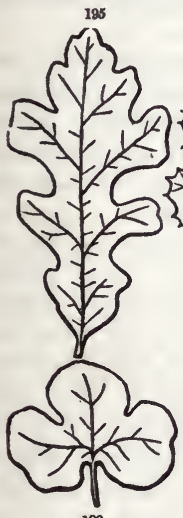

199

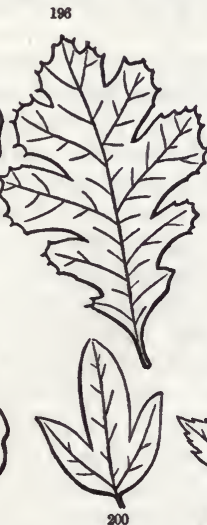

200
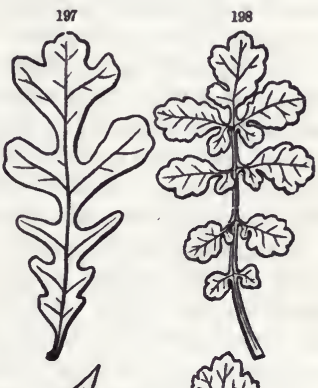
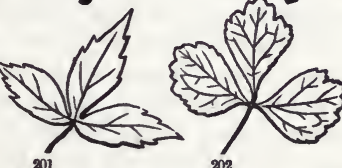

202

palmately disposed. Accordingly, the three leaves of as many species of Oak, Fig. 195, 196, and 197, represent respectively a pinnately lobed, pinnately cleft, and pinnately parted leaf, while the accompanying leaf of Celandine, Fig. 198, is pinnately divided. The first three, however, when the degree of incision is not particularly in question, usually pass under the common term of pinnatifid, Fig. 195 moderately, Fig. 197 deeply. The number of lobes, when definitely marked, may come into the descriptive phrase, as pinnately 7-lobed, pinnately 7-cleft, parted, or divided, as the case may be.

190. Similarly, Figures 199 to 202 represent, respectively, a palmately three-lobed, three-cleft, three-parted, and three-divided, or, in Latin form, trilobate, trifid, tripartite, and trisect or trisected leaf. Fig. 166 is a palmately 5-parted leaf; Fig. 164, palmately 
multifid, \&c. Fig. 162, a leaf of Dragon Arum, is palmately 9-parted. But, as the lateral sinuses are not so deep as the others, the leaf is said to be pedately parted, or pedate, in the early terminology.

191. Moreover, as the lobes or divisions of a leaf may be again similarly lobed or parted, \&c., this composition may be indicated by the prefix twice, thrice, \&c., as twice pinnatifid or bipinnatifid, thrice pinnately parted, thrice palmately parted, and the like. Thus, a word or two, or a short phrase, may describe even a complex leaf, so as to convey a perfectly clear and definite idea of its conformation.

192. A distinction should now be drawn between simple and compound leaves. The distinction cannot be both natural and absolute; for the one may pass variously into the other. Simple leaves, which have been thus far considered, have a single lamina or blade, which may, however, at one extreme be entire, at the other many-parted, and even several times divided.

193. Compound Leaves are those which have from two to many distinct blades, on a common leafstalk. These blades, called Leaflets, may be sessile on the common leafstalk, or they may have leafstalks of their own. As the leaf very commonly separates in age by an articulation of its petiole with the stem, so leaflets are commonly more or less articulated with the common petiole. When the leaf, with its petiole, falls from the stem, the leaflets may as completely separate from the common petiole. They do not always do this. Divided leaves, such as those of Fig. 198 and 202, though ranked among the simple sorts, are compound in the sense of having distinct blades, but without articulation. Some of these blades are apt to be confluent; that is, a divided leaf is often in part merely parted, as in the upper portion of Fig. 198. Such leaves are so intermediate between simple and compound that it becomes indifferent, or a matter of convenience to be settled by analogy, under which head or by what language they shall be described. However, most leaves are so constituted as to leave no doubt whether they are simple or compound.

194. The leaflets of a compound leaf being homologous with the lobes or segments of a simple leaf, indeed being such segments fully isolated, the two sorts fall under the same types. A pinnately veined simple leaf is the homologue of one kind of compound leaf; a radiately veined leaf, of the other. That is, compound leaves are either pinnate or palmate.

195. Pinnate Leaves (Fig. 203-205) are those in which the leaflets are arranged along the sides of a petiole, or rather of its 
prolongation, the RHACHI, which answers to the midrib of a pinnately veined simple leaf. There are three principal sorts, anả some subordinate ones. That is, a pinnate leaf may be
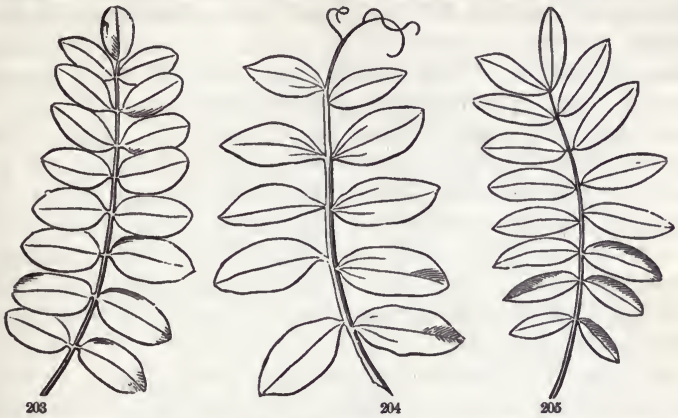

Impari-pinnate, or pinnate with an odd leaflet, i.e. a terminal one, as in Fig. 203; and this is the commoner case.

Cirrhiferous Pinnate, or pinnate with a tendril (Fig. 204), as in the proper Pea tribe and Bignonia. Here either the terminal leaflet only, or the upper lateral leaflets also, are replaced by tendrils.

Pari-pinnate, or Abruptly Pinnate, destitute of a terminal leaflet or of any thing answering to it, as in Fig. 205.

Interruptedly Pinnate denotes merely a striking inequality of size among the leaflets: Lyrately Pinnate, one in which the terminal leaflet is largest and the lower small.

196. Palmate or Digitate Leaves (Fig. 206, 93) are those in which the leaflets all stand on the summit of the petiole. Digitate (fingered) was the old name, when the term palmate was restricted to a simple but palmately lobed leaf of this type. But since the time of DeCandolle the two names have been used interchangeably. Palmate leaves have no primary distinction into sorts, except as to the number of leaflets. These can

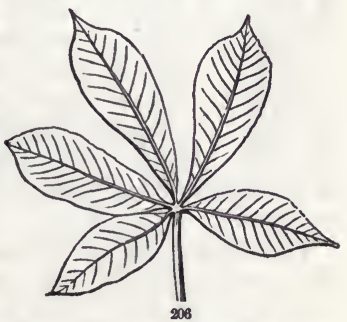
never be very numerous; but there are fully a dozen in some

FIG. 203. An impari-pinnate or odd pinnate leaf. 204. Pinnate with a tendril 205. Abruptly pinnate leaf of a Cassia.

FIG. 206. Palmately or digitately 5-foliolate leaf of a Buckeye, Asculus. 
Lupines. More commonly there are only five to nine, or only three, rarely two, or even a single one.

197. Number of leaflets may be indicated by an adjective expression composed of the proper Latin numeral prefixed to foliolate (Foliolum, diminutive of folium, answering to leaflet). Thus, bifoliolate, of two leaflets; trifoliolate, of three leaflets; quadrifoliolate, of four; quinquefoliolate, of five : plurifoliolate, or multifoliolate, of several or numerous leaflets, \&c. These terms are still more descriptive when accompanied by the word pinnately or palmately, indicative of the kind of compound leaf; as, palmately or digitately trifoliolate (common Clover-leaf, Fig. 211), or 5-foliolate, as in Buckeye (Fig. 206), and so on. Also, pinnately 16-foliolate, as in Fig. 205, or 17-foliolate, as in Fig. 203; pinnately trifoliolate, as in Phaseolus, and in the low Hop-Clover, Trifolium procumbens. ${ }^{1}$

198. But, in either class of compound leaves, the leaflets may be reduced to a minimum number. A pinnately trifoliolate leaf is one of the impari-pinnate kind reduced to three leaflets, to one pair and the odd one; and this is distinguished from a palmately trifoliolate leaf by the attachment of the pair at some distance below the apex of the petiole, and by the articulation above this, which marks the junction of the terminal leaflet's petiole (or its base, if sessile) with the rhachis or common petiole.

199. Unifoliolate compound leaves (by no means a direct con-

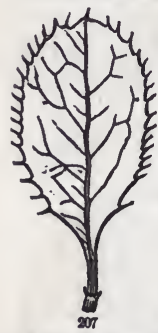
tradiction in terms) are by this articulation distinguished from simple leaves which they simulate. See the leaf of the common Barberry, Fig. 207. In other species, of the Mahonia section, the leaves are all pinnately 3-9-foliolate, with well-developed common petiole : in the true Berberis, they are all thus reduced to the terminal and long-petiolulate leaflet, on an almost obsolete petiole. Orange and Lemon leaves are in similar case, but with the joint close to the blade. A comparison with near relatives shows that these are also unifoliolate leaves of the pinnate kind; though this could not be ascertained by inspection.

200. Decompound or Twice and Thrice Compound Leaves. These are to once pinnate or once palmate leaves what the latter are to

1 In pinnate leaves, each leaflet usually has its opposite fellow, and the number may be indicated by the pairs, as unijugate, bijugate, trijugate, and plurijugate, according to the number of juga, or pairs.

FIG. 207. Unifoliolate leaf of Berberis vulgaris, with partlal petiole articulated to the extremely sho t true petiole. 
simple leaves. As leaflets may be toothed, lobed, or parted, so what answers to a single leaflet may appear as leaflets of a second, or again of a third, or even of a fourth order. Decompound is a good general name for all more than once compounded leaves;

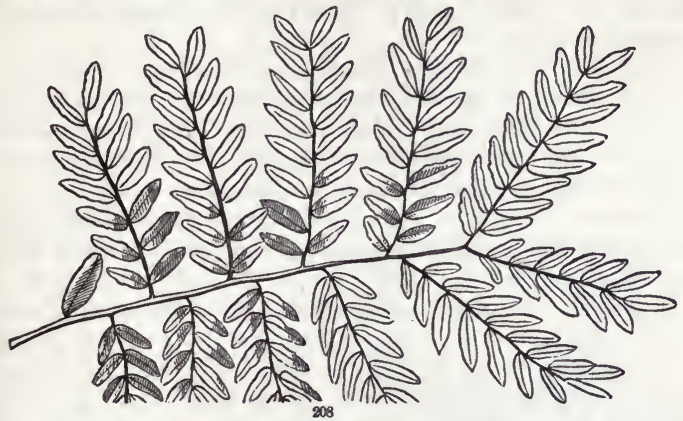

but the name has been applied rather to irregularly many-times parted or dissected leaves (such as those of Dicentra), or to those more than thrice compounded. Of regularly twice or thrice compound leaves, the commonest are the

Bipinnate or Twice Pinnate, of ordinary occurrence in the Mimoseous and Cæsalpineous, but not in the Papilionaceous, Leguminosæ. Fig. 208 represents a bipinnate leaf of the Honey Locust (Gleditschia), with the variation (common with that tree) that some of the partial petioles, in this figure only the lowest, bears a single leaflet, while the others are extended into secondary rhachises furnished with numerous leaflets, mostly in the abruptly pinnate style. On the same tree, the earlier leaves, which are clustered on short spurs, are simply pinnate. The large

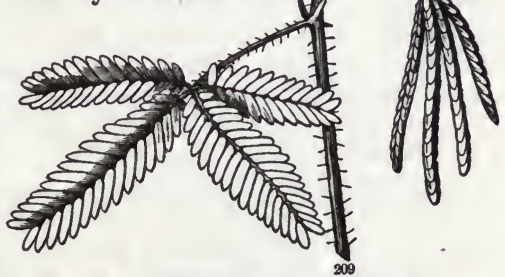
leaves of Gymnocladus are similarly and abruptly bipinnate,

FIG. 208. A bipinnate and multifoliolate leaf of Gleditschia or Honey Locust.

FIG. 209. Bipinnate leaves of Sensitive Plant, Mimosa pudica, with approximate pinnæ. 
except at the base, which is simply pinnate or with one or two pairs of simple leaflets.

Tripinnate or Thrice Pinnate leaves of a regular sort are rare; but, with some irregularity, they occur in many species, as in Aralia, \&c. This extent of division, and even much greater, is rommon in Ferns.

Digitate-Pinnate is where the primary division of the petiole is on the palmate or digitate plan; the secondary, on the pinnate. This seems to be the case in the Sensitive Plant, Mimosa pudica, Fig. 209. But the leaf is here truly bipinnate with the primary divisions very crowded at the apex of petiole.

Conjugate-Pinnate is the same arrangement, with the primary divisions a single pair, at the apex of the petiole, and the leaflets pinnately arranged on these.

Digitately or Palmately Decompound in a nearly regular way

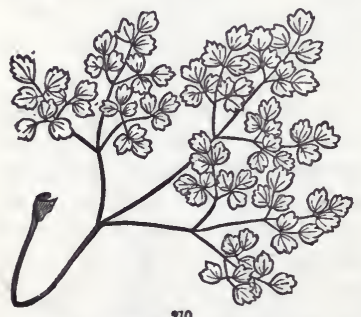

is not an uncommon case. Usually, the petiole is successively three-forked, as in Fig. 210 , when the leaf is said to be biternate (twice ternate), triternate (thrice ternate), or quadriternate (four times ternate), \&c., according to the number of times it divides, or 2-3-4-times ternately compound. The ultimate divisions in such cases of threes are commonly of the pinnately trifoliolate type.

201. Pinnæ is a convenient name for the partial petioles of a bipinnate leaf, taken together with the leaflets that belong to them. Thus, the Sensitive Plant, Fig. 209, has four pinnæ, or two pairs; the Honey Locust, Fig. 208, a greater number. When such leaves are still further compounded, the pinnæ of higher order, or the ultimate ones, take the diminutive term of Pinnule or Pinnules. The blades these bear are the Leaflets.

202. The Petiole or Leafstalk is a comparatively unessential part of the leaf. It is often wanting (then the blade is sessile); it may be absent even in compound leaves of the palmate type, the leaflets rising side by side from the stem. When present, it is usually either round, or half-cylindrical and channelled on the upper side. In the Aspen, it is flattened at right angles with the blade, so that the slightest breath of air puts the leaves in motion. Sometimes it is much dilated and membranaceous at

FIG. 210. Quadri-ternately compound or ternately decompound leaf of Thalictrum Cornuti. 
base, as in many umbelliferous plants; sometimes it forms a sheath, occasionally it is bordered with appendages, \&c. Petioles may assume special functions, to be hereafter considered. The woody and vascular tissue runs lengthwise through the petiole, in the form usually of a definite number of parallel threads, to be ramified in the blade. The ends of these threads are apparent on the base of the leafstalk when it falls off, and on the scar left on the stem, as so many round dots '(Fig. 81, 85, 91), of a uniform number and arrangement in each species.

203. Partial Petioles are the divisions of the petiole in a compound leaf. The footstalk of a leaflet takes the diminutive name of Petiolule.

204. Stipules (157) are lateral appendages, one each side of the base of the petiole, sometimes free from it and from each other (Fig. 142), sometimes attached by one edge to its base (Fig. 211), sometimes united with each other into a single body (Fig. 212) in various ways or degrees. In the latter case, they usually appear to be within the base of the leaf or leafstalk; or, as in the Plane-tree, they may be joined into one over against the leaf, as if opposite to it, but their normal position is supposed to be lateral or marginal to the petiole. Sometimes they are foliaceous in appearance and in function; sometimes they are dry and colorless or scale-like, reduced to mere epidermal tissue, and evidently functionless ; sometimes (as in Magnolia, Fig. 81, Fig-tree, and Beech), they serve as bud-scales, and fall when the leaves develop ; sometimes they are reduced to a mere bristle, or take the

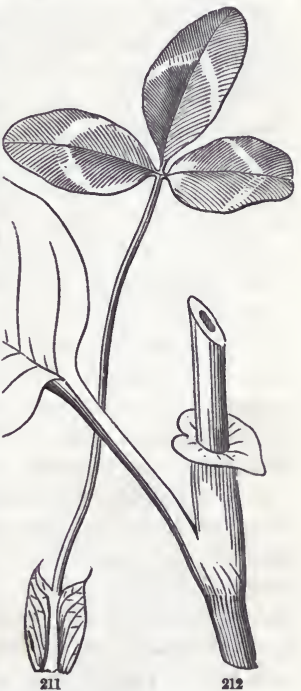
form of a spine, as in the Locust (Robinia). Between salient expansions or wing-like margins of the base of the petiole, such as those of the Saxifrage tribe, and stipules adnate to the margins of the petiole, as in most Rosaceæ, there is no clear limitation. But presence or absence of stipules generally runs

FIG. 211. Clover-leaf, with adnate stipules. 212. Ochreate stipules (ochrea or ocrea) of Polygonum orientale, sheathing the stem for some distance, and ending in a spreading border. 
through a natural order. Yet what are called stipules in one order may pass for expansions or appendages of the petiole in another. In Spergularia, some stipules are connate around the base of the pair of leaves, including them as well as the stem in the sheath. ${ }^{1}$

205. Stipules, which are normally a pair, may unite into one body, either adnate to the inner face of the leaf, as in some species of Potamogeton, or united opposite the leaf, as in Planetree, or united inter se in a sheath, as in Polygonum. Also when the leaves are opposite and the stipules thus brought into proximity, the adjacent half stipules of the two leaves may coalesce, and present the appearance of only two stipules to two leaves, as in many Rubiaceæ. A notch or fork at the apex often indicates the composition.

206. Sheathing stipules, like those of Polygonum (Fig. 212), are said to be ochreate, or (better) ocreate; the sheath, thus likened to a leggin or the leg of a boot, is an OcHreA, as written by Willdenow, or better Ocrea.

207. The Lrgule of Grasses (Fig. 150) is seemingly a thin and scarious extension of the lining to the sheath which answers to petiole in such leaves : it projects at the junction of the sheath and blade, there forming a kind of ocrea; and it is generally regarded as a sort of stipule.

208. Stipels (Stipella) are as it were stipules of leaflets, which are common in certain tribes of Papilionaceous Leguminosæ, e.g. in the Phaseoleæ, in Wistaria, Locust, \&c. ; also in Staphylea. They are small and slender, and, unlike stipules, they are single to each leaflet, except to the terminal one, which has a pair. As leaves furnished with stipules are said to be stipulate, so leaflets with stipels are stipellate.

209. Some unusual modifications of leaves as foliage. In leaves as illustrated thus far, it is the lamina or blade which is expanded to do the work of foliage; which is expanded horizontally, so as to present upper and under surfaces, one to the sky, the other to the ground; which is bilaterally symmetrical or substantially so, the two lateral halves being nearly if not quite alike; and which is affixed to the stem at the basal margin, or some part of it, with or without a petiole. Various deviations or apparent deviations from this pattern occur. Some of them are of comparatively small account and simple explanation, such as

210. Inæquilateral Leaves, being unsymmetrical by the much greater development of one side. This is illustrated in the whole genus Begonia (as in Fig. 161), consisting of many spe-

1 As pointed out by Prof. A. Dickson, in Nature, xviii. 507. 
cies, some of which are moderately, and most of them strikingly, oblique in this way. Elm-leaves, and the like, are more or less inæquilateral at the base.

211. Connate and Perfoliate Leaves. These are explained by the union of contiguous leaf-edges. Peltate leaves, to which a paragraph has already been given (182), come under the same head; the seeming attachment of the petiole to the lower face of the blade being the result of a congenital union of the edges of the sinus. In a sessile leaf, when such a
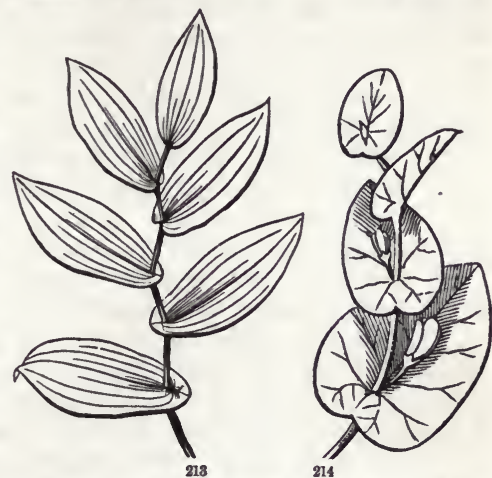
union takes place, it surrounds and encloses that portion of the stem; which is thus perfoliate. (Fig. 213,214 .) It is the stem which is literally perfoliate, i.e. which seemingly passes through the leaf; but it is customary, though etymologically absurd, to call this a perfoliate leaf! Uvularia perfoliata (Fig. 213), in the later growth of the season, reveals the explanation of the perfoliation: the base of the lower leaves conspicuously surrounds and encloses the stem : that of the upper is merely cordate and clasping; the uppermost simply sessile by a rounded base. Baptisia perfoliata (Fig. 214) is a more strongly marked case of perfoliation. But there are good morphological

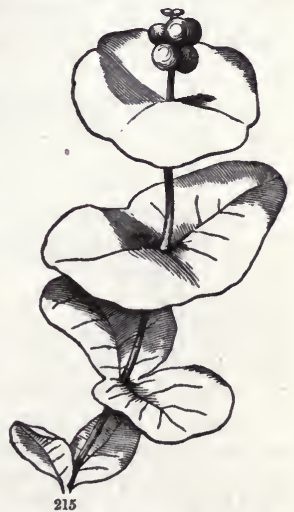
reasons for inferring that this seemingly simple leaf consists of a pair of stipules and a leaflet combined. An occasional monstrosity verifies this supposition.

FIG. 213. Leafy branch of Uvularia perfoliata.

FIG. 214. Leafy and flowering branch of Baptisia perfoliata.

FIG. 215. Lonicera flava, a wild Honeysuckle, connate-perfoliate as to the upper leaves. 
212. When leaves are opposite, the perfoliation (such as that of Honeysuckles, Fig. 215) is obviously the result of a congenital union of the bases of the pair by their contiguous edges. Leaves connate in this way by narrow bases are not rare nor remarkable; but when the two are thus coalescent into one broad foliaceous body, giving this appearance of perfoliation, the term connate-perfoliate is used to express it.

213. Vertical Leaves, those with blades of the ordinary kind, but presenting their edges instead of their faces to the earth and sky, or when erect with one edge directed to the stem and the other away from it, are not uncommon. They prevail in the Australian Myrtaceæ, \&c., and occur with less constancy in the Californian Manzanitas, and in a great variety of herbs and shrubs. The anomaly involves no exception to the rule that a leaf-blade is always expanded in the horizontal plane, when expanded at all ; for, except in equitant leaves, it is the result of a twist of the petiole or of the blade itself. ${ }^{1}$ In strongly marked cases, or in most of them, the organization of the epidermis and superficial parenchyma and the distribution of the stomata are the same on both faces.

214. Equitant Leaves are vertical on a different plan. They are conduplicate, i.e. are folded

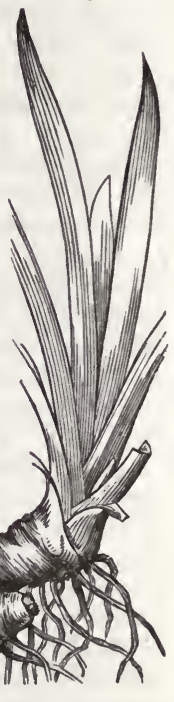

217

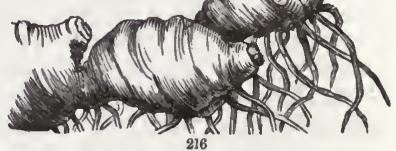

together lengthwise on their middle, the upper surface thus concealed within, the outer alone presented to the air and light.

1 Silphium laciniatum, the so-called Compass Plant, and (hardly less so) S. terebinthinaceum, are good instances of the kind, most of the leaves making a half-twist, the radical ones by their long petioles. In the former species, the pinnately parted blade occasionally makes a farther twist, so as to bring the upper part into a plane at right angles to the lower. The blades place themselves in various directions as respects the cardinal points; but on the prairies the greater number affect a north and south direction of their edges, - a peculiarity first pointed out, in the year 1842, by General B. Alvord, U. S. $\mathcal{R}$.

FIG. 216. Equitant erect leaves of Iris, with the rootstock.

FIG. 217. A section across these leaves at the base, showing the equitant character. 
Being two-ranked and closely crowded, the outer ones at their base fold over or bestride the inner (as shown in the sectional diagram, Fig. 217), whence the name of equitant. Above, the contiguous halves of the inner face congenitally cohere, and so produce the sword-shaped or linear vertical blade which is characteristic of Iris (Fig. 216) and the Iris family. In most there is a farther complication, of an exceptional kind, viz. the development backwards of a portion of blade from the midrib, often forming most of the upper part of such leaves, which therefore may really be said to develop in the vertical plane.

215. Leaves with no distinction of Parts, $i . e$. of blade and petiole. This is the case in Iris (Fig. 216), Daffodil, the Onion, and perhaps of most parallel-veined leaves of Endogens. Those expanded in the horizontal plane may however be regarded as sessile blades: those which are not expanded, but filiform, or needleshaped (acicular), or awl-shaped (subulate), may be regarded either as homologous with petioles, or as unexpanded blades, which amounts nearly

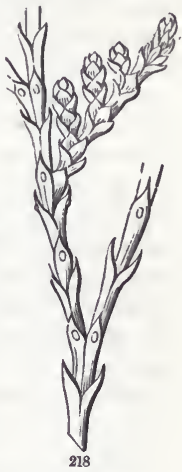
to the same thing where there is no trace of a petiole at base. Under this head may be ranked the leaves of Pines (Fig. 248); also both the subulate and the scale-shaped and adnate leaves of Arbor Vitæ, Red Cedar (Juniperus Virginiana), and other trees of the Cypress tribe. (Fig. 218.)

216. Stipules serving for Blade. Lathyrus Aphaca is a good instance of this (Fig. 219); the petiole becoming a tendril, the leaflets which its relatives bear being wholly wanting, the ample foliaceous stipules assume the appearance of leaves. In some

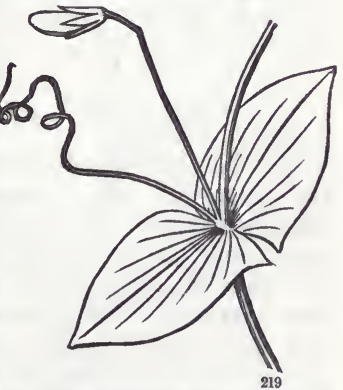
other species of Lathyrus, and in the Pea, equally large stipules share with the pair or pairs of leaflets in the functions of foliage. On morphological evidence, we judge that the singular leaves of

FIG. 218. A twig of Arbor Vitæ, with both awl-shaped and scale-shaped leaves.

FIG. 219. Lathyrus A phaca: portion of stem, bearing a single leaf, which consists of a pair of foliaceous stipules, and a petiole in the form of a tendril; in its axil a flower-stalk. 
Baptisia perfoliata, shown in Fig. 214, are not simple blades, but each a pair of stipules, with or without a terminal leaflet, all completely confluent into one body. The related species of the genus have trifoliolate leaves and foliaceous stipules; hence these simple leaves without stipules are best explained in this way.

217. Phyllodia, or Petioles serving for Blade. Sometimes the petiole develops foliaceous margins, or wings, as in the Bitter Orange and in Rhus copallina. These are efficient as foliage in proportion to their size. These are not to be confounded with the case in which a petiole specially develops as a blade-like organ, which usurps the office of foliage. A petiole-blade of this kind is named a Phyllodium. Occurring only in Exogens, phyllodia are generally distinguished from true blades by the parallel venation, and always by their normally vertical dilatation; $i . e$. they, without a twist, present their edges instead of their faces to the earth and sky. The common and most familiar phyllodia are those of Acacias in Australia (Fig. 223, 224), where they form the adult foliage of over 270 out of less than 300 species. The true lamina of these is bipinnate. It appears on seedlings, and vccasionally on later growths. Several South American species of Oxalis produce phyllodia. So likewise do our tubular or trumpetleaved species of Sarracenia in that portion of the foliage which develops the pitcher imperfectly, or not at all. Indeed, all Sarracenia-leaves are phyllodia with the back in most of them hollowed out into a tube or pitcher; and the terminal hood answers to the blade.

\section{§ 3. Leaves serving Special Offices.}

218. Leaves may serve at the same time both their ordinary and some special use, or even more than one special use. For example, in Nepenthes (Fig. 222) there is a well-developed blade, usually sessile, which serves for foliage, a prolongation of its tip into a tendril, which serves for climbing, then an extraordinary dilatation and hollowing of the apex of this into a pitcher for a very special use, and a peculiar development of the apex of this into a lid, closing the orifice during growth. Among the special purposes which leaves subserve, and the study of which connects singularities of morphology with teleology, the most remarkable is that of

219. Leaves specialized for the Utilization of Animal Matter. This occurs in leaves which also assimilate, or do the ordinary work of vegetation; and the special function is usually taken up by some particular portion of the organ. The details of this 
subject - which has of late become highly interesting - belong to physiology, and therefore to the following volume, to which
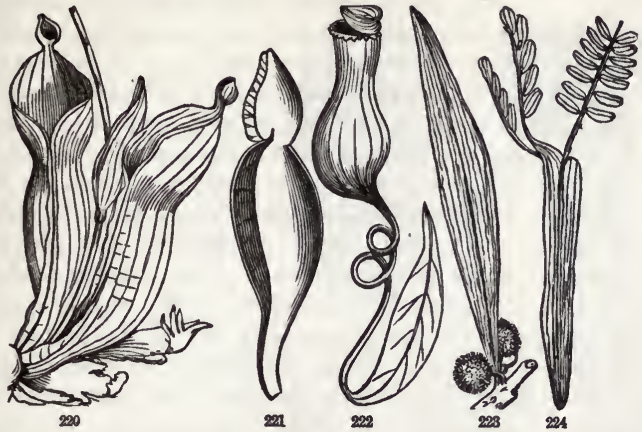

all historical references are relegated. Only the morphology of such leaves is here under consideration.

220. As Ascidia or Pitchers, vessels for maceration, \&c. These occur in several widely different families of plants. The commonest are those of the Sarracenias, natives of Atlantic North America. They are evidently phyllodia (217), the cavity being a hollowed dorsal portion : the wing-like or foliaceous portion, always conspicuous and forming the ventral border, makes the whole organ or most of it in the earlier leaves of the tubular species. The pitchers of S. purpurea (Fig. 221, 225), the only species which extends north of Virginia, are open cups, half filled with water, much of which may be rain, in which abundance of insects are usually undergoing macer-

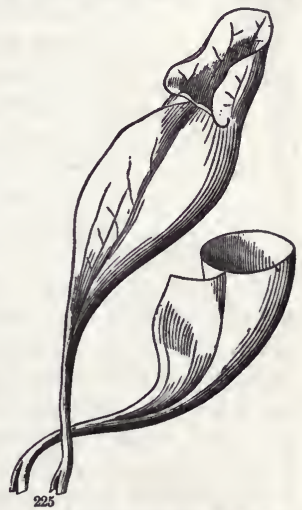
ation. In S. variolaris (Fig. 226), the hooded summit, answering to the blade of the leaf, arches over the mouth in such wise

FIG. 220. Pitchers of Heliamphora; 221. of Sarracenia purpurea; 222. of Nepenthes. 223. A phyllodium of a New Holland Acacia. 224. The same, bearing a reduced com.. pound blade.

FIG. 225. Pitcher-leaves of Sarracenis purpures; one of them with the upper part out sway. 
as to mostly exclude the rain; in S. psittacina (Fig. 227) the inflexed and inflated hood completely excludes it. The water

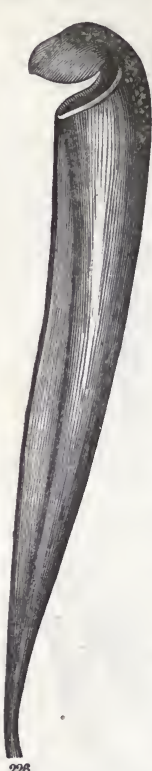
which these contain is undoubtedly a secretion. All entrap flies, ants, and various insects, which in most species are lured into the pitcher by a sweetish secretion around or at some part of the orifice. $^{1}$ Few that have entered ever escape; most are decomposed at the bottom of the cavity. In Darlingtonia Californica (Fig. 228), the Californian representative of Sarracenia, the inflated hood guards against all access of rain, while the orifice is freely open to flying insects from beneath; and a singular two-forked appendage, like to a fish-tail (probably the homologue of the blade), overhangs the front. The inner face of this appendage is besmeared with the sweet and viscid secretion which allures insects to the opening. In this and in Sarracenia variolaris, the sweet secretion in the early season is continued upon the edge of the wing, forming a saccharine trail which leads from near the ground up to the orifice of the pitcher. ${ }^{2}$ Fig. 220 represents pitchers of Heliamphora, a little-known South American representative of Sarracenia. Its wing is narrow and inconspicuous, the mouth widely open and directed upward, and the hood reduced to a minute and upright, probably functionless ap20 pendage. In Cephalotus - an anomalous plant of Australia, of uncertain affinity - the leaves for foliage are dilated phyllodia; among them are others completely transformed into stalked and short pitchers, with thickened rim and a well-fitting lid, hinged by one edge, Fig. 229 .

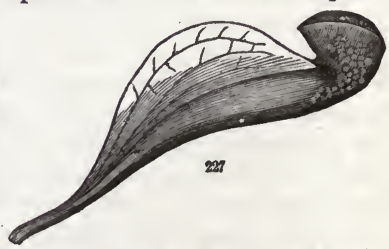
The particular morphology of the parts is not well made ouit.

1 This sweet secretion, which at times is very obvious in the southern species, has also been detected by Mr. Edward Burgess in S. purpurea; but it is rarely seen, and probably plays no important part in the capture and drowning of the multitude of insects which these pitchers are apt to contain.

2 This trail was discovered by Dr. J. H. Mellichamp, of South Carolina. See Proc. Am. Association for Advancement of Science, xxiii. 113 (1871).

FIG. 226. Pitcher of Sarracenia variolaris. 227. Same of S. psittacina. 
221. The pitcher-bearing leaf in Nepenthes has been referred to $(218$, Fig. 222$)$ : of this there are various species, all of them somewhat woody climbing plants of tropical Asiatic and African islands of the southern hemisphere, some of them familiar in conservatory cultivation. Here the tendril may be regarded as a prolonged extension of the midrib of the blade, and the pitcher, with its hinged

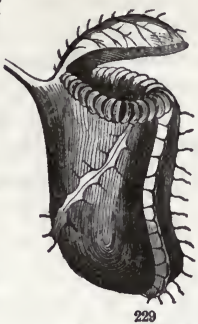

229

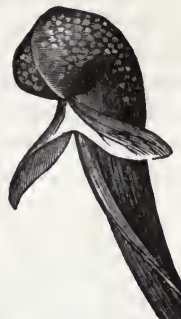
lid, as a peculiar development from its apex. The water contained in the pitcher is a secretion, much of which appears before the lid opens ; and a sweetish excretion at the orifice lures insects. The presence of these in the pitcher increases the watery secretion in which the animals are drowned; and this secretion is ascertained to have a certain digestive power. ${ }^{1}$

222. The aquatic sacs of Utricularia or Bladderwort are diminutive ascidia, always under water, and with lid opening inward, like a valve, preventing the exit of minute animals entrapped therein. ${ }^{2}$ Morphologically, they are doubtless leaves or parts of leaves.

223. As Sensitive Fly-traps. The leaves of all species of Drosera or Sundew are beset with stout bristles tipped with a gland, which secretes and when in good condition is covered by a drop of a transparent and very glairy liquid, sufficiently tenacious to hold fast a fly or other small insect. Adjacent bristles, even if not touched, in a short time bend towards those upon which the insect rests, and thus bring their glands also into contact with it. In Drosera filiformis, the leaves are filiform, with no distinction of petiole and blade. In D. rotundifolia and other common round-leaved species, there is a clear distinc-

1 This was first made out by J. D. Hooker, and announced in his address, as President of the British Association for the Advancement of Science, at Edinburgh, 1871.

2 Darwin, Insectivorous Plants, 395. Cohn, Beiträge zur Biologie der Pflanzen, 1875. Mrs. Treat, in The Tribune, New York, September, 1874, and Gard. Chron. 1875, 303.

FIG. 228. Pitcher of Darlingtonia Californica. 229. Pitcher of Cephalotus follicularis, with lid open. 
tion of petiole and blade, and the stalked glands thickly beset the whole upper surface of the latter. A small insect alighting thereon is helpless, and is soon touched by all the glands within reaching distance; also the blade itself commonly incurves, taking part in the general movement. It has recently been demonstrated that the captured insect is fed upon, and that the plant thereby receives nourishment. Here leaves which do the normal assimilative work of vegetation, but somewhat feebly (having a comparatively small amount of chlorophyll), have
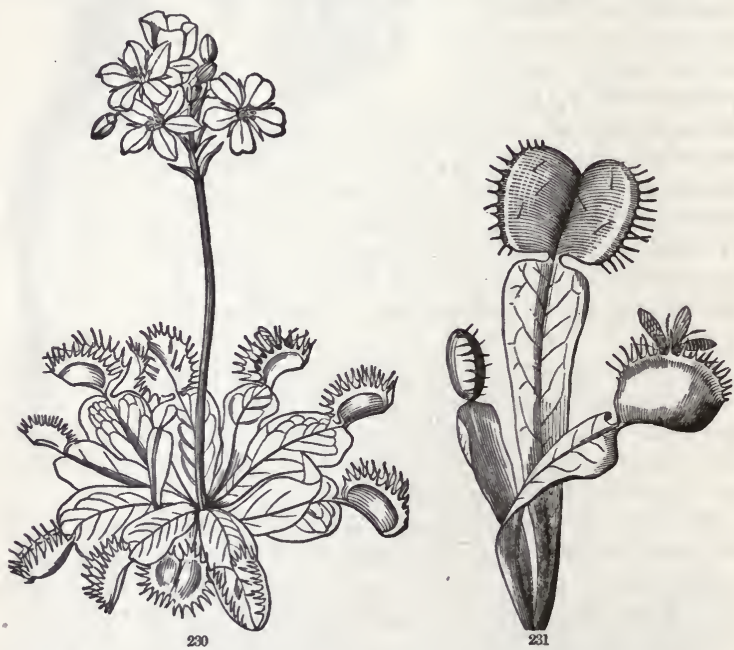

also the power and the habit of obtaining ready-organized food by capture, and are benefited by it.

224. Species of Drosera inhabit most parts of the world, and the genus is numerous in species. A near relative, Dionæa, is of a single species, D. muscipula (Venus's Fly-trap), inhabiting only a limited district in the sandy eastern border of North Carolina. It is more strikingly sensitive and equally carnivorous, but in a different way. It is destitute of stalked and viscid glands. The apparatus for capture and digestion is the twovalved body at the top of each leaf. (Fig. 230, 231.) If this

FIG. 230. A plant of Dionæa muscipula, reduced in size. 231 Three of the leaves, of almost the natural size; one of them open, the others closed. Probably a fly is never caught by the teeth, in the manner here represented. 
be taken for the leaf-blade, the part below would be a broadlywinged foliaceous petiole. If the latter be the true blade, the apparatus in question must be reckoned as a peculiar terminal appendage. Both are moderately green, and act as foliage. The specially endowed terminal portion acts also in a decidedly animal-like manner. When either of the three or four slender bristles of the upper surface are touched, the trap suddenly closes, by a movement ordinarily quick enough to enclose and retain a fly or other small insect. The intercrossing of the stout marginal bristles detains the captive, unless it happens to be small enough to escape by the intervening little openings. Otherwise, the sides soon flatten and are brought firmly into contact, and a glairy secretion is poured out from numerous immersed glands : this, with the extracted juices of the macerated insect, is after some time reabsorbed; the trap, if in a healthy condition, now re-opens and is ready for another capture. For references to the now copious literature of this whole subject, and for its physiological treatment, the succeeding volume should be consulted.

225. Leaves for Storage. Nutritive matter is stored in leaves in many cases, and not rarely in leaves which at the same time are subserving the purpose of foliage. This occurs in all fleshy leaves, to a greater or less extent, according to the degree of thickening or accumulation. The leaves of the Century Plant or Agave, for instance, are green and foliaceously efficient at the surface, while the whole interior is a store-house of farinaceous and other nutritious matter, as much so as is a potato. The leaves of various species of Aloe, Mesembryanthemum, Sedum, and other "succulent" plants (in which a large part of the accumulation is water) are not rarely so obese as to lose or much disguise the foliaceous appearance. Sometimes one portion of a leaf is of normal texture and use, while another is used as a reservoir for the nourishment which the foliaceous part has produced. Fig. 232, a leaf from the bulb of White Lily, the base of which forms one of the bulb-scales, is an instance of the kind. ${ }^{1}$

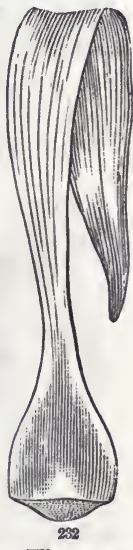

1 In Dicentra Cucullaria and (more strikingly from the sparseness of the grains) in D. Canadensis, the matter elaborated in the much dissected blade is conveyed to the very base of the long petiole, and there deposited in a con-

FIG. 232. A radical leaf of the White Lily, with its base thickened into a bulb-scale which is cut across to show its thickness. 
decisive instance of leaves used for storage of food is in that material provision for the nourishment of the embryo in germi. nation, in which the first leaves, the cotyledons, are turned to this

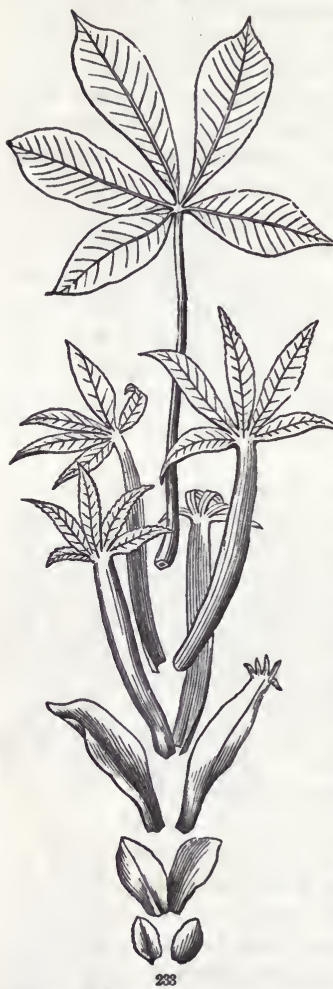
account. (21-37, \&c.) After or while discharging this special duty, the cotyledons may fulfil their general office, by serving as foliage (as in Maples, Fig. 8, and Pumpkins, Fig. 47); or, through various intermediate conditions, they may be wholly devoted to storage, as in the Pea, Oak, Horsechestnut, \&c. (Fig. 37-43.)

226. Leaves as Bulb-scales, however, are for the most part wholly applied to this use, being leaves reduced to short scales or to concentric coats, and thickered throughout by nutritive deposit. The accumulation of such leaves forms the mass of the bulb, as of the Lily, Fig. 118, Onion, Fig. 113, \&c., also of bulblets. (120.)

227. Leaves as Bud-scales, being for protection of nascent parts, have been explained under buds. (70.) The evidence of foliar nature afforded by transition is well exhibited by the Sweet Buckeye, although the whole series of gradations, from bud-scales to compound leaves, is seldom seen united in one bud, as in Fig. 233. In this case, the bud-scales are homologous with petioles. In Magnolia, they consist of stipules (Fig. 81, 82) : in the Lilac, they are homologous with leaf-blades. The two pairs of bud-scales which subtend and protect through winter the nascent head of flowers of Cornus florida are morphologically the apex of

centrated condition, in the form of a solid grain, which remains for next year's use, the whole leaf except this thickened base dying away at the close of the short season's growth.

FIG. 233. Leaves of a developing bud of the Low Sweet Buckeye (Esculus parviflora), showing a nearly complete set of gradations from a scale to a componnd leaf of five leaflets. 
blades. When the blossoms develop in spring, these scales grow from beneath, greatly expand, and become obovate or obcordate petaloid leaves, the brown terminal notch of which is the bud-scale, which was unable to take part in the vernal growth.

$227^{a}$. Leaves as Spines. All gradations may be found between spiny-toothed leaves (as in Holly), in which teeth are pointed and indurated, and leaves which are completely contracted into a simple or multiple spine. Indeed, such a transition is seen in the Barberry, Fig. 234. The foliar nature of such spines is manifest from their position, subtending a bud from which the foliage of the season proceeds, and themselves not subtended by any organ. In some Astragali, the petiole of a pinnate leaf indurates into a slender spine and persists, the leaflets early falling. The spine in Fouquiera is a portion of the lower side of the petiole or midrib, indurated and persistent, the rest of the leaf separating by splitting when it has served its office. ${ }^{1}$

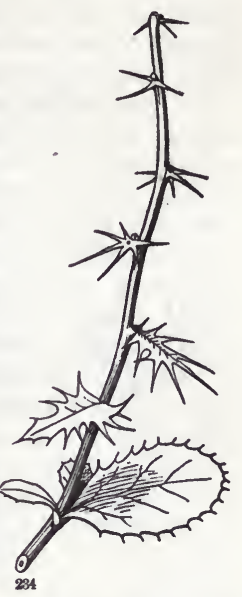

228. Leaves adapted to Climbing. Some plants climb by the action of the stem or of certain branches specially adapted to this purpose (99): others gain the needful support by means of their leaves (101); sometimes by an incurvation of the tips, either of a simple blade as in Gloriosa, or small partial blades, as in Adlumia, and often in Clematis, thereby grappling the support; sometimes by the petiole making a turn or two around a support (as in Maurandia, climbing Antirrhinums, Rhodochiton, and Solanum jasminoides, Fig. 235) ; sometimes by the transformation of one or more leaflets of a compound leaf into tendrils, as in the Pea and Vetch (Fig. 204) ; sometimes by the suppression of all the

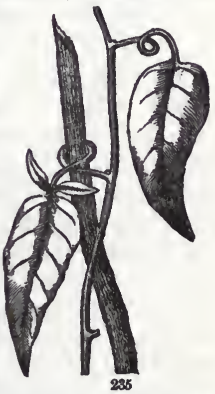
leaflets and the conversion of the whole petiole into a tendril, as in Lathyrus Aphaca (Fig. 219) ; and perhaps by the conversion

1 Described in Plantæ Wrightianæ, ii. 63.

FIG. 234. A vernal shoot of common Barberry, showing a lower leaf in the normal state; the next partially, those stlll higher completely, transformed into spines.

FIG. 235. Solanum jasminoides, climbing by coiling and at length indurating petioles. 
of a pair of stipules into tendrils in Smilax. At least the tendrils here occupy the position of adnate stipules. The tendrils of Cucurbitaceæ are peculiar and ambiguous, on account of their lateral and extra-axillary position and the manner in which the compound ones develop their branches. But they are doubtless partly if not wholly foliar. ${ }^{1}$

229. Petaloid Leaves, Bracts. Certain leaves, situated near to flowers, and developing little or no chlorophyll in their parenchyma, exchange the ordinary green hue and herbaceous texture for the brighter colors and more delicate structure which are commonly seen in and thought to characterize flower-leaves. Such are said to be colored, meaning, as applied to foliage, of some other color than green. As petals are the type of such colored parts, they are said to be petaloid, i. e. petal-like. They are like petals, moreover, in one of the purposes which these subserve. (299.) Examples of these petaloid leaves are seen in the shrubby Mexican Euphorbia called Poinsettia, in Salvia splendens, most species of Castilleia or Painted Cup, also in the white hood of Calla and Richardia Æthiopica (called Calla Lily), and in the four white leaves which subtend the flower-head of Cornus florida, and of the low herbaceous Cornel, C. Canadensis. (Fig. 294.) Such leaves, being in proximity to flowers, and all others which are within a flower-cluster or are borne by flower-stalks, receive the special name of Bracts. More usually bracts are not petaloid, but different in size or shape from ordinary leaves, either by abrupt change or gradual transition. Not uncommonly they are reduced to scales or mere rudiments or vestiges of leaves, of no functional importance.

230. Flower-Leaves. The morphology of leaves extends not only to "the leaves of the blossom," more or less accounted as such in common parlance, but also to its peculiar and essential organs, the relation of which to leaves is more recondite. Their morphology needs to be treated separately, and to be preceded by a study of the arrangement of leaves and of blossoms.

1 The most satisfactory interpretation may be that of Braun and Wydler, adopted by Eichler (Blithendiagramme, i. 304) : that the flower of Cucurbita and its peduncle represent the axillary branch, the tendril by its side answers to one of the bractlets (that of the other side being suppressed), and the supernumerary branch springs from the axil of the tendril. This makes of the tendril a simple leaf, of which the branches are the ribs. But the tendril-divisions are evidently developed in spiral order, and in vigorous growths occupy different heights on the tendril-axis. This favors Naudin's view, that the main tendril is cauline, and its divisions leaves. 


\section{CHAPTER IV.}

\section{PHYLLOTAXY, OR LEAF-ARRANGEMENT.}

\section{Section I. The Distribution of Leaves on the Stem.}

231. Phyllotaxy (or Phyllotaxis) is the study of the distribution of leaves upon the stem and of the laws which govern it. The general conclusion reached is, that leaves are distributed in a manner to economize space and have a good exposure to light, \&c., and that this economy on the whole results from the formation of leaves in the bud over the widest intervals between the leaves next below. ${ }^{1}$ Leaves are arranged in a considerable variety of ways, which all fall under two modes, the Verticillate and the Alternate (13), but which may also be termed the Cyclical and the Spiral.

232. Alternate leaves are those which stand singly, one after another; that is, with one leaf to each node
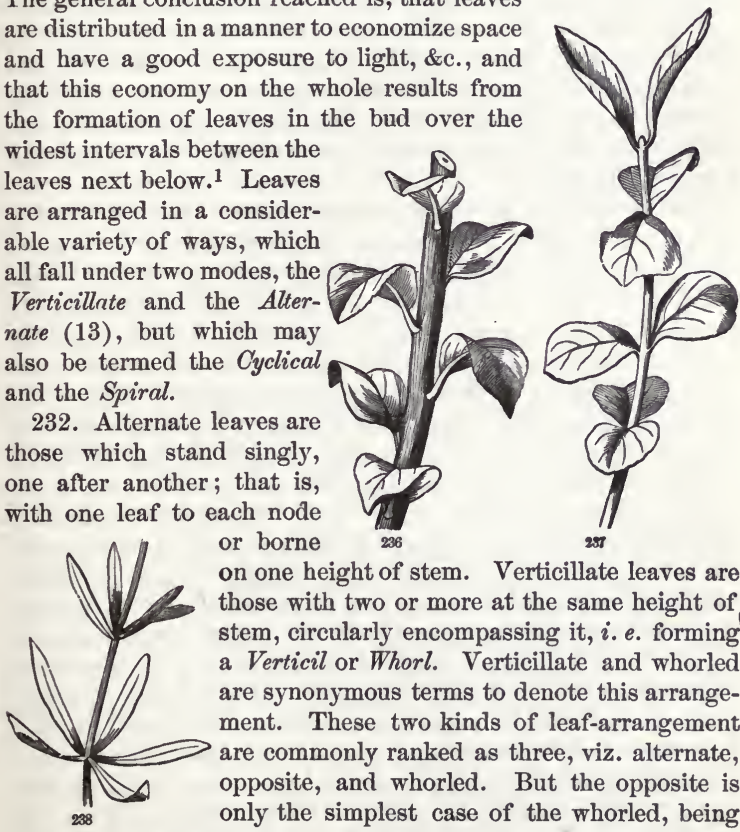
or borne on one height of stem. Verticillate leaves are those with two or more at the same height of stem, circularly encompassing it, $i$.e. forming a Verticil or Whorl. Verticillate and whorled are synonymous terms to denote this arrangement. These two kinds of leaf-arrangement are commonly ranked as three, viz. alternate, opposite, and whorled. But the opposite is only the simplest case of the whorled, being

1 For the most comprehensive discussion of phyllotaxy in connection with development, and in view of these relations, see Hofmeister, Allgemeine Morphologie, \& 11, and Chauncey Wright, Mem. Amer. Academy, ix. 389.

FIG. 236, Alternate, 237, Opposite, 238, Verticillate or whorled leaves. 
that in which the members are reduced to two. This case is so much commoner than whorls of three and of higher numbers that it took from the first its special name of opposite, so that in descriptions the phrase "leaves verticillate" implies more than two leaves in the whorl. But it should be kept in mind that "leaves opposite" is the same as "leaves in whorls of two."

233. The greater number of phænogamous plants (all but the monocotyledonous class) begin with verticillate leaves, mostly of the simplest kind (i.e. cotyledons opposite): some continue verticillate throughout; some change in the first leaves of the plumule or after the first pair into alternate, and again into verticillate in or toward the blossom, in the interior of which the alternate arrangement may be again resumed. As Nature passes madily from the one mode to the other on the same axis, we may expect that the two may be comprised under some common expression. But they have not yet been combined, except by gratuitous or somewhat forced hypotheses; so that for the present they should be treated in morphology as primarily distinct arrangements. 1

234. Verticillate or Cyelical Arrangement. Here the leaves occupy a succession of circles, or form whorls around the stem, two, three, four, five, \&c., in each whorl. According to the number, the leaves are opposite, ternate, quaternate, quinate, and so on. The characteristic of the individual whorl is that the members stand as far apart from each other as their number renders possible, i.e. they divide the circle equally. Thus, when only two, or opposite, their midribs or axes of insertion have an angular divergence (as it is termed) of $180^{\circ}$; when three, of $120^{\circ}$; when four, $90^{\circ}$; when five, $72^{\circ}$.

235. The characteristic of the whorls in relation to each other is, that the members of successive whorls stand over or under the intervals of the adjacent ones. In other words, successive whorls alternate or decussate. This economizes space and light, or gives the best distribution which the cyclical system is capable of. And it is in accordance with the general conclusion of Hofmeister's investigation of the origin of plyyllotaxic arrangements in the nascent bud, viz. that new members originate just over the widest intervals between their predecessors next below. Thus, in opposite leaves or whorls of two (Fig. 237), the successive pairs decussate or cross at right angles, and so four

1 It is readily seen that whorls may be produced by the non-development of the internodes between the leaves of a series of two, three, five, or more in alternate order. The difficulty is that the members of the next whorl do not follow the crder that they should upon this supposition. 
straight equidistant vertical ranks are produced. In ternate or trimerous whorls there are six vertical ranks; in quaternate or tetramerous whorls, eight vertical ranks, and so on.1

236. The cases in which successive pairs of leaves do not decussate at right angles, or the members of whorls are not exactly superposed to intervals, but as it were wind spirally (as in Dipsacus, many Caryophyllaceæ, \&c.), may some of them be explained by torsion of the stem, such as is very manifest in numerous instances; and others may be resolved into

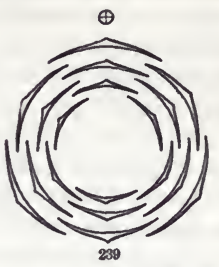
instances of alternate leaves simulating or passing into whorls by the non-development of internodes. ${ }^{2}$

237. Alternate or Spiral Arrangement. Here the leaves are distributed singly at different heights of the stem, and at equal intervals as respects angular divergence. (Fig. 236.) This angular divergence (i.e. the angular distance of any two successive leaves) differs in the various kinds of this system of phyllotaxy, but is always large enough to place the leaves which immediately

1 These vertical ranks have, by some German botanists, been named Orthostichies; but this technical Greek is no clearer and no shorter than the equivalent English, which answers every purpose.

2 In Lilium Canadense, superbum, \&c., with whorls of variable number of leaves and vague relation to each other (when of the same number sometimes the members superposed), and above and below passing into the alternate arrangement normal to the family, these whorls are evidently formed of alternate leaves brought together by non-development of internodes.

Here may also be mentioned the not uncommon anomaly in Fir-cones, notably those of Norway Spruce, the normal phyllotaxy of which is simply spiral, but in occasional instances the cone is composed of pairs of opposite scales, spirally arranged, i.e. the pairs not decussating at right angles, thus forming double spirals. In the abnormal spruce-cones, the fractions usually observed are $\frac{5}{16}$ or $\frac{8}{26}$, or, as expressed by Braun, $\left(\frac{1}{2}\right) \frac{5}{16}$ and $\left(\frac{1}{2}\right) \frac{8}{26}$.

Braun's mode of notation for the ordinary succession (i.e. the decussation) of opposite leaves is $\left(\frac{1}{2}\right) t$, the $\frac{1}{2}$ meaning that the two leaves of the pair are half the circumference of the circle apart, the $t$ denoting that each leaf of the succeeding pair diverges one fourth of the circumference from the preceding. Braun finds cases in which pairs (and equally whorls) are superposed (e.g. certain species of Mesembryanthemum and Euphorbia). these are expressed in this notation by the formula $\left(\frac{1}{2}\right) \frac{1}{2}$, that is, the corresponding leaves of the succeeding pair diverge $180^{\circ}$ from their predecessors. He recognizes also some cases of intermediate divergence; such as $\left(\frac{1}{2}\right)_{6}^{2}$ in the upper leaves of Mercurialis perennis, $\left(\frac{1}{2}\right) \frac{8}{10}$ on certain stems of Linaria vulgaris, $\left(\frac{1}{2}\right)_{1}^{\frac{5}{6}}$ exceptionally in the leares of Epilobium angustifolium and the scales of Norway Spruce, $\left(\frac{1}{2}\right) \frac{8}{26}$ exceptionally in the scales of Norway Spruce. See Ordnung des Schuppen an der Tannenzapfen, 376, \&c.

FIG. 239. Ground-plan diagram of six trimerous whorls, showing their alternation. 
follow each other in the ascending order upon different sides of the axis : it also secures an advantageous spacing of the leaves over the whole length of the axis. Their vertical distance from each other of course depends on the length which the internodes attain, which is a matter of growth and is very variable; but their angular distance is fixed in the kind or numerical plan of the particular phyllotaxy, and is uniform throughout.

238. The leaves are said to be alternate, because they come one after another, now on this side, then on that, as they ascend the stem. The arrangement is said to be spiral, because if a line be drawn or a thread extended from the base or insertion of one leaf to that of the next higher, and so on, taking in all the leaves, it forms a helix, more or less loose or close according to the development of the internodes. (See Fig. 242.) This imagined spiral line ascends continuously, without a break; and on it the leaves are equably laid down. ${ }^{1}$

239. Almost all the ordinary instances of spiral phyllotaxy belong to one series, having very simple arithmetical relations. So that this may be taken as the type, and the few others regarded as exceptions or sometimes as modifications of it. The kinds are simply designated by the number of vertical ranks of leaves: they are technically named by prefixing the proper Greek numeral to the word meaning row or rank. The arrangement called

Distichous, or Two-ranked, is the simplest and among the commonest, occurring, as it does, in all Grasses and many other monocotyledonous plants, in Lindens, Elms, and many dicotyledonous genera. Here the leaves are disposed alternately on exactly opposite sides of the stem (as in Fig. 1); the second leaf being the farthest possible from the first, as is the third from the second ; the third therefore over the first, and the fourth over the second, and so on, thus forming two vertical ranks. The angular divergence is here half the circumference, or $180^{\circ}$; and the phyllotaxy may be represented by the fraction $\frac{1}{2}$, which designates the angular divergence, while its denominator expresses the number of vertical ranks formed.

Tristichous, or Three-ranked, is the next in the series, and is

1 But when we reach a leaf which stands directly over a lower and older one, we say that one set or spire is completed, and that this leaf is the first of a succeeding set or spire. From analogy of such an open spire to the closed cycle of a whorl of leaves, it is not unusual to designate the former likewise as a cycle. Yet it is better (with Eichler) to restrict that term, and the adjective cyclical, to verticillate phyllotaxy, or to whorls, to which it properly and etymologically belongs. 
less common, though not rare in monocotyledonous plants. Fig. 240 illustrates it in a Sedge, and 241 is a diagram in horizontal section, as of a bud; both extending to six leaves or two turns of the spiral. The fraction $\frac{1}{3}$ designates this arrangement. The angular divergence, or distance of the axis of the first leaf from the second, and so on, is one third of the circumference (or $120^{\circ}$ ): consequently the fourth leaf comes over the first, the fifth over the second, the sixth over the third, and so on; that is, the leaves fall into three vertical ranks. The spiral character here begins to be manifest, or becomes so by drawing a line on either figure from the axis or midrib of the first leaf to that of the second, and so on to the sixth, forming a helix of two turns. ${ }^{1}$
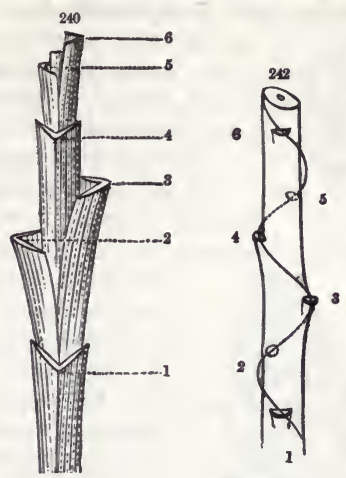

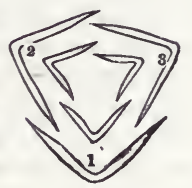

241

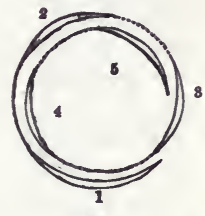

243

Pentastichous, or Five-ranked, sometimes termed the quincuncial arrangement. This is the most common in alternate-leaved dicotyledonous plants. It is shown in Fig. 236 (on a branch of Apple-tree), and by diagrams, displaying the spiral character, in Fig. 242, 243. The angular distance from the first to the second leaf (passing the shorter way) is $\frac{2}{5}$ of the circumference, or $144^{\circ}$. But the spiral line makes two turns round the stem, on which six leaves are laid down, with angular divergence of $\frac{2}{5}$,

1 The line is supposed to follow the nearest way, and the divergence is counted as $\frac{1}{8}$, this being the simplest and most convenient. If for any reason the longer way is preferred, then the angular divergence would be expressed by the fraction $\frac{2}{3}$.

FIG. 240. Plece of a stalk, with the sheathing bases of the leaves, of a Sedge-Grass (Carex crus-corvi), showing the three-ranked arrangement. 241. Diagram of the crosssection of the same. The leaves are numbered in succession.

FIG. 242. Diagram of position of six leaves in the five-ranked arrangement: a spiral line is drawn ascending the stem and passing through the successive scars which mark the position of the leaves from 1 to 6 . It is made a dotted line where it passes on the opposite side of the stem, and the scars 2 and 5, which fall on that side, are made fainter. 243. A plane horizontal projection of the same; the dotted line passing from the edge of the first leaf to the secund, and so on to the fifth leaf, which completes the turn: as the sixth would come directly before, or within, the first. 
and the sixth is the first to come over any one below; the seventh comes over the second, the eighth over the third, \&c. The leaves are thus brought into five vertical ranks; but these

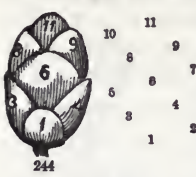
five leaves are laid down on two turns of the helix (the sixth beginning the second revolution); the angular divergence of the leaves in order is $\frac{2}{5}$, or $144^{\circ}$; the angular distance of the vertical ranks, $72^{\circ}$. This is a very advantageous distribution for ordinary foliage on erect or ascending branches. Its formula is $\frac{2}{5}$, expressing the angular divergence, the denominator also indicating the number

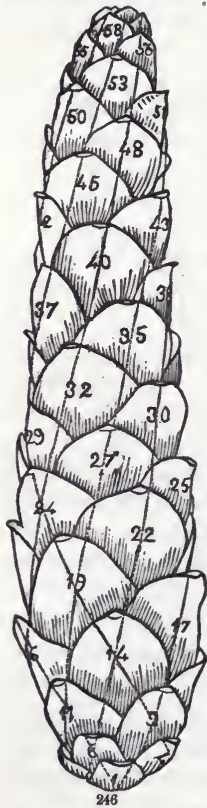
of vertical ranks, the numerator indicating the number of revolutions made in adding one leaf to each rank. Fig. 244 illustrates this arrangement on a cone of American Larch, the scales of which are homologous with leaves, the numbers

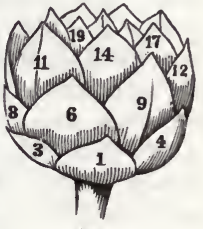

245 in sight are affixed, and those of the whole cone displayed on a plane at the side.

Octostichous, or Eight-ranked, a less common arrangement, occurs in the Holly, Aconite, the radical leaves of Plantago. It has the angular divergence of $135^{\circ}$, or $\frac{3}{8}$ of the circumference, and the leaves in eight ranks, the ninth over the first and at the completion of the third revolution : it is therefore represented by the fraction $\frac{3}{8}$.

240. The obvious relations of the fractions $\frac{1}{2}, \frac{1}{3}, \frac{2}{5}, \frac{3}{8}$, representing the primary forms of spiral phyllotaxy, are that the sum of any two numerators is the numerator of the next succeeding fraction, and the same is true of the denominators; also the numerator is the same as the denominator of the next but one preceeding fraction. Following these indications, the series may be extended to $\frac{5}{13}, \frac{8}{21}, \frac{13}{3}, \frac{21}{5} \frac{1}{5}$, \&c. Now these

FIG. 244. A cone of the small-fruited American Larch (Larix Americana), with the scales numbered, exhibiting the five-ranked arrangement.

FIG. 245. An offset of the Houseleek, exhibiting the 5-13 arrangement; the leaves in sight numbered, the 14th over the first, the 19th over the 6th, \&c.

FIG. 246. Cone of White Pine (PInus Strobus) with scales numbered from bottom. and some secondary spirals marked. 
cases actually occur, and ordinarily only these. ${ }^{1}$ The $\frac{5}{13}$ and $\frac{8}{21}$ are not uncommon in foliage. The rosettes of the Houseleek exhibit the $\frac{5}{13}$ or thirteen-ranked arrangement, as also does the cone of Pinus Strobus, the 14th leaf falling over the first. (Fig. 246.) The $\frac{8}{21}$ is perhaps little less common in foliage upon very short internodes, as likewise are higher ranked. numbers; and in many pine-cones and similar structures $\frac{13}{3}$ and $2 \frac{1}{5}$ phyllotaxy may be readily made out. This actual series, $\frac{1}{2}, \frac{1}{3}, \frac{2}{5}, \frac{3}{8}$, \&c., answers to and may be expressed by the continued fraction, $\frac{1}{2}+t+t+t, \& c .^{2}$

1 When other instances are detected, they are found to belong to other series, following the same law, such as the rare one of $\frac{1}{4}, \frac{1}{6}, \frac{2}{9}, \frac{8}{14}$.

2 "The ultimate values of these continued fractions extended infinitely are complements of each other, as their successive approximations are, and are in effect the same fraction, namely, the irrational or incommeasurate interval which is supposed to be the perfect form of the spiral arrangement. This does, in fact, possess in a higher degree than any rational fraction the property common to those which have been observed in nature; though practically, or so far as observation can go, this higher degree is a mere refinement of theory. For, as we shall find, the typical irrational interval differs from that of the fraction $\frac{8}{8}$ by almost exactly $\frac{7}{1000}$, a quantity much less than can be observed in the actual angles of leaf-arrangements." "On this peculiar arithmetical property . . . depends the geometrical one, of the spiral arrangement, which it represents ; namely, that such an arrangement would effect the most thorough and rapid distribution of the leaves around the stem, each new or higher leaf falling over the angular space between the two older ones which are nearest in direction, so as to subdivide it in the same ratio in which the first two, or any two successive ones, divide the circumference. But, according to such an arrangement, no leaf would ever fall exactly over any other; and, as I have said, we have no evidence, and could have none, that this arrangement actually exists in nature. To realize simply and purely the property of the most thorough distribution, the most complete exposure of light and air around the stem, and the most ample elbow-room, or space for expansion in the bud, is to realize a property that exists separately only in abstraction, like a line without breadth. Nevertheless, practically, and so far as observation can go, we find that the fractions $\frac{8}{8}$ and $\frac{5}{18}, \frac{8}{21}$, \&c., which are all indistinguishable as measured values in the plant, do actually realize this property with all needful accuracy. Thus, $\frac{8}{8}=0.375, \frac{5}{18}=0.385$, and $\frac{8}{21}=0.381$, and differ from $k$ [the nltimate valne to which the fractions of this series approximate, or what is supposed to be the type-form of them] by $-0.007,+0.003$, and -0.001 respectively ; or they all differ by inappreciable values from the quantity which might therefore be made to stand for all of them. But, in putting $k$ for all the values of the series after the first three, it should be with the understanding that it is not so employed in its capacity as the grand type, or source of the distributive character which they have, - in its capacity as an irrational fraction, - but simply as being indistinguishable practically from those rational ones." Chaucey Wright, in Mem. Amer. Acad. ix. 387-390. 
241. The successive grades of angular divergence of atternate loaves, as expressed in degrees, are

$$
\begin{array}{lll}
\frac{1}{2}=180^{\circ} & \frac{2}{5}=144^{\circ} & \frac{5}{3}=138^{\circ} 27^{\prime} 41.54^{\prime \prime} \\
\frac{1}{3}=120^{\circ} & \frac{3}{8}=135^{\circ} & \frac{8}{21}=137^{\circ} 8^{\prime} 34.29^{\prime \prime}
\end{array}
$$

and so on; and beyond, if not in the latter cases, the differences become quite too small for determination by inspection. They all fall within the $\frac{1}{2}$ and $\frac{1}{3}$ as to amount of divergence; and they form a series converging to a deduced typical angle of $137^{\circ} 30^{\prime}$ $28^{\prime \prime}$, which, being irrational to the circumference, would place no leaf exactly over any preceding one, but alternately and more and more slightly on one and the other side of the vertical, and so on, in an endless spiral. That is, according to Bravais, the ranks in the higher grades tend to become curviserial, or actually become so; while in the lower grades they are obviously rectiserial. Unless, indeed, there is some torsion of the axis, by which the vertical ranks are rendered oblique, as is often the case in cones of the Norway Spruce. But, apart from this, the difference between rectiserial in a high order and curviserial soon becomes inappreciable. Any and all of the higher grades, and practically one as low as the $\frac{3}{8}$, secures the utility of the theoretical angle, viz., that " by which the leaves would be distributed most thoroughly and rapidly around the stem, exposed most completely to light and air, and provided with the greatest freedom for symmetrical expansion, together with a compact arrangement in the bud." Even in the simpler grades of commonest occurrence, each leaf (according to Wright) is so placed over the space between older leaves nearest in direction to it as always to fall near the middle of the space, until the circuit is completed, when the new leaf is placed over an old one. ${ }^{1}$

242. It is to be noted that the distichous or $\frac{1}{2}$ variety gives the maximum divergence, viz. $180^{\circ}$, and that the tristichous or $\frac{1}{3}$ gives the least, or $120^{\circ}$; that of the pentastichous or $\frac{2}{5}$ is nearly the mean between the first two; that of the $\frac{3}{8}$, nearly the mean between the two preceding, \&c. The disadvantage of the tworanked arrangement is that the leaves are soon superposed and so overshadow each other. This is commonly obviated by the length of the internodes, which is apt to be much greater in this than in the more complex arrangements, therefore placing them vertically farther apart; or else, as in Elms, Beeches, and the

1 This corresponds with Hofmeister's general rule, that "new lateral members have their origin above the widest gaps between the insertions of the nearest older members." Yet the fact that the character of the leafarrangement is laid down at the beginning in the bud does not go far in the way of the mechanical explanation which he invokes. 
like, the branchlets take a horizontal position and the petioles a quarter twist, which gives full exposure of the upper face of all the leaves to the light. The $\frac{1}{3}$ and $\frac{2}{5}$, with diminished divergence, increase the number of ranks; the $\frac{3}{8}$ and all bejond, with mean divergence of successive leaves, effect a more thorough distribution, but with less and less angular distance between the vertical ranks.

$242^{a}$. The helix or primitive spiral upon which the leaves successively originate ascends, sometimes from left to right, sometimes from right to left, ${ }^{1}$ commonly without change on the same axis, and prevailingly uniform in the same species; but occasionally both directions occur in the same individual. The earliest leaves of a stem or branch, or the last, are often on a different order from the rest; or (as already stated) the spiral may change into the cyclical, or vice versa.

243. The relation of the phyllotaxy of a branch to the leaf from the axil of which the branch springs is somewhat various. But in Dicotyledons, the first leaf or the first pair of the branch is mostly transverse ; that is, the first leaves of the branch stand to the right or left of the subtending leaf. In Monocotyledons, the first branch-leaf is usually parallel to and facing the subtending leaf, as shown in Fig. 304.

244. When the internodes are considerably lengthened, the normal superposition of leaves is not rarely obscured by torsion of the axis : indeed, this may equally occur in short internodes, sometimes irregularly or in opposite directions, sometimes uniformly in one. Thus, in Pandanus utilis, or Screw-Pine, of tristichous arrangement, the three compact vertical ranks become strongly spiral by a continuous torsion of the axis. The later leaves of Baptisia perfoliata, which are normally distichous, become one-ranked by an alternate twist, right and left, of the successive internodes.

245. When the internodes are short, so that the leaves approximate or overlap, it is difficult or impossible to trace the succession of the leaves on the primitive spiral, but it is easy to see which are superposed. The particular phyllotaxy may then be determined by counting the vertical ranks, which gives the denominator of the fraction. But in compact arrangements these vertical ranks are commonly less manifest than certain oblique ranks, which are seen to wind round the axis in opposite directions. (See Fig. 245, 246.) These are termed secondary spirals, also by some parastichies. These oblique spiral

1 That is, of the observer and as seen from without. See p. 51, foot-note. 
ranks are a necessary consequence of the regular ascending arrangement of parts with equal intervals over the circumference of the axis ; and, if the leaves are numbered consecutively, their numbers will necessarily stand in arithmetical progression on the oblique ranks, and have certain obvious relations with the primary spiral which originates them, as will be seen by projecting them on a vertical plane.

$245^{a}$. Take, for example, the $\frac{2}{5}$ arrangement, where, as in the diagram annexed to Fig. 244, the primitive spiral, written on a plane surface, appears in the numbers, $1,2,3,4,5,6$, and so on: the vertical ranks thus formed are necessarily the numbers $1-6-11 ; 4-9-14 ; 2-7-12 ; 5-10-15$; and $3-8-13$. But two parallel oblique ranks are equally apparent, viz. 1-3-5, which, if we coil the diagram, will be continued into 7-9-11-13-15; and also the 2-4-6-8-10 continues into $12-14$, and so on, if the axis be prolonged. Here the circumference is occupied by two secondary left-hand series, and we notice that the common difference in the sequence of numbers is two; that is, the number of the parallel secondary spirals is the same as the common difference of the numbers on the leaves that compose them. Again, there are other parallel secondary spiral ranks, three in number, which ascend to the right; viz. 1-4-7, continued into $10-13 ; 3-6-9-12$, continued into 15 ; and 5-8-11-14, \&c. ; where again the common difference, 3 , accords with the number of such ranks. This fixed relation enables us to lay down the proper numbers on the leaves, when they are too crowded for directly following their succession, and thus to ascertain the order of the primary spiral series by noticing what numbers come to be superposed in the vertical ranks. Thus, in the small cone of the American Larch (Fig. 244), which usually completes only three heights of leaves, the lowest, highest, and a middle one make a vertical row which faces the observer. Marking this first scale 1, and counting the parallel secondary spirals that wind to the left, we find that two occupy the whole circumference. From 1, we number on the scales of that spiral 3-5-7, and so on, adding the common difference 2, at each step. Again, counting from the base the right-hand secondary spirals, we find three of them, and therefore proceed to number the lowest one by adding this common difference, viz. 1-4-7-10; then, passing to the next, on which the No. 3 has already been fixed, we carry on that sequence, $6-9$, \&c. ; and on the third, where No. 5 is already fixed, we continue the numbering, $8-11$, \&c. This gives us in the vertical rank to which No. 1 belongs the sequence 1-6-11, showing that the phyllotaxy is of the five-ranked, or $\frac{2}{z}$ order. 
It is further noticeable that the smaller number of parallel secondary spirals, 2, agrees with the numcrator of the fraction in this the $\frac{2}{5}$ arrangement; and that this number, added to that of the parallel secondary spirals which wind in the opposite direction, viz. 3, gives the denominator of the fraction. This holds good throughout; so that we have only to count the number of parallel secondary spirals in the two directions, and assume the smaller number as the numerator, and the sum of this and the larger number as the denominator, of the fraction which expresses the angular divergence sought. For this, we must, however, take the order of secondary spirals nearest the vertical rank in each direction, when there are more than two, as in all the higher forms. But, in all, it is necessary to count only the most manifest secondary spiral of each direction in order to lay down the proper number on the leaves or scales, and so determine the phyllotaxy. ${ }^{1}$ In a rosette of the leaves of Houseleek (Fig. 245) and a cone of Pinus Strobus (Fig. 246), the numbers which can be seen at one view are appended, and in the latter the conspicuous secondary spirals are indicated: one to left with a common difference of 5 ; and two to the right, of which the most depressed and prominent has the common difference of 3 , the other, nearest the vertical, the common difference 8 . The 14th leaf is superposed to the first, indicating the $\frac{5}{13}$ arrangement. The same conclusion is derived from the number of the higher spirals, the smaller 5 for the numerator, and this added to 8 for the denominator. The mathematical discussion of these relations, and of the whole subject of phyllotaxy, leads into interesting fields. But this sketch may suffice for botanical uses.

246. Relations of Whorls to Spirals. Verticillate and alternate phyllotaxy, or whorls and spirals, in all complete exemplifications, are to be considered morphologically as distinct modes, not to be practically homologized into one. Nevertheless, transitions between the two, and abrupt changes from one to the other on the same axis are not uncommon, the former especially in the foliage, the latter in the blossom. If the spiral be assumed as the fundamental order, it is not difficult to form a clear conception as to how such changes come to pass. A single whorl

1 In applying this method to the determination of the phyllotaxy of a cone, or any such assemblage of leaves, the student should be warned that, although the cones of Pines and Firs are all normally on the alternate plan (while those of Cypresses are on the verticillate), yet in individual cases (common in Norway Spruce) the cone is plainly mate up of pairs of opposite scales which are spirally arranged. See note under 236. 
may most naturally be produced by the non-development of the internodes between any two, three, or more alternate leaves. Two proximate distichously alternate leaves would thus form a pair ; the three leaves belonging to one turn of the spiral in the tristichous ( $\left.\frac{1}{3}\right)$ arrangement would compose a trimerous whorl ; the five leaves of the two turns in the pentastichous $\left(\frac{2}{5}\right)$ arrangement, a 5-merous whorl, \&c. Verifications of this conception, by whorls breaking up or reverting to spirals, are occasionally met - with, and the successive overlapping in spiral order of the members of a trimerous or pentamerous whorl is very common. The few instances among phænogamous plants in which the leaves are opposite and all in the same plane ${ }^{1}$ (that is, the successive pairs superposed) may be deduced from the distichous alternate mode becoming opposite without further change, by the simple suppression of alternate internodes. The frequent disjunction of the members of the pair in similar and analogous cases goes to confirm this view. But the characteristic of whorls ordinarily is that proximate whorls alternate, that pairs decussate. We cannot homologize this with spiral phyllotaxy; for in this lies the fundamental difference between the two plans. We can explain it only by a reference to Hofmeister's law, which generally governs leaf-origination as to position, namely, that succeeding leaves appear directly above the intervals between the nearest preceding (241, note): this gives decussation or alternation of successive pairs or whorls. ${ }^{2}$

247. Hypothesis of the origin of both. Instead of regarding the spiral path on the stem which connects successive alternate leaves as a purely formal representation, it may be conceived to be the line along which the members in some original form were physically connected, in the manner of a leaf-like expansion

1 As in Loranthus Europæus, \&c., according to Braun. See 236, note.

2 This renders the verticillate an advantageous arrangement, perhaps no less so than the distribution which spiral plyyllotaxy effects. Both must be considered to have been determined by and for their respective utilities, and to have been independent determinations. For "there is no continuity or principle of connection between spiral arrangements and whorls" (Chauncey Wright); since, although individual whorls are easily reducible to spirals, each succession is an absolute break of that system.

As whorls of four members often (as especially in calyx, bracts, \&c.) may and sometimes should be viewed as two approximate pairs, so even the spiral of five members, as in a quincuncial caly $x$, has been conceived to consist of two whorls, one of two, the other of three leaves, the second alternating with the first as nearly as possible. But this appears far-fetched and of loose application. It is much clearer as well as simpler to regard the alternate as the fundamental phyllotaxy, and to deduce individual whorls from spirals, if need be, rather than to imagine spirals as somehow evolved from whorls. 
resembling a spiral stairway. Upon this supposition, the leaves would be the relics, or rather the advantageous results, of the segmentation of such a frond-like expansion, the segments separated through the development of the stem in length and firmness, and modified in the various adaptations to the conditions of higher vegetable life; even as leaves themselves are modified into tendrils, bud-

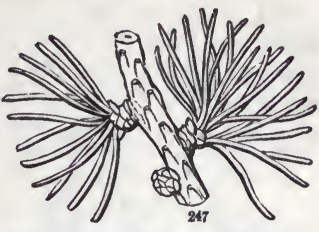
scales, petals, or other usefully specialized structures. The type on this conception would be a frond, consisting of an elongating axis with a continuous leaf-blade on one side, and this taking a spirally twisted form. But the frond of Fucaceous Algæ, Hepaticæ, and the like, is two-bladed. While a one-bladed frond, or with one blade suppressed, might be the original of alternate-leaved spirals, the two-bladed frond, similarly broken up, would give rise to the opposite or other varieties of verticillate arrangement. ${ }^{1}$.

248. Fascicled Leaves need to be mentioned here, in order that they may be excluded from phyllotaxy. They are simply a cluster or tuft of leaves, belonging to more than one node, and left in a crowded condition because the internodes do not lengthen. They may belong either to the alternate or the verticillate series. In Barberry and in the Larch (Fig. 247), they are evidently alternate ; and they may be inferred to be so in Pines (Fig. 248), or even may be seen to be so in the bud-scales which form the sheath surrounding the base of the 2,3 , or 5 foliage-leaves. In Junipers, the leaves of the fascicles are in the verticillate order.

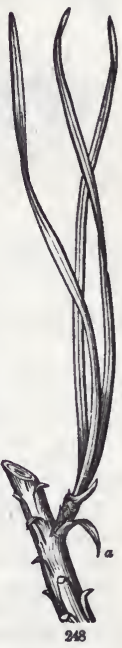

1 This is the conception of the late Chauncey Wright. See his elaborate and most suggestive essay in Mem. Amer. Acad. Arts and Sciences, ser. 2, ix. 379, mainly reprinted in Philosophical Discussions (posthumous), 296-328, in which the whole subject of phyllotaxy is acutely discussed, especially in its relation to questions of origin and developed utilities. His conception

FIG. 247. Piece of a branch of the Larch, with two fascicles of leaves, i. e. two very ghort and stout branchlets, bearing scars of former leaves or bnd-scales below, and a dense cluster of leaves of the season at summit. The main axis bears scars from which the alternate leaves of the developed axis of the preceding year separated.

FIG. 248. Piece of a branch of Pitch Pine, with three leaves in a fascicle or bundle in the axil of a thin scale $(a)$ which answers to a leaf of the main axis. The bundle is surrounded at the base by a short sheath, formed of the delicate scales of the axillary bud, of which the three leaves are the developed foliage. 


\section{Section II. Disposition of Leaves in the Bud.}

249. Vernation and Estivation are terms in general use, under which the disposition of leaves in the bud is treated. The first relates to ordinary leaves in this early condition; the second, to the parts of a flower-bud; not, however, as respects insertion, or position on the axis, which is phyllotaxy (231), but as to

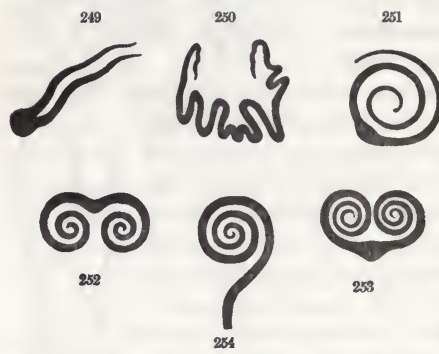

the ways in twhich they are coiled, folded, overlapped, \&c., either per se or inter se. Prafoliation and Prafloration are etymologically better terms, substituted by Richard. ${ }^{1}$

250. The descriptive terms which relate to individual leaves or parts, whether of foli-

age or blossom, mostly range themselves under the heads of plications or of enrolling, and are such as the following, the sectional diagrams of which are copied from the original figures

would make the two plans equally primordial. But the freedom with which these actually interchange on the same axis greatly favors the less hypothetical view that whorls may be condensed spirals. This assumes only the well-known fact that internodes may be completely non-developed.

1 Better formed and more expressive terms: but the Linnæan ones are most in use, and, though fanciful, are not misleading. In English description, it is as convenient and equally terse to say that the parts are imbricate, valvate, \&c., "in the bud." Linnæus, in the Philosophia Botanica, described these dispositions of leaves in the bud under the term Foliatio, - not a happy name,- but did not treat of them in the flower-bud. Later, in Termini Botanici (Amœn. Acad. vi. 1762, reprinted by Giseke in 1781), he introduced the words Vernatio and Estivatio in their now current botanical sense, to designate, not the time of leafing and of flowering (spring and summer condition), but the disposition of the parts in the leaf-bud and flower-bud (at least of the petals) as respects foldings, coiling, \&c., of single parts, and modes of overlapping or otherwise of contiguous parts. The terminology as regards single leaves, Linnæus fixed nearly as it now remains. That of leaves or their homologues in connection, and as respects the flower-bud, was very imperfectly developed until its importance (and much of its terminology) was indicated by Robert Brown, in his memoir on Proteaceæ, 1809, in the Prodromus a year later, and in other publications.

Ptyxis (the Greek name) is coming into use as a general term for the folding, \&c., of single parts.

FIG. 249-254. Linnæan diagrams of sections of leaves in the bud. 249. Condupircate. 250. Plicate or plaited 251. Convolute. 252. Revolute. 253. Involute. 254. Circinate or Cirelual 
in the Philosophia Botanica of Linnæus. They were applied only to foliage, but they are equally applicable to floral parts. Leaves, and all homologous or similar organs, if not simply plane, will be either bent or folded or else more or less rolled up in the bud. The first three of the following terms relate to the former, the remaining terms to the latter. They are as to the mode of packing

Plicate or Plaited (Fig. 250), when folded on the several ribs, in the manner of a elosed fan, as in Maple and Currant. This occurs only in certain palmately veined or nerved leaves.

Conduplicate (Fig. 249), when folded lengthwise, or doubled up flat on the midrib, as in Magnolia; a very common mode. The upper face of the leaf is always within.

Reclinate or Inflexed, when the upper part is bent on the lower, or the blade on the petiole, as in the Tulip-tree (the blade of which is also conduplieate).

Convolute (Fig. 251), when rolled up from one margin, $i . e$. one margin within the coil, the other without, as in Apricot and Cherry.

Involute (Fig. 253), both margins rolled toward the midrib on the upper face, as the leaves of Water Lily, Violet, \&c. ; also the petals of Steironema and Tremandra.

Revolute (Fig. 252), similarly rolled backward from both margins, as the leaves of Azalea and Rosemary.

Circinal or Circinate (Fig. 254), when coiled from the apex downward, as the leaves of Drosera and the fronds of all the true Ferns.

Corrugate or Crumpled, as the petals of a Poppy, applies to the irregular crumpling of the otherwise plane corolla-leaves. This is a consequence of rapid growth in length and breadth in a confined space.

251. The Ptyxis (or folding, \&c.) of an individual leaf, of which the foregoing modifications are the principal, should be distinguished from the arrangement in the bud of the leaves of a circle or spiral in respect to each other. The interest of the latter centres in the flower-bud, i.e. in æastivation. To this the following exposition is devoted, although sometimes applicable to leaf-buds also. ${ }^{1}$

252. The disposition of parts in æstivation, in respect to each other, is the result partly of their relative insertion, that is

1 In the succeeding paragraphs, it becomes necessary to presuppose so much knowledge of the flower as is implied in the free use of such terms as caly $x$ and corolla, sepals or calyx-leaves, and petals or corolla-leaves. See, if need be, Chapter VI. Sect. I. 
their phyllotaxy, and partly of the way in which they comport when their margins meet in growth. Those leaves which are within, or of higher insertion on the axis, will almost necessarily be enclosed or overlapped: those which are members strictly of the same whorl or cycle may fail to come into contact, or may meet without overlapping at the contiguous margins or apex; yet they may be overlapped, since they may have grown unequally or some a little earlier than their fellows. Consequently, no perfectly clear line can be drawn in the flower between cycles and spirals except by their mode of succession. Moreover, æstivation strictly so called should be concerned only with the disposition among themselves of the several members of one whorl, or of one complete spiral. So the alternation of contiguous whorls, as of the three inner with the three outer flower-leaves of a Lily or a Tulip (the alternative æstivation of DeCandolle), is a matter of phyllotaxy, not of æstivation. The latter is properly concerned only with the relations of each three leaves to each other. ${ }^{1}$

253. The proper æstivations may be classified into those in which the parts do not overlap, and those in which they do. Of

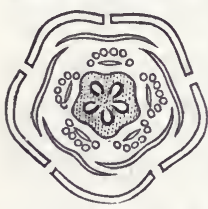

255 the first, there are two kinds, the open (aest. aperta) and the valvate, both characterized and named by Brown. ${ }^{2}$ Of the second, there is one leading kind, the imbricate (adopted by Brown from Linnæus), with subordinate modifications. ${ }^{8}$ Accordingly, the restivation is said to be

254. Open or Indeterminate (ast. aperta), when the parts do not come into contact in the bud, so as to

1 The same applies to the two sets of sepals and of petals in Barberry, in Menispermum, and of the petals in Poppy, \&c. (359).

2 Linnæus, indeed, has, " Estivatio valvata, si petala se expansura instar glumæ graminis ponuntur," - the name, but not the thing: the glumes of grasses are not valvate in the botanical sense. So the term as to its proper use may be said to originate with $R$. Brown.

8 For a brief discussion of " Estivation and its Terminology," see Amer. Jour. Sci. ser. 3, x. 339, 1875.

As to names, it is perhaps more correct to say of the ostivation that it is imbricative, convolutive, valvular, \&c. (ast. imbricativa, convolutiva, valvaris, \&c.), but of the leaves or pieces, that they are imbricate, convolute, valvate, \&c., in astivation; but such precision of form will seldom be attended to in botanical descriptions.

FIG. 255. Diagrammatic cross section of an unopened flower of Linden: its outer ctrcle of floral leaves (sepals) valvate in the bud; the inner (petals) between convolute and imbricate. 
cover those within. The most familiar case is that of the petals of Mignonette and the whole genus Reseda.

255. Valvate or Valvular, when the margins meet squarely in the bud, without any overlapping, like the valves of a dehiscent capsule. Familiar examples are afforded by the calyx of the Linden (Fig. 255) ; also that of the Mallow, Rhamnus, Fuchsia, and the whole of the several natural orders to which these belong. A modification of this, caused by some induplication or involution of the edges of the individual leaves, occurs in most species of Clematis : in Clematis Virginiana, they merely project within (valvate-induplicate); in Clematis Viticella, they are conspicuously involute (valvate-involute), or valvate with margins involute. Some-

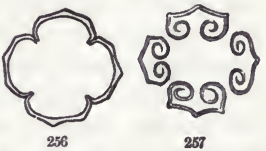
times (as in the calyx of certain Malvacer) the joined edges project outwardly (or are valvate with reduplicate margins), but only slightly so.

256. Imbricate or Imbricative is the general name for æstivation (or vernation) with overlapping. The name is taken from the overlapping of tiles or shingles on a roof, so as to break joints or cover edges. It was first applied, by Linnæus, to leaves or scales on a stem, when thickly set and incumbent in surcessive ranks or heights, the upper partly covered by those next below. The involucre of an Aster or of the common Sunflower is a typical illustration; as also the leaves of a Camellia-flower, the sepals as well as the petals ; and the sepals or outer leaves

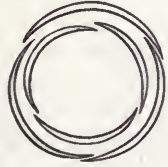

228

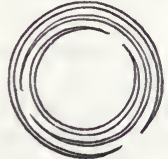

259

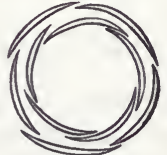

260

of a Flax or a Geranium-flower afford a simpler but similar instance, although, from the parts being nearly of the same size and at the same height, the overlapping is lateral instead of obviously from below. Fig. 258, 259, and the outer part of 260 , also the inner leafy circle of 255 , illustrate in diagram this true and simple imbricative æstivation of a definite number of

FIG. 256. Valvate-induplicate flower-leaves (calyx) of Clematis Virginiana, \&c. 257. Valvate-involute, as in C. Viticella.

FIG. 258-260. Imbricate astivation: 258, in two whorls of three leaves each (calyx and corolla); 260, same of five leaves in the outer circle, those of the inner circle convolnte; 259, a single set of three imbricated leaves (in the corolla of Magnolia), almost completely encircling each other. 
parts. ${ }^{1}$ It is characteristic of it that some parts (one or more) are wholly exterior or covering in the bud, and others (one at least) interior or covered, at least the margins. Imbricative rstivation, it will be seen, naturally attends alternate or spiral phyllotaxy (248, and see Fig. 242, 243); and if it be maintained that these sets of three, five, \&c., in the blossom are not depressed spirals, but whorls or cycles (as may commonly be the case in the corolla, but hardly in the calyx), it is not less true that the parts are apt to comport themselves in the exact manner of a depressed spiral. The kinds of regular imbrication of alternate leaves, \&c., may be specified by the terms or fractions expressive of the particular grade of phyllotaxy $\left(\frac{1}{2}, \frac{1}{3}, \frac{2}{5}\right.$, $\frac{3}{8}, \& c$.). But some of them have received special names, which may be employed, as subordinate to the general denomination of imbricate. The most important of these are the

Equitant, where leaves override, the older successively astride the next younger. The typical instance is that of ancipital or two-ranked $\left(\frac{1}{2}\right)$ conduplicate leaves, successively clasping, at least next the base, as in Iris, Fig. 217. In what Linnæus termed equitant-triquetrous (well seen in Fig. 240, 241), the leaves are three-ranked (being of the $\frac{1}{3}$ order), and each imperfectly conduplicate.

Quincuncial æstivation (as in the outer part of Fig. 260) is simply the imbricate æstivation of five leaves $\left(\frac{2}{5}\right)$, in which necessarily the first and second are external, the fourth and fifth internal, and the third with one margin external, where it overlies the fifth, and the other internal, where it is covered by the first.

Alternative æstivation, as already stated (252), comes from verticillate or cyclic phyllotaxy, and the alternation of successive whorls. When two such whorls, say of three leaves each (as in Fig. 258), are so condensed or combined as to form apparently one set or circle of six members (as in the flower-leaves of most Liliaceæ), three members alternate with and are covered by the other three, and this sort of imbricate æstivation is produced. More properly, the two series are to be considered separately. Where the parts are four (as in Fig. 395), the normal imbrication is decussate, two exterior and two interior. This is some-

1 All the examples referred to result from alternate or spiral phyllotaxy, the former of higher series, the latter of the $\frac{1}{8}$ (Fig. 258, 259), and of the $\frac{2}{5}$ (Fig. 260) order. Instead of separating (with DeCandolle and others) the $\frac{2}{5}$ arrangement as different in kind from the imbricate (under the name of quincuncial æstivation), we should count it as a typical case. Otherwise the $\frac{1}{8}$ arrangement might equally claim a generic distinction, also the $\frac{8}{8}$, \&c. 
times a clear case of binary instead of quaternary, i.e. to be counted as two pairs of opposite leaves; yet it may be a single whorl of four, notwithstanding the imbrication. Or these four leaves may even, in some cases, be regarded as a portion of a depressed spiral, say of the $\frac{2}{5}$ order with one piece omitted, and the others adjusted so as to fill the space.

257. There are various deviations from normally imbricative æstivation, especially where the members are five, occurring some in regular but more in irregular flowers, which need not be referred to here. One, for which no specific name is requisite, is a case merely of excessive overlapping in the regular way; namely, where each piece completely and concentrically encloses the next interior, as shown in Fig. 259, representing three petals of Magnolia Umbrella. This the French botanists have called convolute æstivation, because the individual leaves are involute in a manner approaching the convolute vernation of Linnæus. Another is the Vexillar, as in the Pea tribe (Fig. 306), where members which should be external have somehow developed as internal, both in calyx and corolla. A third (which has received the usually quite meaningless name of Cochlear, spoon-like, and is also that to which most French botanists singularly restrict the name of imbricative) is a state exactly intermediate between the quincuncially imbricate and the convolute or

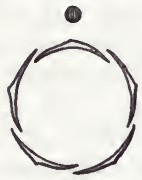

281

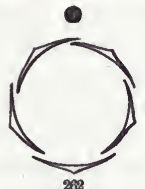

20

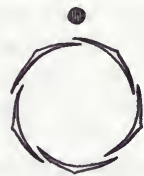

263

contorted. In it, one leaf is wholly outside, one wholly inside, and three with one margin inside and the other outside. It occurs under two modifications, viz. with the innermost leaf remote from the outmost (Fig. 261), and with it next to the outermost as in Fig. 262. In view of the intermediate character, we had applied to this the somewhat awkward name of Convolute-imbricate. ${ }^{1}$ To bring Fig. 261 back to the quincuncially imbricate

1 It would not be amiss, therefore, to name one of these modes, viz. that of Fig. 261, Subimbricate, and the other, Fig. 262, Subconvolute. George

FIG. 261. Quincuncial imbricate modified toward convolute by one edge of the second leaf developing inside instead of outside of the adjacent edge of the fourth.

FIG. 262. Convolute modified toward imbricate by one leaf having a margin inside instead of outside its neighbor.

FIG. 263. Convolute, or convolntive, or contorted (twisted) æativation, in diagram. In these three diagrams, the dark circle above represents the position of the axis, the flowers being axillary. 
form, we have only to reverse a single overlapping on the lefthand side of the figure. To restore Fig. 262 to the convolute, we have only to reverse a single overlapping at the lower righthand side. Changes like these, or the reverse, are not rare in several species, particularly in the corolla. The normal form and the deviation often occur in different flowers on the same individual, thus indicating an easy passage between the imbricate æstivation in the proper sense and the

258. Convolute, otherwise called Obvolute or Contorted, or Twisted, Fig. 263, and inner circle of Fig. 260. Here each leaf successively overlaps a preceding and is overlapped by a following one, all having a slight and equal obliquity of position, so that all alike have an exterior and an interior (or a covering and a covered) margin, and all appear to be as it were rolled up to-

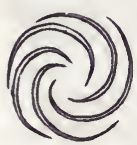

264 gether. This is strikingly so when the parts are broad and much overlapped, as in Fig. 264. Brown included this among the forms of imbricate æstivation, and so does Eichler, particularly distinguishing it, however, under the name here preferred. The occasional transitions would justify such classification. But in most cases it is so uniform, and in the corolla so completely characteristic of whole families (such as Malvaceæ, Onagraceæ, A pocynaceæ, Gentianaceæ, Polemoniaceæ, \&c.), and is so distinct in its nature, that it may well take rank among the primary kinds of æstivation. As to its nature, it is evident that while the imbricate mode (at least the ternary, quinary, \&c.) indicates or imitates spiral phyllotaxy (some members being within or with higher insertion than others), the convolute and the valvate (having all the members of the series on the same plane) answer to verticillate phyllotaxy, or to whorls instead of depressed spirals. ${ }^{1}$ The name which this mode of

Henslow, in Trans. Linn. Soc. ser. 2, i. 178, proposes to call the former halfimbricate; the latter (following the faulty French example) is his imbricate proper.

The subimbricate mode has two varieties, distinguished by Eichler (in Blüthendiagramme) as ascensive, when the lower or anterior (i.e. the pieces next the subtending bract or leaf) are successively exterior (as in Fig. 261), and descensive, when the covering is from the upper side, i.e. from the side next the axis.

1 Still, as those members of a quincunx which normally should be wholly external do sometimes become internal during their development in the bud, similar changes may be conceived to change a quincuncial into a convolute disposition; but, to effect this, three out of the five overlappings would have to be reversed.

FIG. 264. Convolute (also called contorted) æstivation of a corolla. 
æstivation ought to bear is not yet well settled, but that of convolute, here preferred, will probably prevail. ${ }^{1}$

259. In recapitulation, these principal forms of the æstivation of floral circles may be classified in a synopsis. They are: I. those not closed = open or indeterminate: II. closed; and these 1 , with the margins not overlapping $=$ valvate $; 2$, with margins overlapping; $a$, one or more with both margins covered $=i m b r i$ cate; $b$, all with one margin covered, the other uncovered $=$ convolute.

260. Plicate or Plaited, when applied to the flower-bud as a whole, is in a somewhat different category. The term is here used for the plaiting of a tube or cup, composed of a circle of leaves combined into one body. It is well marked in

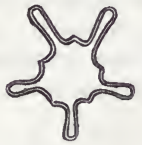

265

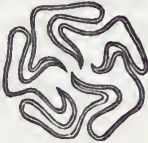

266

the corolla of Convolvulus and of Datura, and in most of the order to which these belong. In Campanula, these plaits are all outwardly salient and straight (Fig. 265); in the corolla of most Gentians, the plaits are internal and straight. In Convolvulus and Datura (Fig. 266-268), the narrow plaits overlap one another in a convolute way, when they are said to be Supervolute. In the common Morning Glory and some other

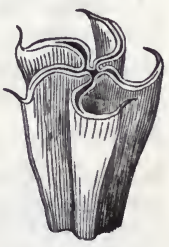

267

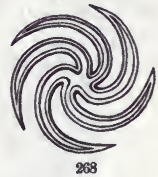
species of Ipómœa, these plaits are besides spirally twisted or

1 See article entitled " Fstivation and its Terminology," above referred to. The earliest name is Obvolute, given by Linnæus to the kind of vernation in which two leaves (conduplicate ones in his diagram) are put together so that one half of each is exterior, the other interior. That is just the mode in question reduced to a single pair of leaves, as it is in the calyx of a Poppy. Mirbel is the only botanist who has applied the term to æstivation, and to a circle of more than two leaves, and it has never been adopted in botanical descriptions. It has the disadvantage that the prefix ob to botanical terms means obversely or inversely. Contorted (contorta), in English Twisted, is in early and is the commonest use, and it is sometimes expressive. The objection to it is, that contortion or twisting of the flower-bud often conspicuously occurs where there is no overlapping of edges (as in many species of Ipomøa); that really no twisting accompanies the overlapping in a majority of cases of this æstivation; and that when there is a twisting it is not rarely in the direction contrary to the overlapping; so that the contortion needs to be

FIG. 265. Cross section of the extrorsely plicate or plaited tube of the corolla of a Campanula in the bud. 266. Same of a Convolvulus (Calystegia), the plaits convolute or supervolute.

FIG. 267. Upper part of nnexpanded corolla of Datura; the plaits convolute or supervolute. 268. Cross section of the same. 
contorted in the opposite direction; that is, the plaits overlap to the right and are twisted to the left. ${ }^{1}$

261. Direction of Overlapping, \&c. This is to be noted in the ternary, quinary, or other forms of spirally disposed imbrication, also in convolute and twisted or contorted æstivation. It may be either to the right (dextrorse) or to the left (sinistrorse). The application of this term depends upon the assumed position of the observer, whether outside or inside. We always suppose him to stand outside, in front of the object: so when the overlapping is from right to left of the observer thus placed, as in Fig. 266, it is sinistrorse; when from his left to right, as in Fig. 267,268 , dextrorse. ${ }^{2}$ The direction is generally constant, but in many cases only prevalent, in the same plant or the same species, or even the same genus : sometimes it is uniform or nearly so throughout a whole natural order.

separately expressed. To describe the æstivation in such cases as dextrorsum contorta et sinistrorsum torta (or in similar English words), when the overlapping is to the right and the twisting to the left, is at least awkward and cumbrous. Convolute is a fitting name, of occasional early application to this æstivation (as by Jussieu to the petals of Malvaviscus), but without definition in this sense; it has for many years been steadily adopted by the present writer, is employed by Eichler in Germany, and has recently been adopted by G. Henslow and others in Great Britain. It has, however, the disadvantage of having been used by Linnæus to express the coiling of single leaves, and in a manner not wholly congruous, but still with one edge outside and the other inside.

1 In our phraseology, dextrorsely convolute and sinistrorsely contorted; in the current phraseology above referred to, dextrorsely contorted or twisted and sinistrorsely twisted!

2 The reasons for adopting this view (in opposition to the authority of Linnæus and DeCandolle) are given in note on p. 51 . 


\section{CHAPTER V.}

\section{ANTHOTAXY, OR INFLORESCENCE.}

262. INFLoRescence, a term which would literally denote the time of flower-bearing, was applied by Linnæus to the mode, that is, to the disposition of blossoms on the axis and as respects their arrangement with regard to each other. ANтнотаху, a name formed on the analogy of phyllotaxy, and denoting flowerarrangement, is a better term. The subject really belongs to ramification $(83,14-16)$, and is also concerned with foliation and with phyllotaxy. It is most advantageously treated apart, immediately preceding the study of the blossom itself.

263. In and near the blossom, both axis and foliage very commonly undergo modification, either abrupt or gradual, giving rise in the former to Peduncles and Pedicels, in the latter to Bracts and Bractlets.

264. A Bract (in Latin Bractea) is a leaf belonging to or subtending a flower-cluster, or subtending a flower, and differing from the ordinary leaves in some respect, usually in shape and size, not rarely in texture and color. ${ }^{1}$ They are commonly, but not always, reduced or as if depauperate leaves, of little or no account as foliage, but sometimes of use for protection, sometimes rivalling the highly colored flower-leaves for show, more often insignificant or

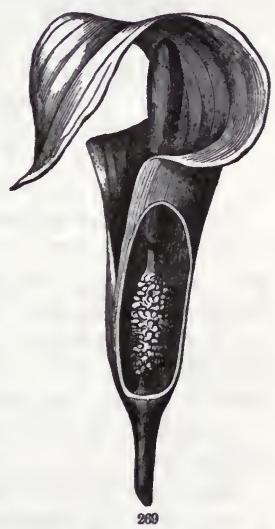
minute and functionless, sometimes obsolete (as in Cruciferæ), or

1 Bracts of the first order are sometimes called floral leaves (Folia floralia), or at least these are not well distinguished from bracts. But the term floral leaves is descriptively more properly and usually applied to leaves below the bracts or proper origin of the flower-clusters, yet near them, and unlike the proper cauline leaves. It is a vague term, and is in some danger of being confounded (as it never should be) with another vague term, viz. flower-leaves, or the leaf-like organs of the flower itself.

FIG. 269. Bract (spathe) of Indian Turnip, partly cut away below to show the fleshy spike (spadix) of flowers which it surrounds. 
fugacious. Each flower is subtended by (grows from the axil of) a bract in Fig. 277-280, \&c. A cluster of flowers is subtended by a conspicuous and colored bract in Fig. 269, 270, 271 ; by a circle of colored bracts, imitating white petals, in Fig. 294.

Spathe is the name given to such an enclosing bract, or to two or more leaves successively enclosing a flower-cluster.

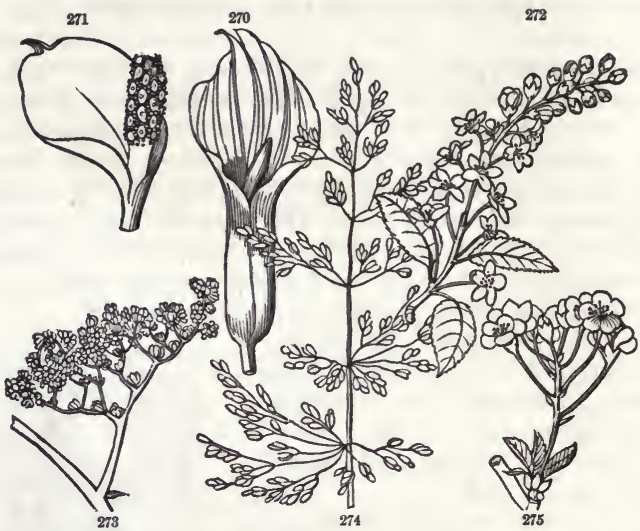

INVOLUCRE is the name given to a circle or spiral collection of bracts around a flower-cluster, as in Cornel (Fig. 294, also in Fig. 280 and 286), or around a single flower, as in Hepatica and Mallow. A compound inflorescence may have both a general and a partial involucre, one for the general flower-cluster, others subtending the partial clusters. The name of involucre is then reserved for the general one; that of

INvoldCEL is applied to the partial, secondary, or ultimate involucres.

Bractlets (Lat. Bracteola, diminutive of bract) are bracts of a secondary or ultimate order. For example, in the slender flower-cluster, Fig. 277, $b$ is a bract, subtending each individual flower-stalk; $b^{\prime}$ is a bractlet, or bract of secondary order, borne on that partial flower-stalk itself. The French naturally translate the Latin bracteola into bractéole (pl. bractéoles) : in English, bractlet is an idiomatic and better diminutive.

Palets (Lat. Palea), also called Chaff, are diminutive or

FIG. 270. Monophyllous spathe of Indian Turnip, with tip more erect. 271. Spathe and spadix of Calla. 272. Raceme of Cherry, leafy at base. 273. Dichotomous cyme. 774. Panicle of Meadow-Grass. 275. A corymb. 
chaff-like bracts or bractlets on the axis (or receptacle) and among the flowers of a dense inflorescence, such as a head of Compositæ $(275$, Fig. 287, 288) ; and the name is also given to an inner series of the

Guumes of Grasses. These are peculiar chaffy bracts or bractlets which characterize the inflorescence of Grasses and Sedges.

265. Peduncle is the general name of a flower-stalk, that is, of an axis or stem, which instead of foliage, or at least ordinary foliage, supports a flower-cluster or a single flower. In Fig. 276, each peduncle (rising from the axil of an ordinary leaf, and therefore answering to a branch)

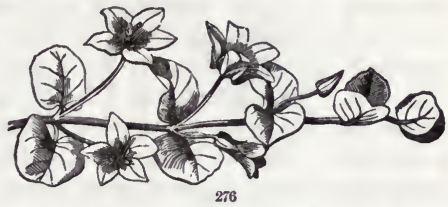
bears a solitary flower. In Fig. 277, the peduncle bears a series of flowers, or a flower-cluster. In this instance, each flower is borne on a flower-stalk of its own, that is, upon a

Pedicel. This is the name given to distinguish a partial flower-stalk, or, more strictly, the stalk of each individual flower of an inflorescence. (Fig. 277-284.) In less simple flower-clusters, with ramification of two, three, or more grades, general peduncle, partial peduncles, and pedicels have to be distinguished: the term pedicel is reserved for the ultimate ramification.

Scape is the name given to a peduncle rising from the ground, as that of most Primulas, of Dodecatheon, Hepatica, and the so-called acaulescent or stemless Violets.

RHACHIs (backbone) is a name given to the axis of inflorescence; that is, the continuation of the stem or peduncle through a somewhat elongated flower-cluster, as in a spike of Birch or of Plantain, Fig. 289, 290. When this axis is short, as in a head (Fig. 285-288), it is usually called the RECEPTACLE, a word also used for the axis or cauline-

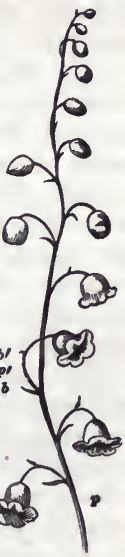

277 part of a flower. The context should show when recéptacle of inflorescence, and when receptacle of the flower itself, is meant. Both belong to axis or stem.

FIG. 276. Moneywort, Lysimachia nummularia, with axillary one-flowered peduncles.

FIG. 277. A Raceme, with a general peduncle $(p)$, pedicels $\left(p^{\prime}\right)$, bracts $(b)$, and brectlets $(b)$. 
266. Position of Flowers or Ciusters. Flower-buds accord with leaf-buds in origin, position, and structure, to this extent at least, that the parts of both are leaves or homologues of leaves, crowded in whorls or spirals upon a short portion of stem or axis ; and as leaf-buds are either terminal or axillary $(15,75)$ so also are flower-buds; as a leaf-bud may give rise to a simple or a compound growth, i.e. may branch again and again, or not branch at all, so flower-bearing branches, or the flower-bearing extremity of a stem or branch, may bear a single flower, or a more or less compound cluster. Thus, in Fig. 276, an axillary peduncle, or naked branch, bears at apex a solitary flower; in Fig. 277, a peduncle bears a loose cluster of flowers, each of which springs from the axil of a small bract; in Fig. 285, a terminal peduncle bears at summit a dense flower-cluster. Flowers are either solitary or in clusters. When solitary, they are naturally without bracts, being subtended instead (as in Fig. 276) by ordinary foliage.

267. The elevation either of a solitary flower or a cluster on a peduncle, or of individual flowers of a cluster on pedicels, is only incidental. The flowers may be stalkless, i. e. sessile.

268. The Kinds of Inflorescence which have received distinctive names are various, but are all reducible to two types, which, generally well marked, may sometimes pass into each other, and which are not rarely combined in the same compound inflorescence. ${ }^{1}$ The two types differ in basis as do axillary from terminal buds; in the one the flowers are axillary or lateral, in the other terminal in respect to the axis from which each flower or its pedicel arises. But inasmuch as every flower, whatever its position, is terminal to its own stalk or axis, it is better to distinguish the two types in other terms, and to name them the

269. Indefinite and Definite, or, in equivalent and similar terms, the Indeterminate and Determinate. ${ }^{2}$ Each may be either simple or compound. It is from the simple that the definitions are to be drawn. In the former type, the rhachis or main axis of the inflorescence is not terminated by a flower, but lateral axes, or pedicels, are. In the latter, both the main or primary and the lateral or secondary axes or stalks are so terminated. An indeterminate flower-cluster may go on to develop internode after

1 Inflorescence, as has been well insisted on by Guillaud (in Bull. Soc. Bot. France, iv. 29), is a mode, not a thing. The things sometimes but inappropriately so called are flower-clusters, for which, if a general technical name is needed, that of Anthemia, in English Anthemy, suggested by Guillaud, is as good as any.

2 Also named by Eichler (Blüthendiagramme, 33, following Guillaud, 1. c.) the Cymose and the Botryose type. 
internode of axis, and one or more leaves (bracts) at each node, and then a flower in the axil of each bract, until its strength or capability is exhausted. Or it may stop short with very few flowers; but the uppermost and youngest one will not really ter-
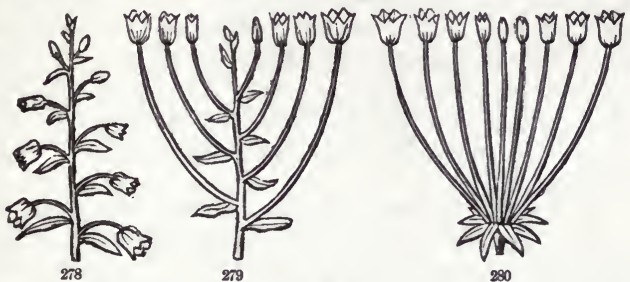

280

minate the rhachis (i.e. come from a terminal bud), though it may appear to do so. (Fig. 272, 277-279, \&c.) The lower flower-buds are evidently the oldest, and accordingly the first to expand; and the expansion will proceed regularly from below upward: wherefore this type of inflorescence has been called the Ascending or Acropetal; likewise the Centripetal, because, when the flowers are brought to the same level or near it (as in Fig. 279,280 ) by a lengthening of the lower pedicels, with or without relative shortening of the rhachis, the evolution

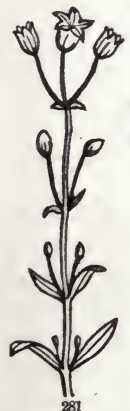
is seen to proceed from circumference to centre. There is thus no lack of names; but, inasmuch as the following type is commonly referred to under the general name of Cymose, to this has recently been given the counterpart name of Botryose. (271.)
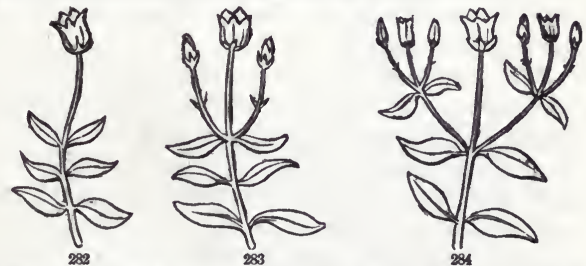

270. A determinate flower-cluster (as seen in its gradual development which is not rarely presented) has the last internode

FIG. 278-280. Diagrams of Indefinite, indeterminate, contripetal, or botryose inflorescence: 278 , Raceme; 279 , Corymb; 280 , Umbel.

FIG. 281-284. Diagrams of definite, determinate, centrifugal, or cymose Inflorescence: 281 , a false or descending raceme; 282 , a solitary terminal flower; 283 , sam七 with two lateral flowers developing, forming a 3-flowered cyme; 284, same with lateral peduncles 3-flowered, or a pair of 3-flowered cymes, beside the central or primary terminal flower. 
of its axis terminated by a flower (Fig. 281-284), which answers to a terminal bud. If more flowers appear, so as to compose a cluster, they spring from the axils, preferably from the highest axils, and are later. The order of evolution is shown in the figures by the size of the flower-buds or degree of expansion of the blossoms. Fig. 281 best shows why a determinate or definite inflorescence is sometimes said to be Descending; Fig. 283 shows why it is called Centrifugal, the central flower first expanding; Fig. 284 exhibits the lateral or circumferential partial clusters later than the central blossom, and their lateral flowers later than their central.

271. Varieties of Indeterminate or Botryose Inflorescence. The names of most of these have been fixed from the time of Linnæus, but defined without reference to the order of evolution of the flowers. They are the Raceme, Corymb, and Umbel, with flowers raised on pedicels; the Spike and Head, with sessile flowers; also some modifications of these, notably the Ament and the Spadix. The raceme may be taken as the type. Botrys is equivalent to racemus, \&c.; and, as the type includes diversity of forms to which the name racemose would seem inapplicable, the term botryose (botrytischen of Eichler) is best chosen as the general name of it, and is a good counterpart to cymose for the other type.

272. A Raceme (illustrated in Fig. 272, 277, and by diagram in Fig. 278) is a simple flower-cluster, in which the flowers, on their own lateral or axillary pedicels and of somewhat equal length, are arranged along a relatively more or less elongated rhachis or axis of inflorescence. The common Barberry, Currant, Choke-Cherry and Black Cherry, and Lily of the Valley are familiar examples.

273. A Corymb (Fig. 275, 279) is a shorter and broader botryose cluster, which differs from a raceme only in the relatively shorter rhachis and longer lower pedicels; the cluster thus becoming flat-topped or convex. The centripetal character is thus made apparent. The greater number of the corymbs of Linnæus and succeeding botanists are cymes, the central flower first expanding. And the term corymbose or corymb-like is still much used in descriptive botany for a ramification which is mainly of the cymose type, and where in strictness the term cymose should be employed.

274. An Umbel (Fig. 280), as in Asclepias, \&c., differs from a corymb only in the extreme abbreviation of the rhachis or axis of inflorescence, and the general equality of the pedicels which thus all appear to originate from the apex of the peduncle, and 
so resemble the rays of an umbrella; whence the name, and whence also the pedicels or partial peduncles of an umbel are termed its Rays. The bracts, brought by the non-development of internodes into a depressed spiral or apparent (or sometimes real) whorl, become an involucre. (264.) An umbel or any similar cluster when sessile (without a common peduncle), and the parts crowded, is sometimes called a Fascicle (or the pedicels said to be fascicled); but this term has been differently defined. (280.) It is better not to use it for any special kind of inflorescence, but simply in the sense of a bundle of whatever sort. This will accord with the sense in which it is applied to an aggregation of leaves. (248.)

275. A Head or Capitulum (Fig. 285) is a globular cluster of sessile flowers, like those of Red Clover, Button-bush, and Plane-tree. The pedicels need not be absolutely wanting, but only very short. An umbel with pedicels much abbreviated thus passes into a head, as in Eryngium, \&c. And a head with rhachis elongated passes into a spike. The short rhachis of a head very commonly takes the name of receptacle. (265.) The whole may be subtended by conspicuous bracts forming an involucre (264) as in Fig. 286 , or may be destitute of any, as in Fig. 285. On account of the compactness and mutual pressure under growth, the bracts among

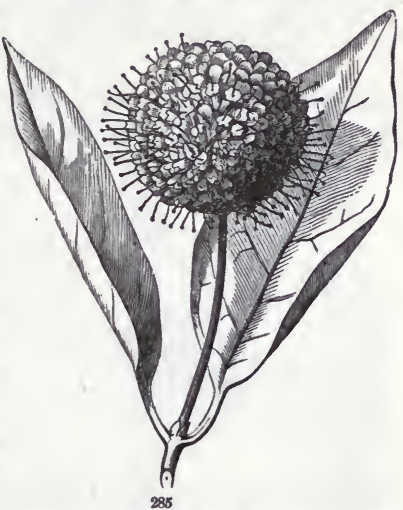
the flowers of such heads (normally one subtending each blossom) are apt to be rudimentary, reduced to little scales, or abortive, or completely wanting. In the latter case, the receptacle is said to be naked (nude), i.e. naked of bracts : when they are present, it is paleate or chaffy. A peculiar sort of head, not undeserving a special name (though this is not necessary in descriptive botany), is the

Anthoprux, the so-called Compound Flower of the $\epsilon$ arlier botanists, which gives the name to the vast order of Compositæ.

FIG. 285. Cephalanthus occidentalis, the Button-bush; a pair of lesves, and a terminal peduncle bearing a dense head (capitulum) of flowers. 
The name means "resembling a flower." Although it has all the characters of a true head, the resemblance to a flower is

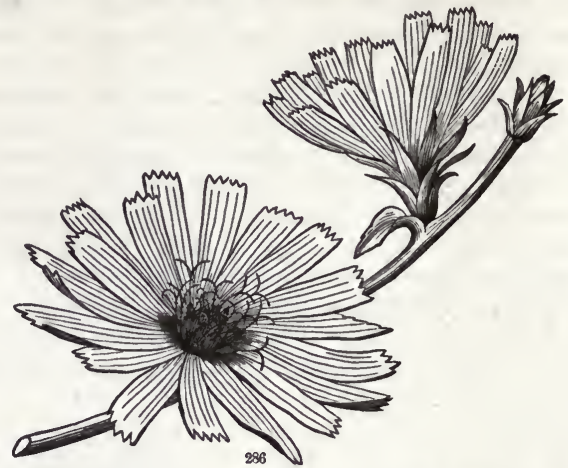

remarkably striking, the involucre imitating a calyx, and the strap-shaped (ligulate) corollas of the several flowers imitating the petals of a single blossom. In some (such as Dandelion

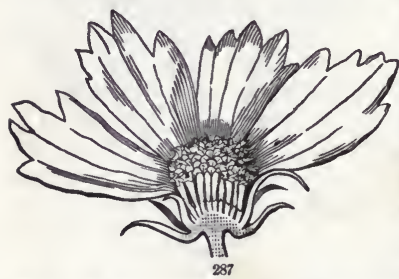
and the Cichory, Fig. 286), all the flowers of the head bear these petal-like corollas; in more (such as Aster, Sunflower, and Coreopsis, Fig. 287 ), only an outer circle of flowers does so ; the remainder, smaller and filling the centre (or disk), may by the casual observer be taken for stamens and pistils, and further the deception. The rhachis or receptacle of a head of this kind is commonly depressed, bearing the flowers on what then becomes the upper surface, which adds to the imitation. ${ }^{1}$

Srconium. This name, given to the Fig-fruit, should be here referred to, as. it is a sort of inflorescence, of the general nature of a head, but with receptacle external and flowers enclosed

1 The receptacle of an Anthodium has been termed Clinanthium or Phoranthium; and its involucre, a Periphoranthium or Periclinium. The head has likewise been named a Cephalanthium.

FIG. 286. Flowering branch of Cichory, with two heads of ligulate flowers, of natural size.

FIG. 287. Vertical section of a head of flowers of a Coreopsis. 
within. See Fig. 657-659 (683), where its morphology is explained and illustrated. Viewed as an inflorescence, it has also been named a HypanthodIUM.

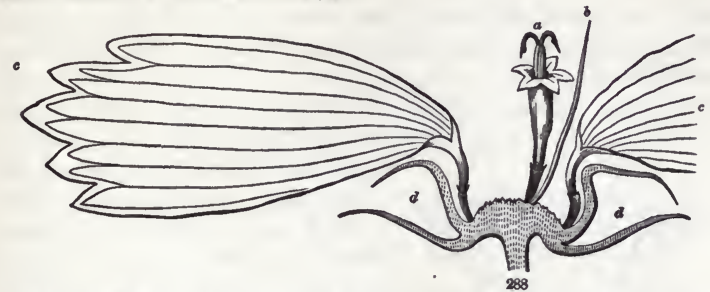

276. A Spike is a cluster of sessile (or apparently or nearly sessile) lateral flowers on an elongated axis. It may be defined by comparison, as a head with the rhachis lengthened (indeed a young head often becomes a spike when older), and equally as a raceme with the pedicels all much shortened or wanting. A common Mullein and a Plantain (Plantago, Fig. 290) are familiar examples. Two modifications of the spike (or sometimes of the head) generally bear distinct names, although not distinguishable by exact and constant characters, viz. : -

SPadix, a spike or head with a fleshy or thickened rhachis. The term is almost restricted to the Arum family and Palms, and to cases in which the inflorescence is accompanied by the peculiar bract or bracts called a spathe (Fig. 269-271). But the two do not always go together: in Acorus and Orontium there is properly no spathe to the spadix; while in the Iris family the bracts are said to form

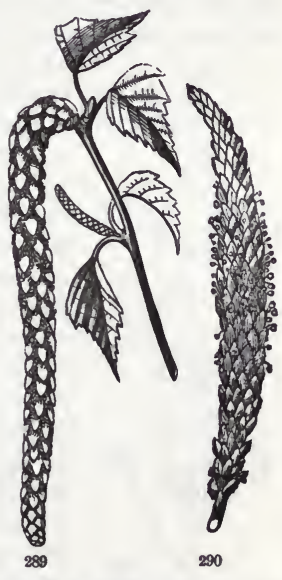
a spathe, and there is no spadix. In Palms, the principal reason for naming the inflorescence a spadix is its inclusion in a spathe before anthesis.

FIG. 288. A slice of Fig. 287, more enlarged, with one tubular perfect flower (a) left standing on the receptacle, and subtended by its bract or chaff $(b)$; also one ligulate and neutral ray-flower and part of another $(c, c):$ in $d, d$, the bracts or leaves of the involncre are seen in section.

IIG. 289. Catkin of White Rirch. 290. Young spike of Plantago major. 
Ament or Catkin. This is merely that kind of spike with scaly bracts borne by the Birch (Fig. 289), Poplar, Willow, and, as to one sort of flowers, by the Oak, Walnut, and Hickory, which are accordingly called amentaceous trees. Catkins usually fall off in one piece, after flowering or fruiting. All true catkins are unisexual.

277. Any of these forms of simple inflorescence may be compounded. Racemes may themselves be disposed in racemes, spikes

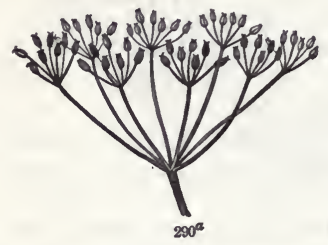
in spikes (as in Triticum), heads be aggregated in heads, umbels in umbels, corymbs may be corymbosely compound, \&c.; forming compound racemes, spikes, umbels, and the like, the terminology of which is easy. The most usual case of truly homomorphous compounding is that of umbels; the Inflorescence of much the larger part of Umbelliferæ being in compound umbels, as in Fig. $290^{a}$. There is then the general

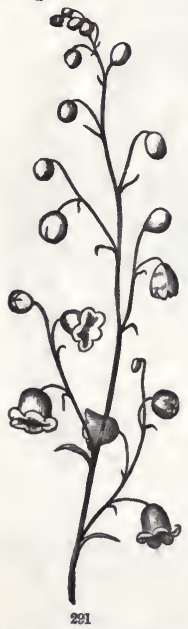
umbel, the rays of which become peduncles to the partial umbels, and the rays of the latter are pedicels. Umbella and Umbellula designate in Latin terminology the general and its partial umbels. Umbellets (coined by the late Dr. Darlington) may well replace the latter as the English diminutive. But umbels are sometimes racemosely arranged, as in Aralia spinosa, heads may be arranged in spikes, and so on.

278. A Panicle, of the simple and normal sort (as illustrated in Fig. 291), is produced when a raceme becomes irregularly compound by some (usually the lower) of its pedicels developing into peduncles carrying several flowers, or more than one, or branching again and again in the same order. But in compound clusters generally the secondary and tertiary ramifications are apt to differ in type as well as in particular mode, giving rise to heteromorphous or mixed inflorescence. (288.)

As Linnæus defined the term, and as it has generally been employed in botanical descriptions, the panicle is a general term

FLG. 290a. Compound umbel of Caraway. 291. A simple panicle. 
for any loose and diversely branched cluster, with pedicellate flowers. It is therefore difficult to restrict it in practice to the indeterminate type.

279. Varieties of Determinate or Cymose Inflorescence. The plan of this type has been sufficiently explained. (270.) Its simplest condition is that of a solitary terminal flower, pedunculate or pedicellate (as in Fig. 282), or sessile. The production of more flowers necessitates new axes from beneath, from the axils of adjacent leaves or bracts. These, being later, render the evolution centrifugal. The simplest flower-cluster (unless we call the solitary flower of Fig. 282 a one-flowered cluster) is that of Fig. 283, where a secondary floral axis or peduncle has developed from the axil of each leaf of the uppermost pair, or where with alternate leaves there is a single uppermost leaf, and then only one such peduncle, and thus is produced a three- (or two-) flowered cymose cluster. The flower of the primary axis is marked by its bractless peduncle (therefore a pedicel); the lateral and secondary peduncles are known (commonly or normally) by their bracts or bract; the portion below the bracts 1s proper peduncle; that above, of single internode, pedicel. Bracts, like other leaves, have potential buds in their axils; these in an inflorescence give the third order of ramification, each branch tipped with its flower; and so on.

280. The Cyme is the general name of this kind of flower-cluster in its various forms. One of these very simple cymes, by itself or as a part of a larger cyme, may be called a Cymule. The regular

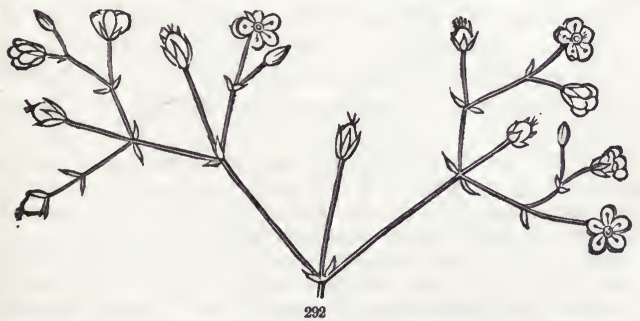

cyme usually accompanies opposite or other grades of verticillate leaves, but is not rare in the alternate arrangement. It is readiest understood in an opposite-leaved plant with regular opposite ramification, as in an Arenaria, Fig. 292. By its constitution, a cyme proceeds from simple to compound. It mat-

FIG. 292. Dichotomous or biparous cyme (cyme bipare of Bravais, Dichasium of Eichler) of Arenaria Michauxii. 
ters little whether its development is progressive, the flowers of the ultimate ramifications expanding after the earlier have matured fruit, and with subtending bracts conspicuous or foliaceous; or whether, as in Elder and Hydrangea (Fig. 293, and in Fig. 273), the bracts are minute and caducous or abortive, and the ramification complete with all the flower-buds well formed before the oldest expand, so that the whole is in blossom almost at the same time. But a cyme may be properly said to be compound when the primary axis in it is a peduncle instead of a pedicel,

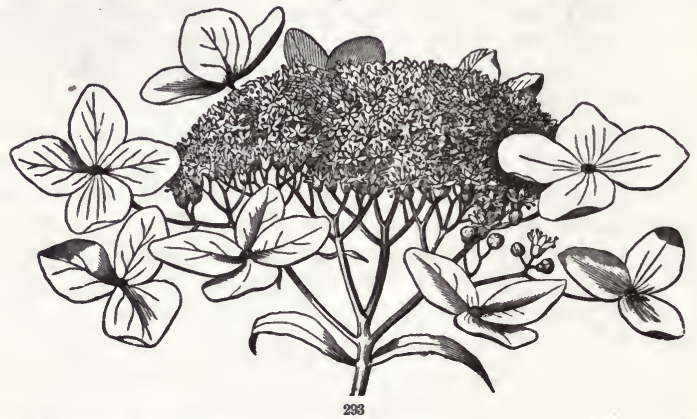

and supports a cluster (cyme or cymule) instead of a solitary central flower at the main divisions. ${ }^{1}$ One form of the regular cyme, on account of its compactness, is named the

Glomerule. This is merely a cymose inflorescence, of any sort, which is condensed into the form of a head, or approaching it. Of this kind is the so-called head of Cornus florida, and of the herbaceous C. Canadensis (Fig. 294), which shows the

1 The dichotomous or two-branched cyme is the commonest, but is sometimes marked by suppression of internodes; as, for example, where the branches are apparently in fours, in an umbelliform way; but these are two sets of two, with the internode between the pairs extremely short; or where, as in Elder, the branches or rays are five, in this case consisting of the same two pairs and a central one, which is a many-flowered continuation of the primary axis. Or 5-rayed cymes, \&c., may be founded upon alternate leaves with shortened internodes, the rays or peduncles axillary to them thus brought into an apparent whorl.

Bravais distinguished cymes as multiparous, with three or more lateral axes; biparous, with two; and uniparous, with only one (cyme multipare, bipare, unipare). To these Eichler gives the substantive names, severally, of Pleiochasium, Dichasium, and Monochasium. Only the latter needs illustration; the others being as it were compounds of this.

FIG. 293. Compound cyme of Hydrangea; with some neutral and enlarged marginal flowers. 
composition best, on close examination. A condensed but less capitate cyme, or cluster of cymes, was called by Rœper and DeCandolle a FASCICLE; and this terminology has been much adopted. It is properly enough said to be a fascicle, which, as used by Linnæus and others, means a bundle, or close collection of parts, whether leaves, peduncles, or flowers ; but a fascicle is not necessarily a cyme (274), nor is there need of a special substantive name for a compact cyme, which may either be simply so called or it may pass into the glomerule.

281. Botryoidal forms of Cymose Type, or False Racemes, \&c. The regular cyme seldom continues with all its ramifications. In Fig. 292, after the second forking, one of the two lateral peduncles mostly fails to appear, and in some

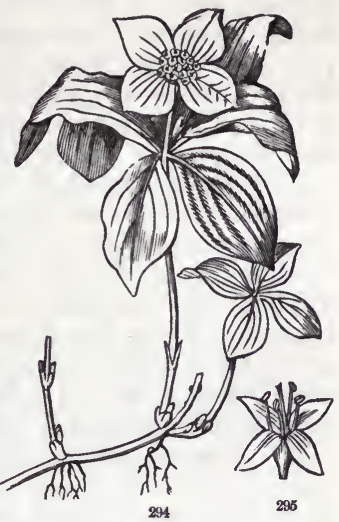
parts one of the bracts also; and ultimately the lateral peduncle present is bractless, like the central, therefore equally incapable of further ramification, being reduced to a pedicel of a single internode. This suppression sometimes begins at the first forking or at the very base; and, when followed throughout, it reduces a biparous or dichotomous cyme to one half, and, converts this half (when the axis straightens) into the semblance of a raceme if the flowers are pedicelled, or of a spike when they are sessile.

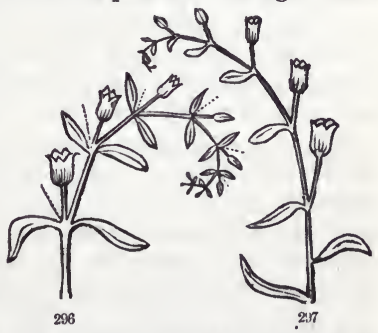

Fig. 296 is a diagram of such an inflorescence as that of Fig. 292, with one lateral branch uniformly suppressed at each division, the wanting members indicated by short dotted lines. Cases exemplifying this occur in portions of the inflorescence of some of our

FIG. 294. Plant of Cornus Canadensis: flowering stem bearing a cluster of leaves above, then continued into a peduncle, and terminated by a glomerule of very smal: flowers; this subtended by a colored and corolla-like involucre of four bracts. 295. One of the flowers taken from the glomerule, enlarged.

FIG. 296. Uniparous cyme or sympodial false raceme, with opposite leaves or bracts.

FIG. 297. Form of the same, with alternate leaves or bracts. 
smaller Hypericums, and notably in H. Sarothra, in which the leaves are all reduced to bracts. It is not always easy to show why this is not a true raceme. But the other bract of the pair, upon that supposition, is unaccountably empty : the successive angular divergence of each joint of the axis of inflorescence in the younger part, which commonly runs into a coil, finds explanation in the view that each portion is the lateral branch from the axil of the subtending leaf : and occasionally the other axil produces a similar one, thus revealing the cymose character. When the bract from the axil of which the missing branch should come disappears also, as sometimes it does, and uniformly on the same side, a state of things like that of the upper part of Fig. 297 occurs. The same figure may serve for the arrangement corresponding to that of Fig. 296, only with alternate leaves. But then, close as the imitation of a raceme here is, the position of each flower in respect to the bract supplies a criterion. While in a true raceme the flower stands in the axil of its bract, here it stands on the opposite side of the axis, or at least is quite away from the axil.

282. Sympodial forms. The explanation is that the axis of inflorescence in such cases, continuous as it appears to be, is not a simple one, is not a monopode, but a sympode $(110,116$, notes), $i . e$. consists of a series of seemingly superposed internodes which belong to successive generations of axes : each axis bears a pair of leaves (Fig. 296) or a single leaf (Fig. 297), is continued beyond into a peduncle (or pedicel in these instances), and is terminated by a flower. From the axil promptly springs a new axis or branch, vigorous enough soon to throw the adjacent pedicel and flower to one side: this bears its leaf or pair of leaves, and is terminated like its predecessor with a flower; and so on indefinitely. The fact that the alternate leaves or bracts are thrown more or less strictly to one side and the flowers to the other, in Fig. 297, shows that these leaves do not belong to one and the same axis; for alternate leaves are never one-ranked or disposed preponderatingly along one side of an axis, as in this diagram, and as is seen in the inflorescence of a Houseleek, \&c.

283. A further difficulty in the morphology of clusters of this class comes from the early abortion or complete suppression of bracts. This is not unknown in botryose inflorescence, occurring in the racemes of almost all Cruciferæ: it is very common in the cymose of all varieties, and especially in the uniparous ones in question, which characterize or abound in Borraginaceæ, Hydrophyllaceæ, and other natural orders. In some genera or species, the bracts are present, or at least the lower ones; in others, 
absent; in some, either occasionally present or wanting in the same species or individual. It is only by analogy, therefore, and by a comparison of allied plants, that the nature of some of these flower-clusters can be made out. With the botanists of a preceding generation, these one-sided clusters were all described as racemes or spikes. Botanists still find it convenient to continue the use of these names for them in botanical descriptions, adding, however, as occasion requires, the qualification that they are false racemes or spikes, or cymose racemes, and the like; or else, by reversing the phrase, with stricter correctness they call them racemiform or spiciform cymes, \&c.

284. Commonly these false racemes or spikes (or botryoidal cymes, if we so name them) are circinate or inrolled from the apex when young, in the manner of a crosier, straightening as they come into blossom or fruiting. Likening them to a scorpion when coiled, the earlier botanists designated this as scorpioid. As the coil is a helix, it has also been named helicoid. ${ }^{1}$ The flowers are then thrown, more or less strictly, to the outer side of the coiled rhachis, where there is room for them; and so these palse racemes or spikes are secund or unilateral. The particular anthotaxy and phyllotaxy of the various sympodial and botryoidal forms of cymose inflorescence become rather difficult; and the sorts which have been elaborately classified into species (and have no little morphological interest) are connected by such transitions, and are based on such nice or sometimes theoretical particulars, that the terminology based on them is seldom conveniently applicable to descriptive botany, at least as to substantive names.

285. One of the latest and simplest classifications of cymes is that of Eichler in his Bluthendiagramme. ${ }^{2}$

1 Scorpioid and Helicoid have been carefully distinguished by later morphologists, on account of some difference in the mode of evolution and arrangement of the flowers along one side of the rhachis, by which they become two-ranked in scorpioid, one-ranked in helicoid. But practically the two kinds of clusters are not always readily discriminated; and in general terminology a single name, with subordinate qualifying terms, is suffcient. Scorpioid is the older and commoner one, therefore the most proper to be used in the generic sense.

2 CYMose TYPE (classified without reference to bracts, which are so often wanting); divided into

a. Lateral axes three or more: Pleiochasium, the multiparous cyme of Bravais.

B. Lateral axes two: Dichasium, the biparous cyme of Bravais.

$\boldsymbol{\gamma}$. Lateral axis one: Monochasium, the uniparous cyme of Bravais.

The latter, or the corresponding divisions of the preceding sorts, may be divided as follows: 
286. Sundry complications and obscurities are occasionally encountered in anthotaxy or phyllotaxy, which cannot here be

* Lateral axes transverse to the relatively main axis.

1. Lateral axes in successive generations always falling on the same side of the relatively main axis: Schradbec [screwlike] or Bostryx [ringlet or curl], the uniparous helicoid cyme of Bravais.

2. Lateral axes falling alternately on opposite sides of the relatively main axis: Wickel or Cincinnus [a curl], the uniparous scorpioid cyme of Bravais.

* Lateral axes medial [in the same plane] relative to the main axis.

3. Lateral axes in successive generations always on the back side of the axis from which it springs: FïcheL, RHIPIDIUM [fan].

4. Lateral axes in successive generations always on the upper side of the axis from which it springs: Sichel, Drepanium [sickle].

The subjoined simple diagrams from Eichler (Fig. 298-303) illustrate these forms. The ramification is given without the bracts, which theoretically or actually subtend the axes of each generation. The student may add them, and so more readily apprehend the characters.

Eichler recognizes the forms with median (antero-posterior) position of

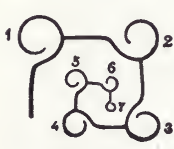

299

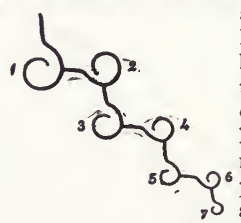

298 from the axil of which said

branch or peduncle springs, $i . e$. is posterior and next the parent axis, as shown in the diagram, Fig. 304, 305.

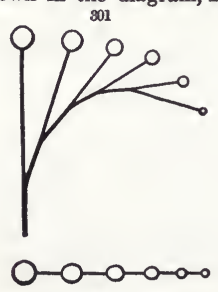

803

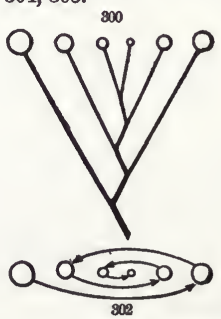

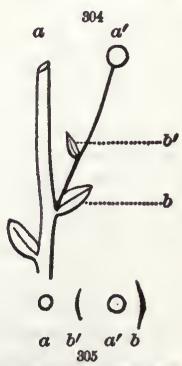

FIG. 298. Diagram of the Cincinnus. 299. Diagram of the Bostryx. The floweraxes numbered in succession.

FIG. 300. Diagram of the Rhipidium. 302. Ground plan, indicating the order of evolution of the flowers.

FIG. 301. Dlagram of the Drepanium. 303. Ground plan, the flowers evolved in snccession, from left to right.

FIG. 304. Diagram showing the position of bractlet or first leaf on a branch in Monocotyledons: $a$ is the primary, $a^{\prime}$ the secondary axis; $b$ is bract, and $b^{\prime}$ bractlet. 
explained, except through full details : such as flowers standing by the side of a leaf, or a small leaf by the side of a larger one,

The transverse or oblique position of secondary axes or peduncles, as in Eichler's first two species, brings the flowers of the false raceme or spike out of line of the sympodial axis and bracts, neither in the axils, as in true racemes, nor opposite them, as in the Rhipidium and Drepanium, but on one side of this plane or the other. This is most common in Dicotyledons (in Drosera, Sedum, Sempervivum, and Hyoscyamus, in Borraginaceæ and Hydrophyllaceæ, \&c.), and is not rare in Monocotyledons, especially with tristichous phyllotaxy, as in Tradescantia. In the Bostryx, Fig. 299, the bractlet is anterior or falls on the same side as the bract, or, in other terms, the successive bracts are all on one side, the inner side, of the helix; and the Drepanium (Fig. 301) is like it: this is the helicoid cyme of Bravais, \&c., and its flowers are commonly one-ranked. In the Cincinnus or true scorpioid cyme (Fig. 298), and equally in the Rhipidium (Fig. 300), the bracts fall alternately on opposite or different sides of the sympodial rhachis, because the single bract $\left(b^{\prime}\right)$ of each successive secondary axis $\left(a^{\prime}\right)$ stands next the axis $(a)$ and over against the bract $(b)$ of the generation preceding. The flowers in these generally fall into two parallel ranks (conspicuously so when crowded) on the upper side of the rhachis, on which, in the cincinnus or true scorpioid cluster, they are usually sessile or nearly so (or spicate), as is well seen in Heliotropes, and in very many Borraginaceous and Hydrophyllaceous species, in Houseleek, Tradescantia erecta, \&c. This comes through antidromy, that is, the phyllotaxy of each successive axis of the sympode (with its one bract, or by suppression without it) changes direction, from right to left and from left to right alternately. Fig. 301 is a plan of this two-ranked unilateral arrangement. When not too crowded, both Cincinnus and Rhipidium are apt to have a zigzag rhachis.

These two last-mentioned kinds are so generally alike in character, as are equally the Bostry $x$ and the Drepanium, that the four species may as well be reduced to two. As these severally include the scorpioid and the helicoid uniparous cymes of modern anthotaxy, these terms may be retained to designate them. Or, if other terms in use be preferred to scorpioid and helicoid, the form with two-ranked flowers may be denominated Cincinnal, that with singleranked Bostrychoidal. But in neither type is the rhachis always coiled up, although commonly more or less so in the undeveloped state.

While these forms generally imitate racemes or spikes, it will be noted that Fig. 300 specially imitates a corymb in form and in seeming acropetal or centripetal evolution. And when, as in this figure, the bracts are all absent, no obvious external difference remains.

FIG. 305a. Ground plan (from Eichler's Blüthendiagramme, 1. 38) of the scorpioid inflorescence of Tradescantia erecta, between bract $(B)$ below and axis $(a)$ above: I., II., III., \&c., the successive fiowers: $v^{1}$ is the bractlet of the first and bract of the second flower, and so the others in succession up to $v^{5}$ and a small undeveloped one beyond. The figure 1 affixed to each flower indicates the firat floral leaf. 
or a pedicel or peduncle above and out of connection with the leaf which should subtend and accompany it. ${ }^{1}$

287. Mixed Inflorescence is not uncommon. This name is given to clusters or ramifications in which the two types are conjoined. Being heteromorphous, they are almost necessarily compound, the two types belonging to different orders of ramification. But under it may be included cases of comparatively simple inflorescence, at least in the beginning, some of which nearly fuse the two types into one. In the Teasel (Dipsacus), an apparently simple head or short spike comes first into flower at the middle, from which the flowering proceeds regularly to the base. Had it begun at the top, it would answer to Fig. 281, which, blossoming from above downward by simple uniflorous lateral axes along a monopodial primary axis, is a simple racemiform cyme, while it may also be called a reversed or determinate raceme. Something of this sort may be seen in certain species of Campanula, with virgate inflorescence, the terminal blossom earliest, the others following irregularly, or partly downward and partly upward. In C. rapunculoides, when rather depauperate and the inflorescence simple, the evolution is that of a true raceme, except that a flower at length terminates the axis and develops earlier than the upper half of the raceme. In Liatris spicata and its near relatives, the heads, on the virgate general axis, come into flower in an almost regular descending order, or are reversely spicate. If in Fig. 281 the lower pedicels were prolonged to the level of the upper, a simple corymbiform cyme would be seen, with simple centrifugal evolution, that is, regularly from the centre to the margin; this is the counterpart of the rhipidium or fan-shaped cyme, of Fig. 300, in which the evolution of the blossoms is as regularly centripetal. The explanation of the paradox is not far to seek.

1 The position of a pedicel at the side of a bract in false racemes is explained in the foregoing note. It may occur in true racemose inflorescence by the reduction of sessile secondary racemes down to an umbel of two flowers, transverse to the bract (as in many species of Desmodium), and thus seemingly lateral to it, or to a single flower on the right or left of it. The coalescence of a pedicel to the axis for a considerable height above the subtending bract in a simple inflorescence, or above the last leaf in a sympodial one (concaulescence of Schimper), is common. So likewise bracts or leaves may be for a good distance adnate to sympodial shoots, whether peduncles or leafy flowerless branches. This (named recaulescence by Schimper) is of most frequent occurrence in Solanaceæ (in Datura, Atropa, most species of Solanum, \&c.), and is the explanation of their so-called geminate leaves, where a large leaf (really belonging lower down) has a small leaf by the side of it. See Wydler in Bot. Zeit. ii. 689, \&c., Sendtner in Fl. Bras. x. 183, and Eichler, Blüthend. i. 199. 
288. Compound mixed inflorescence is very various and common ; but the combinations have hardly called for special terms, being usually disposed of by a separate mention of the generai and of the partial anthotaxy, or that of the main axis of inflorescence and that of its ensuing ramification. ${ }^{1}$ In Compositæ, for instance, the flowers are always in true heads, of centripetal evolution. The heads terminate main stems as well as lateral branches, so that they are centrifugally or cymosely disposed. The reverse occurs in all Labiatæ and most Scrophulariaceæ, where the flowers, when clustered, are in cymes, but these cymes are from axils, and develop in centripetal order. It is this arrangement which mainly characterizes the

Thyrsus. A compound inflorescence of more or less elongated shape, with the primary ramification centripetal or botryose, the secondary or the ultimate centrifugal or cymose. To the definition is generally added, that the middle primary branches are longer than the upper and lower, rendering the whole cluster narrower at top and bottom, and sometimes that it is compact: but these particulars belong only to typical examples, such as the inflorescence of Lilac and Horsechestnut. In the former, the thyrsus is usually compound. A loose thyrsus is a

Mixed Panicle. It is seldom that a repeatedly branching inflorescence of the paniculate mode is of one type in all its successive ramifications. Either the primarily centripetal will become centrifugal in the ultimate divisions, or the primarily centrifugal will by suppression soon run into false botryose forms, into apparent racemose or spicate subdivisions. So that the name Panicle in terminology is generally applied to all such mixed compound inflorescence, as well as to the homogeneously botryose. (278.)

Verticillaster is a name given to a pair of opposite and sessile or somewhat sessile cymes of a thyrsus or thyrsiform inflorescence, which, when full, seem to make a kind of verticil or whorl around the stem, as in very many Labiatæ. The name was originally given to each one of the pair of cymes; but it is better and more commonly used to denote the whole glomerule or false whorl produced by the seeming confluence of the two clusters into one which surrounds the stem.

1 Guillaud (in his memoir on Inflorescence, published in Bull. Soc. Bot. France, iv.) proposes to designate as Cymo-Botryes the mixed inflorescence composed of cymes developed in botryose order, i.e. the thyrsus; and Botry-Cymes, the reverse case of racemes, \&c., cymosely aggregated. For the former, the old name thyrsus serves appropriately and well. 
289. The Relations of Bract, Bractlet, and Fiower should here be noticed, although the subject in part belongs rather to the section on Floral Symmetry. (315.)

290. Anterior and Posterior, otherwise called Inferior and Superior, and therefore Lower and $U_{p p e r}{ }^{1}$ are primary relations of position of an axillary flower with respect to subtending bract and the axis to which the bract pertains. The flower is placed between the two. The portion of the flower which faces the subtending bract is the anterior, likewise called inferior or lower. The opposite portion which faces the axis of ${ }^{\prime}(\underbrace{(((30))}_{b}$ inflorescence is the posterior, or superior, or upper. The right and left sides are lateral. (Fig. 304, 306.) These relations do not appear in a solitary flower terminating a simple stem; but when such an axis produces axillary branches with a terminal flower, the relation of this flower to the preceding axis and its leaf is manifest, just as in indeterminate inflorescence.

291. Median and Transverse. The position of parts which lie in antero-posterior line, or between bract and axis, is median. Thus, in Fig. 304 and 305, the parts are all in the median plane: in Fig. 306, the bractlets, $b^{\prime}, b^{\prime}$, are lateral or collateral, or (being in the opposite plane) transverse.

292. Position of Bractlets. The rule has already been laid down (285) that the first leaf of an alternate-leaved secondary axis is in Monoctyledons usually median and posterior, that is, farthest away from the subtending leaf (as in Fig. 304, 305); in Dicotyledons, lateral or transverse. When these secondary axes are one-flowered peduncles or pedicels, the leaf or leaves (if any) they bear are bractlets. ${ }^{2}$ Commonly there is only this

1 Not (with propriety, although the terms have been so used) exterior or outer for the anterior, and interior or inner for the posterior position. These terms should be reserved for the relative position on the axis of successive circles or parts of circles, spirals, \&c. Covering or overlapping parts are exterior or outer in respect to those overlapped.

2 Latin Bracteolae : not that they are small bracts, but bracts of an ultimate axis. In axillary inflorescence, the distinction between bractlet and bract is obvious: in case of a solitary terminal flower, there is no ground of difference : in terminal or cymose inflorescence, the difference is arbitrary; but we may restrict the term bractlet to the last bract or pair.

German botanists mostly distinguish between bracts, as a leaf subtending a flower or cluster, and bractlets, by terming the former a Deckblatt, and the

FIG. 306. Diagram (cross section) of papilionaceous flower and its relation to axis $(a)$, bract $(b)$, and bractlets $\left(b^{\prime}, b^{\prime}\right)$. 
posterior one to a simple axis in Monocotyledons, and two transverse ones in Dicotyledons, $i . e$. one to the right and the other to the left of the subtending bract, Fig. 306, $b^{\prime} b^{\prime}$. When the latter form a pair, they are perhaps always truly transverse; when alternate, they stand more or less on the opposite sides and transverse. When more than one in Monocotyledons, they may become either median or transverse, or even intermediate. The relation of bractlets or bract, that is, of the last leaves of inflorescence, to the first of the blossom, might be considered either under Phyllotaxy or under Floral Symmetry. In general, it may be noted that successive members stand over the widest intervals $;^{1}$ in other words, that the first leaf of the flower is as far away as may be from the highest bractlet. For instance, when there is a single and posterior bractlet, as is common in Monocotyledons, the first leaf of the flower is anterior, the next two right and left at $120^{\circ}$. When there is a single and lateral bractlet and five leaves in the first circle of the flower (which occurs only in Dicotyledons), the first leaf of this circle is either exactly on the opposite side from the bract, or at a divergence of two fifths, the latter falling into the continuous spiral. When with a pair of bractlets, right and left, the first flower-leaf is at $\frac{1}{3}$ divergence from one (the uppermost) of them when the circle is of three, or at $\frac{2}{5}$ when of five members, or near it; but with many exceptions. ${ }^{2}$

A tabular view of the kinds of inflorescence and their terminology, serving as a key, may aid the student. ${ }^{8}$

latter, being the leaves which the new axis first bears, Vorblätter, which is also the name they apply to primordial leaves in germination.

1 In accordance with Hofmeister's law ; but (as Eichler remarks) not to be explained on his mechanical principle of production in this place because of the greater room: for the position of the first inember of an axillary flower is mostly the same as regards the subtending bract when the bractlets are wanting.

2 When bractlets are wanting, the leaves of the first floral circle if two are right and left; if three, two lateral-posterior and one anterior; when five, the odd one commonly in the median line, either anterior or posterior.

8 INFLORESCENCE is either PURE, all of one type, or MIXED, of the two types combined. The Types are:

I. Main axis not arrested and terminated by a flower. Indeterminate, Indefinite, Acropetal or Ascending, Centripetal, or Borryose.

II. Main and lateral axes arrested and terminated by a flower. Determinate, Definite, Descending, Centrifugal, or Cyмose. 


\section{BOTRYOSE TYPE.}

1. Simple, with lateral axes unbranched and terminated by a single flower, and Flowers on pedicels,

Of somewhat equal length on a comparatively elongated axis, RACEME. The lower ones longer than the upper, and main axis short, . CoRYMB. Of nearly equal length on an undeveloped main axis, . UMBEL.

Flowers sessile on a very short main axis, . . . . . Head.

Flowers sessile on a comparatively elongated main axis, . . . SPIKE.

A fleshy spike or head is a . . . . . . . . . Spadix.

A scaly-bracted spike is an . . . . . . . . . AMrNT or

Catkin.

2. Compound, with lateral axes branched once or more, bearing clusters instead of single flowers.

Irregularly racemosely or corymbosely compound, .. . PANicle.

Homogeneously and regularly compound, as

Racemes in a raceme, . . . . . . . . Compound Raceme.

Corymbs corymbose, . . . . . . . . . Compound Cokyмв.

Umbels in an umbel, . . . . . . . . CoMpound UMBez.

Spikes spicate, . . . . . . . . . . Compound SPIKR.

Homogeneously compound, the secondary ramification

unlike the primary, as Heads racemose, Umbels spiked,

Spikes panicled, \&c.

\section{CYMOSE TYPE.}

1. Simple, with terminal axis of each generation one-flowered.

Monopodial, the axis of each generation evidently resolved into branches, . . . . . . . . True Crme.

These more than two, . . . . Pleiochasium or Multiparous Crme.

These only two, . . Dichasium, Dichotomous or Biparous Crme.

Sympodial, the apparently simple axis continued by a succession of new axes standing end to end, Monochasium, False Raceme or Spike, Botryose or UnIPARous CxMr.

Flowers one-ranked on one side of rhachis, Helicoid Uniparous CYME. Flowers two-ranked on one side of rhachis, Scorpioid Uniparous Crmk.

2. Compound, with terminal axes for one or more earlier generations bearing a cyme instead of a single flower, . . . . . Various sorts of Compound CrMe.

\section{MIXED INFLORESCENCE.}

1. Anomalous simple, with unbranched one-flowered lateral axes (287), such as . . Partly Reversed Spikes or Racemks.

2. Compound, of various combinations, of which there are names for the subjoined:-

Primary inflorescence botryose, with axis elongating; secondary cymose, .. . . . . . . . . Thyrsug.

Pair of such opposite cymes seemingly confluent round the main axis, . . . . . . . . . Verticillaster.

Panicle with some of the ramifications cymose, . . Mixed Panicle. 


\section{CHAPTER VI.}

\section{THE FLOWER.}

\section{Section I. Its Nature, Parts, and Metamorphy.}

293. FLOwER-BUDs are homologous with (morphologically answering to) leaf-buds, and they occupy the same positions. (266.) A Flower is a simple axis or a terminal portion of one, in a phænogamous plant, with its leaves developed in special forms, and subservient to sexual reproduction instead of vegetation.

294. In passing from vegetation to reproduction, it is not always easy to determine exactly where the flower begins. The same axis which bears a flower or floral organs at summit bears vegetative leaves or foliage below. Or when it does not, as when an axillary flower-stalk or pedicel is bractless, the change to actual organs of reproduction is seldom abrupt. Usually there are floral envelopes, within and under the protection of which in the bud the essential organs of the flower are formed. Some or all of these protecting parts, in very many flowers, are either obvious leaves or sufficiently foliaceous to suggest their leafy nature; and even when the texture is delicate, and other colors take the place of the sober green of vegetation, they are still popularly said to be the leaves of the blossom. These protecting and often showy parts, though not themselves directly subservient to reproduction, have always been accounted as parts of the flower. ${ }^{1}$ Between the lowest or outermost of these and the bractlets and bracts there are various and sometimes complete gradations. The axis itself occasionally undergoes changes in such a way as to render the determination of the actual beginning of the flower somewhat arbitrary. Moreover, the flower itself is extremely various in different plants, in some consisting of a great number of pieces, in others of few or only one; in some the constituent pieces are separate, in others combined. The flower is best understood, therefore, by taking some particular specimen or class of flowers as a representative

1 Indeed, the colored leaves, or envelopes in whatever form, essentially were the flower in most of the ante-Linnæan definitions (that of Ludwig excepted), as they are still mainly so in popular apprehension. 
or pattern, and especially some one which is both complete and morphologically simple.

295. Such a flower consists of two kinds of organs, viz. the Protecting Organs, leaves of the blossom, or floral envelopes, which, when of two sets, are CALYx and Conolla; and the Essential Reproductive Organs, which co-operate in the production of seed, the Stamens and Pistils.

296. Floral Envelopes, Perianth, or Perigone, the floral leaves or coverings. The former is a proper English designation of these parts, taken collectively. But in descriptive botany, where a single word is preferable, sometimes the name perianth (Lat. perianthium), sometimes that of perigone (or perigonium), is used. Perianthium, ${ }^{1}$ a Linnæan term, has been objected to, because it etymologically denotes something around the flower; but it seems not inappropriate for the envelopes which surround
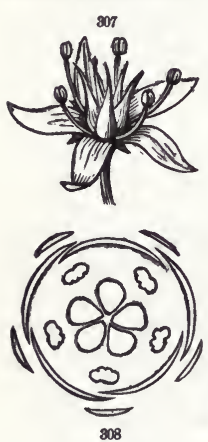
the essential part of the flower. Perigonium, a later term, has the advantage of meaning something around the reproductive organs, which is precisely what it is. Neither name is much used, except where the perianth or perigone is simple or in one set (when it is almost always calyx), or where it is of two

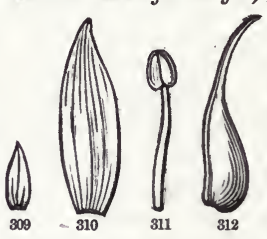
circles having the general appearance of one and needing descriptive treatment as such, as in the petaloideous Monocotyledons. It is also used where the morphology is ambiguous. Generally, the floral envelopes are treated distinctively as calyx and corolla, one or the other of which (mostly the corolla) may be wanting.

297. The Calyx is the outer set of floral envelopes. That is its only definition. Commonly it is more herbaceous or foliaceous than the corolla, and more persistent, yet sometimes, as in the Poppy family, it is the more deciduous of the two. Not rarely it

1 Linnæus (and about the same time Ludwig) used it in the sense of a proper calyx, yet with some vagueness. Mirbel and Brown established it in the sense of the collective floral covering. DeCandolle revived Ehrhart's

FIG. 307. The complete flower of a Crassula. 308. Diagram of its cross-section in the bud, showing the relative position of its parts. The five pieces of the exterior circle are sections of the sepals; the next, of the petals; the third, of the stamens through their anthers; the innermost, of the five pistils.

FIG. 309. A sepal; 310, a petal; 311, a stamen; and 312, a pistil from the flower represented in Fig. 307. 
is as highly colored. A name being wanted for the individual leaves which make up the calyx, analogous to that for corollaleaves, DeCandolle adopted Necker's coinage of the word sepal. Calyx-leaves are SEPals.

298. The Corolla is the inner set of floral envelopes, usually (but not always) of delicate texture and other than green color, forming therefore the most showy part of the blossom. Its several leaves are the Petals. ${ }^{1}$

299. The floral envelopes are for the protection of the organs within, in the bud or sometimes afterward. Also, some of them, by their bright colors, their fragrance, and their saccharine or other secretions, serve for allurement of insects to the blossom, to mutual advantage. (504.) This furnishes a reason for neutral flowers, those devoid of essential organs, which sometimes occur along with less conspicuous perfect ones. "The leaves of the flower" are therefore indirectly subservient to reproduction.

300 . The essential organs, being commonly plural in number, sometimes need a collective name. Wherefore, the aggregate stamens of a flower have been called the ANDrecium; the pistils, the GrNcerum. ${ }^{2}$

301. The Stamens ${ }^{8}$ are the male or fertilizing organs of a flower. A complete stamen (Fig. 311, 313) consists of FILAMENT $(f)$, the stalk or support, and Anther (a), a double sac or body of two cells,

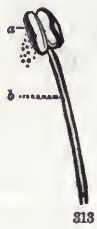
side by side, filled with a powdery substance, PoLlen, which is at length discharged, usually through a slit or cleft of each cell.

well-formed name of perigonium, and in the sense here given. But later (in the Organographie) he proposed to restrict it to cases in which the part is of ambiguous nature, as in Monocotyledons. The earlier definition is no doubt the proper one; but the occasions for using the term in descriptive botany are mainly where the nature may seem to be ambiguous or confused, or where, from the union or close similarity of outer and inner circles, it is most convenient to treat the parts as forming one organ.

1 Fabius Columna, at the close of the sixteenth century, appears to have introduced this term, or, as Tournefort declares, "primus omnium quod sciam Petali vocem proprie usurpavit, ut folia florum a foliis proprie dictis distingueret."

2 The male household and the female household respectively, terms introduced by Rœper (Linnæa, i. 437), in the form of andrœceum and gynoceum; but the diphthong in the latter should also be $\propto$. The orthography androcium and gynoecium (early adopted by Bentham, in Labiatarum Gen. et Spec.) is conformable to the Linnæan Monœcia, Diøcia, \&c.

8 The name (from the Greek and Latin name of the warp of the ancient upright loom, and thence used in the sense of threads) was applied, down to Tournefort and later, to the fllaments; and the anthers were termed

FIG. 313. Stamen, composed of $f$, fllament, and $a$, anther, with cells opening laterally and discharging pollen. 
302. The Pistils, one or more to the flower, are the female or seed-bearing organs. ${ }^{1}$ A complete pistil is distinguished into

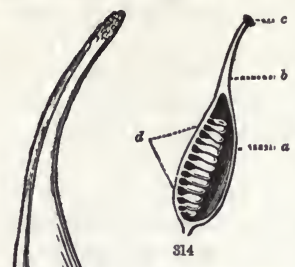
three parts: the Ovary (Lat. Ovarium, Fig. 314, $a$, shown in vertical section, and Fig. 315, by Linnæus named Germen), the hollow portion at the base which contains the Ovules, or bodies destined to become seeds ; the STrue (b), or columnar prolongation of the apex of the ovary ; and the STigma (c), a portion of the surface of the style denuded of epidermis, sometimes a mere point or a small knob at the apex of the style, but often forming a single or double line running down a part of its inner face, and assuming a great diversity of appearance in different plants. The ovary and the stigma are the essential parts. The style (as also the filament of a stamen) may be altogether wanting.

apices. It came in time to be used as now for the whole organ; but Ludwig (Inst. Reg. Veg.), in 1742, apparently first so defined it, and introduced the term Anther for the Apex of Ray, or Theca of Grew.

1 Following Linnæus, this term is here freely used in the plural, and for each actual separate member of the gynoecium, each organ which has an ovary, stigna, and commonly a style. Tournefort, who appears to have introduced the word, employed it in the sense of gynœeium. Many authors define it thus, and then practically eliminate from botany this, one of the oldest of its terms, and one by no means superfluous. The typical pistillum of Tournefort is that of the Crown Imperial (Inst. i. 69, \& tab. 1) and the name is from the likeness to a pestle in a mortar. As it soon became impossible to apply the same name to the pistil of a Fritillaria or of a Plum, the cluster of such organs in Caltha, and the capitate cluster and receptacle of such organs in a Ranunculus or Anemone, Linnæus, and Ludwig before him, took the idea of Tournefort's name, and used it accordingly.

"Pistillum est pars interior et media floris, quæ ex ovario et stylo componitur. . . Ovarium est pars pistilli inferior, quæ futuri fructus delineationem sistit. ... Stylus est pars pistilli ex ovario centro producta. ... Summitas styli vel ejus partium Stigma dicitur." Ludwig, Inst. Reg. Veg. $41-43,1742$. Without mentioning the plural, the pistil is thus deflned in a way which necessitates its use. Linnæus (in Phil. Bot.) first defines Stamen and Pistillum in the singular number, enumerating the three parts of the latter, and afterwards (p. 57) declares that "Pistilla differunt quoad

FIG. 314. Vertical section of a pistil, showing the interior of its ovary, $a$, to one side of which are attached numerous ovules, $d$ : above is the style, $b$, tipped by the stigma, $c$.

FIG. 315. A pistil of Crassula, like that of Fig. 312, but more magnifled, and cut across through the ovary, to show its cell, and the ovules it contains; also pulled open below at the suture. At the summit of the style is seen a somewhat papillose portion, destitute of epidermis, extending a little way down the inner face: this is the stigma. 
303. The Torus, or Receptacle of the flower, also named Thalamus, ${ }^{1}$ is the axis which bears all the other parts, that upon which they are all (mediately or immediately) inserted. These are all homologous with leaves. This is extremity of stem, or floral axis, out of which the organs described grow, in succession, like leaves on the stem; the calyx from the very base, the petals

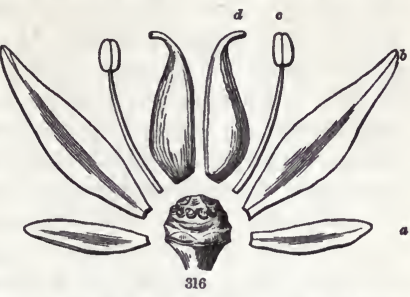
next within or above the calyx, then the stamens, finally the pistils, which, whether several or only one, terminate or seem to terminate the axis. (Fig. 316.)

304. Metamorphosis. If flower-buds are homologous with leaf-buds, and the parts of the flower therefore answer to leaves modified to special functions (293), then the kind of flower here employed in explaining and naming these parts is a proper pattern blossom. For the organs are all separate pieces, arranged on the receptacle as leaves are on the stem, the outermost manifestly leaf-like, the next equally so in shape, though not in color, the stamens indeed have no such outward resemblance, but the ripe pistils open down the inner angle and flatten out into a leaf-like form. The adopted theory supposes that stamens and pistils, as well as sepals and petals, are homolo-

numerum," etc., and so elsewhere, besides founding his orders on the number of pistils. Among even French authors, Mirbel (1815) writes, "Le nombre des pistils n'est pas le même dans toutes les espèces," \&c. MoquinTandon freely refers to pistils in the plural, and Aug. St. Hilaire takes wholly the view here adopted, distinguishing the solitary pistil into simple and compound. DeCandolle, in Théorie Elémentaire, third edition, writes, "Chaque carpel est un petit tout, un pistil entier, composé d'un ovaire, d'un style, et d'un stigmate." Of English authors, no other need be cited than Robert Brown. The terms in question, then, are :-

Gynocium, the female system of a flower, taken as a whole.

Pistil, each separate member of the gynœcium; this either simple or compound.

Ovary, the ovuliferous portion of a pistil. Substituting a part for the whole, this term is often used when the whole pistil is meant.

Carpel, or Carpid, or Carpophyll, each pistil-leaf; whether distinct as in simple or apocarpous pistils, or in combination of two or more to form a compound or syncarpous pistil.

1 By Tournefort, and adopted by Ludwig. Receptaculum floris, Linnæus. Thorus, Salisbury. Torus (the proper form), DeCandolle.

FIG. 316. Parts of the flower of a Stonecrop, Sedum ternatum, two of each sart, and the receptacie, displayed: $a$, sepal; $b$, petal; $c$, stamen; $d$, pistil. 
gous with leaves; that the sepals are comparatively little, the petals more, and the reproductive organs much modified from the type, that is from the leaf of vegetation. This is simply what is meant by the proposition that all these organs are transformed or metamorphosed leaves. What would have been leaves, if the development had gone on as a vegetative branch, have in the blossom developed in other forms, adapted to other functions. Linnæus expressed this idea, along with other more speculative conceptions, dimly apprehended, by the phrase Vegetable Metamorphosis. Not long afterwards, this fecund idea of a common type, the leaf, of which the parts of the flower, \&c., were regarded as modifications, was more clearly and differently developed by a philosophical physiologist, Caspar Frederic Wolff. Thirty years later, it was again and wholly independently developed by Gœthe, in a long-neglected but now wellknown essay, on the Metamorphosis of Plants. Twenty-three years afterwards, similar ideas were again independently propounded by DeCandolle, from a different theoretical point of view ; and finally the investigation of phyllotaxy has completed the evidence of the morphological unity of foliaceous and floral organs. ${ }^{1}$

1 The contribution of Linnæus is on p. 301 of the Philosophia Botanica, 1751 ; and all that is pertinent is in the following propositions :-

Plumulam seminis sæpius terminat aut flos aut gemma.

Principium florum et foliorum idem est.

Principium gemmarum et foliorum idem est.

Gemma constat foliorum rudimentis.

Perianthium sit ex connatis foliorum rudimentis.

His dissertation, Prolepsis Plantarum, in Amœn. Acad. vi. (1760), added nothing but obscure speculations to the former comparatively clear statements.

Kaspar Friedrich Wolff's contribution is in his Theoria Generationis, mainly concerning animals, published in 1759 , and an enlarged and amended edition in 1774. He first clearly conceives the plant as formed of two elements, stem and leaf, but develops only the morphology of the latter, and under the hypothesis that leaves of vegetation become bud-scales or floral organs, as the case may be, through degenerescence or diminution of vegetative force, which is renewed in the bud or in the seed.

Johann Wolfgang Göthe's Versuch die Metamorphose der Pflanzen zu erklären was published in 1790 , in 86 pages. For the translations and reproductions, see Pritzel, Thesaurus. To the French translation by Soret, with German text accompanying (Stuttgart, 1831), and also to that of Ch. Martens (GEuv. Hist. Nat. de Gœthe, Paris, 1837), are joined the author's interesting notes and anecdotes of later periods, down to 1831 . The degenerescence by diminution of vegetative force with renewals by generation, propounded by Wolff, in Gothe's essay takes the form of successive expansion and contraction of organs.

A. P. DeCandolle's Théorie Elémentaire de Botanique appeared in 1813, 
305. It will be understood that metamorphosis, as applied to leaves and the like, is a figurative expression, adding nothing to our knowledge nor to clearness of expression, but rather liable to mislead. The substance of the doctrine is unity of type. Its proof and its value lie in the satisfactory explanation of the facts, all of which it co-ordinates readily into a consistent and simple system. As applied to the flower, two kinds of evidence may be adduced, one from the normal, the other from teratological conditions of blossoms. The principal evidence of the first class is that supplied by

306. Position and Transitions. As illustrated in the preceding chapter, the flower occupies the place of an ordinary bud or leaf-bud. Also the parts of the flower are arranged on the receptacle as leaves are arranged on the stem, $i$. e. they conform to phyllotaxy, as well in passing from leaves and bracts to the perianth, as in the position of the floral organs in respect to each other. This is partly shown in the preceding chapters, and is to be further illustrated. Sepals, petals, stamens, and pistils are either in whorls or in spirals, and have nothing in their arrangements as to position which is not paralleled in the foliage.

307. The evidence from transitions has to be gathered from a great variety of plants. Very commonly the change is abrupt from foliage to bracts, from bracts to calyx-leaves, from these to corolla-leaves, and from these to stamens. But instances abound in which every one of the intervals is bridged by transitions or

a second edition 1819; a third (revised by Alphonse DeCandolle), in 1844, is posthumous. The Organographie Végétale, in which the morphology of the earlier work is developed, appeared in 1827 . The leading idea is that of symmetry, of organs symmetrically disposed around an axis (the homology of foliar and floral organs not at first apprehended), but this symmetry disguised or deranged more or less by unions (solderings) of homogeneous or heterogeneous parts, by irregularities or inequalities of growth, by abortions, \&c.

The reason why the organs in question have a normal symmetrical disposition on the vegetative and floral axes was not reached by DeCandolle, nor was it perceived that the arrangement of leaves and of floral organs was identical. All this was the contribution of phyllotaxy, - a subject which was approached by Bonnet (an associate of DeCandolle's father), and first investigated by the late Karl Schimper and Alexander Braun, beginning about the year 1829 .

It is interesting to know that Wolff's work was wholly unknown to Gœthe in 1790, and that both Wolff's and Gœthe's were unknown to DeCandolle until after the publication of the second edition of the latter's Theorie Elémentaire, in 1819. When the Organographie appeared, the essay of Gothe had come to light; and contemporary contributions to floral morphology by Petit-Thouars, R. Brown, Dunal, and Roper, were adding their influence. 
intermediate forms. The gradual transition from ordinary foliage to bracts and bractlets is exceedingly common. In color

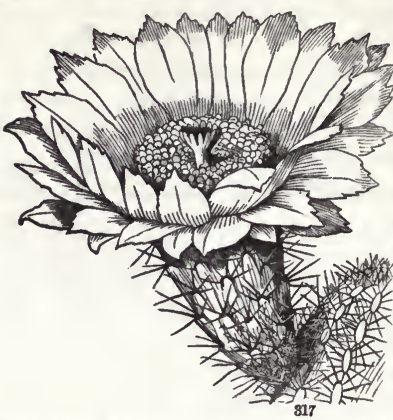
and texture it is not rare to meet with bracts which vie with, or indeed surpass, petals themselves in delicacy and brightness ; and in such cases they assume a principal office of flower-leaves, that of conspicuous show for attraction. Scarlet Sage, Painted-Cup (Castilleia), and the Poinsettia, with other Euphorbias of the conservatories, are examples of this. In the flowers of Barberry, it is by a nearly arbitrary selection that bractlets are distinguished from sepals; in Calycanthus, in many kinds of Cactus, and in Nelumbium,

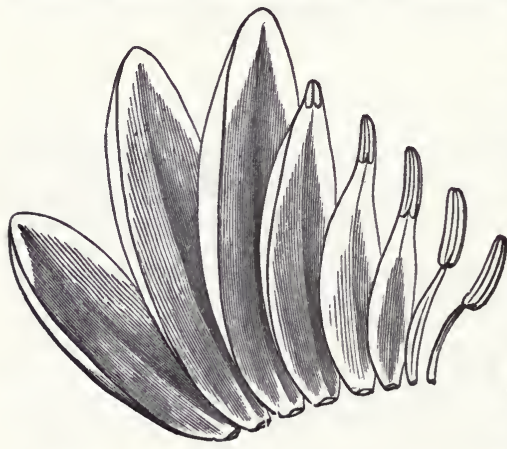

318 the same is true as to bractlets, sepals, and petals ; in Water-Lily (Nymphæa, Fig. 318), there is a gradual transition from the sepals through the petals to stamens; in Lilies and most lily-like flowers, sepals are as brightly colored as petals, and commonly more or less combined with them. When the perianth-leaves are of only one set, it is not at all by color or texture that this perianth can be assigned to calyx or to corolla. Normal transitions from a stamen to a pistil could not, in the nature of the case, be expected.

308. Teratological Transitions and Changes. Teratology is the study of monstrosities. These in the vegetable kingdom

FIG. 317. Cactus-flower (Mamillaria cæespitosa), with bractlets, sepals, and petals passing into each other.

FIG. 318. Series exhibiting transition from sepals to stamens in Nymphæa odorata. 
often elucidate the nature of organs. ${ }^{1}$ The commonest of these changes belong to what was termed by Gœthe retrograde metamorphosis ; that is, to reversion from a higher to a lower form, as of an organ proper to the summit or centre of the floral axis into one which belongs lower down. ${ }^{2}$ The most familiar of all such cases is that of the so-called double flower, better named in Latin flos plenus. In this, the essential organs, or a part of them, are changed into colored flower-leaves or petals. Most flowers are subject to this change under long cultivation (witness "double" roses, camellias, and buttercups), at least those with numerous stamens. It occasionally occurs in a state of nature. The stamens diminish as the supernumerary petals increase in number; and the various bodies that may be often observed, intermediate between perfect stamens (if any remain) and the outer row of petals, from imperfect petals, with a small lamina tapering into a slender stalk, to those which bear a small distorted lamina on one side and a half-formed anther on the other, - plainly reveal the nature of the transformation

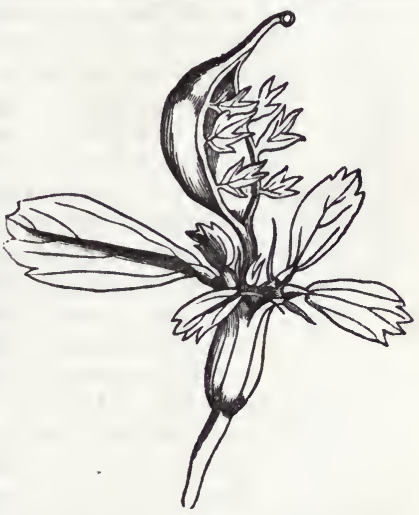

819 that has taken place. Carried a step farther, the pistils likewise disappear, to be replaced by a rosette of petals, as in fully double

1 The leading treatises are Moquin-Tandon's Tératologie Végétale, Paris, 1841, and Masters, Vegetable Teratology, London, published for the Ray Society, 1869. An earlier publication deserves particular mention, viz. the thesis De Antholysi Prodromus, by Dr. George Engelmann, Frankfort on the Main, 1832.

2 To these abnormal changes, the term metamorphosis is obviously more applicable; for here what evidently should be stamens, pistils, \&c., on the testimony of position and the whole economy of the blossom, actually appear in the form of some other organ : yet even here the change is only in the nisus formativus; the organ was not first formed as a stamen, and then transformed into a petal or leaf.

FIG. 319. A flower of the common White Clover reverting to a leafy branch; after Turpin. Calyx with tube little changed, but lobes bearing leaflets. Pistil stalked; the ovary open down the inner edge, and the margins of the pistil-leaf bearing leaves instead of ovules. 
buttercups. ${ }^{1}$ In these the green bue of the centre of the rosette indicates a tendency to retrograde a step farther into sepals, or into a cluster of green leaves. This takes place in certain blossoms of the Strawberry, the Rose, \&c. Such production of "green roses," and the like, has been appropriately called chlorosis, or by Masters chloranthy, from the change to green.

309. A monstrosity of the blossom of White Clover, long ago figured by Turpin (Fig. 319), is such a case of foliaceous rever-

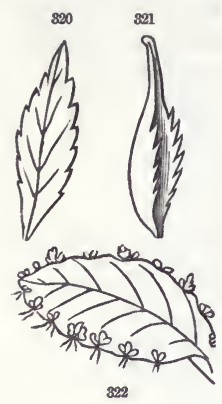
sion, in which even the ovules are implicated. The imperfect leaves which take the place of the latter may be compared with the leafy tufts which form along the margins of a leaf of Bryophyllum, by which the plant is often propagated. (Fig. 322.)

310 . The reversion of a simple pistil directly to a leaf is seen in the Double-flowering Cherry of cultivation (Fig. 320, 321), usually passing moreover, by prolification of the receptacle, into a leafy branch.

311. The reversion of pistils to stamens is rarer, but has been observed in a good number of instances, in Chives, in the Horseradish, in Gentians and Hyacinths, and in some Willows. In the latter, the opposite transformation, of stamens to carpels, is very common, and curious grades between the two are met with almost every spring. So also in the common Houseleek, and in perennial Larkspurs. Certain apple-trees are known, both in the United States and Europe, in which, while the petals are changed into the appearance of minute green sepals, the outer stamens are converted into carpels, these supernumerary and in the fruit superposed to the five normal carpels. ${ }^{2}$ In Poppies, many of the innermost stamens are occasionally transformed into as many small and stalked simple pistils, surrounding the base of the large compound one.

1 It must not be concluded that the supernumerary petals in all such cases are reverted stamens, or stamens and pistils. Some are instances of abnormal pleiotaxy, i.e. of the production of one or more additional ranks of petals (better deserving the name of double flower), with or without reversion of essential organs to flower-leaves.

2 These trees are popularly supposed to bear fruit without blossoming; the reverted green petals being so inconspicuous that the flower is unnoticed.

FIG. 320, 321. Green leaves from the centre of a blossom of Double-flowering Cherry, one still showing, by its partial involution and its style-like apex, that it is a reverted carpel, the other a small but well-formed leaf.

FIG. 322. Leaf or leaflet of Bryophyllum, developing plantlets along the margins. 
312. Another line of teratological evidence is furnished by prolification. The parts of the flower are, by the doctrine, homologous with leaves, and no leaf ever terminates an axis.

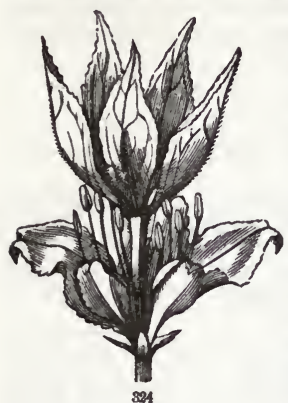

Normally, in fact, the axis is never prolonged beyond the flower, but abnormally it may be. It may resume vegetative growth as a terminal growing bud, either from between the pistils after the whole flower is formed, or at an earlier period, usurping the central part of the flower. Thus, when a rose is borne on a peduncle rising from the centre of a rose, which is not very unusual, or a leafy stem from the top of a pear (Fig. 323), the flower was probably complete before the monstrous growth set in. In Fig. 324, the reversion to foliaceous growth took effect after the stamens but before the pistils

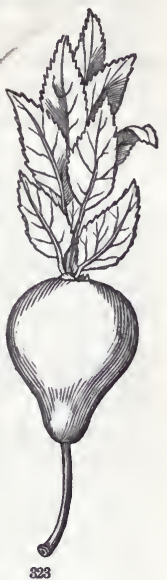
were formed. In rose-buds out of roses, the terminal proliferous shoot takes at once the form of a peduncle; in the shoot from the pear, that of a leafy stem.

313. Again, axillary buds are normally formed in the axil of leaves. No such branching is known in a normal flower. But in rare monstrosities a bud (mostly a flower-bud) makes its appearance in the axil of a petal or of a stamen; and it may be clearly inferred that the organ (not itself axillary) from the axil of which a bud develops is a leaf or its homologue. Fig. 325 exhibits a clear case of the kind, a flower in the axil

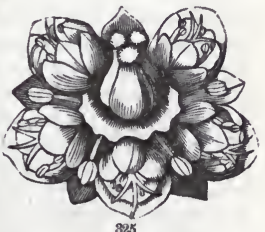
of each petal of Celastrus scandens. Flowers, or pedunculate clusters of flowers, from the axil of petals of garden Pinks are sometimes seen. A long-pedunculate flower from the axil of a

FIG. 323. A monstrous pear, prolonged into a leafy branch ; from Bonnet.

FIG. 324. Retrograde metamorphosis of a flower of the Fraxinella of the gardens, from Lindley's Theory of Horticulture; an internode elongated just above the stamens, and bearing a whorl of green leaves.

FIG. 325. A flower of False Bittersweet (Celastrus scandens) producing other flowers in the axils of the petals; from Turpin. 
stamen of a species of Water-Lily (Nymphæa Lotus) is figured and described by Dr. Masters. ${ }^{1}$

314. In the application of morphological ideas to the elucidation of the flower, nothing should be assumed in regard to it which has not its proper counterpart and exemplar in the leaves and axis of vegetation.

\section{Section II. Floral Srmmetry.}

315. The parts of a flower are symmetrically arranged around its axis. ${ }^{2}$ Even when this symmetry is incomplete or imperfect, it is still almost always discernible; and the particular numerical plan of the blossom may be observed or ascertained in some of the organs.

316. Adopting the doctrine that the parts of the flower are homologous with leaves, the symmetry is a consequence of the phyllotaxy. It is symmetry around an axis, not the bilateral symmetry which prevails in the animal kingdom. For parts of a flower disposed in a continuous spiral (which mostly occurs when they are numerous), the arrangement is that of some order of this kind of phyllotaxy, which distributes the parts equably into superposed ranks. (237.) The much commoner case of

1 The fullest enumeration and discussion of the very various kinds of abnormal structures and deviations in plants is to be found in the Teratology of Dr. Masters, above referred to. Many technical terms are here brought into use, which need not be here mentioned, except the following, which relate directly to floral metamorphosis.

Phyllody (called Phyllomorphy by Morren, Frondescence by Engelmann) is the condition wherein true leaves are substituted for some other organs; i.e., where other organs are metamorphosed into green leaves. There is phyllody of pistils, ovules, filaments, anther, petals, sepals, \&c.

Sepalody, where other organs assume the appearance of green sepals.

Petalody, where they assume the appearance of petals, as normally in Pinckneya and Calycophyllum, in which one caly $x$-lobe enlarges and becomes petal-like, and abnormally in Primroses where all the calyx-lobes imitate lobes of the corolla (this has been termed Calycanthemy); also of the stamens of common "double flowers."

Staminody, where other organs develop into stamens. Cases of this as affecting pistils are referred to above : rarely sepals and petals are so affected.

Pistillody, where other organs develop into pistils, which most rarely happens except with the stamens, as above mentioned.

2 It is stated that Correa de Serra (who published botanical and other papers in London, Paris, and Philadelphia during the first twenty years of the century, but who knew far more than he published) was the flrst botanist to insist on the symmetry of the flower. It was first made prominent by De Candolle, in the Théorie Elémentaire, and elaborated in detail by $\mathbf{A}$. St. Hilaire in his Morphologie Végétale. 
equal number of parts in a cycle, and the cycles alternating with each other, is simply that of verticillate phyllotaxy. (234.) In either case, the members of the successive circles (or of closed spirals as the case may be) will be equal in number; that is, the flower will be isomerous.

317. A Symmetrical Flower is one in which the members of all the cycles (whorls or seeming whorls) are of the same number. ${ }^{1}$ In nature, the symmetry is of all degrees : it is most commonly complete and perfect as to the floral envelopes when it is not so as respects the essential organs. The general rule is that the successive cycles alternate, as is the nature of true whorls. But the superposition of successive parts is not incompatible with symmetry of the blossom, although it is a departure from the ordinary condition, assumed by botanists as the type. An isomerous flower (meaning one with an equal number of members of all organs) is the same as symmetrical, if the reference be to the number in the circles, rather than to the total number of organs of each kind.

318. A Regular Flower is one which is symmetrical in respect to the form of the members of each circle, whatever be their number ; $i . e .$, with the members of each circle all alike in shape.

319. These two kinds of symmetry or regularity, with their opposites or departures from symmetry, need to be practically distinguished in succinct language. For the terminology, it is best to retain the earlier use, generally well established in phytography, as above defined.

320. A Complete Flower is one which comprises all four organs, viz. calyx, corolla, stamens, pistil.

1 This is not only the definition "generally applied in English text-books," but that introduced by DeCandolle, adopted by St. Hilaire, and followed at least by the French botanists generally. The innovating German definition, of a recent date, is that a symmetrical flower is one "that can be vertically divided into two halves each of which is an exact reflex image of the other." But such have immediately to be distinguished into "flowers which can be divided in this manner by only one plane," which Sachs terms "simply symmetrical or monosymmetrical," and those which can be symmetrically divided by two or more planes, "doubly symmetrical or polysymmetrical," as the case may be. Now both these forms have a more expressive and older terminology, adopted by Eichler, viz. :-

Zygomorphous, for flowers, or other structures, which can be bisected in one plane, and only one, into similar halves (median zygomorphous, when this is a median or antero-posterior plane, as it most commonly is; trans. verse zygomorphous, when the plane of section is transverse or at right angles to the median, as in Dicentra);

Actinomorphous for flowers, \&c., which can be bisected in two or more planes into similar halres. 
321. Numerical ground-plan. Many flowers are numerically indefinite in some or most of their kinds of members, as Ranunculus, Magnolia, and the Rose for stamens and pistils, Nymphæa for all but perhaps the sepals, many Cactaceæ for all but the pistil, and Calycanthus for all four components. But more commonly each flower is constructed upon a definite numerical ground-plan; and the number is usually low. Seldom, if ever, is it reduced to unity in a hermaphrodite blossom (even Hippuris, with a single stamen and a single pistil, is not an unequivocal case), and probably never in a complete one. But there are such extremely simplified flowers among those of a single sex. In Monocotyledons, the almost universal number is three, sometimes two; in ordinary Dicotyledons, five prevails ; four and two are not uncommon; three is occasional; and higher numbers are not wanting, as twelve or more in Houseleeks.

322. To designate the particular plan, such familiar terms of Latin derivation as binary, ternary, quaternary, quinary, senary, \&c., are sometimes employed, denoting that the parts of the flower are in twos, threes, fours, fives, or sixes. More technical and precise terms, equivalent to these, are composed of the Greek numerals prefixed to the word meaning parts or members, as

Monomerous, for the case of a flower of one member of each ;

Dimerous, of two, or on the plan of two members of each;

Trimerous, of three, or on the plan of three members ;

Tetramerous, of four, or on the quaternary plan ;

Pentamerous, of five, or on the quinary plan;

Hexamerous, ${ }^{1}$ of six, or on the plan of six members to each circle. But, in Monocotyledons, so-called hexamerous blossoms are really trimerous, the sixes being double sets of three.

323. Pattern Flowers. These should be symmetrical, regular,

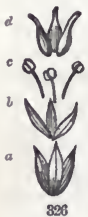

326

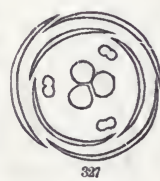

complete in all the parts and without excess or complication of these, and without any of the cohesions or adhesions which may obscure the type, or render it less expressive of the idea that a flower consists of a series of circles or spirals of modified leaves crowded on a short axis. Wherefore the illustration Fig. 307, with its diagram Fig. 308, may serve as a pattern pentanuerons or quinary flower; and Fig. 326, with its diagram, Fig. 327,

1 These may be shortly written 1-merous, 2-merous, 3-merous, and so on up to 10-merous (decamerous), 12-merous (dodecamerous), \&c.

Fig. 326. Parts of a symmetrical trimerous flower (Tillæa muscosa): a. salyx; b. corolla; c. stamens; $d$. pistils. 327 . Diagram of the same. 
as a pattern trimerous or ternary flower; these being simply isomerous, and of one circle of each kind. And the whole

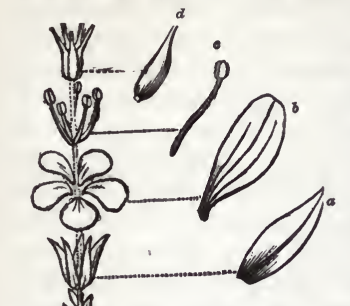
relation of the parts, viewed as modified leaves on the common axis, may be exhibited in such a diagram of a pattern isostemonous 5 -merous flower as that displayed in Fig. 328.

324. Diplostemonous Type. The foregoing patterns are selected upon the idea of the greatest simplicity consistent with completeness. But extended observation leads to the conclusion that the typical flower in nature has two series of stamens, as it has two series in the perianth; that is, as many stamens as petals and sepals taken together. ${ }^{1}$ As the petals alternate with the sepals, so the first series of stamens alternates with the petals, the second series

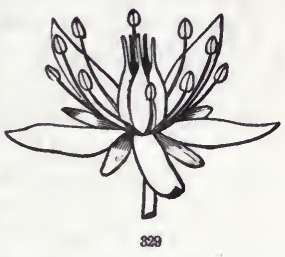
of stamens alternates with the first, and the pistils or carpels when of the same number alternate with these. Thus the outer series of stamens and the carpels normally stand before (are

1 This view of the symmetry of the flower was first taken by Brown (Obs. Pl. Oudney, in Denham and Clapperton Trav. 1826, reprinted in Ray Soc. ed. of Collected Works, i. 293). It is true that Brown declares the same of the pistils; but that is not made out. The evidence of this doctrine is to be gathered from a large and varied induction; from the general presence of the two sets of stamens, and no more, in petaloideous Monocotyledons; the unaltered position of the carpels (before the sepals) when the inner set of stamens is wanting, as in the Iris Family; the very common appearance in haplostemonous flowers among the Dicotyledons of vestiges of a second series, or of bodies which may be so interpreted. The androecium or the blossom is said to be

Isostemonous or Haplostemonous when the stamens are of one series, equal in number to that of the ground-plan of the blossom;

Diplostemonous, when there are two series, or double this number.

FIG. 328. Ideal plan of a plant, with the simple stem terminated by a symmetrical pentamerons flower; the different sets of organs separated to some distance from each other, to show the relative sltuation of the parts. One of each, namely, $a, a$ sepal, $b$, a petal, $c$, a stamen, and $d$, a pistll, also shown, enlarged.

FIG. 329. A pentamerous diplostemonous flower of Sedum. 
superposed to) the sepals, and the stamens of the inner series stand before the petals ; as in the diagram, Fig. $331 .^{1}$

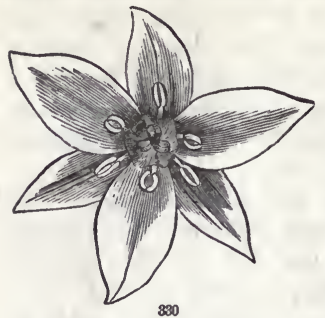

325. Flowers which completely exemplify their type or symmetry are rare, but most exhibit it more or less. Each natural order or group exhibits its own particular floral type, or modification of the common type. ${ }^{2}$ Some of these modifications do not at all affect the symmetry or obscure the plan of the flower, except by combinations which render the phylline character of the floral envelopes and carpels

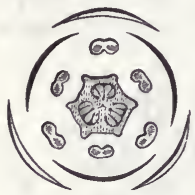

331 less apparent, such combinations being of rare occurrence in foliage. Others gravely interfere with floral symmetry, sometimes to such degree that the true plan of the blossom is to be ascertained only through extended comparisons with the flowers of other plants of the same order or tribe, or of related orders. The symmetry of the blossom finds its explanation in the laws which govern the arrangement of leaves on the axis; that is, in phyllotaxy. The deviations from symmetry and from typical simplicity have to be explained, and in the first instance

1 For convenient reference and the avoidance of circumlocution, some writers term the stamens which are before the petals epipetalous, those before the sepals episepalous; but, as this prefix means upon, it is better to restrict these terms to cases of adnation of stamens to these respective parts of the perianth, and to distinguish as

Antipetalous, those stamens which stand before petals, whether adnate or free, and

Antisepalous, those which stand before sepals. - These terms we find have already been employed in this way by Dr. A. Dickson (in Seemann, Jour. Bot. iv. 275), with the addition of a third, viz.

Parapetalous, for stamens which stand at each side of a petal, yet not necessarily before a sepal, as in many Rosaceæ.

2 These particular types, with their modifications, are set forth in the characters or distinguishing marks of the orders, tribes, genera, \&c. The best generally available illustrations of ordinal types are in Le Maout and Decaisne's Traité Général de Botanique, and in Hooker's English edition and revision, entitled A General System of Botany, Descriptive and Analytical, London, 1873. The best morphological presentation is in Eichler's Blüthendiagramme, \&c. (Flower Diagrams, Constructed and Illustrated), Leipzig, 1875.

FIG. 330. Opened flower of Trillium erectum. 331. Diagram of the same. 
to be classified. To have morphological value, such explanation should be based upon just analogies in the foliage and other organs of vegetation. Whatever is true of leaves and of the vegetating axis as to position of parts, mode of origin and growth, division, connection, and the like, may well be true of homologous organs in the flower.

\section{Section III. Variods Modifications of the Flower.}

\section{§ 1. Enumeration of the Kinds.}

326 . In the morphological study of flowers, these modifications are viewed as deviations from type. Their interpretation forms no small part of the botanist's work. They may be classed under the following heads :-

1. Union of members of the same circle: Coalescence.

2. Union of contiguous parts of different circles: Adnation.

3. Inequality in size, shape, or union of members of the same circle : IrREgularity.

4. Non-appearance of some parts which are supposed in the type: Abortion or Suppression.

5. Non-alternation of the members of contiguous circles: Anteposition or Superposition.

6. Increased number of organs, either of whole circles or parts of circles: Augmentation or Multiplication.

7. Outgrowths, mostly from the anterior or sometimes posterior face of organs: Enation.

8. Unusual development of the torus or flower-axis.

9. To which may be appended morphological modifications, some referable to these heads and some not so, which are in special relation to the act of fertilization. These are specially considered in Section IV.

327. These deviations from assumed pattern are seldom single; possibly all may coexist in the same blossom. Several of them occur even in that one of the orders, the Crassulaceæ, which most obviously exhibits the normal type throughout.

328. Thus, Sedum (Fig. 329), with two circles of stamens, being taken as the true type (324), Crassula (Fig. 307) wants the circle of stamens before the petals ; Tillæa (Fig. 326) is the same, but with the members symmetrically reduced from five to three; Rhodiola loses all the stamens by abortion in one half the individuals and the pistils in the other, sterile rudiments testifying to the abortion; Triactina has lost two of its five carpels, and the three remaining coalesce into one body up to the 
middle; Penthorum (Fig. 335, 336) has its five carpels coalescent almost to the top, and usually loses its petals by abortion; in Grammanthes and Cotyledon (Fig. 332-334), the sepals are coalescent into a cup and the petals into a deeper one, out of

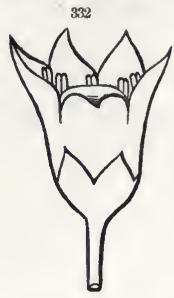

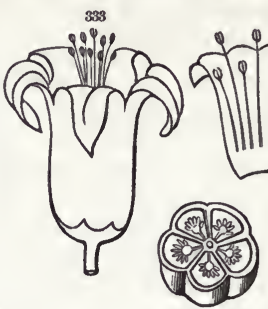

336
334

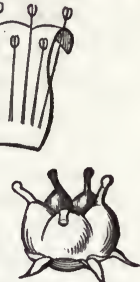

335

which the stamens appear to arise, these being adnate to the corolla. Symmetrical increase in the number of members of each circle is no proper deviation from type, at least in this family (in which flowers on the same plant sometimes vary from 5 -merous to 4-merous and 6-merous); and in Sempervivum (to which Houseleek belongs) these members are always more than five and sometimes as many as twenty in each circle.

\section{§ 2. Regular Union of similar Parts.}

329. Coalescence, or the cohesion by the contiguous margins of parts of the same circle or constituent set of organs, is so frequent that few flowers are completely free from it. The last preceding figures show it in the gynœcium and corolla. Fig. 471-476 further illustrate it in the corolla, and in various degrees up to entire union ; and Fig. $483-488$ illustrate it in the andrœcium. The technical terms which coalescence calls for, and which are needful in botanical description, may be found under the account of the particular organ, and in the Glossary. Such growing together of contiguous members in the blossom is strictly paralleled by connate-perfoliate leaves of ordinary foliage (212, Fig. 215), where it more commonly occurs in upper leaves, and in bracts, which are still nearer the flower.

330. It should now be hardly necessary to explain that the terms coalescence, cohesion, union, and the corresponding phrases

FIG. 332. Flower of Grammanthes. 333. Flower of a Cotyledon. 334. The corolla laid open showing the two rows of stamens inserted on 1t. 335. The five plstils of Penthorum, united. 336. A crose-section of the same. 
in the next paragraph, do not mean that the parts were once separate and have since united. That is true only of certain cases. The union is mostly congenital, equally so in the disks of foliage of the Honeysuckle (Fig. 215) and in the corolla of a Convolvulus. The lobes which answer to the tips of the constituent leaves of the cup or tube are usually first to appear in the forming bud, the undivided basal portion comes to view later. It might be more correct to say that the several leaves concerned have not isolated themselves as they grew. Accordingly, Dr. Masters would substitute for coalescence and adnate the term inseparate. But the common language of morphology needs no change, as it consistently proceeds on the idea, and the prevalent fact, that leaves are separate things, and that the tube, cup, or "inseparate" base of a calyx or corolla, consists of a certain number of these. It is no contradiction to this view that they developed in union. ${ }^{1}$

\section{§ 3. Union of dissimilar or successive Parts.}

331. Adnation is the most appropriate term to denote the organic and congenital cohesion or consolidation of different circles, the

1 If it were seriously proposed to change the language of descriptive botany in this regard, consistency would require its total reconstruction, with the abolition of all such terms as cleft, parted, \&c.; for the structures in question are no more cleft than they are united. While these convenient and long-familiar terms are continued in use (as they surely will be), although quite contrary to literal fact, it cannot be amiss to continue those, such as connate, adnate, coalescent, \&c., which imply and suggest the fundamental fact in the structure of phænogamous and the higher cryptogamous plants, viz. that leaves are normally unconnected organs.

Whether fusion or separation is the more complex condition, and therefore indicative of higher rank, is a question of a different order. It is argued that the fusion or lack of separation is an arrest of development, and therefore an indication of low rank or less perfection than the contrary. But a phylogenetic view of the whole case may reverse this conclusion as respects the blossom. The course of development from thallus and frond to distinct foliage on an axis, from little to full differentiation, is clearly a rise in rank, as also is the differentiation of foliage into ordinary leaves, petals, stamens, and pistils. But there is as much differentiation in the flower of a Convolvulus as of a Ranunculus, and more in that of a Salvia, a Lobelia, and an Orchis. In all such flowers, the combination, the irregularity, and the diversification in many cases of the members of the same circle, all indicate complexity, greater specialization, and therefore higher rank. The production of leaves distinct from the axis is one step in the ascending scale : such specializations and combinations of these as occur in flowers are higher steps; and the most specialized, complex, and therefore highest in rank are complete, corolliferous, irregular flowers, with a definite number of members, and these combined in view of the adaptations by which the ends of fertilization and fructification are best subserved. 
apparent growing of one part on or out of another, - as of the corolla out of the calyx, the stamens out of the corolla, or all of them out of the pistil. This disguises the real origin of the floral organs from the receptacle or axis, in successive series, one within or above the other. Organs in this condition are also and rightly said to be Connate (born united); but, as this term is equally applicable to the coalescence of members of the same circle, the word Adnate is preferable, as applying to the present case only. Adnation is heterogeneous organic co-
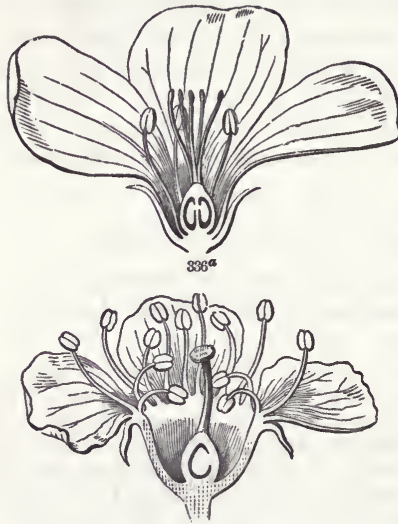

887

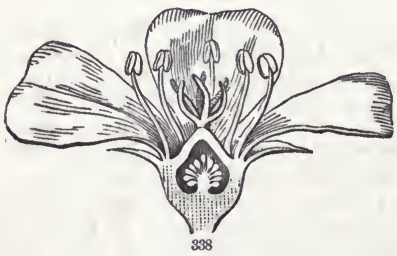

hesion or adhesion: coalescence is homogeneous cohesion or union.

332. Adnation occurs in very various degrees, and affects either some or all the organs of the flower. Its consideration introduces into terminology several peculiar terms, which may here be defined in advance. Three of them, introduced and prominently employed by Jussieu, depend upon the degree of adnation, or the absence of it, viz. :-

Hypogynous (literally beneath pistil), applied to parts which are inserted (i. e. are borne) on the receptacle of the flower, as in Fig. 336. This is the absence of adnation, or the condition which corresponds with the unmodified type.

Perigynous (around the pistil) implies an adnation which earries up the insertion of parts (which always means apparent origin or place of attachment) to some distance above or away from the recep-

FIG. 336\%. Vertical section of a flower of the Common Flax, showing the normal or hypogynous insertion of parts upon the torus or receptacie.

FIG. 337. Vertical section of a flower of the Cherry, to show the perigynous insertion, or adnation to the calyx, of the petals and stamens.

FlG. 338. Similar section of the flower of the Purslane, showing an adnation of ali the parts with the lower half of the ovary. 
tacle, so commonly placing this insertion around instead of beneath the pistil; whence the name. The perigyny may be, as the figures show, merely the adnation of petals and stamens to calyx, the calyx remaining hypogynous, as in Fig. 337; or else the adnation of the calyx, involving the other organs, to the lower part of the ovary, as in Fig. 338 , or up to the summit of the ovary, while the petals

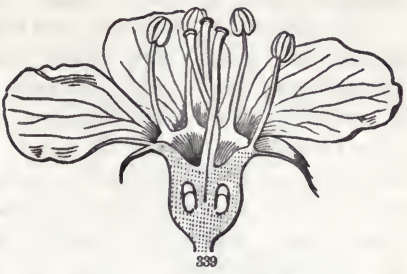
and stamens are adnate still further to the calyx, as in Fig. 339. The latter passes into what is called

Epigynous (on the pistil), where the adnation is complete to the very top of the ovary, and none beyond it, as in Fig. 340, 341. Yet here the parts so termed are not really on the ovary, except where an epigynous disk (394) actually surmounts it.
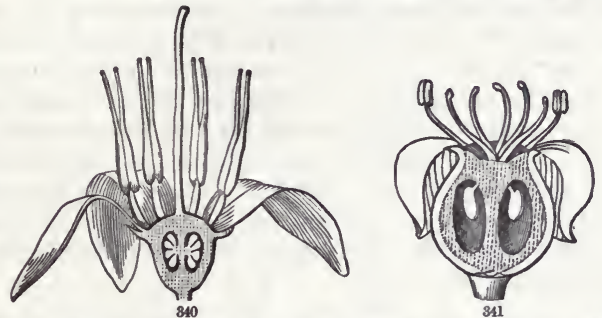

333. Adnation brings some other terms into use in botanical descriptions, especially those of superior and inferior. In this connection, these words (in Latin taking the form of superus and inferus) denote the position in respect to each other of ovary and floral envelopes, - not the morphological, but the apparent position or place of origin. Thus, in Fig. 336 and in 337, the calyx is inferior, or in other words the ovary superior. Here real and apparent origin agree, this being the normal condition, which is otherwise expressed by saying that the parts are free, $i$. e. free from all adnation of one to the other. But, in Fig. 339-341, the

FIG. 339. Similar section of a flower of Hawthorn, showing complete adnation to the summit of the ovary and of the other parts beyond.

FIG. 340. Vertical section of a Cranberry-flower, and 341, of flower of Aralia nudicaulis, with so-called epigynous Insertion of calyx, corolla, and stamens; the calyx of the latter completely consolidated with the surface of the ovary, or its limb obsolete. 
ovary is said to be inferior and the calyx superior, the calyx and other parts, in consequence of the adnation of its lower part, seeming to rise from the summit of the ovary.

334. Adnation of floral envelopes to pistil rarely extends beyond the ovary; yet, in species of Iris having a tube to the perianth, this tube is commonly adnate for most of its length to the style. But when the calyx has its tube or portion with united sepals prolonged, the petals and the stamens are usually adnate more or less to it, i.e. are inserted on the calyx. And, when the petals are united and prolonged into a tube, the stamens, being within the corolla, are commonly adnate to or inserted upon this.

335. No one doubts that the view is a true one which represents the perianth-tube as adnate to the style in Iris, petals and stamens as adnate to calyx in the Cherry (Fig. 337), stamens as adnate to base of corolla in Fig. 334, and a long way farther in Phlox, \&c. That the calyx is similarly adnate to the ovary is nearly demonstrable in certain cases.

336. But, as the lower portion of a pear is undoubtedly receptacle, or rather the enlarged extremity of the flower-stalk, as in a rose at least a portion of the hip is receptacle, as the tube of the flower in a Cereus or other Cactacea has all the external characters and development of a branch, so it is most probable that in many cases the supposed calyx-tube adnate to an inferior ovary is partly or wholly a hollowed receptacle (in the manner of a Fig-fruit) ; that is, a cup-shaped or goblet-shaped development of the base of the floral axis. This would bring the case under § 7. $(326,495$.)

\section{§4. Irregularity of similar Parts.}

337. Irregularity, or inequality in form or in union of members of a circle, is extremely common, either with or without numerical symmetry. One or two examples may suffice.

338. Irregular flowers with symmetrical perfection, except in the gynœcium, are well seen in the Pea Family, to which belongs the kind of corolla called Papilionaceous, from some imagined resemblance to a butterfly. (Fig. 342-344.) This flower is 5 -merous throughout, has the full complement of stamens $(10$, or two sets), but the gynœeium reduced to a single simple pistil. The striking irregularity is in the corolla, the petals of which bear distinguishing names : the posterior and larger one, external in the bud, is the Vexillum or Standard (Fig. 344,a); 
the two lateral next and under the standard, ALe or Wrvgs (b); the two anterior, covered by the wings and partly cohering to
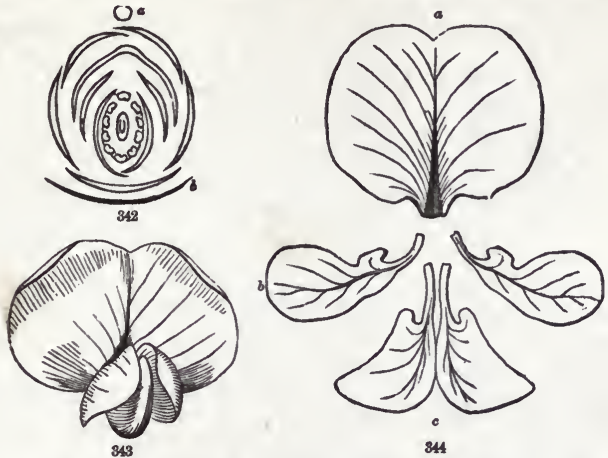

form a prow-shaped body (c), the Carina or KeEL. The calyx is slightly irregular by unequal union, the two upper sepals united higher than the other three. The stamens are much more coalescent, but with an irregularity, nine combined by the lower part of their filaments, and one (the posterior) separate. (Fig. 345.)

339. The plan and
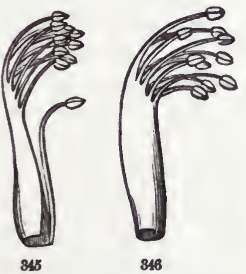

floral symmetry in the Locust-blossom and its relatives are little obscured by the irregularities and the coalescence, hardly more so than in the plainer flower of its relative,

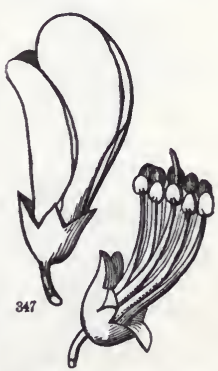

38 Baptisia (Fig. 347, 348), in which the petals are somewhat alike, and the ten stamens are distinct or unconnected. Only the calyx is more irregular, by the union of the two posterior sepals almost to the tip. (Fig. 348.)

FIG. 342. Diagram of flower of the Locust, Robinia Pseudacacia : a, axis of inflorescence; $b$. bract ; first circle of 5 , calyx ; five remaining pieces, corolla; next anthers, 10 in nnmber; in the centre a single simple pistil. 343. Front view of Locust-flower showing only the corolla. 344. This corolla displayed.

FIG. 345. Androeium of the Locust, nine stamens coalescent, one distinct. 346. Same of a Lupine, all ten fliaments coalescent below into a closed tube.

FIG. 347. Calyx and corolla of Baptisia australis. 348. Same with petals fallen, showing ten distinct stamens and tip of the style. 
340. But in a Lupine-blossom, of equally near relationship, a casual observer might fail to recognize the very same type, although disguised only by cohesions. For while the two posterior sepals are united to the tip on one side of the blossom, the

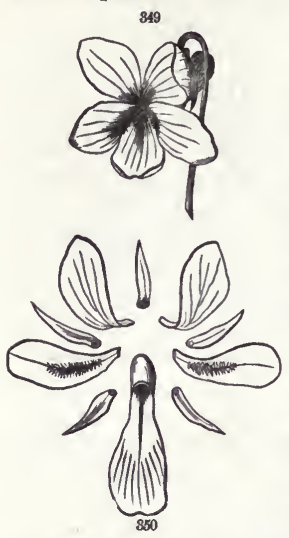

three others are similarly united into one body on the anterior side, giving the appearance of two sepals instead of five : in the corolla, the two keelpetals are more strictly united into a slender scythe-shaped or sickle-shaped body; so that the petals might with the unwary pass for four: in the andrœcium, the coalescence includes all ten stamens (Fig. 346), which is an approach to regularity.

341. The 5-merous symmetry of the Violet-blossom is complete until the gynœcium is reached (but with only one circle of stamens); the main irregularity of the perianth is in the anterior petal, with its nectariferious sac at base (Fig. 349-351) ; the two stamens nearest this send into the sac curious appendages, which the other three do not possess; the gynœeium is composed of three car-

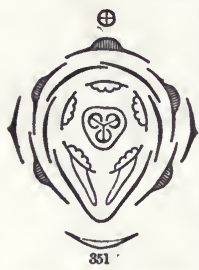
pels coalescent into one compound ovary in a manner hereafter explained. In Antirrhinum and Linaria (Fig. 480, 481), there is a similar irregularity accompanying coalescence of the petals, the anterior one being extended at base into a nectariferous sac or hollow spur. I The flower of a Lobelia (Fig. 488) has the same numerical plan and symmetry as that of Viola (except that the gynœcium is dimerous); but the members are adnate below and coalescent above, and the corolla is irregular through unequal coalescence of the five petals, and the absence of coalescence down one side.

1 Peloria is a name given by Linnæus to an occasional monostrosity of these flowers (imitated in sundry others), in which the base of every petal, or answering part of the corolla, is prolonged downward into a sac or spur. The sac is, morphologically considered, a departure from normal regularity : in the monster, symmetrical regularity is restored by the development of four more sacs.

FIG. 349. Flower of Viola sagittata. 350. Its sepals and petals displayed. 351. Diagram of a Violet-blossom, from Eichler, with bract or subtending leaf (below), a pair of bractlets (lateral), and axis to which the subtending leaf belongs (above or posterior). 


\section{§ 5. Disappearance or Obliteration of Parts.}

342. Abortion or Suppression are somewhat synonymous terms to denote the obliteration or rather non-appearance of organs which belong to the plan of the blossom. Abortion is applied particularly and more properly to partial obliteration, as where a stamen is reduced to a naked filament, or to a mere rudiment or vestige, answering to a stamen and occupying the place of one, but incapable of performing its office ; suppression, to absolute non-appearance. Such vestiges or abortive organs justify the use of these terms, the more so as all gradations are sometimes met with between the perfect organ and the functionless rudiment which occupies its place. Such obliterations, whether partial or complete, may affect either a whole circle of organs or merely some of its members. The former interferes with the completeness of a flower, and may obscure the normal order of its parts. The latter directly interferes with the symmetry of the blossom, and is commonly associated with irregularity.

343. Of parts of a Circle. Among papilionaceous flowers (338), different species of Erythrina have all the petals but one (the vexillum, Fig. 344, a) much reduced in size, in some concealed in the calyx, and in every way to be ranked as abortive organs. In Amorpha, of the same family, these four petals are gone, leaving no trace, reducing the corolla to a single petal. (Fig. $352,353$. ) This one is evidently the vexillum, both by position and shape; and the 5-merous type, also the particular type of the family, are still discernible in the five notches of the calyx, the ten stamens, \&c. In a related genus, Parryella, even this last petal is wanting, and the andrœecium is straight, all irregularity thus disappearing through suppression.

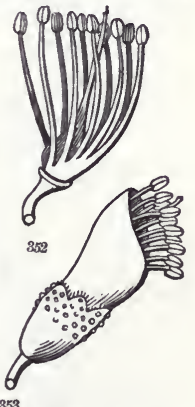

344. Delphinium or Larkspur and Aconite or Monkshood furnish good examples of flowers in which irregularity is accompanied by more or less abortion. The calyx of the Larkspur (Fig. 354-356) is irregular by reason of the dissimilarity of the five sepals, one of which, the uppermost and largest, is prolonged posteriorly into a long and hollow spur. Within these, and alternate with them as far as they go, are the petals, only

FIG. 352. Stamens and pistil of Amorpha fruticosa. 353. An entire flower of the same. 
four in number, and these of two shapes, the two upper ones having long spurs which are received into the spur of the upper sepal; the two lateral ones having a small but broad blade
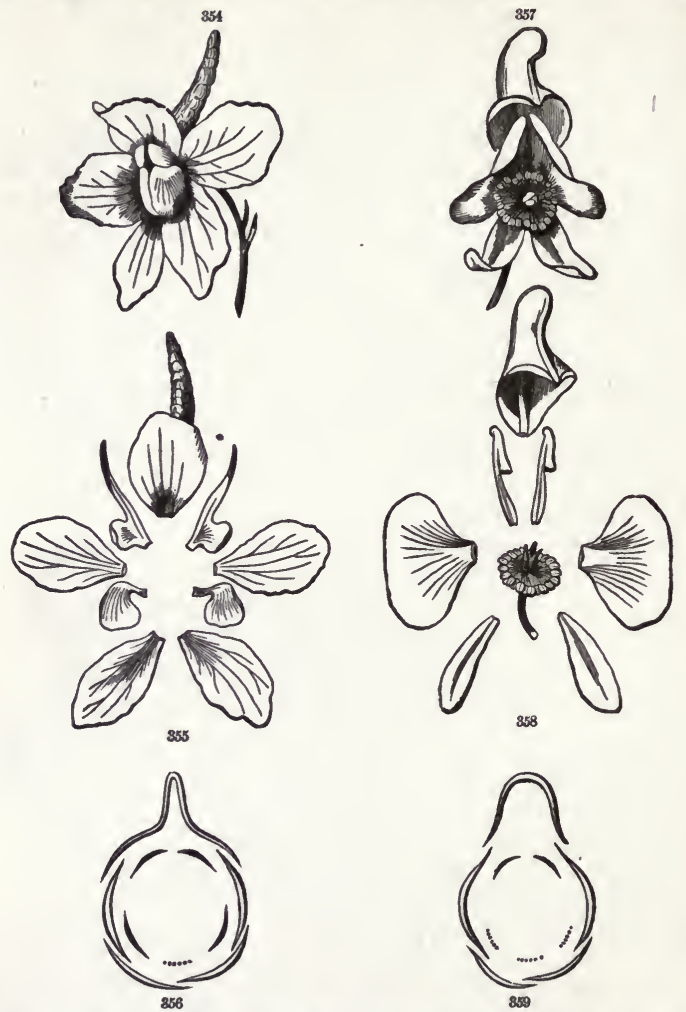

raised on a stalk-like claw; and the place which the fifth and lower petal should occupy (marked in the ground-plan, Fig. 356,

FIG. 354. Flower of a Larkspar. 355. The five sepals (outer circle) and the four petals (inner circle) displayed. 356. Ground-plan of the calyx and corolla.

FIG. 357. Flower of an Aconite or Monkshood. 358. The five sepals and the two small and curiously shaped petals displayed; also the stamens and pistils in the centre. 359. Ground-plan of the calyx and corolla; the dotted lines, as in Fig. 356, representing the suppressed parts. 
by a short dotted line) is vacant, this petal being suppressed: thereby rendering the blossom unsymmetrical. In Aconite (Fig. 357-359), the plan of the blossom is the same, but the uppermost and largest of the five dissimilar sepals forms a helmet-shaped or hood-like body; three of the petals are wanting altogether (their places are shown by the dotted lines in the groundplan, Fig. 359) ; and the two upper ones, which extend under the hood, are so reduced in size and so anomalous in shape that they would not be recognized as petals. One of these, enlarged, is exhibited in Fig. 360. Petals and other parts of this and of various extraordinary forms were termed by Linnæus NeCtaries, a somewhat misleading name, as they are no more devoted to the secretion of nectar than ordinary petals or other parts are. In these flowers, moreover, the stamens are much increased in number.

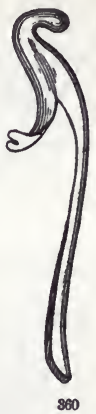

345. Analogous abortion of some of the stamens, along with a particular irregularity of the perianth, especially of the corolla, characterizes a series of natural orders with coalescent petals. ${ }^{1}$ These flowers are all on the 5-merous plan (except that the gynœecium is 2-merous), but with corolla, and not rarely the calyx, irregular through unequal union in what is called the bilabiate or two-lipped manner. The greater union is always median, or anterior and posterior, and two of the coalescent members form one lip, three the other. The two posterior petals form the upper lip, the anterior and two lateral form the lower lip of the corolla; in the calyx, when that is bilabiate, this is of course reversed. In some, as in Sage and Snapdragon, the bilabiation of the corolla is striking (Fig. 479-481), and readily comparable to the two jaws of an animal ; in others, the parts are almost regular. The suppression referred to is, in most of these cases, that of the posterior of the five stamens, as in Fig. 361, where it is complete. In Pentstemon (Fig. 362), a sterile filament regularly occupies the place of the missing stamen. The position sufficiently indicates its nature. This is also revealed by the rare occurrence of an imperfect or of a perfect anther on this

1 These natural orders in which this occurs, or tends to occur, are the Scrophulariaceæ (Snapdragon, Pentstemon, Mimulus, \&c.), Orobanchaceæ (Beech-drops), Lentibulaceæ (Bladderwort), Gesneraceæ (Gloxinia), Bignoniaceæ (Trumpet Creeper, Catalpa), Pedaliaceæ (Martynia), Acanthaceæ, Labiatæ (Salvia, Stachys), \&c.

FIG. 360. A petal (nectary) of an Aconite, much enlarged. 
filament, - a monstrosity, indeed, but the monstrosity is here a return to normal symmetry. The two stamens nearest the

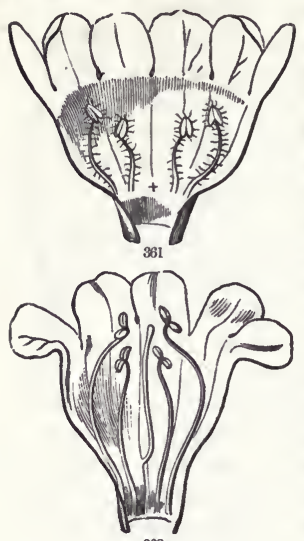

862

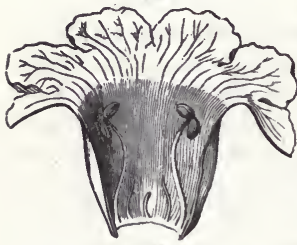

308 suppressed or abortive one generally share in the tendency to abortion, as is shown by their lesser length or smaller anthers: in the flower of Catalpa, these two also are either imperfect or reduced to mere vestiges (as in Fig. 363) : in very many other plants of these families, even these vestiges are not seen, and so the five stamens are by abortion or complete suppression reduced to two.

346. Suppression in the gynœcium to a number less than the numerical plan of the flower (as shown in the perianth) is of more common occurrence than the typical number, and the reduction is comparatively constant throughout the genus or order. A papilionaceous or other leguminous flower with more than one or with all five pistils is exceedingly rare, and except in one pentacarpellary genus is a monstrosity. Suppression of the interior is more common than of exterior organs. Want of room in the bud may partially explain this.

347. Suppression of whole Circles. Such suppression or rather non-production in the actual blossom of whole series of organs which belong to the type, and indeed are sometimes present in that blossom's nearest relatives, is very common. It gives occasion to several descriptive terms, which may be here defined together. First, and in general, flowers are

Incomplete, in which any one or more of the four kinds of organs is wanting, whatever these may be ;

Apetalous, when the corolla or inner perianth is wanting;

Monochlamydeous, where the perianth is simple instead of

FIG. 361. Corolla of Gerardia purpurea laid open, with the four stamens, the place which the fifth should occupy indicated by a cross.

FIG. 362. Corolla of Pentstemon grandifiorus laid open, with its four stamens, and a sterile filament in the place of the fifth stamen.

FIG. 363. Corolla of Catalpa lald open, with two perfect stamens and the vestiges of three abortive ones. 
double, in which case the wanting set is generally (but not quite always) the inner, or the corolla ;

Dichlamydeous, when both circles of the perianth (calyx and corolla) are present;

Achlamydeous, when both are wanting, as in Fig. 365 .

(These three terms are seldom employed.)

Unisexual (also Diclinous or Separated), when the suppression is either of the stamens or the pistils. In contradistinction, a flower which possesses both is Bisexual or Hermaphrodite.

Staminate, or Male, when the stamens are present and the pistils absent;

Pistillate, or Female, when the pistils are present and the stamens absent;

Monocious (of one household), when stamens and pistils occupy different flowers on the same plant;

Dicecious (of two households), when they occupy different flowers on different plants ;

Polygamous, when the same species bears both unisexual and bisexual or hermaphrodite flowers. This may occur in various ways, from the greater or less abortion of either sex, either on the same or on separate individual plants ; - as Monæciously or Diceciously Polygamous, according to the tendency to become either monœcious or diœcious. Recently Darwin has well distinguished the case of

Gyno-diocious, where the flowers on separate individuals are some hermaphrodite and some female, but none male only; and Andro-dicecious, of hermaphrodite flowers and male, but no separate female. The latter is a less common case.

Neutral, as applied to a flower, denotes that both stamens and pistils are wanting, - a case neither rare nor inexplicable on grounds of utility. $(356,504$.)

Sterile and Fertile are more loosely used terms. A sterile flower may mean one which fails to produce seed, as a sterile stamen denotes one which produces no good pollen, and a sterile pistil one which is incapable of seeding. . But commonly a sterile flower denotes a staminate one ; a fertile flower, one which is pistillate, if not also hermaphrodite.

348. Suppressed Perianth. Almost universally, when the perianth is reduced to a single circle, it is the inner, or corolla, which is not produced. Or, rather, when there is only one circle or sort of perianth-leaves, it is called calyx, whatever be the appearance, texture, or color, unless it can somehow be shown that an outer circle is suppressed. For since the calyx is frequently delicate and petal-like (in botanical language, petaloid or colored, as in 
Clematis and Anemone, Fig. 364), and the corolla is sometimes greenish or leaf-like, the only real difference between the two is

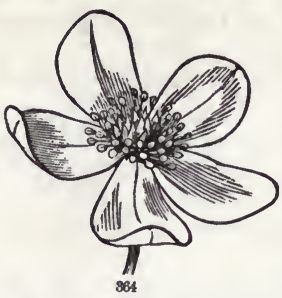
that the calyx represents the outer and the corolla the inner series. Even this distinction becomes arbitrary when the perianth consists of three or four circles, or of a less definite number of spirally arranged members.

349. Yet the only perianth obviously present may be corolla, as when the calyx has its tube wholly adnate to the ovary and its border or lobes obsolete or wanting. ${ }^{1}$ Aralia nudicaulis (Fig. 341) is an instance, likewise many Umbelliferæ, some species of Fedia or Valerianella, the fertile flowers of Nyssa, and those Compositæ which have no pappus. For Pappus, the name originally given to thistle-down and the like, answers to the border or lobes of a calyx attenuated and depauperated down to mere fibres, bristles, or hairs. The name is extended to other and less obliterated forms. (644, Fig. 631-633.) When the obliteration is complete, as in Mayweed (Fig. 630), in some species of Coreopsis, \&c., the corolla seems to be simply continuous with the apex of the ovary. A comparison with related forms reveals the real state of things. ${ }^{2}$

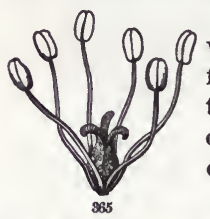

350. So also in Hippuris, in which (along with extreme numerical reduction of the other floral circles) the calyx as well as corolla seems to be wanting; but the insertion of the stamen on the ovary (epigynous) suggests an adnate calyx, and near inspection detects its border.

351. Both calyx and corolla are really wanting in the otherwise complete and perfect (symmetrical and

1 In the flowers of the two common species of Prickly Ash (Zanthoxylum) of the Atlantic United States, one has a double, the other a single perianth (as shown in Gray, Gen. Illustr. ii. 148, t. 156): the position of the stamens gives a presumption that the missing circle of the latter is the calyx ; yet it may be otherwise explained. In Santalaceæ there are some grounds for suspecting that the simple perianth, although opposite the stamens, is corolla; and the foliaceous sepal-lobes of the female flowers of Buckleya would confirm this, if these are true sepals rather than adnate bracts.

2 In the pappus of Compositæ, every gradation is seen between undoubted calyx, recognizable as such by structure as well as position, and diaphanous scales, bristles, and mere hairs, wholly " trichomes" as to structure, although in the place of "phyllomes" and representing them.

FIG. 364. Flower of Anemone Pennsylvanica ; apetalous, the calyx petalol.1.

FIG. 365. Achlamydeous flower of Lizard's-tail (Saururus cernuus), magnided. 
trimerous) flowers of Saururus, Fig. 365. But achlamydeous blossoms are usually still further reduced to a single sex.

352. Suppression of one circle of stamens is of very common occurrence. It is seen in different species of Flax; which have mostly 5-merous perfectly symmetrical and complete flowers with one set of stamens abortive. In some species (as in Fig. 367),

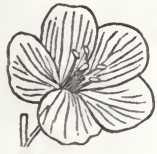

366

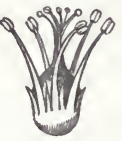

367

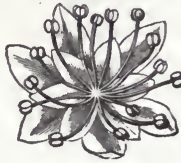

368

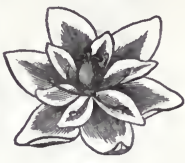

809

vestiges of the missing circle of stamens are conspicuous in the form of abortive filaments, interposed between the perfect stamens; in others, these rudiments are inconspicuous or even altogether wanting.

353. Suppressed Androcium or Gynœeium. This occurs without or along with suppression in the perianth. In cases of the former, vestiges of the aborted organs often remain to signify the exact nature of the loss. Separation of the sexes (moncecious, dicecious, \&c.) is the result of such suppression. In Menispermum (Fig. 368, 369), this is accompanied by an actual doubling of both calyx and corolla. The diœcious flowers of Smilax are similarly complete, except by

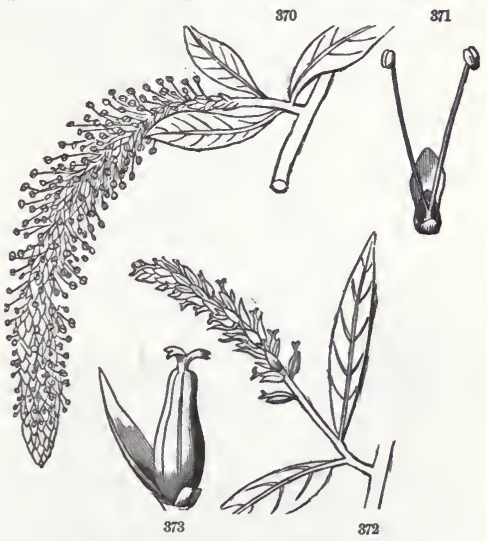
the abortion of one sex, but the calyx and corolla are single.

FIG. 366. Flower of a Linum or Flax. 367. Androcium and gynœeium; the former of 5 perfect stamens, alternating with 5 rudiments of a second set.

FIG. 368, 369. Diceious flowers of Moonseed, Menispermum Canadense: 368, Staminate or male blossom; 369 , Pistillate or female, but with six abortive stamens, before as manj petals.

FIG. 370. A catkin of staminate flowers of a Willow, Salix alba. 371. A single staminate flower detached and enlarged (the bract turned from the eye). 372. A plstillate catkin of the same species. 373. A detached pistillate flower, magnified. 
354. Combined with suppression of Perianth. This, which is found in most amentaceous or catkin-bearing trees, in some with

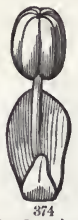
partial suppression of perianth, is well illustrated in Willows, the flowers of which are all achlamydeous and dicecious. (347.) The little scale (gland or nectary) at the inside of each blossom might be supposed to represent a perianth, reduced to a single piece; but an extended comparison of forms refers it rather to the receptacle. Willow-blossoms (Fig. 370-372) are crowded in catkins, each one in the axil of a bract: the staminate flowers consist of a few stamens merely, in this species of only two, and the pistillate of a pistil merely. In Salix purpurea, the male flower seems to be a single stamen (Fig. 374); but it consists of two stamens, united into one

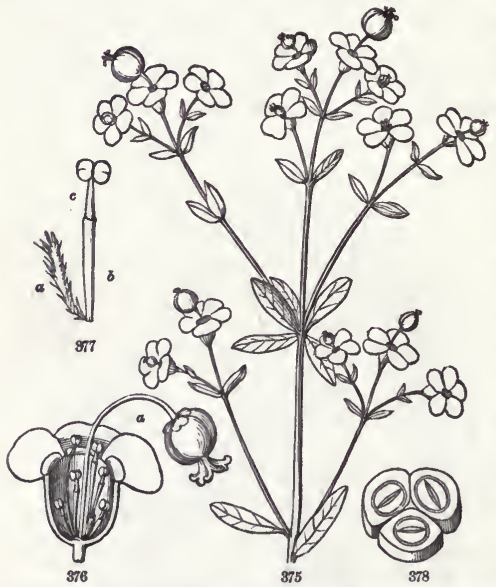

body. Here extreme suppression is accompanied with coalescence of the existing members.

355. Still more simplified flowers, but more difficult to comprehend, are those of Euphorbia, or Spurge. These are in fact monœcious ; and the female flower is a pistil, the male is a stamen. The pistillate flower (of three carpels, their ovaries united into one three-lobed. compound ovary)

surmounts a slender peduncle which terminates each branch of the flowering plant. (Fig. 375.) From around the base of this peduncle rise other smaller and shorter peduncles, each from the axil of a slender bract, and surmounted by a single stamen, which represents a male flower. (Fig. 376, 377.) This umbel-like

FIG. 374. A separate staminate flower of Salix purpnrea, with the stamens coalescent (monadelphous and syngenesious), so as to appear like a single one.

FIG. 375. Flowering branch of Euphorbia corollata. 376. Calyx-like involucre divided lengthwise, showing the staminate flowers aronnd a pistillate flower $(a)$. 377. A more magnified staminate flower detached with its bract, $a$; its peduncle or pedicel $b$, surmounted by the solitary stamen, c. 378. Pistil in fruit, cut across, showing the three one-seeded carpels of which it is composed. 
flower-cluster is surrounded and at first enclosed by an involucre in the form of a cup, which imitates a calyx ; and the lobes of this cup (the free tips of the calyx-leaves) in the present species are bright white, so that they exactly imitate petals. Here, then, is a whole cluster of extremely simplified flowers, taking on the guise of and practically behaving like a single flower, the involucre serving as calyx and corolla; the one-stamened male flowers collectively imitating the andrœcium of a polyandrous blossom, and surrounding a female flower which might pass for the pistil of it. A series of related forms, from various parts of the world, gives proof that this interpretation is the true one.

356. Suppression of both Andrœcium and Gynœeinm. This occurs in what are termed Neutral Flowers (347), such as are conspicuous at the margin of the cymes of Hydrangea (Fig. 293) and of Viburnum lantanoides and Opulus, also at the margin of the head of flowers of Sunflower, Coreopsis (Fig. 287, 288), and the like. In these and most other instances, the perianth of which only the flower consists is much larger and more showy than in the accompanying perfect flowers: in fact, their whole utility to the plant, so far as known, is in this conspicuousness. No plant normally bears neutral flowers only; but in cultivation all sometimes become so by monstrosity, as in the form of Vibur. num Opulus called Snowball or Guelder Rose, also in "full double" roses, pinks, \&c. Occasionally flowers become sterile and neutral by mere depauperation and abortion of perianth as well as of essential organs, as in certain Grasses; but such are mostly vestiges of flowers rather than neutral blossoms.

\section{§ 6. Interruption of normal Alternation.}

357. Anteposition or Superposition is the opposition of successive (or apparently successive) whorls which normally alternate. This result is brought about in different ways, some of which are obvious, while of some the explanation is hypothetical.

358. In the first place, there are cases of seeming anteposition, which are explained away on inspection. In a tulip, lily, and the like, there is a perianth of six leaves and a stamen before each. The simple explanation is that the flower is not 6-merous, but 3-merous : there is a calyx of three sepals, colored and mostly shaped like the three petals, which alternate with these and are clearly anterior in the bud; next, three stamens alternate with the petals or inner circle of the perianth; then the three stamens of the inner circle, alternating with the preceding, necessarily are opposite the three petals, as the first three are 
opposite the sepals. These organs altogether are in four whorls of three, not in two of six members ; and the pistil at the centre, of three combined members, is the fifth and final whorl.

359. The Barberry family exhibits a similar seeming anteposition, which is more striking on account of a multiplication of the members of the perianth. The calyx is of six sepals in two circles, the corolla of six petals in two circles, the stamens equally six; and so each petal has a stamen before and a sepal behind it. But, when properly viewed as a trimerous flower with double circles of sepals and petals as well as of stamens, all is symmetrical and normal. Menispermum in the related Moonseed family is in the same case, but the flower is trimerous, as seen in Fig. 369 : in the male blossom this is obscured in the andrœcium (Fig. 368) by a multiplication of the stamens. ${ }^{1}$ The same thing occurs in the perianth and bracts of certain Clusiaceæ, in which the members counted as in fours are superposed, and in some of which the double dimerous arrangement with apparent anteposition extends through the corolla; while, in other closely related flowers, the corolla changes to simply tetramerous and to alternation with the preceding four sepals. This passes, in the same family and in the allied Ternstrœmiaceæ, into

360. Snperposition by Spirals, as where five petals are anteposed to five sepals, by an evident continuation of pentastichous phyllotaxy; and the stamen-clusters of Gordonia Lasianthus are probably in this way brought before the petals. ${ }^{2}$ The flower of Camellia is continuously on the spiral plan up to the gynœcium ; but upon one which, from the bracts onward, rises from the $\frac{1}{2}$ to the $\frac{2}{5}$ and $\frac{3}{8}$ order or higher, throwing the petals of the rosette in a full-double flower into numerous more or less conspicuous vertical ranks.

361. Anteposition in the Andrœcium. It is in the androcium that real anteposition is most common, and also most difficult to account for upon any one principle. Doubtless it comes to pass in more than one way. This condition is chiefly noticed when the stamens are definite in number, and mainly in isostemonous and diplostemonous flowers. (324.)

362. With Isostemony. Vitis (Fig. 379-381), also Rhamnus (Fig. 415, 416), and the whole Grape and Buckthorn families of

1 In Columbine (Aquilegia), multiplication of the stamens in successively alternating 5-merous whorls similarly brings the andrœcium into ten ranks; so, when these stamens in double flowers are transformed into hollow-spurred petals, these are set one into another in ten vertical ranks.

2 Gen. Illustr. ii. t. 140. But the petals alternate with the sepals in the ordinary manner of the flower, though their strong quincuncial imbrication suggests the spiral arrangement. 
which they are the types, afford familiar cases of a single circle of stamens placed before the petals. In Vitis, there are green nectariferous lobes or processes from the receptacle, alternate with and inside the stamens: there is no good reason to suppose that they answer to a second row of stamens. All isostemonous Portulacaceæ have the stamens before the petals ; and, when the stamens are fewer than the petals, those which exist occupy this position. Among the orders with gamopetalous corolla, such anteposition is universal in Plumbaginaceæ, Primulaceæ, the related Myrsinaceæ, and in most Sapotaceæ, in the latter usually with some complications.

879

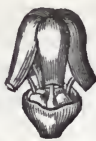

880

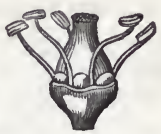

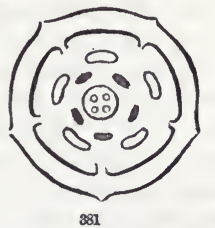

881

363. The earliest and the most obvious explanation of the anomaly is that of the suppression of an outer circle of stamens, and to this view recent morphologists are returning. ${ }^{1}$ Observation supplies no vestige of proof of it in Rhamnaceæ and Vitaceæ ; but, in the group of related orders to which the Primulaceæ belong, evidence is not wanting. For Samolus and Steironema both exhibit a series of rudimentary organs exactly in the place of the wanting circle of stamens, which may well be sterile filaments. In the allied order Sapotaceæ, while Chrysophyllum has in these respects just the structure of Primulaceæ, and Sideroxylon that of Samolus, Isonandra Gutta (the Gutta-percha plant) has a circle of well-formed stamens in place of the sterile rudiments of the preceding; that is, alternate with the petals,

1 Eichler, Blüthendiagramme, passim, and in preface to Part II. xviii., relating chiefly to obdiplostemony. The principal opposing view is that of St. Hilaire, Duchartre, \&c., maintaining that corolla and stamens here represent one circle of organs doubled by median chorisis; upon which see note under a following paragraph. According to that hypothesis, there is no androecial circle in such blossoms, or only vestiges of one, but the petals have supplied the deficiency by a supernumerary production of their own! The more plausible hypothesis of Braun, that of a suppressed interior circle of extra petals, would restore the alternation, and make the extant stamens the fourth floral circle, as does the adopted explanation. Braun's hypothesis, if it insists that an extra row of petals is wanting, supposes the suppression of that which very rarely exists; but, if of stamens, then the supposed suppression is of that which is so generally present, or with indications of presence, as properly to be accounted a part of the floral type.

FIG. 379. Flower of the Grape Vine, casting its petals before expansion. 380. The same, without the petals: both show the giands of the disk distinctly, within the stamens. 381. Diagram of the flower. 
completing the symmetry of the blossom and the normal alternation of its members. This explanation of the anteposition of a single circle of stamens is the more readily received, because it well accords with the idea here adopted, that the andrœcium of a typical flower should consist of two circles of stamens. (324.) The only serious objections to this explanation rise out of the difficulty of applying it to analogous anteposition when both circles are present.

364. For Diplostemony, the condition of two circles of stamens, each of the sáme number as the petals, is also itself very commonly attended by anteposition. In normal or Direct Diplostemony, - that which answers to the floral type completely, - the antisepalous stamens (324, note) are the outer and the antipetalous the inner series, and the carpels when isomerous alternate with the latter and oppose the sepals; the alternation of whorls is therefore complete, as in the diagram, Fig. 382. Such stamens, however, may actually occupy a single
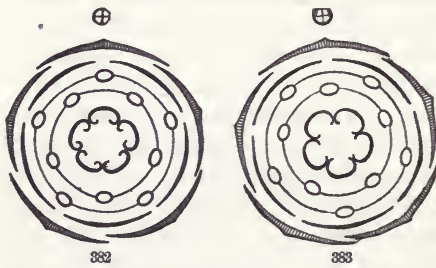
line or coalesce into a tube, without derangement of the type. But it as commonly occurs that the antipetalous stamens are more or less exterior in insertion, and then the carpels, when isomerous, are alternate with the inner and antisepalous stamens, and therefore opposite the petals, as in the diagram, Fig. 383. This arrangement takes the name of Obdiplostemony. In it the normal alternation of successive whorls is interrupted, so as to produce anteposition,

365. With Obdiplostemony. This condition prevails, more or less evidently, in Ericaceæ, Geraniaceæ, Zygophyllaceæ, Rutaceæ, Saxifragaceæ, Crassulaceæ, Onagraceæ, \&c. (but in some of these with exceptions of direct diplostemony); also, accompanied by a peculiar multiplication of members (380), in Malvaceæ, Sterculiaceæ, and Tiliaceæ. The explanation is difficult. The hypotheses may be reduced to three, neither of which is quite satisfactory. There is, first, the hypothesis of St. Hilaire, applied to this as to the preceding case (to Rhamnus, Vitis, \&c.), that these exterior antipetalous stamens belong to the corolline whorl; in other words, that the petal and the stamen before it

. FIG. 382. Diagram of pattern flower with direct diplostemony. 383. Diagram of similar flower with obdiplostemony. Both from Eichler's Blüthendiagramme. 
(whether adnate to or free from it) answer to one leaf which has developed into two organs by a deduplication (372) taking place transversely. This makes the inner and antisepalous stamens the third floral circle or the only truly andrœcial one, and symmetrically alternate with the petals on the one hand and the carpels on the other. The second hypothesis conceives that there is a whorl suppressed between these antipetalous stamens and the corolla : this, ideally restored,

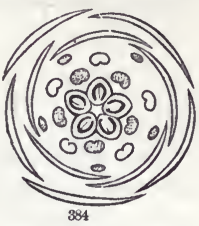
gives symmetric succession and alternation to all the succeeding whorls. The five glands in a Geranium-flower, alternate with and next succeeding the petals (Fig. 384), were plausibly supposed to represent this missing whorl, which according to Braun should be an inner corolla ; according to others rather a primary circle of stamens. The third is the recent hypothesis of Celakowsky, which Eichler adopts : this regards the antipetalous stamens as really the inner or second circle, and conceives that in the course of development it has become external by displacement. The difficulties of this hypothesis are, first to account for this displacement, and then for the anteposition of the carpels to the assumed inner stamens in the great majority of these cases. ${ }^{1}$

1 In the first part of the Blüthendiagramme, Eichler inclined to the first hypothesis, that of St. Hilaire (now very much abandoned on account of the feeble evidence that there is any such thing as transverse or median chorisis); in the second, he discards this in favor of Celakowsky's view (published in Regensburg Flora, 1875). As to members which are morphologically interior becoming exterior by outward displacement, Eichler cites the staminodia or sterile stamen-clusters of Parnassia (Fig. 400, 401), and the corresponding antipetalous stamens of Limnanthes, as clearly interior in the early flower-bud, but exterior at a later period; states that the vascular bundles which enter these stamens generally are either inner as respects those of the episepalous stamens or in line with them; that in some cases (as in many Caryophyllaceæ) the real insertion of the stamens is that of direct diplostemony, while the upper part of their filaments and the anthers are external to the episepalous series; that in most families with obdiplostemony examples of direct diplostemony occur, and still more cases with both stamineal circles inserted in the same line; and that, as a rule, the episepalous stamens are either later or not earlier formed than the epipetalous. As to the position of the carpels before antipetalous stamens and petals, Celakowsky suggests that this may result from the outward recession of those stamens affording more room there, while in the normal case the greater space is over the episepalous stamens. And, indeed, exceptions to the prevalent position are not uncommon both in direct diplostemony

FIG. 384. Diagram (cross-section) of the flower of Geranium maculatum, exhibiting the relative position of parts, and the symmetrical alternation of circles, i.e. sepals, petals, greenish bodies called glands, antipetalous stamens, antisepalous stamens, carpels. 
366. The case of stamens in a cluster before the petals is a complication of either of the foregoing with a peculiar kind of multiplication, termed deduplication or chorisis. (372.)

\section{§ 7. InCreased Number of Parts.}

367. Augmentation in the number of floral members is one of the commonest modifications of the type. It occurs in two ways : 1st, by an increased number of circles or turns of spirals in the flower, which is Regular Multiplication; $2 \mathrm{~d}$, by the production of two or three or of many organs in the normal place of one, Chorisis or Deduplication. The first does not alter the normal symmetry of the blossom, although it may render it difficult or impossible to trace or demonstrate it. The second apparently disturbs, or at least disguises, floral symmetry. Either may be definite, or of a constant and comparatively small number; or indefinite, when too numerous for ready counting, or inconstant, as the higher numbers are apt to be.

368. Regular Multiplication, or Augmentation of floral circles or spirals, may affect any or all the four organs, but most commonly the androcium. When the perianth is much increased in the number of its members, the distinction between calyx and corolla, or even between bracts and corolla, is apt to disappear, as in most Cactaceous flowers (Fig. 317), Nelumbium, Calycanthus, \&c. In these and similar cases, the members of the perianth are prone to take a spiral instead of cyclic arrangement; and this

and in obdiplostemony. Along with the lack of clear analogy to support St. Hilaire's hypothesis of transverse deduplication, the similar orientation of the vascular bundles in the petal and the stamen before it must, as Celakowsky insists, be good evidence that these represent independent leaves, and not superposed portions of one.

The main objection to the second hypothesis (that of a suppressed circle outside of the antipetalous stamens) is that this missing circle, whether of petals or stamens, is not actually met with in any nearly related forms (for in Monsonia the fifteen stamens are otherwise explained); also that there are transitions, as above mentioned, between obdiplostemony and direct diplostemony. To Braun's theory that the glands behind the antisepalous stamens in true Geraniaceæ answer to suppressed phylla, Eichler objects that these are present behind all ten stamens in Oxalideæ; also that all are wanting when the office of nectar-secretion, which they subserve, is undertaken by some other part of the flower, as by the calyx-spur in Pelargonium and Tropæolum. The first objection is forcible: the second mixes morphological considerations with functional, and is inconclusive. Abortive organs, preserved for their utility as nectaries, might totally disappear when rendered useless by a different provision for the same function. 
is even more true of greatly multiplied stamens and pistils, as in Magnolia and Liriodendron, most Anonaceæ, Ranunculus, Anemone, and the like. But in Aquilegia, where the number five is fixed in the perianth, the cyclic arrangement with alternation of whorls prevails throughout

369. The definite augmentation of calyx and corolla by the production of one additional whorl of each, and the seeming anteposition which comes of it when the andrœcium remains simply diplostemonous (in the manner of the Berberidaceæ, Menispermaceæ, \&c., 359) has already been explained.

370. Similar increase to two whorls affecting the corolla only characterizes Anonaceæ, Magnoliaceæ, Papaveraceæ, and Fumariaceæ. In all but the last order, this is accompanied by indefinitely multiplied stamens, and mostly by an increased number of carpels. In Fumariaceæ, which has dimerous flowers, there is a diminution by the suppression in most cases of half the normal andrœcium, and also an augmentation of the other half by chorisis. (372.)

371. Parapetalous Multiplication. Under this head may be described an anomalous arrangement of augmented stamens which prevails in the order Rosaceæ, but is not peculiar to it. ${ }^{1}$ The simplest case, but a rare one, is seen in the 10 -stamened variety of some Hawthorns, as occasionally in Cratægus coccinea and Crus-galli. The ten are in one circle and in pairs, the pairs alternate with the petals. Some would say the pairs are before the petals ; but the space between two stamens before each petal is mostly rather wider than in the pair taken the other way. The next case in order, as in 15-stamened Hawthorns, and constantly in Nuttallia, adds to the above a simple interior circle of five stamens, one directly before the middle of each petal. Next, as in most Pomeæ and many Potentilleæ, there are twenty stamens, thus placed, but with an additional circle of five alternating with the preceding one. Next there are 25 in three circles, the second circle as well as the first having ten stamens; and finally there are from 30 to 50 , all probably in circles of ten each. There is little doubt that the circles develop in centripetal order; the inner successively the later. ${ }^{2}$

${ }^{1}$ It was first clearly described by Dr. A. Dickson, in Trans. Bot. Soc. Edinb. viii. 468, and Seemann's Jour. Bot. iv. 473 (1866). He introduced the term, parapetalous, which is characteristic of it in its elementary form (254, note): it is particularly illustrated by Eichler, in Blüthendiagramme, ii. 495-510. The former interprets it by chorisis, both median and collateral: the latter presents the facts and possible views, but declines to adopt either of then.

2 Accordingly, the whole is probably to be explained by some modificaLitiriay 
372. Chorisis or Deduplication. Both these terms, and the ideas which they denote, originated with Dunal, but were first expounded by Moquin-Tandon. ${ }^{1}$ The first word is Greek for a separating or separation. The second is a translation of Dunal's French word dédoublement (literally undoubling), the ambiguity of which, and of the original presentation of the case, long retarded the right apprehension of the subject. Diremption has been suggested (by St. Hilaire) as a proper term. The meaning simply is, the division of that which is morphologically one organ into two or more (a division which is of course congenital), so that two or more organs occupy the position of one. As thus used, chorisis is restricted, or nearly so, to the homologues of leaves in the flower, and mainly to stamens and carpels ; the division or splitting up of a petal or a sepal, when it occurs, being expressed in the phrases which are applied to leaves. Yet a compound leaf, especially one of the palmate type, is a good type of chorisis, the several blades of a compound leaf answering to the single blade of a simple leaf. It has been objected against the terms chorisis and deduplication that they assume the division of that which has never been united; but so equally does the established terminology of foliage. A divided leaf has never been entire.

373. Chorisis is complete when the parts concerned are distinct or separate to the very insertion, as in the stamen-clusters of Hypericum. The foliar form of this would be represented by

tion of the augmentation of circles. Dickson's hypothesis, that the two, three, or five stamens which are more or less in face of each petal are all deduplications of that petal, would come to be noticed under the next head, but it may be dismissed at once. Yet that the pairs in the outer circle represent each an antisepalous stamen, divided by chorisis (sometimes incompletely) and much separated, is not improbable. The other tenable explanation (which may be harmonized with the last) is that the outer circle of stamens here rightly consists of ten members, respectively alternating with the sepals and petals taken as a whole. This makes them parapetalous, and at the same time brings them under Hofmeister's general law that new organs originate over intervals of those preceding, in this case over the ten perianth-intervals directly. It also accords with Hartog's elucidation of the accessory parts in the flower of Sapotaceæ (in Trimen's Jour. Bot. 1878). The inner circles are there sometimes 5-merous after the primitive type, sometimes 10 -merous in regular alternation to the preceding circles.

1 Moquin-Tandon, Essai des Dédoublemens, \&c., Montpellier, 1826; Considérations sur les Irrégularités de la Corolle, \&c., in Ann. Sci. Nat. xxvii. 237, 1832; Tératologie Végétale, 337. Dunal, Essai sur les Vacciniées, 1819 , cited by Moquin (some pages printed, but never published); Considérations sur la Nature et les Rapports de quelques-uns des Organes de la Fleur, 1829. The next botanist to develop it was St. Hilaire, Morphologie Végétale, 1841. 
such sessile palmately compound leaves as those of some species of Aspalathus. It is incomplete when division does not extend to the base; as in Fig. 387, 393. . Compare, as a proximate homologue of this, a petal of Mignonette, Fig. 385. But proper chorisis requires that the supernumerary organs should be developed like unto the original organ which is thus multiplied, or should complete their symmetry, whatever it be.

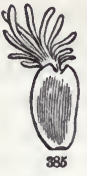

374. St. Hilaire distinguished two kinds of deduplication; viz., collateral when the members stand side by side, and parallel when an organ becomes double or multiple antero-posteriorly. The latter, sometimes called vertical, and sometimes transverse, is better named median chorisis. The collateral is the original and typical chorisis. Most botanists incline to restrict the name to this, and to give some other explanation and name to the median form of augmentation. But some cases, such as those of Tilia and Sparmannia, are clearly of the same nature as the collateral, and may be a disguised form of it; there are others which may be explained in accordance with it; and there are such transitions between some of these and coronal outgrowths that the term chorisis is most conveniently made to comprise augmentation or doubling in either plane. Distinct anteposition, however, may be explained in other ways. (357.)

375. Typical or Collateral Chorisis, in which the members, together answering to one leaf, normally stand side by side; occurs in many families of plants, and in a variety of forms. A few are here presented.

376. Elodes Virginica (a common marsh plant of the Hypericum family), like most of its near relatives, has its calyx and corolla on the plan of five, its stamens and carpels on the plan of

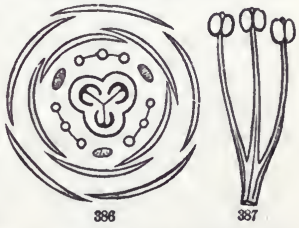
three, as is shown in the diagram, Fig. 386. This makes a break in the symmetry between the corolla and the stamens; but all within is in regular alternation when the three stamens of each cluster are counted as one as their union at base into a phalanx (Fig. 387) may suggest. These phalanges alternate with the three carpels, and therefore stand where single stamens belong. The three conspicuous green projections, which in a general way

FIG. 385. A petal of Mignonette (Reseda odorata), with many parted blade, enlarged.

FIG. 386. Diagram of flower of Elodes Virginica, with three phalanges of stamens forming the inner circle, and three glands answering to the outer circle. 387. A detached phalanx of three stamens. 
are called glands, alternate with the phalanges, and so are taken to represent the outer circle of stamens. The morphologist accordingly sees in the glands the homologues or representatives of the outer series of stamens, reduced to three by abortion, and in the three stamen-clusters only the three alternating stamens of the inner series, trebled by chorisis, and this chorisis incomplete, because it has not quite divided the filament into three. In Hypericum, the glands are completely suppressed, each phalanx is almost or quite divided into a cluster, either of about three stamens each, as in H. Sarothra, or of a few more (in H. mutilum and $\mathbf{H}$. Canadense), or of an indefinite number, as in the common St. Johnsworts. Then in some other species (as in our H. pyramidatum) the carpels and the stamen-clusters rise to five, realizing complete pentamerous symmetry, except that the almost numberless stamens all belong to the one inner circle. Morphologically, they are comparable to the leaflets of five (or in most species three) decompound and sessile or almost sessile leaves. The indefinitely numerous stamens of Ricinus are similarly increased from five by compound ramification.

377. Fumariaceæ, the Fumitory family, may furnish the next illustration. The flower is on the plan of two (dimerous) throughout.

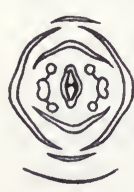

392
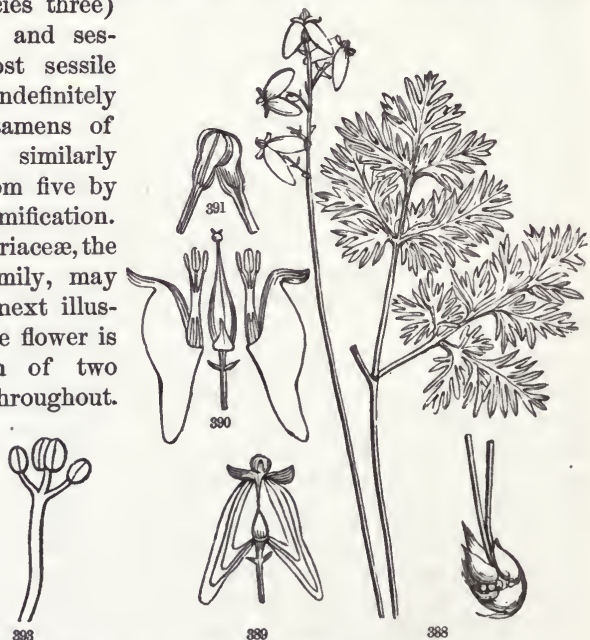

889

Taking Dicentra to show it, there is first a pair of small and scale-shaped sepals, not unlike the pair of bractlets on the

FIG. 388. Dicentra Cncullaria (Dutchman's Breeches), a scape in flower and a leaf, severed from the singular bulb (formed of the enlarged bases of petioles). 389. Detached flower, of natural size, showing also the pair of bractlets on the pedicel. 390 . Same with parts displayed, and 391, inner petals placed above. 392. Diagram of flower of Dicentra or Adlumis, from a section across the summit. 393. One of the phalanges of stamens of Adlumia ; upper part only. 
pedicel below (Fig. 389, 390), and normally alternate with them : alternate with these is a pair of large petals, deeply saccate or spurred below; alternate with these, a pair of smaller petals with spoon-shaped tips which cohere at the apex (the corolla therefore of two circles as in the related Poppy family); alternate with these, two phalanges or united stamen-clusters, of three stamens each; alternate with these is nothing, for the second set of stamens is wanting; alternate with this vacancy is a pair of carpels wholly combined into a compound 2-merous pistil. The statement itself explains the morphology. The three stamens of each phalanx stand in the place of a stamen, and are the divisions of one. In Dicentra the members of the phalanx are almost separate ; in Adlumia (FYg. 393) and Corydalis the undivided filament reaches almost up to the anthers. The middle anther of the phalanx is normal, or two-celled; the lateral anthers are one-celled, as if halved. ${ }^{1}$

1 Eichler adopts this interpretation (proposed in Gray, Gen. Illustr. i. 118), and applies it to the crucial instance of Hypecoum. In the flower of this Old World genus, there are four apparently simple and complete stamens, one before each petal: the simplest interpretation would be that which the facts appear to present, viz. that both dimerous circles of stamens are complete and normal. But Eichler - in view of the early development and the double vascular bundles of the stamens before the inner petals, and some occasional slight disjunction of their anther-cells - considers that the interior stamen-circle is wanting here, no less than in the other genera of the order; that what here takes its place before each inner petal is a stamen composed of the adjacent lateral member of the phalanx, congenitally severed from the group to which it belongs and soldered into one filament, bearing the two one-celled anthers so brought together as to imitate a normal two-celled anther. The organogeny of the blossom is thought to favor this hypothesis; and it certainly favors the view here adopted of the composition of the three-membered phalanx of the family generally. If this interpretation of Hypecoum seems far-fetched, it is no more so than its exact counterpart, through which DeCandolle, Lindley, and others explain the case of the rest of the family. Starting with that genus as the simple type, they conceive that the stamen opposed to each inner petal is each severed into two, and that these half-stamens attached to the sides of the two intact stamens, thus producing the phalanges by coalescence.

A good empirical conception of the formation, from a single leaf, of three stamens in Fumariaceæ, or two in Cruciferæ, is afforded by the petals of Hypecoum, as illustrated by Eichler. The outer petals are slightly threelobed from the apex; the inner are deeply so and narrower. The members of the next circle in the family generally are just such three-lobed bodies, the tip of each lobe transformed into an anther. There is an apparent congruity in the production by the symmetrical middle lobe of a symmetrical two-celled anther, and of a one-celled anther by each unsymmetrical lateral lobe or stipule-like portion. A fuller derelopment of these sides of the leaf, and non-development of the middle portion (somewhat after the analogy of Lathyrus Aphaca, Fig. 219), with anther-formation, would convert the leaf into a pair of stamens 
378. The obvious relationship of Cruciferæ to Fumariaceæ, their agreement in the rare peculiarity of having the two carpels

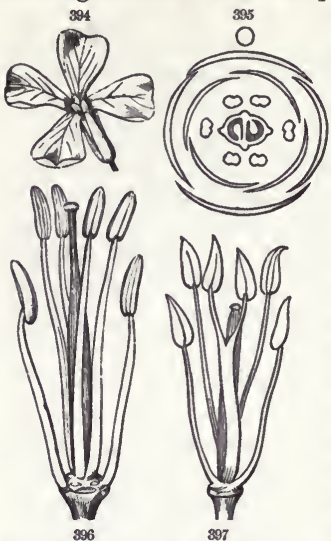

side by side instead of fore and aft (median), and the characteristic anomaly which the andrœcium presents (i.e. the tetradynamy), would give reason to expect that its problems might be solved by chorisis. Indeed, the doctrine was applied to this, long before its application to the other order. Beginning at the centre (Fig. 395, \&c.), the pistil is of two carpels, right and left ; alternate with these is a pair of stamens on the side next the axis, matched by another pair on the opposite side of the pistil, the four longer and interior stamens; alternate with these, and lower in insertion, a single stamen on each side ; next, four petals, of somewhat various overlapping in æstivation, which essentially alternate with the two single stamens and the wwo pairs ; lastly, four sepals, alternating with the four petals as a whole, the anterior and posterior overlapping the lateral ones in the bud. Now the median (i.e. the anterior and posterior) pairs of stamens occasionally have their contiguous filaments conjoined, as in Fig. 397. If this were at all constant, the inference would undoubtedly be that the case is one of chorisis, and that the flower as to its essential organs is dimerous. This is apparently the best explanation to be given. It assumes that the chorisis is normally complete in the andrœcium of Cruciferæ, instead of incomplete, as in Fumariaceæ. ${ }^{1}$ And this view is confirmed by the fact that the median stamens are simple and

1 The hypothesis here adopted, as to the andrœcium, is that of Steinheil (1839), and of Eichler (in Flora, 1865, 1872, and Blüthend. ii. 200), replacing that of Kunth, 1833, \&c., employed in former editions. The rejected view makes the flower 4-merous up to the pistil, and the stamens all of one circle, alternating with the four petals, the median stamens (as in our view) doubled by chorisis. Krause and Wretschko (cited as above by Eichler) would have the floral circles 2 -merous and 4 -merous by turns; the calyx of two 2-merous circles (which it plainly is); the corolla of one 4-merous circle

FIG. 394. A cruciferous flower. 395. Diagram of such a flower, with position of axis marked above it. 396. Tetradynamous stamens and the pistil. 397. A common. monstrosity of the same, two of the four inner stamens combined into a common 2-antheriferous body. 
single in Senebiera and many species of Lepidium, in which the lateral or short stamens are at the same time abortive.

379. It is quite possible that chorisis may be extended to the corolla of the cruciferous flower, and reduce the whole to a symmetrical 2-merous plan, and to congruity in the perianth also with Fumariaceæ. The only obstacle is in the petals forming a whorl of four where all the rest is 2-merous, for the sepals are manifestly two decussating pairs. Now the median petals of Hypecoum are deeply 3-lobed. An abortion of their middle lobe would leave them almost two-parted: a little more would separate them ; then they would imitate the four cruciferous petals as in the diagram, Fig. 395. Applying this view to Cruciferæ, the blossom in the two orders would accord in having a 2 -merous three-whorled perianth, the first and third whorls median $;^{1}$ as also in the dimerous andrœeium, the first whorl of which is lateral. The difference is that in Fumariaceæ the two members of the first whorl of stamens augment by chorisis into three, and the second is wanting, or is present only in Hypecoum ; while in Cruciferæ the first whorl is simple (of the two short stamens), and the second is doubled. In Fumariaceæ only the first whorl of the perianth counts as calyx, and the corolla is of two whorls; in Cruciferæ, the first and second whorls are calyx, the inner sepals answering to the outer petals of Fumariaceæ.

380. Chorisis along with anteposition of stamens is well

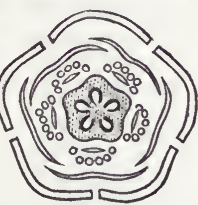

398

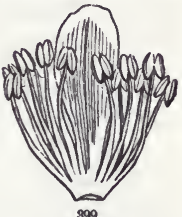

899 seen in Tilia or Linden, at least in the American species. In these the indefinitely numerous stamens are in five clusters, one before each petal (Fig. 398, 399), and there is a petal-like body

alternating with the calyx-members as a whole; the short stamens following as a 2 -merous circle; then the long stamens as a 4 -merous circle; lastly the 2-merous gynocium. G. Henslow (in Trans. Linn. Soc. ser. 2, i. 195) would have the flower 4-merous by the suppression of the fifth members of a 5 -merous type, and a further suppression of half of the remaining exterior stamen-circle, \&c. Finally, there is the much better-maintained view that the cruciferous flower is 2-merous throughout, as explained in the following paragraph, 379 .

1 This view was taken by Steinheil, in Ann. Sci. Nat. ser. 2, 337 (1839), and is essentially reproduced by a Russian botanist, Meschajeff, in Bull. Soc. Imp. Nat. Mosc. 1872.

FIG. 398. Diagram of the flower of Tilia Americana, the common American Linden or Basswood.

FIG. 399. A detached stamen-cluster with its petal-like scale. 
in each cluster with which the stamens cohere. The explanation by chorisis is that each cluster, petal-like body included, is a multiplication of one stamen. The diagram (Fig. 398) accurately shows that most of the stamens originate from the outer side of the base of the petal-like portion : this is most naturally explained by median chorisis. The superposition of the clusters to the petals will take the same explanation as that of Rhamnus, Vitis, \&c. (Fig. 363.) That the andrœcium is here composed of the inner circle merely is partly confirmed by the alternation of the carpels with the clusters. According to Duchartre, ${ }^{1}$ the development of the andrœcium in a Mallow indicates a similar structure; for the whole united mass originates from five protuberances, one before each forming petal and connected with it, this by collateral chorisis forming a cluster of stamens, and the five clusters coalescing as they develop into a tube of filaments, such as in Fig. 485. Now Hibiscus and its near relatives have a naked tip to the stamen-tube, ending usually in five teeth; and Sidalcea, as is most strikingly shown in the Californian S. diploscypha, has two series of stamens, the outer (answering to those of Malva and its relatives) in five membranaceous phalanges, superposed to the petals; the rather numerous inner series, more or less in phalanges, surmounts an interior filament-
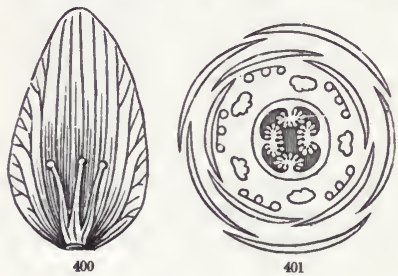
but with the stamen-clusters before the petals wholly sterile, and of fewer divisions, while an inner circle of five stamens

1 Comptes Rendus, 1844, \& Ann. Sci. Nat. ser. 3, iv. 123. Duchartre and others who draw freely upon median chorisis to explain anteposition, and consider that congenital union proves it, take the phalanges in these cases, like the single stamens in Vitis, to be an inner part of the petal itself. But this view appears to have had its day.

2 Gray, Gen. Illustr. ii. 44, 57, 75-82. The position of the carpels before the petals in Pavonia and Malvaviscus brings the former into symmetrical alternation with such an inner stamen-circle; but it is not so in Hibiscus, which has the carpels before the sepals.

FIG. 400. A petal of Parnassia Caroliniana, with a triple staminodium before it.

FIG. 401. Diagram of the flower of Parnassia Caroliniana. 
alternate with the petals forms the effective andrœcium. For the scale-like body before each petal, and even slightly adnate to its base (in P. Caroliniana about 3-parted, as in Fig. 400, but in $\mathrm{P}$. palustris a thin scale, fringed with more numerous glandtipped filaments), is plainly outside the stamens in the full-grown flower-bud. But Eichler and Drude have found that it is inside in the early bud. ${ }^{1}$ Wherefore, if these stamen-like bodies really represent a circle of the androcium, it must be the inner one; and that is the more probable view.

382. Multiplication by chorisis in the gynœcium is not common; but there are well marked instances of it in all degrees. In Drosera, the styles and stigmas are doubled (Fig. 402); in Malvaceæ, the same thing takes place in Pavonia and its allies; while in Malope and two other

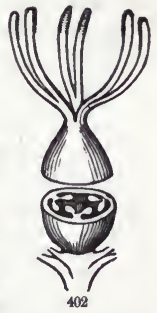
genera of the same order the few normal carpels are multiplied, evidently by chorisis, into an indefinite number of wholly distinct ones.

\section{§ 8. OUTGRowths.}

383. Proper chorisis is the congenital multiplication of one organ into two or more of the same nature and office; or at least into two or mpre organs, even if dissimilar, as in the American Lindens, in which one member of the cluster is a kind of petal. Between this and the production by an organ of appendages, or outgrowths of little or no morphological signification, there are many gradations; as also between these and mere cellular outgrowths from the surface, even down to bristles and hairs. The latter, in all their variety and modifications, are properly outgrowths of the epidermis only, and therefore consist of extended cells, single or combined, unaccompanied by vascular or woody tissue. To them has been given the general name of Trichomes (Trichoma, pl. trichomata), that is structures of which hairs are the type. They may occur upon the surface of any organ whatever. Their morphology is the morphology of cells rather than of organs. They will therefore be most conveniently illustrated ander Vegetable Anatomy as

1 Eichler in Fl. Brasil., Sauvagesiacæ, \& Blüthend. ii. 424; Drude in Linnæa, xxxix. 239. Eichler refers to this as a confirmation of Celakowsky's explanation of obdiplostemony by posterior displacement. (365.)

FTG. 402. Pistil of Drosera filiformis with tricarpellary ovary (transversely divided), and six styles, i. e. three, and each two-parted. 
respects their structure, and in the Glossary as respects terminology.

384. But into some bristles, such as those of Drosera, a subjacent stratum of tissue enters, including one or more ducts or even some woody tissue. Prickles are of this class; and from the most slender, which pass into bristles, there are all gradations of stoutness and induration. Such outgrowths may even be formed in most regular order, as the prickles on the calyx-tube of Agrimonia and scales on the acorn-cup of Oaks, and yet have no morphological importance. On the other hand, true representatives of leaf or stem may, by abortion and depauperation, be reduced to the structure as well as the appearance of trichomes. Examples of this are familiar in the pappus (answering to limb of the calyx) of many Compositæ, and in the bristles which answer to perianth in many Cyperaceæ. The scarious stipules of Paronychia and of Potamogeton, the ligule of Grasses, and even the corolla in Plantago, are equally reduced to mere cellular tissue. So that the structural difference between trichomes and outgrowths $^{1}$ is not at all absolute, and the morphological distinction must rest upon other ground than anatomical structure.

385. Among the corolline outgrowths most akin to chorisis is the Crown (Corona) of Silene and allied Caryophyllaceæ, at the

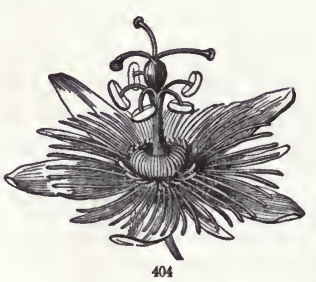

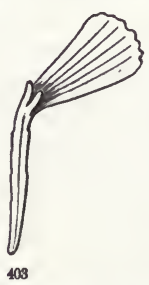
junction of the claw with the blade of the petals (Fig. 403), the analogy and probable homology of which to the ligule of Grasses (Fig. 150) is evident ; also the many-rayed filamentous crown of

Passion-flowers (Fig. 404), which consists of two or more series of such outgrowths. In Sapindus and some other Sapindaceæ, these ligular outgrowths or internal appendages are more like a doubling of the petal; as also in Erythroxylum, where they

1 This is the best English name for the Emergenzen of the Germans, the Epiblastema of Warming, \&c. For the development and discussion of this subject, see Warming, in Kjöbenhavn Vidensk. Meddel. 1872, and a larger treatise on Ramification in Phanerogams, Copenhagen, 1872. Also, Uhlworm in Bot. Zeit. 1873; Celakowsky in Flora, 1874; and Eichler's note on Emergenzen in Blüthendiagramme, i. 48.

FIG. 403. Petal of Silene Pennsyivanica, with its crovon.

FIG. 404. Flower of Passiflora cærulea, reduced in size. 
are often more complicated in structure. They are always on the inner face, and are commonly two-lobed or parted.

386. Similar stamineal appendages are well known in Cuscuta (Dodder), in Larrea (Fig. 405) and other Zygophyllaceæ, and less conspicuously in Gaura.

387. To extend to them the name of Ligule may not be amiss, whether they are regarded as mere outgrowths of floral leaves, without further morphological relations, or whether they be, at least sometimes, interpreted as the homologue of intrapetiolar stipules, as their ordinarily two-cleft form, and their

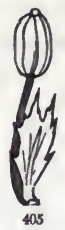
coincidence in Erythroxylum with an intrapetiolar two-cleft stipule suggest.

\section{§ 9. Forms of the Torus or Receptacle.}

388. Torus is the more specific and proper name, RECEPTACLE is the more usual. (303.) A normal receptacle of the flower would be that of Fig. 316, the apex of the flower-stalk somewhat enlarged, roundish or depressed, and with surface mainly covered by the insertion of the several organs; the several internodes which it potentially contains being undeveloped. As the members of the flower multiply and occupy numerous ranks, the receptacle enlarges or lengthens to give them insertion or standing-room.

389. Of elongated forms of receptacle, Magnolia and Liriodendron or Tulip-tree give familiar instances. The lengthening in the former is mainly for the support of both andrœcium and gynœcium; in the latter, as in Myosurus, mainly for the gynœcium only. The fall of the matured carpels reveals it as a very slender or bodkin-shaped prolonged axis. Of broadened forms, the Strawberry, even in blossom, affords a familiar example. (Fig. 406.) In the same order, Rubus odoratus shows a very broad and flat
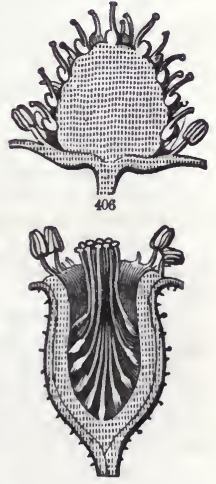

407 receptacle: in roses, it is so deeply concave as to become the reverse of the strawberry (Fig. 407), being urn-shaped with a narrow mouth, upor which the petals and stamens are borne,

FIG. 405. Stamen of Larrea Mexicana, with a conspicuous ligulate appendage at the base within.

FIG. 406. Receptacle of a strawberry in longitudinal section. 407. Same of a rose, in disgram. 
while the pistils line the walls of the cavity, the base or centre of this cavity answering to the apex of the strawberry.

390. Sometimes internodes are lengthened between certain members. In Schizandra, the receptacle, barely oblong in blossom, lengthens greatly in fruiting, so as to scatter the carpels on a long filiform axis.

391. In many Gentians, in Stanleya and Warea among Cruciferæ, and in most species of Cleome, the internode of the

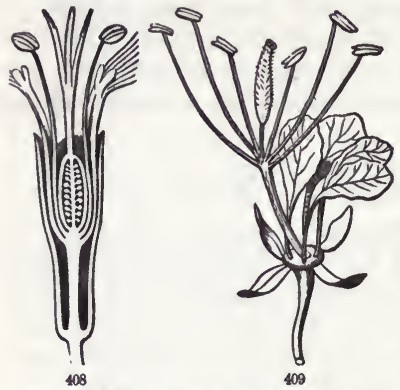
receptacle between stamens and pistil is developed into a long stalk to the latter. Gynandropsis (Fig. 409) is like its near relative, Cleome, except that this very long stalk has the lower part of the stamens adnate to it: the internode between the corolla and calyx is broad and slightly elevated (or in Cleome, \&c., narrower and longer); and so the several floral circles are as it were spaced apart by this unusual development of receptacular internodes. In Silene (Fig. 408) and many other plants of the Pink family, an internode between the calyx and corolla is prolonged into a stalk or Stipe. ${ }^{1}$

1 STIPE is the general name of a stalk formed by the receptacle or some part of it, or by a carpel. To distinguish its particular nature in any case, the following terms are more or less employed:-

TheCaPhORe, for a stipe which belongs to a simple pistil itself (where it is homologous with a petiole), and is no part of the receptacle, as in Coptis or Goldthread.

GrNophore, where the stipe is an internode of receptacle next below the gynœcium, as the pod-stalk in some Cruciferæ, Cleome, and Gynandropsis.

GoNOPHORE, when it elevates both stamens and pistil, as it seemingly does in the lower stipe of Gynandropsis, Fig. 409.

Anthophore, when the stipe is a developed internode between the caly $x$ and corolla, as in the Pink family, Fig. 408.

GYNOBAsE is a term properly applied to a short and comparatively broad portion of receptacle on which the gynœcium rests, as in Rue and Orange (Fig. 414), Houndstongue, Sage, \&c. This may extend up between the carpels and pass into, or the upper part become a

Carpophore, a name properly applied to a portion of receptacle which is prolonged between the carpels as a central axis, as in Geranium (Fig. 411) and many Umbelliferæ, Fig. 412.

FIG. 408. Section of a flower of Silene Pennsylvanica, showing the stipe or anthophore.

FIG. 409. Flower of Gynandropsis, with floral circles separated on the elongated receptecle. 
392. Instead of forming a stalk, the elongation may be continued between the carpels in the form of a slender axis, as in Gera-

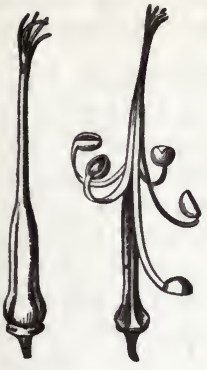

410 nium (Fig. 410, 411), and in the carpophore of the fruit of Umbelliferæ, Fig. 412. In Geranium, this prolongation of receptacle

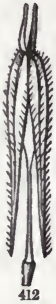

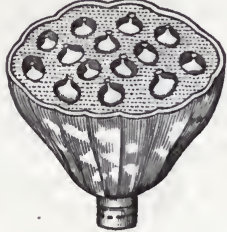

418

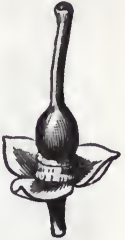

414

extends far above the ovaries as a beak, to which the styles are adnate for most of their length.

393. In Nelumbium (Fig. 413), the gynophore, or portion of receptacle above the stamens, is enlarged into a singular broadly top-shaped body, with a flat summit, in which the pistils (a dozen or more isolated carpels) are separately immersed.

394. A Disk is a part of the receptacle, or a development of it, enlarged under or around the pistil. When under it or around its base and free from the calyx, the disk is hypogynous, as in Orange, Fig. 414. Here it is a kind of gynobase. When adherent to or lining the base of the calyx, it is perigynous, as in

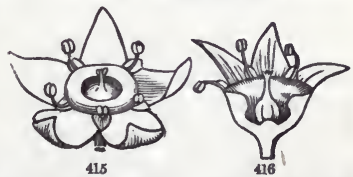
Rhamnus (Fig. 415, 416) and Cherry (Fig. 337) : when carried by complete adnation up to the summit of the ovary, it is epigynous, as in Cornus, in Umbelliferæ, \&c. Not rarely it divides into lobes, as in Vitis (Fig. 379, 380), in Periwinkle and most Apocynaceous plants, and in Cruciferæ. These are termed glands of the disk, and indeed are commonly glandular or nectariferous.

FIG. 410. Gyncelum of Geranium maculatum. 411. The same with fruit mature, the five ovaries or cells and the lower part of thelr styles separated and recurving away from the prolongation of the axis or receptacle, to which they were at flowering-time firmly attached.

FIG. 412. Mature fruit of Osmorrhiza, the two carpels splitting away below from the filiform prolongation of the receptacle, or carpophore.

FIG. 413. The top-shaped receptacle of Nelumbium, with the pistils, Immersed in hollows of its npper face.

FIG. 415. Flower of a Rhamnus or Buckthorn, and 416, section of the same, showing a thlckened perigynous disk. 
It is not possible by any direct demonstration to distinguish between such productions of the receptacle, which are classed as belonging to the axis, and suppressed or undeveloped phyllous organs, such as stamens, which glands of the disk may sometimes represent.

395. Hypanthium. Inspection of Fig. 415, 416, and 337, and comparison with Fig. 339, will suggest an explanation differ-

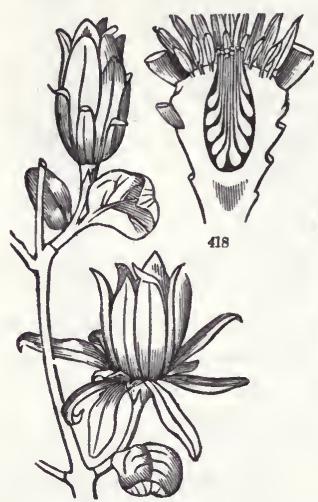

417 ent from that which is generally adopted. Instead of regarding the calyx as beginning on a level with the base of the ovary, and the cup as lined, more or less thickly, by an expansion of the receptacle (the

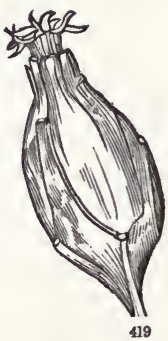
perigynous disk), the calyx may be understood to begin where this and the ovary become free from each other. Underthat view, the receptacle, instead of convex or protu berant, is here concave, has grown up around the ovary, which, however, is free from the cup in the earlier cited figures, but immersed in it in Fig. 339 and the like. A comparison with a rose-hip, an apple, and a pear much strengthens this interpretation, which is rather largely adopted at this day, at least theoretically. It was perhaps first proposed by Link, who introduced the appropriate name of Hrpanthum. A hypanthium or hypanthial receptacle is, as the name betokens, a flower-axis or receptacle developed mainly under the calyx. The name is a good one, in any case; and such structures as those of Calycanthus (Fig. 417-419), a rose, a pear (the lower part of which is evidently an enlargement of peduncle), and of Cactus-flowers (Fig. 317), although quite compatible with the theory of adnation, are more simply explained by it. ${ }^{1}$

1 But, whether the cases are well distinguishable or not, it by no means follows that the receptacle plays such a part in all instances of perigyny and of inferior or partly inferior ovary. Such a view is attended by more difficulties than the other. Unless the mediation of an invisible receptacle must

FIG. 417. Flowering branch of Calycanthus. 418. Vertical section of the urn-shaped receptacle, the imbricated bracts or sepals on its surface cut away. 419. Mature fructiferous receptacle entire, showing some scars from which the bracts have fallen. 
Section IV. Certan Adaptations of the Flower to the Act of Fertilization.

\section{§1. In General.}

396. The introduction into morphological botany of the considerations now to be mentioned should have dated from the year 1793, in which Christian Conrad Sprengel published his curious treatise on the structure of flowers in special reference to insect aid in their fertilization. For this book, which was wholly neglected and overlooked for more than sixty years, contains along with some fanciful ideas the germs of the present doctrine and many excellent illustrations of it. ${ }^{1}$ The interest in the doctrine now prevalent is witnessed by a copious special literature, beginning with the publication, in 1862, of Darwin's book on the fertilization of Orchids by the aid of insects. ${ }^{2}$

be invoked whenever there is a junction of two dissimilar organs, the petals and stamens of a Lythrum or a Cuphea are united with the calyx itself, instead of calyx beginning at the top of a long and simple tube. And if three or more of the floral whorls may be congenitally united, why not these also with the remaining one? Van Tieghem, in his Anatomie Comparée de la Fleur, maintains wholly the old view, founding it upon anatomical structure and his ability to trace down to the base of the ovary the distinct vascular bundles of the several involved organs.

1 C. C. Sprengel, Das entdeckte Geheimniss der Natur im Bau und der Befruchtung der Blumen, Berlin, 1793. Even earlier, Koelreuter (Vorlaufige Nachricht, etc., 1761-1766) recognized the necessity of insect-aid to various blossoms, and described some special contrivances for the purpose.

${ }^{2}$ Charles Darwin, On the Various Contrivances by which British and Foreign Orchids are fertilized by Insects, and on the Good Effects of Intercrossing, London, 1862. Ed. 2, 1877. This last contains a list of the papers and books which bear upon the subject, published since 1862 .

Other leading works and papers on the subject are, exclusive of the other volumes and papers of Darwin, more or less referred to hereafter.

Treviranus, Ueber Dichogamie, \&c., in Bot. Zeitung, xxi. 1863.

Hugo von Mohl, Einige Beobachtungen über dimorphe Blüthen, Bot. Zeitung, xxi. 1863.

Delpino, Pensieri sulla Biologia Vegetale, \&c., 1867. Relazione sull' Apparecchio della Fecondazione nelle Asclepiadie, \&c., 1867. Ulteriore Osservazioni sulla Dichogamia, \&c., 1868-69, 1870, and later papers.

Axell, Om anordningarna för de Fanerogama Växternas Befruchtung, Stockholm, 1869.

Hildebrand, Die Geschlechter-Vertheilung bei den Pflanzen, 1867, and other papers.

Hermann Müller, Die Befruchtung der Blumen durch Insekten, 1873, and papers in "Nature" and elsewhere.

"Flowers and their Unbidden Guests," an English translation of a work by Professor Kerner, which describes arrangements in blossoms for excluding unwelcome guests, has not yet reached us. It introduces the new terms Autogamy and Allogamy, defined on the following page; the latter compre- 
397. The subject, here considered as a part of morphology, must be fully treated, as regards acts and processes, under physiology. Every thing in the flower is in relation to fertilization and fructification, directly or indirectly. This section is concerned with those adaptations of structure by means of which agents external to the blossom are brought into service for its fertilization.

398. Linnæus and his successors taught that the adjustments in hermaphrodite flowers were such, on the whole, as to secure the application of the pollen of its stamens to the stigma of its pistil or pistils. The present view is, that this is doubtless strictly secured in certain flowers of a moderate number of species, but never in all the flowers of any such species; that in ordinary flowers, where it may commonly take place, it is not universal; that in the larger number of species there is something or other in the floral structure which impedes or prevents it. Some flowers are adapted for close fertilization; some for cross fertilization; some for either. Here two terms need definition, viz. :

Close fertilization or Self-fertilization, or Autogamy, the application and action of a flower's pollen upon its own pistil ;

Cross fertilization, or Allogamy, the action of the pollen of one flower on the pistil of some other flower of the same species. This may be near, as when between flowers borne in the same cluster or on the same plant; remote, when between flowers of distinct plants of the same immediate parentage ; most remote, when between different races of the same species. Any thing beyond this is hybridization, or crossing of species.

\section{§ 2. Adaptations for Allogamy or Intercrossing.}

399. The doctrine now maintained appears to have been first propounded by Sprengel in the statement that "Nature seems to have wished that no flower should be fertilized by its own pollen," - a proposition which is not wholly tenable, for there are blossoms specially adapted to self-fertilization. It was reaffirmed in our day by Darwin, in a similar adage, "Nature abhors perpetual self-fertilization," - a metaphorical expression to which no effective exception has been taken. And the inference was drawn by him, that some important good to the species must result from propagation through the union of distinct individuals, and especially of individuals which have been distinct for several or many generations.

hending Geitonogamy, fertilization by pollen of other flowers of the same plant, and Xenogamy, by pollen from a flower on another plant. 
400. The actual proposition, simply stated, is that flowers are habitually intercrossed, and that there are manifold structural adaptations which secure or favor intercrossing, to such extent as to justify the proposition. The proof of the proposition is an induction from a very great number of particular observations. That intercrossing is beneficial is a rational inference from the array of special adaptations for which no other sufficient reason appears, or (to resume the metaphor) from the vast pains which seem to have been taken to secure this end. This inference has been to some extent confirmed by direct experiment. ${ }^{1}$

401. Separation of the sexes is a direct adaptation to intercrossing, rendering it necessary between individuals in diœcious, and largely favoring it in most monœcious and polygamous flowers. Strictly close fertilization can occur in hermaphrodite flowers only ; but it is in these that the most curious adaptations for intercrossing are revealed.

402. The agencies to the one or the other of which most flowers are structurally adapted in reference to intercrossing are mainly two; viz., the winds and animals, of these chiefly insects. Delpino has accordingly classified flowers into Anemophilous and Entomophilous ; literally wind-lovers and insect-lovers, but denoting wind-fertilized and insect-fertilized, according to the agent by which pollen is transported. ${ }^{2}$ There are hermaphrodite and unisexual flowers of both classes, but most wind-fertilized flowers are unisexual.

403. Wind-fertilizable or anemophilous flowers are mostly neutral or dull in color, destitute of odor, and not nectariferous. Their principal structural adaptations to this end, besides the separation of the sexes in most of them, are the superabundance, incoherency, dryness, and lightness of the pollen, rendering it very transportable by wind and currents of air. The immense abundance of pollen, its lightness, and its free and far diffusion through the air in Pines, Firs, Taxodium, and other Coniferæ, are familiar. Their pollen fills the air of a forest during anthesis; and the "showers of sulphur," popularly so-called, the yellow powder which after a transient shower accumulates as a scum on the surface of water several or many miles from the

2 Darwin, The Effects of Cross and Self-Fertilization in the Vegetable Kingdom, London, 1876. American Edition, New York, 1877.

2 Ornithophilous, i. e. bird-fertilized, flowers are to be ranked with entomophilous. The large blossoms of Trumpet Creeper (Tecoma radicans) and of Trumpet Honeysuckle (Lonicers sempervirens), and others, are commonly visited and probably fertilized by humming-birds as well as by moths; and other birds are known to play a similar part in equatorial regions.. 
nearest source, testifies to these particulars. All amentaceous trees (Willows excepted), Hemp, Hops, \&c., are wind-fertilized ; and, among perfect flowers, those of most Grasses, Sedges, and Plantago. In the latter families especially, the anthers are protruded or hung out in the air only when just ready to discharge their pollen, and are at that moment suspended on suddenly lengthened capillary drooping filaments, fluttering in the gentlest breeze; and the stigmas are either dissected into plumes, as in most Grasses, or beset with copious hairs on which pollen is caught. One physiological adaptation, very common in the following class, is not unknown among hermaphrodite wind-fertilizable flowers, where it is important for securing intercrossing, viz. Dichogamy. It is best seen in the common species of Plantago or Plantain, and is described below. (408.)

404. Insect-fertilizable or entomophilous flowers are correlated with showy coloration (including white, which is most showy at dusk), odor, or secretion of nectar, often by all three modes of attraction to insects combined. Some insects, moreover, visit flowers for their pollen, a highly nutritious article, and ordinarily produced in such abundance that much may be spared. The showiness of corolla or other floral envelopes is an attractive adaptation to fertilization, enabling blossoms to be discerned at a distance; nor do we know that fragrance or other scent or that nectar subserves any other uses to the flower than that of alluring insects. Adaptations in the pollen of such blossoms for transportation by insects are various. Commonly the grains are slightly moist or glutinous, or roughish, or studded with projections, or strung with threads (as in Enothera), so as not to be readily dispersed in the air, but to have some slight coherence as well as capability of adhering to the head, limbs, or bodies of insects, especially to their rough surfaces; and in two families (Orchidaceæ, Asclepiadaceæ) the pollen is combined in masses and with special adaptations for being transported en masse. (421.) With this the stigma is usually correlated, by roughness, moisture, or glutinosity. ${ }^{1}$

405. Adaptations of the flower itself in reference to insect visitation are wonderfully various ; and most of these are found upon investigation to favor, or often to necessitate, intercrossing. In diœcious flowers, this is necessitated by the separation; in monœcious and polygamous flowers, of various kinds and

1 Thus nearly every Orchid genus but one has a persistently glutinous stigma ; in the exceptional one, Cypripedium, it is moist and minutely roughened, in correlation with the loosely granular or pultaceous pollen which it is to receive. 
vagrees of separation, pollen is very commonly borne from plant to plant; in hermaphrodite flowers only are more special arrangements needed to secure intercrossing or a certain measure of it, and in these such arrangements abound.

406. Irregularity is one of the commonest modifications of the flower $(326,337)$ : it is never conspicuous except in blossoms visited by insects and generally fertilized by their aid; and it finds rational explanation on the score of utility in this regard. ${ }^{1}$

407. Dichogamy, a term introduced by C. C. Sprengel, who first noticed and described it, is one of the most usual and effectual (rather physiological than morphological) adaptations for the promotion of intercrossing between hermaphrodite flowers. It means that such intercrossing is brought to pass by a difference in the time of maturity of anthers and stigma; this rendering dichogamous blossoms practically the same as diœcious or monœcious in respect to fertilization, while there is the economical gain that all the flowers are fertile. According to whether the anthers or the stigmas are precocious, dichogamous flowers are

Proterandrous (or Protandrous), when the anthers mature and discharge their pollen before the stigma of that blossom is receptive of pollen;

Proterogynous (or Protogynous), when the stigmas are in receptive condition before the anthers have matured their pollen.

Symanthesis, ${ }^{2}$ the maturing of the two sexes simultaneously or nearly so, is however made to secure the same result through special arrangements.

408. Proterogyny. The Plantains, such as Plantago major and $P$. lanceolata, are familiar instances of this in a wind-fertilized genus with hermaphrodite flowers. The anthesis proceeds from base to apex of the spike in regular order, and rather slowly. While the anthers are still in the unopened corolla and on short filaments, the long and slender hairy stigma projects from the tip and is receiving pollen blown to it from neighboring plants or

1 This did not escape the attention of Sprengel in the last century, and along with it the fact that strictly terminal and also vertical flowers, whether erect or suspended, are seldom irregular, while comparatively horizontal or obliquely set flowers more commonly are so. The irregularity is in reference to a landing place for the visiting insect, or also to storage of or accessibility to nectar, \&c.

Darwin (Forms of Flowers, 147) remarks that he does not know of a single instance of an irregular flower which is wind-fertilized.

2 Synacmy is the term proposed by A. W. Bennett, in Journal of Botany, viii. (1870), 316, with its opposite, Heteracmy, for proterandry and proterogyny. The latter names, in their shorter form (protandry and protogyny), appear to have originated with Hildebrand. 1867. 
spikes : a day or two afterwards, the corolla opens, the filaments greatly lengthen, and the four anthers now pendent from them give their light pollen to the wind; but the stigmas of that flower and of all below it on that spike are withered or past receiving pollen. Among Grasses, Anthoxanthum is in the same case. The arrangement is somewhat similar to the Plantain in Amorpha, which is fertilized by insects, the simple stigma projecting beyond the corolla in bud, while the anthers are still immature
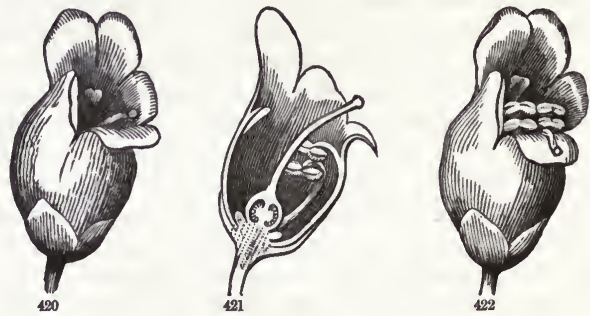

and enclosed. Scrophularia is a good instance of proterogyny in flowers fertilized by bees. The flower is irregular (Fig. $42(-422)$, and is approached from the front, the spreading lower lobe being the landing place. Fig. 420 represents a freshly opened blossom; and Fig. 421, a section of it. Only the style tipped with the stigma is in view, leaning over the landing place; the still closed anthers are ensconced below. The next day or a little later all is as in Fig. 422. The style, now flabby, has fallen upon the front lobe, its stigma dry and no longer receptive : the now-opening anthers are brought upward and forward to the position which the stigma occupied before. A honey-bee, taking nectar from the bottom of the corolla, will be dusted with pollen from the later flower, and on passing to one in the earlier state will deposit some of it on its fresh stigma. Self-fertilization here can hardly ever take place, and only through some disturbance of the natural course.

409. Proterandry. The process is the reverse, and is attended with much more extended movements in Clerodendron Thompsoniæ, a Verbenaceous tropical African climber now common in conservatories. The adaptations in this flower (which we indicated long ago) are exquisite. The crimson corolla and bright white calyx in combination are very conspicuous. The long filiform filaments and style, upwardly enrolled in the

FIG 420,421. Early opened flower of Scrophularia nodesa, and a longitudinal sectlun. 422. Flower a day or two later. 
bud, straighten and project when the corolla opens : the stamens remain straight, but the style proceeds to curve downward and backward, as in Fig. 423. The anthers are now discharging pollen : the stigmas are immature and closed. Fig. 424 represents the flower on the second day, the anthers effete, and the filaments recurved and rolled up spirally; while the style has

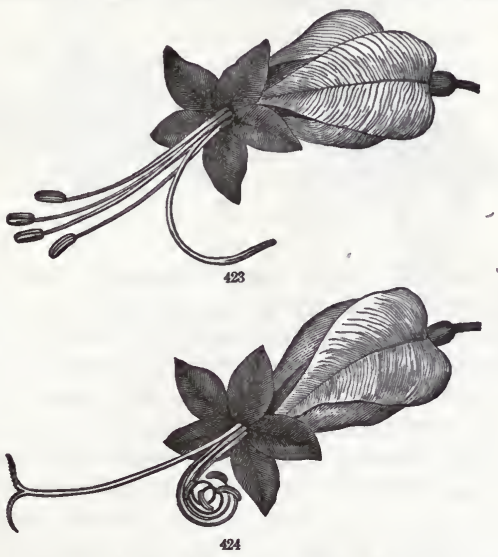

taken the position of the filaments, and the two stigmas now separated and receptive are in the very position of the anthers the previous day. The entrance by which the proboscis of a butterfly may reach the nectar at bottom is at the upper side of the orifice. The flower cannot self-fertilize. A good-sized insect flying from blossom to blossom, and plant to plant, must transport pollen from the one to the stigma of the other.

410. Proterandry abounds among common flowers. It is conspicuous in Gentians and in nearly all that family. But, while in Gentians the short style is immovable and erect, in Sabbatia it is thrown strongly to one side, out of the way of and far below the stamens, the branches closed and often twisted, so that the stigma is quite inaccessible until the stamens have shed their pollen : then the style becomes erect, untwists, its two flat branches separate, and expose the stigmatic surface of their inner face in the place which the anthers occupied. In Sabbatia angularis, Lester F. Ward ${ }^{\mathrm{I}}$ observed that the anthers of freshly

1 In Meehan's Gardeners' Monthly, September, 1878, 278.

FIG. 423. Flower of Clerodendron Thompsoniz, first day; 424, second day. 
opened blossoms are all thrown to one side almost as strongly as the style is thrown in the opposite direction. One of our common Fireweeds, Epilobium angustifolium or E. spicatum, as it is variously called, which is common all round the northern hemisphere, is similar to Sabbatia in behavior. In the freshly opened flower, while the anthers are in good condition and are

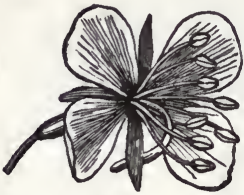

125

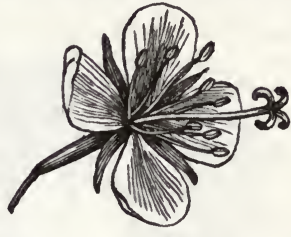

426

giving their pollen to bees, the still immature style is strongly curved downward and backward, as in Fig. 425. Two or three days later, when the pollen is mostly shed, the style straightens, lengthens to its full dimensions, and spreads its four stigmas over the line of the axis of the blossom (Fig. 426), in the very position to be pollinated by a bee coming from an earlier flower.

411. In the following instances of proterandry, the style is made the instrument of distributing the pollen which it is not

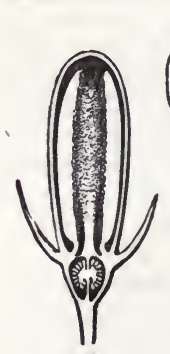

47

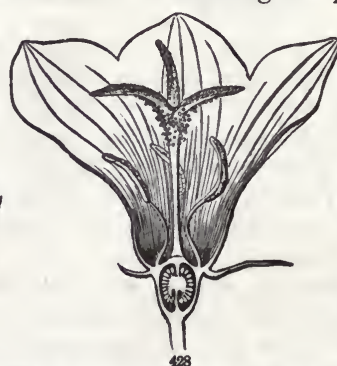

itself to use. The anthers of a Campanula discharge all their pollen in the unopened bud, and it is nearly all deposited on the style which they surround, the upper part of which is clothed with a coat of hairs for holding the pollen. (Fig. 427.) In the open flower, the stamens are found to be empty and withered, as in Fig. 428. These flowers are visited by bees and other insects for the pollen. While this is going on, and while the pollen is fresh and plentiful, no stigma is apparent. Later, the top of the style opens into three (in some species five) short and spreading branches, the inner faces of which are the stigmas. Although

FIG. 425,426 . Flowers of Epllobium angustifolium or spicatum; in the first, freshly expanded; in the second, a few days older.

FIG. 427. Vertical section of an unopened flower of Campanula rapunculodes: the broad white lines are sections of two anthers. 428. Same of an older flower. 
so close at hand, little if any of the pollen of that flower can reach the stigmas. These actually get fertilized by pollen brought by bees, which come loaded with it from other flowers and other plants. Symphyandra differs from a true Campanula chiefly in the continued cohesion of the five anthers into a tube around the style. (Fig. 429, 430.) The pollen is discharged on and held by the hairy upper portion of the style. Soon after, the corolla expands, the lower part of the style lengthens, and carries the pollen-loaded part out of and above the anther-tube, as in Fig. 430 ; lastly, the three connivent tips of the style diverge and expose the stigmas to pollen mainly brought by bees from other flowers. By a slight further modification in Lobelia and in Compositæ, pollen is pushed out of the anther-tube by the tip of the style as it lengthens, or by the very back of the two stigmas, the faces of which, afterwards exposed, are not to receive this, but other

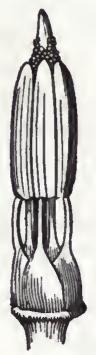

429

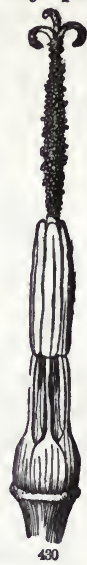
pollen, though it may at times receive some of its own. The arrangement in Compositæ is here illustrated from Leptosyne maritima (Fig. 431-435), a showy plant of Southern California, now not very rare in cultivation. The large flowers around the

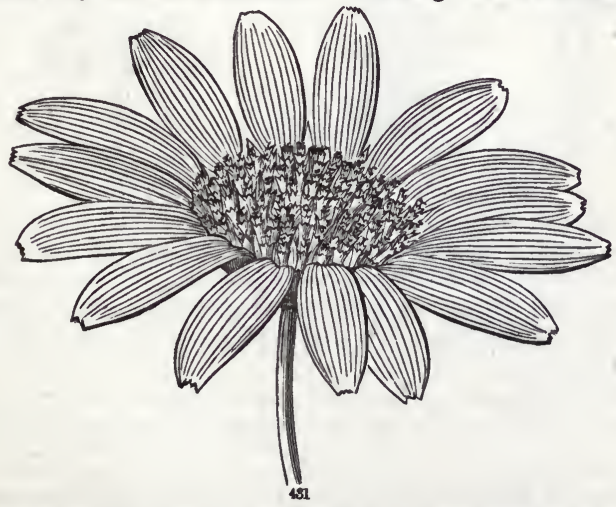

FTG. 429. Stamens and pistil of a young, and 430, same from an old flower of Symphyandra pendula.

FIG. 431. Head of flowers of Leptosyne maritima, of the natural size. 
margin (ray-flowers, with ligulate corolla), one of which is separately shown in Fig. 432, are pistillate only: the enlarged and

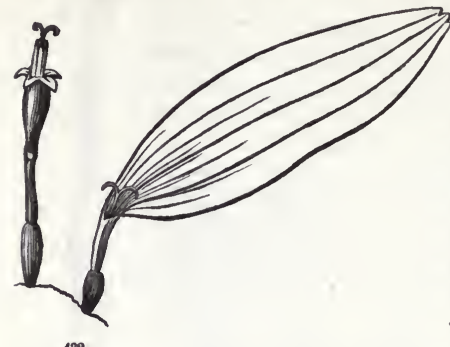

492 extended open part of the corolla (bright yellow in color) serves for attraction, the circle of rays gives the appearance as of a single large flower. The flowers of the disk or whole central part are hermaphrodite, and with narrow tubular corollas, from the orifice of which - projects the greater part of the tube of five coalescent anthers. The pollen is early discharged into the interior of this tube. The style, with somewhat enlarged and brush-like

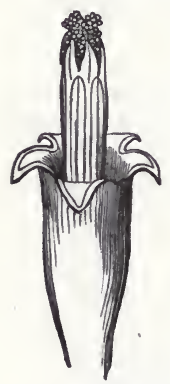

438

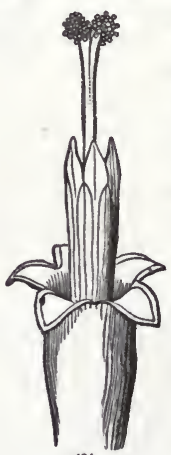

434 tip, at first reaches only to the bottom of the anther-tube: it slowly lengthens, pushes the pollen before it out of the tube (Fig. 433) and into the way of insects of various kind, which, travelling over the surface, convey it to older flowers of the same

head and of other plants. The style, elongating yet more, raises some of the pollen still higher (as in Fig. 434); and at length its two branches separate and diverge (Fig. 435), exposing to other pollen the stigmatic receptive surface which until now was unapproachable.

412. In Parnassia, which has sessile stigmas, their receptive surface is actually not formed until the anthers become effete;

FIG. 432. A ligulate female flower of the same, and a central hermaphrodite flower 433. Upper part of the latter, more enlarged, the tube of anthers projecting from the corolla, and the pollen projecting from apex of the anther-tube, being pushed np by the lengthening of the style beneath. 434. This style now projecting, and some pollen still resting on its tip. 435. Tip of same style (more advanced and magnified); the two branches spreading, still carrying some pollen on the apex $\alpha$ each arm or branch, and by the divergence now exposing the stigmatic inner faces. 
and, as the plants or stems are single-flowered, they are functionally diœcious while structurally hermaphrodite.

413. The adaptations for hermaphrodite intercrossing with synanthesis (407), i.e. where there is no essential difference of time in the maturing of anthers and stigma, are manifold. They may be classed into those without and those with dimorphism of stamens and pistils, or, in other words, those with Homogonous and those with Heterogonous flowers. ${ }^{1}$

414. The cases without dimorphism are the most various, certain families having special types; and are of all degrees, from those that require intercrossing to those that merely favor or permit it. For the present purpose, having only morphology in view, it suffices to bring to view two or three cases or types of

415. Particular Adaptations in hermaphrodite blossoms, not involving either dichogamy or dimorphism. These are exceedingly various; but they may be distinguished into two general kinds, namely: 1, where loose and powdery pollen is transported from blossom to blossom in separate grains, and 2, where pollen-masses or the whole contents of anthers are bodily so transported.

416. Papilionaceous flowers (such as pea-blossoms, 338) - having ten stamens enclosed with a single pistil in the keel of the corolla, their anthers in close proximity to the stigma were naturally supposed to be

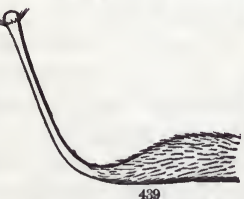

439
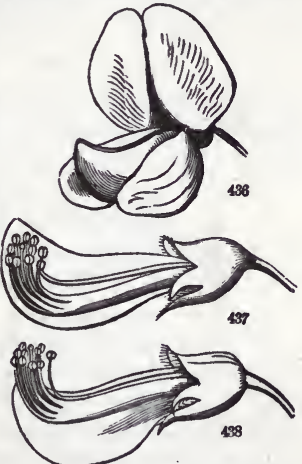
self-fertilizing; and so they sometimes are, yet with marked adaptations for intercrossing. None are less so than those of

1 Terms proposed in Amer. Jour. Sci. ser. 3, xiii. 82, and in Amer. Naturalist, January, 1877. Dimorphism in flowers may affect the perianth only, and not the yovh or essential organs; or there may be two kinds of flowers as respects these also, but with no reciprocal relations, as in cleistogamous dimorphism (534); or of two kinds essentially alike except in stamens and pistil, and these reciprocally adapted to each other, which is heterogonous dimorphism, or, when of three kinds, trimorphism.

FIG. 436. Flower of Wistaria Sinensis, natural size. 437. Same enlarged, with standard, wings, and half the keel removed. 438. Same with the keel depressed, as it is when a bee alights on this its usual landing place, the cluster of anthers and stigma thus brought up against the bee's abdomen. 439. Style and stigma, with part of the ovary, more magnified, a fringe of fine bristles around the stigma. 
Wistaria (Fig. 436-439), in which the light fringe of stiff hairs around the stigma (shown in Fig. 439) would not prevent pollen of surrounding anthers from falling upon it. Yet when a bee

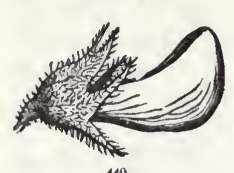

40

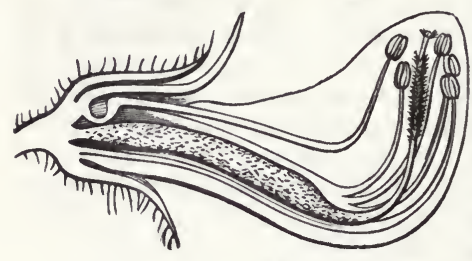

42

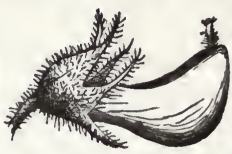

441

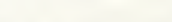

alights upon the keel,

with head toward the base of the flower, and proboscis is inserted for nectar between the foot of the standard and the keel, the latter is depressed by the weight, so that the abdomen of the insect is brought against the ten anthers and the stigma, becoming thereby smeared with pollen, some of which when other blossoms are vis-

ited cannot fail to be applied to their stigmas. The very similar flower of Locust (Robinia), like that of the Pea, adds an adaptation in favor of intercrossing. The style for some length below the stigma is covered with a short beard of hairs, as is seen in Fig. 442. The anthers open early and discharge their pollen, which mainly lodges on this beard (Fig. 443), in a manner which may thus far be likened to the case of Campanula. (411.) The wings and the keel are yoked together, and are together depressed by the weight of an alighting bee. This does not bring out the anthers as in 443

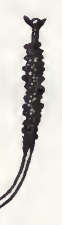

Wistaria, stigma and the pollen-laden part of the style (Fig. 441) are projected against the bee's abdomen, which, by the oblique movement, is first touched by the stigma and next brushed over with pollen by the style below. So that, in visiting a succession of blossoms, some pollen of one flower is transferred to the body of the bee, and thence to the stigma of the next flower, which flower immediately gives to the same spot some of its pollen, to be transferred to the next flower's stigma, and so on.

417. Two special modifications of the papilionaceous type

FIG. 440. Flower of Robinia hispida, the standard and wings removed. 441. Same, as depressed by the weight of a bee, causing the stigma and pollen-laden tip of the style to protrude. 442. Enlarged section of same in the bud, leaving one keel-petal, half the stamens, and the plstil in view. 443. Style and stigma at a later period, the beard losded with pollen; more magnifled. 
need particular mention. One of them, the Bean-blossom, is well known to botanists; the other not so. The peculiarity in the common Bean, Phaseolus vulgaris, and its nearest relatives, is that the keel, enclosing the stamens and pistil, is prolonged
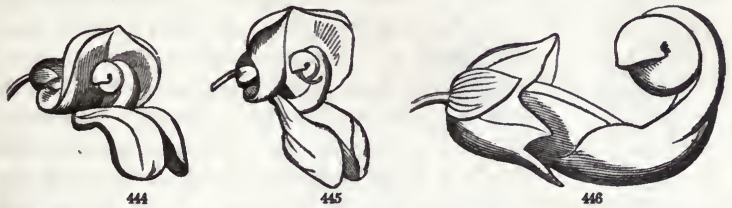

into a narrow snout which is spirally coiled (as in Fig. 444-446) ; that the stigma is oblique on the tip of the style, and the beard on the style is mainly on the same side that the stigma is : the wing-petals stand forward and turn downward, forming a convenient landing place for bees. As in the Locust-blossom, the anthers early discharge their pollen, much of which adheres

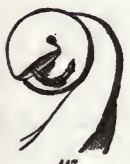

417

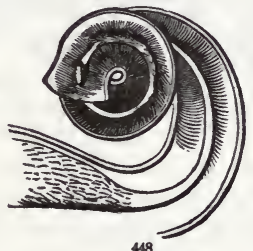

48

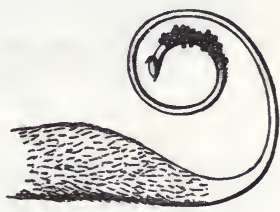

49

lightly to the beard of the style. In the untouched flower, all from first to last is concealed in the coiled keel. Press down the wing-petals, and first the stigma and then the pollen-laden tip of the style projects from the orifice: remove the pressure, and they withdraw within. When this pressure is made by a bee, resting on the wing-petals while searching for nectar within the base of the blossom between the keel and the standard, the same movement occurs: the stigma first, and then the pollen on the style, strikes against a certain portion of the front or side of the bee's body, and the repetition of this operation causes the fertilization of each blossom by other than its own pollen. A slighter pressure or lighter movement of the wing-petals suffices

FIG. 444. Flower of Garden Bean, Phaseolus vulgaris. 445. Same with wingpetsls pressed down and tip of style projecting from the orifice of the keel. 446. Same as 444 enlarged, and standard and wings removed. 447. Upper part of keel, in the condition of 445, enlarged, showing plainly the projecting style. 448 Section of the keel, enlarged, showing the style within before the anthers open: stamens for sake of clesrness not delinested. 449. Pistll detached from an older flower; the brush loaded with pollen. 
to jostle some of the pollen down upon its own stigma, so that self-fertilization is not uncommon.

418. Apios tuberosa, a near relative of Phaseolus, exhibits a different and equally curious modification of the same parts.

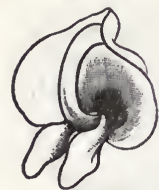

450

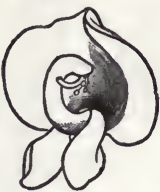

451

The wing-petals for landing place are similar: the standard is proportionally large, firm in texture, and shell-shaped or concave, with a small boss at the tip as seen from behind, or a shallow sac as seen from the front: the keel is narrow and sickle-shaped; it arches across the front of the flower, and the blunt apex rests in the notch or shallow sac of the tip of the

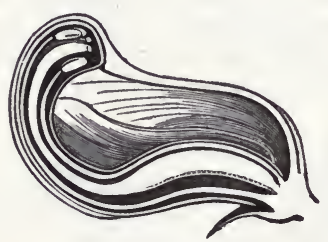

452

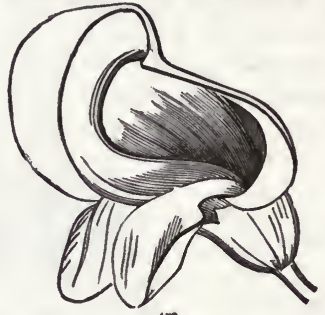

458

standard. (Fig. 450, 452, 453.) So it remains if untouched until the blossom withers : no self-fertilization has ever been observed,

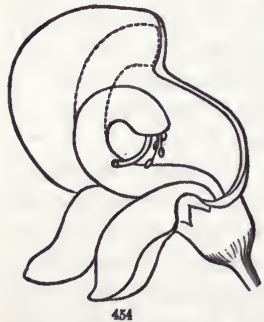
and none ordinarily occurs. The anthers are assembled close around the stigma, but a little short of it (Fig. 452); the pollen is not early nor copiously shed in the enclosure: the small terminal stigma is at first covered with a pulpy secretion, which at length collects into a soft ring around its base over or through which no pollen passes. But when the keel is liberated by lifting from underneath, it curves promptly into the shape shown in Fig.

FIG. 450. Flower of Apios tuberosa, unvisited. 451. Same after visitation, the keel dislodged from the retaining notch, and more incurved; the tip of the style protruded and thrust forward, followed by the anthers.

FIG. 452. Enlarged vertical section of flower-bud of Aplos tuberosa. 453. A flower with half the standard cut away, to show the blunt apex of the keel resting in the notcil. 454. Diagram of flower, with half of the standard cut away, to show what takes piace when the apex of the keel is liberated. The figures (also those from 423 to the present), and the first account of the adaptations of Aplos, were published in the Ameriosn Agriculturist in 1876. 
451, or better in Fig. 454, where the dotted lines indicate its original position; and first the end of the style, tipped with its stigma, is pushed forward, and then the anthers come into view. The flowers are visited by humble-bees, and sometimes by honey-bees. In searching for nectar at the base of the flower, they probably push forward into the space under the arching keel, and by slightly elevating dislodge its apex; when first the stigma and then the anthers are brought against some portion of the insect's body, and against the same portion in succeeding blossoms, thus effecting cross-fertilization. This rationally explains a remarkable adaptation, which seems to be not otherwise intelligible.

419. Special Adaptations. Two of these, each peculiar to the genus, may here be referred to. In Kalmia-blossoms (Fig.
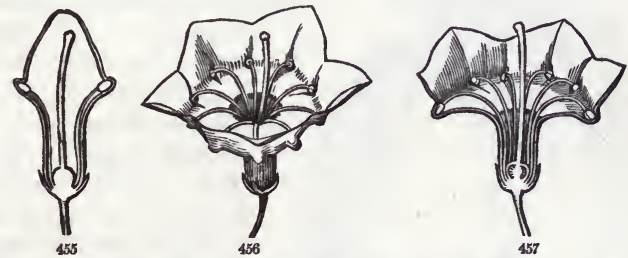

455-458), the anthers discharge the pollen through a small orifice at the apex of each cell, in this respect agreeing with Rhododendrons and their other relatives; but none of them utilize this family peculiarity in the manner of Kalmia. In the flower-bud, each of the ten anthers is lodged in a small cavity or pocket (externally a boss) of the corolla, in a way analogous to that in which the keel of Apios is lodged in the tip of the standard (418): the expansion of the border of the corolla in anthesis curves the filaments outward and backward; and when the bowed

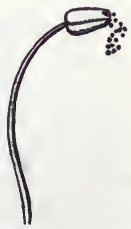
stamens are liberated by rough jostling they fly up elastically, and the pollen is projected from the two orifices. Some pollen may possibly be thrown upon the single small stigma at the tip of the style, which rises much above the stamens. But the anthers are not dislodged when undisturbed, at least until after the elasticity of the filaments is lost: they are dislodged by humble-bees, which circle on the wing over the blossom, the

FIG. 455. Vertical section of a flower-bud of Kalmia latifolia, showing the anthers lodged in the pockets of the corolla. 456. Expanded flower, with bowed stamens. 457. Vertical section of the same. 458. A stamen, enlarged. 
under side of the abdomen frequently touching the stigma, while the proboscis is searching round the bottom of the flower, liberating the stamens in the process, which one by one project their pollen upon the under side of the insect's body. In the passage from flower to flower, pollen is thus conveyed from the anthers of one to the stigma of another.

420. Iris has three stamens, one before each sepal or outer lobe of the perianth, and behind each petal-like lobe of the style

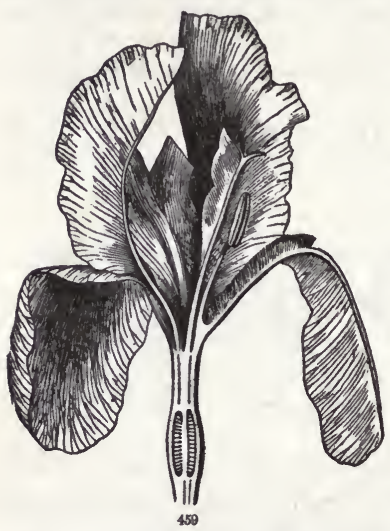

(Fig. 459) : the stigma, a shelf-like plate of each lobe, is just above the anther; but, as the anther faces outward and the stigma is higher and faces inward, no pollen can find its way from the one to the other. But the adaptation of parts is admirable for conveyance by bees, which, standing upon the only landing place, the recurved sepal, thrust the head down below the anther, and in raising it carry off pollen, to be afterwards lodged upon the stigmas of other flowers which they visit.

421. Transportation of Pollinia, or of all the pollen in a mass, is effected in most of the species of two large orders, not otherwise allied, the Asclepiadaceæ and the Orchidaceæ. While in the Iris family the number of stamens is reduced from six to three, in all the Orchis family, except Cypripedium, the stamens are further reduced to a single one; but the pollen is peculiarly economized. That of Arethusa is in four loose and soft pellets, in an inverted casque-shaped case, hinged at the back, resting on a shelf, the lower face of which is glutinous stigma, over the front edge of which the casque-shaped anther slightly projects; and this anther is raised by the head of a bee when escaping out of the gorge of the flower. The loose pellets of pollen are caught upon the bee's head, to the rough surface of which they are liable to adhere lightly and so to be carried to the flower of another individual, there left upon its glutinous

FIG. 459. Flower of Iris pumila, with front portion and half of one petalold style. lobe and stigma cnt away. The section of the stigma is seen edgewise: the rongh upper surface only is stigmatic. 
stigma by the same upward movement which immediately afterward raises the anther-lid and carries away its pollen, to be transferred to a third blossom, and so on.

422. But it is in Orchis and in the commoner representatives of Orchis in North America (viz. Habenaria, \&c.) that the most exquisite adaptations are found, and the greatest economy secured; paralleled, however, by most of the very numerous and various epiphytic and by various terrestrial Orchids of warmer regions. A single illustration may here suffice; and Darwin's volume on the Fertilization of Orchids (396, note), with its references to the copious literature of the subject, may be studied for full particulars and their bearings. The flower is trimerous, and the perianth adnate to the ovary, therefore apparently developed upon its summit. The three external parts of the perianth, which in Habenaria orbiculata (Fig. 460) are much the broader, are the sepals: the three alternate and internal, the petals :

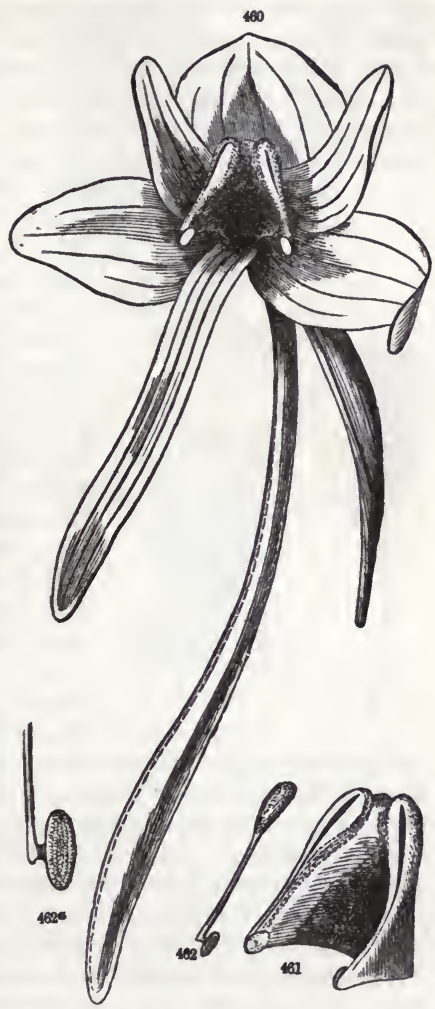
the base of the long and narrow petal which is turned downward is hollowed out and extended below into a long tube, closed at bottom, open at top (the spur or nectary), in which nectar is

FIG. 460. Flower of Habenaria or Platanthera orbiculata, enlarged. 461. Combined stamen and stigma, more enlarged. 462. One of the two pollen-masses (pollinia), witb. Its stalk and glutinous disk or gland. $462^{\circ}$. Lower part of this stalk and its disk, more magnified. 
copiously secreted and contained. The central part of the blossom, beyond the orifice of the nectary (shown separately in Fig. 461), consists of one anther and a stigma, fused together (the clinandrium) : the marginal portions, opening by a long chink, are the two cells of the anther, approximate at their broader portion above, widely divergent below: most of the lower part of the space between is excessively glutinous, and is the stigma. The grains of pollen are united by means of short threads of very elastic tissue into small masses, and these into larger, and at length into pellets, having stalks of the same
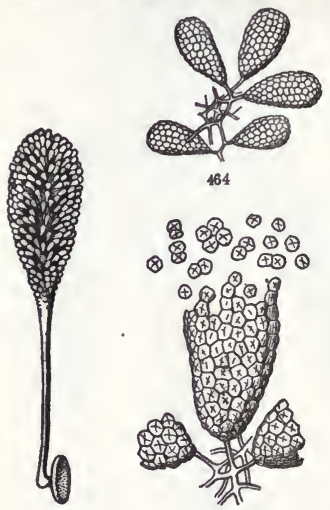

465 elastic tissue, by which they are all attached to a firmer central stalk, or caudicle. (Fig. 463-465.) To the lower end of this caudicle (directly to the end of it in our Habenariæ and Orchises generally, in this instance to the inner side of the end, with a thick intermediate base intervening), is attached a button-shaped disk, the face of which is exposed, and is on a line with the surface of the anther; so that these two disks look toward each other across the broad intervening stigmatic space, as seen in Fig. 461. The exposed face of the disk being covered with a durable layer of very viscid matter, the body itself is sometimes termed a gland, and not improperly. The viscidity is nearly of the same nature as that of the intervening stigma, of which the glands are generally supposed to be detached portions. If so, then a portion of the stigma is cut off from the rest and specialized to the purpose of conveyance of the pollen. When a finger's end or any smaller body is touched to these disks, they adhere so firmly that the attached pollinia or pollen-masses are dragged out of the cell and carried away entire. Some of these pollen-masses have been found attached by the disk to the eyes of a large moth. When a moth of the size of head and length of proboscis of Sphynx drupiferarum visits a spike of these flowers, and presses its head into the centre of the

FIG. 463. A more magnified pollen-mass of Platanthera orbiculata, with its stalk and gland. 464. Five of the separate portions or pollen-packets, with some of the elastic threads of tissue connecting them. 465. A portion more highly magnified, with some of the pollen-grains in fours detached. 
flower so that its proboscis may reach and drain the bottom of the nectariferous tube, a pollen-mass will usually be affixed to each eye: on withdrawal, these will stand as in Fig. 466. Within a minute they will be turned downward (Fig. $466^{a}$ ), not by their weight, but by a contraction in drying of one side of the thick piece which connects the disk with the stalk. When a moth in this condition passes from the last open flower of one spike to that of another plant, and thrusts its proboscis down a nectary, the transported pollen-masses will be brought

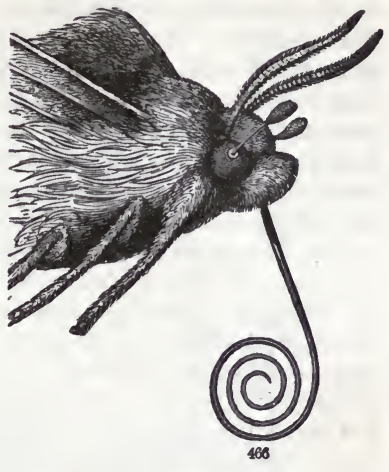
in contact with the large glutinous stigma: on withdrawal, either some of the small pellets of pollen will be left adherent to the stigma, the connecting elastic threads giving way; or else a whole pollen-mass will be so left, its adhesion to the glutinous

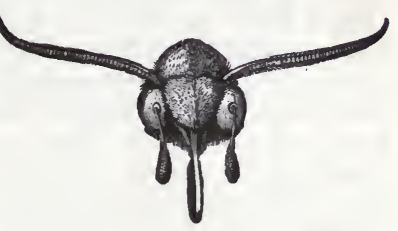
stigma being greater than that of the disk to the moth's eye. The former is a common and a more economical proceeding, as then a succession of flowers are abundantly fertilized by one or two pollen-masses. In either case, new pollen-masses are carried off from fresh flowers and applied to the fertilization of other blossoms on the same and eventually on those of different individuals. Cases like this, and hundreds more, all equally remarkable, serve to show how sedulous, sure, and economical are the adaptations and processes of Nature for the intercrossing of hermaphrodite flowers.

$422^{a}$. An arrangement analogous to that of Orchids, and similarly subservient to cross-fertilization, characterizes the otherwise widely unlike Asclepias family. In Asclepias (Milkweed) there are five stamens surrounding a large stigmatic

FIG. 466. Front part of Sphynx drupiferarum, bearing a pollen-mass of Platanthers orbiculata affixed to each eye, in the eariy position. $466 \mathrm{a}$. Front view of the head, later, showing the pollen-masses deflexed. 
body, and alternating with these five two-cleft glands, the vertical chink or groove of which is glutinous. To each gland is firmly attached, by a caudicle or stalk, a pollen-mass of an adjacent anther. (Fig. 522.) A slight force upraising the gland detaches it from the stigma and drags the pair of suspended pollen-masses out of their cells. Insects visiting the blossoms commonly dislodge them, the gland adhering to their legs or tongues when these happen to be drawn through the adhesive chink, and convey them from one flower to another. Without such aid the flowers of Asclepias rarely set seed. ${ }^{1}$

423. Dimorphism, $i . e$. the case of two kinds of blossoms, both hermaphrodite, on the same species, is another adaptation to intercrossing. Not all dimorphism, however, for in cleistogamous dimorphism (434) the intent to self-fertilize is evident. There may also be dimorphism as to the perianth, not particularly affecting fertilization. One kind, however, and the commonest, is a special adaptation to intercrossing, viz. :

424. Heterogonous Dimorphism. (413, note.) This term is applied to the case in which a species produces two kinds of hermaphrodite flowers, occupying different individuals, the flowers essentially similar except in the andrœeium and gynœcium, but these reciprocally different in length or height, and the adaptations such that, by the agency of insects, the pollen from the stamens of the one sort reciprocally fertilizes the stigma of the other. ${ }^{2}$ This dimorphism has been detected in about forty genera belonging to fourteen or fifteen natural orders, widely scattered through the vegetable kingdom; but there are far more examples among the Rubiaceæ than in any other order. Sometimes all the species of a genus are heterogonous, as in Houstonia, and

1 The reported sensitiveness of the gland, referred to in the first issue of this volume (1879), was founded upon misinterpreted observations.

This peculiar arrangement has been long known in a few plants, such as Primula veris, P. grandiflora, and Houstonia. In Torrey and Gray's Flora of North America, ii. 38, 39 (1843), these flowers are said to be diœciodimorphous, not denoting that they are at all unisexual, but that the two forms occupy different individuals. Their meaning was detected by $\mathrm{C}$. Darwin, and made known in his paper "On the Two Forms or Dimorphic Condition in the Species of Primula, and on their Remarkable Sexual Relations," published in the Journal of the Linnean Society, vi. (1862), 77 : republished, in 1877, as the leading chapter of his volume entitled "The Different Forms of Flowers on Plants of the Same Species." Mr. Darwin had termed these flowers simply Dimorphic; but in this volume he adopted Hildebrand's name of Heterostyled for this kind of blossom. The difference, however, affects the androcium, and even the pollen, as well as the style; wherefore we proposed for it the name of Heterogonous or Heterogone dimor phism, as mentioned in a former note, 413. 
Cinchona, sometimes only a part of them, as in Primula and Linum. In Hottonia, a Primulaceous genus of two species, the European one has heterogonous dimorphism ${ }^{1}$ for cross-fertilization: the American one has homogonous showy flowers with only the general chance for intercrossing, and earlier flowers which are cleistogamous for self-fertilization.

425. The nature of heterogone dimorphism may be well nnderstood from a single example. The most familiar one is that of Houstonia; but, in larger blossoms, Gelsemium is a fine illustration in the Southern United States, and Mitchella (Fig. 467) mostly in the Northern. Raised from the seed, the individuals

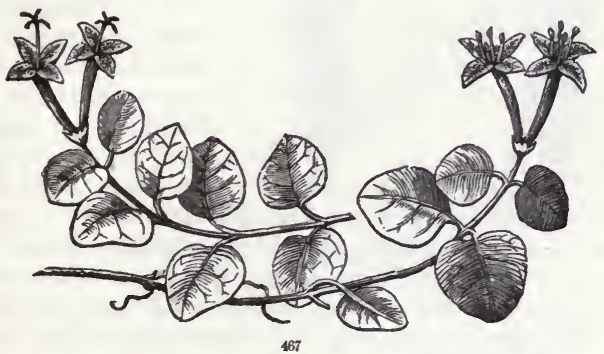

are about equally divided between the two forms: namely, one form with long style and short or low-inserted stamens; the other with short style and long or high-inserted stamens. The stigmas in one rise to about the same height as the stamens in the other, both in the tall or exserted organs and in their low and included counterparts, as is shown in Fig. 468, answering to the left hand and Fig. 469 to the right hand flowers of Fig. 467. A bee or other insect with proboscis of about the length of the corolla-tube, visiting the blossoms of Mitchella, will brush the same part of its body against the high anthers of the longstamened and the high stigmas of the long-styled forms; and

1 C. C. Sprengel, as Darwin mentions, had noticed this, before 1793. He, "with his usual sagacity, adds that he does not believe the existence of the two forms to be accidental, though he cannot explain their purpose." Darwin, Forms of Flowers, 51.

Some heterogonous Primulas are said to produce homogonous varieties in cultivation. In Primula, and in other genera, there are species which seem as if of one sort only, no reciprocal sort being known, as if one form had become self-fertile and the other had disappeared.

FIG. 467. Partridge Berry, Mitchells repens, in the two forms, vir. long-stamened and short-styled, and short-stamened and long-styled. 
the same part of the proboscis against the low anthers of the short-stamened and the low stigmas of the short-styled form.
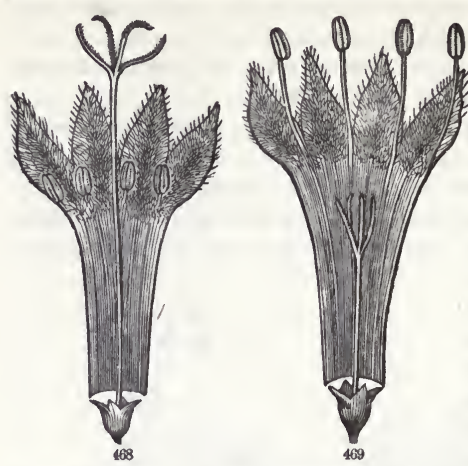

426. Moreover, Darwin has ascertained by microscopical examination that the pollen of the two differs in size or shape, and by experiment that it is less active upon its own stigma than upon the other; indeed, that in many cases (as in some species of Linum) it is quite inactive or impotent not only upon its own stigma but upon its own-form stigma, while

it is prepotent on the other, and this reciprocally of the two forms. ${ }^{1}$ Here, then, are flowers structurally hermaphrodite, but functionally as if diœcious, securing all the advantages of the latter, along with the economical advantage that both sorts of individual and every blossom may bear seed. With diœcism only about half the plants could be fruitful.

427. Heterogonous Trimorphism. A threefold heterogonism is known in certain species of a few genera ; and this complication may have certain conceivable advantages over dimorphism. Where seedling dimorphous individuals are few and far between (those multiplying from root would all be alike), there would be an even chance that any two near each other were of the same form and therefore sterile or imperfectly fertile. But if the organization were of three forms, any two of which intercrossed with perfect fertility, the chances (as Darwin remarks) are two to one that any two plants were of different forms, and therefore by fertilizing each other completely fruitful.

428. The earliest known instance of three forms as to reciprocal relative length of stamens and pistil is that of Lythrum

1 Impotence of own pollen, either absolute or relative, occurs no less in certain flowers which are not dimorphous, as in Corydalis, some species of Passiflora, \&c. ' On the contrary, many dimorphous flowers are in a certain degree self-fertile, especially in the long-stamened and short-styled form. These subjects are physiological, and belong to another volume.

FIG. 468. Long-styled flower of Fig. 467, laid open. 469. Long-stamened flower of the same laid open. Both equally enlarged. 
Salicaria. This was indicated by Vaucher in 1841, more particularly described by Wirtgen in 1848, but was interpreted by Darwin, and the more recondite differences brought to notice, in 1864. ${ }^{1}$ " The three forms may be conveniently called, from the unequal length of their pistils, the long-styled, mid-styled, and short-styled. The stamens also are of unequal lengths, and these may be called the longest, mid-length, and shortest." The pollen of the different classes of stamens is of two sorts as to color, and of three as to size, the largest grains from the largest stamens. "The pistil in each form differs from that in either of the other forms, and in each there are two sets of stamens, different in appearance and function. But one set of stamens in each form corresponds with a set in one of the other two forms. Altogether, this one species includes three females or female organs, and three sets of male organs, all as distinct from one another as if they belonged to different species; and, if smaller functional differences are considered, there are five

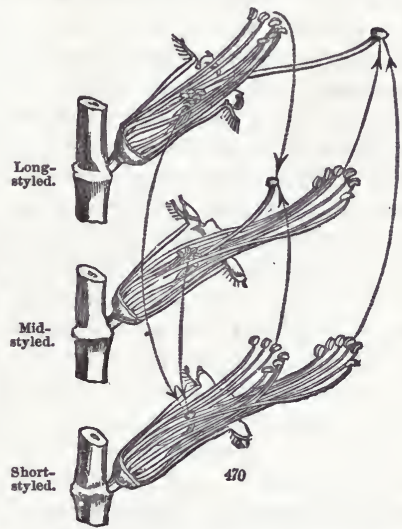
distinct sets of males. Two of the three hermaphrodites musc coexist, and pollen must be carried by insects reciprocally from one to the other, in order that either of the two should be fully fertile; but, unless all three forms coexist, two sets of stamens will be wasted, and the organization of the species as a whole will be incomplete. On the other hand, when all three hermaphrodites coexist, and pollen is carried from one to the other, the scheme is perfect: there is no waste of pollen and no

1 In an article On the Sexual Relations of the Three Forms of Lythrum Salicaria, in Jour. Linn. Soc. viii. 169. Also on the Character and Hybridlike Nature of the Offspring of the Illegitimate Unions of Dimorphic and Trimorphic Plants. Ibid. x. 393, 1868. Reproduced and extended in his volume entitled "Forms of Flowers," 1877.

FIG. 470. Diagram of the flowers of the three forms of Lythrum Salicaria, in their natural position, with the petais and calyx removed on the near side. The dotted lines with the arrows show the directions in which polien must be carried to each stigma to ensure full fertility. (From Darwin.) 
false coadaptation." The whole arrangement is displayed in the annexed diagram (Fig. 470), and in the following account of the operation. ${ }^{1}$ "In a state of nature, the flowers are incessantly visited for their nectar by hive and other bees, various Diptera, and Lepidoptera. The nectar is secreted all round the base of the ovarium; but a passage is formed along the upper and inner side of the flower by the lateral deflection (not represented in the diagram) of the basal portions of the filaments; so that insects invariably alight on the projecting stamens and pistil and insert their proboscides along the upper and inner margin of the corolla. We can now see why the ends of the stamens with their anthers and the end of the pistil with the stigma are a little upturned, so that they may be brushed by the lower hairy surfaces of the insects' bodies. The shortest stamens, which lie enclosed within the calyx of the long- and mid-styled forms can be touched only by the proboscis and narrow chin of a bee: hence they have their ends more upturned, and they are graduated in length, so as to fall into a narrow file, sure to be raked by the thin intruding proboscis. The anthers of the longer stamens stand laterally farther apart and are more nearly on the same level, for they have to brush against the whole breadth of the insect's body. . . Now I have found no exception to the rule that, when the stamens and pistil are bent, they bend to that side of the flower which secretes nectar. . . . When nectar is secreted on all sides, they bend to that side where the structure of the flower allows the easiest access to it, as in Lythrum. . . . In each of the three forms, two sets of stamens correspond in length with the pistil in the other two forms. When bees suck the flowers, the anthers of the longest stamens, bearing the green pollen, are rubbed against the abdomen and the inner sides of the hind legs, as is likewise the stigma of the long-styled form. The anthers of the mid-length stamens and the stigma of the mid-styled form are rubbed against the under side of the thorax and between the front pair of legs. And, lastly, the anthers of the shortest stamens and the stigma of the short-styled form are rubbed against the proboscis and chin; for the bees in sucking the flowers insert only the front part of their heads into the flower. On catching bees, I observed much green pollen on the inner sides of the hind legs and on the abdomen, and much yellow pollen on the under side of the thorax. There was also pollen on the chin, and, it may be presumed, on the proboscis, but this was difficult to observe. I had, however,

1 All from Darwin, Forms of Flowers, 137-147, \&c. 
independent proof that pollen is carried on the proboscis ; for a small branch of a protected short-styled plant (which produced spontaneously only two capsules) was accidentally left during several days pressing against the net, and bees were seen inserting their proboscides through the meshes, and in consequence numerous capsules were formed on this one small branch. . . . It must not, however, be supposed that the bees do not get more or less dusted all over with the several kinds of pollen; for this could be seen to occur with the green pollen from the longest stamens. . . Hence insects, and chiefly bees, act both as general carriers of pollen, and as special carriers of the right sort."

429. Finally, a long series of experiments (requiring eighteen distinct kinds of union) proved that both kinds of pollen are nearly or quite impotent upon the stigma of the same flower, and that no ovary is fully fertilizable by other than a "legitimate union," i.e. by stamens of the corresponding length; but that the mid-length pistil is more prolific than either of the others under illegitimate union of either kind; which might perbaps be expected, as the pollen proper to it is intermediate in size of grains between that of the long and that of the shortest stamens.

430. Nesæa verticillata, a common Lythraceous plant of the Atlantic United States, is similarly trimorphous, but has not yet been particularly investigated. Several South African and American species of Oxalis are equally trimorphous, and have been investigated by Darwin and Hildebrand, ${ }^{1}$ with results quite as decisive as in Lythrum Salicaria. One genus of Monocotyledons has trimorphous blossoms, viz. Pontederia, of which the North American P. cordata is a good illustration. ${ }^{2}$

431. All known flowers exhibiting reciprocal dimorphism or trimorphism are entomophilous : no such wind-fertilized species is known. Few of them are irregular, and none very irregular: they do not occur, for instance, in Leguminosæ, Labiatæ,

1 Monatsber. Akad. Berlin, 1866; Bot. Zeit. 1871, \&c. According to Darwin, Fritz Mueller " has seen in Brazil a large field, many acres in extent, covered with the red blossoms of one form [of an Oxalis] alone, and these did not produce a single seed. His own land is covered with the short-styled form of another species, and this is equally sterile; but, when the three forms were planted near together in his garden, they seeded freely." Forms of Flowers, 180.

2 Detected by W. H. Leggett. See Bulletin of Torrey Bot. Club, vi. 62, 170 ; and for the original discovery in Brazilian species, by Fritz Mueller, see Darwin's Forms of Flowers, 183, \&c. Pontederia has three lengths of style and counterpart stamens, as in Lythrum Salicaria, each flower having two sets of stamens, three in each set. 
Scrophulariaceæ, Orchidaceæ, \&c. Nature is not prodigal, and does not endow with needless adaptations flowers which are otherwise provided for.

\section{§ 3. Adaptations for Close Fertilization.}

432. Even where cross-fertilization in bisexual flowers is obviously arranged for, it is apt to be tempered with more or less of close-fertilization. The more exquisite the arrangements for the former are, the more completely is the plant dependent upon insect visitation. Failure to intercross is a remote and small evil compared with failure to set seed at all. In order therefore that the plan of cross-fertilization may not defeat even its own end, through too absolute dependence on precarious assistance, some opportunity for self-fertilization will usually be advantageous. Also there is a long array of insect-visited flowers, especially polyandrous ones, in which close fertilization must be much the commoner result, except where the pollen of another but wholly similar flower has greater potency.

433. Subsidiary self-fertilization is secured in a great variety of ways. In Gentiana Andrewsii, which is proterandrous, and usually cross-fertilized by humble-bees entering bodily into the corolla, an exposed surface of pollen long remains fresh upon the ring of anthers girding the base of the style : when the stigmas separate, they remain for some days simply divergent, but they at length become so revolute that the receptive surface is brought into contact with the ring of pollen below. The opening and closing of blossoms by day or night, the growth of style, filaments, or corolla after anthesis commences, or other changes of position, may secure a certain amount of self-fertilization in a subsidiary or even in a regular way. Then certain species, such as Chickweed, which blossom through a long season, closefertilize even in the bud in early spring, when insects are scarce, but are habitually intercrossed by insects in summer. Somewhat similarly, according to Hermann Mueller, ${ }^{1}$ certain species, such as Euphrasia officinalis and Rhinanthus Crista-galli, habitually produce two kinds of blossoms, one larger and more showy, usually affecting sunny localities, and with parts adapted to intercrossing by insects ; the other smaller or inconspicuous, and with anthers adjusted for giving pollen to the adjacent stigma without aid. There are gradations between these last arrangements, and the more special and remarkable one of dimorphism with

1 Befruchtung der Blumen durch Insekten, 294 ; Nature, viii. 433. 
434. Cleistogamy. Here the intention and the accomplishment of self-fertilization are unmistakable. This peculiar dimorphism consists in the production of very small or inconspicuous and closed flowers, necessarily self-fertilized and fully fertile, in addition to ordinary, conspicuous, and much less fertile, though perfect flowers. Two cases were known to Linnæus, ${ }^{1}$ and one of them to Dillenius before him; those of Viola have long been familiar in the acaulescent species; Adrien Jussieu made out the structure of the cleistogamous flowers in certain Malpighiaceæ in 1832, and recorded in 1843 that Adolphe Brongniart had well investigated those of Specularia, and that Weddel had discovered them in Impatiens Nolitangere. A full account of the then known cases was given by $\mathrm{Mohl}^{2}$ in 1863 ; but $\mathrm{D}$. Mueller, of Upsala, who examined Viola canina, is said by Darwin to have given, ${ }^{8}$ in 1857, "the first full and satisfactory account of any cleistogamic flower." The appropriate name of cleistogamous was given by Kuhn, ${ }^{4}$ in 1867 , and is now in common use.

435. Cleistogamous flowers are now known in about 60 genera, of between twenty and thirty natural orders, of very various relationship, though all but five are Dicotyledons. All but the Grasses $^{b}$ and Juncus are entomophilous as to the ordinary flowers, and most of these such as have special arrangements for their intercrossing, either by dichogamy, heterogone dimorphism or trimorphism (in Oxalis), or such special contrivances as those of Orchids.

436. It has been said that the ordinary flowers in such plants are sterile, and perhaps they always are so except when crossfertilized: in most cases they are habitually infertile or sparingly fertile. Probably they suffice to secure in every few generations such benefit as a cross may give, while the principal

1 Campanula (now Specularia) perfoliata and Ruellia clandestina, the latter a cleistogamous state of R. tuberosa. Linnæus did not make out the structure of the flowers, but supposed them to want the stamens.

2 In Bot. Zeitung, xxi. 309.

8 In Bot. Zeitung, xvi. 730 .

4 Ibid. xxv. 65. The name (denoting "closed np" union or fertilization) has been written cleistogenous, which is not so proper. We prefer cleistogamous to cleistogamic (and so of similar terms), as best harmonizing with the Latin adjective form, both in form of termination and in euphoniously taking the accent upon the antepenult.

5 Amphicarpum (Milium amphicarpon, Pursh) is the earliest recognized cleistogamous Grass, except perhaps Leersia oryzoides. Some species of Sporobolus are like the latter, and Mr. C. G. Pringle has recently detected such flowers concealed at the base of the sheaths in Danthonia. Amer. Jour. Sci. January, 1878, 71. 
increase is by cleistogamous self-fertilization, which thus offsets the incidental disadvantage of the former mode.

437. In general, the cleistogamous are like unto the ordinary flowers arrested in development, some arrested in the almost fully formed bud, most at an earlier stage, and in the best marked cases with considerable adaptive modification. In these, "their petals are rudimentary or quite aborted; their stamens are often reduced in number, with anthers of very small size, containing few pollen-grains, which have remarkably thin transparent coats, and generally emit their tubes while still enclosed within the anther-cells; and, lastly, the pistil is much reduced in size, with the stigma in some cases hardly at all developed. These flowers do not secrete nectar or emit any odor: from their small size, as well as from the corolla being rudimentary, they are singularly inconspicuous. Consequently, insects do not visit them; nor, if they did, could they find an entrance. Such flowers are therefore invariably self-fertilized; yet they produce an abundance of seed. In several cases, the young capsules bury themselves beneath the ground, and the seeds are there matured. These flowers are developed before, or after, or simultaneously with the perfect ones." 1 In Grasses, however, as in some Dicotyledons, there is much less modification and more transition. For when Leersia half protrudes its panicle, in the usual way, the included half is fertile and the expanded portion sterile (or almost always so), although the flowers may open and exhibit well-developed anthers, ovaries, and stigmas. But when similar panicles remain enclosed in the leaf-sheaths, they are mostly fruitful throughout.

438. Fully to apprehend the economy of cleistogamy in pollensaving alone, - and contrariwise to estimate the expense of intercrossing, - one should compare the small number of pollengrains which so completely serve the purpose in a typical cleistogamous flower (say 400 in Oxalis Acetosella, 250 in Impatiens, 100 in some Violets) with the several thousands of all entomophilous cross-fertilized flowers, rising to over three and a half millions in the flower of a Peony, also their still greater number in many anemophilous blossoms. To this loss should be added the cost of a corolla and its action, also of the production of odorous material and of nectar. No species is altogether cleistogamous. Thus cleistogamy, with all its special advantage, testifies to the value of intercrossing.

1 Darwin, Forms of Flowers, 310. 


\section{Section V. The Perianth, ${ }^{1}$ or Calyx and Corolla in PARTICULAR.}

439. The distribution of the floral leaves around the axis, which belongs to phyllotaxy, and their particular disposition in the bud (æstivation), have already been considered in Chap. IV. Sect. I., II. And most of the morphology of calyx and corolla has been outlined in the preceding sections of the present chapter. What remains chiefly relates to particulars of form and to terminology.

440. Duration. The differences in this respect give rise to a few terms, such as the following. Calyx or corolla may be

Persistent, not cast off after anthesis, but remaining unwithered until the fruit is formed or matured; as the calyx in Labiatæ, in Physalis, and most Roses.

Marcescent, withering or drying without falling away; as the corolla of Heaths, Drosera, \&c.

Deciduous, falling after anthesis and before fructification; as the petals of Roses, the calyx and corolla of Columbine.

Ephemeral or Fugacious, lasting for only a day ; as the petals of Poppy, Helianthemum, Purslane, and Spiderwort. In the two former, they are cast or early deciduous, the anthesis lasting but a day: in the two latter, the anthesis is equally or more brief, but the petals deliquesce or decay at once without falling, as does the whole flower of Cereus grandiflorus and other nightblooming Cactaceæ.

Caducous, falling when the blossom opens; as the calyx of Poppy and Baneberry.

441. Numerical Terms, succinctly denoting the number of leaves, either of the perianth as a whole, or of any one of its circles, are common in descriptive botany. The most general are those which simply specify the number of component leaves, by prefixing Greek numerals to the Greek name of leaves, expressing them in Latin form, or transferring them to the English. Thus

Diphyllous, of two leaves (sepals or petals) ; Triphyllous, of three ; Tetraphyllous, of four ; Pentaphyllous, of five; Hexaphyllous, of six, and so on. A tulip and a Tradescantia flower have a hexaphyllous perianth, but composed of two circles, answering to calyx and corolla; each Triphyllous. ${ }^{2}$ When the character

1 Perianthium, alias Perigone or Perigonium. (296.)

2 As elsewhere explained, when numerical composition is indicated without reference to nature of parts, the terms dimerous, trimerous, tetramerous, penta merous, \&c., may be used. (322.) 
of the organ, i.e. whether calyx or corolla is to be specified, the word sepal or petal is employed in the combination; as,

Disepalous, of two sepals ; Trisepalous, of three; Tetrasepalous, of four; Pentasepalous, of five (also written 5-sepalous, and accordingly 2-sepalous, 3-sepalous), and so on: also,

Dipetalous, Tripetalous, Tetrapetalous, Pentapetalous petalous), \&c., when the corolla is concerned.

442. Monophyllous, Monosepalous, and Monopetalous are the proper terms for perianth (calyx, corolla, \&c.) composed of a single leaf. Likewise Polyphyllous, Polysepalous, and Polypetalous for the case of a considerable but unspecified number of members. Unfortunately, in the Linnæan and long-prevalent use, monopetalous was the term employed to designate a corolla of one piece in the sense, or the fact, of a coalescence or growing together of two, three, five, or more petals into a cup or tube; and so of a calyx, of a whorl of bracts, \&c. And polypetalous, polysepalous, and polyphyllous were the counterparts of this, meaning of more than one distinct piece, whatever the number. The misleading use, consecrated by long prescription, is not yet abandoned, but will in time be obsolete. In present descriptive botany, a polyphyllous calyx, or a polypetalous corolla, or a 5-petalous corolla, would be taken to mean that the sepals or petals (as the case may be) were distinct or uncombined, and a monopetalous corolla to be one with petals combined by coalescence. (329.)

443. Terms of Union or Separation. The proper term for a corolla or a calyx the leaves of which are more or less coalescent into a cup or tube is

Gamopetalous for such a corolla, Gamosepalous for the calyx; these terms meaning united petals or sepals. The older and misleading names Monopetalous and Monosepalous, although current up to a recent day, should be discontinued. Another term is not rarely used in Germany, that of Sympetalous, for the gamopetalous (or formerly monopetalous) corolla, - therefore Synsepalous for a similar calyx. It is perhaps a more apt term than gamopetalous, and of the same etymological signification; but the latter is already well in use.

Choripetalous is, on the whole, the most fitting name for a corolla the petals of which are separate (as it literally expresses this), that is, for what is still commonly called Polypetalous, as already explained. (442.) It is adopted by Eichler, \&c. Chorisepalous is the term applied to the calyx. Dialypetalous (employed by Endlicher) has the same meaning. Both this term and choripetalous carry the implication of separated, rather 
than of typically separate, parts. Eleutheropetalous (literally free-petalled) has also been used, but is inconveniently long.

444. Degree of coalescence is most correctly expressed by the phrases united (connate, or coherent, or coalescent) at the base, to the middle, or to the summit, as the case may be. But it is more usually and tersely expressed in botanical description by employing terms of division, identical with those used in describing the lobing or toothing of leaves and all plane organs. (184-188.) That is, the calyx or corolla when gamophyllous is for description taken as a whole, and is said to be parted (3-parted, 5-parted, \&c.), when the sinuses extend almost to the base ; cleft, when about to the middle; lobed, a general term for any considerable separation beyond toothing; dentate or toothed (3-toothed, 5-toothed, \&c.), when the union extends almost to the summit; entire, when the union is complete to the summit or border.

445. Parts of Petals, \&c. The expanded portion of a petal, like that of a leaf, is the LAMINA or BLADE : any much contracted base is the Unguis or Claw. The latter is very short in a rose-

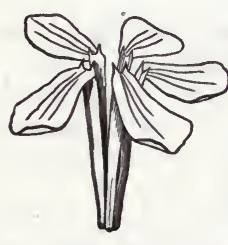

47

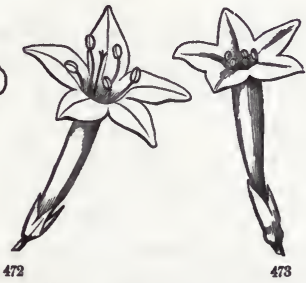

478

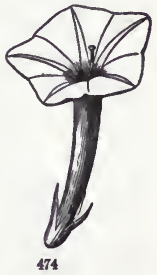

474

petal, but long and conspicuous in a pink and all flowers of that tribe (Fig. 471), in many Capparideæ (Fig. 409) and Cruciferæ. A sepal is very rarely distinguishable into lamina and claw.

446. Parts of Gamophyllons Perianth. The coalescent portion of a corolla, calyx, or of a perianth composed of both (such as a Lily or Crocus-blossom), so far as the sides are parallel or not too spreading, is its TUBE : an expanded terminal portion, either divided or undivided, is the Lrmb or Bonder. The limb may

FIG. 471. Corolla of Soapwort, of five separate long-clawed or unguiculate petals, with a crown at the junction of claw and blade.

FIG. 472. Flower of Gilia coronoplfolia; the parts answering to the claws of the petals of the last figure here all united into a tube.

FIG. 473. Flower of the Cypress-Vine(Ipomca Quamoclit); the petals a little farther nuited into a five-lobed spreading border.

FIG. 474. Flower of the Ipomca coccinea; the five component petals perfectly united into a trumpet-shaped tube, and beyoud into an almost entire spreading border. 
be parted (that is, the component parts not united) quite or nearly down to the tube or base, as in Fig. 472, 475 ; or less so,

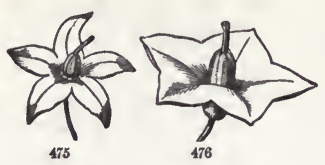
as in Fig. 473, 476 (with limb 5 -lobed); or with merely angles or points to represent the tips of the component members, as in Fig. 474 ; or with even and entire border, as in common MorningGlory, Fig. 482.

447. The line, or sometimes a manifest or conspicuous portion, between the limb and tube (in the corolla always a portion above or at the insertion of the stamens, when these are borne by the corolla) is called the Throat, in Latin Faux, pl. fauces. 'This is mostly more open than the tube, yet less expanded than the limb ; but it often presents insensible gradations from the one to the other.

448. Such appendages as the Conona or Crown (385, shown in Fig. 403, 404, 471) usually belong to the throat of a gamopetalous corolla or perianth, as in Oleander, Comfrey, Borrage, Narcissus, \&c., or to a corresponding position when the parts are not coalescent.

449. Forms of Corolla, Calyx, \&c. As to terminology, some of these are special and are applicable to corolla only, as the

Papilionaceous, the peculiar irregular corolla of the typical portion of Leguminosæ (388, Fig. 342-334), which has been already illustrated, and in which the petals, two pairs and an odd one, take particular names. Also the

Caryophyllaceous, or Pink-flower (Fig. 471), a regular corolla, of five long-clawed (unguiculate) petals, the claws enclosed in a tubular calyx and the blades spreading; and the

Cruciferous, of four somewhat similar petals, the four abruptly spreading blades in the form of a cross (cruciate), as in Fig. 394.

Rosaceous, with roundish and widely spreading petals on very short or hardly any claws, as in Rose and Apple-blossoms.

Liliaceous, a 6-phyllous perianth of campanulate or funnelform shape ; the members either distinct, as in most common lilies and tulips, or gamophyllous, as in Lily of the Valley. All but the first and last of these sorts are examples of regular and choripetalous perianth.

Orchidaceous flowers are of a peculiar irregularity, combining both calyx and corolla: one member, the petal in front of the

FIG. 475. Rotate or wheel-shaped and five-parted corolla of the Bittersweet (SoLanum Dulcamara).

FIG. 476. Wheel-shaped and fire-lobed corolla of the common Potato. 
stamen and stigma, differs from the rest in shape and in being nectariferous (as in Fig. 460); it is named the LABELLUM.

Galeate is a term applied to a corolla the upper petal or part of which is arched into the shape of a casque or helmet, called the Galea; as in Aconite (Fig. 357) and Lamium, Fig. 479. In the former the galea is of a single petal; in the latter, it consists of two, completely united.

450. Gamophyllous forms with special names are chiefly the following. Illustrations are usually taken from the corolla, but the forms and terms are not peculiar to it, excepting the first, viz. the

Ligulate or Strap-shaped corolla (Fig. 288, \&c.), which is nearly confined to Compositæ. Here a corolla, formed of three or five petals, imitates a single petal, except at its very base, which is commonly tubular: the remainder is as though the tube had been split down on the upper side and flattened out. The corolla of Lobelia, type of a family most nearly related to Compositæ, illustrates this. (Fig. 488.)

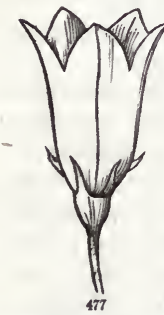

451. The names of the general forms are mostly taken from some resemblance to common objects. All those in common use will be found in the Glossary : a few leading ones are here specified. They may be divided into the regular and the irregular. The principal irregular form with a special name is the

Labiate, or lipped, also termed Bilabiate, as there are two lips, an upper and a lower (superior and inferior, or anterior and posterior, 290), although one of them is sometimes obscure or abortive. This bilabiate character in the corolla, and often in the calyx also, pervades several orders with gamopetalous flowers, and gives name to one of them, the Labiatæ, to which

FIG. 477. Campanulate corolla of the Harebell, Campanula rotundifolia. 478. Salverform (hypocraterimorphons) corolla of Phlox. 479. Labiate (ringent) corolla of Laminm; a side view 480. Personate corolla of Antirrhinum or Snapdragon. 481. Personate corolla of Linaria, spurred (calcarate) at the base. 
the Sage and Mint belong. Such flowers are 5-merous, and have two members specially united to form one lip, and three in the other. The odd sepal being posterior (or next the axis of inflorescence), and consequently the odd petal anterior, the calyx has its lower lip of two sepals and its upper of three; while the corolla has its upper lip of two petals and its lower of three. But in Leguminosæ, where the calyx is sometimes bilabiate, and where the odd sepal is anterior (or toward the bract), this is 'reversed, and two sepals or lobes of the calyx form the upper lip and three the lower. A bilabiate corolla is

Ringent, that is gaping or open-mouthed, when the throat is freely open, as in Lamium, Fig. 479 ;

Personate, or masked, when the throat is closed, more or less, by a projection of the lower lip called the Palate, as in Antirrhinum and Linaria, Fig. 480, 481.

452. Of regular forms, there are the following, beginning with that having least tube :

Rotate, or Wheel-shaped (Fig. 475, 476), widely spreading from the very base, or from a short and inconspicuous tube.

Crateriform, or Saucer-shaped, like rotate except that the broad limb is cupped by some upturning toward the margin.

Hypocrateriform, or rather (not to mix Latin and Greek) Hypocraterimorphous, in English Salverform, when a rotate or
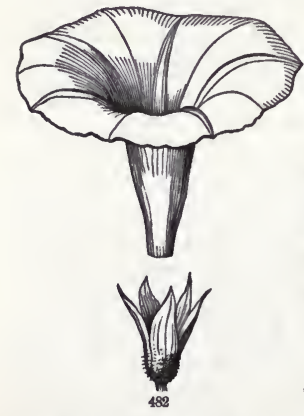
saucer-shaped limb is raised on a slender tube which does not much enlarge upward; that is, where a long and narrow tube abruptly expands into a flat or flattish limb, as in Fig. 478. In Fig. $472-474$ are seen salverform corollas with somewhat more upwardly dilated (trumpetshaped) tube. The salver or hypocraterium, which the name refers to, with a stem or handle beneath, is now to be met with only in old pictures.

Tubular, when strictly used, denotes a gamophyllous perianth with limb inconspicuous in proportion to the tube, as in Trumpet Honeysuckle, or as Fig. 472-474 would be if the limb were much diminished or wanting. But it is sometimes used in the sense of having a conspicuous tube.

FIG. 482. Calyx and funnelform (infundibuliform) corolla of a common MorningGlory, Ipomces purpurea. 
Infundibuliform, or Funnelform, such as the corolla of common Morning-Glory (Fig. 482), denotes a tube gradually enlarging upward from a narrow base into an expanding border or limb.

Campanulate, or Bell-shaped (Fig. 477), denotes a tube of length not more than twice the breadth, moderately expanded almost from the base, the sides above little divergent.

\section{Section VI. The Andrecium, or Stamens in particular.}

453. The whole Stamen. For the general character and some of the modifications of the stamens, see the first (301) and portions of the succeeding sections of the present chapter. The terms peculiar to these organs, and of common use in botanical description, were nearly all coined by Linnæus, and employed as the names of classes in his sexual system. (672.) The substantive names of those classes which are characterized by the number of stamens, and which were designated by Greek numerals prefixed to andria (the Greek word for man being used metaphorically for stamen), are put into adjective form, as follows :

Monandrous, for a flower with a solitary stamen; Diandrous, for a flower with two stamens; Triandrous, with three; Tetrandrous, with four; Pentandrous, with five; Hexandrous, with six; Heptandrous, with seven; Octandrous, with eight; Enneandrous, with nine; Decandrous, with ten; Dodecandrous, with twelve;

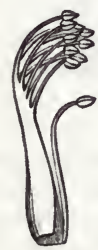

483

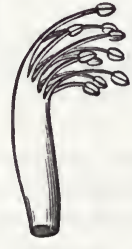

484

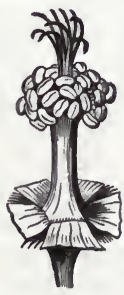

485

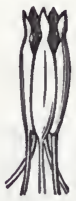

486

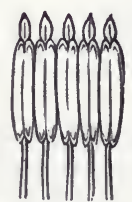

487

Polyandrous, with a greater or indefinite number, or Icosandrous (meaning twenty-stamened) when a polyandrous flower has the stamens inserted on the calyx, as in the Cherry (Fig. 337), Pear, \&c.

FIG. 483. Diadelphous stamens ( 9 and 1) of a Pea. 484. Monadelphons stamens of a I.nnine. 485. Monadelphous stamens, \&c., of Mallow.

FIG. 486. Five syngenesious stamens of a Composita. 487. The same, laid open. 
Didynamous is a term applied to an andrœcium of four stamens in two pairs, a longer and a shorter, as in Fig. 361.

Tetradynamous is similarly applied to that of six stamens, two of them shorter, in the manner characteristic of Cruciferæ, Fig. 396.

454. Terms which denote coalescence of stamens, whether by their filaments or their anthers, are

Monadelphous, that is, in one brotherhood, by coalescence of the filaments into a tube, as in the Mallow (Fig. 485), Lupine (Fig. 484), Lobelia (Fig. 488), \&c.

Diadelphous, in two brotherhoods, by coalescence of the filaments into two sets; sometimes an equal number in each, as in Fumariaceæ (Fig. 390), sometimes nine in one set and one separate, as in the Pea (Fig. 483) and most Papilionaceæ.

Triadelphous, with filaments united in three sets or clusters, as in Hypericum.

Pentadelphous, in five sets, as in Linden, Fig. 398, 399. But in general, when the sets are several, without regard to the number the stamens are said to be Polyadelphous.

Syngenesious, when the stamens are united by their anthers into a tube or ring; as in the whole vast order of Compositæ

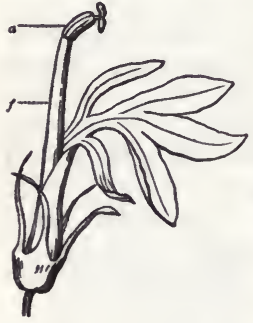

488

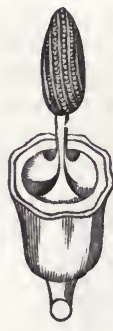

489

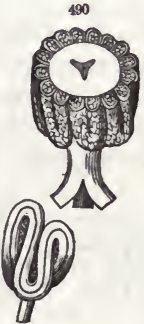

491

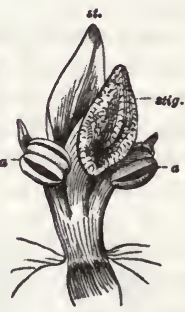

492

(Fig. 486, where they are five in number and the filaments distinct), in Cucurbita (Fig. 489, 490, where they are three in number and the filaments partly monadelphous), and in Lobelia (Fig. 488, where they are also five and the long filaments are mainly monadelphous).

FIG. 488. Flower of Lobelia cardinalis, with tube of corolla divided on one side; flaments and anthers united into a tube: $f$. tube of flameuts; $a$. of anthers.

FIG. 489. Male flower of Cucurbita (Squash), with limb of caiyx and corolla cut away, to show the stamens, viz., three filaments, separate at base but monadelphous above, and three syngenesious anthers in a kind of head. 490 . Stamens of the same, enlarged and the upper part cut away, to show the union. The anthers are sinuous. 491. A detached stamen of the Melon, with loosely sinuous anther.

Fig. 492. Stamens and style of a Cypripedium, united into one body or column: a. anthers; st. enlarged sterile stamen; stig. the stigma. 
455. Of terms relating to adnation of stamens, besides the general ones of hypogynous, perigynous, epigynous (332), and epipetalous, or adnate with corolla, there is the special one of

Gynandrous, having stamens borne upon the pistil, as in Orchidaceæ. In Cypripedium, the filaments of two stamens, and an enlarged sterile stamen behind, are adnate to a style, while the two anthers are quite free (Fig. 492); in the proper Orchis tribe (as in Fig. 460,461), anther and stigma are consolidated into one mass, and there is no evident style.

456. A complete stamen consists of Filament and Anther. The latter is the functionally essential part of the organ, and therefore is wanting only in abortive or sterile stamens. (345, 352 , \&c.) The filament, being only a stalk or support, may be very short or wholly wanting; then the anther is sessile, just as the blade of a leaf is said to be sessile when there is no petiole.

457. The Filament, although usually slender and stalk-like, assumes a great variety of forms: it is sometimes dilated so as to resemble a petal, except by its bearing an anther; as in the transition states between the true petals and stamens of Nymphæa, shown in Fig. 318.

458. Such petaloid filaments would indicate that this part of the stamen answered to blade rather than to footstalk, while others would harmonize better with what seems at first sight to be the more natural view, that the filament is the homologue of the petiole, the anther of the blade of a leaf. Remembering that in large numbers of leaves there is no distinction into petiole and lamina or blade, such homologies should not be insisted on. The filament may be variously appendaged by outgrowths. Some of these appendages are very conspicuous, such as the scale of Larrea (Fig. 405), which is on the inside, and the nectariferous hood of Asclepias on the outside; or there may be a tooth on each margin, as in species of Allium.

459. The Anther, the essential organ of the stamen, containing the pollen, surmounts the filament, when that is present. It normally consists of two cells or lobes, the word cell being here used in the sense of sac. But, as each sac is not rarely divided into two cavities (locelli), the best technical name for anther-sac is that of ThecA. The two thecæ, lobes, or cells are commonly connected by a more or less evident and sometimes conspicuous common base or junction, which is mostly a prolongation of the filament, the ConNectrvuM, or in English Connective.

460. For the discharge of the pollen, the cells of a normal anther open at the proper time by a line or chink, usually 
extending from top to bottom (Fig. 493), the suture or line of dehiscence. Commonly this line is lateral or marginal: not rarely it faces forward or backward. In the vast genus Solanum,

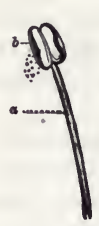

498

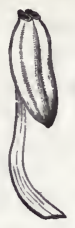

494

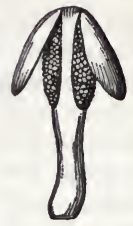

496
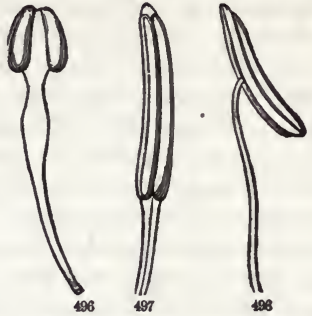

to which the Potato belongs, in most Ericaceous plants (Fig. $458,494)$, in Polygala, and in many other flowers, the anthercells open only by a hole (foramen or pore), or at most a short

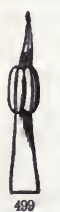
chink, at the tip, through which the pollen has in some way to be discharged. In Vaccinium (Cranberry, Blueberry, \&c.), the pore-bearing tip of the anther-cell is prolonged considerably, often into a slender tube, as in Fig. 340. In the Barberry (Fig. 495 ) and in most of that family, also in Lauraceæ, the whole face of each anther-cell separates by a continuous line, forming a kind of door, which is attached at the top, and turns back, as if on a hinge : in this case, the anthers are said to open by uplifted valves. In the Sassafras and many other plants of the Laurel family, each lobe of the anther opens by two smaller valves of the kind, like trap-doors.

461. The attachment of the anther to the filament presents three principal modes, which are connected by gradations. These are the

Innate (Fig. 495, 496), in which the anther directly continues and corresponds to the apex of the filament, the cells usually dehiscent strictly marginally, the lobes or cells not looking or projecting either inward or outward.

FIG. 493. A stamen, with its anther, $b$, surmonnting the fllament, $a$, and opening in the normal manner down the whole length of the outer side of each cell.

FIG. 494. Stamen of a Pyrola; each cell of the anther opening by a terminal orifice or pore.

FIG. 495. Stamen of a Barberry; the cells of the anther opening each by an nplifted valve.

FIG. 496. A stamen of Isopyrum biternatum, with innate anther. 497. Stamen of Liriodendron, or Tulip-tree, with adnate extrorse anther. 498. Stamen of CEnothera glanca, with the anther fixed by its middle and versatile.

FIG. 499. A stamen of Asarum Canadense, with adnate anther and prolonged tip to connective. 
Adnate, in which the connective appears to be a direct continuation of the filament, having the anther adherent to the anterior or posterior face of it, and the lines of dehiscence therefore looking inward or outward. Magnolia, Liriodendron (Fig. 497), and Asarum (Fig. 499) furnish good examples; the latter conspicuously so, on account of a prominent prolongation of the connective or tip of the filament.

Versatile, when the anther is attached at some part only of its back or front to the tip of the filament, on which in anthesis it lightly swings ; as in Plantain, in all Grasses, the Lily, Evening Primrose (Fig. 498), \&c.

462. The direction to which an anther faces, whether inward (toward the centre of the flower), or outward (toward the perianth), has to be considered; except in the case of an innate anther with strictly lateral or marginal dehiscence. An anther is

Extrorse, i. e. turned outward, or Posticous, when it faces toward the perianth, as in Magnolia and Liriodendron (Fig. 497), Asarum (Fig. 499), and Iris; these all being cases of adnate and extrorse anthers, the cells attached for their whole length to the outside of the summit of the filament or the connective.

Introrse, i. e. turned inward, or Anticous, when it faces toward the axis of the flower; as in Nymphæaceæ (Fig. 318), in Violet and Lobelia (which are adnate and introrse), and in Enothera. In the common Evening Primroses (as in Fig. 498) the anther is fixed near the middle, introrse, and versatile.

463. The direction in which the anther may be said to face, outward or inward, depends upon two characters, which do not always coincide, viz. the insertion or attachment of the cells, and the position of their line of dehiscence. In such a strongly characterized adnate anther as that of Liriodendron (Fig. 497), both the attachment and the dehiscence are plainly posticous or extrorse : in most species of Trillium, the cells are introrse as to attachment, but some are nearly marginal and some are even rather extrorse as to dehiscence : in the related Medeola, and in Lilium, where the anthers are extrorsely affixed toward the base or middle to a slender tip of the filament, the dehiscence is either introrse or nearly marginal. Parnassia is in similar case ; the anthers being clearly extrorse as to insertion and more or less introrse as to dehiscence.

464. Adnate anthers are perhaps as frequently extrorse as introrse. Others, whether basifixed or medifixed, are more commonly introrse. Those fixed by the middle, or at any other part of the back, and lying on the inner side of the filament, are said to be Incumbent. 
465. The connective may be appendaged either by a prolongation or otherwise from the tip (as in Fig. 499), or from the back, as in Violets and in many Ericaceous plants.

466. The normal anther is two-celled, bilocular, or (to use a less common term) dithecous, and its lobes or cells parallel, right and left; but the cells at first, and sometimes at maturity, are bilocellate, that is each is divided into two by a partition which stretches from the connective to the suture or line of

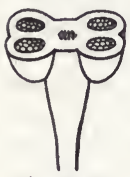

s00

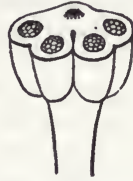

501

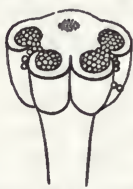

502 dehiscence. In an innate anther, and in many others, this line of dehiscence is marginal or lateral, either strictly or nearly so, as in Fig. 500. When introrse or extrorse (as in Fig. 501, 502), the sutures may still be considered to represent the margins turned inward or outward. The pollen is accordingly produced in four cavities or separate portions of the interior. But the two locelli on the same side of the midrib or connective (right and left) are usually confluent into one pollen-filled cavity or cell at maturity if not earlier, or at least the partition between them breaks up at dehiscence. Sometimes it remains, and, the groove at the sutures being deep, the anther is strongly fourlobed or quadrilocular at maturity, as in Menispermum (Fig. 504) ; but morphologically this is still only bilocular (dithecous) although quadrilocellate, and the anther opens at the sutures and through these partitions.

467. A stamen being the homologue of a leaf, the natural supposition is that the anther is homologous with the blade or an apical portion of the blade, therefore the two lobes or thecæ with the right and left halves of it, the intervening connective with the midrib, and the line of dehiscence with the leaf-margins. ${ }^{1}$ This conception is exemplified by the accompanying

1 This is the view long ago taken by Cassini and Rœper, and it may still be maintained as the best morphological conception. Mohl interposed some objections to its universality; but, as presented in Sachs's Text-Book, they are not incompatible with the common morphology. Sachs takes the filament with the connective to be the homologue of the whole leaf, and the anther-cells as appendages. Others, in likening the anthers to glands, adopt a similar view.

FIG. 500. Innate anther, same as Fig. 496, in younger state, with transverse section, showing the fonr locelli. 501. Same of an adnste extrorse anther, such as Fig. 497. 502. Same as the preceding but mature and dehiscent, the two locelli becoming one cell by the vanilehing or breaking ap of the partition. 
diagram, Fig. 503, which should, however, show the median partitions in the cross-section, or traces of them. Pollen is a special development into peculiar cells of what would be parenchyma in a leaf. Its formation normally begins in four places, which may remain separate up to maturity, or the two on each side of the axis or connective may early be confluent into one cell.

468. Of the many deviations of the typical twocelled anther, with its cells parallel and united longitudinally by a connective, the simplest and commonest is that in which (as in Fig. 505) the two cells diverge below and remain united only at their apex. Next, the two cells may, in their early development, become confluent at the apex, as in the
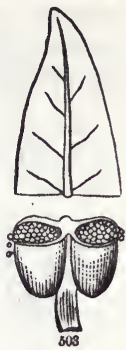
Mallow family (Fig. 506), so as to form a continuous polliniferous cavity within, opening by a continuous suture round the margin : here the anther is unilocular or one-celled by confluence. In another way, the anthers of some species of Orthocarpus (generally resembling Fig. 505, but the lobes or cells quite distinct or even separated at apex) lose one of the cells by partial or complete non-development and so become one-celled by abortion. The anther of Gomphrena (Fig. 507) is completely unilocular by abortion or suppression of the companion cell. Thus losing one half, it is said to be dimidiate, or halved.

469. The two anther-cells, such as those of Fig. 505, sometimes diverge so much that they form a straight line transverse to the filament, as in Monarda (Fig. 508 ), in which their contiguous ends so coalesce as to give the appearance of a one-celled anther fixed by the middle. Or, again, the two cells may be separated by the enlargement of the connective between them, as in Calamintha, Fig. 509. This enlargement is extreme in the great genus Salvia, in which a very long and narrow connec-

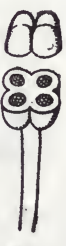

504

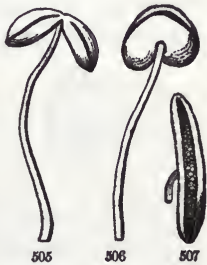

$506 \quad 507$ tive gives the appearance of a filament astride the apex of the

FIG. 503. Diagram to illustrate the morphology of the stamen, on the Ides that the anther answers to leaf-biade: the lower portion belng flament and a part of the anther, in section, the upper a part of a leaf.

FIG. 504. Stamen of Menispermum Canadense, the quadrilocellate anther divided.

FIG. 505. Stamen of Pentstemon pubescens, with anther-cells divergent.

FIG. B06. Stamen of Mallow (one of the cluster of Fig. 485), the two cells and wntures confluent into one.

FIG. 507. Anther of Gomphrena or Globe Amaranth, medifixed, of a single cell, dehiscent. 
proper filament, and bearing an anther-cell at each end. In a few species, the two anther-cells are nearly alike; in more, the lower one is imperfect, as in Fig. $510^{\alpha}$; in more, it is abortive or wanting altogether, as in Fig. $510^{b}$. Then, in the related Californian genus Audibertia, the lower half of this connective

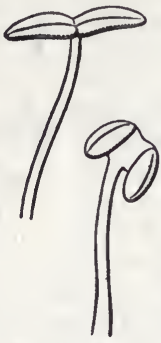

808

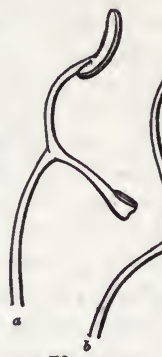

810

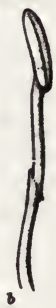

511

is reduced to a short tail, as shown in Fig. $511^{\circ}$, or even in most of the species to so minute a vestige that, except for these transitions, the stamen might be supposed to consist of a simple filament, with an interruption like a splice in the middle, and surmounted by a one-celled anther, as shown in Fig. $511^{b}$. In Rosemary, the continuity is complete, although a minute reflexed tooth sometimes indicates the junction.

470. Pollen, the product of the anther, is usually a powdery substance, which when magnified is seen to consist of separate grains, of definite size and shape, uniform in the same plant,

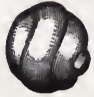

512

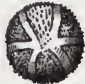

513

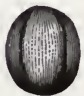

514

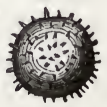

815

but often very different in different species or families. The grains are commonly single cells, globular or oval in shape, and . of a yellow color. But in Spiderwort they are oblong; in the

FIG. 508-511. Anthers, with upper part of filament, of several Labiatæ. 508. Of Monarda. 509. Of a Calamintha. 510. Of two species of Salvia, with long and slender connective, the upper fork of which bears one anther-cell; the lower in $a$ (from Salvia Texana), bearing the other cell in an imperfect condition; in $b$ (from $\mathbf{S}$. coccinea), bearIng none at all. 511. $a$. Same of Audibertia grandifiora, the lower fork of the connective reduced to a naked spur; $b$, from $A$. stachyoides, in which this lower fork is nearly wanting, and the upper is in a straight line with the filament which it seems to continue.

FIG. 512-515. Forms of pollen: 512, from Mimulus moschatus; 513, Sicyos; 514, Echinocystis; 515, Hibisous. 
Cichory and Thistle tribes, many-sided; in the Musk-plant, spirally grooved; in the Mallow family and the Squash and

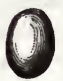

816

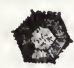

517

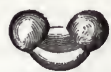

518

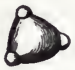

519

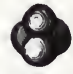

520

Pumpkin, beset with briskly projections, \&c. The pollen of Pine, as well as that of the Onagraceæ, is not so simple, but appears to consist of three or four blended cells ; that of most Ericaceæ evidently consists of four grains or cells united. (Fig. 512-521.) The most extraordinary shape is that of Zostera, or the Eel-grass of salt-water, in which the grains (destitute of the outer coat) consist of long and

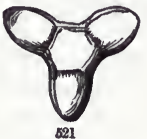
slender threads, which, as they lie side by side in the anther, resemble a skein of silk.

471. Pollen-grains are usually formed in fours, by the division of the living contents of mother cells first into two, and these again into two parts, which become specialized cells. As the pollen completes its growth, the walls of the mother cells are usually obliterated. But sometimes these cells persist, either as shreds, forming the cobweb-like threads mixed with the pollen of Evening Primrose, or as a kind of tissue combining the pollen into coherent masses, of various consistence. Of this kind are the elastically coherent pollen-masses (or Pollinia, sing. Pollinium) of Orchises (Fig. 463),

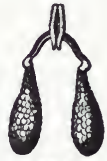

022 and the denser waxy ones of many other orchids and those of Asclepias or Milkweed, Fig. 522.

472. A pollen-grain has two coats. The outer coat is comparatively thick, and often granular or fleshy. This is later formed than the inner, and by a kind of secretion from it: to it all the markings belong. The inner coat, which is the proper cell-wall, is a very thin, delicate, transparent and colorless membrane, of considerable strength for its thickness. The pollen of Zostera and of some other aquatic plants is destitute of the outer coat.

473. The cavity enclosed by the coats is filled with a viscid substance, which often appears slightly turbid under the higher powers of ordinary microscopes, and, when submitted to a mag-

I fG. 516-521. Forms of polien: 516, Lily; 517, Cichory; 518, Pine; 519, Circæa; 520. Kalmia; 521, Evening Primrose.

F1G. 522. A pair of pollinia of Asclepias, annexed by their caudicles to the gland. 
nifying power of about three hundred diameters, is found to contain a multitude of minute particles (fovilla), the larger of which are from one four-thousandth to one five-thousandth of an inch in length, and the smaller only one fourth or one sixth of this size. When wetted, the grains of pollen promptly imbibe water by endosmosis, and are distended, changing their shape somewhat, and obliterating the longitudinal folds, one or more in number, which many grains exhibit in the dry state. Soon the more extensible and elastic inner coat inclines to force its way through the weaker parts of the outer, especially at one or more thin points or pores; sometimes forming projections, when the absorption is slow and the exterior coating tough. In many kinds of pollen, the grains, when immersed in water, soon distend to bursting, discharging the contents. ${ }^{1}$

474. Pollen-tubes. In others, and in most fresh pollen, when placed in ordinarily aerated water, at least when this is slightly thickened by syrup or the like, and submitted to a congenial temperature, a projection of the inner coat through the outer appears at some one point, and by a kind of germination grows into a slender tube, which may even attain two or three hundred times the diameter of the grain; and the richer protoplasmic contents tend to accumulate at the farther and somewhat enlarging extremity of this pollen-tube. ${ }^{2}$

475. In cleistogamous flowers (434), the pollen, while still in the anther, sends out its tubes, which may grow to a great length, in the mere moisture of the flower-bud, the growing tip always directing itself toward the stigma in a wonderful way. Similarly, in the open flower of Milkweeds, the pollen-tubes sometimes start from the pollen-mass even while yet in the anther, and in vast numbers, forming a tuft or skein of pollen-tubes, which may attain considerable length and direct itself toward the somewhat distant stigma. Commonly, however, the pollen remains

1 In Coniferæ, the grains of pollen have a peculiar internal structure or rather a development (suggestive of a homology with the microspores of some of the higher Cryptogamia), the contents at or before maturity undergoing division into two or three internal cells, only one of which acts in fertilization. When they act upon the ovule or are placed in water, and the inner coat swells by absorption, the bursting outer coat is commonly thrown off. In Pines and Firs (but not in Larch and Hemlock Spruce), the grain of pollen is singularly compound, consisting (as in Fig. 518) of a central arcuate body (the proper pollen-cell) bearing at each end an empty roundish cell. These are vesicular protrusions or appendages of the proper pollen-grain, of no known functional importance, except that they render such wind-dispersed pollen more buoyant for transportation.

2 Van Tieghem, in Ann. Sci. Nat. ser. 5, xii. 812, \&c., 1869. 
unaltered until it is placed upon the stigma. The more or less viscid moisture of this incites a similar growth, and also doubtless nourishes it; and the protruding tube at once penetrates the stigma, and by gliding between its loose cells buries itself in the tissue of the style, descending thence to the interior of the ovary and at length to the ovules. Fertilization is accomplished by the action of this pollen-tube upon the ovule, and upon a special formation within it. Consequent

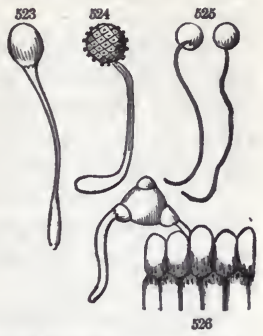
upon this an embryo is formed; and the ovule now becomes a seed.

\section{Section VII. The Pistils, or Grnectum.}

\section{§ 1. In Angiosperms.}

476. The succinct description of the pistil in the first section of this chapter (302), as also what has been stated of the modifications of the gynœcium in Section III., relates to the most typical conditions of this part of the flower. The essential characteristics of all ordinary pistils, whether simple or compound, are : 1. a closed ovary, in which one or more ovules are included; and 2. a stigma, upon which pollen for fertilizing the ovules is received, and through which the pollen acts upon them. There is a more simplified condition, in Gymnosperms, in which naked ovules are exposed to the direct action of the pollen. In contradistinction to this, the ordinary pistil is said to be Angiospermous; that is, with the seeds enclosed in a sac or covering, this in the flower being the ovary. ${ }^{1}$ And plants with such gynœecium are denominated ANgiosperms or Angiospermods plants. To such only the present subsection specifically relates.

477. The several terms which apply to the Gynceium or female system of a flower, and to its components, have been

1 Although thus originated, the seeds are not in all cases matured in a closed pistil. In the Blue Cohosh, Caulophyllum thalictroides, the ovules rupture the ovary soon after flowering, and the seeds become naked; and in Mignonette they are imperfectly enclosed, the ovary being open at the summit from an early period of fructification.

FIG. 523. A pollen-grain of Datura Stramonium, emitting its tnbe. 524. Pollengrain of a Convolvulus, with its tube. 525. Other pollen-grains, with their tubes, less strongly magnified. 526. A pollen-grain of the Evening Primrose, resting on a portion of the stigma, into which the tube emitted from one of the angles penetrates; the opposite angle also emitting a pollen-tube. All highly magnified. 
enumerated and defined already (302, note) : the elementary term is that of

478. Carpel, Lat. Carpeluum. This is the term coined by Dunal, and is in common use. The better-formed word CARPIDIUM (English Carpid) has been proposed, and best of all CARPoPHYLLUM, in English Carpophyll. For carpels are, as the word carpophylla denotes, pistil-leaves, or leaves of the gynœeium, $i$. e., seed-bearing or fructiferous phylla. They occupy the central or uppermost region of the flower. A carpel may be a pistil of itself, either the only one of a blossom or one of several, or it may be a constituent of a more complex pistil. In either case, a carpel is the homologue of a leaf.

479. The morphological conception of an uncombined carpel is that of the blade of a leaf incurved lengthwise, so that the margins meet, and join by a suture, thus forming a closed sac, the ovary. A prolongation of the tip of the leaf is the style: some portion of this, usually the apex, not rarely a single or double line down the side which answers to the suture of the leaf-margins, and may be regarded as its continuation, is the stigma. The carpellary leaf is always incurved : the lower sur-
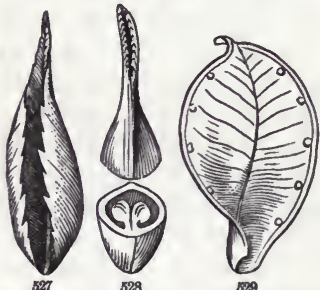

689

face of the leaf is represented by the exterior surface of the ovary, the upper by the interior. The conjoined margins of the leaf, or whatever they bear, are internal in the ovary: the stigma may be regarded as a portion of leafmargins presented externally, destitute of epidermis and formed of loose cellular tissue, which in anthesis is moist by some secretion. The ovules are peculiar structures normally arising as outgrowths from the margins of the leaf, or some part of them, sometimes from the whole or a special portion of the upper or inner surface of the leaf.

480. The carpellary leaf being involute, the suture, on which the ovules are normally borne, always looks toward the axis or centre of the flower. It is the only proper suture (or seam) a carpel can have. From its position it takes the name of Inner or Ventral Suture. And the opposite line or ridge, answering to the midrib of the leaf, being sometimes prominent and of the

FIG. 527. A leaf incurving, to illustrate the morphology of a simple plstil or carpel. 528. A carpel (of Isopyrum biternatum), cut across, the lateral stigma (here manifestly a double line) and the suture bearing the ovules turnod toward the eye. 529. A ripe carnel of Marsh Marigold whlch has opened and shed the seeds: the points of attachment of the latter conspicuous along the edges of the carpel. 
appearance of a suture, has been somewhat incongruously named the Outer or Dorsal Suture.

481. The number of carpels in a gynœcium is simply expressed by adjective terms consisting of Greek numerals prefixed to this word : e. g., Monocarpellary, of a solitary carpel ; Dicarpellary, of two carpels ; Tricarpellary, of three; Tetracarpellary, of four; Pentacarpellary, of five, and so on up to Polycarpellary, of many or at least of several and an indefinite number. Less general and only partially synonymous terms are such as Monogynous (of one pistil), Digynous (of two), Polygynous (of many), \&c. These are adjective forms of the names of the orders, from Monogynia to Polygynia, in the Linnæan artificial classification, which either supposes the carpels to be separate or partly so, or confounds simple and compound pistils.

482. When the gynœcium is of a solitary carpel, the position of this as regards the axis of inflorescence is not uniform; but commonly its back or dorsal suture is before the subtending bract, or in other words the ventral or ovule-bearing suture faces the axis of inflorescence. When there are two carpels, they face each other, bringing their ventral sutures into opposition, and as to axis of inflorescence either median or transverse (291), but usually median, that is antero-posterior or in the line of bract and axis. Cruciferæ, Capparidaceæ, and Fumariaceæ are somewhat remarkable for having their two carpels right and left, that is, collateral or, in other words, transverse. When three, four, or a greater number, they divide the circle equally, or when numerous they take a spiral instead of verticillate order, and occupy several or many ranks, as in Ranunculus, Magnolia, Potentilla, \&c.

483. The Gynœcium may be either of separate carpels (Apocarpous), or of carpels coalescent into one body (Syncarpous), or of all grades between the two. Apocarpous pistils are simple; a syncarpous pistil is compound.

484. In both, the essential parts are the ovary and the stigma. The style may be conspicuous and widely separate these two, as in Fig. 536-538; or hardly any, as in Fig. 532-535; or none at all, as in Fig. 530, 531, 533.

485. Placenta. This name ${ }^{1}$ is applied to any surface in the interior of the ovary on which ovules are borne. It has been stated (579) that these are usually borne upon the margins of

1 Taken from a remote analogy with the placenta of the higher animals. The name appears to have been introduced into botany by Adanson. It bas been termed Trophospermum or Spermophorum by some of the early modern botanists. 
the carpellary leaf, or upon some portion of what answers to them. When the ovules are numerous, and sometimes when they are few, the combined leaf-edges enlarge to form a kind of receptacle for their attachment or support: this is the Placenta. In Fig. 530, the placenta is well developed, and also in such syncarpous ovaries as are illustrated in Fig. 536, 537,544 , and 545 . In very many others (such as

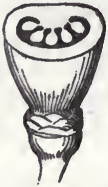

590 Fig. 528, 531, 533), there is no particular enlargement of the leaf-margins visible, and no particular ground for the use of this special term. Still it is commonly used, as occasion serves, even for the mere line or spot on which ovules are borne, as well as for a more prominent development to which the name was originally applied.

486. Simple or Apocarpous Pistils may be solitary, several, or numerous. When indefinitely numerous, they are seldom in one circle, but are capitate or spicate upon a proportionately enlarged or prolonged receptacle, as in Anemone, Ranunculus, and most strikingly in Myosurus; when reduced to a single one, as in Actæa, Podophyllum, ${ }^{1}$ Barberry, and Plum or Cherry, the carpel mostly appears as if it were an actual termination of the

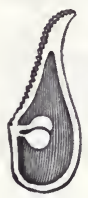

581

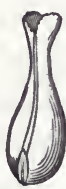

582

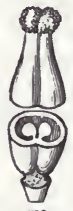

$\mathbf{s} 8$

floral axis. But even then the pistil is hardly ever quite symmetrical in shape: the ovary is somewhat gibbous or unequal-sided (as in Fig. $312,315,316,528,531-533)$, and the stigma more or less oblique or even wholly lateral. The continuation of the latter down the whole length of the ventral side of the style (as in Fig. 528, and also Fig. 549) is not uncommon. In Schizandra (Fig. 531) it is continued downward on the ventral edge of the ovary as far as to its middle. ${ }^{2}$

1 Abnormal specimens of Podophyllum peltatum are occasionally found having a gynœcium of from two to six separate carpels.

2 Pleurogyne, a Gentianaceous genus so named on this account, has no style nor apical stigma whatever, but has a long stigma extending down the outside of each ovuliferous suture of its dicarpellary ovary for most of its length.

FIG. 530. Single simple pistil of Podophyllum, cut across to show the placenta, \&c.

FIG. 531. Vertical section of a pistil of Schizandra coccinea; a side view showing the stigma decurrent down to the middle of the ovary. 532. Pistll of Hydrastis; ventral view. 533. Pistil of Actæa rubra, cut across, so as to show the interior of the ovary; ventral view. 
487. As the placenta of a simple pistil belongs to the two united margins of the carpellary leaf, there is naturally a double row of ovules, one to each margin. If the leafmargins which are turned inward in the ovary below to bear the ovules are turned outward above to receive the pollen (see Fig. 531), then the typical stigma should also be double or bilamellar. So it is seen to be in such carpels as those of Fig. 528, $531-533$, and indeed in very many stigmas of this class. Such division, or even a greater bifurcation of a monocarpellary stigma into two lobes or halfstigmas, is not anomalous.

488. The ovary of a simple pistil should be unilocular, that is, should have a single cavity or cell (loculus), although, as will soon be seen, the converse does not hold true. Yet this cell in certain instances becomes bilocellate, being divided by a growth or intrusion from the back into two locelli. This occurs more or less in the larger number of species of the Leguminous genus Astragalus, and the mode is shown in Fig. 534.

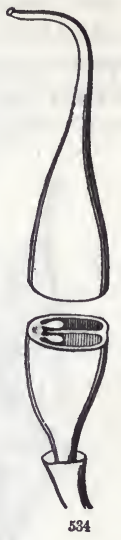

489. Compound or Synearpous Pistil. ${ }^{1}$ This consists of two, three, or a greater number of carpels coalescent into one body. A true compound pistil represents a whorl (in the simplest case a pair) of carpels united into one body, at least as to the ovary. 490. The coalescence of a capitate or spicate mass of carpels or simple pistils of the same flower, imbricately heaped on the torus, as in Magnolia (Fig. 648) and Liriodendron, cannot properly be said to form a compound pistil. This heap of pistils may be called a Sorema.

491. Morphologically, a compound pistil, as to the ovary, may be a pair or a circle of closed carpels or simple pistils brought into contact, and the contiguous parts united: this is illustrated in Fig. 535-538. Or it may be formed of a whorl of open carpellary leaves, joined each to each by the contiguous margins,

1 The terms apocarpous and syncarpous for pistils, the first of separate, the second of combined carpels, were introduced by Lindley. They have little advantage over the terms simple and compound. Moreover, the word syncarp or syncarpium had been appropriated to a sort of fruit of the class now called multiple, formed by the coalescence of several flowers, and also to that of a heap, head, or spike of carpels more or less cohering at maturity, as in a blackberry, or confluent in the flower, as in Magnolia.

FIG. 534. Ovary or forming legume of Astragalus Canadensis, transversely divided, to show the false partition which, intruded from the back, divides the simple cell into two half-cells or locelli. 
in the manner of Fig. 542-545. Between these two there is every gradation. The first forms a compound ovary,

492. With two or more Cells and Axile Placentæ. For it is evident that, if the contiguous parts of a whorl of two or more closed carpels cohere, the resulting compound ovary should have as many cells as there are carpels in its composition, and that the placentæ (one in the inner angle of each carpel) will all be
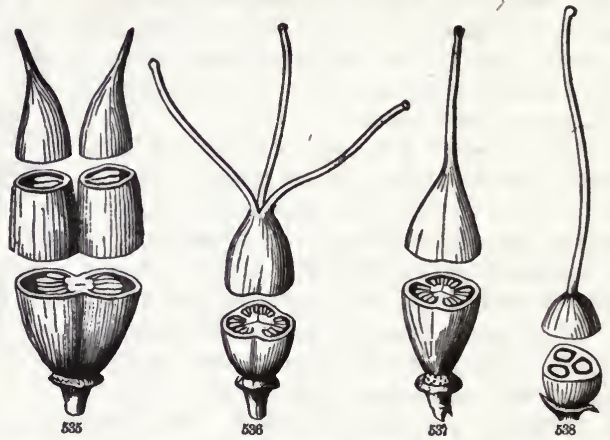

brought together in the axis of the compound pistil. And the partitions, termed Disseprments, which divide the compound ovary into cells, manifestly consist of the united contiguous portions of the walls of the carpels. These necessarily are composed of two layers, one belonging to each carpel; and in fruit they often split into the two layers. True dissepiments and the true cells must accordingly be equal in number to the carpels of which the compound pistil is composed. That is, the ovary, or the resulting fruit, is bilocular or 2-celled, trilocular or 3-celled, quadrilocular or 4-celled, and so on, according to the number of dissepiments or cells.

493. There may also be false dissepiments, mostly of the same character as that which in Fig. 534 divides the cell of a singie carpel. Such are found in Flax (Fig. 539-541), in Amelanchier or Service-berry, in Huckleberry (Gaylussacia), and in most of

FIG. 535. Pistil of a Saxifrage composed of two carpels or simple pistils united below, but distinct above; cut across both above and below.

FIG. 536. Pistil of common St. Johnswort, of three united ovaries; their styles distinct.

FIG. 537. The same of another species of St. Johnswort (Hypericum prolificum), the styles also united into one, which, however, may split apart in the fruit.

FIG. 538. Pistll of Tradescantia or Spiderwort, even the three stigmas united into one. The ovary in all cut across to show the internal structure. 
the American species of Vaccinium. In all these, the false partition is a growth from the middle of the back of each carpel, which divides its cell more or less completely into two.

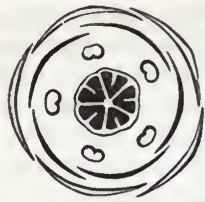

899

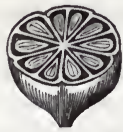

540

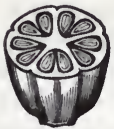

541

494. On the other hand, even the true dissepiments which belong to such a compound ovary may be abortive or evanescent, the placentæ remaining in the axis combined into a column. (499.) The second modification of the compound pistil (491) normally has an ovary,

495. With one Cell and Parietal Placentæ. That is, the placentæ are borne (as the term denotes) on the wall or parietes

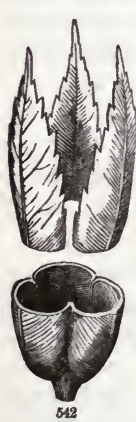
of the ovary, as in the Poppy, Violet, Sundew, Cistus or Helianthemum (Fig. 543), Cleome, Gentian, and in all or most of the orders from which these examples are cited. The diagram Fig. 542 illustrates the morphological conception of a compound pistil of this kind. Not that it is ever supposed to be formed by the actual combination of once

separate leaves, any more than a gamophyllous calyx or corolla is actually so produced. The conception in all such cases is that

FIG. 539. Transverse dlagrammatic section of a flower of the common Flax, showIng the ovary with false partitions extending one from the back of each cell. 540. Section of a mature frnit and seeds of the same, the false partitions now complete, dividing the five celis into ten, each one-seeded. 541. Same of a wild Flax (Linum perenne), in which the false partitions remain incomplete.

FIG. 542. Plan of a one-celled ovary with three parietal placentre, cnt across below; the upper part showing the top of the three leaves it is theoretically composed of, approaching, but not united.

FIG. 543. Ovary of Helianthemum Canadense, cnt across, showing the ovules on three parietal placentæ.

FIG. 544. Transverse section of the ovary of Hypericum graveolens; the three large placentæ meeting in the centre, but not cohering. 545. Similar section of a ripe capsule of the same; the placentæ now evidently parietal. 
of a congenital development of organs in union which, in the development of a vegetative shoot, would be leaves. This case is represented by the combination of open carpellary leaves, as the preceding one is by that of closed ones. As the edges of the leaves must needs be turned in, to bear the ovules, a compound ovary with parietal placentation may be likened to the unopened calyx of a Clematis, as shown in Fig. 256, 257. Every gradation is found between axile and parietal placentation. Sometimes the placentæ are strictly on the parietes or wall (Fig. 543, 547); sometimes borne inwards on incomplete dissepiments (Fig. 548); and sometimes they are brought firmly together in the axis, as in Fig. 544, though separable, and indeed separated in the fruiting stage.

496. A compound ovary with parietal placentæ is necessarily one-celled (unilocular) ; except it be divided by an anomalous partition, such as is found in Cruciferæ (Fig. 395) and in many Bignoniaceæ.

497. Normal placentæ are necessarily double: when parietal, the two halves belong to different leaves; when axile, to the same leaf. These two halves may diverge or be widely separated,

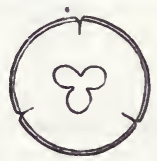

546

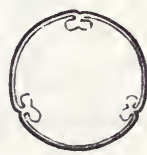

547

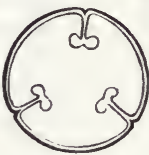

548

sometimes even at their origin, as in Aphyllon and some other Orobanchaceæ, in which a dicarpellary ovary has four almost equidistant placentæ; or in such cases the placentæ may be regarded as intra-marginal instead of marginal.

498. The placentæ of a two-several-celled ovary, such as in Fig. 536, 537, \&c., may be described in the plural number, being one in each carpel; or when consolidated into a central column, and well covered with ovules, they may be said to form one (compound) placenta. Then when the dissepiments early disappear, or are abortive from the first, the result is a compound ovary of this class,

499. With one Cell and Free Central Placenta. In Caryophyllaceæ (Fig. 549, 550) and Portulacaceæ, this evidently results from the obliteration of the dissepiments (as many as there are styles or stigmas), vestiges of which may be sometimes

FIG. 546. Diagram (ground-plan) to illustrate free central placentation produced by abortion of dissepiments. 547. Same of strict parietal placentation. 548. Same with the placentw carried inward on imperfect dissepiments. , 
detected, while certain plants of the same families, of otherwise identical structure, retain the dissepiments even in the fruit.

500. But a similar condition may equally arise from a modification of parietal placentation, namely, with the margins of the leaves ovuliferous only at bottom, and the placentæ there conspicuously developed and completely united. The basal placentation of Dionæa is unavoidably so explained, its nearest relative, Drosera (Fig. 553), having parietal placentæ. And this leads to a probable explanation of the case in Primulaceæ, where a large free central placenta fills the centre of the cell, and no trace of dissepiments can be detected. ${ }^{1}$

501. The idea maintained in former editions is still adhered to; namely, that placentæ belong to carpels and not to the cauline axis, in other words,

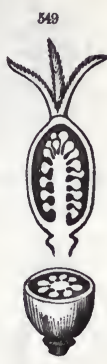

850 that ovules are productions of and borne upon leaves, usually upon their margins, not very rarely upon other portions of their upper surface, rarely over the whole of it. ${ }^{2}$

502. Ovules cover the whole internal face of the carpels in Butomus and its relatives, also of the Water-Lilies (both Nym phæa and Nuphar, Fig. 551) excepting the inner angle, to whick they are usually restricted in other plants. And in the allied Brasenia and Cabomba, where the ovules are reduced to two or three, one or more of them is on the midrib, but none on the

1 The placenta in this and like cases is rather to be regarded as an outgrowth from the base of the carpellary leaves, combined over the floral axis. Upon this interpretation, a central portion of the column may be (and sometimes must be) of axile nature, yet the ovules be borne upon foliar parts. See Van Tieghem, in Ann. Sci. Nat. ser. 5, xii. 329 (1869); Celakowsky, Vergleichende Darstellung der Placenten, \&c. (1876) ; Warming, in Ann. Sci. Nat. ser. 6, v. 192.

2 This view was first maintained as a general theory, and on critical grounds, by Brown, in Plantæ Javanicæ Rariores, 107-112. Schleiden, Endlicher, and others took the opposite view, i.e., that ovules are productions of the axis, even in parietal placentation, - an exceedingly far-fetched supposition. In later days, the commoner view has regarded ovules as of both origins, as productions of the carpels in parietal, of the axis in at least some free central or basilar placentation. But at present the theory of foliar origin without exception, revindicated by Van Tieghem, and especially by Celakowsky and Warming, again prevails. For the bibliography and an abstract of the various views, see Eichler, Blüthendiagramme, especially the note in the preface to the second part (where he gives his entire adhesion to this conclusion); also Warming's memoir, De l'Ovule, in Ann. Sci. Nat. ser. 6, v. 1877-78.

FIG. 549. Vertical section through the compound tricarpellary ovary of Spergularia rubra, showing the free central placenta. 550. Transverse section of the same. 
margins of the carpellary leaf. In many species of Gentian, as

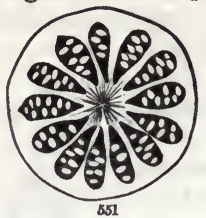
also in Obolaria and Bartonia, of the same family, the whole internal face of a dicarpellary ovary is thickly ovuliferous.

503. Perhaps the parietal placentæ in Parnassia (Fig. 552) are borne on the midribs of the carpels, for they are directly under the stigmas, instead of alternate with them, as they normally should be. The same thing occurs in Poppies and many other Papaveraceæ, also in some Cruciferæ ;

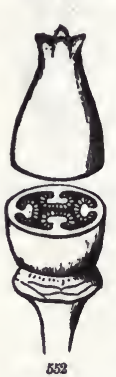
and in some of the cases each stigma is more or less two-lobed. This suggests the explanation, ${ }^{1}$ here probably the true one, which supposes that the placentæ are borne on the leaf-margins in the normal way, but that each stigma is two-parted (as if the carpellary leaf were deeply notched at the apex, and so its two stigmatic leafmargins separate, as Drosera illustrates, Fig. 553), and that the two half-stigmas of adjacent carpels have coalesced into one body, which would

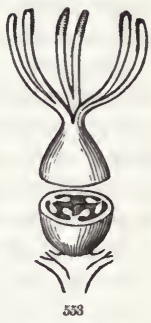

553

of course stand over the parietal placentæ beneath. Each stigma in such a case, as well as each parietal placenta, would consist of the united margins of two adjacent carpels.

\section{§ 2. In Grmnosperms.}

504. Grunospermous (that is, naked-seeded) plants are so named because the ovules, or bodies which are to become seeds, are fertilized by direct application of the pollen, which reaches and acts upon the nucleus of the ovule itself, not through the mediation of stigma and style. In the structure of their flowers, these plants are of a low or simplified type, in some respects not obviously homologous with the Angiosperms which now constitute the immense majority of phænogamous plants. But, up to a comparatively late geological period, Gymnosperms appear to have been the only flower-bearing plants. They are represented

1 Given by Brown, in the Plantæ Javanicæ Rariores, above referred to.

FIG. 551. Transverse section of an ovary of Nymphæa odorata, the carpels ovuliferous over the whole interior surface.

FIG. 552. Pistil of Parnassia, with ovary transversely divided.

FIG. 553. Pistil of Drosera filiformis, with ovary transversely divided. 
in the extant vegetable kingdom by three (or four) groups or orders, two of them small, and one comparatively ample and of wide distribution; and all are so strikingly different from each other that they cannot be illustrated by a common description. The largest order, Coniferæ, is familiar, and contains a good share of the most important forest trees of temperate climates. The smallest, Gnetaceæ, chiefly tropical or of warm regions, lies between Gymnosperms and common Dicotyledons. The third, Cycadacer, is most remote from them, and as much so from Monocotyledons, except that it imitates Palms, as it also does the Tree-Ferns, in habit, both as to stem and foliage. The particular morphology of Gymnosperms would require for its illustration copious details and the history of various conflicting hypotheses. It must be relegated to the special morphology of the natural orders, premising, however, a brief "ketch of the general floral structure. ${ }^{1}$

505. In Gnetaceæ, Gymnosperms and Angiosperms almost tome together. The flowers have a perianth (diphyllous or letraphyllous); the stamens have a distinct filament and anther ; and the gynœcium is a sac (presumably of two carpophylls) open at the top and filled at bottom by a single ovule of the simplest kind, i.e. consisting of a nucleus destitute of coats. This pistillary body is attenuated and prolonged above the ovule into a style-shaped tube, with open and commonly two-cleft orifice. In the almost hermaphrodite sterile flower of Welwitschia, this takes the form of a much dilated stigma, which is even beset with seeming stigmatic papillæ. If only the pollen were here to grow forth into pollen-tubes (with or without a closing of the tube), angiospermy would be attained. But, in fact, the pollengrains bodily reach the ovule itself through the tube, fertilizing it directly. ${ }^{2}$ This interesting group of plants consists of the

1 References to the literature of gymnospermy and to the steps of the prolonged controversy over it, also the points of morphology still in part unsettled, need not here be given. The history and the idea of gymnospermy began with Robert Brown's paper on Kingia, "with Observations . . . . on the Female Flower of Cycadeæ and Coniferæ," read before the Linnean Society in the year 1825, and published in King's Voyage in 1827 ; and the bibliography down to a recent date is given by Eichler in Flora Brasiliensis, Gymnospermia, iv. 435, and in Blüthendiagramme, i. 55-69; also ii. preface x. See also Alph. DeCandolle, Prodr. xvi. ${ }^{2} 345,524$. In this volume, the late Prof. Parlatore adhered to the ancient ideas in his monograph of the Coniferæ.

2 The view here implicitly adopted is that of Beccari, founded on the study of Gnetum, and published in Nuovo Giornale Botanico Italiano, ix. 1877. It was before nearly or quite reached in successive steps, by J. D. Hooker, in his classical memoir on Welwitschia, in Trans. Linn. Soc. xxiv.; Stras. burger, Die Coniferen und die Gnetaceen, 1872; and W. R. McNab. in Trans. Iinp Spc. xxviii. 1872. 
genus Gnetum, shrubs or trees, with nearly the aspect of Angiosperms, having broad and pinnately-veined leaves; Welwitschia of tropical W. Africa, remarkable for its persistent cotyledons which form the only foliage of a woody and longenduring plant, and for its stem or trunk which broadens without lengthening, except in its flower-stalks; also Ephedra, of much branched shrubs, mainly of warm-temperate regions, leafless or nearly so, one species of which inhabits Europe and two the southern borders of the United States.

506. The flowers in all Gymnosperms are diclinous, either diœeious or monœcious ; except that those of the strange Gnetaceous genus Welwitschia are structurally polygamous, the male flowers having a well-formed but sterile gynœcium.

507. In Coniferæ, the largest and most important type, are embraced all the familiar Gymnosperms of temperate regions,

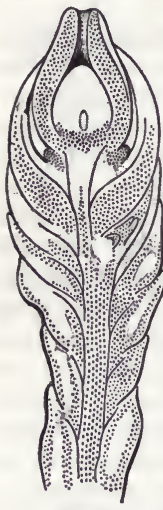

555 Pines, Firs, Cedars, Cypresses, which bear their flowers in catkin-like clusters and their fruit in cones, and also the Yews and allied trees which do not produce cones. Perianth being want-

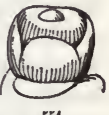
ing and the sexes wholly separate, the floral type is so degraded that it becomes doubtful whether each cluster of anthers, or of ovuliferous scales or ovules, constitutes a blossom or an inflorescence. Certain botanists look upon a whole catkin, and others upon a male catkin only, of a Pine or Fir as forming one flower. It is here assumed that each stamen of the one and each ovuliferous scale of the other answers to a flower of the simplest sort. ${ }^{1}$ The anthers are extrorse, the cells or

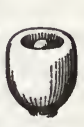

556

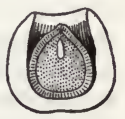

687

pollen-sacs belonging to the outer or lower side of a scale or a

1 It will be seen that, for the female flowers, this follows of course from generally accepted view; and, where this is conceded, analogy may extend it to the male catkins also: yet in such cases, where all the phylla of an indefinite simple axis are stamens, spirally arranged on it, the difference between inflorescence and male flower completely vanishes.

FIG. 554. Female flower of a Yew, an ovule surrounded by its bracts. 555. Longitudinal and more enlarged section of a female flower of Yew and of the upper part of the shoot it terminates: the thick coat of the ovule open at the top, the nucleus within, and the beginning of the disk outside of the cost, are seen in section. After Strasburger.

FIG. 556. Young fruit (berry-like cup surrounding the seed) of Yew. 557. Longitudinal section of a mature frult of the same. After Decaisne. 
connective : sometimes these sacs or cells are two, and the organ evidently homologous with an ordinary stamen : often they are more numerous (from three to twenty) and variously disposed.

508. The Yew Family (Taxineæ) is next to Gnetaceæ in structure. It is generally ranked as a suborder of Coniferæ,

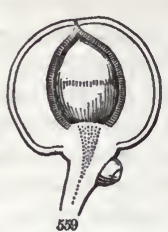

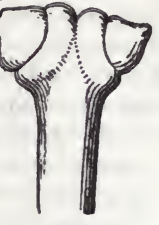

$558^{a}$

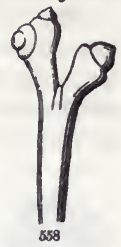
but it may claim to be a distinct order. The gynœcium is a naked ovule, terminating a stem, ${ }^{1}$ and surrounded by several bracts. After fertilization, an outgrowth of the receptacle (or a kind of disk, 394) makes its appearance as a ring girding its base: this grows in height and thickness, and becomes a soft-fleshy cup, imitating a hollow berry, in the bottom of which the stony-coated seed nestles. (Fig. 554-557.) Very similar is the gynœcium of Torreya, except that the cupshaped disk develops almost simultaneously with the ovules, and as it grows becomes adnate to the large seed in the form of a fleshy coating. In the Gingko, two or more similar ovules are nakedly developed on a naked peduncle, unaccompanied even by a bract (Fig. 558 ), and one or more of these ripens into the berry-like seed, Fig. 559. In Podocarpus there are some subtending bracts, and the naked ovule

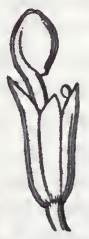

560

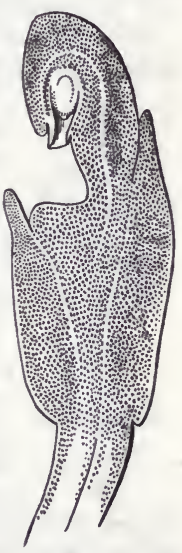

861

1 It does not therefore follow that the ovule is a part of the axis, or is terminal in the sense of being its direct continuation. In this regard it may be only what the pistil of a Cherry is, which to all appearance is equally a terminal production, but is really the representative of the last leaf of the axis. If so, that leaf is here suppressed to the utmost, and replaced by what is ordinarily its outgrowth, the ovular nucleus and its coat. The structure of Podocarpus favors this interpretation.

FIG. 558. Female flowers of Gingko blloba or Salisburia adiantifolia. 558a, Portion of the same enlarged. After Strasburger. 559. A drupaceons seed of the same, in vertical section, exhibiting the mature disk which forms the fiesh, the crustaceons seedcoat, within which is the kernel of the seed; at the base on one side a sterile ovule is seen. After Decaisne.

FIG. 560. Female flower of Podocarpns (an ovule inverted on a column or elevated support), subtended by bracts. After Eichler.

FIG. 561. Magnifled vertical section of a similar flower of Podocarpus. After Strasburger. 
is inverted on a more or less lengthened and stout support, which is conceived to represent the carpel. (Fig. 560, 561.)

509. In the true Coniferæ, to which Pines, Cypresses, and all such cone-fruiting trees belong, the ovules are borne on or in the axils of scales which are imbricated on a simple axis, in a spicate or capitate manner; and the male flowers, each a single stamen, are also similarly spicate or capitate. Both are commonly termed aments or catkins; and the female ones properly so, according to the present view; but the only scales of the male catkins are parts of the anther, being a dilated tip of the counective in Pines, and a scale bearing anther-cells or pollensacs on its back in Cypress.

508

510. In the Pine tribe the flowering female catkin consists of bracts, spirally imbricated on the cauline axis : in the axil of

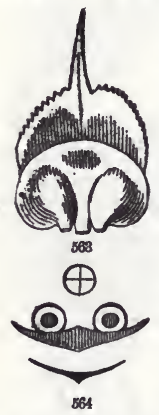
each bract or sterile scale is developed a scale which bears two ovules, and is therefore regarded as of carpellary nature. These ovules are produced on the lower part of the upper face of this carpellary scale, and are wholly adherent to it quite to the orifice, which is directed downward. (Fig. 562, 563.) The ovuliferous scale in becoming fructiferous usually much and soon outgrows the bract, which is concealed in the Pinecone (or sometimes obliterated); but it remains conspicuous in sundry Fir-cones. After fertilization, the scales, successively covering each other in close imbrication, protect the growing seeds as effectually as would a closed ovary. Sooner or later after ripening the scales diverge, and the seeds peel off the face of the scale with a wing attached, and fall or are dispersed by the wind. ${ }^{1}$

1 Among those who admit as well as those who reject gymnosperniy, there has been much controversy over the morphology of the parts. With the former, the discussion turns on the character of the ovuliferous scale. As to this, the hypothesis originally proposed by Mohl, and adopted by Braun, is now said to be satisfactorily demonstrated by Stenzel, in Nov. Act. Nat. Cur. xxxviii. 1876. See note by Engelmann in Amer. Jour. Sci. Dec. 1876 , and also the preface to the second part of Eichler's Blüthendiagramme,

FIG. 562. View of the upper face of a carpellary scale of a Larch, showing the pair of adnate ovules.

FIG. 563. Similar view of a carpellary scale of a Larch, and of a bract behind it. 564. Ground plan of the same in diagram, reversed; the upper figure denoting the axis of the cone, the lower the bract, the middle one the carpellary scale and the two ovules borne on its face. After Eichler. 
511. In the Araucaria tribe the ovuliferous or carpel-scale is throughout smaller than the bract, and is completely adnate to it, or with only the tip free; that of Araucaria (Fig. 565) bears only one ovule, high on the carpel, the orifice downward as in the Pine tribe. In Taxodium, Sequoia, and the like, the conescale is equally inferred to be composed of bract and carpel-scale united; and indications of this composition are to be observed. The ovules (from two to several) are at the base of the scale, erect and free. The cone-scales are alternate and spiral on the axis, but indistinctly so in Taxodium, the Bald Cypress or so-called Cypress of the Southern United States.

512. In the true Cypress tribe (Cupressineæ) the cone-scales, which are never numerous, are opposite or verticillate, i.e. like the foliage-leaves, in whorls of twos, threes, or sometimes fours; and the ovules are from two to

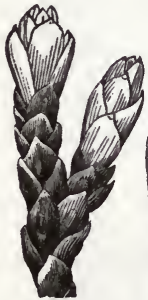

566

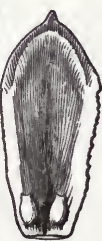

567

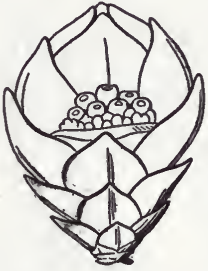

b68

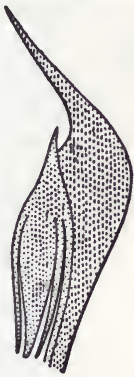

565

1878 , where it is fully adopted. It was suggested by certain rather common monstrosities, and by the two combined leaves of Sciadopitys.

According to this view, the ovuliferous scale in the Pine tribe is composed of two leaves of an arrested and transformed branch from the axil of the bract, which are in the normal manner transverse to the subtending bract, are here carpellary, each bearing an ovule on the dorsal face; the two are coalescent into one by the union of their posterior edges, and the scale thus formed is thus developed with dorsal face presented to the axis of the cone, the ventral to the bract. It is therefore a compound open carpel, composed of two carpophylls. This character of being fructiferous on the back or lower side of the leaf occurs in no other phænogamous plants, but is the rule in Ferns, from something like which Coniferæ may be supposed to have been derived; the ovules of the one in this regard corresponding to the sporangia of the other.

FIG. 565. Vertical section (in diagram) of a bract, adnate carpel-scale, and adnate ovule of Araucaris imbricata. After Eichler.

FIG. 566. Branchlet of the American Arbor-Vitæ, considerably larger than in nature, with a forming fertile cone. 567. One of the scales removed and more enlarged, the inside exposed to view, showing a pair of naked erect ovules on its base.

FIG. 568. Fertile flowers of true Cypress (Cupressus sernpervirens), after Baillon: a forming cone, with one scale cut away, to show the cluster of ovules under it. 
several at or on the base of each cone-scale, always with orifice upward. Arbor-Vitæ (Fig. 566, 567) has a single pair of ovules to the scale; Junipers, sometimes only one ; true Cypresses (as in Fig. 568), often a dczen or more. At flowering time, the conescales mostly appear as if simple; but in most genera they soon thicken greatly within; and they are usually understood to be composed of bract and carpel-scale combined, the latter of the same constitution as that of Pines and Spruces, but perfectly consolidated and confluent with the bract-scale. ${ }^{1}$

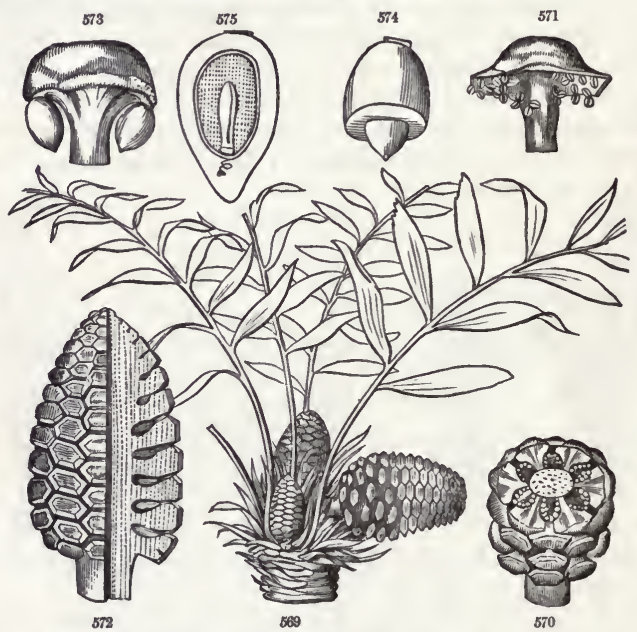

513. In Cycadacex, the type of the flower of Angiosperms is almost or quite lost; yet the organs may be homologized with those of Coniferæ, which these plants are wholly unlike in habit.

1 This internal and ovuliferous scale may seem to be wholly hypothetical, and assumed to homologize the cupressineous with the abietineous cone. Without it, we should have to consider that, while in Abietineæ the ovules belong to leaves of a secondary axis, in Cupressineæ they are borne on those of a primary axis, or else are axillary productions without carpels. But in the Araucaria tribe the internal scale is obvious; and there are suffi-

FIG. 569-575. Zamia, chiefly Z. media, after Richard. 569. A male plant. 570. Lower part of a male catkin. 571. A stamen removed, showing numerous small pollensacs nnder the peltate top. 572. A female catkin, with a quarter section cut away. 573. A female flower or carpel, with two enlarging ovules or young seeds. 574. Ripe seed, with the thick fleshy coat cut away at apex. 575. Longitudinal section of ripe seed, more enlarged. 
Their likeness to Palms and other Monocotyledons is confined to the port of their unbranched trunks and their pinnate leaves with parallel-veined or simple-veined leaflets; nor have they any further resemblance to Ferns, except that in some the leaflets are circinate in vernation. Although a tropical type (of small present importance, compared with the part which it played in the Devonian and Cretaceous periods), it has one small representative (Zamia media, the Coontie) at the south-eastern extremity of
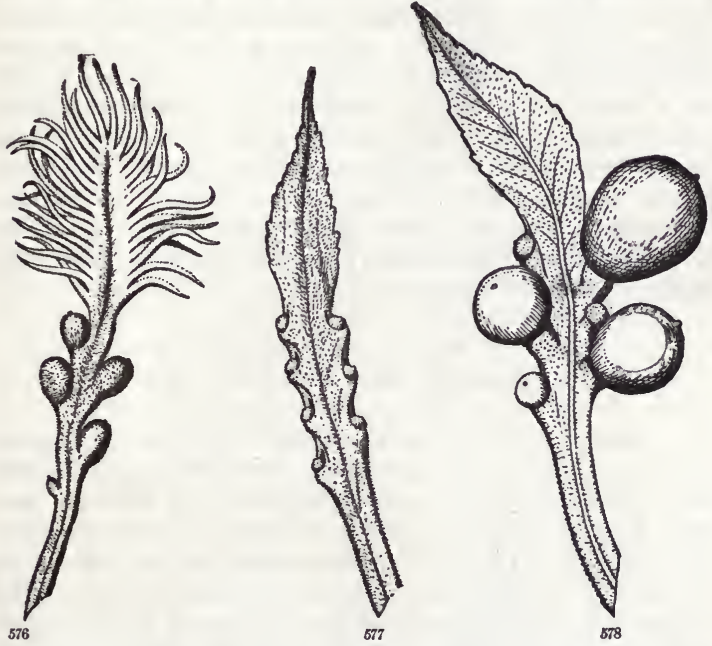

the United States, and a more striking one (Cycas revoluta, well known in cultivation) in the southern parts of Japan.

514. Following the analogy of Coniferæ, each scale (whether of the pollen-bearing or the ovule- and seed-bearing ament) of Zamia (Fig. 569-575) is here regarded as a flower. Here the phylla, or scales with peltate top and stalk-like base, are exter-

cient indications of similar composition in the cupressineous cone-scales te induce the adoption of it by Parlatore, who rejected the idea of gymnospermy: aud, finally, this composition is nearly demonstrated by Van Tieghem (1868) upon the anatomical structure, and by Strassburger (1872) on the development.

FIG. 576-578. Carpophylla of Cycas revoluta, much reduced in size. 576. One bearing ovules below and leaflets or leaf-lobes towards the apex. 577. A similar carpophyll with leaf-lobes reduced to mere teeth, and ovules in place of the lower teeth. 578. A similar carpophyll in mature fructification, bearing the large drupaceous naked seeds. The last two after Richard. 
nally much alike in the two sexes, which throughout the family occupy separate plants. The male flower (Fig. 568) or stamen, if it may be so termed, bears indefinite pollen-sacs on the under side of the peltate portion, sometimes extending to the upper part of its stalk. The homologous female flower, or carpophyll, bears a suspended ovule on each side of the stalk (Fig. 573), which becomes a large fleshy-coated seed. In Cycas the male ament is not very dissimilar, although on a larger scale. But the carpophylls are evident leaves, not condensed into an ament, but loose or spreading, of a character and aspect intermediate between the lax bud-scales which precede and the pinnate foliageleaves which follow them in development. Along the margin of what would be leaf-blade they bear ovules in place of leaflets, lobes, or teeth (Fig. 576-578); and these, when fertilized from the male flowers, mature into large and drupaceous naked seeds. Even without fertilization, such seeds grow to their full size on the female plant of the common Cycas (or falsely so-called Sago Palm), but form no embryo.

\section{Section VIII. The Ovule. ${ }^{1}$}

515. Ovules (302) are peculiar outgrowths or productions of carpels which, upon the formation of an embryo within, become seeds. In the angiospermous gynœcium (476) they are normally produced along the margins, or some part of the margins, of the carpellary leaf (478), either immediately, or by the intermediation of a placenta (485), which is a more or less evident development of the leaf-margins for the support of the ovules. Rarely, yet in a considerable number of cases $(501,502)$, ovules are developed from the whole internal surface of the ovary, or from various parts of it, in no definite order, directly from the walls, and without the intervention of any thing which can be regarded as placenta. In Gymnosperms (504-514) the ovules are borne on the face of the carpellary scale or at its base; or on leaf-margins, as in Cycas ; or, when there is no representative of the carpel, on the cauline axis, seemingly as a direct growth of it. (508, note.)

516. As to attachment, ovules are either sessile, $i$.e. stalkless, or on a stalk of their own (Fig. 582, 584), the Funiculus or Podosperm. As to number they are either solitary, few, or

1 Lat. Ovulum, pl. Ovula, diminutive of ovum (egg), perhaps first used by Adanson 
indefinitely numerous. They may also be indefinite or variable in number when not particularly numerous.

517. As to situation and direction within the ovary, the terms are somewhat special. Ovules are erect, when they rise from the very bottom of the cell, as in Fig. 580; ascending, when attached above its bottom and directed upward, as in Fig. 579 ; horizontal, when borne on one or more sides of the cell and not directed either upward or downward, as in Fig. 314, 315, 530 ;
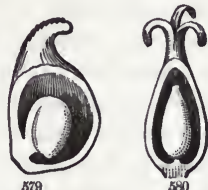

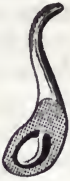

581 pendulous, when more or less hanging or declining from the side of the cell; suspended, when hanging from the apex of the cell, as in Fig. 581.

518. The body and only essential part of an ovule is its Nucleus. This in most cases is invested by one or two proper coats. The coats are sacs with a narrow orifice, the Foramen. In the seed, the closed vestige of this orifice is termed the Micropyle; wherefore this name is sometimes applied to it in the ovule likewise. When the ovule has two coats, the foramen of the outer one is called Exostome, of the inner Endostome; literally the outer and the inner orifice. The coats themselves have been named Primine and SecunDINE, but with an ambiguity in the application which renders these names unadvisable: for in their formation the coats appear later than the nucleus, the inner coat earlier than the outer; and the name of primine has by some writers been applied to the earlier

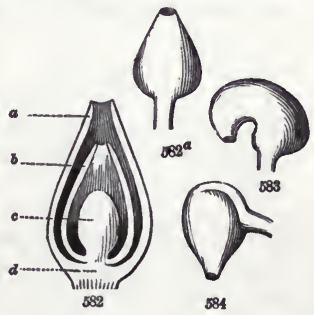
formed, by others to the external coat. The proper base of the ovule, from which the coats originate and where these and the nucleus are confluent, is the Chalaza. The attachment of the ovule to its funiculus or support, which in the seed becomes the

FIG. 579. Ovary of a Buttercup, divided lengthwise, to display its ascending ovule. 680. Same of Buckwheat, with an erect ovule. 681. Same of Anemone, with a suspended ovule.

FIG. 882. Diagrammatic section of a typical or orthotropous ovule (such as that of Fig. 682a), showing the outer coat, $a$, the inner, $b$, the nucleus, $c$, the chalaza, or place of junction of these parts, $d$. (The coats are never so separated and the nucleus so reduced in size as is represented in this mere diagram.) 583. An ovule similar to the preceding, but curved, or campylotropous. 584. An amphitropous ovule. 
Hrum, takes also this latter name in the ovule. In the simplest form of ovule (as in Fig. 582, 580), hilum and chalaza are one. So also in cases where the body of the ovule incurves, as in Fig. 583. But very commonly the place of attachment, which becomes the hilum, is more or less distant from the chalaza ; as in Fig. 584 and 587; where the hilum is lateral, but the chalaza at the larger end, the two being connected by a short ridge; and in Fig. 588 the two are separated by the whole length of the ovule.

519. The simplest and most rudimentary ovule is that without a coat, as in Mistletoe and the whole order Loranthaceæ, and in Santalaceæ and Gnetaceæ. This has been called a naked ovule; but long before ovules of such simplicity were known this term had been appropriated to those of Gymnosperms, in the sense of destitute of ovarial or pericarpial covering, $i . e$. to uncovered ovule, not to uncovered nucleus. The ovule consisting only of nucleus may be termed (after Alph. DeCandolle) simple, or better achlamydeous. ${ }^{1}$

520. The tunicated or chlamydeous ovule is of three principal kinds, with one or two subordinate modifications. These are the orthotropous, campylotropous, and anatropous, and the modification called half-anatropous, or amphitropous. ${ }^{2}$

521. Orthotropous (Fig. 580,582, 585), or straight osule, is the simplest but least common species, being that in which the
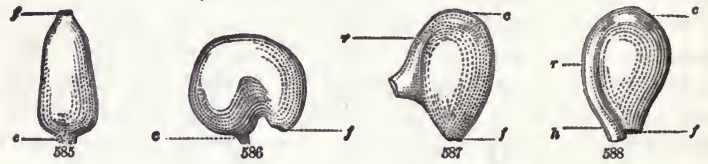

chalaza is at the evident base, and the orifice at the opposite extremity, the whole ovule straight (as the first part of the name denotes) and symmetrical. Atropous, meaning not turned at all, is a later and etymologically much better name, but it has

1 An epidermal stratum or tegument may not be wanting to such ovules, forming a sort of adherent covering; but this in nature and origin is not similar to the ovular coats.

2 In Latin form, orthotropa, campylotropa, anatropa, amphitropa, - names given by Mirbel, and referring to the way in which the ovule is turned either on itself or on its support. Some English botanists incongruously write ortho. tropal, campylotropal, \&c.

FIG. 585. Orthotropous or Atropous ovule of Buckwheat. 586. Campylotropous ovule of Chickweed. 587. Amphitropous ovule of Mallow. 588. Anatropous ovule of a Violet. The letter $h$ indicates the hilum; $c$, the chalaza, which in 585 and 586 corresponds to the hilum; $f$, the foramen or orifice; $r$, the rhaphe. 
not come into general use. This ovule is characteristic of Polygonaceæ, the proper Urticaceæ, Cistaceæ, \&c.

522. Campylotropous (Fig. 583, 586) is the name of the ovule which in the course of its growth is curyed on itself so as to bring the orifice or true apex down close to the base, here both chalaza and hilum. This and the orthotropous ovule begin their development on the placenta in the same way, but the campylotropous develops unequally, one side enlarging much more than the other, especially at the base, until the ovule becomes reniform, and chalaza and orifice are brought into close proximity. Campylotropous ovules are characteristic of Cruciferæ, Capparidaceæ, Resedaceæ, Caryophyllaceæ, and Chenopodiaceæ.

523. Amphitropous (Fig. 584, 587), also termed Heterotropous and sometimes Half-anatropous, is between the preceding and the following; and it passes in various instances either into the one or into the other. The body of the ovule is straight or straightish, but it stands as it were transversely or at riglit angles to the funiculus and hilum; and it is fixed by the middle, the chalaza at one end, the orifice at the other. An apparent continuation of the funiculus, adherent to the outer coat, extends from the hilum to the chalaza. Compared with the preceding form, the explanation is, that the unequal development at its formation is confined to the basal half, and the axis remains straight, while the whole is half inverted by the very unequal growth. Compared with the next form, the inversion is less and the later growth or extension of the apical portion greater. The amphitropous ovule is characteristic of Primulaceæ, and is common in Leguminosæ.

524. Anatropous (Fig. 588, also 579, 581, 597) is the name of far the commonest species of ovule, that in which the organ, under the course of its growth, is quite inverted on its base; so that, instead of standing at right angles with the funiculus, it is parallel with it, or rather with the apparent continuation of it, which is adherent to its surface as a sort of ridge or cord extending along the whole length of the ovule, from hilum to chalaza. The latter occupies the seeming apex of the seed; and the organic apex or orifice is at the other end, close beside the hilum. At maturity, the ovule is straight, but not wholly symmetrical, the attachment being oblique or somewhat lateral, and the ridge or cord on that side not rarely prominent.

525. The cord or ridge, which extends along the whole length of the anatropous ovule, and for half its length in the amphitropous (Fig. 588, 587, $r$ ), is named the RHAPHe. This is not 
at all a seam, as the Greek word denotes. Its origin, and the whole structure of such ovules will be apprehended by comparing various stages of its growth.

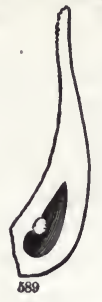

526. An ovule of any kind at the beginning is an excrescence or outgrowth of the placenta, or of some part of the leaf-surface if there is no developed placenta. This incipient ovule is the nucleus (518), or the nucleus surmounting a rudimentary funiculus. The nucleus is soft cellular tissue only, from first to last. The achlamydeous ovule (519) undergoes no further development except in size or shape. Indeed sometimes (as in Balanophoreæ) this bare nucleus is reduced to a few cells of parenchyma.

527. In ordinary ovules a new growth early begins around the base of the nucleus, or is sometimes coetaneous with it, at first as a ring (or part of a ring), soon as a cup, at length as an enclosing sac or covering, open at the top; this is the inner coat of the ovule when there are two. The outer coat begins and goes on in the same way, and at length grows over and encloses the inner coat as that did the nucleus. (Fig. 590-595.) Whenever there is a third and more exterior coat it is formed during the growth of the fertilized ovule into the seed, to which therefore it belongs, and in which it takes the name of arillus. (597.) At the time of fertilization the apex of the nucleus, or a prolongation of it, usually projects beyond the orifice and there receives the descending pollen-tube. Some fibro-vascular tissue, especially spiral ducts, may be found in the funiculus and chalaza, sometimes extending into the coats.

528. The development of the orthotropous or atropous (unturned) ovule proceeds symmetrically, without distortion, the

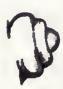

$\$ 00$

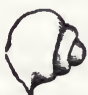

001

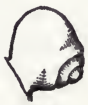

592

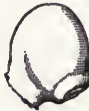

593

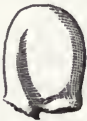

594

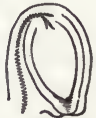

s95

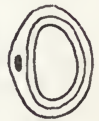

596

parts keeping their primitive direction. In the campylotropous, the whole of one side of the ovule greatly outgrows the other.

FIG. 589. Magnified view of a vertical section of a carpel of Magnolia Umbrella, about a month before anthesis, showing one of the two nascent oviles, at this tiine only nucleus.

FIG. 590-597. Further development of the ovule of Magnolla Umbrella, showing the formation of the coats and the anatropy. 590. Ovule a week older than in 589. 591. Same a week or two later. 692. Same a few days later. 593. Same from a nearly fullgrown flower-bnd. 594. Same at time of anthesis. 595. Vertical section of the last through the middle of the rhaphe. 596. Cross-section of the same. (See Jour. Linn. Soc. il. 108.) 
In the anatropous, the inequality of growth is mainly confined to the base or chalazal region, which ends by becoming uppermost; and the full-grown ovule has the appearance of being inverted on and adherent to the upper portion of its funiculus, the rhaphe. Fig. 589-597 illustrate the course of development from a comparatively early period.

529. The direction of anatropy or of other turning of the ovule in the course of growth is somewhat diverse. But in general, whenever ovules are in pairs, the two turn from

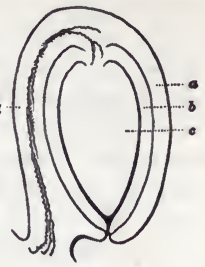

597 each other, in the manner of Fig. 315, and so present their rhaphes back to back. The rhaphe-bearing may therefore be called the dorsal side of the anatropous ovule. The same is true in the case of numerous ovules, viz., those of one half of the placenta (or one leaf-margin) turn their backs to those of the other. When such ovules are solitary or in single rows, and either ascending or hanging, the rhaphe is usually on the side next to the placenta or ventral suture, as in Fig. 579: it is then said to be ventral ( $i$. e., next the ventral suture), or adverse to the placenta. In certain cases, mostly in hanging ovules, as in Fig. 581, the rhaphe looks in the opposite direction, toward the dorsal suture or midrib of a simple ovary : it is then said to be dorsal or averse from the placenta. ${ }^{1}$

1 By comparison of Fig. 578 with 576 and the like, it may be perceived that the difference is explicable by a kind of resupination of the ovule of the former. That of Ranunculus, if inserted higher, would become horizontal; and if the insertion were transferred to the very summit of the cell, it would be suspended and the rhaphe averse, as in Fig. 581. Upon this conception, Euphorbia and its allies has normally suspended ovules, the rhaphe being next the placental axis, and Buxus and its allies, resupinately suspended ovules, the rhaphe averse. The propriety of regarding the adverse rhaphe as the normal condition is confirmed by the fact that the only instance we know of solitary erect ovules from the base of the cell having the rhaphe averse is that of Rhamnus and its allies; and here it was shown by Bennett (in Pl. Javan. Rar. 131), and confirmed by the analyses of Sprague (Gray, Gen. Ill. ii. 168, plates 163-169), that the rhaphe of the young ovules is ventral, so that the dorsal position, when it occurs, is the result of torsion. J. G. Agardh (in his Theor. Syst. Pl. 178, \&c.) maintains the contrary, but is not sustained by later observers.

Accordingly, even if we adopted Agardh's estimate of the botanical value of the characters here considered, we should prefer to express these differences in the phraseology above indicated, and not to adopt his terms,

FIG. 597. Same as 595 more magnified; the outer coat (a), the inner $(b)$, nucleus (c), and the bundle of spiral ducts $(d)$ in the rhaphe (running from placenta to chalaza) indiaated. 
530. Origin and Nature of the Ovule. It has been already stated in general terms that ovules are peculiar outgrowths or productions, generally of the margins of carpellary leaves (515) ; that they are composed of parenchymatous cellular substance, at least as to the nucleus, of which the simplest ovule wholly consists (526); that the coats originate subsequently to the nucleus; and that the outer coat is of later origin than the inner one. (518.) The mamiliform protuberance of which the forming ovule at first consists originates in one or more cells of a layer directly beneath the epidermis. ${ }^{1}$

531. The morphological nature of the ovule has been much discussed. The commonly prevalent view was that the ovule is homologous with a leaf-bud, and that its nature is in some degree illustrated by such buds as those which develop on the margins of the leaves of Bryophyllum, as shown in Fig. 322. But such buds, and the bulblets or fleshy buds which appear on the face of certain leaves, follow the universal order of budding growth, that is, are centripetal in development, the outermost parts being the earlier and the inmost the later formed. The ovule, on the contrary, is basipetal or centrifugal in development, the nucleus being first and the outer coat last formed; therefore the coats are not homologous with sheathing leaves, nor the nucleus with a vegetative axis. The older theory has accordingly given way to the present one, in which the ovule answers to the lobe of a leaf peculiarly transformed, or to an outgrowth of a leaf, whether from its edges or surface. The

apotropous, epitropous, and heterotropous (the first two new, the last employed in a new sense), the more so since the application is confused with hypothetical considerations and the necessity of bringing the ovules ideally back to ascending or horizontal positions. It may be stated, briefly, that Heterotropous, in Agardh's terminology, applies to the normal position of collateral ovules, with rhaphes back to back, in opposite directions on the two halves of the placenta; Apotropous, to an erect or ascending ovule with its rhaphe next the placental axis, and a hanging one has its rhaphe averse from it; Epitropous, when an erect or ascending ovule has its rhaphe averse, and a hanging one has it adverse.

1 Hofmeister's statement that the simple ovule of Orchis originates in the division of a single epidermal cell (and is therefore a trichome) is controverted by Strasburger and by Warming. The latter adds the remark, that even if it were so in cases of extreme simplicity, this would not invalidate the proposition that the ovule is to be regarded as the homologue of the lobe of a leaf. Such a lobe is not rarely reduced to a single bristle. For the whole subject of the origin, development, morphology, and theory of the ovule, see Warming's very elaborate and perspicuous memoir, De l'Ovule; also the papers of Celakowsky, Van Tieghem, \&c., referred to in notes to paragraphs 500,501 . 
great advantage of this view is that it serves to homologize the fructification of Flowering Plants with that of the higher Flowerless Plants, or the Ferns, the sporangia or analogues of the ovule being outgrowths of the leaf. ${ }^{1}$

532. Origination of the Embryo. tilization and the resulting production of the embryo, also the history of the subject, belongs to the succeeding volume, involving as they do questions of minute anatomy and of physiology. But a general idea may here be given of the way in which the embryo originates. The tube which a grain of pollen sends forth into the stigma $(574,575)$ penetrates the style through loose conducting tissue charged with nourishing liquid, reaches the cavity of the ovary, enters the orifice of an ovule to reach the apex of the nucleus, although the latter sometimes projects to meet the pollen-tube. Meanwhile a cavity (the embryosac, which is formed by the great enlargement of a single cell of the tissue, or of two or more cells the product of a mother cell) forms in the nucleus, the upper part of it commonly reaching nearly or quite to the apex of the nucleus, which the pollen-tube impinges on or The whole process of fer-

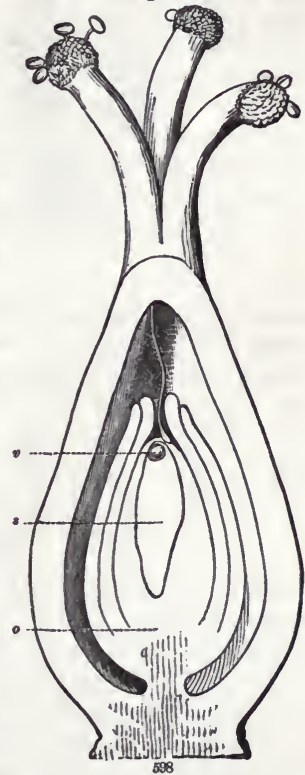
sometimes penetrates. A particular portion of the protoplasm contained in the embryo-sac forms a globule, and this at the time

1 The advocates of this view naturally maintain that ovules and placentre always belong to leaves, and never truly to a cauline axis; that in the pre central placentation of Primulaceæ, the actual ovuliferous surface is an outgrowth of the bases of the carpellary leaves coalescent with each other and adnate to a prolongation of the torus; also that in those Gymnosperms which have no carpophyll, such as Yew, the whole nascent carpellary leaf, or rather the papilla which would otherwise develop as such, is directly developed into ovule. This, being solitary and the last production of the axis, necessarily appears to terminate it. $(500,501$, notes.)

FIG. 598. Diagram representing a magnified pistil of Buckwheat, with longltudinal section through the axis of the ovary and orthotropous ovule; some polien on the stigmas, one grain distinctiy showing its tube, which has penetrated the style, reappeared in the cavity of the ovary, entered the month of the solitary ovule $(0)$, and reached the embryo-sac (8) near the embryonal vesicle (v). 
of fertilization is found at the apex of the sac, at or adjacent to the part reached by the pollen-tube. Not rarely it adheres to the

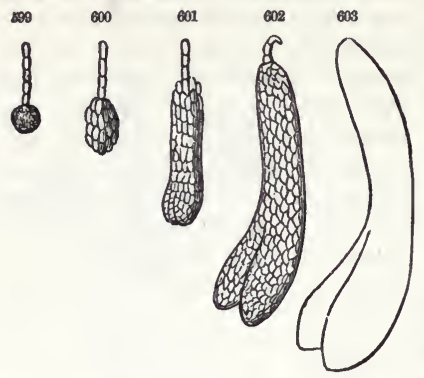

wall of the sac exactly opposite the termination of the pollen-tube. This is called the embryonal vesicle. To it the contents of the pollen-tube are in some manner transferred. Upon which it takes a more definite shape, acquires a wall of cellulose, and so becomes a vegetable cell. This divides into two, the lower again into two, and so on, forming a chain (the suspensor or proembryo). The terminal cell of this divides again and again in three directions, producing a mass of cells which shapes itself
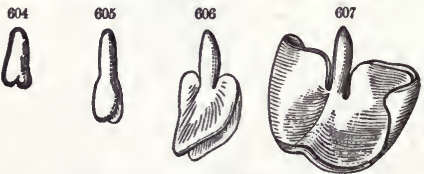

into the embryo, the initial plant of a new generation. Ordinarily the suspensor soon disappears. It is attached to the radicular end of the embryo, which consequently always points to the foramen or micropyle of the seed. The process in Gymnosperms is more complex, and has to be separately described.

533. Polyembryony, the production of two or more embryos in one seed, is not uncommon in Gymnosperms (there being a kind of provision for it), and is of occasional but abnormal occurrence in Angiosperms, in the seed of Mistletoe, Santalum, \&c. In these it results from the production and fertilization of more than one embryonal vesicle. Strasburger has recently ascertained that the commoner polyembryony in the seeds of Onions, Oranges, Funkia, \&c., results from the production of adventive embryos, which originate in the nucleus outside of the embryosac and wholly independent of fertilization. ${ }^{1}$ Two kinds of

1 Strasburger, Ueber Polyembryonie, in Zeitschr. Naturwis. Jena, xii. 1878 (see Amer. Jour. Sci. April, 1879). It was found that when, by exclusion of pollen, the formation of a normal embryo was prevented, no adventive

FIG. 599. Diagram of the snspensor and incipient embryo at its extremity. 600 . The same, with the embryo a little more developed. 601. The same, more developerl still, the cotyledons faintly indicated at the lower end. 602. Same, with the incipient cotyledons more manifest. 603 . The embryo nearly completed.

FIG. 604-606. Forming embryo from a haif-grown seed of Buckwheat, in three stages. 607. Same, with the cotyledons fully developed. 
anomalous reproduction are therefore now known, which are intermediate between sexual and non-sexual, between budding and fruiting propagation, viz., -

Apogamy, which is budding growth or prolification in place of that which should subserve sexual reproduction. This was discovered in Ferns by Prof. Farlow, while a pupil of De Bary, by whom our knowledge of the process has recently been extended, and this name imposed. ${ }^{1}$ The production of bulblets in place of seed or em 3ryo answers to this in Flowering plants.

Parthen rgeny, the counterpart analogue of apogamy, is the non-sexunl origination of an embryo extraneous to the embryonal vesicle $\boldsymbol{\tau} \boldsymbol{x}$ even the embryo-sac. However abnormal, its occurrenco probably not so rare as has been supposed.

\section{CHAPTER VII.}

\section{THE FRUIT.}

Section I. Its Structure, Transformations, and Dehiscence.

534. The Fruit consists of the matured pistil or gynœcium (as the case may be), including also whatsoever may be joined to it. It is a somewhat loose and multifarious term, applicable alike to a matured ovary, to a cluster of such ovaries, at least when somewhat coherent, to a ripened ovary with calyx and other floral parts adnate to it, and even to a ripened inflorescence when the parts are consolidated or compacted. Fruits, accordingly, are of various degrees of simplicity or complexity, and should be first studied in the simpler forms, namely, those which have resulted from a single pistil. Such a fruit consists of Pericarp with whatever may be contained in it and incorporated with it.

embryo appeared in those seeds which habitually produce them. To this Cælebogyne offers an exception. The female of this diceious plant habitually matures fertile seeds, with a well-formed embryo, in Europe when there are nu male plants in the country. 'Strasburger ascertained that the embryo thus formed is adventive, the embryonal vesicle perishing. Parthenogenesis, of which Cælebogyne was the most unequivocal case, is thus confirmed, and is shown to occur in most polyembryony; but it is at the same time explained to be a kind of prolification.

1 See Farlow, in Proc. Am. Acad. ix. 68; De Bary, Bot.Zeit. xxxvi.465-487. 
535. The Pericarp, or Seed-vessel, is the ripened ovary. It should, therefore, accord in structure with the ovary from which it is derived. Yet alterations sometimes take place during fructification, either by the abortion or obliteration of parts, or by accessory growth.

536. Internal Alterations. Thus, the ovary of the Oak consists of three cells, with a pair of ovules in each; but the fruit has a single cell, filled with a solitary seed, only one ovule being matured, while two cells and five ovules are suppressed, the remains of which may be detected in the acorn. The ovary of the Chestnut has six or seven cells, and a pair of suspended ovules in each; but only one of the dozen or fourteen ovules ever develops into a seed, except as a rare monstrosity. The three-celled ovary of the Horsechestnut and Buckeye is similar in structure (Fig. 608-611), and seldom ripens more than one or two seeds; but the
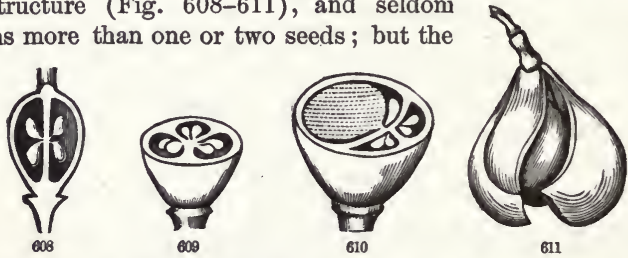

abortive seeds and cells are obvious in the ripe fruit. The ovary of the Birch and of the Elm is two-celled, with a single ovule in each cell : the fruit is one-celled, with a solitary seed; one of the ovules being uniformly abortive, while the other in enlarging thrusts the dissepiment to one side, and obliterates the empty cell. Similar suppressions in the fruit of parts actually extant in the ovary are not uncommon.

537. On the other hand, there may be more cells in the fruit than there are primarily in the ovary. Thus the fruit of Datura is dicarpellary and normally two-celled, with a large placenta projecting from the axis far into the cells. But each cell becomes bilocellate, that is, divided into two, by a false partition growing out from the back of each carpel and cohering with the middle of the adjacent placenta. So the 5-carpellary and normally five-celled ovary of common Flax early becomes spuriously ten-celled (morphologically speaking, not 10-locular, but 10locellate), by a false partition extending from the back of each

FIG. 608. Longitudinal section of the ovary of a Buckeye (Asculus Pavia), showing the pairs of ovules in two of the cells. 609. Transverse section of the same displaying all three cells and six ovules. 610. Same of half-grown fruit, with single fertile seed, aborthe ovules and obliterating cells. 611. Dehiscent one-seeded fruit, diminished in size. 
carpel across its cell (Fig. 539-541) ; and the solitary carpel is similarly divided lengthwise in many species of Astragalus, as in Fig. 534. Transverse divisions or constrictions across a maturing ovary (such as is seen in Fig. 620) are not uncommon, especially in legumes and other pods, and are of little morphological significance.

538. External Accessions may here be referred to. The wing of the pericarp in Maple, Ash, and the like (Fig. 625-627), are familiar instances of this; and of the same nature are the imbricated scales which cover some Palm-fruits; the prickles on the pod of Datura, Ricinus, \&c., and the hooked or barbed prickles of many small pericarps (as in various Borraginaceæ), which thus become burs and are disseminated by adhering to the hairy coat of cattle. All these are of the nature of superficial outgrowths, and these especially affect the pericarp or parts connected with it.

539. Persistence of Connected Organs. An adnate calyx (331), being consolidated with the ovary, necessarily makes a constituent part of the fruit, in the pome (575) doubtless a very large part. The limb or lobes of such adnate organ may persist, as the tips of the sepals on an apple or quince, and may be turned to useful account, as is the pappus of Compositæ for dissemination. Or, in small pericarps, the style may persist as part of the fruit, and subserve the same ends, either by becoming feathery for aerial dissemination, as in Clematis and in one section of Geum, or by becoming hooked at the tip for adhesion to fleece, \&c., as in other species of the latter genus. Or adjacent parts which are not actually incorporated with the pericarp may play similar parts in the economy, as the hooks on the calyx-tube of the dry calyx of Agrimonia, which at maturity is detached with the included fruit, the fleshy fructiferous calyx of Gaultheria (Fig. 651 ) and of Mulberry (Fig. 654); and the pulpy fructiferous receptacle of the strawberry (Fig. 653) : the ultimate utilities in both classes of instances being similar, viz., wide dispersion of the seed by animals, whether by external carriage, or by being devoured and the voided seeds of fleshy fruits thus disseminated.

540. Transformations in Consistence. In the change from ovary to mature pericarp, various kinds of transformations may take place. In some the wall of the ovary remains thin and becomes in fruit foliaceous or leaf-like, as in a pea-pod, the carpels of Columbine, and Marsh Marigold (Caltha), or the pod of Colutea or Bladder Senna. In others it thickens and becomes at maturity either dry throughout, as in nuts and capsules; or fleshy or pulpy throughout, as in berries ; or hard-rinded with- 
out but soft within, as in a pepo ; or fleshy or berry-like without, but indurated within, as in all stone-fruits, such as the cherry and peach.

541. When the walls of a pericarp consist of two layers of dissimilar texture (as in a peach) the outer layer is called Exocarp, the inner ENDOCARP, these terms meaning exterior and interior parts of a fruit. When the external layer is a comparatively thin stratum or film, it is sometimes termed the EPICARP. When it is fleshy or pulpy it is named SARCOCARP. When the endocarp within a sarcocarp is hard and bony or crustaceous, forming a shell or stone, this is termed a Putamen. When three concentric layers are distinguishable in a pericarp, the middle one is called Mesocarp.

542. Fruits may be divided into two kinds, in reference to their discharging or retaining the contained seeds. They are dehiscent when they open regularly to this end ; indehiscent when they remain closed. There is a somewhat intermediate condition, when they rupture or burst irregularly, as in Datura Metel, \&c. Dry pericarps with single seeds are commonly indehiscent; those with several or many seeds mostly dehiscent. Seeds provided with a wing or coma or any analogous help to dispersion are always in indehiscent pericarps. Permanently fleshy pericarps are indehiscent, stone-fruits as well as berries. But in some stone-fruits ( $i$. e., with indurated endocarp and fleshy exocarp), such as those of Almond (Fig. 640) and Hickory, the barely fleshy exocarp or sarcocarp dries or hardens, instead of softening, as maturity is approached, and at length separates from the putamen by dehiscence.

543. Dehiscence, the opening of a pericarp for the discharge of the contained seeds, is rngular or irregular; or, better, is normal and abnormal. For most of the abnormal or non-typical modes are as determinate and uniform in occurrence as the typical modes. A good English name for dehiscent pericarps in general is that of PoD.

544. Regular or normal dehiscence is that in which a pericarp splits vertically, for its whole or a part of its length, on lines which answer to sutures or junctions, that is, along lines which correspond to the margins or midribs of carpellary leaves, or to the lines and surfaces (or commissures) of coalescence of contiguous carpels. The pieces into which a pericarp is thus sundered are termed VaLves.

545. The normal dehiscence of a carpel is by its inner, ventral, or ovuliferous suture, that is, by the disjunction of the leaf-margins, as in Fig. 618. Its only other line of normal dehiscence is by the opposite or dorsal suture, that is, down 
the midrib. Legumes usually dehisce by both sutures (as in Fig. 619), therefore into two valves.

546. A dehiscent pericarp formed of two or more carpels is called a CAPsule. The two leading terms descriptive of capsular dehiscence were based upon the modes of opening of pericarps having as many cells as carpels : they are the septicidal, that is, as the term denotes, cutting through the septa or dissepiments; and the loculicidal, that is, cutting into the loculi or cells.

547. Septicidal, the dehiscence through the dissepiments, is the disjunction of a pericarp into its constituent carpels, these then usually themselves dehiscing down their ventral suture, as in Fig. 612, illustrated by the diagram, Fig. 613. Good examples are furnished by the $\int$ Hypericum Family (the pistil illustrated in Fig. 536, 537), where the placentæ which compose the axis are carried away on the edges of the partitions or introflexed valves; also by Rhododendron, Kalmia, and the like, in which the placentæ remain combined into a column in the axis (the Columella or column), from

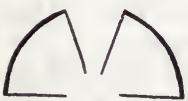
which the edges of the valves break away.

548. The septicidal disjunction of the carpels does

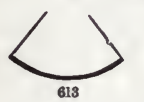
not of itself open the cells. Such separated carpels when one-seeded not rarely remain closed, as in Mallow, Ver-
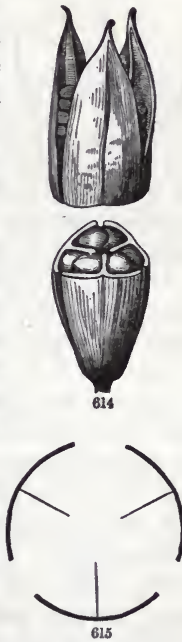

bena, \&c. Or when dehiscent they may open both by the ventral and dorsal sutures; $i$.e., the pericarp may first divide into its constituent carpels, and then each carpel break up into half carpels, as in Euphorbia.

549. Loculicidal, the dehiscence into the loculaments, loculi, or cells of the pericarp (shown in Fig. 614, and the diagram, $615)$, is that in which each component carpel splits down its

FIG. 612. Septicidally dehiscent tricarpellary capsule of Elodes Virginica. 613. Diagram of septicidal dehiscence.

FIG. 614. Loculicidally dehiscent tricarpellary capsule of an Iris, divided transversely at the middle. 615. Diagram of loculicidal dehiscence. 
dorsal suture, as in Iris, Hibiscus, Enothera, \&c. In this, the dissepiments remain intact. If they break away from the centre then they are borne on the middle of the valves, as in the figures above cited. If they remain coherent in the axis but break away from the valves, the result is one form of what is called -

550. Septifragal dehiscence, $i . e$. , a breaking away of the valves from the septa or partitions, as shown in Fig. 616. This represents the loculicidal form of the septifragal mode, which is less common than that of the accompanying diagram, Fig. 617.

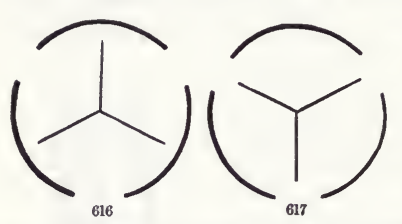

Here the partitions alternate with the valves; that is, the dehiscence of the pericarp is of the septicidal order, as near as may be, but the partitions do not split, wherefore the valves break away at the common junction. To this the term marginicidal has been applied. It occurs in the 2-3carpellary capsule of Ipomæa (especially in the common Morning Glory), in the 5-carpellary capsule of the North American species of Bergia ; likewise in the 2-carpellary pod of Cruciferæ (Fig. $623)$, with a difference that the placentæ from which the valves break away are here parietal and the partition is abnormal.

551. The terms septicidal and loculicidal apply equally in plan, though not with etymological correctness, to one-celled capsules with either parietal (495) or free central (599) placentæ. When the dehiscence is of the septicidal type and the placentation parietal, the (half) placentæ are borne on the margin of the valves, as in the Gentian family and the species of Hypericum with onecelled capsule. When the placentæ are borne on the middle of the valves, as in Violets, the dehiscence is of the loculicidal type. In the case of free central placentæ with no trace of partitions, the character of the dehiscence may usually be determined by the position of the styles or stigmas relative to the valves.

552. Dehiscence may be quite normal although very partial, as when confined to the apex of the capsule of Cerastium and of Primula, and even to the pores under the radiate stigmas of Poppy.

553. Irregular or abnormal dehiscence is such as has no respect to the normal sutures; as where the dehiscence is transverse;

FIG. 616. Diagram of loculicldally septifragal dehiscence. 617. Same of septicidally or rather marginicidally septifragal dehiscence. 
either extending part way round, as in the pod of Jeffersonia, or completely round, so that the upper part falls off like an unhinged lid. This circumscissile dehiscence occurs in many plants of widely different orders; such, for example, as Purslane (Fig. 621), genuine Amaranths, Plantain, Pimpernel, and Henbane. In other cases, as in Antirrhinum (Snap-dragon) and its allies, the cells burst by irregular laceration at a definite point, and discharge the seeds through the ragged perforation; or one or more neat valvular orifices are formed on some parts of the wall, as in Campanula.

\section{Section II. The Kinds of Frutt.}

554. Frutrs have been minutely classified and named $;^{1}$ but the terms in ordinary use are not very numerous. A rigorously exact and particular classification, discriminating between the fruits derived from simple and from compound pistils, or between those with and without an adnate calyx, is too recondite and technical, and sometimes too hypothetical, for practical purposes. It is neither convenient nor philosophical to give a substantive name to every modification of the same organ. For all ordinary purposes, both of morphological and systematic botany, it will suffice to characterize the principal kinds under the four classes of -

Simple fruits, those which result from the ripening of a single pistil ;

Aggregate, those of a cluster of carpels of one flower crowded into a mass ;

Accessory or Anthocarpus, where the principal mass consists of the surroundingś or support of either a simple or an aggregate fruit;

Multiple or Collective, formed by the union or compact aggregation of the pistils of several flowers, or of more than one.

555. Simple Fruits may be distinguished, upon differences of texture, into Dry Fruits, Stone Fruits, and Baccate Fruits; or, better, into Dry and Fleshy; and the first may be divided into

1 The greater part of the forty-three substantive names of Desvaux's, and even of the thirty-8ix of Dumortier's and of Lindley's elaborate classifications of fruits have never found employment in systematic botany, and doubtless never will be used. Yet a detailed carpological classification has its uses for the student. Among the more recent attempts are the successive ones of Dickson, McNab, and Masters. See Nature, iv. 347 (also in Trimen's Jour. Bot. 1871, 310), iv. 475, and v. 6 . 
dehiscent and indehiscent kinds. 1 Theoretically, each kind may be divided into those of a simple and those of a compound pistil, and some would make the primary division on this character. Some also would separate fruits with adnate or superior calyx from those free of all such combination. But in practice these differences can seldom be indicated by substantative names. The name of berry is equally applicable to the fruit resulting from the single carpel of Actæa, the syncarpous ovary of the grape, and the similar ovary with adnate calyx of a gooseberry and cranberry. It should be understood that the kinds shade off one into another most freely.

556. Dehiscent Fruits (543), or Pods, are distinguishable into apocarpous, or of single carpels, and syncarpous, of more than one carpel, i.e. the first of a simple, the second of a compound pistil. The first kind is mainly represented by the Follicle and the Legume; the second, by the Capsule and its modifications.

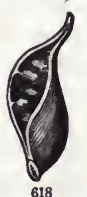

557. A Follicle is a pod formed of a simple pistil, and dehiscent by one suture (this almost always the ventral or inner suture) alone ; as in the Larkspur, Columbine, Peony, and Marsh-Marigold (Fig. $618)$; also in Milkweed and Dogbane. There may be several follicles or only one to a flower, even in the same genus, as in Larkspurs, Cimicifuga, \&c. In Magnolia (Fig. 648-650), fleshy carpels become follicles dehiscent by the dorsal suture.

558. A Legume is the pod formed of a simple pistil which is dehiscent by both sutures (as in the Pea, Fig. 619), so dividing into two pieces or valves. (544.) This is the fruit of the Pulse Family, accordingly named Leguminosæ (Leguminous plants): indeed,

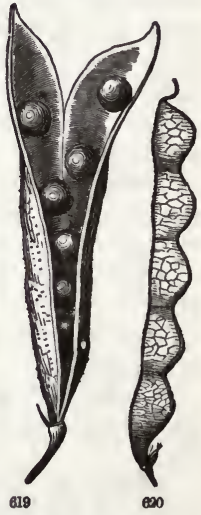
the name of legume is restricted to the fruits of this family, and in descriptive botany is extended to all the modifications

1 Dr. Masters's modification of Dickson's and McNab's classification of simple fruits, as to primary kinds, is into

1. Nuts, or Achonocarps, dry and indehiscent;

2. Pods, or Regmacarps, dry, dehiscent ;

3. Stone-fruits, or Pyrenocarps, fleshy without, indurated within, indehiscent;

4. Berries, or Sarcocarps, fleshy throughout, indehiscent.

FIG. 618. A dehlscent follicle of Marsh-Marigold, Caltha palustris.

FIG. 619. Legume of a Sweet Pea, already dehiscent. 620 . Loment of a Desmodium. 
which that crder presents. Some of these, in fact, are indehiscent and reduced to akenes; some break up at maturity into one-seeded indehiscent articulations or joints, which are dispersed as if they were so many seeds. A legume of the latter kind takes the special name of LoMent, Lat. Lomentum. (Fig. 620.) In Mimosa (Sensitive-plant, \&c.), such articulations dehisce into two valves. They also fall away from the sutures, or from a persistent marginal border of them, or in some cases the valves thus fall away entire. The persistent frame which remains has been called a REPLUM, an architectural word, here taken in the sense of door-case.

559. A Capsule is the pod, or dehiscent fruit, of any compound pistil. When regularly and completely dehiscent, as already stated (544), the pod splits lengthwise into pieces or valves. The modes of regular dehiscence are illustrated in Fig. 612617. Two modifications of the capsule have received distinctive names which are in common use, viz. the Pyxis and the

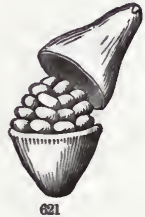

6 (2)
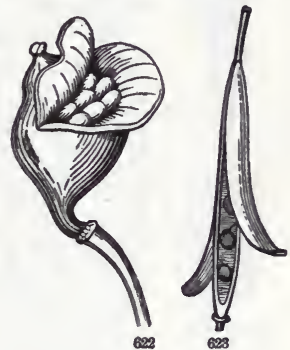
Silique.

560. A Pyxis or Pyxidium is a dry fruit which opens by a circular line, cutting off the upper part as a lid; $i . e$., the dehiscence is circumscissile. (553, Fig. 621.) In the Purslane, Pimpernel, Henbane, and Plantain, the pyxis is a capsule; in Amaranths (Fig. 637) it is a utricle ; in Jeffersonia (Fig. 622) it is a modification of the follicle, being of one carpel which dehisces transversely, and not all round, so that the lid remains attached.

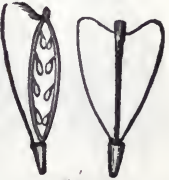

621

561. A Silique is a narrow two-valved capsule, with two parietal placentæ, from which the valves separate in dehiscence; as in plants of the Cruciferous or Mustard family (Fig. 623), to the fruit of which this term is restricted. Usually, a false partition is stretched across between the two placentæ, render-

FIG. 621. Pyxis of Purslane, Portulaca oleracea, the top separating entirely and falling away.

FIG. 622. Pyxis-like follicular fruit of Jeffersonis diphylla; the lid remaining attached dorsally.

FIG. 623. Silique of Cardamine, in dehiscence. 624. Silicle of Capsella or Shepherd'sPurse, lateral view, and an oblique view of the same with one valve removed. 
ing the pod two-celled in an anomalous manner. A Sulcle (Silicula, diminutive of siliqua) is merely a short silique, the length of which does not more than twice or thrice surpass the breadth; such as that of Shepherd's-Purse (Fig. 624), and of Lunaria, Candytuft, \&c.

562. Indehiscent Dry Fruits are almost always one-seeded or very few-seeded. If numerous, the seeds thus placed would not

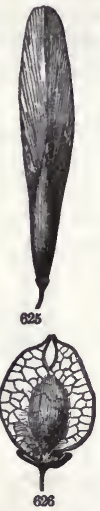
be dispersed. The ordinary kinds are strictly oneseeded, and in common language are often confounded with seeds. The ways in which such fruits are dispersed are various. In the following case, the adaptation of the pericarp to dispersion by wind distinguishes the species of fruit.

563. The Samara, sometimes called in English a $K e y$, is an indehiscent one-seeded fruit provided with a wing. In the White Ash the wing is terminal (Fig. 625); in other species the whole fruit is wing-margined; in Birch and Elm (Fig. 626) the wing surrounds the body of the pericarp; and the Maple fruit is a double samara or pair of such fruits, conspicuously winged from the apex.

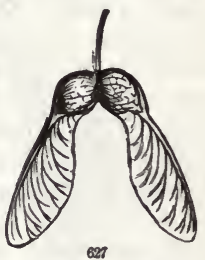

627

564. Akene (Lat. Achenium) is a general name for all the one-seeded, dry and hard, indehiscent and seed-like small fruits,

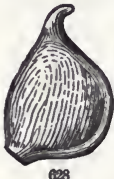

628

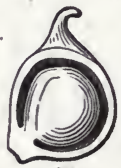

629 such as are popularly taken for naked seeds. But that they are true pistils, or ovaries ripened, is evident from the style or stigma they bear, or from the scar left by its fall; and a section brings to view the seed within, provided with its own proper integuments. The name has been restricted to the seed-like fruits of simple pistils, such as those of the Buttercup (Fig. 628,629), Anemone, Clematis, and Geum. The style in some species of the latter remains on the fruit as a long and feathery tail, in others as a short and hooked one, both being agents of dissemination. The grains of the strawberry (Fig. 653) are also akenes. The name is extended to all one-celled seed-like fruits resulting from a

FIG. 625. Samara or key of White Ash, Fraxinus Americana. 626. That of White Elm, Ulmus Americana. 627. Double samara of Red Maple, Acer rubrum.

FIG. 628. Achenium of a common Buttercup. 629. Vertical section, showing the soed within. 
compound ovary, and even when invested with an adnate calyxtube. Of the latter is the fruit of Compositæ. (Fig. 630-635.) Here the tube of the calyx is incorporated with the surface of the ovary; and its limb or border, obsolete in some cases (Fig. 630), in others appears as a crown or cup (Fig. 631), or set of teeth or of scales (Fig. 632,633), or as a tuft of bristles or hairs (Fig. 634,

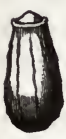

690

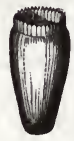

631

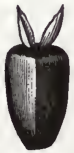

632

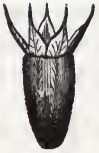

633

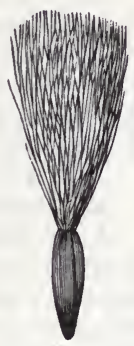

634

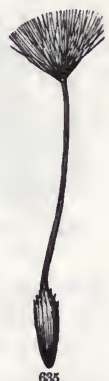

635

635), \&c., called the Pappus. In the Lettuce and Dandelion (Fig. 635), the achenium is rostrate, or beaked, $i$. e. its summit is extended into a slender beak. An akene with adnate ealyx has been termed a CrPsela.

565. The Utricle is the same as the akene, only with a thin and bladdery loose pericarp, like that of Goosefoot. (Fig. 636.) This thin coat sometimes bursts irregularly, discharging the seed. In the true Amaranths, the utricle opens by a circular line, and the upper part falls as a lid, converting the fruit into a small pyxis (560), - a transition form. (Fig. 637.)

566. A Caryopsis or Grain differs from the utricle or akene in having the seed completely filling the cell, and its thin coat firmly consolidated throughout with the very thin pericarp; as in wheat, Indian corn, and all other cereal grains. Of all fruits this is the kind most likely to be mistaken for a seed.
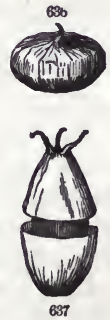

567. A Nut is a hard, one-celled and one-seeded, indehiscent fruit, like an achenium, but larger, and usually produced from an ovary of two or more cells with one or more ovules in each, all but a single ovule and cell having disappeared during its growth (536); as in the Hazel, Beech, Oak (Fig. 638), Chest-

FIG. 630. Achenium of Mayweed (no pappus). 631. That of Cichory (its pappus a shallow cup). 632. Of Sunflower (pappus of two deciduous scales). 633. Of Sneezeweed (Helenium), with its pappus of five scales. 634. Of Sow-Thistle, with its pappus of delicate downy hairs. 635. Of the Dandelion, tapering below the pappus into a long beak.

FIG. 636. Utricle of Chenopodium album, or common Goosefoot. 637. Utricle of an Amaranth, by transverse dehiscence becoming a pyxis. 
nut, and the like. The nut is often enclosed or surrounded by a kind of involucre, termed a Cupule; such as the cup at the base of the acorn, the bur of the chestnut, and the leaf-

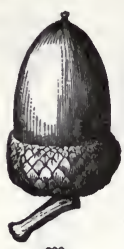

698 like covering of the hazel-nut. The name Glans (sometimes Gland in English) is technically applied to such nuts, this being their classical Latin name.

568. The fruit of the Walnuts and Hickory is apparently a kind of drupaceous nut, or something intermediate between a stone fruit and a nut. But certain monstrosities give reason for supposing that the seeming exocarp (541), which in Hickory hardens and at maturity dehisces in four valves, is of the nature of an adnate involucre. The cocoanut is a sort of fibro-drupaceous nut.

569. Nutlet, or in Latin form Nucule (Nucula), is sometimes superfluously employed in a literal sense, as a diminutive nut. ${ }^{1}$ Of late it has acquired a good and fairly legitimate use as the name of the seed-like, or rather akene-like, closed parts or lobes, of crustaceous or other hard texture, into which certain bilocular or plurilocular pericarps separate at maturity, $i$. e. for the segments of a schizocarp, 571, which resemble akenes. ${ }^{2}$ These are sometimes carpels, sometimes half-carpels, as in Verbena, also in Borraginaceæ and Labiatæ (in which the segments are greatly separated in the ovary), and sometimes, as in Nolana, they are portions of compounded carpels which have been exceedingly multiplied by chorisis.

570. There are complete transitions between dry nutlets, with a thin and herbaceous epicarp, and the pyrence (574) or stony inner portion of such carpels when drupaceous or composing a drupe of two or more stones. It is therefore a hardly incongruous and very convenient use which extends the term nutlet to include these small seed-like stones also, as, for example, to those of Holly, Bearberry, Hawthorn, and the like.

571. The pair of achenium-like or often samara-like carpels,

1 Nut and akene, between which there is no fixed distinction, will cover this ground. The fruit of Cyperaceæ, for instance, is truly an achenium, if this name is ever to be used (and it now commonly is) for any other than a monocarpellary fruit. It is often termed a nut, sometimes a nutlet, and by a late writer, Boeckler, a caryopsis.

2 Cocci (sing. Coccus, from a Greek word for kernel) is another name for fruit-carpels, or separating lobes of a dry pericarp, as well for dehiscent ones (of Euphorbia) as for indehiscent. Hence such lobed or partible fruits are said to be dicoccous, tricoccous, \&c., according to the number of lobes or carpels.

FIG. 638. Acorn (nut) of White Oak, with its cup, or cnpule. 
united by their inner face but separating entire at maturity, which constitute the fruit of Umbelliferæ, takes the name of Cremocarp (Lat. Cremocarpium); and the halves are called Mericarps. These names it may sometimes be convenient to use ; yet it is not advisable to have special names for the fruits of particular families; and mericarp is here synonymous with carpel. For dry fruits in general (or such as become dry) which are composed of two or more carpels, and which at maturity split up or otherwise separate into two or more closed oneseeded portions, an appropriate recent name is that of ScHIzocaRP. The component carpels of such a fruit were long ago named $\mathrm{Car}$ cerules (carceruli, little prisons) by Mirbel.

572. Fleshy Fruits, which from their texture are naturally indehiscent, may be either fleshy throughout, or with a firm rind or shell, or fleshy externally and hard or stony internally. Of the latter, the type is

573. The Drupe or Stone Fruit proper (Fig. 639), that of the cherry, plum, and peach. True drupes are of a single carpel, one-celled and one-seeded (or at most two-seeded), in the ripening of which the outer portion of the pericarp becomes fleshy or pulpy, and the inner stony or crustaceous, $i$. e. divides into sarcocarp and putamen.

But the name is extended to
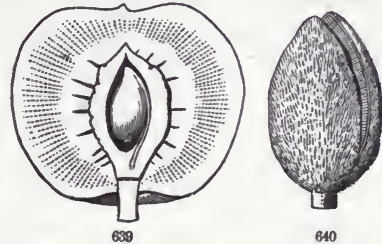

pericarps of similar texture resulting from a compound pistil, either of a single cell, as in Celtis, and (by abortion) in the olive, or of two or several cells, as in Cornus, Rhamnus, \&c. The several pericarps of the aggregate blackberry and raspberry are diminutive drupes or Drupelets.

574. Small drupes are often confounded with berries, and the stone or stones taken for seeds. Especially is it so in drupes or drupaceous fruits of more than one cell, ripening into separate or separable.hard endocarps or stones, each filled by a seed. ${ }^{1}$ Bearberries (Arctostaphylos) and Huckleberries (Gaylussacia) are good illustrations of this. The seed-like endocarps of this

1 The term Acinus, the original name of such a berry as a grape, has been used in descriptive botany for a small drupe or drupelet, and the ripened carpels of Rubus have been termed acini or acines, but without discriminating them from berries.

FIG. 639. Vertical section of a peach. 640. An almond; in which the exocarp, the portion of the pericarp that represents the pulp of the peach, remains juiceless, and at length separates by dehiscence from the endocarp, or shell 
sort are PrRene; and the fruits are dipyrenous, tripyrenous, tetrapyrenous, \&c., according as they contain two, three, or four pyrenæ. When the sarcocarp is thin and dries up at maturity, these pyrenæ pass by gradations into nuculæ (569) or nutlets: hence pyrenæ are not uncommonly in English descriptions called nutlets or nucules.

575. The Pome (Fig. 641, 642) is the name of the apple, pear, and quince. These are fleshy fruits, composed of two to several carpels (rarely by abortion only one), of parchment-like or (in Hawthorns) bony texture, enclosed in flesh which morphologically belongs to adnate calyx and receptacle; as may be apprehended by comparing a rose-hip (Fig. 407 , in flower) with an apple or a pear. Of the quince', the whole flesh is calyx or hypanthium (395); in the apple and pear, the inner or core-portion of the flesh is of the nature of disk, investing the carpels. In the fruit of Hawthorns, the carpels become bony pyrenæ (574), and so the fruit is drupaceous, is indeed nothing more than a syncarpous drupe. In Eriobotrya, or Cumquat, the carpels becoming very thin and membranaceous, the pomaceous fruit is in fact a kind of berry.

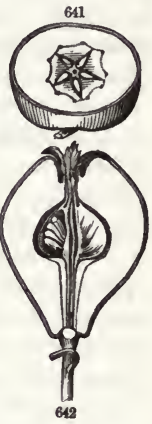

576. The Pepo, or Gourd-fruit (Fig. 643), of which the gourd and squash are the type, and the melon and cucumber equally

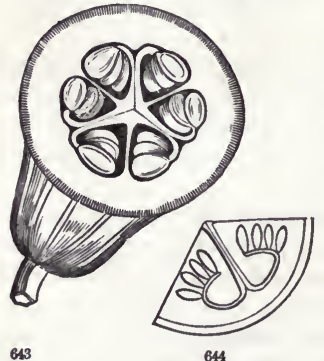
familiar illustrations, is the characteristic fruit of Cucurbitaceæ, fleshy internally and with a hard or firm rind, all or part of which is referable to the adnate calyx completely' incorporate with the ovary. 'This is either one-celled with three broad and revolute parietal placentæ, or these placentæ, borne on thin dissepiments, meet in the axis, enlarge, and spread, unite with their fellows on each side, and are reflected to the walls of the pericarp, next which they bear their ovules. As the fruit enlarges, the seed-bearing placentre usually cohere with the walls, and the partitions are obliterated, giving the

FIG. 641. Pome or apple in transverse section. 642. Quince in vertical section: the inner flesh answering to disk in the apple and pear is here wanting.

FIG. 643. Section of the ovary of the Gourd. 644. Diagram of one of its constituent carpels. 
appearance of a peculiar abnormal placentation, which the study of the ovary readily explains. In the watermelon the edible pulp all belongs to the greatly developed placentæ. Fruits of this family in which the rind also is soft at maturity are true berries.

577. The Hesperidium (orange, lemon, and lime) is the fleshy fruit of a free many-celled ovary with a leathery rind, and is a mere variety of the berry. The name is applied only to fruits of the Orange tribe.

578. The Berry (Lat. Bacca) comprises all simple fruits in which the pericarp is fleshy throughout. The grape, gooseberry, currant, cranberry (Fig. 645), banana, and tomato are familiar examples. The first and last consist of an ovary free from the calyx; in the others, calyx and ovary are combined by adnation.

579. Aggregate Fruits are those in which a cluster of carpels, all belonging to one flower, are crowded on the receptacle into one mass, as in the raspberry and blackberry taken as a whole. (Fig. 646.) They may be aggregates of any kind of simple

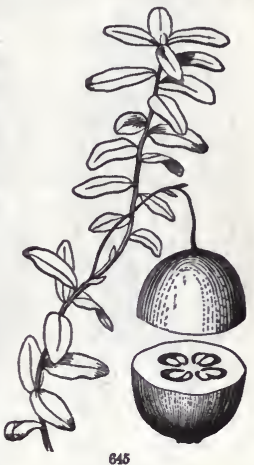

645 fruits. But when dry and not coherent, the mass would simply and properly be described as a head or spike of carpels, more commonly of akenes, as in Ranunculus, Anemone, \&c. Yet when numerous carpels thus compacted become fleshy, and sometimes more or less coherent, the aggregate may need to be taken into account. The best name for it is that of SYNCARPIUM, or in English form Srncarp. But the term has been applied to multiple fruits as well. ${ }^{1}$ In Hydrastis, the numerous carpels imbricated on the upper part of the torus are baccate, that is, become berries ; in a raspberry,

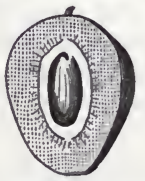

647

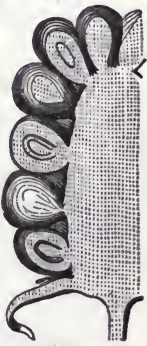

646 the seemingly baccate grains are drupaceous (being drupelets, 573),

1 The syncarp which is a gynœcium might be designated a simple syncarpium; that which is an inflorescence, a complex syncarpium, which may be biflorous, pauciflorous, or multiflorous.

FIG. 645. The larger Cranberry, Vaccinium (Oxycoccus) macrocarpon; the berry transversely divided.

FIG. 646. Vertical section of half of a blackberry (of Rubus villosus), enlarged; and, 647, of one of its drupelets more magnified. 
and, slightly cohering together (though without organic union), they fall as one body from the conical dry torus at maturity. It is the same in blackberries or bramble-berries (Fig. 646, 647), except that the drupelets persist on the torus, which partakes of the juiciness. ${ }^{1}$ In the aggregate fruit of Magnolia (Fig. 648-650), such carpels, imbricated over one another, cohere more or less

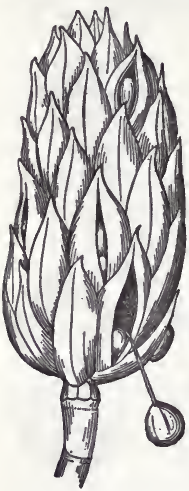

648

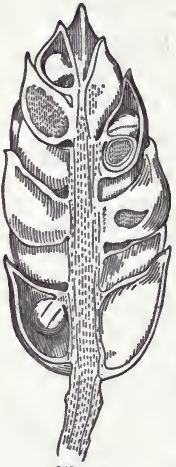

649 at all contiguous parts, and become drupaceous; nevertheless, at maturity each opens dorsally, allowing the seeds to fall out: in age it dries and hardens, and also separates from its connec-

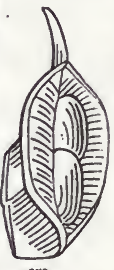

650 tions, and so becomes a follicle, but with the remarkable peculiarity of dorsal instead of ventral dehiscence. (Fig. 650.) In Liriodendron, a tree of the same family, such carpels are

dry and indehiscent throughout ; and they largely consist of long and flat styles, imbricated in a cone, but separating from each other and from the slender torus at maturity, when each becomes a samara.

580. Accessory or Anthocarpous Fruits are those of which some conspicuous portion of the fructification neither belongs to the pistil nor is organically united with it, except by a common insertion. The part thus imitating a fruit, while it is really no part of the pericarp, is sometimes called a Pseudocarp, or an Anthocarp or Anthocarpium. This condition may occur either in simple, in aggregate, or in multiple fruits.

1 The aggregate fruit like that of Rubus (named by some Conocarpium, by others an Eterio, Erythrostomum, \&c.) was termed by Dumortier a Drupetum. A similar aggregation of baccate carpels he termed a Baccetum; of follicles, a Follicetum, \&c. All such names may look well in a system; but they are both superfluous and unmanageable in phytography.

FIG. 648. Aggregate fruit of Umbrella-tree, Magnolia Umbrella, reduced in size; a seed from a lower dehiscent carpel hangs on a thread, consisting of a tuft of extensile spiral ducts unravelled. 649. Same in longitudinal section. 650. One of the carpels detached, at full maturity, dried up, dorsally dehiscent, exposing the pair of seeds of the natural size. 
581. Gaultheria procumbens, the aromatic Wintergreen (Fig. $651,652)$, affords a good example of the first. Its seeming berry (the checkerberry), with summit crowned by the tips of the calyx-lobes, well imitates the true berry of a Vaccinium, such as that of Fig. 645. But it comes from a flower with thin calyx, underneath and free from the ovary. Its fruit is really a capsule : in the process of fructification, the calyx enlarges, becomes
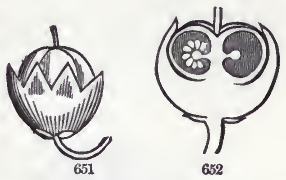
succulent, completely encloses the capsule or true fruit, yet without adhering to it, and in ripening counterfeits a red berry. So in Shepherdia, or Buffalo Berry, the seeming sarcocarp of a drupe is really a free calyx, accrescent and succulent, enclosing an akene. So, also, the apparent achenium or nut of Mirabilis, or Four-o'clock, and of its allies, is the thickened and indurated base of the tube of a free calyx, which contracts at the apex and encloses the true pericarp (a utricle or thin akene), but does not cohere with it.

582. Likewise the torus, although not conspicuous, may be said to be an accessory part of the aggregate fruit of the Blackberry or Bramble (579) : it becomes the solely conspicuous and the sole edible part of a strawberry (389, Fig. 406, 653), the akenes or true fruits dispersed over the surface being apparently insignificant. Equally in many

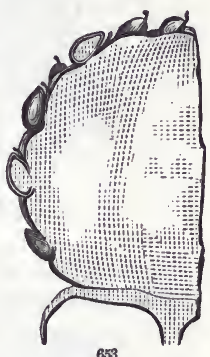

653 multiple fruits the conspicuous flesh belongs to receptacle (either torus or rhachis), to calyx, or even in part to bracts, or to all these parts combined, as in a pine-apple.

583. Multiple or Collective Fruits ${ }^{1}$ are those which result from the aggregation of several flowers into one mass. The simplest of these are those of the Partridge-Berry (Mitchella, Fig. 467),

1 Collective is the preferable name. The term multiple was applied by DeCandolle to what are here (following Lindley) called aggregate fruits; and the aggregate fruits of DeCandolle are here called multiple or collective. Moreover, the distinction between accessory or anthocarpous and collective or multiple fruits was not recognized by Lindley, who combined the two in his original "Introduction to Botany." In this work four classes are given: 1. Fruit simple, Apocarpi ; 2. Fruit aggregate, Aggregati ;

FIG. 651. Forming capsule of Gaultheria procumbens, with enlarging calyx partly covering it. 652. Same, more advanced, and in longitudinal section.

FIG. 653. Vertical section of half a str\&wberry. Compare with Fig, 406. 
and of certain species of Honeysuckle, formed of the ovaries of two blossoms united into one fleshy fruit. The more usual sorts are such as the pine-apple, mulberry, and the fig. These are, in fact, dense forms of inflorescence, with the fruits or floral envelopes matted together or coherent with each other; and all or some of the parts succulent. The grains of the mulberry (Fig. 654-656) are not the ovaries of a singie flower, like those

658

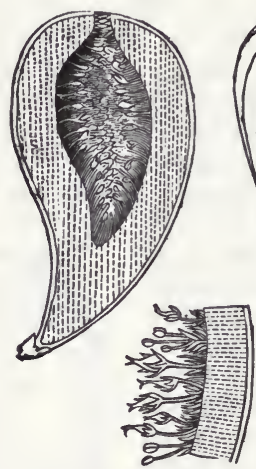

659
657

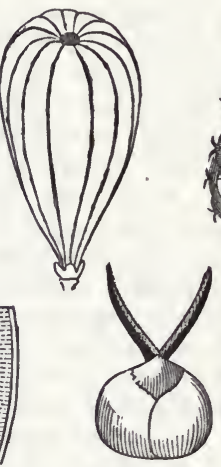

655
654
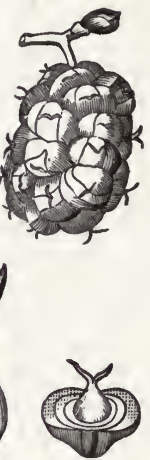

658

of the blackberry, which it superficially resembles: they belong to as many separate flowers ; and the pulp pertains to the calyx, not to the pericarp, which is an akene. So that this, like most multiple fruits, is anthocarpous as well as multiple. Similarly, the mostly indefinite fructiferous masses of Strawberry Blite may resemble strawberries; but the pulpy part is the calyx of many flowers, not the succulent receptacle of one. In the pine-apple, the flowers are spicate or capitate on a simple axis, which grows on beyond them into leafy stem; this when rooted as a cutting

3. Fruit compound (ovaria compound), SyxcARPI ; 4. Collective fruits, Anthocarpi.

Later, in his "Elements of Botany," Lindley reduced the classes to two: 1. Simple Fruits, those proceeding from a single flower; 2. Multiple fruits, those formed out of several flowers.

FIG. 654. A mulberry. young. 655. One of the fleshy grains at flowering time, showing it to be a pistillate blossom with fleshy calyx. 656. The same later, with the succulent sepals in transverse section.

FIG. 657. A young fig. 658. Longitudinal section of the same later, but in flowering time. 659. A small slice, magnified. showing some of the flowers. 
bears another pine-apple, and so on : the constituent flowers have through immemorial propagation in this way become sterile and seedless, and all its parts, along with the bracts and the axis of the stem, blend in ripening into one fleshy and juicy mass. Few fruits of this class have ever been technically named, at least with names which have come into use. But the two following deserve special appellations, although only the latter is familiar either in ordinary language or in descriptive botany.

584. The Syconium or Hypanthodium, the Fig fruit. (Fig. 657659.) This results from a multitude of flowers concealed in a hollow flower-stalk, if it may be so called, which becomes pulpy and edible when ripe; and thus the fruit seems to grow directly from the axil of a leaf, without being preceded by a blossom. The minute flowers within, or some of them, ripen their ovaries into very small akenes, which are commonly taken for seeds. The fig is to the mulberry what a rose-hip is to a strawberry. (389, Fig. 406, 407.) It is further explained by a comparison with a near relative of the Fig-tree, Dorstenia, in which similar flowers cover the upper surface of a flat peltate disk. This disk or plate sometimes becomes saucer-shaped by an elevation or incurvation of the margin. A greater degree of this would render it cup-shaped, or even pitcher-shaped; from which it is a short step to the contraction of the mouth down to the small orifice which is found in the fig.

585. The Strobile or Cone (Fig. 660) is a scaly multiple fruit, resulting from the ripening of certain sorts of catkin. The name is applied to the fruit of the Hop, where the large and thin scales are bracts; but it more especially belongs to the Pine or Fir cone, the peculiar fruit of Coniferæ (507), in which naked seeds are borne on the upper face of each fructiferous scale (Fig. 661), or some-

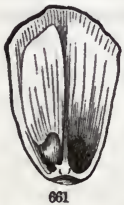
times in their axils. Such a cone when spherical, and of thickened scales with narrow base, as that of Cypresses, has been termed a

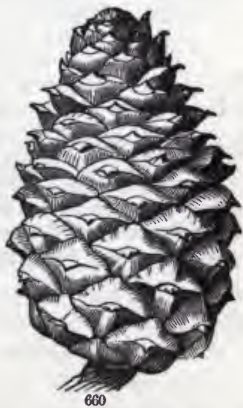

662

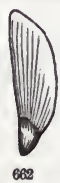

GaLBULUs, an unnecessary name. The galbulus of Juniper is a

FIG. 660. Strobile or Cone of a Pitch Pine, Pinus riglda. 661. Inside view of ono of the scales, showing one of the winged seeds, and the place from which the other, 662 , has been detached. 
remarkable transformation into a seeming berry; the few scales cohering with each other as they grow and becoming fleshy at maturity, completely enclosing a few bony-coated seeds.

586. A Synopsis of the kinds of Fruit, as characterized in this chapter, is appended. The analysis extends only to simple fruits. For there are no commonly used special names of kinds of Aggregate (579), Accessory (580), or Multiple (583) fruits, except that of Strobile.

\section{SIMPLE FRUITS are}

Dry and dehiscent, monocarpellary,

Opening by one (chiefly the ventral) suture, . . . . . FolLicLE.

Opening by both sutures, . . . . . . . . . LEG UME.

Or transversely jointed, . . . . . . . . . . Loment.

Dry and dehiscent, bi-pluri-carpellary, . . . . . . . Capsule.

When its dehiscence is circumscissile, . . . . . . Prxis.

When dehiscent by two valves from two parietal placentæ,. . Silieve.

A short and broad silique, . . . . . . . . Silicle.

Dry and bi-pluri-carpellary, splitting into one-seeded carpels, . SchizocarP.

The dimerous schizocarp of Umbelliferæ, . . . . . Cremocarp.

Each of its halves or carpels, . . . . Hemicarp or Mericarp.

The akene-like or nut-like parts into which Schizocarps generally

divide, . . . . . . . . . . Nucules or Nutlets.

Dry and indehiscent, one-celled, one-two-seeded,

Winged, ............. SAMARA.

Wingless, and with the

Thin pericarp consolidated with the seed, . . . . . CARYopsis

Thin pericarp loose and not filled by the seed, . . . . Utriche.

Thick or hard pericarp free from the seed,

Small, from a one-celled one-two-ovuled ovary, AKene or Achenrum.

Larger, mostly from a two-several-celled and ovuled ovary, . Nut.

Nut borne in a cupule or involucre, . . . . . . GLaNs.

Fleshy and indehiscent,

Heterogeneous in texture, having

A stone (putamen) or nutlets within an exterior sarcocarp, . DRUPE. Papery or cartilaginous carpels in an inferior sarcocarp, . P Pome. A harder or firm rind or exterior, and soft interior,

From an inferior ovary (confined to Gourd Family), . . . Pepo.

From a superior ovary (confined to Orange Family), Hesperidrum. Homogeneous, fleshy throughout, ......... BerRY. 


\section{CHAPTER VIII.}

\section{THE SEED.}

5ชิ7. THE SEeD is the fertilized ovule (515), with embryo formed within it. It consists, like the ovule, of a nucleus or kernel, enclosed by integuments. The seed-coats are those of the ovule, viz. two, or sometimes only one, in certain plants none. Occasionally an accessory coat appears after fertilization; and certain appendages may be produced, as outgrowths from some part of its surface or from its base. The nucleus or kernel is composed either of the embryo alone, or of a nutritive deposit in addition. (19-41.) All the parts of a seed are indicated in Fig. 663.

588. The Seed-stalk or Podosperk, when there is one, is the funiculus of the ovule (516), and retains, this name. So also do the Chalaza, Rhaphe, and Hilum; the latter being the scar left by the separation of the seed from its funiculus or directly from the placenta. The foramen of the ovule, now closed, is the MICROPYLE of the seed.

589. The terms which denote the character of the ovule, such as orthotropous,

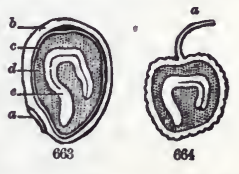
campylotropous, amphitropous, and anatropous, apply equally to the resulting seed.

590. Seed-Coats. The integuments of the seed answer to the primine and secundine of the ovule. The main seed-coat is the exterior integument of the ovule when there is more than one. Being the most firm coat, and not rarely crustaceous in texture, it takes the name of TESTA, which is equivalent to seed-shell. It has also been named SPERmoderm (seed-skin), and sometimes Episperm. The latter name (meaning upon the seed) is best applied to the pellicle or outer layer, sometimes a thick one, which the testa of certain seeds forms. The testa is extremely various in form and texture, is either close and conformed to

FIG. 663. Vertical magnified section of the (anatropons) seed of the American Linden; with the parts indicated, viz. the hilum $(a)$; testa $(b)$; tegmen $(c)$; albumen $(d)$; embryo $(e)$. 664. Vertical section of the orthotropous seed of Helianthemum Cansdense, with its funiculus, $a$. 
the nucleus, or loose and cellular (as in Pyrola-seeds), or variously appendaged.

591. The inner coat, called Tegmen and sometimes ExdoPLECRA, when present is always conformed to the nucleus, and is thin or soft and delicate. Sometimes it is inconspicuous through cohesion with the nucleus or with the inner surface of the testa. In ovules of one coat it is necessarily wanting.

592. Appendages or outgrowths of the testa generally have reference to dissemination. Two characteristic kinds of such

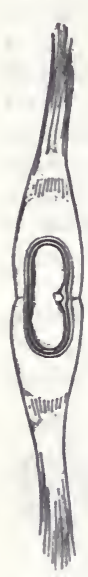
appendages are the wing and the coma, both pertaining only to the seeds of dehiscent fruits and calculated, by rendering seeds buoyant, to facilitate dispersion by the wind. The wing of a Pine-seed (Fig. $661,662)$ is a part of the carpellary scale upon which the two ovules grew. In Trumpet Creeper (Fig. 665), an entire wing surrounds the body of the seed. In the related Catalpa (Fig. 666), it is mainly extended from the two ends, and almost dissolved into a coma, the name given to the tuft of soft hairs like that which forms the down at one end of the seed of Milkweed (Fig. 667), and of Epilobium, and at both ends in several Apocynaceæ. In the Cotton-plant, very long and soft hairs, admirably adapted for spinning, thickly cover the whole seedcoat. The wing and coma of seeds are

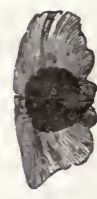

665

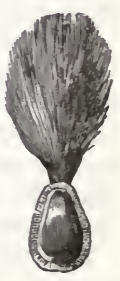

607

functionally identical with the wing and the pappus of the pericarp in the samara and the akenes of Compositæ $(563,564)$, but morphologically quite unlike them.

593. There are other (mainly microscopic) structures on some seed-coats which come usefully into play in arresting farther dispersion at a propitious time or place. In many but not all Polemoniaceæ (notably in Collomia), in certain Acanthaceæ, such as Ruellia tuberosa (and equally in certain Compositæ of the Senecio tribe and in Salvias, \&c., among Labiatæ, where this structure is transferred to akenes and nutlets), the testa is coated with short hairs, which when wetted burst or otherwise open and discharge along with mucilage one or more very atten-

FIG. 665. Winged seed of Trumpet Creeper, Tecoma radicans. 666. That of Catalpa, becoming comose: the body divided lengthwise through the embryo.

FIG. 667. Comose seed of Milkweed, Asclepias Cornuti. 
uated long threads (spiricles) which were coiled within. These, protruding in all directions and in immense numbers, form a limbus of considerable size around the seed, and evidently must serve a useful end in fixing these sma'l and light seeds to the soil in time of rain, or to moist ground, favorable to germination. In cress and flax-seed, the abundant mucilage developed when wetted comes from the gelatination of epidermal cell-walls, and subserves a similar use.

594. While the testa in many seeds is hard and crustaceous or bony, imitat-

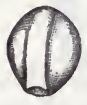

668

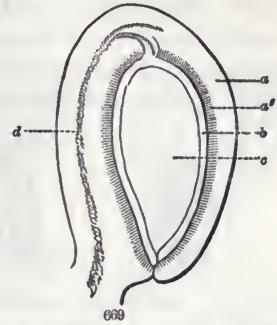

669 ing the pericarp of a nut, in others (such as Pæonia) it becomes berry-like (baccate), and in Magnolia, drupaceous. ${ }^{1}$ (Fig. 668671.) These may also be regarded as adaptations for dissemi-

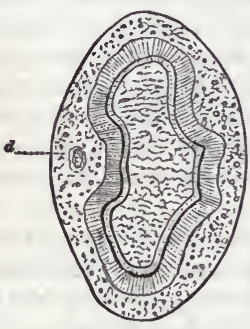

672

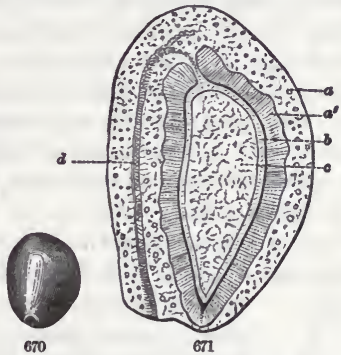

671

nation, here by the agency of birds, attracted by bright coloring and edible pulp.

595. The rhaphe of an anatropous seed (shown in Fig. 681, 685 ) is sometimes so salient as to form a conspicuous appendage, as in Sarracenia, Fig. 672. Again it may be wholly

1 See article On the Structure of the Ovule and Seed-coats of Magnolia, in Jour. Linn. Soc. ii. 106, from which the accompanying figures and Fig. 589-597 are reproduced.

FIG. 668. Forming seed (one eighth of an inch iong) of Magnolla Umbrella; the rhaphe toward the eye. 669. Magnified view of the same divided lengthwise through the rhaphe; the outer coat, $a$, beginning to form a hard inner layer, $a^{\prime}$. Within and distinct from this is the inner coat $(b)$ immediately enclosing the nucleus, $c$. The opposite side of the testa is thicker on account of the rhaphe, in which $d$ indicates the cord of spiral ducts.

FIG. 670. A nearly full-grown seed, of the natural size. 671. Longitudinal section, eniarged, showing the crustaceous or stony inner stratum of the testa well developed: the parts lettered as in Fig. 669. 672. A transverse section in the same position. 
inconspicuous, as in the ripe seed of Magnolia, where it is at length completely merged and imbedded in the fleshy drupaceous testa, as shown in Fig. 670-672.

596. Crest-like or other appendages are not uncommon either on the rhaphe or at the hilum. These are outgrowths produced during the development of the ovule into the seed. In Sanguinaria, such a crest develops from the whole length of the rhaphe

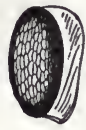

672

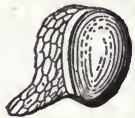

673

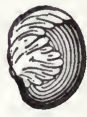

674

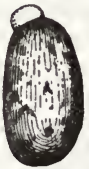

675

(Fig. 673) ; in Dicentra, Corydalis (Fig. 674), \&c., from some part of it, mostly from its base next the hilum, or from the hilum itself, or even from just below it. Such an appendage, especially when attached to the base of the seed, is named a Strophiole. A similar and commonly a wart-shaped appendage in Euphorbia, Ricinus (Fig. 675), \&c., is produced by an outgrowth of the external orifice of the ovule, the micropyle of the seed. This properly takes the name of Caruxcle. But the two terms are not always discriminated. By further development, either of these may give rise, in certain seeds, to an accessory covering called

597. The Aril or Arillus. This term, rather vaguely employed by Linnæus, was first well defined by Gærtner. The true arillus

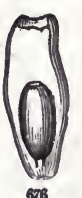

676 is an accessory seed-covering, more or less incomplete, formed between the time of fertilization and the ripening of the seed, by a growth from the apex of the funiculus (when there is any) at or just below the hilum, in a manner similar to that in which the coat or coats of the ovule are formed. That of Nymphæa (Fig. 676) is a typical example ; only the arillus is developed from the funiculus at a point distinctly below its apex : here a ring forms, which grows into a cup, and this is soon extended into a sac, loosely enclosing the seed, and open at the top. This is membranaceous ; commonly it is fleshy. When there is absolutely no funiculus, the aril may originate from the placenta, as it does in Podophyllum, in which most of

FIG. 672. Anatropons seed of Sarracenia purpurea, with very salient rhaphe. 673 . Same of Sanguinaria or Bloodroot, with rhaphe crested for its whole length. 674. Seed of Corydalis aurea, with crest or strophiole, attached at or near the hilum. 675. Seed (suspended) of Ricinus, with its caruncie.

FIG. 676. Seed of White Water-Lily, Nymphres odorata, in its loose and thin arillus. 
the pulp of the berry consists of these fleshy arils, much compacted. (Fig. 677, 678.)

598. The laciniate aril of the nutmeg (mace) and, it is said, the bright red and pulpy aril of Euonymus and Celastrus begin in the manner of a caruncle, and are formed (mainly if not wholly) of an outgrowth at or around the micropyle. So that, if an orthotropous seed ever developed an aril of this sort, it would
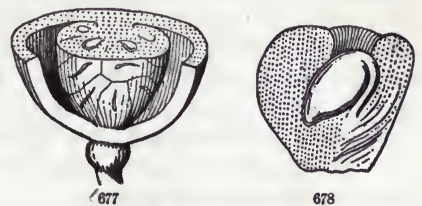

be seen to begin at the apex of the seed and cover it from above downward. Planchon, who distinguished this from the true aril, gave to it the name of ArILlode (Arillodium) or False Arillus.

599. The Nucleus, or kernel of the seed, consists of the Albumen, when this substance is present, and the Embryo.

600 . The Albumen, as described in the second chapter $(25, \& c$.$) ,$ is the name generally employed by systematic botanists for a store of nutritive matter in the seed outside of the embryo, whatever its chemical composition. It is not here the name of a chemical substance (albumen or albumin), but of a cellular structure, the cells of which are loaded commonly with starchgrains (as in the Cerealia), more or less mingled with other matters, or else filled with an encrusting deposit of some equivalent substance, as in the cocoanut, coffee-grain, \&c. The cells in which this deposit is made belong either to the original tissue of the nucleus, or to a new formation within the embryo-sac, mostly to the latter. (503.)

601. Albumen may be said to belong to all seeds in the growing stage. In what are called albuminous seeds it persists and forms either almost the whole kernel, the embryo remaining minute (as in Fig. 23, 54, 680), or forms a large portion of it (Fig. $13,17,19,21,48,663,664)$, or, by the growth of the embryo displacing it, it may in the ripe seed be reduced to a thin stratum or mere lining to the contiguous seed-coat; or it may disappear altogether, as in the seeds of Maple, Almond, Squash, Pea, and the like, which are therefore said to be exalbuminous. The difference between albuminous and exalbuminous seeds is that the maternal nutritive deposit is transferred to the embryo in

FIG. 677. Section of pericarp and placenta of Podophyllum peltatum; the pulp of the latter mainly of the nature of arillus, investing the seeds. 678. The arllius of one seed detached and enlarged, divided lengthwise, showing the seed within. 
the former during germination, in the latter during the growth of the seed.

602. The albumen was named Perisperm by Jussieu, and Endosperm by Richard (25, note); but neither name has in systematic botany displaced the earlier one of Grew and Gærtner. But both names have recently been brought into use to distinguish between two kinds of albumen, that formed within the embryo-sac, which is specifically termed ENDOSPERM, and that formed without, which takes the name of Perispery. This use comports with the etymology of the two words, the former referring to a comparatively internal and the latter to an external portion of the seed or kernel.

603. In most seeds the albumen is endosperm : in Canna it is all perisperm. In Nymphæa and its allies (except Nelum-

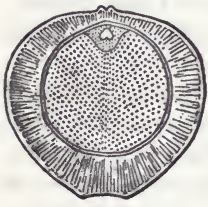

679 bium, which has none) most of it is perisperm ; but a thin and condensed layer of endosperm surrounds the embryo, where with the persistent embryo-sac (or the apex of it) it forms the fleshy sac in which the embryo is enclosed. It is the same in the Pepper Family (Fig. 679), except that there is a larger quantity of endosperm or inner albumen.

604. When the nucleus of a ripe seed is hollow, as in the cocoanut and nux vomica, the formation of endosperm, which usually begins next the wall of the embryo-sac, has not proceeded so as to fill the cavity. The embryo-sac in the cocoanut attains enormous size, and the cavity is filled by the milky fluid.

605. The texture or consistence of the albumen differs greatly. It is farinaceous or mealy when, consisting mainly of starch-

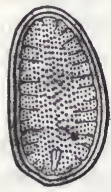

680 grains, it may readily be broken down into a powder, as in wheat, buckwheat, \&c. ; oily, when saturated with a fixed oil, as in poppy-seed; fleshy, when more compact, but readily cut with a knife, as in the seed of Barberry ; mucilaginous, when soft and somewhat pulpy, as in Morning Glory and Mallow, but when dry it becomes fleshy or harder; corneous, when of the texture of horn, as in coffee and the seed of Caulophyllum; and even bony, as in the vegetable ivory, the seed of Phytelephas. It is mostly uniform ; but in the nutmeg,

FIG. 679. Longitudinal magnified section of a seed of Black Pepper; showing the large episperm, the small endosperm in the persistent embryo-sac, and in this the minute embryo.

FIG. 680. Longitudinal section of a seed of the so-called Papaw, Asimina triloba, with ruminated albumen and minute embryo. 
in the seeds of Asimina (Fig. 680) and all the Custard-Apple family, it is marked by transverse lines or divisions (caused by inflexions or growths of the inner seed-coat), giving a section of it either a marbled appearance, or as if it had been slit by incisions : it is then said to be ruminated.

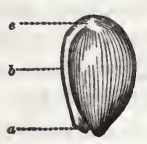

681

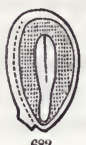

682

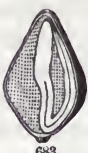

683

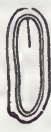

684

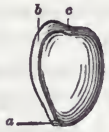

685

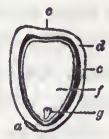

686

606. The Embryo, ${ }^{1}$ being an initial plantlet or individual of a new generation, is of course the most important part of the seed. To its production, protection, and support, all the other parts of the fruit and flower are subservient.

607. In an embryo of full development, namely, one in which all the parts are manifest antecedent to germination, these parts are the Caulicle, otherwise called Radicle, the Cotyledons, and the Plumule. $(20,30$.) The first is the initial axis or stem, a primary internode; the second consists of the leaves of the primary node; the third is a beginning of a farther growth which is to develop more stem and leaves. Such an embryo is usually unaccompanied by albumen, having in the course of its growth taken into itself (mostly into the cotyledons) the provision

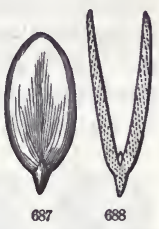
which in other seeds is mainly accumulated external to it until it is drawn upon in germination.

1 The word Embryo or Embryon was applied to this body in plants by Bonnet (Considérations sur les Corps organisées), in 1762, and was introduced into systematic botany at about the same time (1763) by Adanson: it was taken up by Gærtner in 1788. Jussieu in the Genera Plantarum (1789) held to the term Corculum (the cor seminis) which came down from Cæsalpinus.

Being the germinal part of the seed, the embryo of the plant, like that of the animal, is in general language often called the Germ.

FIG. 681. Seed of a Violet (anatropous), enlarged; with hilum or scar (a), rhaphe $(b)$, and chalaza (c) lndicated. 682. Vertical section of the same, showing the straight embryo in the axis of the mealy albumen.

FIG. 683. Vertical section of the (orthotropous) seed of Buckwheat, showing the embryo folded ronnd in the mealy albumen.

FIG. 684. Vertical section of the (anatropous) seed of Elodea Virginica, the embryo completeiy filling the coats.

FIG. 685. Seed of Delphinium tricorne (anatropous), enlarged; the hllum, the rhaphe, and the chalaza lettered as in Fig. 681. 686. Vertical section of the same with $c$, the chalaza, $d$, the testa, $e$, the tegmen, $f$, the albumen, $g$, the minute embryo near the hilum $(a)$.

FIG. 687. Embryo of the Pumpkin, with its short radicle and large and fiat cotyle dons, seen flatwise. 688. A vertical section of the same; viewed edgewise. 
608. The opposite extreme is an embryo (as in Fig. 686) which appears as a mere speck in the albumen, but in which close microscopical inspection may commonly reveal some differentiation, such as a slight notch at one end (that farthest removed from the micropyle) of a dicotyledonous embryo, indicating the future cotyledons. Indeed, in Monotropeæ, Orobanchaceæ, and some other parasitic dicotyledonous plants, and in Orchids among the monocotyledonous, the embryo is a globular or oblong particle, with no adumbration of organs whatever antecedent to germination. There are all grades between the most rudimentary and the most developed embryos.

609. Under the circumstances of its formation (532), the radicular end of the embryo is always near to and points towards the micropyle of the seed, viz. to what was the orifice of the ovule; and if the embryo be straight, or merely partakes of the curvature of the seed, the cotyledons point to the opposite extremity, that is, to the chalaza.

610. The position of the radicle as respects the hilum varies with the different kinds of seed. In the orthotropous form, as in Helianthemum (Fig. 664) and Pepper (Fig. 679), the radicle necessarily points directly away from the hilum. ${ }^{1}$ In the anatropous form, as in Fig. 663, 682, and 684-686, the extremity of the radicle is brought to the immediate vicinity of the hilum;

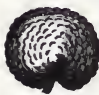

689

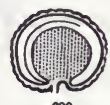

690 and so it is, although in a different way, in the campylotropous seed (Fig. 689, 690); while in the amphitropous the radicle points away from the hilum laterally. As the nature of the ovule and seed may usually be ascertained by external inspection, so the situation

1 Two technical terms, early introduced by Richard to indicate the direction of the radicle (caulicle), or rather its relation to the hilum, are

Antitropous, when the embryo directs its radicle away from the hilum, as it must in all orthotropous seeds ;

Orthotropous, also homotropous, when directed to the hilum (more strictly to the micropyle close to the hilum), as in anatropous seeds. These two terms are still employed by many botanists, although superfluous when the ovule or seed is stated to be anatropous or orthotropous, \&c. And the term orthotropous, so used, is liable to be confused with orthotropous as applied to the ovule.

Richard, moreover, termed the embryo amphitropous when curved or coiled, as in Chickweed (Fig. 689) and all such campylotropous seeds; and heterotropous when neither radicle nor cotyledons point to the hilum, as occurs in the semi-anatropous or amphitropous ovule. Many botanists describe the last by the expression " radicle vague," or, better, "embryo transverse."

FIG. 689. Campylotropous seed of common Chickweed, magnifled. 690 . Section os the same, showing the embryo colled into a ring around the albumen. 
of the embryo within, and of its parts, may often be inferred without dissection. But the dissection of seeds is not generally difficult.

611. The direction of the radicle with respect to the pericarp is also noticed by systematic writers; who employ the terms radicle superior or ascending when this points to the apex of the fruit; radicle inferior or descending when it points to its base ; centripetal, when turned toward the axis of the fruit; centrifugal (or peritropous), when turned toward the sides; and vague, when it bears no evident or uniform relation of the kind to the pericarp.

612. The position of the embryo as respects the albumen, when that is present, is various. Although more commonly in the axis, it is often excentric, or even external to the albumen, as in all Grasses and cereal Grains (Fig. 56-61), in Polygonum, \&c. When external or nearly so, and curved circularly around the albumen, as in Chickweed (Fig. 690) and Mirabilis (Fig. 17 ), it is said to be peripheric.

613. The embryo may be very variously folded or coiled in the seed. The two cotyledons, instead of plane and straight, may be crumpled; or they may be simply convolute or rolled up from one edge, as in Calycanthus (Fig. 691) ; or circinately con-

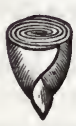

691

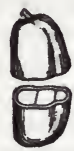

692

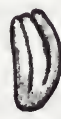

69

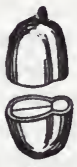

69

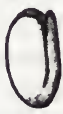

698

volute from the apex, as in Bunias; or else doubled up and thus biplicately convolute, as in Sugar Maple, Fig. 2. Two modifications are more common, and are of such classificatory importance in Cruciferæ as to need special reference. Namely, when cotyledons are

Incumbent (as in Fig. 692, 693), being so folded that the back of one is laid against the side of the radicle; and

Accumbent (Fig. 694, 695), when the edges of the pair of cotyledons are longitudinally applied to the radicle. These differences were first employed in the classification Cruciferæ by

FIG. 691. Convolute embryo of Calycanthus, the upper half cut away.

FIG. 692. Seed of a Cruciferous plant (Sisymbrium), with incumbent cotyledons, divided. 693. Embryo of the same detached entire.

FIG. 694. Seed of a Cruciferous plant (Barbarea) with accumbent cotyledons. 695. The embryo entire. 
Robert Brown, and were adopted as primary and tribal characters by DeCandolle.

614. As to number of cotyledons, the two types of embryo are the

Monocotyledonous, with a single cotyledon, $i$. e. leaves at the first nodes alternate (39); and

Dicotyledonous, with a pair of cotyledons, i.e. leaves of the first node in the most simple whorl, a pair, in other words, oppo site (21); with its modification of

Polycotyledonous (38), the leaves of the first node in whorls of three, four, or more. This occurs with constancy in a majority of Coniferæ (Fig. 48, 49), occasionally and abnormally in sundry ordinary dicotyledonous species.

615. There are several embryos of the cotyledonous type in which one cotyledon is smaller than the other, viz. the inner one when the embryo is coiled or folded. And in all the species of Abronia (a genus allied to Mirabilis, Fig. 18) this cotyledon is wanting, so that the embryo becomes technically monocotyledonous. In another genus, the Dodder (Fig. 78, 79), both cotyledons are constantly wanting; and the plumule shows only minute scales, the homologues of succeeding leaves reduced almost to nothing.

616. Sometimes the two cotyledons are consolidated into one body by the coalescence of their contiguous faces; when they are said to be conferruminate. This occurs more or less in the Horsechestnut and Buckeye (Fig. 41, 42), and is striking in the seed of the Live Oak, Quercus virens.

617. The general morphology of the embryo and its development in germination were described at the commencement of this volume. And so the completion of this account of plant, flower, fruit, seed, and embryo brings the history round to the starting point. (12-19, \&c.) Having mastered the morphology and general structure of the higher grade of plants, the pupil may go on to the morphology and structure of cells (or Vegetable Anatomy or Histology), and to the study of Cryptogamous Plants in all their grades. 


\title{
CHAPTER IX.
}

\author{
TAXONOMY.
}

\section{Section I. The Principles of Classification in Natural HistorY.}

618. TAxonomy, from two Greek words which signify arrangement and law, is the study of classification. This is of utmost importance in Natural History, on account of the vast number of kinds to be set in order, and of relations (of agreement and difference) to be noted. Botanical classification, when complete and correct, will be an epitome of our knowledge of plants. Arrangement according to kinds, and of special kinds under the more general, is common to all subjects of study. But the classification in Biological Natural History, that is in Botany and Zoology, has a foundation of its own.

619. The peculiarity of plants and animals is that they exist as individuals, propagating their like from generation to generation in a series. Of such series of individuals there are very many kinds, and the kinds have extremely various and unequal degrees of resemblance. There are various gradations, but not all gradations of resemblance. Between some, the difference is so wide that it can be said only that they belong to the same kingdom; between others, the resemblance is so close that it may be questioned whether or not they came from common parents or near ancestors.

620. The recognition of the perennial succession of similar individuals gives the idea of SpEcres. The recognition of unequal degrees of likeness among the species is the foundation of Genera, Orders, Classes, and other groups of species.

621. Individuals are the units of the series which constitute species. The idea of individuality which we recognize throughout the animal and vegetable kingdoms is derived from ourselves, conscious individuals, and from our corporeal structure and that of the higher brute animals. This structure is a whole, from which no part can be abstracted without mutilation. Each individual is an independent organism, of which the component parts are reciprocally means and ends. Individuality is a main 
distinction between beings and things; but, although the tendency to individuation begins with life itself, it is completely realized only in the higher animals.

622. In plants, as also in some of the lower animals, individu. ality is merged in community. No plant (except one reduced to the simplicity of a single cell, of circumscribed growth, and without organs) is an individual in the sense that a man or a dog is. $(16,156$.$) The herb, shrub, and tree are neither$ indivisible nor of definite limitation. Whether their successive growths are to remain parts of the previous plant, or to be independent plants, depends upon circumstances; and there is no known limit to budding propagation.

623. There is, however, a kind of social or corporate individuality in those animals, or communities (whichever we call them) of the lower grade which are multiplied by buds or offshoots as well as by ova, and in which the offspring remains, or may remain, organically connected with the stock. The polypidom or polyparium commonly has a certain limitation and a definite form; and certain polyps may become organs with special functions subordinate to the common weal. This is more largely true in the vegetable kingdom. So that for descriptive purposes, and in a just although somewhat loose sense, the herb, shrub, or tree is taken as an individual. But only while it forms one connected body. Offshoots when separately established are equally individuals in this sense.

624. What it is in plants which philosophically answers to the individual in the higher animals is another question, to which various answers have been given. ${ }^{1}$ Some insist that the whole vegetative product of one seed makes one individual, whether connected or separated (as may happen) into a million of plants. But a common and less strained view restricts the individual to such product only while organically united. Others (of which Thouars at the beginning and Braun at the middle of the present century are leading examples) take each axis or shoot with its foliage to represent the individual, of which the leaves and their homologues are organs, the branches being usually implanted upon the parent axis as this is implanted in the soil, but also equally capable of producing roots by which they may make their own connection with the soil. Still others, on pre-

1 For the history of opinion upon and a full presentation of this topic, see Alexander Braun's Memoir (originally published in the Abhandl. Akad. Wissenschaften zu Berlin, 1853), Das Individuum der Pflanze, \&c., and a translation by C. F. Stone in Amer. Jour. Sci. ser. 2, xix. xx. 1855. 
cisely similar grounds, carry the analysis a step farther, and regard each phytomer (16) as the individual. Finally, some, in view of their potentially independent life, take the cells, or units of anatomical structure, to be the true individuals; and this with sufficient reason as regards the simplest cryptogamous plants. Upon the view here adopted, that plants do not rise high enough in the scale of being to reach true individuality, the question is not whether it is the cell, the phytomer, the shoot, the tree, or the whole vegetative product of a seed which answers to the animal individual, but only which is most analogous to it. In our view, its analogue is the cell in the lowest grades of vegetable life, the phytomer in the higher. ${ }^{1}$ But, in botanical description and classification, by the individual is meant the herb, shrub, or tree, unless otherwise specified.

625. Species in biological natural history is a chain or series of organisms of which the links or component individuals are parent and offspring. Objectively, a species is the totality of beings which have come from one stock, in virtue of that most general fact that likeness is transmitted from parent to progeny. Among the many definitions, that of A. L. Jussieu is one of the briefest and best, since it expresses the fundamental conception of a species, $i$. e. the perennial succession of similar individuals perpetuated by generation.

626. The two elements of species are : 1 , community of origin ; and, 2, similarity of the component individuals. But the degree of similarity is variable, and the fact of genetic relationship can seldom be established by observation or historical evidence. It is from the likeness that the naturalist ordinarily decides that such and such individuals belong to one species. Still the likeness is a consequence of the genetic relationship; so that the latter is the real foundation of species.

1 For just as successive branches are repetitions and progeny of the parent branch or stem, the phytomers of the branch are repetitions and progeny each of the preceding one, so forming a series of vegetative generations; and the whole tree might almost as well represent the individual as one of its branches. The phytomer, as well as the branch, is capable of compieting itself by producing roots, but is itself indivisible except by mutilation. Least tenable of all is the conception that the whole product of a seed may be taken to represent the vegetable individual. For then individuals increased by buds and division are wholly unlimited both in extent and in duration, so far as observation can show, and a multitudinous race, not only of the present and past, but perhaps in perpetuity, nay consist of a single individual. There are, indeed, theoretical reasons for inferring that a bud-propagated race may not last so long as a seed-propagated species : but there is no proof of it. See Darwiniana, Art. xii. 
627. No two individuals are exactly alike; and offspring of the same stock may differ (or in their progeny may come to differ) strikingly in some particulars. So two or more forms which would have been regarded as wholly distinct are sometimes proved to be of one species by evidence of their common origin, or more commonly are inferred to be so from the observation of a series of intermediate forms which bridge over the differences. Only observation can inform us how much difference is compatible with a common origin. The general result of observation is that plants and animals breed true from generation to generation within certain somewhat indeterminate limits of variation; that those individuals which resemble each other within such limits interbreed freely, while those with wider differences do not. Hence, on the one hand, the naturalist recognizes Varieties or differences within the species, and on the other Genera and other superior associations, indicative of remoter relationship of the species themselves.

628. Varieties are forms of species marked by characters of less fixity or importance than are the species themselves. They may be of all grades of difference from the slightest to the most notable: they abound in free nature, but assume particular importance under domestication and cultivation; under which variations are most prone to originate, and desirable ones are preserved, led on to further development, and relatively fixed.

629. If two seeds from the same pod are sown in different soils, and submitted to different conditions as respects heat, light, and moisture, the plants that spring from them will show marks of this different treatment in their appearance. Such differences are continually arising in the natural course of things, and to produce and increase them artificially is one of the objects of cultivation. Striking as they often are (especially in annuals and biennials), they are of small scientific consequence. When spontaneous they are transient, the plant either outlasting the modifying cause or else succumbing to its continued and graver operation. But, in the more marked varieties which alone deserve the name, the cause is occult and constitutional; the deviation occurs we know not why, and continues throughout the existence and growth of the herb, shrub, or tree, and consequently through all that proceeds from it by propagation from buds, as by offsets, layers, cuttings, grafts, \&c.

630 . Some varieties of cultivation originate in comparatively slight deviations from the type, and are led on to greater differences by strict selection of the most marked individuals to breed from. Most appear as it were full-fledged, except as to 
luxuriance or development, more or less under the control of conditions, their origin being wholly unaccountable. They arise in the seed-bed, or sometimes from buds, which as the gardeners say "sport." 1 That is, some seedlings, or some shoots, are unlike the rest in certain particulars. ${ }^{2}$

631. Most varieties originate in the seed, and therefore the foundation for them, whatever it may be, is laid in sexual reproduction. But Bud-variation, or the "sporting" of certain buds into characters in branch, flower, or fruit unlike those of the stock, is known in a good number of plants. ${ }^{8}$ It might also occur in corals, hydras, and other compound animals propagated by budding. Once originated, these varieties mostly persist, like seedling varieties, through all the generations of budding growth, but are not transmitted to the seed.

632. Upon the general principle that progeny inherits or tends to inherit the whole character of the parent, all varieties must have a tendency to be reproduced by seed. But the inheritance of the new features of the immediate parent will commonly be overborne by atavism, $i$.e. the tendency to inherit from grandparents, great-grand-parents, \&c. Atavism, acting through a long line of ancestry, is generally more powerful than the heredity of a single generation. But when the offspring does inherit the peculiarities of the immediate parent, or a part of them, its offspring has a redoubled tendency to do the same, and the next generation still more ; for the tendency to be like parent, grandparent, and great-grand-parent now all conspire to this result and overpower the influence of remoter ancestry. Close-breeding (398) is requisite to this result. In the natural wild state, varieties - many and conspicuous as they often are - must be much repressed by the prevalent cross-fertilization which takes place among the individuals of almost all species. Cultivators and breeders in fixing varieties are careful to secure close breeding as far as this is possible. This has fixed the particular sorts of Indian Corn, Rye, Cabbage, Lettuce, Radishes, Peas, \&c., and

1 Both the technical English term, Sport, and its Latin equivalent, Lusus, are sometimes used for bud-variation only, yet as commonly for seedling variation also.

2 Darwin assumes that variation is of itself indefinite or vague, tending in no particular direction, but that direction is wholly given by the elimination in the struggle for life of all but the fittest for the conditions. But what we observe in the seed-bed does not suggest this view. Nægeli, Braun, and myself incline to the opinion that each plant has an inherent tendency to variation in certain general directions.

8 A list of known bud-varieties is given in Darwin's Variation of Animals and Plants under Domestication, Chapter xi. 
indeed of nearly all our varieties of cultivated annual and biennial esculent plants, as well as of several perennials, many of which have been fixed through centuries of domestication, while others are of recent establishment. What is now taking place with the Peach in this country may convince us that heritable varieties may be developed in trees as well as in herbs, and in the same manner; and that the reason why most races are annuals or biennials is because these can be perpetuated in no other way, and because the desired result is obtainable in fewer years than in shrubs or trees. Varieties of this fixity of character are called 633. Races (Lat. Proles). A race, in this technical sense of the term, is a variety which is perpetuated with considerable certainty by sexual propagation. This distinction of varieties pertains chiefly to botany. In the animal kingdom all permanent varieties must be races. So are all indigenous varieties of plants. ${ }^{1}$ In most of these, the position of species and variety is more or less arbitrary or accidental, and capable of interchange. What is called the species may be only a commoner or betterknown form, or the one first recognized and named by botanists ; whence the other forms as they come to be recognized are made to rank in the books as varieties. Instead of one varying from the other, all the forms have probably varied ages ago from a common type.

634. These varieties of the highest order and most marked characteristics, being perpetuable by seed, have the principal attributes of species. They are a kind of subordinate derivative species. Hence they are sometimes called Subspecies. We judge them not to be so many species, either because in the case of cultivated races we know something of their origin or history, and more of the grave changes which long domestication may bring to pass; or because the forms, however stable, differ among themselves less than recognized species generally do; or because very striking differences in the extremes are connected by intermediate forms. And our conclusions, it must be under'stood, " are not facts, but judgments, and largely fallible judgments." ${ }^{2}$ For while some varieties appear strikingly different, some species are very much alike. ${ }^{3}$

1 The Horseradish and a few other plants of spontaneous growth, which through long dependence on bud-propagation seem to have lost the power of setting seed, can hardly be called varieties.

2 Darwiniana, 35.

8 Wherefore, since we hardly need the term race in the restricted sense of seed-propagated variety, it is sometimes convenient to use it in the manner proposed by Bentham (Anniversary Address to the Linnean Society, 
635. One distinction between varieties and species is noteworthy and important, even if it may not serve as a criterion. The individuals of different varieties in plants interbreed as freely as do those of the same variety and are equally prolific. Their union produces

636. Cross-breeds. ${ }^{1}$ In nature, cross-breeding doubtless represses variation or prevents the segregation of varieties into what would be ranked as species. In cultivation and domestication, it is turned to important account in producing intermediate new varieties (cross-breeds) variously combining the different excellencies of two parent individuals or two varieties. Thus the great number of forms produced by variation (especially as to flowers and fruits) have been further diversified, and selected forms improved for special uses by judicious combination.

637. In general, the individuals of distinct species do not interbreed, although many are capable of it. There is great diversity in this regard among plants, some (such as Willows, Verbascums, and Verbenas) interbreeding freely and reciprocally; some interbreeding in one direction, but not reciprocally ; others, even when very similar, refusing to unite. But, on the whole, there seems to be few nearly related species in which the pollen of the one cannot be made to act upon the ovules of the other by persistent and proper management. Such crossing is an important resource in horticulture. Crossing, of species, when successful, produces

638. Hybrids. In these, the characteristics of the two species are combined, sometimes in equal proportions, sometimes with great preponderance of one or the other parent; and there is often a difference in the result in reciprocal fertilizations. Hybrids do not play a very prominent part in nature, apart from cultivation, although the limits of some species may be obscured by them, possibly of more than is generally supposed. In the animal kingdom, all the most familiar hybrids are sterile : in the vegetable kingdom, a majority may have a certain but very low degree of fertility; but this is also the case in many unions

May, 1869, 5) as the common designation of any group or collection of individuals whose characters are continued through successive generations, whether it be permanent variety, subspecies, species, or group consisting of very similar species, the term not implying any decision of this question. If this use of the term race prevails, Subspecies will probably take its place as the designation of the highest grade of variety. The objection to this is that the subspecific and specific names would be more liable to be confused.

1 Half-breed is a common equivalent term in the animal kingdom : Latin, Mistus or Mixtus ; French, Métis. 
within the species, and especially in the application of the pollen to the stigma of the same blossom. Commonly the sterility of hybrids is owing to the impotence of the stamens, which perfect no pollen; and most such hybrids may be fertilized by the pollen of the one or the other parent. Then the offspring either in the first or second generation reverts to the fertilizing species. Moreover, certain hybrids, such as those of Datura, which are fully fertile per se, divide in the offspring, partly in the first generation, and completely in two or three succeeding generations, into the two component species, even when close-fertilized. ${ }^{1}$ (In part this may come from adventive embryo-formation, 533.)

639. There appears, therefore, to be a real ground in nature for species, notwithstanding the difficulty and even impossibility in many cases of defining and limiting them.

640. Species is taken as the unit in zoological and botanical classification. Important as varieties are in some respects, especially under domestication and cultivation, they figure in scientific arrangement only as fractions of species. Species are the true subjects of classification. The aim of systematic natural history is to express their relationship to each other.

641. The whole ground in nature for the classification of species is the obvious fact that species resemble or differ from each other unequally and in extremely various degrees. If this were not so, if related species differed one from another by a constant quantity, so that, when arranged according to their resemblances, the first differed from the second about as much as the second from the third, and the third from the fourth, and so on, - or if the species blended as do the colors of the rainbow, - then, with all the diversity in the vegetable kingdom there actually is, there could be no natural foundation for their classification. The multitude of species would rende: it necessary to classify them, but the classification would be wholly artificial and arbitrary. The actual constitution of the vegetable kingdom, however, as appears from observation, is that some species resemble each other very closely indeed, others differ as widely as possible, and between these the most numerous and the most various grades of

1 According to Naudin in Comptes Rendus, xlix. 1859, \& lv. 1862. See also Naudin's memoir on hybridity in plants in Ann. Sci. Nat. ser. 4, xix. 1863 , pp. $180-203, \&$ in Mem. Acad. Sci. . . . For the literature on vegetable hybrids, see Kœlreuter, Nachricht, \&c., 1761, and Appendices, 1763-1766; Herbert, on Amaryllidaceæ, 1837 ; C. F. Gertner, Versuche und Beobachtungen ueber die Bastarderzeugung in Pflanzenreich, 1849; Wichura, Die Bastardbefruchtung im Pflanzenreich, erläutertert an den Bastarden der Waiden; and the memoir of Naudin referred to. 
resemblance or difference are presented, but always with a manifest tendency to compose groups or associations of resembling species, - groups the more numerous and apparently the less definite in proportion to the number and the nearness of the points of resemblance. These various associations the naturalist endeavors to express, as far as is necessary or practicable, by a series of generalizations, the lower or particular included in the higher or more comprehensive. All kinds of differences are taken into account, but only the most constant and definite ones are relied on for characters, i. e. distinguishing marks. Linnæus and the naturalists of his day used names for only three grades of association, or groups superior to species, viz. the Genus, the Order, and the Class; and these are still the principal members of classification.

642. Genera (plural of Genus) are the more particular or special groups of related species. They are groups of species which are much alike in all or most respects, - which are constructed, so to say, upon the same particular model, with only circumstantial differences in the details. They are not necessarily nor generally the lowest definable groups of species, but sre the lowest most clearly definable groups which the botanist recognizes and accounts worthy to bear the generic name; for the name of the genus with that of the species added to it is the scientific appellation of the plant or animal. Constituted as the vegetable and animal kingdoms are, the recognition of genera, or groups of kindred species, is as natural an operation of the mind as is the conception of species from the association of like individuals. This is because many genera are so strongly marked, at least so far as ordinary observation extends. Every one knows the Rose genus, composed of the various species of Roses and Sweetbriers; the Bramble genus, comprising Raspberries, Blackberries, \&c., is popularly distinguished to a certain extent; the Oak genus is distinguished from the Chestnut and the Beech genus ; each is a group of species whose mutual resemblance is greater than that of any one of them to any other plants. The number of species in such a group is immaterial, and in fact is very diverse. A genus may be represented by a single known species, when its peculiarities are equivalent in degree to those which characterize other genera. This case often occurs; although, if this were universally so, genus and species would be equivalent terms. If only one species of Oak were known, the Oak genus would have been as explicitly discerned as it is now that the species amount to three hundred; and better defined, for now there are forms quite intermediate between Oak and 
Chestnut. Familiar illustrations of genera in the animal kingdom are furnished by the Cat kind, to which belong the domestic Cat, the Catamount, the Panther, the Lion, the Tiger, the Leopard, \&c. ; and by the Dog kind, which includes with the Dog the different species of Foxes and Wolves, the Jackal, \&c. The languages of the most barbarous as well as of civilized people everywhere show that they have recognized such groups. Naturalists merely give to them a greater degree of precision, and indicate what the points of agreement are.

643. If most genera were as conspicuously marked as those from which these illustrations are taken, genus would be as definitely grounded in nature as species. But popularly recognized genera, rightly based, are comparatively few. Popular nomenclature, embodying the common ideas of people, merely shows that generic groups are recognizable in a considerable number of cases, but not that the whole vegetable or the whole animal kingdom is divisible into a definite number of such groups of equally or somewhat equally related species. The naturalist discerns the ground of genera in characters which the casual and ordinary observer overlooks; and, taking the idea of genera from the numerous well-marked instances as the norm, applies it as well as possible to the less obvious or less natural cases, and groups all known species under genera. Resemblances among the species when rightly grouped into genera, though real, are often so unequal in degree, that certain species may be about as nearly related to neighboring genera. So that the recognition of genera even more than of species is a matter of judgment, and even of conventional agreement as to how and where a certain genus shall be limited, and what particular association of species shall hold the position of genus. All the species of a genus must accord in every important structure; but extended observation only can settle the question as to what are important and what are incidental characters. For example, the pinnatifid or sinuate leaf might have been thought as essential to the Oak genus as the acorn-cup; but many Oaks are now known with entire leaves, resembling those of Willow or Laurel. An open acorncup beset with imbricated scales is a character common to all European and American Oaks; but in numerous Asiatic species the cup bears concentric or spiral lamellæ instead, and in others the cup takes the form of a naked and closed sac. Maples have palmately-veined and lobed leaves; but one species has undivided and pinnately-veined leaves. The Apple and the Pear under one view are of the same genus, under another they represent different genera. 
644. The genus must be based on close relationship of species, but not necessarily on the closest. Raspberries differ from Blackberries, but must be ranked in the same genus; and so of Plums and Cherries. For the groups which are to bear the generic name must be as distinct and definite as possible.

645. Orders are to genera what genera are to species. They are groups of a higher rank and wider comprehension, expressive of more general resemblances, or, in other language, of remoter relationship. As all species must be ranked in genera, so all genera must be ranked in orders. FAMILY in botany is synonymous with order : at least natural orders and families (however distinguished in zoology) have always in botany been interchangeable terms, and will probably so continue. 1

646. As examples of orders in the vegetable kingdom take the Oak family, composed of Oaks, Chestnuts, Beeches, \&c. ; the Pine family, of Pines, Spruces, Larches, Cedars, Araucaria, Cypresses, and their allies ; the Rose family, in which Brambles, Strawberries, Plums and Cherries, Apples and Pears are associated with the Rose in one somewhat multifarious order.

647. Classes are to orders what these are to genera. They express still more comprehensive relations of species ; each class embracing all those species which are framed upon the same broad plan of structure, however differently that plan may be carried out in particulars.

648. Kingdom must be added, to represent the highest generalization. All subjects of biological classification belong either to the vegetable or animal kingdom. Mineralogy, Chemistry, \&c., may use the same terms (genus, species, \&c.) in an analogous way; but the classification of substances rests on other foundations than that of beings.

649. The sequence of groups, rising from particular to universal, is Species, Genus, Order, Class, Kingdom; or, in descending from the universal to the particular,

KnNGDOM,

Class,

ORDER,

Genus,

Spectes.

1 Order is the older term, and that which associates best with the technical Latin names. Family is a happy term, which associates itself well with English names. But its use is attended with this incongruity, that the tribe (653) in natural history classification is subordinate to the family. In zoology, order is distinguished from family as the next higher grade. 
650. This is the common framework of natural history classification. All plants and all animals belong to some species; every species to some genus; every genus to some order or family; every order to some class; every class to one or the other kingdom. ${ }^{1}$ But this framework, although all that is requisite in some parts of natural history, does not express all the observable gradations of relationship among species. And even gradations below species have sometimes to be classified. The series is capable of extension; and extension is often requisite on account of the large number of objects to be arranged, and the various degrees of relationship which may come into view.

651. This is effected by the intercalation of intermediate grades, to be introduced into the system only when there is occasion for them. And in botany one or more grades superior to the classes are needful; for first and foremost is the great division of all plants into a higher and a lower Series ${ }^{2}$ (or subkingdom), the Phænogamous and the Cryptogamous.

652. The grades intercalated into the long-established sequence of Class, Order, Genus, and Species, with new names, are mainly two, Tribe and Cohort.

653. Tribe has been for a generation or two thoroughly established in both kingdoms, as a grade inferior to order and superior to genus. In botanical classification, much use is made of this grade, genera being grouped into tribes.

654. Cohort (Lat. Cohors) is of more recent introduction, at least in Botany, but is becoming established for a grade next above that of order. Orders are grouped into cohorts. Lindley hit upon a good English name for this grade, that of Alliance. But this word has no available Latin equivalent; while cohort takes equally well a Latin or an English form.

655. Finally, each grade is capable of being doubled by the recognition of one like it and immediately subordinate to it, and with designation directly expressive of the subordination. For

1 Not recognizing Hæckel's third kingdom of Protista, consisting of those lowest forms of being from which the animal and vegetable kingdoms emerge.

2 Answering to the French Embranchement in zoology. For this it is proposed to use the word Division (Divisio): see Laws of Botanical Nomenclature adopted by the International Botanical Congress held at Paris in August, 1867 ; together with a Historical Introduction and a Commentary, by Alph. DeCandolle, - English translation, London, 1868; the original French edition, Paris, 1867. Perhaps no better name can be found; but the elder DeCandolle brought Divisio into common use for a grade subordinate to tribe. Endlicher employed the term Regio. We have used Series, and much prefer it. 
example, if Dicotyledones and Monocotyledones be the two classes of Phænogamia, the former (and only the former) is divided upon very important characters into two branches, of far higher rank than the cohorts, viz. the Angiospermæ and the Gymnospermæ, which take the name of Subclasses. Orders, especially the more comprehensive ones, often comprise two or more groups so distinct that it may fairly be a question whether they are not of ordinal rank: such take the name of Suborders. Tribes in like manner may comprise groups of similar relative value: these are Subrribes. Genera may comprise sections of species which might almost as well rank as genera themselves: to mark their importance and pretension (which may come to be allowed), they are termed Subgenera. Finally, forms which are ranked as varieties, but which may establish a claim to be distinct species, are sometimes termed Subspecres. Even what we regard as a variety may comprise more or less divergent forms, to be distinguished as Subvarieties.

656. Some of the larger and most diversified orders, tribes, genera, or species may require all these analytical appliances, and even more, for their complete elucidation; while others, comparatively homogeneous, offer no ground for them. But when these grades, or some of them, come into use, they are always in the following sequence:-

\section{KINGDOM,}

/ Srries or Division, or Sub-kingdom,

Class, Subclass, Cohort,

Order or Family, Suborder, Tribe, Subtribe, Genus, Subgenus, Section,

Subsection, Species, Subspecies or Race, Variety, Subvariety.

657. Nature and Meaning of Affinity. These grades, the higher including the lower, denote degrees of likeness or difference. Plants belonging respectively to the two great series or primary divisions may accord only in the most general respects, in that which makes them plants rather than animals. Plants of the same variety are generally as much alike as if they were of the 
same immediate parentage. All plants of the same species are so much alike that they are inferred to have descended from a common stock, and their differences, however grave, are supposed to have arisen from subsequent variation, and the more marked differences to have become fixed through heredity. This is included in the idea of species. Descent from a common origin explains the likeness, and is the only explanation of it.

658. But what is the explanation of the likeness between the species themselves? As respects nearly related species, the answer is clear. Except for practical purposes and in an arbitrary way, no certain and unfailing distinction can be drawn between varieties of the highest grade and species of closest resemblance. It cannot reasonably be doubted that they are of similar origination. Then there are all gradations between very closely and less closely related species of the same genus of plants.

659. The Theory of Descent, that is, of the diversification of the species of a genus through variation in the lapse of time, affords the only natural explanation of their likeness which has yet been conceived. The alternative supposition, that all the existing species and forms were originally created as they are, and have come down essentially unchanged from the beginning, offers no explanation of the likeness, and even assumes that there is no scientific explanation of it. The hypothesis that the species of a genus have become what they are by diversification through variation is a very old one in botany, and has from time to time been put forward. But until recently it has had little influence upon the science, because no clear idea had been formed of any natural process which might lead to such result. Doubtless, if variation, such as botanists have to recognize within the species, be assumed as equally or even more operative through long anterior periods, this would account for the diversification of an original species of a genus into several or many forms as different as those which we recognize as species. But this would not account for the limitation of species, which is the usual (but not universal) characteristic, and is an essential part of the idea of species. Just this is accounted for by

660. Natural Selection. This now familiar term, proposed by Charles Darwin, was suggested by the operations of breeders in the development and fixation of races for man's use or fancy ; in animals by breeding from selected parents, and selecting for breeding in each generation those individuals only in which the desired points are apparent and predominant; in the seed-bed by rigidly destroying all plants which do not show some desirable variation, breeding in and in from these, with strict selection of 
the most variant form in the particular line or lines, until it becomes fixed by heredity and as different from the primal stock as the conditions of the case allow. In nature, the analogous selection, through innumerable generations, of the exceedingly small percentage of individuals (as ova or seeds) which ordinarily are to survive and propagate, is made by competition for food or room, the attacks of animals, the vicissitudes of climate, and in fine by all the manifold conditions to which they are exposed. In the Struggle for Life to which they are thus inevitably exposed, only the individuals best adapted to the circumstances can survive to maturity and propagate their like. This Survival of the Fittest, metaphorically expressed by the phrase natural selection, is in fact the destruction of all weaker competitors, or of all which, however they might be favored by other conditions, are not the most favored under the actual circumstances. But seedlings varying, some in one direction, some in another, are thereby adapted to different conditions, some to one kind of soil or exposure, some to another, thus lessening the competition between the two most divergent forms, and favoring their preservation and farther separation, while the intermediate forms perish. Thus an ancestral type would become diversified into races and species. Earlier variation under terrestrial changes and vicissitudes, prolonged and various in geological times since the appearance of the main types of vegetation, and the attendant extinctions, are held to account for genera, tribes, orders, \&c., and to explain their actual affinities. Affinity under this view is consanguinity ; and classification, so far as it is natural, expresses real relationship. Classes, Orders, Tribes, \&c., are the earlier or main and successful branches of the genealogical tree, genera are later branches, species the latest definitely developed ramifications, varieties the developing buds. ${ }^{1}$

661. Except as to those changes in size, luxuriance, or depauperation and the like, in which plants, especially seedlings, respond promptly to external influences, as to heat or cold,

1 For the inception of this theory of descent in the form which has within the last twenty years profoundly affected natural history, and developed a copious literature, see a short paper On the Variation of Organic Beings in a State of Nature; On the Natural Means of Selection; and On the Comparison of Domestic Races and True Species, by Charles Darwin, also On the Tendency of Varieties to depart indefinitely from the Original Type, by Alfred Russell Wallace, both read to the Linnean Society, July 1, 1858, and published in its Journal of the Proceedings, iii. (Zoology) 45-62. For the development of the doctrine, see Darwin's "Origin of Species by Means of Natural Selection," "The Variation of Animals and Plants under Domestication," and various other works; Wallace's "Geographical Distribution of Animals," \&c. For some expositions, see Gray's "Darwiniana," 
moisture or dryness (which are transient and comparatively unimportant), variation, or the unlikeness of progeny to parent, is occult and inexplicable. If sometimes called out by the external conditions, it is by way of internal response to them. In Darwin's conception, variation of itself does not tend in any one particular direction: he appears to attribute all adaptation to the sorting which results from the struggle for existence and the survival of the fittest. We have supposed, and Nægeli takes a similar view, ${ }^{1}$ that each plant has an internal tendency or predisposition to vary in some directions rather than others; from which, under natural selection, the actual differentiations and adaptations have proceeded. Under this assumption, and taken as a working hypothesis, the doctrine of the derivation of species serves well for the co-ordination of all the facts in botany, and affords a probable and reasonable answer to a long series of questions which without it are totally unanswerable. It is sup. ported by vegetable palæontology, which assures us that the plants of the later geological periods are the ancestors of the actual flora of the world. In accordance with it we may explain, in a good degree, the present distribution of species and other groups over the world. It rationally connects the order of the appearance of vegetable types in time with the grades of differentiation and complexity, both proceeding from the simpler, or lower and more general, to the higher and more differentiated or special; it explains by inheritance the existence of functionless parts ; throws light upon the anomalies of parasitic plants in their various gradations, upon the assumption of the most various functions by morphologically identical organs, and indeed illuminates the whole field of morphology with which this volume has been occupied. It follows that species are not " simple curiosities of nature," to be catalogued and described merely, but that they have a history, the records of which are impressed upon their structure as well as traceable in their geographical and palæontological distribution. This view, moreover, explains the remarkable fact that the characters in which the affinities of plants are mainly discerned (and which therefore serve best for orders, tribes, and other principal groups) are commonly such as are evidently of small if any importance to the plant's wellbeing, and that they run like threads through a series of species of the greatest diversity in habit, mode of life, and particular adaptations to conditions. ${ }^{2}$

1 Entstehung und Begriff der naturhistorischen Art. Zweite Auflage, 1865.

2 This is a corollary of natural selection, which can take effect only upon useful characters, i. e. upon structures which play some actire part 
662. The fixity of species under this view is not absolute and universal, but relative. Not, however, that specific changes are necessitated in virtue of any fixed or all-controlling natural law. Some of the lowest forms have existed essentially unchanged through immense geological periods down to the present time; some species even of trees are apparently unchanged in the lapse of time and change of conditions between the later tertiary period and our own day, during which most others have undergone specific modification. Such modifications are too slow to effect in any wise the stability and practical application of botanical classification.

\section{Section II. Botanical Classification.}

663. Natural and Artificial Classiflcations may be distinguished. A natural classification in botany aims to arrange all known plants into groups in a series of grades according to their resemblances, and their degrees of resemblance, in all respects, so that each species, genus, tribe, order, \&c., shall stand next to those which it most resembles in all respects, or rather in the whole plan of structure. For two plants may be very much alike in external appearance, yet very different in their principal structure. Artificial classifications single out one or more points of resemblance or difference and arrange by those, without reference to other considerations, convenience and facility being the controlling principles. The alphabetical arrangement of words in a dictionary, and the sexual system in botany by Linnæus (or rather a part of it), - in which plants are arranged in classes upon the number of their stamens, and in orders upon the number of pistils, - are examples of artificial classification. The arrangement of the words of a language under their roots, and with the derivative under the more primitive forms, would answer to a naturai classification.

in the life of the plant, and which therefore undergo modification under changing conditions. Unessential structures accordingly are left unaltered or are only incidentally modified. And so these biologically unessential points of structure, persisting through all adaptive changes, are the clews to relationship. Thus, Rubiaceæ are known by insignificant stipules, Anonaceæ by ruminated albumen, Rhamnaceæ by a valvate calyx and stamens before the petals, \&c. Paradoxical as it may seem, it is not although, but because, they are of small biological importance that they are of high classificatory (i.e. of genealogical) value.

On considerations like these, characters are divided into adaptive or biological on the one hand, and genealogical or genetic on the other. The sagacious naturalist seizes upon the latter for orders and the like; while the former are prominent in genera, \&c. 
664. No artificial classification of plants could fail to be natural in some portions and some respects; because plants which agree in any point of structure likely to be used for the purpose will commonly agree in other and perhaps more important characters. On the other hand, no natural classification can dispense with artificial helps; nor can it express in lineal order, or in any other way, all the various relationships of plants, even if these were fully determined and rightly subordinated. Naturalists now endeavor to make classification as natural as possible ; that is, to base it in every grade upon real relationships. What real relationships are, and how to express them in a general system and throughout its parts, has been the task of the leaders in botany from the beginning of the science until now; and the work is by no means completed.

665. Linnæus was perhaps the first botanist to distinguish clearly between a natural and an artificial classification. He labored ineffectually upon a natural classification of the genera of plants into orders ; and he devised an effective artificial classification, which became so popular that it practically superseded all others for more than half a century, and has left a permanent impression upon the science. The last generation of botanists who were trained under it has not quite passed away.

666. Ante-Linnæan Classiffeation. Linnæus, in his Philosophia Botanica, divided systematists into heterodox and orthodox: the former, those who classify plants by their roots, herbage, time of flowering, place of growth, medical and economical uses, and the like ; the latter, by the organs of fructification. It is remarkable that all the orthodox or scientific classifications anterior to Linnæus made a primary division of the vegetable kingdom into Trees and Herbs, referring the larger shrubs to the former and the under-shrubs to the latter, - an arrangement which began with Theophrastus and was continued by Ray and Tournefort.

667. The three most important names in botanical taxonomy anterior to Linnæus are those o: Cesalpini, Ray, and Tournefort. Scientific botany commenced with the former, in Italy, in the latter half of the sixteenth century. He first used the embryo and its cotyledons in classification, distinguished differences in the insertion of floral parts, and, indeed (excepting the primary division into trees and herbs), founded all principal characters upon the organs of fructification, especially upon the fruit and seed. Conrad Gesner of Zurich had somewhat earlier recognized this principle, but Cesalpini first applied it.

668. A century later (1690-99) this principle was carried into practice by Rivinus (a name latinized from Bachmann), of 
Leipsic, in a wholly artificial classification founded on the corolla. His contemporary in England, Robert Morison, somewhat earlier began the publication of his great work, the Universal History of Plants. In this was first attempted a grouping of plants into what are now called natural orders ; and these were defined, somewhat loosely, some by their fruit, inflorescence, and flowers, others by their stems, the nature of their juice, \&c. But the two great systematists of the time, who together laid the foundations of modern scientific botany, were John Ray in England and Joseph Pitton de Tournefort in France.

669. Ray's method of classification was sketched in 1682 , and was anterior to Tournefort's, but was amended and completed in 1703. The leading fault of both was the primary division into trees and herbs. The great merit of Ray was his division of herbs into Flowerless and Flowering, and the latter into Dicotyledonous and Monocotyledonous. These great classes he divided and subdivided, by characters taken from the organs of fructification, into what we should call natural orders or families, but which he unfortunately called genera. He noted the coincidence of nerved leaves with the monocotyledonous embryo, although he did not notice that his first division of arborescent plants was monocotyledonous; and he had a clear apprehension of genera.

670. Tournefort's method was published in French in the year 1694, in Latin in 1700 . It is more definite but more artificial than that of Ray, being founded like that of Rivinus almost wholly upon modifications of the corolla, and it overlooked the distinction between monocotyledonous and dicotyledonous embryos. Its great merit is that here genera, as we now understand them, are first established and defined, and all the species then known referred to them; so that Tournefort was justly said by Linnæus to be the founder of genera. Ray may be said to have indicated the primary classes, Jussieu (in the next century) to have established natural orders, and Tournefort to have given to botany the first Genera Plantarum.

671. Linnæan Classification. Linnæus, the great reformer of botany in the eighteenth century, thoroughly revised the principles of classification, established genera and species upon a more scientific basis, and, in designating species by a word instead of a descriptive phrase, introduced binomial nomenclature. (704.) He likewise established for the stamens, and indeed for the pistils also, their supreme importance in classification (probably without knowledge of the clear suggestion to this effect made by Burckhard in a letter to Leibnitz, printed in 1702); their functions, so long overlooked, being now ascertained. He also 
drew a clear and practical distinction between natural and artificial classifications (663), and deferring all endeavors to make the former available, except for genera, he devised a practical substitute for it, as a key to the genera, viz. his celebrated

672. Sexual System, or arrangement of the genera under artificial classes and orders, founded upon the stamens and pistils. Although now out of use, this artificial classification has been so popular and influential, and has left so deep an impression upon the science and especially upon the language of botany, that it needs to be presented. The primary divisions are the classes, twenty-four in number. But the 24th class, Cryptogamia, consists of plants which have not stamens and pistils and consequently no proper flowers, and is therefore the counterpart of the remaining twenty-three classes, to which the corresponding name of Phanerogamia or, in shorter form, Phænogamia (Phænogamous plants) has since been applied. These twenty-three classes are characterized by certain modifications and associations of the stamens, and have substantive names, of Greek derivation, expressive of their character. The first eleven comprise all plants with perfect (i.e. hermaphrodite) flowers, and with a definite number of equal and unconnected stamens. They are distinguished by the absolute number of these organs, and are designated by names compounded of Greek numerals and the word andria (from $\alpha v \eta^{\prime} \varrho$ ), which is used metaphorically for stamen, as follows : -

Class 1. Mosandria includes all such plants with one stamen to the flower: as in Hippuris.

2. Diandria, those with two stamens, as in the Lilac.

8. Triandria, with three stamens, as in the Valerian and Iris.

4. Tetrandria, with four stamens, as in the Scabious.

5. Pentandria, with five stamens, the most frequent case.

6. HexandrIA, with six stamens, as in the Lily Family, \&c.

7. Heptandria, with seven stamens, as in Horsechestnut.

8. Octandria, with eight stamens, as in Evening Primrose and Fuchsia.

9. Enmeandria, with nine stamens, as in the Rhubarb.

10. Decandria, with ten stamens, as in Rhododendron and Kalmia.

11. Dodecandria, with twelve stamens, as in Asarum and the Mignonette; extended also to include those with from thirteen to nineteen stamens.

673. The two succeeding classes include plants with perfect lowers having twenty or more unconnected stamens, which, in

12. Icosandria, are inserted on the calyx (perigynous), as in the Rose Family; and in

13. Polyandris, on the receptacle (hypogynous), as in the Buttercup, Anemone, \&t. 
674. Their essential characters are not indicated by their names : the former merely denoting that the stamens are twenty in number; the latter, that they are numerous. - The two following classes depend upon the relative length of the stamens, namely :-

14. Didynamia, including those with two long and two short stamens, as in the majority of flowers with bilabiate corolla.

15. Temradynamia, those with four long and two short stamens, as in flowers with cruciferous corolla.

675. These names signify in the former that two stamens, and in the latter that four stamens, are most powerful. - The four succeeding are founded on the connection of the stamens, viz. :-

16. Monadelphia (meaning a single fraternity), with the filaments united in a single set, tube, or column, as in the Mallow.

17. Diadelphia (two fraternities), with the filaments united in two sets or parcels, as in Corydalis and in many Leguminosæ.

18. Polyadelphia (many fraternities), with the filaments united in more than two sets or parcels, as in Hypericum.

19. Srngenesia (from Greek words signifying to grow together), with the anthers united in a ring or tube, as in the Sunflower and all Compositæ.

676. The next class, as its name denotes, is founded on the union of the stamens to the style :-

20. Gynandrin, with the stamens and styles consolidated, as in Cypripedium and all the Orchis Family.

677. In the three following classes, the stamens and pistils occupy separate blossoms :-

21. Monocis (one household) includes all plants where the stamens and pistils are in separate flowers on the same individual; as in the Oak and Chestnut.

22. Diøcin (two households), where they occupy separate flowers on different individuals; as in the Willow, Poplar, Moonseed, \&c.

23. Polygamia, where the stamens and pistils are separate in some flowers and associated in others, either on the same or two or three different plants; as in most Maples.

678. The remaining class is essentially flowerless ; or rather its organs of reproduction are more or less analogous to, but not homologous with, stamens and pistils. But, although Linnæus suspected a sexuality in Ferns, Mosses, Algæ, \&c., there was no proof of it in his day. So he named the class, containing these,

24. Cryptogamia, meaning clandestine marriage, the sexes, if existent, hidden from view.

679. The characters of the classes may be presented at one view, as in the subjoined table:- 


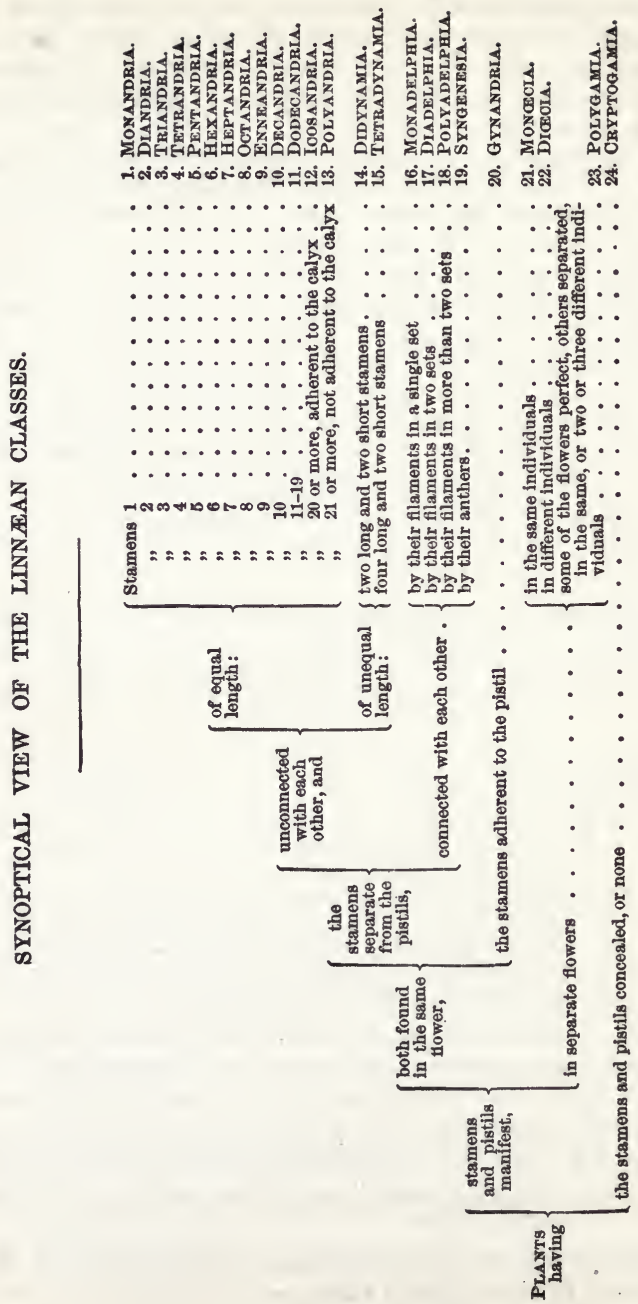


680. The orders, in the first thirteen classes of the Linnæan artificial system, depend on the number of styles, or of the stigmas when the styles are wanting; and are named by Greek numerals prefixed to the word gynia, used metaphorically for pistil, as follows :-

Order 1. Monog YNia, those with one style or sessile stigma to the flower.

2. Digrnin, those with two styles or sessile stigmas.

3. TRIG YNIA, those with three styles.

4. Tetragraia, those with four styles.

5. Pentagynia, those with five styles.

6. HeXAGYNIA, those with six styles.

7. Heptagria, those with seven styles.

8. Octogria, those with eight styles.

9. ENNEAG YNIA, those with nine styles.

10. Decagrnia, those with ten styles.

11. Dodecag ynia, those with eleven or twelve styles.

12. Polyg ynia, those with more than twelve styles.

681. The orders of class 14, Didynamia, are only two and are founded on the pericarp, namely :-

1. Grmospermin, meaning seeds naked, the achenia-like fruits of a 4-parted pericarp having been taken for naked seeds.

2. Anaiospermin, with the seeds evidently in a seed-vessel or pericarp, i. e. the pericarp undivided.

682. The 15th class, Tetradynamia, is also divided into two orders, which are distinguished merely by the form of the pod : -

1. Silicdrosa; the fruit a silicle (561), or short pod.

2. Siliquosa ; fruit a silique (561), or more or less elongated pod.

683. The orders of the 16th, 17th, 18th, 20th, 21st, and $22 \mathrm{~d}$ classes depend merely on the number of stamens; that is, on the characters of the first thirteen classes, whose names they likewise bear: as Monandria, with one stamen, Diandria, with two stamens; and so on.

684. The orders of the 19th class, Syngenesia, are six, namely :

1. Polygamia aquals, where the flowers are in heads (the so-called compound flower), and all hermaphrodite.

2. Polygamia superfuda, the same as the last, except that the rays, or marginal flowers of the head, are pistillate only.

3. Polygamia frostranea, those with the marginal flowers neutral, the others perfect.

4 Polygamia necessaria, where the marginal flowers are pistillate and fertile, and the central staminate and sterile.

5. Polygamia segregata, where each flower of the head [or glomerule] has its own proper involucre.

6. Monogamia, where solitary flowers (that is, not united into a head) have united anthers, as in Lobelia. 
685. The 23d class, Polygamia, has three orders, two of them - founded on the characters of the two preceding classes and bearing their names, and the third named upon the same principle, namely :-

1. Monacis, where both separated and perfect flowers are found in the same plant.

2. DI৫CIA, where they occupy two different plants.

3. Triecis, where one individual bears the perfect, another the staminate, and a third the pistillate flowers.

686. The orders of the 24th class, Cryptogamia, the Flowerless Plants, are so many natural orders, and are not definable by a single character. They are :-

1. Filices, the Ferns.

2. Muscr, the Mosses.

3. Ala s, which, as left by Linnæus, comprised the Hepaticæ, Lichens, \&c., as well as the seaweeds.

4. Fungl, Mushrooms, \&c.

687. In its day, this artificial system well fulfilled its purpose, and was preferred to all others on the score of facility and definiteness. Now no botanist would think of employing it, nor would it be chosen for a key to genera, which was its only legitimate use.

688. The Natural System was rightly appreciated by Linnæus, who pronounced it to be the first and last desideratum in systematic botany; and he early attempted to collocate most known genera under natural orders (e. g. Piperita, Palma, Scitamina, Orchidea, Amentacea, \&c., sixty-seven in number, including his four cryptogamic orders), but without definition or arrangement. In his later years, he was unable to accomplish any thing more. The difficult problem was taken up by Linnæus's contemporary and correspondent, Bernard de Jussieu, who planted the botanic garden at Trianon with plants grouped into natural orders, but published nothing. His pupil, Adanson, who when a young man lived for several years in Senegal, and who was as remarkable for eccentricity as for erudition and ability, published in 1763, in his Familles des Plantes, the first complete system of natural orders. But he seems to have taken little from his teacher, and with all his genius to have contributed little to the advancement of the natural system.

689. Antoine Laurent de Jussieu, nephew of Bernard, has been called the founder of the natural system of botany, and to him more than to any other one person this honor may be ascribed. In his Genera Plantarum secundum Ordines Naturales disposita, 1789 , natural orders of plants, one hundred 
in number, were first established and defined by proper characters, and nearly all known genera arranged under them. His primary division of the Vegetable kingdom was into Acotyledones, Monocotyledones, and Dicotyledones, adopted from Ray, with a change which was no improvement. For his Acotyledones, the Cryptogamia of Linnæus, are the "plants without flowers" of Ray : they are, to be sure, destitute of cotyledons (though not in the manner of Cuscuta), because destitute of embryo altogether. The Acotyledones forming his first class, Jussieu divided the Monocotyledones into three classes upon single and artificial characters, namely upon the insertion of the stamens, whether hypogynous, perigynous, or epigynous ; and the Dicotyledones, into eleven classes on similar characters, preceded by a division into Apetala, Monopetala, Polypetala, and Diclines irregulares, i. e. first upon the character of the perianth, then upon the insertion of the stamens or in Monopetalæ of the corolla. The following is the scheme:-

Acotyledones . . . . . . . . . . . . . CuAss I

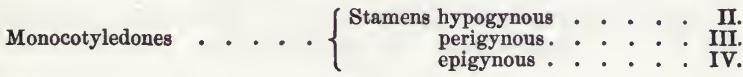

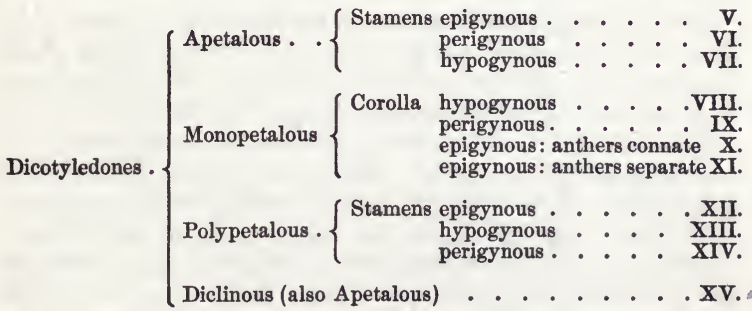

690. Auguste Pyrame DeCandolle was the next great systematist. Reversing the order of Jussieu, who proceeded from the lower or simpler to the higher or more complex forms, DeCandolle began with the latter, the phænogamous or flowering plants, and with those having typically complete flowers. On account of its convenience and the greater facilities for studying the higher plants, this order has been commonly followed ever since. His primary division on anatomical structure, into Vascular and Cellular plants, was a backward step, confusing a portion of the lower series with the higher; and the duplicate names of Exogena and Endogena, appended to Dicotyledoneæ and Monoco- 
tyledoneæ, as it now appears should have been omitted. The grades of the Candollean system superior to the orders, in their final form, are mainly these :-

Div. I. VASCULAR (more properly PHANOGAMOUS) PLANTS.

Chass I. Dicotyledonous or Exogenous.

Subclass I. Thalamiflorous : petals (distinct) and stamens on the torus, i. e. free.

II. CaLYciflorous : petals (distinct or coalescent) and stamens adnate to the calyx.

III. Corolliflorous : petals (mostly coalescent) not adnate to calyx, bearing the stamens.

IV. MoNochlamydeods: petals wanting.

Class II. Monocotyledonous or Endogenous. (No subclasses.)

Div. II. CELLULAR (more properly CRYPTOGAMOUS) PLANTS.

Cuass I. Ethrogamous: with sexual apparatus, and Vascular tissue. (Equisetacea-Filices.)

Only cellular tissue. (Musci and Hepatice.)

Class II. Amprigamous : destitute of sexual organs and of other than cellular tissue. (Lichenes, Fungi, Algae.)

691. Cryptogamous plants of all orders are now known to be provided with sexes; and the Jussiæan divisions of the Dicotyledones into Apetala (including Diclines), Monopetala, and Polypetala, are generally preferred to those of DeCandolle. Into the present views of the classification of the Cryptogamia it is unnecessary here to enter. Their general arrangement into classes, \&c., is not yet well settled, and the whole taxonomy of the lower Cryptogams is at present in a state of transition.

692. John Lindley in successive attempts (between 1830 and $1845)$ variously modified, and in some few respects improved, the Candollean arrangement. But, as neither his groupings of the natural orders nor the new classes which he adopted have been approved, his schemes need not be here presented. He must be credited, however, with the first attempt to carry into effect a suggestion made by Brown, that the orders should themselves be disposed as far as possible into superior and strictly natural groups. In Lindley's first attempt, such groups of two grades were proposed, the lower called nixus (tendencies), the higher cohorts. In his later and largest work, The Vegetable Kingdom, these were reduced to one, and the name of alliance was coined. But this word has no good Latin equivalent, and the term cohort (cohors) is preferred. 
693. Robert Brown, next to Jussieu, did more than any other botanist for the proper establishment and correct characterization of natural orders. Having in the year 1827 published his discovery of the gymnospermy of Coniferæ and Cycadaceæ, it was in Lindley's works that this was first turned to proper systematic account by dividing the class of Dicotyledones into two subclasses, the Angiosperma and the Gymnosperma. The latter has been elevated by the vegetable palæontologists to the rank of a class.

694. Stephen Ladislaus Endlicher, of Vienna, a contemporary of Lindley, of less botanical genius, but of great erudition and aptness for classification, brought out his complete Grenera Plantarum secundum Ordines Naturales disposita, between the years 1836 and 1840. This elaborate work follows that of its predecessor, Jussieu, in beginning with the lower series of plants and ending with the higher. Its primary division is into two regions: 1. Thallophyta, plants without proper axis of growth (developing upward as stem and downward as root), no other tissue than parenchyma, and (as was thought) no proper sexes. This answers to the lower or Amphigamous Cellular plants of DeCandolle. 2. Cormophyta, plants with an axis (stem and root), with foliage, \&c. The Cormophyta, or plants of the higher region, Endlicher divided into three great sections: 1. Acrobrya, answering to the higher \&theogamous Cryptogamia of DeCandolle, with which was wrongly associated a group of rootparasitic flowering plants (the Rhizantheæ) which were fancied to bear spores instead of embryo in their seed; 2. Amphibrya, which answer to Monocotyledones; and, 3. Acramphibrya, which answer to Dicotyledons. These last contain five cohorts: 1 . Gymnospermea; 2. Apetala; 3. Gamopetala (the Monopetalæ of Jussieu better named); 4. Dialypetala (the Polypetalæ of Jussieu, \&c.). The cohort in Endlicher's classification, it will be seen, is a higher grade than that to which this name was applied by Lindley in the more recent use. For the latter, $i . e$. for the grade between these and the order, Endlicher employe $i$ the name of class.

695. Finally, the Genera Plantarum, now in course of publication by George Bentham and Joseph Dalton Hooker, adopts in a general way the Candollean sequence of orders, with various emendations ; divides the class of Dicotyledons into two subclasses, Angiospermous and Gymnospermous; the former into the Polypetalous, Gamopetalous, and Apetalous divisions; and the first of these into the Thalamiflorous, Disciflorous, and Calyciflorous "series" (the middle one composed of the latter part 
of DeCandolle's Thalamifloræ with some of his Calycifloræ); and under these the orders are arranged in cohorts, - fifteen cohorts in the Polypetalæ, and ten under three "series" in the Gamopetalæ. The remainder of this particular classification has not yet appeared in print, although partly sketched by its authors. It will generally be adopted in this country, with some occasional minor modifications.

696. Various modifications have been from time to time proposed. One of the best of them in principle is that initiated by Adolphe Brongniart and adopted by many European botanists, which, recognizing that most apetalous flowers are reductions or degradations of polypetalous types, intercalates the Apetalæ or Monochlamydeæ among the Polypetalæ. But this has never yet been done in a satisfactory manner, or without sundering orders which should stand in contiguity.

697. It should be borne in mind that the natural system of botany is natural only in the constitution of its genera, tribes, orders, \&c., and in its grand divisions; that its cohorts and the like are as yet only tentative groupings; and that the putting together of any or all these parts in a system, and especially in a lineal order, necessary as a lineal arrangement is, must needs be largely artificial. So that even the best perfected arrangements must always fail to give of themselves more than an imperfect and considerably distorted reflection of the plan of the vegetable kingdom, or eren of our knowledge of it. ${ }^{1}$

1 In the first place, the relationships of any group cannot always be rightly estimated before all its members are known and their whole structure understood; so that the views of botanists are liable to be modified with the discoveries of every year. The discovery of a single plant, or of a point of structure before misunderstood, has sometimes changed materially the position of a considerable group in the system, and minor alterations are continually made by our increasing knowledge. Then the groups which we recognize, and distinguish as genera, tribes, orders, \&c., are not always, and perhaps not generally, completely circumscribed in nature, as we are obliged to assume them to be in our classification. This might be expected from the nature of the case. For the naturalist's gronps, of whatever grade, are not realities, but ideas. Their consideration involves questions, not of things, between which absolute distinctions might be drawn, but of degrees of resemblance, which may be expected to present infinite gradations. Besides, although the grades of affinity among species are most various, if not wholly indefinite, the naturalist reduces them all to a few, and treats his genera, tribes, \&c., as equal units, or as distinguished by characters of about equal value throughout, - which is far from being the case. And in his works he is obliged to arrange the groups he recognizes in a lineal series; but each genus or order, \&c., is very often about equally related to three or four others: so that only a part of the relationship of plants can in any way be indicated by a lineal arrangement. 
698. Even the great classes cannot be arranged in a single line, beginning with the highest Phænogams and leaving the lowest in contiguity with the higher Cryptogams. The Dicotyledons take precedence of the Monocotyledons in rank. Yet a part of them, the Gymnosperms, are much the lowest of all known Phænogams as regards simplicity of floral structure; and through them only is a connection with the higher Cryptogams to be traced. The Monocotyledons stand upon an isolated side line, and have no such simplified representatives. In placing the latter class between the Dicotyledons and the Acrogens, the chain of affinities is widely sundered. If, yielding to a recent tendency, we raise the Gymnosperms to the rank of a class, and place it between the Monocotyledons and the Acrogens, then the much nearer relationship of Gymnosperms to Angiosperms through Gnetaceæ and Loranthaceæ is not respected. (606, \&c.)

699. Nor can the angiospermous Dicotyledons be disposed lineally according to rank. The apetalous and achlamydeous must be the lowest. Some are evidently reduced forms of Polypetalæ or even of Gamopetalæ : the greater part cannot without violence be thrust into their ranks. The Gamopetalæ, especially those with much floral adnation, should represent the highest type, the organs being at the same time complete and most differentiated from the foliar state. If a natural series could be formed, these would claim the highest place, with the Compositæ perhaps at their head. In the Candollean sequence, they occupy the middle; and the series begins, not without plausible reason, with orders having generally complete blossoms, and such as most freely and obviously manifest the homology of their organs with leaves, then rises to those of greater and greater combination and complexity, and ends with those plants which, with all their known relatives, are most degraded or simplified by abortions and suppressions of parts which are represented in the complete flower. These are low in structure, equally whether we regard them as reduced forms of higher types, or as forms which have never attained the full development and diversification which distinguish the nobler orders.

700. Actual classifications, in their leading features and in their extension to the cohorts, orders, \&c., must be studied in the systematic works where they are brought into use. In these are the applications of the principles which are here outlined. A separate volume of this text-book should illustrate the structure, relations, and most important products of the phænogamous natural orders, as another is to illustrate the 
cryptogamous orders. A synoptical view of the great divisions only, as at present received and named, is appended. Definitions and characters may be sought in the present and preceding chapters.

SERIES I. PHANOGAMOUS OR FLOWERING PLANTS.

Class I dicotyledons.

SUBCLASS I. ANGIOSPERMS.

Div. 1. Polypetalous.

Div. 2. Gamopetalous. (Monopetalous.)

Div 3. Apetalous.

SUBCLA8S II. GYMNOSPERMS.

Cuass II. MONOCOTYLEDONS.

Div. 1. SPadiceous.

Div. 2. Petaloideous.

Div. 3. Glumaceots.

SERIES II. CRYPTOGAMOUS OR FLOWERLESS PLANTS.

CuAss III. ACROGENS.

Div 1. Vascular. (Ferns and their allies.)

Div. 2. Cellular. (Mosses and Liverworts.)

Class IV. THALLOGENS OR THALLOPHYTES. 


\section{CHAP TER X.}

\section{PHYTOGRAPHY.}

\section{Section I. Nomenclature.}

701. Phytography is the department of botany which relates to the description of plants. This includes names and terms, also figures and signs, as well as characters and detailed descriptions. It comprises two sorts of names, one used to designate organs or modifications of organs, the other to distinguish plants or groups of plants. The former is Glossology or (to use the more common but less proper word) Terminology. The latter is properly Nomenclature.

702. Names of Plants were at first only generic names. The language of botany being Latin, and the plants which the old herbalists knew being mostly European, their scientific names were mainly adopted from the ancient Romans or, through Latin literature, from the Greeks. Ex. Quercus, Prunus, Rosa, Rubus, Trifolium; and of Latinized Greek names, Agrostis, Aristolochia, Colchicum, Melilotus. - To the classical names others were added from time to time; as, from the Latin, Bidens, Convallaria, Dentaria ; from the Greek, Anacardium, Glycyrrhiza, Loranthus, \&c. Some barbarous or outlandish names were early adopted, such as Alhagi from the Arabs, and Adhatoda and Nelumbo from India. These are mostly such as were or could be conformed to Latin; as Datura and Ribes from the Arabic, and later Thea and Coffaa. Of American aboriginal names, Hura, Guaiacum, and Yucca are examples. Some ancient names of plants commemorated distinguished men. Ex. Asclepias, Euphorbia, Lysimachia, Paonia. Tournefort and his contemporaries resumed this practice, and named plants in memory or in honor of distinguished botanists. Ex. Begonia, Bignonia, Casalpinia, Fuchsia, Gerardia, Lobelia, Lonicera, Magnolia.

703. When among plants of the same name or kind different species were known, these were distinguished by annexed epithets. For example, among the Pines there were: Pinus sylvestris, vulgaris; Pinus sylvestris, montana altera ; Pinus sylvestris, montana tertia; Pinus sylvestris maritima, conis firmiter ramis adharentibus ; Pinus maritima minor; Pinus maritima altera, \&c. 
And as the number of known species increased, so did the length of the phrases which were needed for their discrimination. These "differentiæ," thus used as specific names (the nomina specifica of Linnæus), became extremely cumbrous. It was about in the middle of his career that Linnæus suggested what he called trivial names (nomina trivialia) for the specific name, consisting of a single word; and in the Species Plantarum, in 1753, he carried this idea into full effect in Botany. The step was a simple one, but most important; and Linnæus himself, who generally did not underrate his services to science, seems hardly to have appreciated its practical value. ${ }^{1}$

704. The Binomial Nomenclature in Natural History, thus established, first separated the name of a plant or of an animal from its diagnosis, descriptive phrase, or character, and reduced the appellation to two words, the first that of its genus, the second that of its species. The generic name very nearly answers to the surname of a person, as Brown or Jones; the specific answers to the baptismal name, as John or James. Thus, Quercus alba is the botanical appellation of the White Oak; Quercus being that of the genus, and alba (white) that of a particular species; while the Red Oak is named Quercus rubra; the Scarlet Oak, Quercus coccinea; the Live Oak, Quercus virens; the Bur Oak, Quercus macrocarpa: Magnolia grandiflora is Large-flowered Magnolia ; M. macrophylla, Long-leaved Magnolia, and so on. The name of the genus is a substantive, or at least is a word taken as a substantive. That of a species is mostly an adjective adjunct, always following the generic name and in the same gender. ${ }^{2}$ This combination of generic and specific name is the name of the plant. ${ }^{8}$

705. By this system, not only is the name of the plant reduced to two words, but a comparatively moderate number of words serves for the complete designation of more than 120,000 plants, ${ }^{4}$

1 Moreover, he may be said to have adopted rather than originated the idea; for single-worded specific names were used half a century previous by Bachmann, alias Rivinus.

2 It is to be noted that the classical Latin names of trees are all feminine, therefore Quercus alba, Pinus rigida, \&c.

3 The name of a subgenus is sometimes written in between the two parts of the plant's name, as Prunus (Padus) Virginiana. This is the name of the plant and something more. In addition to the name of the species, that of the variety or even subvariety is sometimes added.

4 Alphonse DeCandolle several years ago estimated the known species of Flowering Plants at between 100,000 and 120,000 . The larger number may perhaps include the higher orders of the Flowerless series. In the present state of our knowledge of the lower orders of Cryptogams, no close estimate can be well formed of the actual number of species. 
in a manner which avoids confusion and need not overburden the memory. The generic part of the name is peculiar to each genus. The specific adjunct is not available for more than one species of the same genus, but may be used in any other genus. They are so widely thus employed that the number of specific may not exceed that of generic appellations.

706. To render this system of nomenclature most serviceable for the ready identification of such numbers of plants or groups, and for the clear and succinct presentation of or reference to what is known and recorded of them, rules are indispensable, and conformity to admitted rules is a manifest duty. Such rules were systematically formulated first by Linnæus, in his Fundamenta, Critica, and Philosophia Botanica, chiefly for generic names, some of them being of the nature of laws, some rather of recommendations. The most important of them remain in full force, while many of the more particular rules restricting the choice of names have been abandoned. The code was judiciously revised (in his Théorie Élémentaire) by DeCandolle "who was ruled by the idea of having the law of priority properly respected," was critically considered by Lindley in his Introduction to Botany, and has of late been reformulated by Alphonse DeCandolle under the sanction of a Botanical Congress neld at Paris in 1867.1

707. Rules for Naming Plants. These "should neither be arbitrary nor imposed by authority. They must be founded on considerations clear and forcible enough for every one to comprehend and be disposed to accept. The essential point in nomenclature is to avoid or to reject the use of forms or names

1 Lois de la Nomenclature Botanique, etc., Geneva and Paris, 1867. In the English edition, translated by Weddell : Laws of Botanical Nomenclature adopted by the International Botanical Congress held at Paris in August, 1867, together with an Historical Introduction and a Commentary, London, Reeve \& Co., 1868. The Laws, simply, were reprinted in the American Journal of Science and Arts, July, 1868. A few special points have been more recently discussed by various critics, especially in the Bulletin of the Botanical Society of France, and in that of the Royal Botanical Society of Belgium. See likewise American Journal of Science and Arts for September, 1870, and August, 1877 ; also, Bentham in Journal of the Linnean Society, xvii. 189-198, in which a just distinction is indicated between changing a well-established name and giving a new name to a new plant. See American Journal of Science for April, 1879.

Mention should also be made of Strickland's Report of a Committee on Nomenclature to the British Association in 1842, of Agassiz's classical preface on the nomenclature of genera in his Nomenclator Zoologicus, and of Dall's thorough and well-digested Report of the Committee on Zoological Nomen. clature to the American Association for the Advancement of Science, 1877, - these dealing primarily with zoology. 
that may create error or ambiguity, or throw confusion into science. Next in importance is the avoidance of any useless introduction of new names. Other considerations, such as absolute grammatical correctness, regularity or euphony of names, a more or less prevailing custom, respect for persons, \&c., notwithstanding their undeniable importance, are relatively accessory.' (Alph. DeCandolle, l. c.)

708. The following are universal rules in scientific nomenclature :-

1. Names must be in Latin or be Latinized. Those from the Greek (which are more and more abundant, owing to the facility of this language for compounding) take Latin form and termination. ${ }^{1}$ Those from modern or other than classical languages should at least have a Latin termination. ${ }^{2}$ Hybrid names, namely, those formed by the combination of two languages (at least of Latin and Greek), should not be made. ${ }^{8}$

2. For each plant or group there can be only one valid name, and that always the most ancient, if it is tenable.

3. Consequently, no new name should be given to an old plant or group, except for necessity. That a name may be bettered is no valid reason for changing it.

709. Names of Genera are substantive and singular, of one word; and the same name cannot be used for two genera of plants. ${ }^{4}$ They may be derived from any source whatever, from

1 Thus, words ending with the Greek os generally change it to us, and with on to $u m$. A rule not always observed; for while we have Epidendrum and Oxydendrum, Linnæus himself variously wrote Liriodendrum and Liriodendron, Rhododendrum and Rhododendron; and the Greek form now prevails.

2 In this as in other cases, some exceptions are well established by custom, but they ought not to be extended. The rule as to Latinization is restricted as respects orthography by the necessity of preserving modern commemorative names in a recognizable form.

8 But we cannot change numerous old names for this fault, such as convolvuloides, fumarioides, ranunculoides, and scirpoides (though they ought to have been convolvulina, ranunculina, and scirpina); and modern botanists have not scrupled to append the expressive and convenient Greek term -oides (signifying likeness) to generic names not of classical origin. Ex. abutiloides, bixoides, davallioides, fuchsioides, gentianoides, lobelioides, tournefortioides. In English, some hybrids will perpetuate themselves, as for instance terminology, centimetre, millimetre, beaurocracy, \&c.

4 Very many, indeed, are adjectives used as substantives, as Arenaria, Clavaria, Saponaria, Impatiens, Trientalis, and even Gloriosa, Mirabilis, \&c.

Some two-worded generic names anterior to Linnæus, such as Dens Leonis, Vitis Idrea, Bursa Pastoris, remain for sections and species, but not for genera. When two words are confluent into one, they are not objectionable, as Laurocerasus, Carlemania (commemorating Charles Leman, Carolus Lemanus), \&c. 
prominent or peculiar character or appearance, from localities, from the names of persons (especially of discoverers), from indigenous or vulgar names, or even from arbitrary combinations of letters. Unmeaning names, if not in principle the best, are never misleading. The main requisite is that they should be euphonious, not too long, and that they should be adaptable to the Latin tongue. Characteristic names, when possible, are among the best; such as Sanguinaria for an herb with red juice, Hamatoxylon for the Logwood tree, Lithospermum for a plant with stony seeds (or seeming seeds), Myosurus for a plant with gynœcium resembling the tail of a mouse. Names of this sort do not always hold out well ; for Chrysanthemum, so called from its golden yellow blossoms, now has many white-flowered species, Polygala is wholly destitute of milk, and many species of Convolvulus do not twine. Neat anagrams are not bad, such as Brown's Tellima for a genus nearly related to Mitella. Personal generic names are wholly proper when dedicated to botanists, especially to the discoverer of the plant, or to other naturalists, or to persons who have furthered botanical investigation or exploration. Ancient names of this kind have been mentioned, also some of those which commemorate the earlier botanists. (702.) At present, almost every devotee of the science is thus commemorated, from Linnæus and Jussieu downward. In forming such names, the name of the person, cleared of titles and accessory particles (thus Candollea, not Decandollea), takes the final $-a$ or $-i a$ and becomes feminine; and its orthography is preserved as far as possible, making only necessary concessions to euphony and to the genius of the Latin language. ${ }^{1}$

The Linnæan canon forbade the use of the same generic name in botany and zoology, - a rule now impossible to maintain. Perhaps we cannot prevent the duplication of phænogamous names in the lower Cryptogamia.

1 Thus, we may write Lescuria instead of Lesquereuxia, although Michauxia is the form for the genus dedicated to Michaux, however pronounced. The genus dedicated to Strangways is written Stranvoesia (although Strangwaysia might have been tolerable); to Andrzeiowsky, Andreoskia ; to Leeuwenhoek, Levenhookia (although the elder DeCandolle restored all the vowels), \&c. As specimens of overdone simplification, there is Gundelia, named for Gundelsheimer, and Goodenia, named for Bishop Goodenough, although Gundelsheimera would not in these days be objected to, and Goodenovia is faultless. Yet the names having been so introduced into the science should remain, fixity being of more importance than perfection. Mistaken orthography of the name itself may, however, be set right. Brown's Lechenaultia is Leschenaultia, Nuttall's Wisteria (named after Dr. Wistar) is Wistaria. The rule laid down in the code as drawn up by Alphonse DeCandolle is: "When a name is drawn from a modern language, it is to be maintained just as it was made, even in the case of the spelling having been misunder 
710. The etymology of a new genus should always be given. Of the Linnæan restrictions, one holds, viz. that the names of genera are not to end in -oides, as many of the older names did.

711. Names of Species are commonly and by preference adjectives, agreeing with the name of the genus, and expressive of some character, habit, mode or place of growth, time of flowering, or commemorating the discoverer, first describer, or some one otherwise connected with its history. Thus, in the genus Ranunculus, $R$. bulbosus is named from the bulb-like crown or base of the stem; $R$. acris, from the acridity of the juica; $R$. sceleratus (the accursed), in reference to the same property ; $R$. repens, from the creeping habit of the stems; $R$. pusillus, from general insignificance; $R$. aquatilis, from its growing in water; $R$. nivalis, from living near eternal snow; $R$. Pennsylvanicus, from country or State whence it was first made known to botanists; $R$. Bonplandianus, in honor of Bonpland, one of the discoverers; and so on. More commonly, when a discoverer or investigator of a species is commemorated in the name, this is a substantive, in the genitive, as Ranunculus Nuttallii, i. e. the Ranunculus of Nuttall, instead of $R$. Nuttallianus, the Nuttallian Ranunculus. Yet the latter form is preferred when the species is named in honor of some one who did not discover nor treat of it (which should seldom be); but this distinction is a custom rather than a rule, and the form of the commemorative name may be settled by euphony or convenience. In any case, the personal name should have a capital initial.

712. Many specific names are substantives, occasionally a common substantive, as Stellaria nemorum (of the groves), Convolvulus sepium (of the hedges), Cassia pumilio (the dwarf); more commonly it is a substantive proper name, and this usually an old generic name reduced to that of a species. Ex. Ranunculus Flammula, R. Thora, and R. Cymbalaria; also Lirio-

stood by the author, and justly deserving to be criticised." But this is somewhat too absolute, since it is allowed that obvious errors in the construction of names of Latin or Greek derivation may be corrected, provided the change does not affect the initial letter or syllable, and that no ancient names are to be disturbed.

The clause that forbids changes in the orthography of ancient names, even to make them classical, is a very proper one. The botanical Latin of Tournefort, Linnæus, Jussieu, and their contemporaries, has by prescription rights which botanists are bound to respect. Wherefore Pyrus is the botanical name of the pear-tree, notwithstanding the classical Pirus. So lovis, as a specific name for a smooth plant (and as distinguished from lěvis, a light or slight one), is fixed by long botanical use, although only levis is classical; and it is unnecessary to change Ranunculus acris to $R$. acer. 
dendron Tulipifera, Rhus Toxicodendron, Dictamnus Fraxinella. These proper specific names take a capital initial letter. ${ }^{1}$ Rarely such a name is in the genitive ; as Heterotheca Chrysopsidis, meaning a species of Heterotheca with the aspect of a Chrysopsis.

713. Specific names should be of a single word. Some few are compounded, as purpureo-caruleum; and some of ancient origin (once quasi-generic) are of two words. Ex. Panicum Crus galli, Capsella Bursa pastoris, Taraxacum Dens leonis.

714. A specific name cannot stand alone. It is nothing except as connected with the genus to which it pertains. A Japonica by itself is wholly meaningless. A plant is named by the mention of its generic appellation followed by the specific.

715. Names of Varieties. These are in all particulars like specific names. Many are specific names reduced to a lower rank. The varietal name is written after the specific, thus: Ranunculus Flammula, var. reptans, and $R$. aquatilis, var. trichophyllus. Varieties of low grade need not be named. They may be designated by numbers, or by the small letters of the Greek alphabet, $\alpha, \beta$, \&c. When the varieties are marked $\alpha$ and $\beta$, the first is supposed to be the type of the species, or both to be equally included in the common character. But when the $\alpha$ is not used, the varieties rank as deviations from the assumed type of the species. Varieties of cultivation, half-breeds or cross-breeds, and the like, should have only vernacular names, at least not Latin ones such as may be confounded with true botanical names.

716. Names of Hybrids are difficult to settle upon any complete system. When of unknown or uncertain parentage, they have been named in the manner of species, but distinguished by the sign $\times$ prefixed. Ex. $\times$ Salix capreola. Hybrids of known parentage are named by combining the names of the two parents, thus: $S$. purpureo $\times$ daphnoides, or $\times S$. purpureo-daphnoides, for a cross between S. purpurea and S. daphnoides, of which the first supplied the pollen to fertilize the second. The counterpart hybrid is $\times S$. daphnoideo-purpurea.

1 In respect to the initial of geographical specific names, being adjectives, such as Americana, Canadensis, Virginiana, Europaea, Anglica, usage governs, and this is divided. But the elder DeCandolle, who ruled in all such matters in the preceding generation, always employed the capital initial, and two generations of DeCandolle follow the example. Most English authors until recently and some continental ones adopt this usage; and it accords with the genius of the English language, in which we always write European, British, American, \&c., with a capital initial. Of late it is a usual practice to write such geographical specific names with a small initial. 
717. The Fixation and Precision of Names. The name of a plant is fixed by publication, and takes its date from the time when it is thus made known to botanists.

718. A genus or other group is published when its name and characters (or the differences between it and all other such groups) are printed in some book, journal, or other adequate vehicle of publication, which is placed on public sale, or in some equivalent way is distributed among or within the reach of botanists. A printed name without characters, and characters without name, do not amount to publication. ${ }^{1}$

719. A species is not named unless it has assigned to it both a generic and a specific name. It is not published until it is made known, by name and characters (or by name along with sufficient information as to its characteristics), in the manner aforesaid. (718.) Adequate distribution, among botanists and public herbaria, by sale or otherwise, of a collector's or distributor's specimens, accompanied by printed or autograph tickets, bearing the date of the sale or distribution (that is, publication by named Exsiccata in place of printed descriptions), is held to be tantamount to publication. ${ }^{2}$

720. Characters, references to date and place of publication, and the like, belong to bibliography or particular phytography, not to nomenclature; but proper identification of names requires that the name of the author and the time and medium of publication should be taken into account. Anterior to the binomial nomenclature, the botanical name of the common tall Buttercup was "Ranunculus pratensis erectus acris," according to Bauhin, in his Pinax, p. 179. Under the new nomenclature, which reduced the specific part of the plant's name to one word, this became Ranunculus acris in Linnæus, Species Plantarum (ed. 1), p. 554; and a brief character gave its distinctions. In later works it has been more fully described, in some illustrated by figures. The citation of these works arranged in chronological order (or in some order), with reference to volume, page, and in some cases figures, is the bibliography of the plant. ${ }^{8}$ A bot-

1 Names may be communicated, in manuscript or otherwise, by the propounder to an author who may make them known by publication; but the date of the genus or other group is that of actual publication.

2 This does not cover all the conditions of publication, since it does not specify the characters (and the same may be said of a published figure, with analyses); but, on the other hand, it conveys to the competent person receiving the same all this information and more: so that it should carry the rights of true publication as against any author to whom such names are or should be known. That is, such are not in the category of "unpublished names," which generally ought to be left untouched.

- For good êxamples of bibliography, see such detailed works as De- 
anist, in referring to this or any other plant, might cite any work which describes it, or none at all. Ranunculus acris by itself, as it happens, would lead to no ambiguity. Not so with many names. For the accurate indication of the species, it is generally needful, or highly convenient, to specify at least the name of the author who first published the adopted appellation. So we write Ranunculus acris, Linn., or L., the abbreviated name of Linnæus. $^{1}$ Here we have the name of the plant, and the bibliography reduced to its initial. To this, further citation and other references may be added or not, as the particular case requires. But, so far as citation or reference proceeds, it should simply state the history correctly and clearly.

721. When a species is said to be of Linnæus or DeCandolle or Bentham, it is simply meant that the adopted name of the plant (consisting of the generic and specific parts together) was first published by this author. Some other author may have named it differently, and even earlier. The earlier name may have been discarded because the specific portion of it was untenable, either on account of preoccupation or for other valid reasons. Or the later author may have differed from the earlier in his views, and have referred the plant to some other genus. As instances of the first, Euphorbia nemoralis, Darl., is a good species, first named by Darlington in his Flora Cestrica. But the name of Euphorbia nemoralis had already been applied to and was the recognized name of a different species of the south of Europe. Whereupon, as the North American species had no other trivial name, a new one had to be given to it; and it was named $E$. Darlingtonii, in honor of the discoverer and first describer. The common Milkweed of Atlantic North America was named by Linnæus Asclepias Syriaca. As this plant is not indigenous to any part of the Old World, and does not at all inhabit Syria, this trivial name is not merely faulty but false; so it was changed by Decaisne into A. Cornuti, in commemoration of an ante-Linnæan botanist who collected it in Canada and gave the first account and figure of it. As an instance of the second, take the pretty little vernal plant Anemone thalictroides, $L$., meaning an Anemone resembling a Thalictrum. When it was seen that the essential characters were rather those of Thalictrum, the plant was placed in the latter genus. This was first done in Michaux's Flora ; and so the accepted name is Thalictrum

Candolle's Systema Vegetabilium, and Sereno Watson's Bibliographical Index to North American Botany, in the Smithsonian Miscellaneous Collections.

1 For Abbreviations of Authors' Names, see 385. 
anemonoides, Michx., meaning an Anemone-like Thalictrum, and Michaux is the authority for this name. The names which for any reason are superseded become Synonyms. ${ }^{1}$ (755.)

722. A later author may circumscribe a species or a genus differently from the originator of the name. To a greater or less extent, this must continually happen in the course of time. But "Ricinus communis, Linn.," stands unmoved by the subsequent admission of various species (known or unknown to Linnæus) and the final reduction of all to one by a thorough monographer. So does Silene Gallica, Linn., although S. quinquevulnera, Linn., of the same date, is reduced to it. There is no sufficient reason for writing Myosotis, Brown, or Cynoglossum, Brown, because this author restricted the limits of these genera; nor to write Gilia, Benth., because Bentham vastly extended

1 The synonymy is an essential part of the bibliography or scientific history of a genus or species. But synonymous and admitted names ought to be kept distinct. Keeping this principle in view, - also the decisively affirmed doctrine of the founder of our nomenclature, that the specific name is a nullity apart from the generic (so that only the combination of the two makes the name of the plant, as truly as the constituent halves make the scissors), and bearing in mind the fundamental importance and absoluteness of the rule that no new names ought to be made where there are tenable old ones, - the student need not be misled by the confusing (however specious) innovation countenanced by many zoologists and some botanists, and which has of late years been very fully discussed.

The true rule is: "For the indication of the name or names of any group to be accurate and complete, it is necessary to quote the author who first published the name or combination of names in question." (A. DC.) Thus, Leontice thalictroides, Linn., fulfils the condition, except where a reference to the work as well as the name of the originator of the name is demanded. Then the citation would continue, "Spec. Pl. 312," and might be further extended. In the Flora of Michaux, this plant was treated as distinct from Leontice in genus; and some botanists adopted this view, while others of equal authority did not. Those who adopt Michaux's genus name the plant Caulophylum thalictroides, Michx.

Now some naturalists quote for the species the author who originated the trivial appellation even when transferred to another genus. They would adopt the genus Caulophyllum, yet write: Caulophyllum thalictroides, Linn. Or else they would avoid direct falsification of the facts by adding (sp.), this being explained to mean that the specific part of the name only was given by Linnæus. Then, as this omits all mention of the original generic part of the name, others add this in a parenthesis, and write: "Caulophyllum thalictroides (Linn. sub Leontice) Michx.," or "Caulophyllum (Michx.) thalictroides, Linn. sub Leontice," or "Caulophyllum (Leontice, Linn.) thalictroides, Michx." All such endeavors to mix synonymy with nomenclature appear to be faulty in principle and unwieldy in practice. In the most abbreviated form, they state that which is not true : in the others, they impair the simplicity and brevity of the binomial nomenclature. It is all but certain that, if the genus Caulophyllum had been published in the lifetime of Linnæus, he would not have adopted it 
the comprehension of this genus. Yet in their proper place such changes may be indicated by " pro parte," or "char. mutatis," "excl. sp.," and the like, - useful qualifying statements, but no part of the name.

723. Exactness requires that when a group is changed from a higher to a lower rank, or the opposite, the name of the author who made the change should be quoted. ${ }^{1}$ He alone is responsible for it. But this rule has only recently been strictly observed.

724. In transferring a species from one genus to another, its specific name must be preserved (with alteration of the gender, if need be), unless there is cogent reason to the contrary. It must necessarily be changed when there is already in that genus a species of the same name; and then synonymous names of the transferred species have their claim in order of date. But whatever name is first employed under the accepted genus, being unobjectionable, should hold, even against an older unobjectionable one coming from a wrong genus. This is an application of the stringent rule that no needless names should be created."

1 Thus, Potentilla Canadensis, L., var. simplex, Torr. \& Gray, and not of Michaux, for it is the species P. simplex, Michx. Geum, subgen. Stylipus. Torr.\& Gray, not of Raf., for it is the genus Stylipus of Rafinesque, who neither made the subgenus nor approved it. So, also, for the genus Laburnum we write "Laburnum, Griseb.;" for even if it exactly corresponded with Cytisus sect. Laburnum of DeCandolle, the latter is not a group of equivalent rank.

But, as to genera and subgenera, this precision should not be insisted on for times quite anterior to the recognition of such rules and of their need. Spergularia began with Persoon as a subgenus in the year 1805, and this date has been assigned to the genus, although it was taken up as such only in 1819 by Presl and in 1824 by Bartling.

2 Thus, in the case of an older specific name being known, as that of Chilopsis saligna, Don, recognized as Bignonia linearis, Cav., though Don ought to have adopted the latter trivial name, yet as he did not (and the rule was not then really in force as now), there was no need for the introduction of a third name, Chilopsis linearis, DC. "So, again, an Indian Grass was first named and described by Willdenow as Coix arundinacea, then named by Roxburgh as Coix barbata, and entered in Sprengel's Systema with Willdenow's character as Coix Konigii. All these names were defective as referring to a wrong genus. Brown corrected the error by creating the new genus Chionachne, and selected Roxburgh's specific name as the one most generally known and the least liable to misinterpretation; and Brown's Chionachne barbata is therefore the first correct name; for which Thwaites afterwards substituted Chionachne Koenigii, an entirely new and useless name, which falls by the law of priority. It should be well borne in mind that every new name coined for an old plant, without affording any aid to science, is only an additional impediment." Bentham (Notes on Euphorbiaceæ, in Jour. Linn. Society, xvii. 197, 198, November, 1878). The following 
725. Names of Subgenera or of other sections of genera are like those of genera; indeed very many of them, and the most fitting, are old generic names which have been comprehended in the genus by reduction. Unlike genera and higher groups, however, sections, when of Greek derivation, may properly take the termination in -oides, ${ }^{1}$ and the typical section may bear the name of the genus with the prefix $E u .^{2}$ Sections need not be named at all, and only those of comparatively high rank should

is a farther extract from the same protest against the practice "of creating a new name in order to combine an old specific with a new generic one:" "In Ferns, the wanton multiplication of ill-defined or undefinable genera, according to the varied fancies of special botanists, has had the effect of placing the same species successively in several, sometimes seven or eight, different genera ; and it is proposed to maintain for the specific appellation the right of priority, not only in the genus alone in which it is placed, but in the whole of the genera to which, rightly or wrongly, it has been referred. This has been carried to such an extent as to give to the specific name a general substantive aspect, as if the generic ones were mere adjuncts, a serious encroachment on the beautiful simplicity of the Linnæan nomenclature; and it is to be feared that there is a tendency in that direction in phænogamic botany. When a botanist dismembers an old genus, the rule requires that he should strictly preserve the old specific names in his new genera; and, when he has wantonly and knowingly neglected this rule, it may be right to correct him. But where a botanist has established what he believes to be a new species, and has therefore given it a new name, the changing of this name after it has got into general circulation, because it has been discovered that some other botanist had previously published it in a wrong genus, is only adding a synonym without any advantage whatever, and is not even restoring an old name; for the specific adjective is not of itself the name of a plant. ... A generic name is sufficiently indicated by one substantive; for no two genera in the regetable kingdom are allowed to have the same name; but for a species the combination of substantive and adjective is absolutely necessary, the two-worded specific name is one and indivisible; and combining the substantive of one with the adjective of another is not preserving either of them, but creates an absolutely new name, which ought not to stand unless the previous ones were vicious in themselves, or preoccupied, or referred to a wrong genus. It is probably from not perceiving the difference between making and changing a name that the practice objected to has been adopted by some of the first among recent botanists." Bentham, l. c.

1 A genus could not properly have one of its sections called by its own name with the addition of -oides or -opsis, as Asteroides or Asteropsis, for it is senseless to declare that an Aster resembles an Aster; but sectional names of this composition may be excellent for sections of other genera, as expressing analogy or resemblance. Latin generic names used for sectional ones properly take the addition of ella, or -ina, or -astrum.

${ }_{2}^{2}$ The prefix $E_{u}$ (Greek for much, very, or true), prefixed to a generic name of Greek origin, is the proper designation of the typical section of that genus, meaning the group which should bear the generic name if such genus were divided. The rule against hybrid names should in strictness exclude this prefix from Latin names, but it has not always done sa. 
have substantive names. Designations, however, are convenient for lower sections; and the name of a leading species may be used, in the plural; as Aster, section Amelli, and sect. Concinni. Subgenera need not agree in gender with the genus they belong to. When written with the name of the plant, the subgeneric name is parenthetically inserted between the generic and specific appellation. Ex. Pyrus (Malus) coronaria.

726. Names of Tribes, Orders, \&c. The names of all groups superior to genera are adjectives plural, and with few exceptions are the names of genera lengthened by some adjective termination. Ex. From Rosa, Rosea, Rosacea, Rosales; from Myrtus, Myrtea, Myrtacea, Myrtales ; from Berberis, Berberidea ; from Tamarix, Tamaricinea; from Salix, Salicea, Salicinea. The substantive Planta being understood, the groups are Roseous, or Rosaceous, or Rosal plants, \&c.

727. Tribal Names, and names of whatever grade between genera and orders, are formed by adding to the root of a generic name a final -ea. Ex. Rosea, Phaseolea, Antirrhinea, Oxalidea, \&c. Some subtribes take the name of the tribe with the prefix Eu, as Euphaseolea for that subtribe of the tribe Phaseoleæ which comprises the representative genus Phaseolus. Tribal names may take the same prefix, as Eucasalpinea for the tribe of the suborder Cæsalpineæ which contains the typical genus Cæsalpinia.

728. Ordinal Names are formed in the same way, but with a preference for certain terminations which may denote their rank, especially that of -acea, - as Rosacea, Myrtacea, Cucurbitacea, meaning Rosaceous, Myrtaceous, and Cucurbitaceous plants.

729. The names of what we now call natural orders, as sketched or adopted by Linnæus, were mostly descriptive, such as Ensata, Spathacea, Coronaria, Papilionacea, Conifera, Amentacea, Umbellata; but a few took their names from genera, as Orchidea, Liliacea. Jussieu, with whom the system of natural orders properly began, had no suborders, tribes, or any such gradation of groups to deal with. His one hundred ordinal names are some of them of the descriptive kind, as several of the above, also Leguminosa, Corymbifera, \&c. But the greater part are simply plurals of generic names, such as Asparagi, Junci, Lilia, Musa, Orchides, Lauri, Convolvuli, Erica, Acera, Cacti. To a few was given the lengthened termination in -ea, as Polygonea, Solanea, Berberidea, Caryophyllea ; to some, the termination in -acea, as in Cichoracea, Campanulacea, Rubiacea, Ranunculacea, Malvacea, Tiliacea, Cucurbitacea. Subsequent authors have necessarily changed all names which were plurals of gen- 
era ; and the strongly prevalent tendency has been to give the termination in -acea to all such ordinal names, and to restrict this termination to orders. Lindley insisted upon making this an absolute rule even for names not formed from generic appellations; but this will not be adopted.

730. In the first place, several large orders which have been known from the first by such characteristic names as Cruciferce, Leguminosa (and its suborder Papilionacea), Guttifera, Umbellifera, Composita, Labiata, Cupulifera, and Conifera, also Palmea and Graminea, Filices, and even Aroidea and Ficoidea, will retain these appellations; but no new ones of the kind will be made.

731. Also, names formed from genera which do not well take the termination in -acea may be allowed as orders to retain their natural form in -inea, -idea, -ariea, and the like. Ex. Tamariscinea, Salicinea, Scrophularinea, Berberidea, Lentibulariea. We may prefer for the sake of uniformity to write Salicacea, Berberidacea, Lentibulariacea, and Scrophulariacea (as we should write Violacea), but this form cannot be insisted on. On the other hand, a termination in -acea has been allowed in the names of certain tribes to avoid excessive iteration of vowels. Thus, for the tribe of which Vernonia is the leading genus, authors write Vernoniacea, to avoid Vernoniea, which ends with four vowels. Spiræa and Staphylea are the types of tribes, for which the names, if they followed the rule, would be Spirceer and Staphyleer, ending one in five the other in four consecutive vowels. Some avoid this by writing Staphyleacea and Spircacea. Others write Staphylea, but this is only the plural of the generic name.

732. A few orders or other groups took their names long ago from superseded generic names. Ex. Caryophyllacea or Caryophyllea, Onagracea or Onagrariea, and Lentibulariea.

733. Names of Cohorts are distinguished by the termination in -ales. This was proposed by Lindley, and is adopted by Bentham and Hooker in the Genera Plantarum. Ex. Ranales, Parietales, Malvales, Rosales, Passiflorales, \&c., most of them founded on the names of representative genera and orders. Euphony requires some to take other terminations. Ex. Polygalina, Caryophylina.

734. Names of Classes and other great divisions are plurals, either adjective or adjective nouns, expressive of the leading character. Ex. Polypetala, Gamopetala, Apetala; Angiosperma and Gymnosperma; Dicotyledones and Monocotyledones. The names of the two great series or sub-kingdoms, following the analogy of the Linnæan classes, end in -ia, and are Phanogamia, or Phanerogamia, and Cryptogamia. 


\section{Section II. Glossology or Terminologr. ${ }^{1}$}

735. This is nomenclature as applied to organs or parts and their modifications. The actual botanical terminology owes its excellence in the first place to Linnæus, and then to DeCandolle. The Théorie Élémentaire of A. P. DeCandolle (the first edition of which was published in 1813) is still classical authority, and until recently has received few additions as regards terms need ful in phænogamous botany.

736. The fundamental rule is that each organ or part shall have a substantive name, and that modifications of organs shall be designated by adjective terms. These names or terms should be as precise as possible : each object ought to be known by only one name, yet synonyms are unavoidable; and no term ought to be used with two different meanings. The word flower, for instance, must not be used for a cluster of flowers, however it may imitate the appearance of one, nor for the corolla or other portions of a flower. Still, some terms have to be used in two or more senses, to be determined only by the connection, or else as having both a special and a more general meaning. Leaf ( folium) is a notable instance. A bract, to go no farther, is a sort of leaf; and the imperfect stamens of a Catalpa-flower and Pentstemon are stamens, although likewise called staminodia: these are liable to be called sometimes by one, sometimes by the other name. But, however frequent such ambiguities may be in morphological treatment, they are usually avoidable in descriptive botany, in which terms are held to their more special or particular sense. Yet no rule can absolutely determine whether leaf or bract, bract or bractlet, is the proper term in many cases. Moreover, substantive names must also be applied to certain mere modifications of the same organ. In the same family, a simple carpel, differently modified in fruiting, is an akene in a Ranunculus, a follicle in Aquilegia, a berry in Hydrastis and Actæa; while in another family an additional line of dehiscence makes it a legume. Moreover, in this latter family it is called a legume when it is not dehiscent at all, and even when it becomes a drupe! Arbitrary rules cannot absolutely fix technical any more than ordinary language.

737. Experience and judgment must determine what modifcations of organs should be regarded as a kind, and bear sub-

1 Although the former is the better name, the latter is well established in use as an English word, and perhaps it need not be objected to, inasmuch as the Latin terminus comes from the Greek réppa, of the same meaning. 
stantive instead of merely adjective names. But the former should not be unnecessarily multiplied.

738. The classical language of scientific botany being Latin, all the organs of plants and their principal diversities are designated by a Latin or Latinized name. Modern languages have also their own names and terms. Greatly to its advantage, English botanical terminology has adopted and incorporated terms from the Latin and Greek, with slight changes, not obscuring the identity, thus securing all their precision, and rendering the simple botanical Latin of descriptions of easy acquisition to the English student.

739. In a text-book like this, the principal names and terms applied to organs and their leading modifications, as also those which relate to their action (physiological terms), or to our study of them (didactic terms, such as phytography, phyllotaxy, glossology), are defined and illustrated in course. There remain the more numerous and varied characteristic terms, chiefly adjectives, applicable to more than one or to all organs, and which compose the greater part of glossology. These, which DeCandolle arranged systematically with much elaboration, may best be reached by a glossary or dictionary, such as that at the end of this volume, which comprises the substantive terms likewise.

740. From characteristic adjective terms are derived the greater number of specific names of plants; of which, therefore, the glossary may elucidate the meaning.

741. Capable as the existing system is, it cannot in single words define all observed forms and grades, nor well avoid various ambiguities of meaning. Some defects of the first kind are remedied by combining with a hyphen two congruous terms to denote an intermediate state. Ex. ovato-lanceolatus, or ovatelanceolate, for an outline between the two. Also a term may be qualified by the prefix $s u b$, in the sense of somewhat, as in $s u b$ rotundus, subcordatus (somewhat round or slightly heart-shaped), or diminutives (such as integriusculus), or superlatives (integerrimus) or other strengthened forms (such as perangustus) may be employed. Among terms of more than one form of meaning are such as calycinus, which may mean, according to the context, pertaining to the calyx, or of the appearance of calyx ; cymosus may mean in cymes, or bearing cymes, or in the manner of a cyme; and paleaceus may mean provided or beset with chaff, or resembling chaff in texture. Often the form of the word should distinguish the sense; as foliatus, furnished with leaves, foliosus, with abundance of leaves, while foliaceus may mean either bearing leaves, or properly of leaf-like texture or appearance. 
742. Absence of an organ or quality may be expressed by means of a prefix with privative signification, as indehiscent, not dehiscent, exannulate, destitute of a ring, apetalous, without petals. But the Greek privative $\alpha$ should not be prefixed to Latin words, nor the Latin sub to terms taken from the Greek.

743. When the Latin preposition $o b$ is prefixed to an adjective term, it means obversely ; thus obcordatus is cordate inversed, that is, the broader end with its notch at the apex (instead of the base) of the leaf or other plane organ.

\section{Section III. Description.}

744. Under this head may be conveniently comprised all that relates to the form of the exposition, in botanical terms, of the differences by which the species and groups of plants are distinguished and recorded, the structure exemplified, and the history or bibliography indicated in systematic works or writings. Linnæus, in the Philosophia Botanica, treated these topics under the head of "Adumbrationes."

745. Descriptions may be full and general, comprising an account of all that is known of the structure and conformation of a plant or group, or rather all that is deemed worth recording, or they may be restricted to what is thought most important. In the former, the description is independent of all relative knowledge, or takes no notice of relationship to other plants or groups. The latter intends to portray the species or group in its relations to others, and to indicate the differences solely. Exhaustive descriptions of the former kind are seldom drawn up, but partial or supplementary ones are common. Descriptions of the latter kind, when reduced to what is essential or differential, are termed Characters, or the Character, of the group so described. There are all gradations in practice between characters and descriptions; but the distinction should be maintained.

746. Characters are specific, generic, ordinal, \&c. They are the differentia, or marks which distinguish a group from any related group of the same rank with which it may properly be compared. According to the occasion and purpose, they may specify only the fewest particulars which will serve as a diagnosis, or they may be extended to all the known constant differences between two or more related species, genera, orders, \&c. ${ }^{1}$

1 The former would answer to what have been termed differential characters, the latter to essential characters. Linnæus divided (generic) characters into factitious, essential, and natural; by the former denoting any difference which may effectively distinguish between any two groups brought arti- 
What is now termed the specific character was the specific name with Linnæus and his predecessors; what we call the specific, Linnæus called the trivial name. (703.)

747. Subordination of characters and the avoidance of vain repetitions require that as far as possible - regard being had to the form of the work - the ordinal character should contain only what is needful to circumscribe it, and to exhibit clearly its morphology ; that the characters of tribes or other divisions should not reassert any portion of the ordinal character, nor the generic character that of the superior groups; and so of the sections and subdivisions of all grades down to the species. Equally from the specific character should be excluded every thing which belongs to the generic, or is common to its relatives generally, or has been already specified in the section or its subdivisions. So, likewise, of the varieties under the species. This can be done only by so arranging the species as best to exhibit their relationships, that is, by bringing together or into proximity those of greatest resemblance in all respects, or in the more important respects. What these are, and how a just subordination of characters is to be apprehended, cannot be taught by rules, but must be learned by experience and from the critical study of the classical botanical works. No one is competent to describe new plants without such study, and without a clear conception of the position which a supposed new species should occupy in its genus, or a genus in its order.

748. Characters of orders, genera, and of all intermediate groups, are drawn almost without exception from the organs of fructification. In the description, these parts are mostly taken in order, beginning with the calyx and ending with the ovary, the fruit, seed, embryo. But, as to the orders, some writers prefer to preface these proper characters with a general sketch of those derived from the vegetation, which, albeit of less systematic value generally, are often very characteristic of particular families. Rubiaceæ, for example, are known by their opposite entire and simple leaves and intervening stipules, along with a few floral characters; Sarraceniaceæ, by tubular or pitcher-like leaves, along with a certain combination of a few other charac-

ficially together, as they might be in an artificial key, and as very anlike genera often were in his sexual system; by the second meaning the distinctions, the fewer the better, which will separate a group from its nearest relatives; by the third, all real marks of difference, $i . e$. all afforded by the organs of fructification, which only were taken into account for genera, \&c. Upon the construction of this natural character Linnæus prided himself, and justly. These are the characters in his Genera Plantarum. 
sers, and so on. Where brevity is aimed at, such external and obvious characters, followed by a few diagnostic marks, may practically take the place of a full enumeration of particulars, many of which may be common to other orders, though not in the same combination. Generic characters always commence with the calyx or most external of the floral organs and proceed to the ovary, thence to the fruit and seed, and end with subsidiary (but often no less diagnostic) particulars furnished by the vegetation and mode of growth.

749. Detailed descriptions of species, as distinguished from technical characters, commence with the root, and proceed in order to the stem, leaves and their parts or appendages, inflorescence, bracts, flowers, calyx, corolla, stamens, with filament, anther, and pollen, the disk, if any, gynœcium and its parts, ovules; then the fruit, seed, albumen, if any, embryo and its parts. But descriptions of this sort in most works and in ordinary cases are partial and subsidiary, comprising only certain details supplementary to or in amplification of the character of the species or genus. In condensed works, such description is wholly omitted, or is reduced to a few specifications which do not readily find their way into the character.

750. Specific characters usually follow the same order of enumeration, from root to seed, so far as the several organs are mentioned; and in Latin the phrases are expressed in the ablative case. But these particulars are often very conveniently prefaced by statements applying to the whole plant rather than to any one organ; and these are given in the nominative, and agree with the name in gender. ${ }^{1}$

751. Linnæus required that neither the essential character of a genus, nor a specific character (his nomen specificum), should exceed twelve words. Latin characters take fewer words than English. But this arbitrary rule is wholly out of date. Yet such characters should be brief and diagnostic : otherwise, their advantage is lost, and the distinction between them and descriplions disappears. In monographs and floras, the desirable brevity, or such as the case admits, is secured by proper grouping under a subordination of sections, subsections, and other subdivisions. ${ }^{2}$

1 Ex. "Nepeta Cataria: erecta, elata, cano-pubescens; foliis petiolatis," etc. In English, these adjectives without any substantive expressed will be seen to belong, as here, to "plant" or "herb" understood.

2 In the Synoptical Flora of North America, such a system of successive divisions is thoroughly carried out. And, if the specific characters are by no means short, it is mostly because nearly all separate descriptive matter is 
752. Punctuation. In proper descriptions, and in characters of genera and of higher groups, the account of each organ forms a separate sentence; and in Latin the terms are in the nominative case, except subsidiary portions, which are often thrown into the ablative. Excepting the latter part, the adjective terms are separated by commas. A specific character is always in one sentence. In Latin, its clauses are mainly in the ablative; and much diversity prevails as to the punctuation. ${ }^{1}$ Subgeneric and other sectional characters are commonly framed like those of

dispensed with: consequently various particulars are added to the character which do not strictly belong to it. In Bentham's great Flora Australiensis, also in English, specific characters are replaced by a characteristic synopsis at the head of each genus; and a terse description under each species completes the account. Moreover, Bentham, in recent works, such as his revision of the Genus Cassia, also that of the Mimosex, which have Latin characters, writes these in the nominative case and each member in a separate sentence, in the descriptive form, abandoning the long-used ablative form.

1 Linnæus employed only the comma in the specific character, along with a subsidiary use of the colon in a manner very unlike its ordinary use in punctuation, making it a point of less value than the comma. Thus,

"Chenopodidm AlbUM foliis rhomboideo-triangularibus erosis postice integris : summis oblongis, racemis erectis." Spec. Pl. ed. 2, 319.

Here, while the two main members of the sentence are separated by a comma, a subsidiary portion of the first member, relating to the uppermost leaves, is separated by a colon. Linnæus employed the colon in the same way in generic characters. This anomalous usage is now abandoned. But most authors have followed the Linnæan pattern in distinguishing the principal members by commas only, so that these become the only points in the specific character, however complicated that may be. Thus,

"Randnculds acris (Linn. Spec. 779) foliis pubescentibus subglabrisve palmato-partitis, lobis inciso-dentatis acutis, summis linearibus, caule erecto plurifloro subpubescente, pedunculis teretibus, calyce subvilloso, carpellis mucrone suberecto terminatis." DeCandolle, Prodromus, i. 36.

This is the punctuation throughout the Prodromus and in most contem. porary systematic works. Its imperfection is shown in the above-cited specimen. The primary members of the sentence, which characterize the leaves, stem, peduncles, calyx, and carpels, are distinguished by the same grade of punctuation which serves for the parts of the first member, viz. the lobes of the leaves, and for a still subordinate portion, viz. the form of the uppermost lobes. This want of subordination is to be remedied by the use of semicolons between the principal members, and of the commas only for the secondary ones, - a punctuation now not uncommon, and which is adopted in the recent first volume of the Monographiæ Phanerogamarum of the DeCandolles, which supplements the Prodromus. The portion of that volume contributed by Dr. Masters better exemplifies this than does the rest of the volume. For the latter sacrifices the advantage of the change by the insertion of commas between each adjective of a continuous ablative phrase (as, "Smilax laurifolia; limbis foliorum oblongis vel ovato-oblongis, coriaceis, 3-5-nerviis, subtus pallidioribus," etc.), where they are generally deemed 
genera. Or the members may be united in one sentence, but in that case the principal ones are best separated by colons.

753. Should a point intervene between the specific name and that of the author cited? The practice varies. But, if the name is Latin, the comma is superfluous ; for the abbreviated name of the author is supposed to be in the genitive, and to read thus : Ranunculus repens Linnæi. Still, since when the author's name is cited in full it is never written in the genitive, and since in English the comma is normally required, it seems on the whole proper to insert it.

754. In citations, the classical practice is to separate the references from each other and from the name by periods; thus, "Anemone cylindrica, Gray, Ann. N. Y. Lyc. 3. 221. Torr. \& Gray, Fl. 1. 113," ${ }^{1}$ \&c. It is becoming equally customary to separate the several citations by semicolons, thus bringing all the references under one name into one sentence. The bibliography of a species or group of species which a describer or other author has to refer to '(with more or less fulness, according to the form of his work) is to be sought partly under the admitted name, and partly in the

755. Synonymy. This includes all other than the admitted names. Ex. Hydropeltis of Michaux is a synonym of Brasenia of Schreber, the latter being the earlier published name. Nectris of Schreber is a synonym of Cabomba of Aublet, the latter having priority. Thalictrum anemonoides of Michaux has for synonyms Anemone thalictroides of Linnæus and of many subsequent authors who followed him in referring this ambiguous plant to Anemone (721); and also Syndesmon thalictroides of Hoffmannsegg and Anemonella thatictroides of Spach, who proposed to consider

superfluous. The preferable punctuation of the character above-quoted from the Prodromus would be

Ranunculus aCRis (Linn.) : foliis pubescentibus subglabrisve palmatopartitis, lobis inciso-dentatis acutis, summis linearibus; caule erecto plurifloro subpubescente; pedunculis teretibus; calyce subvilloso; carpellis mucrone suberecto terminatis.

The advantages of this style of punctuation will more and more appear, when applied to less simple cases. Commas between the ablative adjectives are superfluous and confusing.

In English characters, commas are required between the adjectives which follow the noun. Rightly to express the subordination of characters, the plan adopted in the Synoptical Flora of Nortl America is recommended; that is, with colons separating the principal members, scmicolons for subordinate and dependent ones, and commas between the adjectives of the same noun.

1 See Watson's Bibliographical Index to North American Botany (where this style is adopted) for a general model for the arrangement of synonymy and citations. 
it an intermediate genus between Thalictrum and Anemone. In systematic works, the specific character immediately follows the name, and generally forms a part of the same sentence; and is followed first by citations of authors who have adopted the name, and then by the synonymy, or as much of it as the plan of the work calls for. The synonymous names and the references under them should be cited in the order of their publication. But, to economize space, all the authorities for the same name are brought together into one sentence, and arranged according to their date. Also, where the synonymy is not elaborately displayed, the various synonyms of the same generic name are usually placed in consecutive order.

756. Iconography. The leading and most essential citation is that of the author by whom and the work in which a plant is named and described, and also the work in which it is best characterized. Among the characterizations, published figures hold a prominent place. The citation of these is an important part of the synonymy. The best botanical plates are those which give detailed analyses of the parts of the flower, fruit, and seed, displaying their structure.

757. Habitat and Station are recorded in a sentence or paragraph following the name, character, and synonymy of a species. The habitation is the place, district, or region at or within which the plant is known to be indigenous, or to grow spontaneously. The complete habitat is the geographical range. The station is the situation it affects, whether in water, in marshes, on shores, on hills or mountains, in forests, on open plains, \&c.

758. Discoverer, \&c. To the habitat and station of newly discovered, rare, or local plants should be appended the name of the discoverer or the collectors by whom the species has become known to science, at least when the plant is first published. Date of discovery should also then be indicated.

759. Time of Blossoming should be recorded, either the month or the season, to which may be added that of the maturity of the fruit. When the month or season is mentioned without farther explanation, flowering-time is intended. In a flora, this may sometimes be indicated under the genus for all the species. In the flora of an extensive region, and in respect to species of considerable range in latitude or longitude, the time of flowering differs so widely at the extremes of the geographical range that it cannot well be specified except in general terms, as spring, summer, autumn, \&c.

760. Etymology of Names. When a new generic name is published, its origin and meaning should always be given, if the 
nature of the publication will allow it. So likewise of species, except where the source or signification of the name is manifest. This is commonly the case as respects most characteristic specific names, and also those drawn from station, habitat, and the like.

761. Accentuation of Names. The pronunciation of botanical names is settled by the rules of Latin prosody. All that is usually attempted in those botanical works which take this into account is to mark the syllable upon which the principal accent falls. This in words of two syllables is always the first; in words of three or more syllables, either the penult (the last syllable but one) or the antepenult (next preceding syllable). When the penult is a long syllable, it takes the accent; when short, this recedes to the antepenult. The accentuation may accordingly be sufficiently indicated by marking the quantity of the penult, either long as in Erīca, or short as in Arbütus and Gladîôlus. Or else the accent may be marked by a proper sign, as Erica, Árbutus, Gladiolus. An endeavor has been made to represent the longer sound of the vowel by the grave accent-mark, as Erica, and the short by the acute, as Gladiolus. But this plan is encumbered with practical difficulties.

762. Abbreviations are required, both of the name of the author, when of more than one or two syllables, and of the titles of the works cited. There are also the customary abbreviations in the citation of volume, page, plate, \&c., in which there is nothing peculiar to botany.

763. The simple rule for the abbreviation of an author's name is to abridge it of all but the first syllable and the first letter of the following one (as Lam. for Lamarck, Hook. for Hooker), or the first two letters following the vowel when both are consonants (as Linn. for Linnæus, Juss. for Jussieu, Rich. for Richard). Sometimes more of the name must be given, in order to distinguish those beginning with the same syllable. So we write Michx. to prevent confusion of the name Michaux with that of Micheli, which, being the earlier, claims the abbreviation Mich., and Bertol. to distinguish Bertoloni from Bertero. Sometimes a much-used name of one syllable is abbreviated, as $B r$. (or $R$. $B r$.$) for Robert Brown. Initials or abbreviations of the bap-$ tismal name are needed to distinguish botanists of the same name; as P. Browne in distinction from Robert Brown, Ach. Rich., Adr. Juss., Alph. DC., to distinguish the younger from the older Richard, Jussieu, and DeCandolle. Or, where father and son, the abbreviation for the latter may be Juss. fil., Hook. fil., or Hook. f., \&c. Certain, but very few, well-known and eminent 
names are abbreviated to a sign; as L. for Linnæus, DC. for DeCandolle, HBK. for Humboldt, Bonpland, and Kunth, the latter too long after ordinary abbreviation. ${ }^{1}$ Care should be taken to affix the period by which abbreviations may be distinguished from full names, such as Don, Ker, Blytt.

764. Abbreviations of titles of works follow the same rules as those of names, or at least are in no wise peculiar in botany.

765. Abbreviations of the names of organs follow the same rule: Cal. for calyx, Cor. for corolla, Stam. for stamen or stamina, Pist. for pistillum or pistil, Fr. for fructus or fruit, $P e r$. for pericarpium or pericarp, Sem. for semen or seed, are the most common. Hab. for habitat or geographical station, Herb. for herbarium, Gen. for genus, Sp. or Spec. for species, Var. for variety, and the like, every one will understand. But some abbreviations which are common in botanical writings, at least those in Latin, may need explanation to the elementary student. A list of abbreviations is appended. See p. 390 .

766. Signs. Under this head might be ranked such abbreviations as $v . v$. for vidi vivam, $v$. s. for vidi siccam, to note that the writer has seen the plant, either alive or in a dried specimen; or, more particularly, $v$. s. s., when it is a spontaneous specimen that has been examined in a dried state, and $v . s . c$. , when it was a cultivated specimen; $v . v . c$. , when the living plant was seen in a garden only, and $v . v$. s., when the spontaneously growing plant was seen alive. There are also proper signs, of which the most common are those which indicate the sexes of blossoms, the duration of a plant, and the like. Also the interrogation point (?) used to express doubt; the exclamation point (!) to indicate the certainty that is given by the actual sight of an authentic original specimen. See p. 391.

767. The marks used to indicate the subordination of sections under a genus, or in the synoptical arrangement of genera, and the like, are not settled by any fixed rule. An approved arrangement is to employ the following marks in the given order, $\S *++=$. The first one, for sections of the highest order, takes numerals after the sign. Ex. $\S 1$, and so on. When

I As Alph. DeCandolle remarks, the proper abbreviation of the name he bears is Cand. But the form $D C$. was very early adopted by the first of the illustrious name, and has been continued for almost three quarters of a century. Alphonse DeCandolle would prefer to write it D.C., but has not adopted that mode, nor should we; for DC. and HBK. are convenient abbreviations reduced to signs. But such forms should not be increased. For ordinary names they would be unintelligible.

Names which are not too long, and of which an abbreviation by the ordinary rule is insufficient, such as Decaisne, should rather be written in full. 
such sections are followed by a substantive name, they are equivalent to subgenera. ${ }^{1}$ Ex. Phacelia, Juss., § 1. Euphacelia, i.e. the true or typical Phacelia; $\$ 2$. Cosmanthus, Gray, \&c. Sections next in rank to these are marked with asterisks, * for the first, $* *$ for the second, $* * *$ for the third one of the same cank. Divisions of these have the + prefixed; and so on in the same way. Still farther subdivisions may be marked by the small letters of the alphabet consecutively, $a, b, c$. When capital letters are used for division marks, it is mostly for those of a high grade.

768. Floras, Monographs, \&c. A systematic work describing in proper order the plants of a country or district is generally called a Flora. A Flora of a small district takes the diminutive name of a Florula. A universal work of the kind when it extends to the species is a System, Systema Vegetabilium or Systema Regni Vegetabilis. The latest completed Systema Vegetabilium Is that of Sprengel (1825-1828), in five octavo volumes, on a very condensed plan. A compendious Flora or Systema is often termed a Prodromus, literally meaning a forerunner or preliminary work. But, as even this is more than most botanists are able to complete, the name of Prodromus is now applied to works which are not intended to precede fuller ones by the same author. The principal work of this kind is the Prodromus Syst. Nat. Regni Vegetabilis, commenced by DeCandolle in the year 1824, continued by his son Alphonse DeCandolle (aided by various botanists) to its close in 1873, down to vol. xvii., or essentially twenty very compact octavo volumes, these carrying the work only through the great class of Dicotyledones. But the publication of the monocotyledonous orders has commenced in a series of Monographs (Monographice Phanerogamarum). A Monograph is a systematic account of all the species of a genus, order, or other detached group.

769. Specimens of botanical characters and descriptions, citations, \&c., illustrating this chapter, might be given here. But, for those in Latin, the classical works of DeCandolle and others, and for the genera those of Jussieu, Endlicher, Bentham and Hooker, may be taken as models. In English, those of the latter authors, and in the United States the better-known writings of the present author, especially the later ones, may be referred to.

1 DeCandolle in the Prodromus employed the word Sect. (Sectio) for what answers to subgenus or at least to the highest grade of sections; then $\S 1, \S 2$, \&c., for the next grade below subgenus ; and then the asterisk, and other marks. 
Section IV. Specimens; Directions for their Examination, Preservation, \&c.

770. Implements. Those necessary for the examination of phænogamous plants, Ferns, and the like, are a simple pocket lens, a simple dissecting microscope; also a sharp thin-bladed knife and some needles of various fineness, mounted in handles, for dissection.

771. For a single hand lens, one magnifying only from four to six diameters is the most useful. A doublet, or a parabolic lens of Tolles, of about an inch focus, is better, but much more expensive. The simple stage-microscope for dissection need have only two lenses (doublets or otherwise) with large field and good definition, one of an inch and the other of about half inch focal distance; and a glass stage of at least an inch and a half in diameter. A compound microscope is useful for all minute investigation, and is essential in the study of vegetable anatomy and of all lower cryptogamic botany.

772. For making thin slices, a razor is the best knife ; for dissection on the stage of the simple microscope, beside needles, small scalpels or some of the cutting instruments used by oculists are very convenient. But an expert hand is able to do almost every thing with a common knife or scalpel and a pair of mounted needles. Slender forceps are almost indispensable : those made for the use of dentists are the best.

773. Analysis. In the examination of an unknown plant with a view to its determination, its whole structure should be made out, so far as the materials allow, before a step is taken to ascertain its name and place in the system. In respect to the stem, its duration and consistence and its internal structure, whether exogenous or endogenous, are to be noted. As to the foliage, the venation and the phyllotaxy, also the presence or absence of stipules, are most important. The anthotaxy or inflorescence is to be examined and referred to its proper type. In the flower, the numerical plan and symmetry, its ground-plan and the nature of the deviations from the general or the family type, are to be considered; also the æstivation or arrangement of the parts in the bud, the character and extent of coalescence and adnation; the manner in which the anther is borne upon the filament, and its place and mode of dehiscence, \&c. Note also whether, when the blossom is hermaphrodite, the anthers and the stigmas mature at the same or at different periods. The placentation and the character and position of the ovules should be 
determined. Two sections of the flower should be made : one of them vertical and directly through the centre, in the manner of Fig. 336-341, - this will display the adnation, insertion, \&c., of all the parts ; the other transverse and through the middle of the ovary, also above the ovary when this is inferior, and if possible in the unopened but full-grown flower-bud; this, among other things, will bring to view the æstivation. (Fig. 351, 386, 398, \&c.) Not rarely fruit and seeds are to be had at the same time, or upon the same specimen, and these are equally to be investigated. In fresh seeds, even those of minute size, the embryo may almost always be extracted or brought to view under the microscope, either by tearing away the seed-coat with needles or by sections with a keen knife. When hard and dry, they have only to be soaked or slightly boiled.

774. Diagrams and also sketches of the parts should be made, such as those referred to in the foregoing paragraph. Such diagrams can be drawn by any one with a little practice; and they may be made to express the whole floral structure, even to the coalescence and adnation. ${ }^{1}$ But in the process of determination the student should beware of trusting wholly to his diagrams and sketches without direct verification.

775. Dried specimens, when well prepared and in sufficient abundance, in the hands of a skilled botanist are in most cases but little inferior to fresh ones. When needed, flowers, or clusters of blossoms, or fruits may be detached and prepared for examination and dissection by somewhat prolonged soaking in warm water or by a short immersion in boiling water. This restores flower-buds and small flowers and fruits, or their parts, to a condition not essentially unlike the living state. Consequently, the Herbarium or Hortus siccus of the botanist is to him more essential than the botanical garden, important as that may be.

776. Herborizing. ${ }^{2}$ The collector's outfit will essentially consist of a Vasculum or botanical box, a Portfolio, a Trovel, a pocket Lens, and a small but stoutly covered Note-book. Some use a' portfolio only, others the botanical box; but on a long excursion it is well to have both. The former is preferable in most cases, except when specimens are collected for the immediate use of a

1 See Eichler's Blüthendiagramme (Leipsic, 1872, 1878), an admirable work, which may serve as a model.

2 These articles, from paragraph 776 to 802 inclusive, were obligingly prepared, at the author's request, by Lyman H. Hoysrad, of Pine Plains, New York. They form an abstract or a new edition of a series of notes on the subject which were published in the Bulletin of the Torrey Botanical Club, in the year 1878. 
class. When well stocked with paper, it is of almost unlimited capacity ; and most plants of delicate texture (as many of the smaller aquatics, and those with fugaclous or delicate corollas) need to be consigned directly to the paper in which they are to be pressed, and to be kept meanwhile under some pressure.

777. The Vasculum is very useful for holding plants that are to be examined fresh, and for thick roots, large fruits, \&c. It is made of tin, and should be of oval-cylindrical shape, about 17 inches long and 4 by 6 inches wide, and provided with a light strap to throw over the shoulder. The lid opens nearly the whole length of one of the flat sides ( 15 by $4 \frac{1}{2}$ inches, with one fourth inch lap), is made to fit as close as possible, and fastens by a simple spring catch. When no portfolio is used, a larger box may be required. Plants may be kept fresh in such a box for many days. For a several-days excursion, when it is desirable to bring home a large number of fresh plants, a tin chest, made somewhat after the pattern of an old-fashioned trunk, will be found very convenient. It should be about 21 inches long, 10 inches wide, and 10 inches high to the top of the convex and hinged lid, which forms the whole top, and to which a handle is fitted.

778. A good form of Portfolio is made of two pieces of binder's board covered with enamel cloth, and fastening together with two long straps with buckles. Handles similar to those on a carpetbag may be attached for carrying. The usual size of portfolio is 18 by 12 inches, but $16 \frac{1}{2}$ by $11 \frac{1}{2}$ inches may be better, as there would then be little danger of making specimens of too great length for the herbarium. (784.) Or the back may be of soft leather, an inch or so in width, and a light strap and buckle at the front edge and at each end. The portfolio should contain a good quantity of folded sheets of thin unsized paper, similar to grocer's tea-paper, and of a size only a little smaller than the sides of the portfolio. Very thin manilla paper, or what is so called, is excellent for this purpose, being sufficiently bibulous and rather strong.

779. The specimens as soon as gathered should be laid neatly in these folded sheets (called specimen sheets), and kept under a moderate pressure in the portfolio. The sheets with the specimens are afterwards transferred to the home press, but the specimens should be left continuously in their sheets through all the changing of driers, until cured. Indeed, the specimens may well remain in the sheets after drying, until wanted for mounting or for exchanging. For fine specimens, the use of this specimen paper is very important. Many plants are so extremely delicate and sensitive that they will not bear the least handling without 
curling and shrivelling, unless thus enclosed: also without these sheets much time is lost in transferring small specimens one by one from one drier to another in the drying process.

780. For digging up roots, bulbs, \&c., a small and sharp pointed triangular Trowel or stout knife will answer. One of the best "diggers" is made from a large file. Let a blacksmith bend the lower half of the blade to a gentle curve, so that the point will be about an inch out of the true line. Grind off the teeth and re-temper the blade. The total length with handle, which is over one third, should be about twelve inches. A leather case may be made for convenience of carriage. The advantages of this strong tool are many. ${ }^{1}$

781. A Note-book should be carried upon every excursion, in which the station of rare plants, dates, colors, and various particulars which cannot be learned from the specimens, may be recorded on the spot, instead of being left to uncertain memory.

782. For most plants, the best time for collecting flowering specimens is in the morning, soon after the dew has disappeared. Vespertine flowers have to be secured earlier, or at nightfall.

783. Care should be taken to have the specimen of the proper size, neither too small nor too large, and to comprise all that is necessary for complete botanical illustration, - flowers, fruit, and leaves, both cauline and radical when possible. Inexperienced botanists suppose that a small sprig, containing a flower or two with a few leaves, will answer all purposes as a botanical specimen; but later he comes to know better, and also learns that the flower is only one of the component parts of a specimen, and not always the most important one. In various genera and orders, the fruit is the most distinguishing characteristic, as with the Potamogetons, the Cruciferæ, the Umbelliferæ, and the Cyperaceæ. With many plants the radical-leaves, with others the character of the subterranean stem, whether a rootstock, tuber, corm, or bulb, or of the root itself, whether annual, bien. nial, or perennial, becomes important. Consequently, all the organs have their value in an herbarium specimen, and each and all should receive due consideration from the botanist when col. lecting. Specimens may be often secured that exhibit both

1 [There is an English herborizing trowel of excellent quality, with blade six or eight inches long, less than two inches wide, the sides slightly incurved, the stout shank an inch and a quarter wide, and one sixth of an inch thick : this forms the whole back of the handle, the front of which is a piece of lignum vita riveted fast to the steel. It is nearly impossible to break it.] 
flowers and fruit in the same plant, or fruit may be frequently obtained from more advanced plants at the same time. If not, fruit must be collected later, as in case of shrubs and trees, of which generally only a branchlet with flowers, or with flowers and leaves, can be gathered first. But subsequently the fruit and mature leaves, should always be taken, if practicable, from the same individual as the flowers. Of diœcious shrubs or trees, like the Willows, each species should be represented by four pieces : first, the sterile and fertile catkins will have to be obtained, and the respective individuals marked, so that later corresponding twigs with mature leaves, stipules, and fruit may be gathered, and the specimens rightly matched.

784. A specimen should be so arranged as to be no larger when pressed than can be neatly mounted on the herbarium paper. A slender plant not over three feet in height should generally be preserved entire, root and all. This can be done by bending or partially breaking it at one, two, or three places, and doubling so that the sections will not rest upon each other in drying. If broken twice, it may be neatly arranged in the $\mathbf{N}$ form when put in portfolio. Very large herbaceous plants will have to be divided and the parts preserved separately, or, better, take a suitable portion of the upper stem, having leaves, flowers, and fruit, and a convenient part of the lower stem containing radical leaves and with it sufficient root to show whether the plant is an annual, biennial, or perennial. Thick stems, roots, tubers, bulbs, and the like, should be divided or thinned down with a knife, but in such a manner that the original shape can be easily made out.

785. Carices should be always collected when the fruit is fullgrown, but not so ripe as to fall away. So also should other Cyperaceæ; yet it is well to collect also earlier specimens of these in flower. Grasses, on the other hand, should generally be collected soon after they come into blossom. For when imature the spikelets in many species break up and fall away in drying. The culm, leaves, and root of Sedges and Grasses should be preserved, as well as the inflorescence. The root is no less important. Cespitose species should be so collected and preserved as to show the tufted character. The culms of most sedges and grasses act stubbornly when bent for arrangement in portfolio or press, and are not disposed to stay in place. This difficulty is promptly remedied by crushing with the teeth the angles made by the bending. Or these may be thrust through slits of paper. In drying Sedges and Grasses, very moderate pressure should be employed. 
786. Some aquatic plants (Algæ especially) are so soft and flaccid that, to secure them in their proper shape, they must be placed in clear water and floated out by inserting beneath them the paper on which they are to remain permanently, either the regular mounting paper, or a thinner white paper which when dry can be pasted on the herbarium sheet. If likely to adhere to the sheet or drier above them in the press, a piece of oiled or stearine paper may be laid directly on the specimens to prevent their sticking. Also viscous or glutinous plants which are liable to adhere to the sheets enclosing them may be sprinkled with Lycopodium spores, powdered soapstone, or some similar substance.

787. The name of the plant if known, but by all means the locality and date of collection, with any other descriptive remarks regarded necessary, should be written on a ticket or on the sheet when it is put into the press. Never omit to record the time and place of collection, as a specimen of unknown date and locality loses much of its value and interest.

788. Drying Specimens. The chief requisite for good herbarium specimens is the extraction of the moisture from the green plant as rapidly as possible under a pressure which obviates brittleness. This is to be affected by placing the thin sheets containing the specimens between layers of bibulous paper, callel driers, and applying moderately strong pressure to the pile. For driers nothing can be better than thick blotting paper, except that it is too expensive, and the same may be said of an English drying paper made for the purpose. Equally good driers are made of the thick and felt-like brown paper which, after saturation with coal-tar, is here largely used under the clapboards of wooden houses and under slate-roofing. It is a cheap material, and is to be obtained, cut into sheets of 18 by 12 inches. Or driers may be made of old newspapers or of any soft wrapping paper, cut or folded to the proper size, and stitched (very expeditiously by a sewing-machine), or joined by eyelet paper-fasteners at two corners, in packages of a dozen or more leaves to a drier. It is well to have a large supply of driers and specimen-sheets ready for use.

789. A half dozen or more pieces of thin boards, 18 inches long and 12 inches wide, should be provided. They are used at the top and the bottom of the pile when pressing, and also for dividing it into suitable sections, especially for separating the packages of plants which were put into press at different periods, and dividing up these packages themselves, if too large. For the plants dry better in small sections and with the pressure 
evenly distributed. Hence it is best to have these sections not over five or six inches in thickness, nor should the pile itself be carried too high, never exceeding two feet. Painted binders' boards may be used, instead of the common boards, to separate interior divisions. Some botanists use a kind of lattice made of two layers of thin strips or laths, crossing each other. This is said to allow free escape of the moisture by evaporation, and so to accelerate drying, as in the case of the wire press.

790. For giving pressure, various ways have been contrived. The Screw-press is convenient and compact, but objectionable, because it does not follow up the pressure as the plants shrink in drying. This objection does not apply to the Lever-presses, but they are usually unwieldy. Fortunately, one of the best forms of the drying-press, as well as the simplest and cheapest, is merely a board with weights placed on the top of the pile of specimens. Here the pressure is continuous, constantly following the shrinkage of the plants. The weight on a pile should vary from 25 to 100 pounds, according to the nature of the specimens and the quantity in the press. On an average, 60 pounds is sufficient for most plants. If much greater pressure is used, there is danger of crushing the more delicate parts of the specimen, and thereby impairing its scientific value. For weights, bars or masses of iron may be used, boxes filled with sand, stones, and the like."

791. Specimens brought home in the botanical box must be placed in such thin specimen-sheets as are used in portfolio. In putting plants in specimen-sheets, whether in portfolio or press, it is well to take some pains to spread out the specimens neatly ; for a little care now may save much later labor. However, with most species, any carelessness in this respect can be remedied at the first change of driers. But there are some plants, previously referred to, so peculiarly sensitive that whatever adjustment they receive must be given at the time they are first placed in their sheets.

792. Although plants can, if necessary, be kept fresh for several days in box or portfolio, on returning from a collecting trip they should be transferred to the home press as early as possible. In the transference, particular care should be taken to straighten out and remove all folds and crumpling of the leaves, petals, fronds, \&c., and to arrange the specimen as naturally as possible, so as to show the proper habit. Both sides of the flowers and leaves should be exhibited. Plants that were put directly into press should receive this special attention at the first change of driers, which on this account should be made within 
several hours afterwards. The stubbornness and elasticity, so troublesome in specimens when first put in, will then have mostly disappeared, and the whole specimen will be found sufficiently flaccid to have every part stay as arranged. If this first change is deferred longer than ten or twelve hours, the specimens of many species become too dry for making the alterations required. At this time small pieces of bibulous paper may be placed between leaves, or other portions of the plant which overlap, to prevent moulding or discoloration, and to hasten drying. It is well to change these fragments of paper with the driers for the first day or two: afterwards they may remain with no detriment.

793. To have the specimens retain their natural color and general appearance, they should be dried as rapidly as possible; and this result is best secured by frequent changing of the driers. These should be changed at least once a day for the first four or five days, and afterwards every other day, until the specimens are thoroughly dried. But a marked improvement in the specimens will result from more frequent changes during the first day or two. The first day with Grasses, Sedges, and their allies, and the first two days with most other plants, are of more importance than all the subsequent time. As an experienced collector declares: "Two or three changes of the driers during the first twenty-four hours will accomplish more than a dozen changes after the lapse of several days. The most perfect preservation of the beautiful colors of some Orchids has been effected by heating the driers and changing them every two hours during the first day."

794. Heated driers are very efficient; and the best mode of heating is to expose them to the sunshine, and bringing them in hot to make the change at once, or as soon as possible.

795. The number of driers interposed between the specimensheets should depend upon the plants and the frequency of the changes : two will suffice when the driers are changed very often; but more must be employed when the plants are thick and succulent. Uniform pressure may be secured with large and coarse plants by placing strips of pasteboard or pieces of cotton-batting about the sides of the package. Ringlets of cotton may be placed about some of the larger flower-heads of the Compositæ, \&c.

796. The time required to dry specimens varies with different species and with the season: it depends also on the frequency of the changes and the temperature of the driers. By changing daily, the time is usually from four or five days to a week. But, with two changes a day for the first day or two and with heated driers, the process may be completed in half the usual time, ana 
the specimens will be in much finer condition. An experienced collector has no difficulty in ascertaining whether a plant is completely cured or not, while to a novice it is often a matter of uncertainty. A thoroughly dried plant can be usually told by its peculiar hay-like rattle when disturbed; also by placing the plant against the cheek. If there is a sensation of coolness, the plant is still moist.

797. If the thick leaves of fleshy plants are immersed for a few moments in hot water, the period of desiccation will be greatly hastened; but they frequently turn dark as a consequence of the immersion. The drying of such plants, and particularly of the Monocotyledons, may be advantageously expedited by placing them between several driers and ironing them with hot irons. Small plants may be very neatly dried in old books. Very beautiful specimens may be made by placing the plant in a tall and narrow vessel, and pouring over it a sufficient quantity of clean and dry sand. When the moisture is absorbed, it may be flattened in a press.

798. In shifting the driers of a collection, place the package to be changed at the left hand on the table or counter, the new pile in front with its length parallel to the person, - a position the most favorable for giving any needed attention in arranging specimens, - while fresh driers may be placed at the right hand, or beyond the pile in front. Thus arranged, the sheets of specimens can be rapidly shifted into their fresh driers.

799. The moist driers may be spread out in the sunshine to dry, or strung on a line in a warm room, or in the open air, if not too windy. Very moist driers may be thoroughly dried within an hour, if spread in the hot sunshine. In inclement weather, they must be dried by the fire.

800 . To recapitulate the most important points in good specimen-making: Use specimen-sheets to hold the plants undisturbed during the whole process of drying: use plenty of the most bibulous driers, sun-dried and heated when practicable: do not make the piles too large : make the first shift of driers within a few hours, at that time making all needed adjustment of the flaccid specimens : change the driers twice a day for the first day or two.

801. For collecting and preserving specimens on a journey, or when moving from place to place, some modification of the stationary press is requisite. The Travelling-press must be portable: accordingly the pressure is applied by strong leather straps with buckles. There should be three straps, one girding the package around each end, and one lengthwise. The top and 
bottom, if of thin boarls, must be cleated, or compounded of wood with the grain in opposite directions, or very stout binder's board or trunk-board may. be advantageously used. This should be covered with coarse cotton or linen cloth, glued fast and well painted. While stationary, the pressure may be given by means of weights when more convenient.

802. The Wire press, now much in use, is a press of this portable kind, in which the boards are replaced by sheets of wire netting, with wide meshes, and surrounded and strengthened by a strong but light iron border. Straps with buckles are used to hold the parts and contents together and to apply the pressure, as in the ordinary travelling-press. Besides its portability, the advantages of such wire presses are that, in a small way, they may serve both as portfolio for collecting and as press for drying; also that, as the drying takes place mainly by evaporation instead of absorption, much less paper is required, and the trouble of changing the driers is saved. ${ }^{1}$ In fair weather, the press filled with plants may be hung in the wind or sunshine, in foul weather near a fire. The disadvantage is that specimens dried in this way are apt to be brittle. To use this system advantageously, the botanist should have at least two such presses in operation, one for collecting, while the other is in use for drying.

803. Poisoning. Dried specimens are liable to the depredations of certain insects, especially of their larvæ. The principal pest is a small brown beetle, Anobium paniceum, L. ; the perfect insect does considerable damage, the larva vastly more. Plants with milky juice, such as Asclepiadeæ, Apocynaceæ, and Euphorbiaceæ, those containing bitter principles, such as Gentians and Willows, and generally such plants or such organs as contain much protoplasm or azotized matter, are most subject to attack. Ranunculaceæ, Umbelliferæ, and Compositæ are seldom spared; while Labiatæ mostly escape, probably on account of the volatile oil which they contain. Even Ferns are liable to have the parts of fructification eaten away. To a certain extent, the impregnation of the herbarium-cases with camphor, naphthaline, or strong-scented oils, may exclude the vermin. But safety is secured only by poisoning.

804. The proper poison is corrosive sublimate, dissolved in strong (95 per cent.) alcohol. Drop into the alcohol as much cor.

1 Prof. A. Wood seems to have been the first to call the attention of American botanists to this system, which he has earnestly advocated.

An improved form of this wire press, well adapted both for collecting and pressing in moderate quantity, is made and sold, at a small price, by Paul Roessler, optician, at New Haven, Connecticut. 
rosive sublimate as it will take up, then add a trifle more of alcohol, so as to keep the solution just below the point of saturation. The stronger the solution the better, except that, at full saturation and where copiously used, an efflorescence may sometimes be left on the surface of the poisoned specimens upon the evaporation of the alcohol. Some add to the solution some carbolic acid, at the rate of a fluid ounce to each quart of alcohol. The solution may be applied with a soft brush (one with no metal in its fastening), or by a dropping bottle, or even the specimens may be dipped in the solution placed in a flat porcelain dish. The brush (using a pretty large and soft one) is the most convenient and efflcient. The moistened specimens should be placed between driers and in shallow piles until the alcohol evaporates.

805. Thoroughly poison all specimens before admitting them to the herbarium. It is well to poison all specimens whatever, as soon as they are made or at the close of the botanizing season, as well those intended for exchanges as for the collector's own herbarium.

806. Keep all specimens between sheets of paper, or within folded sheets, not too crowded or overlaid, away from dust, and in a perfectly dry place, so as to avoid mould. When attacked by mould, the corrosive-sublimate solution should be applied. A properly dried specimen, duly cared for, should be as lasting as the paper which holds it.

807. The Herbarium, called by the earlier botanists Hortus Siccus, is a collection of dried specimens, named and systematically arranged. It is indispensable to the working systematic botanist, and every devotee of botany should possess, or have access to an herbarium containing representatives of the plants of the immediate vicinity or district, if not of the. whole country. Or an herbarium may be restricted to a particular family of plants, made the object of special study. A general herbarium should contain specimens representing all the natural orders and as many of their genera and species as possible.

808. The form of the herbarium as to the size of its sheets is considerably variable. That of Linnæus is of the size of foolscap paper: this would now be universally regarded as much too small. The principal British herbaria adopt the size of $16 \frac{1}{2}$ by $10 \frac{1}{2}$ inches, which is rather too narrow, rarely permitting two specimens of the same species of any considerable size to be placed side by side on the same sheet. In the United States, $16 \frac{1}{2}$ inches in length by $11 \frac{3}{4}$ in width is adopted; that is, for the genus-covers, the species-paper being a quarter of an inch narrower. 
809. The specimens representing each species may either be laid within a doubled sheet, loosely (as in some European herbaria), or fastened in place by narrow slips of gummed paper (which is much better), or else they may be glued bodily to single sheets of strong and stiff white paper.

810. The former is an excellent plan for a limited collection. It is an advantage that a specimen can be taken up and examined on all sides; also, that indifferent specimens can at any time be exchanged for better ones. But a large herbarium on this plan becomes cumbrous and inconvenient for ready reference and comparison.

811. The best plan in a large herbarium, and one much to be consulted, is to attach the specimens completely, by any kind of strong and light-colored glue, to single sheets, or rather half sheets. The specimens are thus safe from injury under reasonable handling, and can be turned over and examined with as much facility as a series of maps or engravings. The speciespaper should be of writing-paper stock, or of equal firmness, of compact texture, well sized and calendered, and of a weight in size of $16 \frac{1}{4}$ by $11 \frac{1}{2}$ inches of about 18 pounds to the ream of 480 flat sheets. The paper should be furnished square-cut on all sides, in the manner of "flat cap." Stiffness is the great desideratum.

812. In no case should more than one species be knowingly attached to the same sheet. But of very many species there will be room for more than one specimen. And specimens from different localities, of different forms, and in various stages of flowering and fructification, are always desirable. The full name of the plant should be written at the lower right-hand corner of the sheet, or a ticket should there be attached by glue or tragacanth paste. Each specimen should have its ticket, similarly attached, or a memorandum upon the sheet, indicating the habitat or the special locality, date of collection, name of collector, and any other desirable information which the specimens themselves do not furnish. When there are loose flowers or fruits, or when any of these have been detached for dissection and microscopical investigation, it is well to preserve them, placing them in little paper pockets or envelopes and pasting these upon the sheet close to the specimen to which they pertain. Sketches of parts dissected may be drawn upon the sheet. Notes and memoranda received with the specimen or too extended to be entered upon the sheet may be folded, inserted in such envelopes, and made fast to the sheet. Many botanical collections are distributed with printed tickets. These, and all authenticating tickets 
or notes, should be attached to the sheet near to the specimen they belong to. In view of this, printed and written tickets should be of small size. ${ }^{1}$ A ticket which exceeds four by two

1 All printing on an herbarium ticket should be in plain type; and fancy borders, uselessly occupying room, should be avoided. If any border is thought needful, it should be of plain lines. It is not desirable to parcel out the space on a ticket with separate lines and headings for habitat, date of collection, time of flowering or fruiting, name of collector, and the like. These particulars may conveniently be entered at the bottom or top of the ticket, as may be convenient, leaving the rest of the space free for the name of the plant, the authority, and perhaps a synonym.

Tickets for specimens distributed among other botanists may well have a head-line indicating the source, such as "EX CoLL. c. C. PARRY," or "EX HERB." or, in English, "From the Herbarium of" the botanist who communicates the specimen. The following may serve as an example of a simple ticket for the sending out of dried specimens, and of the way in which the ticket may be fllled out with the name of the plant, its habitat and station, name of collector and time of collection.

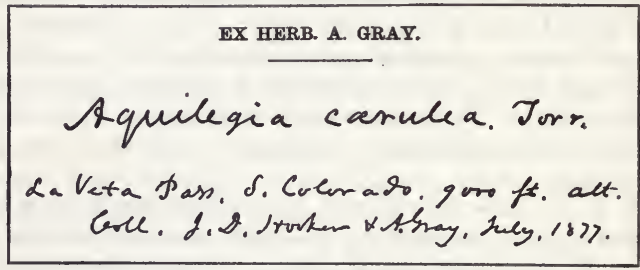

For the botanist's own herbarium, it is well to use a blank ticket with a printed heading like the specimen above, but with the "ex" omitted.

When a considerable collection is made in any particular botanical exploration or excursion, and numerous or several specimens of the same species are gathered, to be distributed among botanists in the way of exchange or otherwise, these are commonly given out under numbers and with a printed heading to a special ticket. The following is an approved form of such a ticket, and of the mode in which it may be filled up in writing by inserting the name of the species, the locality, \&c.

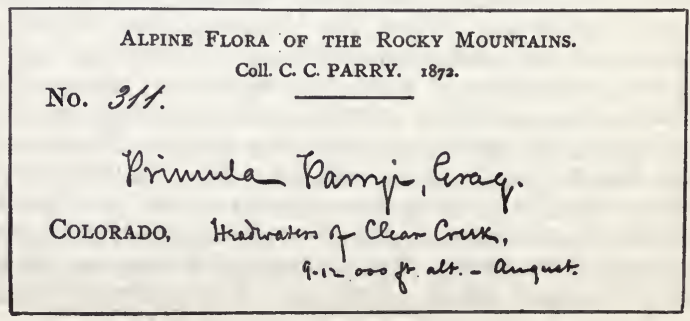


inches is a nuisance; and those of an inch and a quarter or an inch and a half in width and three or four inches in length are most commodious.

813. The sheets of all the species of the same genus, when not too numerous, or of a particular section of it, or any convenient number, should be consigned to one genus-cover. The best genus-covers are of manilla-rope paper, the "bleached manilla" such as that of which tags are made is the neatest article, but rather more expensive : they are in whole or folded sheets (preferably in quarter quires), accurately trimmed at top, bottom, and front edge to the size of $16 \frac{1}{2}$ by $11 \frac{3}{4}$ inches; that is, the fclded sheet as used is a trifle longer and a quarter of an inch wider than the species-sheets it holds. The sheets to be firm enough should weigh $1 \frac{1}{2}$ or $1 \frac{3}{4}$ ounces each, or from 45 to 52 pounds the ream. The generic name should be written in a bold hand on the lower left-hand corner ; that is, on the upper face next the back : at or near the lower right-hand corner, the name of the contained species may be written either with a pencil or in ink.

814. The genera should be arranged in the herbarium according to some systematic work, and numbered accordingly on the covers.

815. The herbarium must be preserved in close cabinets or cases free from the access of dust. Tin cases, just deep and wide enough to receive comfortably the genus-covers, and about six inches high, the hinged lid being one end, may be recommended for a small collection, as they are dust and insect proof, are portable, and may readily be arranged on shelves. But, for any herbarium of considerable size and continued growth, wooden cabinets with well-fitted doors are to be preferred; the interior of the cabinets being divided into pigeon-hole compartments, fully 12 inches wide in the clear and 17 inches deep, and not over 6 inches or in small herbaria not over 4 inches high. Into such pigeon-holes, the genus-covers with their contents will slide readily, and may be compactly stowed away. An index to the genera of each order may be affixed to the interior of the cabinet doors, or pasted upon the upper face of thin boards, inserted at the beginning of each order. The name of the order, written or printed in bold letters, may be pasted upon the front edge of this board, or upon a flap of card-board affixed to it. Moreover, it is well to write the name of the order upon each genus-cover.

816. Except in public collections, where fixed cases may be preferred, the cabinets should individually be small, only three or four feet high, and containing only two or four vertical rows 
of compartments. Such cabinets can be increased in number as required, are portable, and can be disposed in any order, side by side or one surmounting another, as may be most convenient. The doors should be so constructed as to open and shut readily, but to close tightly, so as to exclude dust and insects. ${ }^{1}$

1 An excellent plan for small and inexpensive herbarium cabinets, of a portable character, is proposed and illustrated by Dr. Parry, in the American Naturalist, viii. 471. Each small case is in fact a plain wooden box, wide enough to hold two tiers of pigeon-hole compartments, and of any desirable height (three compartments high in Dr. Parry's plan, but double the number might be better): the entire front consists of a pair of doors meeting in the centre, there fastened by a flush spring catch; the doors bevelled on the inside, with a corresponding bevel on the case, to which they are attached by outside hinges, so that in opening at a right angle there are no sharp corners to hinder the drawing out of the herbarium papers; also allowing the cases to stand close side by side, as well as one upon another, without interfering with the free opening of the doors. These, moreover, may swing quite back against the sides without in any way straining the hinges. For lifting, a pair of flush handles, countersunk to the level of the wood, may be attached to the sides. When the herbarium has to be removed to a distant place, these cases, having no projecting knobs or handles, will go readily into ordi. nary packing-boxes. 


\section{ABBREVIATIONS.}

\section{OF NAMES OF BOTANISTS AND BOTANICAL AUTHORS.}

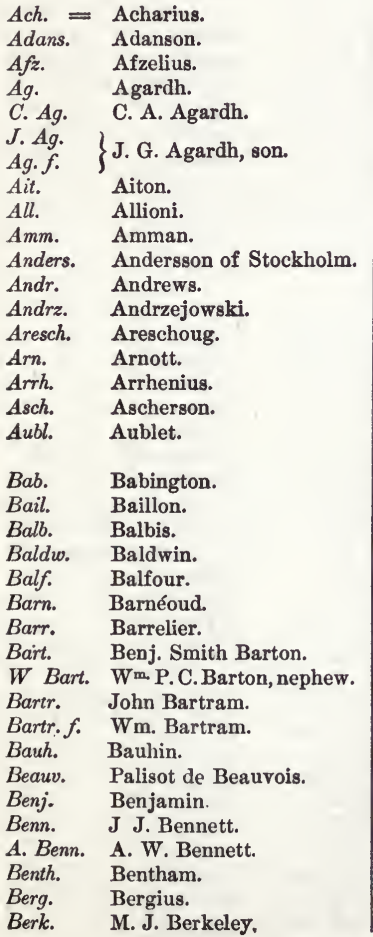

\begin{tabular}{|c|c|}
\hline Berkh. $=$ & Berkhey. \\
\hline Berken. & Berkenhout. \\
\hline Berland. & Berlandier. \\
\hline Bernh. & Bernhardi. \\
\hline Bert. & Bertero. \\
\hline Bertol. & Bertoloni. \\
\hline Bess. & Besser. \\
\hline Bieb. & Marschall von Bieberstein. \\
\hline Bigel. & Jacob Bigelow. \\
\hline Bisch. & Bischoff. \\
\hline Bøehm. & Bœhmer. \\
\hline Boerh. & Boerhaave. \\
\hline Boiss. & Boissier. \\
\hline Boland. & Bolander. \\
\hline Bong. & Bongard. \\
\hline Bonpl. & Bonpland. \\
\hline Bork. & Borkhausen. \\
\hline Borsz. & Borszcow. \\
\hline Brack. & Wm. D. Brackenridge. \\
\hline Brebis. & Brebisson. \\
\hline Bref. & Brefeld. \\
\hline $\begin{array}{l}\text { Brew. \& } \\
\text { Wats. }\end{array}$ & $\begin{array}{l}\text { W. H. Brewer \& Sereno } \\
\text { Watson. }\end{array}$ \\
\hline Brid. & Bridel. \\
\hline Brong. & Brongniart. \\
\hline Brot. & Brotero. \\
\hline Brouss. & Broussonet. \\
\hline$B r ., R . B r$ & Robert Brown. \\
\hline P. Br. & Patrick Browne. \\
\hline Brunf. & Brunfels. \\
\hline Buckl. & Buckley. \\
\hline Bull. & Bulliard. \\
\hline Burm. & Burman. \\
\hline Buxb. & Buxbaum. \\
\hline Cam. & Camerarius. \\
\hline Camb. & Cambe \\
\hline
\end{tabular}


Campd. $=$ Campdera.

Cand. DeCandolle, usually DC.

Casp. Caspary.

Cass. Cassini.

Catesb. Catesby.

Cav. Cavanilles.

Cerv. Cervantes.

Cham. Chamisso.

Chapm. A. W. Chapman.

Chav. Chavannes.

Chois. Choisy.

Clayt. Clayton.

Clus. Clusius.

Collad. Colladon.

Colm. Colmeiro.

Comm. Commelin.

Corn. Cornuti.

Coss. Cosson.

Cunn. Cunningham, A. or J.

Curt. Wm. Curtis.

M. A.Curt. M. A. Curtis.

\section{Dalech. Dalechamps. \\ Dalib. Dalibard. \\ Darl. Darlington. \\ DeC. $\quad\}$ A. P. DeCandolle.}

A. $D C$. Alphonse DeCandolle,son. Cas. DC. Casimir DeCandolle, the

Decne. Decaisne. [grandson.

Deless. Delessert.

Dennst. Dennstedt.

Desc. Descourtilz.

Desf. Desfontaines.

Desj. Desjardins.

Desmar. Desmazières.

Desmoul. Desmoulins.

Desv. Desvaux.

Dicks. Dickson.

Diesb. Diesbach.

Dieter. Dieterich.

Dietr. Dietrich.

Dill. Dillenius.

Dillw. Dillwyn.

Dod. Dodonæus (Dodoens).

D'Orb. D'Orbigny.

Dorst. Dorstenius.

Dougl. Douglas.

Drej. Drejer.

Dryand. Dryander.

Dufr. Dufresne.

Duham. Duhamel du Moncean.

Dumort. Dumortier.

Dun. Dunal.
Eat. $=$ Amos Eaton.

D. C. Eat. D. C. Eaton, grandson.

Edgew. Edgeworth.

Edw. Edwards.

Ehren. Ehrenberg.

Ehrh. Ehrhart.

Eichl. Eichler.

Eiseng. Eisengrein.

Ell. Elliott.

Endl. Endlicher.

Engelm. Engelmann.

Engl. Engler.

Eschs. Eschscholtz.

Eschw. Eschweiler.

Ettingsh. Ettingshausen.

Fendl. Fendler.

Feuil. Feuillée.

Fingerh. Fingerhuth.

Fisch. Fischer.

Forsk. Forskâl.

Forst. Forster.

Fourn. Fournier.

Fresen. Fresenius.

Freyc. Freycinet.

Froel. Frolich.

Gartn. J. Gærtner.

Gortn.f. C. T. Gærtner.

Gardn. Gardner.

Garid. Garidel.

Gasp. Gasparrini.

Gaud. Gaudin.

Gaudich. Gaudichaud.

Germ. Germain.

Gesn. Gesner.

Gilib. Gilibert.

Ging. Gingins de Lassaraz.

Gis. Giseke.

Gled. Gleditsch.

Gleich. Gleichen.

Glox. Gloxin.

Gmel. J. G. Gmelin.

C. Gmel. C. C. Gmelin of Baden.

S. Gmel. S. G. Gmelin.

Godr. Godron.

Gœepp. Gœppert.

Good. Goodenough.

Gren. Grenier.

Grev. Greville.

Griseb. Grisebach.

Groen. Grœnland.

$\left.\begin{array}{l}\text { Gron. } \\ \text { Gronov. }\end{array}\right\}$ Gronovius. 
Guett. = Guettard.

Guib. Guibord.

Guillem. Guillemin.

Guimp. Guimpel.

Gunn. Gunnerus.

Guss. Gussone.

Hagenb. Hagenbach.

Hall. Haller.

Ham. Hamilton.

Hanb. Hanbury.

Hanst. Hanstein.

Hartm. Hartmann.

Hartw. Hartweg.

Harv. Harvey.

Hass. Hassall.

Hassk. Hasskarl.

Hausm. Hausmann.

Haw. Haworth.

Hebens. Hebenstreit.

Hedw. Hedwig.

Hegelm. Hegelmaier.

Hegetsch. Hegetschweiler.

Heist. Heister.

Heldr. Heldreich.

Helw. Helwing.

Hemsl. Hemsley.

Henck. Henckel.

Henfr. Henfrey.

Hensl. Henslow.

Herb. Herbert.

Herm. Hermann.

Hild. Hildebrand.

Hochst. Hochstetter.

Hoffm. G. F. Hoffmann.

$H$. Hoffm. Hermann Hoffmann

Hoffmanns.Hoffmannsegg.

Hofm. Hofmeister

Hohen. Hohenacker.

Holmsk. Holmskiold.

Homb. Hombron.

Hook. Wm. J. Hooker.

Hook. f. J. D. Hooker, son.

Hopk. Hopkirk.

Hornem. Hornemann.

Hornsch. Hornschuch.

Horsf. Horsfield.

Houst. Houston.

Houtt. Houttuyn.

Huds. Hudson.

Hueb. Huebener.

Humb. Humboldt.

HBK. \{ Humboldt, Bonpland, and
Jacq. = N. J. Jacquin.

Jacq. $f$. J. F. Jacquin, son.

J. St. Hil. Jaume St. Hilaire.

Jord. Jordan.

Jungh. Junghuhn.

Juss. A. L. Jussieu.

Adr. Juss. Adrien Jussieu, son.

Kæтр. Kæmpfer.

Karst. Karsten.

Kaulf. Kaulfuss.

Kindb. Kindberg.

Kirschl. Kirschleger.

Kit. Kitaibel.

Koelr. Kœlreuter.

Korth. Korthals.

Kostel. Kosteletzky.

Kremp. Krempelhuber.

Kromb. Krombholz.

Kuetz. Kuetzing.

L. Linnæus.

Labill. La Billardière

Last. Læstadius.

Lag. Lagasca.

Lall. Lallement. [Marck]

Lam. Lamarck (Monnet de La

Lamb. Lambert.

Lamour. Lamouroux.

Langsd. Langsdorf.

La Peyr. La Peyrouse.

La Pyl. La Pylaie.

Ledeb. Ledebour.

Lehm. Lehmann.

Lem. - Lemaire.

Lesq. Lesquereux.

Less. Iessing.

Lestib. Lestiboudois.

Lev. Léveillé.

L'Her. L'Heritier.

L'Herm. L'Herminier.

Liebm. Liebmann.

Lightf. Lightfoot.

Lilij. Lilijeblad.

Lindb. $\quad$ Lindberg.

Lindbl. Lindblom.

Lindenb. Lindenberg.

Lindh. Lindheimer.

Lindl. Lindley.

Linn. Linnæus. Also $\boldsymbol{L}$.

Linn.f. C. Linnæus, son.

Lodd. Loddiges.

Lofl. Lofling. 


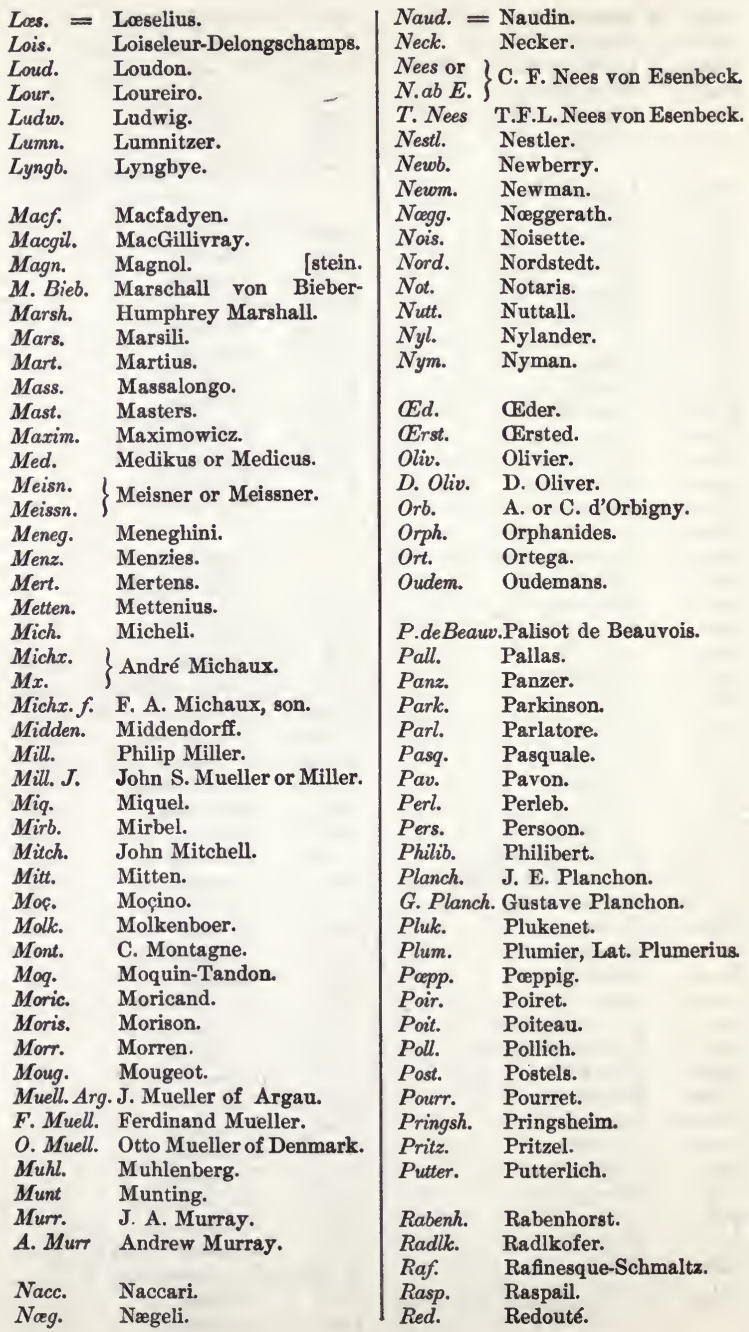


Reich. = Reichard.

Reichenb. H. G. L. Reichenbach.

Reichenb. f. H. G. Reichenbach, son.

Reinw. Reinwardt.

Reiss. Reisseck.

Retz. Retzius.

Reut. Reuter.

Rich. L. C. Richard.

Rich.f: $\}$ Achille Richard.

Richards. John Richardson.

Richt. Richter.

Ridd. Riddell.

Riv. Rivinus.

Rœhl. Rœhling.

Roem. J. J. Romer.

M. J. Rœm.M. J. Rœmer.

$\left.\begin{array}{c}\text { Roem. \& } \\ \text { Sch. }\end{array}\right\}$ Roemer \& Schultes.

Rop. Rœper.

Rohrb. Rohrbach.

Rostk. Rostkovius.

Rothr. Rothrock.

Rottb. Rottboll.

Rottl. Rottler.

Roum. Roumegère.

Roxb. Roxburgh.

Roy. Royen.

Rudb. Rudbeck.

Rupr. Ruprecht.

Sacc. Saccardo.

Sadl. Sadler.

St. Hit. A. Saint-Hilaire.

Salisb. Salisbury.

Salm-Dyck.Prince Jos. Salm-Riffer-

Sauss. Saussure. [schied-Dyck.

Schimp. Schimper.

Schk. Schkuhr.

Schlecht. Schlechtendal.

Schleich. Schleicher.

Schomb. Schomburgh.

Schrad. Schrader.

Schreb. Schreber.

Schueb. Schuebeler.

Schult. Schultes.

Schultz | C. H. Schultz, Bipontinus

Bip. $\}$ (Zweibrucken).

Schum. Schumacher.

Schnitzl. Schnitzlein.

Schwogr. Schwægrichen.

Schwein. Schweinitz.

Schweinf. Schweinfurth.

Schwend. Schwendener.

$\begin{array}{ll}\text { Scop. }= & \text { Scopoli. } \\ \text { Seem. } & \text { Seemann. } \\ \text { Sendt. } & \text { Sendtner. } \\ \text { Seneb. } & \text { Senebier. } \\ \text { Ser. } & \text { Seringe. } \\ \text { Seub. } & \text { Seubert. } \\ \text { Sibth. } & \text { Sibthorp. } \\ \text { Sieb. } & \text { Sieber. } \\ \text { Sieb. } & \text { Siebold. } \\ \text { Soland. } & \text { Solander. } \\ \text { Sow. } & \text { Sowerby. } \\ \text { Spenn. } & \text { Spenner. } \\ \text { Spreng. } & \text { Sprengel. } \\ \text { Sternb. } & \text { Sternberg. } \\ \text { Steud. } & \text { Steudel. } \\ \text { Stev. } & \text { Steven. } \\ \text { Sull. } & \text { Sullivant. } \\ \text { Sw. } & \text { Swartz. }\end{array}$

Targ. Targioni-Tozetti.

Ten. Tenore.

Thoms. Thomas Thomson.

Thuill. Thuillier.

Thunb. Thunberg.

Thurb. Thurber.

Thurm. Thurman.

Tod. Todaro.

Torr. Torrey.

Torr.\& Gr.Torrey \& A. Gray.

Tourn. Tournefort.

Tratt. Trattinick.

Traut. Trautvetter.

Trev. Treviranus.

Trin. Trinius.

Tuck. Tuckerman.

Turcz. Turczaninow.

Turn. Turner.

Turp. Turpin.

Vaill. Vaillant.

Veill. Veillard or Vieillard.

Vauch. Vaucher.

Vent. Ventenat.

Vill. Villars, or Villar.

Vis. Visiani.

Vittad. Vittadini.

Viv. Viviani.

Vog. T. Vogel.

Wahl. Wahlenberg.

Wahlst. Wahlstedt.

Walds. Waldstein.

Wall. Wallich.

Wallm. Wallman. 
Wallr. = Wallroth.

Walp. Walpers.

Walt. Walter.

Wang. Wangenheim.

Warm. Warming.

Wats. P. W. Watson.

H.C.Wats.H. C. Watson.

S. Wats. Sereno Watson.

Web. Weber.

Wedd. Weddell.

Weinm. Weinmann.

Welw. Welwitsch.

Wender. Wenderoth.

Wendl. Wendland.

Wiks. Wikstrom.

$\begin{array}{ll}\text { Wildb. }=\text { Wildbrand. } \\ \text { Willd. } & \text { Willdenow. } \\ \text { Willk. } & \text { Willkomm. } \\ \text { Wils. } & \text { Wilson. } \\ \text { Wimm. } & \text { Wimmer. } \\ \text { Wisliz. } & \text { Wislizenus. } \\ \text { With. } & \text { Withering. } \\ \text { Woodv. } & \text { Woodville. } \\ \text { Wulf. } & \text { Wulfen. } \\ & \\ \text { Zanard. } & \text { Zanardini. } \\ \text { Zetterst. } & \text { Zetterstedt. } \\ \text { Zucc. } & \text { Zuccarini. } \\ \text { Zuccag. } & \text { Zuccagini. }\end{array}$

\section{ABBREVIATIONS OF NAMES OF ORGANS AND TERMS USED IN BOTANICAL WRITINGS.}

Est. Astate, in summer.

Est. Estivation.

Alb. Albumen.

Anth. Anther.

Art. Artificial.

Auct., Auctt. Auctorum, of authors.

Aut. Antumnal.

$B$. or Beat. Beatus, "the late," recently deceased.

Br. Bract.

Cal. Calyx.

Cel. Celeberrimus, or Very celebrated.

Cent. Centimetre.

$\mathrm{Cl}$. Clarissimus.

Char. Character.

Coll. Collection.

Cor. Corolla.

Cult. Cultivated.

Decim. or $D_{e c}{ }^{m}$. Decimetre.

Descr. Description.

Diff. Differentiæ, the distinguishing marks.

Ed. Edition.

Embr. Embryo.

Ess. Essential, as Char. Ess.

Excl. Excluding, or being excluded.

Excl. Syn. Excluding the synonym or synonyms.
Fam. Family.

Fil. Filament of the stamen.

$\mathrm{Fl}$. Flower (flos); Flora, or sometimes Floret, it flowers.

Foem. Female plant, flower, \&c.

Fol. Folium, leaf.

Fr. Fruit.

Fructif. Fructification.

Gen. Genus or Generic.

Germ. Germen, Linnæan name for ovary; also Germination.

H. Herbarium.

Hab. Habitat, place of growth; sometimes for Habeo, I have.

Herb. Herbarium.

Hort. Hortus, garden.

Hortul. Hortulanorum, of the gardeners.

Ic. Icon, a plate or figure.

IIl. Illustris, illustrious.

Ined. Unpublished.

Inf. Inferior.

Infl. Inflorescence.

Inv. Involucre.

Lat. Lateral, or relating to width.

Lin. Linea, a line (the 12 th of an inch).

Lit., Litt. In a letter or letters.

l. c. Loco citato, in the place cited. 
Masc. Male plant, flower, \&c. Mill. or mm. Millimetre.

Mss. Manuscripts.

Mus. Museum.

$N$. or No. Number.

Nat. Natural.

Nom. Nomen, name.

Obs. Observation.

Ord. Order.

Ov. Ovary.

p. Page, or sometimes Part.

Ped. Peduncle or Pedicel, or for

Pedalis, a foot long or high.

Peric. Pericarp.

Perig. Perigonium.

Pet. Petal or Petiole.

Pist. Pistil.

Plac. Placenta.

Poll. Pollicaris, an inch long.

p. p. Pro parte, in part.

Prodr. or Prod. Prodromus.

Rad. Radix, root; or Radical.

Ram. Ramus, branch.

6. Seu, or Sive, Latin for or.

Sect. Section.

Segm. Segment.

Sem. Semen, seed.
Sep. Sepal.

Ser. Series.

Sicc. Siccatus or Siccus, dried or dry. Spec. or Sp. Species, or specimen.

Spont. Spontaneous.

Stam. Stamen or Staminate.

Sup. Superior.

Syn. Synonym or Synopsis.

$T$. or Tab. Tabula, plate.

$T$. Tomus, volume.

V. Volume : sometimes for Vel, or; sometimes Vide, see.

Var. Variety.

Veg. Vegetation, characters of

Vern. Vernal.

v. s. Visa sicca, or Vidi siccam.

v. $v$. Visa viva, or Vidi vivam; the first indicating that a dried specimen of the plant, the second that the living plant has been examined.

v. s. c. and v. s. s., indicates that the dried specimen was cultivated (c) or spontaneous (s).

$v$ v. $c$. and $v$. v. s., that the living plant seen was cultivated (c) or spontaneous (s).

\section{S I G N S.}

\section{SIGNS USED BY LINNAUS.}

$\odot$ An annual plant.

f A biennial.

24 A perennial.

3 A tree or shrub.

* Affixed to a reference, means that a good description will be found there.

+ Indicates an obscure or doubtful species.

\section{SIGNS USED BY DECANDOLLE AND LATER WRITERS.}

$\odot$ A monocarpic plant, i. e. which dies after once flowering and fruiting,

(1) Annual.

(2) Biennial.

(2) Monocarpic perennial, such as Agave. 
24 Perennial herb.

5 Suffrutex, an undershrub.

5 Frutex, a shrub.

5 Arbuscula, a tree-like shrub of ten to twenty-five feet in height.

5 Arbor, a tree.

$\cap$ A climbing plant.

$\triangle$ An evergreen.

o Male plant or flower.

\% Female plant or flower.

భ. Hermaphrodite plant or flower.

$\infty$ Indefinitely numerous, e. $g$. $\infty$-andra, polyandrous.

? A sign of doubt. "Thalictrum? Japonicum," doubts if the plant is really a Thalictrum. "Thalictrum Japonicum, Thunb.?" doubts if the plant in hand is truly the species of Thunberg. Thalictrum Japonicum, Thunb., Willd.? doubts whether Willdenow's $T$. Japonicum is really that of Thunberg.

I A sign of certainty. As "Thalictrum anemonoides, Michx.! Fl. Bor. Am. p. 322 ," as used by DeCandolle, affirms that he has seen an authentic original specimen of this author. Affixed to the name of a collector, as "Virginia, Clayton!" it affirms that the writer has examined a specimen collected by the person to whose name it is appended.

- Between two figures, as in "Stamens 5-10," indicates the extremes of difference, as that the stamens are from five to ten.

- / / The signs for degrees, minutes, and seconds, as $1^{\circ}, 2^{\prime}, 3^{\prime \prime}$, are used in Gray's Manual of Botany of the Northern United States, for feet $\left({ }^{\circ}\right)$, inches $\left({ }^{\prime}\right)$, and lines ('). With European authors, usually the sign for minutes is for feet; that of seconds for inches: thus 1', a foot high; 1", an inch long; and $1^{\prime \prime \prime}$, a line long.

$\mathrm{O}=$ Cotyledons accumbent to the radicle.

Oll Cotyledons incumbent on the radicle. 


\section{GLOSSAR Y,}

OR

\section{DICTIONARY OF BOTANICAL TERMS, ENGLISH AND LATIN,}

COMBINED WITH AN INDEX.

Thrs Glossary is intended to contain all the principal technical terms (substantive as well as adjective) of structural and systematic Botany, as far at least as concerns Phænogamous plants. Most of the special terms relating to the lower Cryptogamia and to Vegetable Anatomy and Physiology are relegated to the volumes devoted to those departments. The annexed numbers refer to pages of this volume. Very many of the terms are seldom employed, or are wholly out of use. The principal Latin terms are given separately only when there is no English equivalent differing merely in the termination. When the word is essentially the same, the Latin termination (of adjectives in the nominative masculine only) is annexed to the English word in a parenthesis. The changed termination goes back mostly to the penultimate consonant. It is unnecessary in a work like this to accentuate all the technical words; but, in the case of words liable to mispronunciation, an accent-mark is placed over the syllable which takes the principal accent. The glossary, as here drawn up, may serve to indicate the meaning of the commoner descriptive specific names of plants.

$A$, privative, as the initial in many words of Greek derivation, signifies the absence of the organ mentioned; as, Apetalous, destitute of petals; Aphyllous, leafless. In words beginning with a vowel, this prefix is changed to an; as, Ananthous, flowerless ; Anantherous, antherless.

Abbreviations, 385.

Aberrant. Wandering, applied to species, genera, \&c., which differ in some respect from the usual or normal character of the group they belong to.

Abnormal (Abnormis). Differing from the normal or usual structure.

Aboriginal. Strictly native; indigenous. Abortion (Abortus). Imperfect development or non-development of an organ ; $179,187$.

Abortive (-ivus). Defective or barren. Abrupt (Abruptus). Terminating suddenly; the opposite of tapering.
Abruptly pinnate. Pinnate without a terminal leaflet or appendage; 101 .

Acanthócladous (-us). Having spiny branches.

Acanthóphorous (-us). Spine-bearing.

Acaulescent (-ens). Stemless, or apparently so, with no proper caulis; 45 .

Acaulis. Stemless; same as Acaulescent.

Accessory. Something additional, or of the nature of appendage.

Accessory Buds, 44.

Accessory Fruits, 300.

Accrescent (-ens). Increasing in size with age, as often occurs with the calyx after flowering.

Accrete (-us). Grown together, or consolidated with some contiguous body.

Accumbent (-ens). Lying against another body.

Accumbent Cotyledons. With edges against the radicle; 313.

Acephalous (-us). Headless. 
Acerose (-6sus). Needle-shaped, like the leaves of Pines.

Acetábuliform (-ormis). In the form of a shallow open cup or saucer.

Achoenium or Achenium. A small, dry and hard, one-celled, one-seeded, indehiscent fruit; strictly one of a single and free carpel; but extended to similar ones of more than one carpel, and also with adnate calyx; 294. (Achoenium is etymologically the proper orthography; but achenium is becoming the commoner form.)

Achoenocarp (-arpium). General name of a dry and indehiscent fruit; 292.

Achenodium. Such a double achenium as that of Umbelliferæ; a Cremocarp.

Achlamýdeous (-eus). Destitute of perianth; 191.

Acicula. A bristle.

Acicular (-aris). Bristle-shaped, or slender needle-shaped.

Acináciform (-ormis). Scymitar-shaped; curved with rounded point, thicker on the straighter edge than on the convex edge.

Acinosus. Like grapes or grape-seed.

dícinus. Classically a berry, particularly a grape, or its stony seed, or a bunch of berries; now sometimes applied to the separate carpels of an aggregate baccate fruit, or to the contained stone or seed; 297.

Acorn. Fruit of the Oak.

Acotyleddon, pl. Acotyledons, Acotylédones. A plant or plants destitute of cotyledon, or

Acotylédonous (-eus). Without cotyledons; as the embryo of Cuscuta; 26, 38. Mostly applied, as by Jussieu, to plants which have no proper seed nor embryo, and therefore no cotyledon ; 339.

Acramphibrya. Plants producing side as well as terminal buds or growths ; 341 .

Acrobrya. Plants growing from apex only; 341.

Ácrogen (Aerogenex). Name of class of plants which in growth are said to be

Acrógenous. Growing from the apex or by terminal buds only.

Acrosárcum. Desvaux's name for a berry from an ovary with adnate calyx.

Acrospira. An old name of the plumule of a grain in germination.

Aculeate (-eatus). Prickly; beset with aculei.
Aculeosus. Abounding with prickles.

Aculeolate (-atus). Beset with diminutive prickles, or

Aculéoli. Diminutive of aculei.

Acrilers. A prickle; a pointed small excrescence of the bark.

Acúmen. A tapering point.

Acuminate (-atus). Ending in a tapering point; 96 .

Acute (Acutus). Terminating in an acute angle; 97.

Acrópetal. Developing from below upward, or from base toward apex.

Actinomorphous (-us). Capable of bisection through two or more planes into similar halves, as is a regular symmetrical flower; 175 .

Acutiusculus. Somewhat acute; acutish. Adelphous (-us, Adelphi, brothers). Stamens with coalescent or clustered filaments are monadelphous, diadelphous, \&c., according to the number of Adelphia or brotherhoods.

Aden. Greek for gland, is compounded with Greek words with this meaning; as, Adenophorus, gland-bearing; $A d-$ enophýllus, leaves bearing glands, \&c. Adglutinate (-atus). Same as accrete.

Adherent (Adhorens). Generally same as adnate; may refer to adhesions not congenital.

Adnate (-atus). Congenitally united to ; as the calyx-tube of the gooseberry to the ovary; 182. Adnate anther is one seemingly borne on the outer or inner face of the filament; $i$. e. extrorsely or introrsely fixed by its whole length to the connective; 253.

Adnation. The state of being adnate; 179, 181.

Adpressus. Latin of appressed.

Adscendens. Latin of ascending.

Adsurgens. Latin of assurgent.

Adventitious, Adventive. That which has come from abroad or as a stranger; as a plant lately or by chance introduced from another country.

Adventitious Buds; 45.

Equilaterális. Equilateral, equal-sided. Equaliflorus. When all the flowers of the same head or cluster are alike in form as well as character.

Equális, Equans. Equal ; equalling. Aërial roots, \&c.; 33.

Aërophytes. Air-plants; 35.

Eruginosus. Verdigris-colored.

Estival (-ális). Relating to summer.

Estivation (-io). The disposition of the parts of a flower in the bud; 132. 
Eterio. A form of aggregate fruit; 300 . Atheogamia, Ethogamous, 340.

Affinity. True and near relationship; $327,330$.

Ágamous or Agamic. Destitute of sexes. Agglomerate. $\quad$ Heaped or crowded Aggregate(-atus). $\{$ into a dense cluster,

Aggregate Fruits. Those formed of aggregate carpels of the same flower; $298,301$.

Agrestis. Growing in fields.

Air-plants. Plants unconnected with the ground; 35.

Akene, Akenium. See Achænium.

Ala (pl. alas). A wing. Also the side petals of a papilionaceous corolla; 185. Has also been used in the sense of axilla.

Alabástrum. A flower-bud; 40.

Alar (Alaris). From ala in the sense of axilla, therefore axillary or in the forks. Alate (-atus). Winged.

Albescens, Albicans. Whitened, whitish, or hoary.

Albrimen of the seed. Any deposit of nutritive material within the seedcoats, and not in the embryo; $14,309$.

Albuminous or Albuminose (Albuminosus). Said of seeds provided with albumen; 13, 309.

Alburnum. Sapwood; the newer wood of an exogenous stem; 80.

Albus. White.

Allagostémonous. With stamens alternatively inserted on the torus and on the petals.

Alliaceous (-eus). Having the smell of garlic.

Alliance. Synonym of Cohort; 326 .

Allogamy. Fecundation of the ovules of a flower by other than its own pollen; cross fertilization, 216.

Alpestrine (Alpestris). Growing on mountains below an alpine region or one unwooded from cold.

Alpine (-inus). Growing on the higher parts of the Alps, or (by extension of meaning) on other mountains above the limits of trees.

Altérnate (Alternus). One after another; as of leaves placed singly instead of in pairs (opposite) or in whorls. Also, standing before intervals; as stamens alternate with petals instead of before them; 6, 119.

Alternative (-ivus). In æstivation, with an inner whorl alternating with an outer one; 134, 136.
Alvéolate(-atus). Honeycombed; having deep angular cavities (Alvéoli) separated by thin partitions, as the receptacle of cotton-thistle.

Ámbitus. The ray or circumference of a head, \&c.

Ament (Améntum). A catkin, or poculiar scaly spike; 150 .

Amentaceous (-eus). Bearing catkins, or catkin-like.

Amorphous (-us). Shapeless; of indefinite form.

Amphanthium. One of the (needless) names coined for a dilated receptacle of inflorescence.

Amphibrya. Equivalent to Monocotyledones; 341.

Amphicarpous (-us). Producing two kinds of fruit.

Amphigamous Cryptogams, 340.

Amphigastria. Peculiar leaves (of Hepaticæ) imitating stipules.

Amphisarca. A hard-rinded berry, or fruit succulent within and woody or crustaceous without, as a calibash.

Amphispermium. Link's name for a one-seeded pericarp which is conformed to the seed; an akene.

Amphitropous ( $-u s)$, wrongly Amphitropal. Turned both ways; applied to an ovule with hilum intermediate between micropyle and chalaza; 279.

Ámphora. A pitcher; and the lower part of a pyxis.

Amplectens, Amplexans, Amplexus. Embracing, clasping.

Amplexicaul (-aulis). Clasping a stem, as does the base of certain leaves.

Ampliate (-atus). Enlarged or dilated.

Ampúlla. A bladder or flask-shaped organ, as of Utricularia.

Ampullaceous (-us), or Ampullaform. In the form of a bladder or short flask. Amylaceous (-eus). Resembling or composed of starch, or Amylum.

Amyloid. Analogous to starch.

Analogy (Analogia). Likeness in certain respects. As distinguished from affinity, it means resemblance in certain respects only, not in the plan of structure. Thus, a Ranunculus is analogous to a Potentilla, but there is no near affinity or relatiouship between the two. And the tendril of a Pea, that of a Smilax, and that of the Grape-vine are analogues; i. e., are analogous organs, but are not homo logues; for the first answers to a leaf, the second to stipules, and the third 
to a stem. The spur of a Larkspur is analogous to one of the five spurs of Columbine, but not homologous with it; for the first is a sepal, and the second a petal.

Anandrous. Destitute of stamens.

Anantherous (-us). Destitute of anthers. Ananthous (-us). Flowerless.

Anastomosis. The connection of veins, \&c., by cross-veins, forming reticulation.

Anátropous (-us), wrongly Anatropal. The reversed ovule, with micropyle close by the side of the hilum, and chalaza at the opposite end; 279 .

Anceps, Engl. Ancipital. Botanically always used in the sense of twoedged.

Ander, andra, andrum. In Greek compounds, the male.

Andro-dicecious. With flowers on one plant hermaphrodite, and on another staminate only; 191.

Androcium. The stamens of a flower collectively ; 165, 249.

Androgynous (- $u s)$. Said of an inflorescence composed of both male and female flowers.

Ándrophore (Andróphorum). A support or column on which stamens are raised.

Androus. See Ander.

Anemophilous. Literally wind-loving. Said of flowers which are fecundated by wind-borne pollen; 217 .

Anfractuosus. Abruptly bent bither and thither, as the stamens of Cucurbita.

Angiocarpous (-us). When a fruit is covered by some envelope.

Angiospermia. A Linnæan artificial order; 337.

Angiospermous, Angiosperma, Angiosperms. Plants with seeds borne in a pericarp; 259.

Angular Divergence of leaves; 123.

Anisómerous (-us). Unequal in number in the different circles of the flower; unsymmetrical.

Anisopétalous (-us). With unequal petals. Anisophýllous (-us). Unequal-leaved; i. e., the two leaves of a pair nnequal. Anisostemonous (-us). When the stamens are not of the number of the petals.

Annótinus. A year old, or in yearly growths.

Annual (Annurs). Of only one year's duration; 30 .
Annular (-aris). In the form of a ring; or marked transversely by rings. The latter more properly.

Annulate (-atus). Marked with rings.

Ánnulus. A ring, such as that with which the sporangia of some Ferns and Mosses are furnished.

Ánophytes (Anophýta). Name of group comprising Mosses, \&c.

Anteposition Same as Superposition; $179,195$.

Anterior, as to position, denotes the front side, or averse from the axis of inflorescence; 160 .

Anthéla. A deliquescent and paniculate cyme, with median ramification, and the lateral axes overtopping the central, as in Juncus tenuis, \&c. May be either a Drepanium or a Rhipidium.

Anthemy, Anthemia. A flower-cluster of any kind; 144.

Anther (Anthéra). The polliniferous part of a stamen; 165, 251.

Antheridium. An analogue of the anther in Cryptogans.

Antheriferous (-us). Anther-bearing Ánthesis. The time at which a flower is perfected and opens; or the act of expansion of a flower.

Anthocarpous(-us), Anthocarpum. Fruits in which some organ exterior to the pericarp is concerned; 300 .

Anthoclinium. Name of a receptacle of inflorescence, such as that of Compositæ.

Anthodium. A name for the head of flowers (or so-called compound tlowers) of Compositæ; 147.

Antholysis. A retrograde metamorphosis of a flower, in which normally combined parts are separated.

Ánthophore (Anthophorum). The stipe when developed between calyx and corolla; 212.

Anthus or Anthos. A flower, in Greek compounds.

Anticous (Anticus). Facing anteriorly; 253.

Antitropous (-us), less properly Antitropal. Said of an embryo with radicle pointing to the end of the seed opposite the hilum; 312 .

Antrorse. Directed npward or forward. Apetalous (-us). Having no petals; 190. Apex. Besides its ordinary meaning, the top of a thing, it was once the technical name of an anther; 166. Aphyllous (-us). Leafless. 
Apical (-alis). Relating to the apex or tip. Apices. The name for anthers anterior to Ludwig and Linnæus; 166.

Apiculate ( $u s)$. Ending in a short pointed tip or apicula.

Apocarpous (-us). When carpels of a gynocium are separate; 261, 262.

Apophysis. An enlargement or swelling of the surface of an organ at some particular part.

Apothecia. The "shields" or fructifying disks of Lichenes.

Apótropous (-us). Said of an anatropous ovule which when pendulous has rhaphe averse; 282.

Appendage, Appendix. Any superadded or subsidiary part.

Appendiculate (-atus). Furnished with a small appendage (Appendiculum), or with any appendage.

Appositus. Placed side by side.

Appressed (Lat. Adpressus). Lying flat against or together for the whole length.

Ápricus. Growing in dry sunny places. ápterous (-us). Wingless; not alate. Aquatic (-icus). Living in water.

Aquátilis. Living under water.

Arachnoid (-oideus). Cobwebby ; composed of slender entangled hairs.

Araneose (-osus), Araneus. Like spiderweb; same as Arachnoid.

Arbor. A tree; 50.

Arboreous (Arboreus). Tree-like, or relating to a tree.

Arborescent (-ens). Tree-like; approaching the size of a tree.

Arborétum, also Arbustum. A place where trees are grown; an arranged collection of trees.

Arbuiscula. A small shrub of tree-like growth or form.

Arbuscularis. Ramified like a little tree. Archegonium. The spore-case of mosses, \&c., in an early state.

Árcuate (-atus). Moderately curved, as if bent like a bow.

Aréola, pl. Areolae. Spaces marked out on a surface, as by the reticulation of veins, \&c.

Aréolate (-atus). Marked with areolæ.

Arenosus, Arenarius. Growing in sand or sandy places.

Argentate (-atus, Argénteus). Silvery, or shining white with a tinge of gray.

Argillosus. Growing in clayey soil.

Argos. Greek for pure white, used in compounds; as, argophyllus, whiteleaved.
Argítus. Sharp-toothed; said of the serration of leaves.

Argyros. Greek for silvery; used in compounds; as, argyrophyllus, silveryleaved.

Arhizal (Arhizus). Rootless.

Arillate (-atus). Having an arillus.

Áril, Arillus. An extraneous or lateformed seed-coat or covering, or an appendage growing from or about the hilum of a seed; 308 .

Arilliform (-ormis). In the form of an arillus.

Arillode, Arillodium. A false arillus, or one which does not originate from or below the hilum, but from the micropyle or rhaphe; 309 .

Arista. An awn.

Aristate (-atus). Awned; bearing an arista.

Aristulate (-atus). Bearing a diminutive awn.

Arrect (Arrectus). Brought into an upright position.

Arrow-shaped, Arrow-headed. Same as Sagittate; 96.

Articulated (-atus). Jointed, or having the appearance of a joint or articulation (Articulus). As of the word joint itself, the context must show whether the articulations mean the portions which are connected by a joint, or the place of connection.

Artificial Classification, 331.

Ascending (Adscendens). Rising upward. Sometimes used for directed upward, as when the stem is termed the Ascending Axis (11); more commonly denotes curving or rising obliquely upward; 53.

Ascidium. A pitcher-shaped or flaskshaped organ or appendage; 111.

Ascus. A sac; a kind of spore-cases, as in certain Fungi and Lichenes.

Aspáragi. A name for Turiones, or any scaly shoots from underground, as those of Asparagus.

Aspergilliform (-ormis). Brush-shaped, i. e. like the aspergillum, or brush used to sprinkle holy water; made up of numerous spreading bairs, \&c., in a tuft, as the stigmas of Grasses.

Asperous (Asper). Rough to the touch.

Assimilation. The action or process by which extraneous matter or crude food is converted into vegetable matter.

Assurgent (Adsurgens). Rising or curving upward; 53.

Astichous (-us). Not in rows. 
destomous (-us). Withont a stoma or month.

átavism (-mus). Ancestral resemblance. Ater. Pure black.

Áthera. Greek for Arista or Awn.

Atrátus. Blackened or turning black.

átropous (-us), wrongly Atropal. Not turned; applied to an ovule the same as orthotropous; 277.

Attenuate (-atus). Slenderly tapering or narrow.

Auctus. Same as accrescent; enlarged after flowering; augmented by an addition.

Augmentation. Increase beyond the normal number; 179, 200.

Aurantiacus. Orange-colored.

Auratus, Aureus. Golden-colored, or yellow with golden lustre.

Áuricle (Auricula). An ear or earshaped appendage.

Auriculate (-atus). Furnished with an auricle; 96 .

Autocarpous. A fruit consisting of pericarp alone, having no adnate parts.

Autogamy. Close-fertilization, the fecundation of a flower by its own pollen; 215, 216.

Avenius. Veinless.

Awl-shaped. Narrow, terete or somewhat so, and attenuate from a broader base to a slender or rigid point.

Awn. A bristle-shaped appendage, such as the beard of Rye and Barley.

Avoned. Furnished with an awn.

Axil (Axilla). The angle formed on the upper side of the attachment of a leaf with the stem, or the point just above this attachment; 6 .

Áxillary (-áris). In or relating to an axil; 7 .

Axile, Axial (Axilis). Relating or belonging to the axis.

Axis. The stem; the central part or longitudinal support on which organs or parts are arranged; the central line of any body.

Bacca. A berry; 299.

Baccate (-atus). Berry-like; pulpy throughout.

Baccétum. An aggregation of berries in one flower; 300 .

Badius. Chestnut-brown.

Balausta. Name applied to the fruit of the Pomegranate, with firm rind, crowned with the lobes of an adnate calyx, baccate within, and manyseeded.
Banner. The vexillum, standard, of npper petal of a papilionaceous corolla; 184.

Barb. A bristle or stout hair, which is hooked or double-hooked, or retrorsely appendaged at the tip.

Barba. Beard.

Barbate (-atus). Bearded; beset with long and weak hairs.

Barbellate (-atus). Beset with shorter and stiffer hairs or barbella.

Barbellulate (-atus). Diminutive of the preceding.

Bark. The rind or cortical portion of a stem, especially of an exogen; 76 .

Basal (Basilaris). Relating to the base.

Basal-nerved. With nerves all from the base of the leaf; 92 .

Base (Basis). The extremity by which an organ is attached to its support.

Basidia. Cells of the fructification of Mushrooms which bear the spores.

Basifixed (-us). Attached by the base or lower end; 253.

Basigynium. Synonym of Carpophore or Thecaphore.

Basinerved (-ius). When the ribs proceed from the base of a leaf.

Basipetal. Developing from apex toward the base.

Bast, or Bass. Inner fibrous bark; 77.

Bast-cells. The essential components of bast; long and flexible but thick-walled attenuated cells; 77 .

Beak. A narrowed or prolonged tip.

Beaked. Ending in a beak.

Bell-shaped. Same as Campanulate; 249.

Berried. Baccate.

Berry. A fruit, the whole pericarp of which is fleshy or pulpy; 299.

Bi- or Bis. As a prefix to Latin words (Greek words have $D i$ ), two, twice, or doubly.

Biacuminate (-atus). Two-pointed, as malpighiaceous hairs, fixed by the middle and tapering to each end.

Biarticulate (-atus). Two-jointed.

Biauriculate (-atus). Two-auricled.

Bibracteate (-atus). With two bracts.

Bibracteolate (-atus). With two bractlets.

Bicallose (-osus). With two callosities.

Bicárinate (-atus). Two-keeled.

Biceps. With two supports or stalks Bicipital. or two-headed.

Bicolor. Two-colored.

Bicónjugate (-atus). Twice paired.

Bicornis. Two-horned.

Bicornute. Same as preceding. 
Bicruris. Two-legged, or with two supports.

Bidentate (-atus). Having two teeth. (Not doubly dentate.)

Biduus. Lasting two days only.

Biennial (Biennis). Of two years' duration; 31.

Bifarious (-ius). Two-ranked; in two vertical rows.

Biferus. Double-bearing; fruiting twice a year.

Bifid (-idus). Two-cleft, to the middle or thereabout.

Biflórous (-us). Two-flowered.

Bifoliate. Two-leaved.

Bifbliolate. Of two leaflets.

Biforate (-atus). Having two openings.

Biformis. Two-formed; in two shapes.

Bifrons. With two faces or aspects.

Bifúrcate (-atus). Two-forked; i.e. of two prongs or forks. But it may mean bis furcatus; i. e., forked and again forked.

Bigeminate (-atus). Twice twin; same as Biconjugate.

Bigener. The offspring of a cross between two generically different plants.

Bijugate (Bijugus). Two-paired, as a pinnate leaf of two juga or pairs of leaflets.

Bilabiate (-atus). Two-lipped; 247.

Bilámellate (-atus), or Bilamellar. Of two plates or lamellos.

Bilóbed (Bilobus), or Bilóbate. Of two lobes, or cleft into two segments.

Bilócellate. Divided into two locelli; 263.

Bilocular (-aris). Two-celled.

Biméstris. Lasting two months.

Bimus. Lasting two years; two years old.

Binary (-arius). Consisting of two members; 176.

Binate (-atus). In pairs or twos.

Bini. Twin, or two together.

Binódal (Binódis). Having two nodes.

Binomial Nomenclature, 346.

Biology. The natural history of plants and animals, $i$. e. of living things; 1 .

Bipalmate (-atus). Twice palmately compound.

Biparous. Bearing two; as a cyme of two rays or axes; $152,155$.

Bipártible (-ibilis). Capable of division into two similar parts.

Bipártite (-ítus). Divided almost into two pieces; two-parted.

Bipes. Same as Bicrurie.
Bipinnate (-atus). Donbly or twice pinnate; 103.

Bipinnátifid (-idus). Twice or doubly pinnatifid; 100.

Bipinnátisect ( $-u s)$. Twice pinnately divided.

Biplicate (-atus). Twice folded or plaited.

Bipórose (-osus). Opening by two pores.

Biradiate (-atus). Of two rays.

Birimose (-osus). Opening by two slits.

Bisected (-us). Completely divided into two parts; 99.

Biseptate (-atus). With two partitions.

Biserial (-ialis), or Biseriate (-iatus). In two series, one above the other.

Biserrate (-atus). When serratures are again serrate; doubly serrate.

Bisexual. Having both stamens and pistil; hermaphrodite; 191.

Bisulleate (-atus, Bisulcus). Two-grooved; having two furrows.

Bitérnate (-atus). Twice ternate.

Bladdery. Thin and inflated.

Blade. The lamina, limb, or expanded portion of a leaf, \&c.; 85, 245.

Blastema. The budding or sprouting part or point. First used for the axis of an embryo; now used for the initial growth out of which any organ or part of an organ is developed.

Bloom. Besides its use as equivalent to blossom, it denotes the white powdery and glaucous covering of the surface of many fruits and leaves, of a waxy nature.

Boat-shaped. Of the shape of a boat, of the deeper sort, with or without a keel.

Bostrychoidal. Having the form or character of a ringlet, or Bostryx; 157.

Bastryx. An uniparous helicoid cyme; 156.

Bothrénchyma. Tissue of plants composed of dotted or pitted ducts.

Botry-cymose. Racemes or any botryose clusters cymosely aggregated; 159 .

Botryose (-osus), Botryoidal. Of the racemose type; 144, 145, 146, 153.

Botrys. The equivalent of Raceme; 146.

Botuliformis. Sausage-shaped.

Bráchiate (-iátus). With spreading arms, as branches (especially opposite and decussate) widely diverging.

Brachys. Greek for short, and used in compounds; as, Brachýpodus, shortstalked.

Bract, Bractea. The leaves (more of less modified) of a flower-cluster; 118, 141.

Bracteate (-eatus). Having bracts. 
Bractéola, Bracteole. See Bractlet. Bracteolate(-atus). Having bractlets.

Bractlet. A bract of the ultimate grade, as one inserted on a pedicel or ultimate flower-stalk, instead of subtending it; $141,142,160$.

Bracteose (-osus). Full of, or with conspicuous bracts.

Branches. Secondary axes, or divisions of an axis; 47.

Branchlets. Ultimate branches or divisions of an axis; 47.

Breathing-pores. See Stomata, 89.

Bristle. A stiff hair, or any slender body or outgrowth which may be likened to a hog's bristle.

Bristly. Beset with bristles.

Brunneus. Deep brown.

Brush-shaped. See Aspergilliform.

Bryology. The botany of Mosses.

Bud. The undeveloped state of a stem or branch, with or without leaves; $6,40$.

Bud-scales. The teguments of a bud; 40 .

Bulb (Bulbus). A leaf-bud (commonly subterranean) with fleshy scales or conats; $43,62$.

Búbiceps. A stem with bulbous base.

Bulbiferous (-us). Bulb-bearing.

Bulbillus, Búlbulus. Diminutive bulb. Same as

Bulblet. A small bulb, especially such as is produced in the air, in the axil of ordinary leaves, or upon them; 63.

Bulbodium. A synonym of Corm, the "solid bulb."

Bulbo-tuber. Synonym of Corm.

Bulbous, Bulbosus. Having bulbs or the structure of a bulb.

Bullate (-atus). Saia of a puckered surface (as if blistered), thrown into portions which are convex and projecting on one side and concave on the other. Also used in specific names, in its more literal sense for inflated.

Bursicula. A small pouch (bursa); such as that which encloses the disk or gland of the caudicle of the pollinium of an Orchis.

Bursiculatus. Furnished with a bursicula or pouch.

Byssaceous (-eus). Composed of fine threads, like byssus or fine flax.

Caduicous (-us). Dropping off very early, as the calyx of a Poppy at the time of expansion; 243.

Carruleus. Sky blue, or pure blue.
Casius. Lavender-color; pale green with whitish or gray.

Calathidium, Cálathis. Literally a basket; a name for the head of flowers (or better for the involucre only) of Compositæ.

Calathiform (-ormis). Cup-shaped; of somewhat hemispherical outline.

Calcar. A spur; mostly used for the nectariferous one of a calyx or corolla.

Cálcarate (-átus). Furnished or produced into a spur.

Cálceolate (-atus), or Calceiformis. Shaped like a slipper or shoe.

Callose (-osus). Bearing callosities (calli), or hard protuberances.

Calvus. Bald, as an akene without pappus.

Calycanthemy. Name of the monstrosity in which the calyx imitates an exterior corolla ; 174.

Calyciflorous (Calyciflora), 340.

Calycine (Calycinus). Relating to calyx.

Calýculate (-atus). Bearing bracts next the calyx which imitate an external or accessory calyx.

Calýculus. An involucre or involucel imitating an additional calyx.

Calyptra. The hood or veil of the spore-case of a Moss; or some covering body like it.

Calyptrate (-atus). Furnished with a calyptra, or something like it.

Calyptriform (-ormis). Calyptra-shaped; as the calyx of Eschscholtzia.

Calyx. The flower-cup, the exterior perianth ; 164.

Cámara and its diminutive Camérula (chamber) are sometimes used for the cells of a fruit.

Cambium. Old name of the viscid matter between bark and wood in common trees or shrubs in spring; now used for the nascent structure there forming, or Cambium layer; 78.

Campánulate (-atus). Bell-shaped; elongated cup-shaped or shorter, and broad from the base; 249.

Campaniformis. Same as Campanulate. Campylospérmous (-us). Curved-seeded. Said of seed-like fruits or carpels, as those of some Umbelliferæ, in which the contained seed is involute by the lateral edges, so as to produce a longitudinal furrow on the ventral face.

Campylotropous (-us), or less correctly Campylotropal, or Campulitropous. An ovule or seed which is curved in its formation so as to bring the 
micropyle or true apex down near to the hilum; 279.

Canalicaulate (-atus). Channelled, or with a longitudinal groove.

Cáncellate (-átus). Latticed; resembling lattice-work.

Cándidus. Pure white.

Canescens. Hoary, usually with gray pubescence.

Canus. Gray-white; whiter than the preceding.

Capillaceous(-eus). $\begin{aligned} & \text { So slender that it } \\ & \text { may be compared } \\ & \text { with the hairs of } \\ & \text { animals. }\end{aligned}$

Cápitate (-atus). Head-shaped, or collected in a head; 147.

Capitellate (-atus). Diminutive of Capitate.

Capitulum. A head of or simple globular cluster of sessile flowers; 147.

Capréolate (-atus). Bearing a tendril (capreolus).

Capsule (-ula). A dry and dehiscent pericarp composed of more than one carpel ; 289, 293.

Capsular. Of the nature of, or relating to, a capsule.

Capsuliferous. Capsule-bearing.

Carcerulus. An unused name for an indehiscent and several-celled dry fruit; 297.

Carina. A keel; used either for the two combined lower petals of a papilionaceous corolla (185); or for a salient longitudinal projection on the centre of the lower face of an organ, as on the glumes of many Grasses.

Cárinate (-atus). Keeled.

Cariopsis or Caryopsis. A grain; a seedlike fruit with thin pericarp adnate to the contained seed; 295 .

Carneus. Flesh-colored, very pale red.

Caro. Flesh, as the pulp of a melon, or the fleshy part of a drupe.

Carpadilium. Synonym of Cremocarp. Carpel, Carpéllum. A simple pistil, or an element of a compound pistil, answering to one leaf; 167,260 .

Carpid, Carpidium. Synonym of carpel.

Carpology. The botany of fruits.

Cárpophore (Carpóphorum). A portion of receptacle prolonged between the carpels; 212.

Cárpophyll (Carpophýllum). Literally fruit-leaf; synonym of Carpel ; 260.

Cartilaginous or Cartilagineous (-eus). Of the texture of cartilage or gristle; firm and tough.
Caruncle (Carincula). An excrescence at or about the hilum of certain seeds; 308.

Caryophyllaceous(-eus). Resembling or relating to the corolla of Dianthus Caryophyllus (246), or to the Pink family.

Caryopsis. See Cariopsis.

Cassideus. Helmet-shaped.

Cassus. Empty, as an anther containing no pollen.

Castrate (-atus). Said of a stamen which wants the anther.

Catapetalous $(-u s)$. Where petals are united only by cohesion with united stamens, as in Mallow.

Cataphylla. Answers to the German " Niederblätter," or under-leaves, those at the beginning of a growth, cotyledons, bud-scales, scales on rhizomes, \&c.; 6.

Catenulate (-átus). Formed of parts united end to end, like the links of a chain.

Catkin. A scaly spike (see Ament); 150. Caudate (-atus). Furnished with a tail (cauda), or with a slender tip or appendage resembling a tail.

Caudex. A trunk or stock of a plant; 50.

Caudicle (Caudicula). The stalk of a pollinium, \&c.

Caulescent (-ens). Having an obvious stem.

Caúlicle (Cauliculus). The initial stem in an embryo, generally named the Radicle; 10.

Cauline (-inus). Belonging to the stem.

Caulis. Greek form Caulon. The stem of a plant.

Caulocárpic or Caulocarpous. Applied to plants which live to flower and fructify more than once or indefinitely.

Caulóme, Caulóma. The stem-part of a plant.

Cephalanthium. One of the names of the head or capitulum in Compositæ; 148.

Cell (Cellula). The anatomical element of plants; 28. The cavity of an anther which contains the pollen, or an anther-lobe, thus taken in the sense of the circumscribing wall as well as the cavity; 251, 254. The cavity, or any one cavity of an ovary or pericarp, containing the ovules or seeds; 262.

Cellular Plants, Cellulares, 340.

Celllule $(-u l a)$. Diminutive of cell; of 
the same meaning as Cell in vegetable anatomy; 28.

Céllulose. The material, chemically considered, of which the wall of the cell consists.

Cenobium. A name of the peculiar fourparted fruit (or the four nutlets around a common style) which distinguishes Labiatæ and Borraginaceæ.

Centrifugal. Tending or developing from the centre outward.

Centripetal. Tending or developing from without toward the centre.

Cephalanthium. Synonym of Anthodium.

Ceratium. A siliquiform capsule, such as that of Corydalis, Cleome, \&c.

Cereal. Belonging to corn and the allied grains.

Cérinus. Of the color of wax.

Cérnuous (-uus). Nodding.

Chata. Greek for a bristle, Latin Seta.

Chaff. Small scales; dry and depauperate bracts; such as those on the receptacle of a sunflower and many other Compositæ ; also glumes of Grasses.

Chaffy. Provided with or having the texture of chaff.

Chaláza. The part of an ovule where coats and nucleus are confluent; 277.

Channelled. Hollowed out longitudinally like a gutter. See Canaliculate.

Character. A diagnostic description, or the enumeration of essential differences; 361.

Chasmogamy. The opening of the perianth at flowering time; the opposite of Cleistogamy.

Chartaceous (-eus). Having the texture of writing-paper.

Chlorophyll. The green matter of leaves and other vegetation; $\mathbf{7 6 , 8 8}$

Chloros. Greek for green. Enters into compounds, such as Chloranthus, green-flowered, Chloranthy, same as Chlorosis, as when petals turn green; 172.

Chlorósis. Literally becoming green, as some flowers in retrograde metamorphosis. Also used contrariwise for the loss of a normal green enlor; 172.

Chorda Pistillaris. A line of tissue reaching from stigma to orary.

Choripetalous (-us). Same as Polvpetalous, i. e. petals unconnected: 244.

Chorisepalous. Same as Polysepalous, \&c.

Chorisis. The separation of a leaf or phyllum into more than one; 202.

Choristophyllus. Separate-leaved.
Chromule (-ula). Coloring matter of plants other than chlorophyll, especially that of petals.

Chrysos. Greek for golden, or goldenyellow; as

Chrysanthus. Yellow-flowered, \&c.

Cicatrix, Cicatricula. A scar left by the fall of a leaf or other organ.

Ciliate (-atus), Ciliaris. Marginally fringed with hairs.

Cilium, pl. cilia. Marginal hairs, forming a fringe, like the eyelash. (The name has been extended in scientific books to undividual hairs, and of a surface as well as edge.)

Cincinnus. A curl : name of a uniparous scorpioid cyme, which is Cincinnal; 156, 157.

Cinénchyma. Laticiferous tissue.

Cinerascens, Cineraceus. Ash-grayish.

Cinereous (-eus). Ash-gray.

Cinnabarinus. Cinnabar-color ; scarlet touched with orange.

Circinal (-alis). Involute from the tip into a coil; 133.

Circinate, or Circinnate (-atus). Same as preceding; or sometimes meaning coiled into a ring ouly.

Circumscissile, or Circumcissile (Circumscissus). Cut circulary and transversely; divided transversely; 291, 293.

Circumscription (-io). The general outline of the margin of a flat body.

Cirrhiferous (-us) and Cirrhose. Tendril-bearing.

Cirrhus. A tendril; 54.

Citreus, Citrinus. Lemon-colored.

Clados. Greek for branch; whence such terms as

Cladodium. Same as Cladophyllum.

Cládophyll, Cladophýlla. Branches assuming the form and function of foliage; 65,66 .

Clavate (-atus), Claviformis. Clubshaped.

Clavellate. Diminutive of Clavate.

Claviculate (-atus). Furnished with claviculoe; viz., tendrils, hooks, or other appliances for climbing.

Class, 325.

Classification, 315 .

Clathrate (-atus). Latticed.

Claw. The narrowed base or stalk which some petals, \&c., possess; 245.

Cleistógamy, Cleistogamons, Cleistogamic. Close-fertilization in unopened blossoms ; 241.

Cleistógeny, Cleistogenous, 241. Same as Cleistogamy. 
Cleft. Cnt half-way down or thereabout; 98.

Climbing. Risung by laying hold of surrounding objects for support; 51 .

Clinandrium. The anther-bed in Orchidaceæ.

Clinanthium. A name for the receptacle of inflorescence in Compositæ; 148.

Clinium. Used in Greek compounds for receptacle, e.g. Periclinium, for an involucre around the receptacle of inflorescence.

Close-fertilization. Fecundation by own pollen; 216, 280.

Cloves. A gardener's name for young bulbs developed around a mother bulb.

Club-shaped. Gradually thickened upward from a slender base.

Clustered. Collected in a bunch of any sort. Cluster is a good indefinite name for any assemblage of flowers on a plant.

Clypeate (-atus), Clypeiformis. Buckler-shaped.

Coacérrate (-atus). Heaped together.

Coádnate (-atus), Coadunatus. Same as Adnate.

Coalescence. Union of similar parts; 179, 180.

Coalescent (-ens), Coalitus. Cohering; properly applied to the organic cohesion of similar parts.

Coarctate (-atus). Crowded together.

Coated. Composed of layers as an onion, or furnished with a covering or rind.

Cobwebby. Bearing long and soft entangled hairs.

Coccineus. Bright red or scarlet (red with a little yellow).

Coccus. Greek for a kernel or nutlet, from which the Latin Coccum, the kermes or scarlet grain (supposed berry) of the Quercus coccifera; nsed botanically, mostly in the form of "coccus," for the portions into which a schizocarp, or lobed fruit with oneseeded cells, splits up; these portions are Cocci or Coccules; 296.

Cochlear (Cochlearis). Spoon-shaped. Unmeaningly applied also to a form of imbricative rstivation with one piece exterior; 137.

Cochleate (-atus). Shell-shaped, i.e. spiral in the manner of a snail-shell.

Calospérmous (-us). Hollow-seeded; applied to seed-like carpels of Umbelliferæ with ventral face incurved at top and bottom, as in Coriander.
Conanthium. Synonym of Clinanthium. Coenobio. Synonym of Carcerulus.

Cohesion. The congenital union of one organ with another; either similar parts (coalescence), or dissimilar parts (adnation).

Cohort. In classification a group next superior to order, 326.

Coleorhiza. Root-sheath; the investment (belonging to the cotyledon or plumule) through which the primary root in many Monocotyledons bursts in germination; 26.

Collar (Collum). Name of an imaginary something intermediate between primary stem and root.

Collateral. Standing side by side.

Collective Fruits. The aggregation of the fruits of several flowers into one mass; 301.

Colored. Of other color than the green of herbage; 118.

Columélla. The persistent axis of certain capsules, spore-cases, \&c.; 289.

Column (Columna). Body formed by the union of the filaments among themselves (as in a malvaceous flower), or with the style or stigma, as in $\mathrm{Or}$ chids; 250.

Columnar. Column-shaped ; pillar shaped.

Coma. Literally a head of hair; a tuft of hairs of any sort; specially a tuft of hairs on a seed; 306 . Also the name of the whole head of a tree.

Commissure (-ura). The face by which two carpels cohere, as in Umbelliferæ.

Common (Communis). General or principal, as opposed to partial.

Comose (-osus), sometimes Comatus. Furnished with a coma.

Complanate (-atus). Flattened.

Complete (Completus). Having all the parts belong to it or to the type; $\mathbf{1 7 5}$. Cómplicate (-atus). Folded upon itself.

Compound. Said of similar parts aggregated into a common whole. Compound Flower, 147. Compound Pistil, 263. Compound Inflorescence, 159.

Compound Leaf. One divided into separate blades; 100 .

Compressed (-us). Flattened lengthwise.

Concaulescence. A name for the coalescence of axes; 158.

Conceptacle (-aculum). Originally used by Linnæus for what is now called Follicle; and later for the pair of follicles of Asclepiadacer and Apocynacem. 
Conchiformis. Shaped like one valve of a bivalve shell.

Concinnus. Neat or elegant.

Cóncolor. Of the same or of uniform color.

Condúplicate (-atus), Conduplicativus. Folded together lengthwise; 133.

Cone. See Strobile.

Confertus. Closely packed or crowded.

Conferruminate (-atus). Stuck together by adjacent faces, as the cotyledons of Horsechestnut; 314 .

Confluent (-ens). Blended into one; passing by degrees the one into the other.

Conformed (-ormis). Similar to in form; or closely fitted to, as a seed-coat to the nucleus.

Congested (-us). Crowded together.

Conglobate (-atus). Collected into a ball.

Conglomerate (-atus). Densely clustered or heaped together.

Coniferous (-us). Cone-bearing.

Cónjugate (-atus). Coupled; in single pairs. Conjugate-pinnate, 104.

Connate (-atus). United congenitally; 107, 182.

Connate-perfoliate. United at base in pairs around the supporting axis; 108.

Connéctive (-ivum). A portion of a stamen which connects the two cells or lobes of an anther; 251.

Connivent (-ens). Coming into contact or converging.

Conocarpium. An unused name for an aggregate fruit, such as a strawberry, consisting of many carpels on a conical receptacle; 298.

Consolidated. When unlike parts arc coherent.

Continuous. The reverse of articulated or interrupted.

Contorted (-us). Twisted; or bent or twisted on itself. In Estivation, the same as Convolute; 138.

Contortuplicate (-atus). Twisted and plaited or folded.

Contracted. Either narrowed or shortened.

Contrary (-arius). Opposite in direction to the part compared with; as a silicle compressed contrary to the dissepiment.

Convolute (-utus) or Convolutive (-ivus). Rolled up from the sides or longitudinally. In Æstivation, 138. In Vernation, 133.

Córalioid (-eus). Coral-like.

Cbrculum. Old name for the embryo, or Cor seminis; 311.
Cordate (-atus), sometimes Cordiform (-ormis). Heart-shaped; like the figure of a heart on cards; the stalk at the broader and notched end; 96 .

Coriaceous (-eus). Leathery in consistence.

Cork, 81.

Corky. Of the texture of cork.

Corky Envelope, 76.

Corm (Cormus). A bulb-like fleshy stem, or base of a stem ; a "solid bulb;" 61.

Cormophytes (Cormophýta), 341.

Corneous (-eus). Of the texture of horn.

Corniculate (-atus). Furnished with a little horn.

Cornu. A horn; i.e. a horn-like process; sometimes used for Calcar, a spur.

Cornute (-utus). Furnished with a hornlike process or spur.

Corolla. The interior perianth, composed of petals; $165,243$.

Corollaceous (-eus), Corollinus. Pertaining to, or resembling corolla.

Corolliferous (-us). Bearing a corolla.

Corolliflorous, Corolliflora, 340.

Coróllula. Diminutive of corolla.

Coróna. A crown; an inner appendage to a petal, or to the throat of a corolla; 210,246 . Or any coronet-like appendage at the summit of (crowning) an organ.

Coromate (-atus). Crowned, having a corona, \&c.

Corbniform (-ormis). Shaped like a crown or coronet.

Córrugate (-atus or -ativus). Wrinkled or in folds; 133.

Cortex. Rind or bark.

Cortical (-alis). Relating to bark.

Corticate (-atus). Coated with a bark or with an accessory bark-like covering.

Corymb (Corymbus). A flat-topped or merely convex and open flower-cluster of the indeterminate or centripetal order; 146.

Corymbiferous (-us). Bearing corymbs. Corymbose. In corymbs, or in the manner of a corymb. The corymb of Linnæus and of other writers down to Rœper included most cymes. So that much cymose inflorescence is in descriptions loosely said to be corymbose, or a stem is said to be corymbosely branched, even when the evolution is centrifugal; 146.

Costa. A rib; when single, a midrib or mid-nerve. 
Costal-nerved. With nerves springing from a midrib; 92 .

Costate (-atus). Ribbed; furnished with one or more longitudinal primary veins or ribs.

Cotylédons (Cotylédon, pl. Cotyledones). The "seed-lobes," being the leaves or first leaves of the embryo; viz., the one, or the pair, or rarely the whorl of leaves borne by the radicle or caulicle; $10,311,313$.

Cotyliformis. Dish-shaped, or wheelshaped with an erect or ascending border.

Craterriform (-ormis). In the shape of a goblet or cup, of hemispherical contour or more shallow ; 248.

Crémocarp (Cremocárpium). A dry and seed-like fruit, composed of two oneseeded carpels, invested by an epigynous calyx, and separating at maturity; 297.

Creeping. Running along or under ground and rooting; 53.

Crena, Crenatura. A rounded tooth or notch.

Crenate (-atus). Toothed by crenatures; scalloped; 98.

Crenel, Crenelled. Same as Crenature and Crenate.

Crénulate (-atus). Diminutive of Crenate, $i$. e. with small crenatures.

Crested. Furnished with any elevated line, ridge, or conspicuous elevation on the surface, especially such as may be likened to the crest of a helmet.

Cretaceus. Chalk-white; chalky.

Cribrose (-osus) and Cribriform (-ormis). Pierced like a sieve.

Cribriform Cells, 77.

Crinitus. Bearded with long and weak hairs.

Crispatus. Curled or crispy.

Cristate (-atus). Crested.

Croceus, Crocatus. Saffron-colored, i.e. deep reddish-yellow.

Cross-breeds. The progeny of interbred varieties; 321 .

Cross-fertilization. Fecundation by pollen of another flower and of another individual ; 216.

Crown. See Corona, 210; 246.

Crowned. See Coroule.

Crowning (Coronans). Borne on the summit of an organ.

Cruciate (-atus), Cruciform (-ormis). Cross-shaped.

Crucíferous (-us). Cross-bearing; used in the sense of Cruciform; as the "cruciferous" corolla of the order Cruciferæ; 246.

Crumpled. See Corrugate.

Crustaceous (-us). Of hard and brittle texture.

Cryptos. Greek for concealed; whence

Cryptogamia. Cryptogamous or Cryptogamic plants ; $3,335,344$.

Cryptógamous. Pertaining to the above. Cúcullate (-âtus), Cuculláris, Cuculliformis. Hooded, or hood-shaped, cowled.

Culm (Culmus). The peculiar stem or straw of Grain-plants and Grasses; 50.

Cultrate (-atus), Cultriformis. Shaped like a broad knife-blade.

Cúneate (Cuneatus), Cúneiform (-ormis). Wedge-shaped; triangular with an acute angle downward; 95.

Cup-shaped. In the form of a drinkingcup.

Cupule (Cupula). The acorn-cup and the like; 296.

Cupularis, Cupulatus. Furnished with or subtended by a cupule or any resembling body.

Cupuliferous (-us). Cupule-bearing.

Curvinerved (-ius). When the ribs of a leaf are curved in their course; $\mathbf{9 2}$.

Curvisérial. In curved or oblique ranks; 124.

Cushion. The enlargement at or beneath the insertion of many leaves.

Cuspidate (-atus). Tipped with a Cusp, or sharp and rigid point; 97.

Cut. Same as incised, or in a general sense as cleft.

Cuticle ( Cuticula). The outermost skin or pellicle.

Cutting. A severed portion of a plant used for bud-propagation; 43.

Cyáneus. A clear bright blue.

Cyáthiform (-ormis). Cup-shaped; in the form of a

Cyáthus. A drinking-cup, such as a goblet or wine-glass.

Cycle. A circle. Sometimes used for one turn of a helix or spire; 122.

Cyclical. Relating to a cycle; or coiled into a circle; $119,120$.

Cylindraceous. Somewhat or nearly cylindrical.

Cylindrical (-us). Elongated and with circular cross-section; in the form of a cylinder.

Cymbaform or Cymbiform (-ormis). Boat-shaped.

Cyme (Cyma). A flower-cluster of the determinate or centrifugal type, 
especially a broad and flattish one; 151.

Cymo-botryose. When cymes are arranged in botryose manner; 159 .

Cymose (-osus). Bearing cymes, or relating to a cyme; 151 .

Cymule (Cymula). Diminutive cyme, or a portion of a cyme; 151 .

Cynarrhodium. Name of such a fruit as that of the Rose; fleshy, hollow, and enclosing achenia.

Cýpsela. Name of an achenium invested by an adnate calyx, as the fruit of Compositæ; 295.

Cystolith. One of the mineral and usually partly crystalline concretions of the cells of the epidermis of or subjacent tissue of the leaf in various plants, especially in Urticaceæ.

Cýtoblast. An obsolete name for the nucleus of a cell of cellular tissue.

Dáctylose (-osus). Fingered, or fingershaped.

Dasyphýllous (-us). Woolly-leaved.

Dealbate (-atus). Whitened over (as if whitewashed) with a white powder or minute pubescence.

Deca. Greek for ten, compounded with various words, such as

Decagýnia. One of the Linnæan artificial orders; 337.

Decágynous (-us). With ten styles or carpels.

Decámerous (-us). Of ten members; 176.

Decandria. A Linnæan class with ten stamens; 334.

Decándrous (-us). With ten stamens; 249.

Decapétalous (-us), Decasepalous, \&c. With ten petals or sepals, \&c.

Deciduous (-us). Falling, or subject to fall in season, as petals after anthesis, and leaves (except of evergreens) in antumn; 243.

Déclinate (-atus), or Declined. Bent or curved downward or forward.

Decompound. Several times compounded or divided; 102, 104.

Decompositus. Decompound.

Decumbent (-ens). Reclining, but with summit ascending; 53.

Decurrent (-ens), Decursive. Running down into; as where leaves are seemingly prolonged below their insertion, and so run down the stem.

Decuissate (-atus). In pairs alternately crossing at right angles.
Deduplication, Fr. Dédoublement. Same as Chorisis; 202.

Definite (-itus). Of a fixed number, not exceeding twenty; or of a fixed order.

Definite Inflarescence. Where axes of inflorescence end in a flower; 144, 151.

Deflexed (-us). Bent or turned abruptly downward.

Deflorate (-atus). Past the flowering state.

Defoliate (-atus). Having cast its leaves. Defoliation, 87.

Dehiscence (-entia). The mode of opening of a capsule or anther by valves, slits, or regular lines; 288.

Dehiscent (-ens). Opening by regular dehiscence; 292.

Deliquescent (-ens). Dissolving or melting away, as a stem divided into branches; 48 .

Deltoid (-oides). Having the shape of the Greek letter $\Delta$.

Demersed ( us). Under water; same as submersed.

Dendritic (-icus), Dendroid (-oideus). Tree-like.

Dendron. Greek for tree.

Deni. Ten together.

Dens. A tooth.

Dentate (-atus). Toothed; specially with salient teeth not turned forward ; 98 .

Denticulate (-atus). Minutely toothed; having denticulations, or diminutive teeth.

Denudate (-atus). Made naked; stripped.

Deorsum. Downwards.

Depauperate (-atus). Impoverished; as if starved; or diminutive for want of favorable surroundings.

Depressed (-us). Having the appearance or shape as if flattened from above.

Derma. Greek for skin or surface of a plant or organ.

Descending (-ens). Tending or turning gradually downward.

Descending Axis. Primary root; 11.

Determinate. Limited in number or extent; as are the axes of determinate inflorescence; 144, 151.

Désinens. Terminating in.

Desmos. Greek for things bound, or as if chained together.

Dextrorse (Dextrorsus: adv. Dextror sum). Toward the right hand, or relating to it; 51, 140.

$D i, D i s$. In Greek compounds, two, or double.

Diachenium. Synonym of Cremocarp. 
Diadélphia. A Linnæan (335) class having the stamens.

Diadelphous (-us). Combined by their filaments into two sets; 250 .

Diagnósis. A brief distinguishing character.

Dialypétalos, 341

Dialypetalous (-us). Same as polypetalous, $i$. e. of separate petals; 244.

Dialyphýllous (-us). Bearing separate leaves.

Diandria. A Linnæan class with perfect flowers having only two stamens; 334.

Diandrous (Diander, \&c.). Having two stamens; 249.

Diaiphanous (-us). Letting the light shine through.

Dicarpellary. Composed of two carpels or pistil-leaves; 261.

Dichásium. A two-parted or two-rayed cyme; $152,155$.

Dichlamýdeous (-eus). Having a double perianth; 191.

Dichótomous (-us). Forked in pairs; two-forked.

Dichogamous (-us), Dichogamy. Hermaphrodite with one sex earlier developed than the other in the blossom; 219.

Diclésium. Name of a fruit consisting of an achenium within a separate and free covering made of perianth, as that of Mirabilis.

Diclinous (Diclinis). When flowers are of separate sexes; 191.

Dicóccous (-us). Fruits of two cocci.

Dicotylédons, Dicotylédones. Plants of the class marked by having two cotyledons; $27,339,340,344$.

Dicotylédonous (-eus). Having a pair of cotyledons; 10,314 .

Didymous (-us). Twin, found in pairs.

Didynámia. The Linnæan class marked by didynamy (335), $i$.e.

Didynamous (-us). When a 4-androus flower has the stamens in two pairs, and one pair shorter than the other; 250.

Dierésilis. Mirbel's name for a dry fruit composed of several cells or carpels connate around a central axis, and separating at maturity, as that of Mallow.

Difformis. Of unusual formation.

Diffuse (-usus). Widely or loosely spreading.

Digamous (-us). Of two sexes in the same cluster.
Digitate (-atus). Fingered; a compound leaf in which all the leaflets are borne on the apex of the petiole; 101.

Digitately. In a digitate mode; same as Palmately.

Digitate-Pinnate, 104.

Digýnia. A Linnæan order characterized by having the gynœcium

Digynous. With two separate styles or carpels ; 261.

Dimerous ( $-u s)$ Of two members in each circle; 176.

Dimidiate (-atus). Halved, or as if onobalf was wanting.

Dimorphous (-us), Dimorphic, Dimorphism. Occurring under two forms; 225, 234.

Diøecia. Linnæan class (355) of plants with the flowers

Dicecious (Diocius, Dioicous). Unisexual, and the two sexes borne by distinct individuals; 191.

Diocio-polygamous. When some individuals bear unisexual and others bisexual flowers.

Dipetalous (-us). Two-petaled; 244.

Diphýllous (-us). Two-leaved; 243.

Diplo. See Duplo.

Diplostémonous, Diplostémony. Having twice as many stamens as petals or sepals; $177,198$.

Diplotegium. A capsule or other dry fruit, invested with adnate calyx; an inferior capsule.

Dipterous -(us). Two-winged.

Diremption (-io). Syn. of Chorisis; 202.

Disciferous (-us). Disk-bearing.

Disciform (-ormis). Depressed and ciscular, like a disk or quoit.

Discoidal or Discoid (Discoideus). $\Lambda p$ pertaining to a disk. A discoid head is one destitute of ray-flowers.

Disc or Disk (Discus). A word used in several senses. The disk or disc of a flower is a development of the torus within the calyx, or within the corolla and stamens ; 213 . In a capitulum or head of flowers it is the central part of the cluster, or the whole of it as opposed to a border or ray. It is the face or surface of any organ, such as a leaf-blade, as opposed to the margin. In vegetable anatomy, certain round spots or markings on cell-walls are termed discs.

Discolor. When the two faces of a leaf, $\& c$. , are unlike in color.

Discrete (-etus). Separate; not coalescent. 
Disepalous (-us). Two-sepaled; 244.

Disk-flowers. Those belonging to the disk, or body, and not to the margin or ray of a capitulum.

Dissected (-us). Deeply cut or divided into numerous segments.

Dissépiment (-ēntum). A partition in an ovary or pericarp; 264.

Dissilient (-ens). Bursting asunder or in pieces.

Distichous (-us). Disposed in two vertical ranks; 122.

Distinct (Distinctus). Separate from; not united.

Distractile (-ilis). Carried widely apart.

Dithécous (-us). Of two thecæ, or cells, as are most anthers; 254 .

Diurnal. Daily; occurring in the day; sometimes used for ephemeral.

Divaricate (-atus). Extremely divergent.

Divergent, Diverging (-ens). Inclining away from each other.

Divided (Divisus). Where lobing or segmentation extends to the base; 98 .

Dodeca. Greek for twelve. Used in

Dodecagýnia. Linnæan order with flowers.

Dodecágynous. Having twelve styles or distinct carpels.

Dodecámerous $(-u s)$. Of twelve parts in the circle.

Dodecandria. A Linnæan class (334) with the flowers.

Dodecandrous. Having twelve (or from 12 to 19$)$ stamens; 249.

Dodrantális. A span (about nine inches) long.

Dolabriform (-ormis). Axe-shaped or hatchet-shaped.

Dorsal (-alis). Relating to the dorsum or back.

Dorsal Suture. That which answers to the midrib of a carpel; 261 .

Dorsiferous. Borne on the back.

Double. Has a technical use when a flower is said to be "double;" this denoting one in which the leaves of the flower are monstrously increased mostly at the expense of the essential organs.

Downy. Pubescent with fine and soft hairs. Loosely synonymous with softpubescent, tomentose, \&c.

Drepánium. A sickle-shaped cyme; 156.

Drupaceous (-eus). Resembling or relating to a drupe.

Drupe (Drupa). A stone fruit; 297.

Drupelet, Drupel (Drupéola). A diminutive drupe; 297.
Drupétum. An aggregation of drupes; 300.

Duct. In vegetable anatomy, an elongated cell or tubular vessel, found especially in the woody (fibro-vascular) parts of plants.

Dumetose (-osus). Pertaining to Dumetum, a thicket, or Dumus, a bush.

Dumose (-osus). Bushy, or relating to bushes.

Duplo. Twice as many. In Greek compounds, Diplo.

Duramen. The heart-wood of an exogenous stem; 80 .

Dwarf. Of small size or height compared with its relatives.

Dyclesium. See Diclesium.

$E$ - or $E x$ - As a prefix to Latin words, carries a privative meaning, as Ecostate, without ribs, Exalbuminous, without albumen.

Eared. Same as Auriculate.

Ebracteate, Ebracteolate (-atus). Destitute of bracts or bractlets.

Eburneus. Ivory-white.

Ecálcarate (-atus). Spurless.

Echinate (-atus). Beset with prickles, like a bedgehog.

Echinulate (-atus). Beset with diminutive prickles.

Edentate (-atus). Toothless.

Effete (-etus), or Effetus. Past bearing; functionless from age.

Efflorescence (-entia). The time or state of blossoming; anthesis.

Effuse (-usus). Very loosely spreading, more so than diffuse.

Eglandulose (-osus). Destitute of glands.

Egg-shaped. See Ovate.

Elaiter. One of the spiral or spirally marked threads in the spore-cases of certain Hepaticx.

Elátus. Tall or lofty.

Eleutheros. In Greek compounds, separate or distinct.

Eleutheropetalous (-us). Same as Choripetalous or Polypetalous; 245.

Ellipsoidal (-eus). An elliptical solid; sometimes used for nearly elliptical.

Elliptical (-us). In the form of an ellipse. Oval or oblong with regularly rounded ends; 95 .

Emarcidus. Flaccid or withered.

Emarginate (-atus). With a notch cut out of the margin; or, as usually applied, ont of the extremity; 97.

Embracing. Clasping by the base. 
Embryo or Embryon. The rudimentary plantlet formed in a seed; 9,311 .

Embryonal. Relating to the embryo; as Embryonal Vesicle; 284.

Embryo-sac. The cell in the ovule in which the embryo is formed; 283.

Embryógeny. Embryo-formation.

Emersed (Emersus). Raised above and out of the water.

Enantioblaistus. With embryo at the end of the seed diametrically opposite the hilum.

Enation. Having outgrowths from the surface, \&c.; 179.

Endeca. In Greek compounds, eleven; as in

Endecándrous, Endecágynous. With eleven stamens or eleven styles, \&c.

Endemic. Confined geographically to the particular region.

Éndocarp (-árpium). The inner layer of a pericarp; 288.

Éndochrome (-óma). Peculiar coloring matter in cells; especially the coloring matter of Algæ.

Éndogens, Endogena. Endogenous Plants; 70.

Endógenous structure, 70.

Endopleura. Inner seed-coat; 306.

Endophloeum. Inner bark; 77.

Endorhizal (-us). Said of an embryo which has the radicle sheathed by the cotyledon or plumule wrapped around it in many Monocotyledons; hence

Endorhizae. Synonym of Monocotyledones.

Endosperm (-ermium). Synonym of the albumen of a seed; or the inner albumen; 14, 310.

Endostome (-oma). The foramen of the inner coat of an ovule; 277.

Endothecium. Inner lining of the cell of an anther.

Enérvis, Enervius. Nerveless; no ribs or veing visible.

Ennea. In Greek compounds, nine; as in

Enneagýnia. A Linnæan ordinal name, and

Enneágynous. With nine separate styles or carpels; 337.

Enneandria. Linnæan class, and Enneandrous, with nine stamens; $249,334$.

Enódal (Enodis). Without a node.

Ensátus. Same as Ensiform.

Ensiform (-ormis). Sword-shaped; i. e. like a broad sword, or the leaf of an Iris.
Entire. Without toothing or division; the margin whole and even; 97.

Entomóphilous. Said of flowers which are habitually fecundated by pollen carried by insects ; $217,218$.

Entophytes (Entophyta). Plants growing in or out of other plants, as certain Fungi, \&c.; 4.

Ephemeral. Lasting only for one day.

Epi. In Greek compounds, upon.

Epiblast (-rs). Name sometimes given to the first (and an undeveloping) leaf of the plumule of the embryo of grasses and grain.

Epiblastéma. A superficial outgrowth from leaves, \&c. ; 210.

Epicalyx. Name sometimes given to an involucel resembling an accessory calyx.

Épicarp (Epicarpium). The external layer of a pericarp; 288.

Epichilium. The terminal portion of the labellum of an Orchid, when this is of two parts.

Epiclinal (-us). Upon a torus.

Epicórolline. Upon a corolla.

Epidermis. The skin of a plant; 76, 89.

Epigaeous (-eus). Growing on or out of the ground.

Epigynous (-us). Literally on the pistil; meaning on the ovary, or seemingly so; 183.

Epipetalous ( $-u s)$. Borne on (adnate to) the petals; also used in the sense of placed before the petals.

Epiphloum. The outermost or corky bark; 76.

Epiphyllous (-us). Growing on leaves.

Epiphýtal. Pertaining to

Epiphytes (Epiphyta). Plants growing on other plants by way of attachment, but not parasitic; air-plants; 35.

Epipterous (-us). Winged or wingbearing at summit.

Episepalous. On the sepals; also used in the sense of standing before a sepal.

Exisperm (Epispermium). The coat or outer coat of a seed; 305 .

Épitropous (-us). Name (by Agardh) of an anatropous ovule with rhaphe averse when ascending, adverse when suspended; 282.

Equal (Aqualis). Alike as to length or number, \&c., as the case may be.

Equitant (-ans). Riding; folded around, as if straddling over; 108, 138.

Erect (Erectus). Standing npright, mostly in relation to the ground, 
sometimes when perpendicular to the surface of attachment.

Erion. Greek for wool; used in compound words, as

Erianthus. With woolly flowers.

Eriophorus. Wool-bearing.

Eriophy'luss. Woolly-leaved.

Eróstrate (Erostris). Beakless.

Erose (Erosus). As if gnawed; applied to an irregularly toothed or eroded margin.

Erythros. Greek for red, used in compound terms from the Greek.

Erythrostomum. Name given by Desvaux for such an aggregate fruit as a raspberry; 300 .

Estivation. See Fstivation.

Etcerio. Name of aggregate fruits, especially of fleshy ones, such as a black berry.

Etiolated. Blanched by darkness.

Eu. Prefixed to words of Greek derivation denotes very, true, or much so. Frequently used in names of sections or other groups ; 357.

Euphýlla. Foliage-leaves, or true leaves.

Eútropic (-icus). Name suggested for twining "with the sun;" 51 .

Evalvular (Evalvis). Not opening by valves.

Evergreen. Bearing green foliage all the year round.

Evittatus. Not vittate.

$E x$. A prefix in place of $E$ privative when the following part of the compound begins with a vowel; as

Exalbuminous (-osus). Destitute of albumen; 14, 309.

Exálate (-atus). Destitute of wing.

Exanthemata. Eruptive excrescenses on the surface of leaves, \&c.; blotches.

Exaristate (-atus). Destitute of an arista or awn.

Exasperate (-atus). Rongh with hard projecting points.

Excentric (-icus). Out of the centre; one-sided.

Excurrent (-ens). Running through to the very summit or beyond; 48 .

Exiguus. Small or mean.

Exilis. Lank or meagre.

Eximius. Distinguished, as for size or beauty.

Exo-. In Greek compounds, external or outward; as

Exocarp (Exocarpium). The outer layer of a pericarp ; 288.

Exógenous. Outside growing, as the wood of Dicotyledons; 69, 73.
Exogens, Exogena. Exogenous Plants; 69,340 .

Exorhizo. Name equivalent to Exogen, from

Exorhizal (-us). The radicle not sheathed, so the primary root in germination has no covering to break through.

Exostome (Exóstoma). The foramen of the outer coat of the ovule; 277.

Exothécium. The outer wall of an anther.

Explanate (-atus). Spread out flat.

Exsért, Exserted (Exsértus). Protruding beyond or out of, as stamens beyond the corolla.

Exstipulate (-atus). Destitute of stipules.

Exterior. External in the sense of outer. But also in the flower sometimes nsed in the sense of anterior.

Extine. Outer coat of a pollen-grain.

Extra-axillary. Beyond or out of the axil.

Extrorse (Extrorsus, Extrorsum). Directed outward; 253.

Eye. A gardener's name for an undeveloped bud.

Facies. Face; the general aspect.

Falcate (-atus), and Falciform (-ormis). Scythe-shaped or sickle-shaped ; plain and curved, with the edges parallel.

Family. In botany, synonymous with Order; 325.

Fan-shaped. See Flabelliform.

Farina. Starch.

Farinaceous (-eus). Of the nature of starch, or containing it.

Farinose (-osus). Covered with a meallike powder.

Fasciate (-atus). Said of monstrous expansions of stems, giving the appearance as of several stems coalescent in one plane.

Fascicle (-icula). A close cluster or bundle, whether of flowers, stalks, roots, or leaves; 147, 153.

Fascicled (Fasciculatus, Fascicularis). In a fascicle; 131.

Fastigiate (-atus). Said of branches when parallel, clustered, and erect.

Faux, pl. fauces. The gorge or throat of a gamophyllous calyx or corolla; either at the orifice, or a portion between the limb and the proper tube; 246.

Fáveolate (-atus), Favose (-osus). Honeycombed; same as Alveolate.

Feather-veined. Having veins all proceeding from the sides of a midrib.

Feathery. See Plumose. 
Fécula or Facula. Starch-like matter. Applied to a pistillate flower, or to a plant producing only such flowers.

Fenéstrate (-atus), Fenestralis. Pierced with large holes, like windows.

Ferrugineous or Ferruginous (Ferrugineus). Colored to imitate iron-rust.

Fertile (-ilis). Fruitful, fruiting, or capable of producing fruit; as a fertile flower is one provided with a wellformed pistil; 191. In English descriptions, Flower fertile usually means a pistillate or female flower. Stamens or anthers are also said to be fertile when polliniferous and capable of fertilizing.

Fertilization. Synonym of fecundation, as of the ovule by pollen; 215 .

Fibre (Fibra). Any fine filament; the elementary components of wood, \&c. ; delicate roots, \&c.

Fibril (-illa). A diminutive fibre.

Fibrillate (-atus), Fibrillose (-osus). Furnished or abounding with fibres or fibrils.

Fibrous, Fibrose (-osus). Composed or of the nature of fibres.

Fibro-vascular. Consisting of woody fibres and ducts.

Fiddle-shaped. Obovate and with a sinus or contraction on each side.

Fidus. A Latin termination for cleft or lobed.

Filament (-entum). The stalk or support of an anther; 165, 251. Also any fibre-shaped or thread-like body.

Filamentous, Filamentose (-osus). Composed of threads or filaments.

Filicology. The botany of Ferns: replaced by Pteridology.

Filiform (-ormis). Thread-shaped; long, slender, and terete.

Filipéndulous ( $-u s)$. Hanging from a thread.

Fimbria. A fringe, or dissected border.

Fimbriate (-atus). Fringed; bordered by slender processes or marginal appendages.

Fimbrillate (-atus), Fimbrilliferous (-us). Bearing Fimbrilloe or diminutive fringe.

Fingered. See Digitate.

Fissiparous. Multiplying by the division of one body into two, and so on.

Fissus. Split or cleft. See Fidus.

Fistular, Fistulose (-osus). Hollow through the whole length, as the leaf and stem of an Onion.

Flábellate (-atus), Flabelliform (-ormis). Fan-shaped; much dilated from a wedge-shaped base, and the broader end rounded.

Flabellinerved. With radiating straight nerves; 92.

Flágellate (-atus), Flagellaris. Produe ing filiform runners (Flagella), or runner-like branches.

Flagélliform (-ormis). Runner-like; long, slender, and supple like a whiplash or Flagellum; 53.

Flammeus. Flame-colored.

Flavescent (-ens). Yellowish or pale yellow.

Flavus. Pale yellow or ochre-yellow.

Fleshy. Succulent; of the consistence of flesh.

Flexuous, Flexuose (-osus). Zigzag; bent alternately in opposite directions.

Floating. Borne on the surface of water.

Floccose (-osus). Bearing or clothed with locks of soft hairs or wool (flocci).

Flocculent. Diminutive of floccose.

Flora (Goddess of flowers). The aggregate of the plants of a country or district; or the name of a work which systematically describes them; 369 .

Floral. Belonging to the flower.

Floral Envelopes. Flower-leaves; 164.

Floret. A small flower, one of a cluster.

Floribundus. Abundantly floriferous.

Floriferous (Florifer, Floriferus). Bearing flowers.

Florrula. A small Flora; the Flora of a restricted district.

Flos. Latin for flower. - Flos plenus. A "double" flower; that is, one in which petals are increased abnormally, commonly at the expense of the androcium or the gynoecium also; 171 .

Flósculus. Latin for floret.

Flower. The whole reprodnctive apparatus in a phænogamous plant; 163 .

Flower-bud. An unexpanded blossom or undeveloped cluster; 40.

Flowering Plants, 3, 344.

Flowerless Plants, 3, 344.

Fluitans. Floating.

Fliviatile, Fluviátilis. Belonging to a river or running water.

Fly-traps, 113.

Fomineus. Feminine or female flower, plant, \&c. ; 191.

Foliaceous (-eus). Leaf-like in texture or appearance; or bearing leaves.

Foliar (Foliaris). Relating to leaves. Foliation (Foliatio). Leafing out.

Foliate (-atus). Having leaves. With

Latin numerical prefix, bifoliate, th 
foliate, and so on, according to the number.

Foliiform (-ormis). Leaf-shaped.

Fóliolate (-atus). Having leaflets: their number may be indicated by Latin numerals, as bifoliolate, trifoliolate, \&c.; 102.

Foliolum. A leaflet; 102.

Foliose. Bearing numerous leaves.

Folium. Latin for leaf; 85 .

Follicétum. A whorl or aggregation of follicles; 300 .

Follicle (-iculus). Fruit of a single carpel dehiscent by one (the ventral) suture; 292. Name of the earlier botanists for any kind of capsular fruit.

Follicular (-aris). Pertaining to or like a follicle.

Foot-stalk. Petiole, 85; or Peduncle, 143.

Forámen. An aperture of any kind; specially that of the coat of the ovule; 277.

Foraminulose (-osus). Pierced with many small holes.

Fórcipate (-atus). Like forceps or pincers.

Forked. Divided equally into branches.

Fornicate (-atus). Arched over, as by scales (Fornices) covering the throat of the corolla of Hound's-tongue, \&c.

Foveate (-atus), and diminutive Foveolate. Pitted; impressed with shallow depressions or pits, Fovea.

Fovillk. Minute granules in a liquid, in the protoplasm of the pollen-grain, \&c.; 258.

Free. Not adnate to other organs. Sometimes used in the sense of distinct, $i$. e. unconnected with others of the same sort.

Fringed. See Fimbriate.

Frond (Frons). An old name for leaf : employed mainly for the leaf of Ferns and other Cryptogamia, and certain Phænogamous plants which serve for fructification as well as foliage; also for the peculiar foliage of Palms; 67 .

Frondescence (-entia). The act of leafing. Has also been emplorsd to express the metamorphosis of floral organs into foliage-leaves; 174.

Frondose (-osus). Sometimes used in the sense of leafy; also frond-like, or bearing fronds.

Fructification. The act or the organs of fruiting or reproduction through flower and seed, or their analogues.

Fructus. Latin for Fruit.

Fruit. The immediate product of fruc- tification; in phrnogamous plants, the seed-vessel and contents, along with all intimately connected accessory parts; 285.

Fruit-dots in Ferns. See Sorus.

Frumentaceous. Relating to grain (Frumentum).

Frustulose (-osus). Consisting of similar pieces or Frustules ( frustula).

Frutex. A shrub.

Frutescent (-ens). Shrubby, or becoming so.

Fruticose (-osus). Shrubby, or relating to shrubs.

Fruticulose (-osus). Relating to a diminutive shrubby plant.

Fruticulus. A minute or low shrubby plant.

Fugacious. Falling or fading very early; lasting a very short time.

Fulvous (-us). Tawny; orange-yellow and gray mixed.

Fulcra. Accessory organs, such as tendrils, stipules, spines, and the like.

Fulcrate (-atus). Propped, supported by, or provided with accessory organs.

Fuliginous (-asus). Sooty-brown.

Fungiform (-ormis and Fungilliformis). Mushroom-shaped.

Fungose (-osus). Spongy in texture; fungus-like.

Fúnicule, Funiculus. The stalk of an ovule or seed; 276.

Funnelform, Funnel-shaped; 249. See Infundibuliform.

Furcate (-atus). Forked; or divergently branched.

Furcellatus. Diminutively forked.

Furfuraceous (-eus). Scurfy; covered with bran-like scales or powder.

Furrowed. See Sulcate.

Fuscous (-us). Grayish-brown in hne.

Fusiform (-ormis). Spindle-shaped ; terete and tapering gradually to each end; 31.

Gálbulus. The peculiar strobile of $\mathrm{Cy}$ press and Juniper, composed of upwardly thickened or fleshy scales; 303.

Galea. A helmet; name given, from its shape, to the upper sepal of Aconitum, and the upper lip of certain forms of bilabiate corolla; 247.

Galeate (-atus). Having a galea; helmet-shaped; 247.

Gamo-. In Greek compounds, denotes union by the edges or coalescence. 
Gamopetalous. A corolla of coalescent petals; formerly Monopetalous ; 244.

Gamophýllous (-us). Composed of coalescent leaves.

Gamosepalous. A calyx of coalescent sepals; 244.

Geitonógamy. Fecundation of a pistil by pollen of another flower of the same plant; 216.

Geminate (-atus). Twin; in pairs; two side by side.

Gemma. A bud, specially a leaf-bud.

Gemmation. Budding-growth; or the disposition of buds.

Gemmule (Gëmmula). Diminutive of gemma; minute and simple buds or bodies analogous to buds; also $8 y$ nonym of Plumule. For a time used by Endlicher and others for the ovule.

Genera. Plural of Genus; 323.

General (-alis). Opposed to partial; as general involucre.

Generic. Relating to genus.

Genetic. Genealogical; that which comes by inheritance.

Geniculate (-atus). Bent abruptly, like a knee.

Genitalia. The stamens and pistils or their analogues.

Genus. Kind or group superior to species, and which with the species gives the name to the plant; 323 .

Geoblast (-astus). A plumule which in germination rises from underground, such as that of the Pea.

Germ. A growing point or initial growth, as of a bud; or the Embry.0; 311 . Or in the sense of

Germen. The Linnæan name of the ovary; 166.

Germination (-atio). The act of development of the embryo of a seed into a plant.

Gerontogoons (-aus). Belonging to the Old World.

Gibbous, Gibbose (-osus). Swelling out on one side into a gibber or gibberosity.

Gigantéus. Of unusual height.

Gilvus. Dirty yellow with a tinge of red. Glabrous (Glaber). Smooth in the sense of not pubescent or hairy.

Glabrate (-atus). Somewhat glabrous, or becoming glabrous.

Glabriúsculus. Almost but not quite glabrous.

Gladiate (-atus). Sword-shaped; in the form of a sword-blade, whether straight or somewhat curred. See Ensiform.
Gland for Glans. An acorn and the like; 296.

Gland (Glandula). A definite secreting surface or structure on the surface of any part of a plant, or partly imbedded in it, extended to any protuberance or structure of similar nature which may not secrete.

Glandular, Glandulose (-osus). Bearing glands or having the nature of glands.

Glanduliferous (-us). Gland-bearing.

Glareosus. Growing in gravel.

Glaucescent (-ens). Verging upon or becoming glaucous.

Glaucous $(-u s)$. Covered or whitened with a bloom, like that on a Cabbageleaf.

Globose (-osus). Having or approaching a spherical form.

Globular (-aris), Globulose (-osus). Somewhat or nearly globose.

Glochideous, Glochidiate (-atus). When bristles and the like are barbed at tip.

Glochis. A barb.

Glomerate (-atus). Compactly clustered, especially into a

Glómerule (Glomérulus, Glomus). A cyme condensed into a head or capitate cluster; 152.

Glossology, 3, 359.

Glumaceous (-eus). Pertaining to or resembling glumes.

Glume, Gluma. One of the chaff-like bracts of the inflorescence of Grasses and their relatives; 143 .

Glumella. Diminutive of gluma; an inner or secondary glume.

Glutinous (-osus). Covered with a sticky exudation.

Gónophore (Gonóphorum). A stipe which elevates both stamens and pistil; 212.

Gossypine (-inus). Cottony; flocculent.

Grácilis. Slender.

Grain. See Caryopsis.

Gramineous (-eus). Relating to grass or grain-bearing plants.

Granular (-aris), Granulose (-osus). Composed of small grains or Granules. Granulate (-atus), Granuliferus. Bearing grains or grain-like bodies.

Gravéolens. Unpleasantly strong-scented.

Griseus. Gray or bluish-gray.

Grumous (Grumosus). Consisting of clustered grains.

Guttate (-atus). Spotted as if by drops. Gymnánthmus (-us). Naked flowered.

Gymnos. Greek for naked; used in compounds such as

Gymnocárpous (-us). Naked-fruited. 
Gymnospermia. A Linnæan artificial order of Didynamia, in which the nutlets resulting from four divisions of an ovary were taken for naked seeds; 337.

Gymnosperms, Gymnosperma. A subclass of naked-seeded plants ; 268,344 .

Gymnospermous (-us). Naked-seeded, as opposed to Angiospermous.

Gynandria. A Linnæan class, characterized by the flower being

Gynandrous. Stamens borne on (adnate to) the pistil, even to the style or stigma ; 251, 335.

Gýnobase (Gynobasis). An enlargement or production of the torus on which the gynœcium rests or is somewhat elevated; 212.

Gyno-diocious. Diœcious with some flowers hermaphrodite and others pistillate only; 191.

Gynocium. The pistil or collective pistils of a flower; the female portion of a flower as a whole; 165.

Gýnophore (Gynophorum). The stipe of a pistil; 212.

Gynostegium. A sheath or covering of the gynœeium, of whatever nature.

Gynostemium. The column of an Orchid, consisting of androcium and summit of the gynœeium combined.

Gyrate (-atus). Curved into a circle, or taking a circular course.

Gyrose (-osus). Curved backward and forward in turns.

Habit (Habitus). The general appearance of a plant.

Habitat. Habitation; the geographical limits or station; 366.

Hamatitic (-icus). Brown-red.

Hairs. Outgrowths of the epidermis, consisting of single elongated cells, or of a row of cells.

Hairy. Descriptively applied to pilosity or pubescence, in which the hairs are separately distinguishable.

Halbert- or Halberd-shaped. See Hastate.

Halved. See Dimidiate; with one half sbsent or appearing to be so.

Hamate (-atus). Hooked at the tip.

Hámulate or Hamulose (-osus). Diminutive of Hamate.

Haplos. In Greek compounds, simple or simply, as

Haplopetalus (-us). With only one row of petsls.
Haplostémonous (-us). With a single series of stamens; 177.

Hastate (-atus), Hastilis. Halberdshaped, like the head of a halberd, $i$. e. sagittate, but the basal lobes directed outward or at right angles to the midrib of the leaf; 96 .

Head. The form of inflorescence termed Capitulum, viz. \& cluster of sessile flowers on a very short axis and centripetal in evolution; 147.

Heart-shaped. Ovate with a sinus at base; 96.

Heart-wood. The older and matured wood of an exogenous stem; 80 .

Hébetate (-atus). Having a dull or blunt and soft point.

Helicoid (-oideus), Helicoidal. Coiled into a helix, or like a snail-shell. In true helicoid inflorescence, the flowers are all in a single row; 155,157 .

Helmet. See Galea.

Hélvolus. Dull and grayish yellow.

Hemi. Half or halved; in Greek compounds, such as

Hemi-anatropous. Half anatropons.

Hemicarp (-arpium). Half or one carpel of a Cremocarp.

Hemitropous (-us). Same as amphitre pous or half anatropous.

Hepta. The Greek numeral seven.

Heptagýnia. A Linnæan artificial order, having seven styles or distinct carpels; 337 .

Heptámerous (-us). Of seven members.

Heptandria. The Linnæan class with seren stamens; 334.

Heptandrous. Seven-stamened; 249.

Herb (Herba). A plant with no persistent woody stem above ground; 50 .

Herbaceous. Of the texture, color, or other characters of an herb.

Herbarium, Herbal. A collection of dried specimens of plants, systematically arranged; 380 .

Hercógamous (-us). Said of hermaphrodite flowers when some structural obstacle prevents autogamy.

Hermaphrodite (-itus). Of both sexes; 191.

Hesperidium. A hard-rinded berry, like an orange and lemon; 299.

Heteracmy. Synonym of Dichogamy; 219.

Heteros. In Greek compounds, denotes diverse or various, as

Heterocarpous (-us, Heterocarpicus). Producing more than one kind of fruit. 
Heterocéphalous (-us). Bearing two kinds of head or capitulum.

Heteroclite (-itus). Anomalons in formation.

Heterocline (-inus). Nearly same as Heterocephalous; on separate receptacles.

Heteródromous (-us). Spirals of changing direction.

Heterógamous (-us). Bearing two kinds of flowers.

Heterogeneous. Not uniform in kind.

Héterogone or Heterógoneus. When the flowers are dimorphous or trimorphous as respects relative length, \&c., of stamens and pistil; 225, 234.

Heterostyled. Same as Heterogone; 234.

Heterómerous. Of members not corresponding in number.

Heterophýllous (-us). Having leaves of more than one form.

Heterotrópous (- $-u s)$. Turned in more than one direction, or in an unusual direction; same as Amphitrópous; 279. (Also used by Agardh for collateral ovules turned back to back; 282.)

flexa. Greek numeral six; from which is formed

Aexagynia. Linnæan artificial order, of flowers with six styles or distinct carpels ; 337.

Hexágynous. Having the character of Hexagynia.

Hexámerous (-us). Of six members; 176.

Hexandria. Linnæan class with perfect flowers of six stamens; 334 .

Hexándrous. Having six stamens; 249.

Hexapétalous (-us). Having six petals.

Hexaphýllous. Six-leaved.

Hexápterous (-us). Six-winged.

Hexasépalous. Having six sepals.

Hexastemonous. Having six stamens.

Hibernaculum. A winter-bud; 40.

Hidden. Concealed from sight; as

Hidden-veined, where the veins are invisible, as in the leaves of Pinks and Houseleeks.

Hiemal (-alis). Relating to winter

Hilar (Hilaris). Belonging to the hilum.

Hilum. The scar or place of attachment of the seed; 277, 305 .

Hippocrepiform (-ormis). Horseshoeshaped.

Hirsute (-utus). Pubescent with rather coarse or stiff hairs.

Hirtéllous (-us). Minutely hirsute.

Hirtus. Hairy, nearly same as Hirsute.

Hispid (-idus). Beset with rigid or bristly hairs or with bristles.
Hispidulous (-us). Minutely hispid.

Hoary. Grayish-white with a fine and close pubescence. See Canescent.

Holosericeous (-eus). Covered with fine and silky pubescence.

Homocarpous (-us). With fruit all of one kind.

Homódromous (-us), Homodromy. With spirals all of uniform direction.

Homógamous (-us).' Bearing one kind of flowers.

Homogeneous. All of one nature or kind. Homogonous or Homogóne. Homomorphous as respects the stamens and pistil; opposed to dimorphons; 225.

Homologue. A homologous organ or part.

Homólogous. Of one name or type, such as leaves and parts answering morphologically to leaves; 6 .

Homomállus. Said of leaves and the like which are all turned in one direction.

Homomorphous (-us). All of one form.

Homostyled. Same as Homogone.

Homótropous (-us). Curved or turned in one direction; applied also to the embryo of an anatropous seed, with radicle next the hilum; 312 .

Hood. See Cucullus.

Hooded. Bearing or in form of a hood.

Hornus, Hornotinus. Of the present year.

Horny. Of the consistence of horn. See Corneus.

Hortensis, Hortulainus. Pertaining to the garden.

Hortus siccus. Old name of an herbarium.

Humi. On the ground.

Humifüsus, Humistrátus. Spread over the surface of the ground.

Humilis. Low of stature.

Hyaline (-inus). Transparent or translucent.

Hybrid. A mongrel, or cross-breed of two species; 321.

Hydrophýtes (Hydrophýta). Waterplants.

Hyemális. See Hiemalis.

Hypanthium. An enlargement or other development of the torus under the calyx; 214.

Hypo. In Greek compounds, denotes under, beneath, lower.

Hypanthodium. Same as Syconium; 149, 303.

Hypochilium. The basal portion of the labellum of an Orchid.

Hypocraterimorphous (-us), or Hypocrateriform, but the latter is a hybrid of 
Greek and Latin. Salverform or salver-shaped; that is, in the form of a salver raised on a central support or stem beneath. Said of a corolla and the like with slender tube abruptly expanded into a flat limb; 248 .

Hypogceous (-aus). Growing or remaining underground; 19.

Hypógynous (-us). Under or free from the gynoecium or pistil; 182.

Hypophyllous (-us). Growing on the under side of a leaf.

Hypophýllium. An abortive leaf or scale under another leaf, or seeming leaf, as in Asparagus and Ruscus.

Hypsophylla. Answers to the German "Hochblätter," or high leaves, those of the inflorescence, $i$. e. bracts and the like; 6.

Hysteranthous (-us). With leaves produced later than the blossoms.

Icosandria. The Linnæan class with twenty stamens (as the name denotes) or a larger number, inserted on the calyx ; 334 . Icosandrous is the corresponding adjective; 249 .

Imberbis. Not bearded.

Ímbricate (-atus), Imbricative. Overlapping so as to "break joints," like tiles or shingles on a roof; either with parts all in one horizontal row or circle, as in the æstivation of a calyx or corolla, when at least one piece must be wholly external and one internal; or with the tips of lower parts covering the bases of higher ones in a succession of rows or spiral ranks; 135.

Immarginate (-atus). Not margined or bordered.

Immersed (-us). Growing wholly under water.

Impari-pinnate. Pinnate with an odd terminal leaflet; 101.

Incequilateral (-alis). Unequal-sided.

Inanis. Empty, as an anther containing no pollen.

Inappendiculate (-atus). Not appendaged.

Incanescent. Same as Canescent.

Incanus. Hoary-white.

Incarnate (-atus). Flesh-colored. See Carneus.

Incised (-us). Cat irregularly and sharply; 98.

Included (Inclusus). When the part in question does not protrude beyond the surrounding organ.
Incomplete (-us). Wanting some essential component part; 190.

Incrassate (-atus). Thickened.

Íncubous (-us). The tip of one leaf or other part lying flat over the base of the next above it.

Incumbent (-ens). Leaning or resting upon.

Incumbent Anther. One lying against the inner face of filament; 253.

Incumbent Cotyledons, when the back of one lies against the radicle; 313 .

Incurved $(-u s)$. Bending from without inward.

Indefinite (-itus). Relates usually to number, this either uncertain or too many for easy counting.

Indefinite Growth, 49.

Indefinite Inflorescence, same as Indeterminate; 144.

Indehiscent (-ens). Not opening by valves, chinks, or along regular lines; 288.

Indeterminate. Not terminated absolutely, as the inflorescence in which no blossom ends the axis of the flowereluster; 144, 146.

Indigenous ( $-u s)$. Native and original to the country.

Individuals, 315.

Indivisus. Undivided, i. e. not cleft, lobed, or parted.

Induméntum. Any hairy covering or pubescence which forms a coating.

Induplicate (-atus). With edges folded in or turned inward.

Indusium. The proper (often shieldshaped) covering of the sorus or fruitcluster of a Fern.

Induviate (-atus). Clothed with withered parts or Induvia (clothing).

Inequilateral. Unequal-sided; 106.

Inérmis. Unarmed, without prickles, thorns, \&c.

Inferior (Inferus). Said of one organ when below another. In the blossom also in the sense of anterior; 160. An inferior calyx is one below the ovary, or free; 183. An inferior ovary is one with adnate or superior calyx ; 183.

Inflated (-atus). Bladdery.

Inflexed (-us). Bent or turned abruptly inward.

Inflorescence. Mode of disposition of flowers ; less properly used for a flowercluster itself; 141.

Infra-axillary (-aris). Below the axil. Infundibuliform (-ormis), Infundibular (-aris). Funnelform, funnel-shaped; 249. 
Innate (-atus). Borne on the apex of the supporting part; in an anther the counterpart of adnate; 252.

Innovation (-io). A new-formed shoot.

Inosculating. Same as Anastomosing.

Inseparate, Inseparation. Terms proposed by Masters to express coalescence; 181.

Inserted (-us). Attached to or growing out of.

Insertion $(-i o)$. Is the mode or place where one body is attached to that which bears it.

Integer. Entire in the sense of undivided, or not lobed ; 97.

Integerrimus. Entire in the sense of quite entire, i.e. the margin without dentation; 97.

Inter. Between; as in Intercellular, between the cells, \&c.

Interfoliaceous (-eus). Between the leaves of a pair, as the stipules of many Rubiaceæ.

Internode (-odium). The portion of stem between two nodes; 6 .

Interpetiolar (-aris). Between the petioles.

Interruptedly pinnate. Pinnate without a terminal leaflet.

Intine. The inner coat of a grain of pollen.

Intrafoliaceous (-eus). Within or before a leaf.

Introflexed (-us). Same as inflexed.

Introrse (-orsus). Turned inward or toward the axis ; 253.

Introvenius. Same as hidden-veined.

Intruse (- $u s u s)$. Pushed or projecting inward.

Involucellate (-atus). Provided with a secondary involucre or

Involucel (éllum). An inner or secondary involucre, that of an umbellet, \&c.; 142.

Involucrate (-atus). Provided with an involucre.

Ínvolucre (Involucrum). A circle of bracts subtending a flower-cluster; 142.

Ínvolute (-utus). Rolled inward; 133.

Irregular (-aris). Exhibiting a want of symmetry in form; 184.

Irregularity, 179, 184, 219.

Isadelphous (-us). Equal brotherhood, as when the number of stamens in two phalanges is equal.

Téchrous. All of one color or hue.

lsomerous (-us). The members of successive circles equal in number; 175.
Isostémonous (-us). The stamens just as many as the petals, \&c.; 177.

Isostemony, 196.

Jointed. See Articulated.

Juba. A loose panicle, with axis deliquescent.

Jugum, pl. juga. A pair of leaflets. So pinnate leaves are unijugate, with a single pair of leaflets; bijugate, with two pairs; trijugate, with three pairs or juga, \&c. Also the ridges on the fruit of Umbelliferæ are termed juga.

Julus. Same as Amentum or Catkin.

Julaceous (-eus). Catkin-like, Amentaceous.

Keel. A central dorsal ridge, like the keel of a boat. The two anterior petals of a papilionaceous corolla, which are united into a body shaped like the keel or the prow of a vessel; 185.

Keeled. Having a keel. See Carinate.

Kernel. The nucleus of an ovule, or of a seed, $i$. e. the whole body within the coats.

Kermesinus. Of the color of carmine.

Key-fruit. See Samara; 294.

Kidney-shaped. Crescentic with the ends rounded; very oblately cordate; 96.

Kingdom, 325.

Labellum. One of the petals of an Orchideous flower, which is nnlike the others.

Labiate (-us). Lipped, mostly Bilabiate; 247.

Labiatiflorous (-us). Said of certain Compositæ with bilabiate corollas.

Labiose (-osus). Said of a polypetalous corolla which has the appearance of bilabiation.

Labium. See Lip.

Lacerate (Lacerus). Irregular cleft as if torn or lacerated.

Lacinia. A slash; used for a slender lobe.

Laciniate (-atus). Slashed; cut into narrow incisions.

Lacinula. A diminutive lacinia or narrow lobe.

Lactescent (-ens), Yielding milky juice.

Lacteus. Milk-white.

Lácunose (-osus). Abounding in pits, holes, or depressions (lacuna).

Lacústrine (Lacustris). Belonging to or living in lakes or ponds. 
Lavigate (-atus). Smooth as if polished. Laevis (this form, and not levis, has always been used in botany). Smooth in the sense of not rough.

Lageniform (-ormis). Shaped like a Florence flask or a gourd (the fruit of Lagenaria).

Lagópus. Hare-footed. Densely covered with long hairs.

Lamélla. A thin plate.

Lamellar (-aris), Lamellate (-atus), Lamellose (-osus). Composed of thin plates or lamellæ.

Lámina. The blade or expanded part of a leaf, \&c.; 85, 245.

Lanate (-atus), Lanose (-osus). Bearing long and implexed hairs or wool (lana).

Lánceolate (-atus). Shaped like a lance or spear-head; narrower than oblong, and tapering to each end, or at least to the apex; 95 .

Lanuginous (-osus). Cottony or woolly; clothed with soft and implexed hairs or down (lanúgo).

Lappaceus. Like a bur (lappa).

Lasianthus. Woolly-flowered.

Latent. Undeveloped or dormant, as certain buds ; 40.

Lateral (-alis). Belonging to or borne on the sides.

Lateritious (-ius). Of a brick-red color.

Latex. Proper juice, milky juice, and the like.

Laticiferous. Containing or conveying latex.

Latiseptus. With broad partition.

Lavender-color. Pale blue with some gray.

Laxus. Loose.

Leaf. The principal sort of appendage or lateral organ borne by the stem or axis ; 85.

Leaf-blade. The lamina of a leaf.

Leaf-bud. A bud which develops into a leafy branch or its continuation; 40 .

Leaflet. A blade or separate division of a compound leaf; 100.

Leaf-scar. The cicatrix left by the articulation and fall of a leaf : 47 .

Leafstalk. A petiole or footstalk to a leaf-blade; 85, 104.

Leathery. See Coriaceous.

Lecus. A synonym for Corm.

Légume (Legimen). The seed-vessel of Leguminosæo, a carpel which normally dehisces by both the ventral and the dorsal snture; 292.

inguminowe. Pertaining to a legume, or to the order to which the legume gives its name.

Lenticels (Lenticelloe). Lenticular spots on young bark.

Lenticular (-aris). Lens-shaped, that is the shape of a lentil or a double-convex' lens.

Lentiginosus. Covered with minute dots or freckles.

Lepal, Lepalum. A made-up word to signify a stamen transformed into a scale, nectary, \&c.

Lepicéna. Unused name for a glume of Grasses.

Lepidote (-otus). Beset with small scurfy scales.

Lepis. Greek term for a scale.

Leptos. Greek for slender; as in Leptophyllus, slender-leaved.

Leucos. Greek for white; whence

Leucanthus. White-flowered.

Leucophyllus. White-leaved, \&c.

Liber. The inner and often fibrous bark; $77,81$.

Lid. See Operculum.

Ligneous (-eus), Lignosus. Woody.

Ligule (Ligula). A strap or strapshaped body, such the principal part of a ray-corolla in Compositz. The thin and scarious projection from the summit of the sheath of the leaf of Grasses, \&c.; 106. Or a similar outgrowth of the inner face of certain petals; 211.

Ligulate (-atus), Liguliform (-ormis). Furnished with a ligule; 148, 247.

Liguliflorous (-us). Said of the head of those Compositæ which contain only ligulate corollas.

Liliaceous. Lily-like; 246.

Limb (Limbus). A border, i. e. the expanded part of a gamophyllous perianth, \&c., as distinguished from the tube and throat; 245 . Sometimes the term is applied to the lamina or blade of a petal or a leaf.

Limbate (-atus). Bordered.

Line (Linea). The twelfth part of an inch. By some reduced to the tenth of an inch; but the decimal line is unusual in botanical measurement.

Linear (-aris). Narrow, several times narrower than wide, and the margins parallel; 95.

Lineate (-atus). Marked with lines.

Lineolate (-atus). Marked with fine or obscure lines.

Linguaformis or Linguiformis, also Lingulate (atws). 'lougue-shaped. 
Lip. One of the two divisions of a bilabiate corolla or calyx, i. e. of a gamophyllous organ which is cleft into an npper (superior or posterior) and a lower (inferior or anterior) portion or lip (labium).

Litoral or Littoral (-alis). Belonging to or growing on the seashore or rivershore.

Livid (-idus). Pale lead-colored.

Lobe (Lobus). Any division of an organ; or specially a rounded division or projection; 98.

Lobate (-atus) or Lobed. Divided into or bearing lobes; 98 .

Lobulate (-atus). Divided into small lobes: Lobelets, or Lobules; 98.

Locellate (-atus). Divided into locelli; 263.

Locéllus. A secondary cell; as where a proper cell (loculus) of an anther or an ovary is divided by a partition into two cavities; 251, 263.

Lóculament (-entum). Same as Loculus; 289.

Lócular (-aris). Celled; as bilocular, two-celled; trilocular, three-celled, quadrilocular, four-celled, \&c.

Loculicidal (-idus), Loculicide. Dehiscent into the cell or cavity of a pericarp by the back, i. e. through a dorsal suture; 289.

Lbculus. The cell or cavity in an ovary or an anther.

Loculose (-osus). Partitioned off into cells.

Lbcusta. Name of a spikelet in Grasses.

Lodicule, Lodicula. One of the small scales next to the stamens in the flower of Grasses.

Lomentaceous (-eus). Bearing or resembling a

Loment (Loméntum). A legume which is constricted or which separates into one-seeded articulations ; 293.

Lorate (-atus). Strap-shaped or thongshaped; same as much-elongated linear.

Lucid (-idus). With a shining surface.

Lunate (-atus). Half moon-shaped; crescent-shaped.

Luinulate (-atus). Diminutive of Lunate.

Lipuline (-inus). Resembling a head of Hops.

Lurid (-idus). Dingy-brown.

Lusus. A "sport" or variation from seed or bud; 319.

Luteolus. Yellowish; diminntive of Luteus.
Lutescent (-ens). Becoming yellow, or faintly yellow.

Liteus. Latin for yellow.

Lycótropous (-us). Said of an orthotropons ovule when bent into an open curve or horseshoe form.

Lyrate (-atus). Lyre-shaped; a pinnatifid form with terminal lobe large and rounded and one or more of the lower pairs small; hence Lyrately pinnate; 101, \&c.

Macros. Greek for large or more properly long; hence Macranthus, longflowered; Macrocephalus, largeheaded; Macropodus, long-footed, or with long stalk, \&c.

Macrospore. The larger kind of spore in Lycopodiaceæ, \&c.

Máculate (-atus). Spotted or blotched, i. e. with maculos.

Malpighiaceous Hairs. Those fixed by the middle and tapering both ways.

Mámillate (-atus), Mamillar (-aris). Bearing teat-shaped processes.

Mammaform (-ormis). Breast-shaped or teat-shaped; conical with rounded apex.

Mammosus. Breast-shaped.

Mancus. Deficient or wanting.

Mánicate (-atus). Said of pubescence so dense and interwoven that it may be stripped off like a sleeve.

Marcescent (-ens), Marcidus. Withering without falling off; 243.

Marginate (-atus). Furnished with a margin of a distinct character or appearance.

Marginicidal. Dehiscent by the disjunction of the united margins of earpels; 290.

Marmoratus. Marbled; traversed by veins or shades of color.

Maritime (Maritimus). Pertaining to the sea or seacoast.

Mas, Masculus, Masculinus. Belonging to the stamens, or staminate plant, or flower; 191, \&c.

Masked. See Personate.

Mealy. See Farinaceous.

Medial, Median (Mediánus). Belonging to the middle; in the plane of bract and axis; 160 .

Medifixus. Fixed by the middle; 253.

Meduilla. Pith; 75.

Medullary. Relating to the pith. Medullary Rays, 74 ; Medullary sheath, 75.

Meiostemonous. With fewer stamens than petals. 
Melleus. Having the taste or smell of honey.

Melligo. Honey-dew.

Membranous, Membranaceous (-eus). Thin and rather soft or pliable, like a membrane.

Meniscoid (-oideus). Concavo-convex, like a meniscus.

Mericarp (-arpium). One of the akenelike earpels or a closed half-fruit of Umbelliferæ ; 297.

Merismatic. Dividing into parts or similar portions.

Merithallus. Synonym of Internode.

Merous (-us). In Greek compounds, denotes parts or members; hence Dimerous, of two parts, \&c.

Mesocarp (-arpium). The middle layer of a pericarp; 285.

Mesophloum. The middle or green bark; 76.

Metamorphosis, Metamorphy, 167.

Micropyle (-ýla). The spot or point in the seed at which was the orifice of the ovule; 277,305 .

Microspore. The smaller kind of spore in Lycopodiaceæ, \&c.

Midrib. The central or main rib; 92.

Miniate (-atus). Vermilion-color.

Mistus or Mixtus. A cross-breed; 321.

Mitrceform or Mitriform (-ormis). Mitre-shaped or cap-shaped.

Monadelphia. The Linnæan class containing flowers with Monadelphous stamens, i.e. those united by their filaments into a tube or column; 250 , 335.

Monandria. The Linnæan class (334) containing flowers with Monandrous, that is, a single stamen; 249.

Monánthous (-us). One-flowered.

Moniliform (-ormis). Necklace-shaped; cylindrical and with contractions at intervals.

Monocarpellary. Of one carpel; 261.

Monocárpic (-icus). Monocarpous, Monocarpian. Only once fruiting; 33.

Monocephalous ( $-u s)$. Bearing a single capitulum.

Monochasium. A cyme with one main axis ; $152,155$.

Monochlamýdeous (-eus). Having but one kind of perianth; 190,340 .

Monoclinous (- $u s)$. Synonym of Hermaphrodite.

Monocotylédon, Monocotylèdones, adj.

Monocotyledonous (-eus). Plants or embryo with a single cotyledon; 23,27 , 314, 339.
Monolocular (-aris). One-celled.

Moncecia. Name of Linnrean class (335) with flowers.

Monoecious (-ius), or Monoicous (-us). With stamens and pistils in separate blossoms on the same plant; 191 .

Monogamia. Name of a Linnæan artificial order, in class Syngenesia; 337.

Mónograph. A systematic account of particular genus, order, or other group; 369.

Monogynia. Name of a Linnæan artificial order, with solitary pistil, or style; 337 ; hence, adjectively, Monógynous; 267.

Monómerous. Formed of a single member; 176.

Monopetálous (-us). Literally onepetalled; but always used in the sense of Gamopetalous, which term is to be preferred; 244.

Monophýllous (-us). One-leaved.

Mónopode (Monopódium), Monopodial. A stem of a single and continuous axis; 55 .

Monópterous (-us). One-winged.

Monopyrénus. Containing a single stone or nutlet.

Monosepalous (-us). Equivalent to Gamosepalous; but literally of a single sepal; 244.

Monospérmous (-us). One-seeded.

Monostichous (-us). In a single vertical rank.

Mondstylous (-us). With a single style.

Monosymmetrical. That which can be bisected into equal halves in only one plane; 175.

Monótocous (-us). Bearing progeny (fruiting) only once, as annuals and biennials; 33.

Monster (Monstrum). A monstrosity, or unnatural development.

Morphology, 5.

Moschate (-atus). Exhaling the odor of musk.

Mucilaginous, Mucilaginosus. Slimy; of the consistence or appearance of mucilage.

Mucro, Mucronation. A short and abrupt small tip to a leaf, \&c.

Mucronate (-atus). Tipped with a mucro; 97.

Mucrónulate (-atus). Minutely mucronate.

Mule. A hybría or cross-breed.

Multicipital (Multiceps). Many-headed; many shoots or stems from the crown of one root. 
Multifarious (-us). Many-ranked, as leaves in several vertical ranks.

Múltifid (-idus). Cleft into many lobes or segments.

Multiflorous (-us). Many-flowered.

Multijúgate (Multijugus). In many pairs or juga.

Multilócular (-aris). Many-celled or several-celled.

Multiparous. Many-bearing ; said of a several-branched cyme; 152, 155.

Multiple fruits. The fructification of a flower-cluster when confluent into one mass ; 301.

Multiplication. Same as Angmentation; $179,200$.

Multiserial (-alis), Multiseriate (-atus). In several series.

Múricate (-atus). Rough with short and firm excrescences.

Muriculate (-atus). Minutely muricate. Muscariformis. Fly-brush-shaped.

Musciform (-ormis). Moss-like in appearance.

Muscology. The botany of Mosses. But is a hybrid word, and is replaced by Bryology.

Muiticous (-us). Pointless, blunt, awnless.

Mycélium. The filamentous vegetative growth of a Fungus.

Mycology, Mycetology. The botany of Fungi.

Mycropyle. Micropyle misspelled.

Naked. Wanting some usual covering as flowers without perianth, ovules without coats, seeds not in a pericarp, buds without scales.

Napiform (-ormis). Turnip-shaped; 31.

Nanus. Dwarf.

Natant (-ans). Floating or swimming under water.

Navicular (-aris). Boat-shaped. Same as Cymbiform.

Nebulose (-osus). Clonded or misty.

Neck. See Collum.

Necklace-shaped. See Moniliform.

Nectar. The sweetish secretion by various parts of the blossom from which bees make honey.

Nectary (Nectarium). The place or thing in which nectar is secreted: formerly applied also to any anomalous part or appendage of a flower, whether known to secrete honey or not; especially to the hollow spurs of a Violet, Larkspur, Columbine, and the like.
Nectariferous (-us). Nectar-bearing.

Needle-shaped. See Acerose.

Nemorosus, Nemoralis. Inhabiting groves.

Nervation. Same as Venation, or unbranched venation.

Nerve (Nervus). In botany, this is a simple or unbranched vein, or a slender rib.

Nerved, Nervose (-osus), Nervate (-atus).

- Having nerves in the botanical sense.

Nervulose (-osus). Diminutive of nervose.

Netted. Same as Reticulated; Nettedveined; 92.

Neurose (-osus). Same as Nervose. Neura being the Greek for nerve.

Neuter, Neutral. Sexless ; as a flower which has neither stamen nor pistil; 191, 195.

Niger. Black or blackish.

Nigricans. Turning black or verging to black.

Nitidus. Smooth and shlning.

Nivális. Growing in or near snow.

Niveus. Snow-white.

Nodding. Hanging down.

Node (Nodus). Literally a knot; the portion of a stem which normally bears a leaf or whorl of leaves; 6 .

Nodose (-osus). Knotty or knobby.

Nódulose (-osus). Diminutive of Nodose.

Nomenclature, 3, 345.

Normal (-alis). According to rule; agreeing with type.

Notate (-atus). Marked by spots or lines.

Nothus. False or bastard.

Notorhizal (-izus). Synonym of incumbent, as applied to the embryo of Cruciferæ.

Nuciform (-ormis). Nut-like in shape.

Nucleus. A kernel of an ovule, seed, \&c.; 277. A soft solid interior part of a vegetable cell in the early condition; 309 .

Nuculanium. Name given by Richard to a drupaceous or baccate fruit containing more than one stone or stony seed; adopted by Lindley for a superior stony-seeded berry, such as a grape.

Nucule (-ula). A diminutive nut or stone; same as Nutlet; 296.

Nucumentaceus (-eus). Nut-like in character.

Nudicaulis. Naked-stamened; stem not leafy.

Nudus. Naked, in its various senses. 
Numerous (Numerosus). Used in the sense of indefinite in number.

Nut $(N u x)$. A hard and indehiscent one-seeded pericarp resulting from a compound ovary; 295.

Nutlet. A diminutive Nut. See Nucule.

Nutant (-ans). See Nodding.

Ob. Over against; as a prefix denotes inversely or oppositely, as

Obcompressed (-us). Flattened the other way, antero-posteriorly instead of laterally.

Obconical (-icus). Conical, but attached at the apex.

Obcordate (-atus). Inverted heartshaped, the notch at the apex; 97 .

Obdiplostemonous (-us), Obdiplostemony. When the stamens are double the number of the petals, but the outer series opposite the latter; 198.

Obimbricate. Imbricated or successively overlapping downward.

Oblánceolate. Lanceolate but tapering toward the base more than toward the apex; 95 .

eblique (Obliquus). Unequal-sided or slanting.

Oblong (Oblongus). Considerably longer than broad and with nearly parallel sides; 95.

Obovate (-atus). Ovate with the broader end toward the apex; 95 .

Obovoid. Solid obovate.

Obtectus. Covered by something.

Obtuse (-usus). Blunt or rounded at the extremity; 97.

Obtusiusculus. Somewhat obtuse; diminutive of obtuse.

Obvallatus. Guarded on all sides or surrounded as if walled in.

Obverse, Obversely. Same as the prefix $\mathrm{Ob}$.

Obvolute (-utus). A modification of Convolute; 138, 139 .

Ocellate (-atus). With a circular patch or a ring of color.

Ochraceous (-eus). Ochre color; light yellow with a tinge of brown.

Óchrea. Ócrea. A leggin-shaped or tubular stipule or rather combined pair of stipules; 106.

Ochreate, Ocreate (-atus). Furnished with ochrea or sheaths; 106.

Ochroleucous (-us). Yellowish-white or between white and yellow.

Octo. Eight. In composition gives sucb terms as the following.

Octagýnia. Linnæan artificial order with Octagynous (eight-styled) flowers ; 337.
Octámerous. Composed eight parts in the circle.

Octandria. The Linnæan class with Octandrous, i. e. eight-stamened flowers; $249,334$.

Octoni. In eights.

Octopetalous (-us). Eight-petalled.

Octosepalous. With eight sepals.

Octóstichous (-us). In eight vertical ranks; 124.

Oculate (-atus). Same as Ocellate.

Officinal (-alis). Used in medicine or the arts, therefore in the shops.

Offset. A short lateral shoot for propagation; 53.

Oides, Oideus, -odes and -ides. Greek for likeness, used as terminations, indicate similarity to; as Dianthoides, resembling a Pink.

Oleraceons (-eus). Esculent in the way of a pot-herb.

Óligos. Greek for few; in compounds giving such terms as

Oligandrous (-us). With few stamens.

Oliganthous $(-u s)$. Few-flowered.

Oligómerous (-us). Of few members.

Oligospérmous (-us). Few-seeded.

Olivaceus (-eus). Olive-green.

Omphalodium. A mark (navel) on the hilum of a seed, through which passed vessels to the chalaza or rhaphe.

One-sided. Either turned to one side, or with parts all turned one way, or unequal-sided.

Oophoridium. The spore-case for the larger spores in Selaginella, \&c.

Opaque (Opácus). Mostly used in the sense of not shining or dull.

Opérculate (-atus). Furnished with an Operculum or lid.

Opérculum. A lid; a top "which separates by a transverse line of separation as does that of a pyxis.

Opposite (-itus). Set against; as leaves over against each other when there are two on one node; or one part before another, as a stamen before a petal ; 6, 120, 178 .

Oppositifolius (-ius). Placed opposite a leaf, as is a tendril or peduncle in Vitis, \&c.

Oppositipetalous (-us). Placed before a petal.

Oppositisepalous (-us). Situated before a sepal.

Orbicular (-aris), Orbiculate (-atus). Said of a flat body with a circular outline; 95.

Orchidaceous, 246. 
Order $(O r d o)$. Group between genus (or tribe) and class; 328 .

Ordinal. Relating to orders.

Organógeny (Organogénesis). The formation or early development of organs; 2.

Organography, Organology. The study of organs and their relations; 2.

Organs of Vegetation, 11.

Orgyális. Six feet high, or of the height of a man.

Ornithophilous. Said of flowers which are habitually fecundated by pollen brought by birds; 217.

Orthoploceus. Said of an embryo when incumbent cotyledons are folded around the radicle, as in Mustard.

Orthos, Greek for straight; whence compounds such as the following

Orthostichies. Vertical ranks; 121.

Orthostichous. Straight-ranked.

Orthótropous (-us), Orthotropal. Denotes an ovule or seed with straight axis, chalaza at the insertion, and orifice at the other end; 277. Has been applied to an embryo with radicle pointing to the hilum; 312.

$\mathrm{Os}$ (oris). The mouth or orifice.

Osseous (-us). Of the texture of bone.

Ossiculus. A little stone, same as Pyrena.

Ostiolate (-atus). Furnished with a small orifice or little door (Ostiolum).

Outgrowths, 209.

Oval (Ovalis). Broadly elliptical; 95 .

Ovary (Ovarium). The ovuliferous part of a pistil; 166.

Ovate (Ovatus). Of the shape of the longitudinal section of a hen's egg, the broader end basal; 95 . Used also for an egg-shaped solid.

Ovoid (Ovoideus). Used either for solid ovate or solid oval, more properly for the latter.

doulate (-atus), Ovuliferous. Bearing ovules.

Ovule, Ovuium. The body in the flower which becomes a seed; 166, 276.

Pagina. The surface of any flat body, such as a leaf.

Palaceous (-eus). When the edges, as of a leaf, are decurrent on the support.

Palate (Palatum). A projection in the throat of a personate gamopetalous corolla; 248.

Palea. A chaff, or chaff-like bract, such as the chaffy scales on the receptacle of the head in many Compositæ; also an inner bract or glume in Grasses; 142.

Paleaceous (-eus). Chaffy; furnished with paleæ; or chaff-like in texture.

Paléola. A diminutive palea, or one of a secondary order; one of the names of the Lodicule or Squamella in Grasses.

Paléolate (-atus). Furnished with paleolæ.

Palets (Pales of some English botanists). Same as Paleæ; 142.

Palmáris. A palm's breadth or length; $i$. e. equalling the breadth of the four fingers of the palm.

Palmate (-atrus). Lobed or divided so that the sinuses point to or reach the apex of the petiole or insertion; 101.

Palmately (Palmatim or Palmati-). In the palmate manner.

Palmately veined, 93.

Palmatifid (-idus), Palmatilobate, Pulmatisect). Palmately cleft, lobed, oe divided.

Palminerved. Palmately nerved; 93.

Páludose (-osus), Palustrine (Palustrve or Paluster). Inhabiting marshes.

Pándurate (-atus), Pandiriform (-ormus , See Fiddle-shaped.

Panicle (Panicula). A loose compouna flower-cluster, such as is produced by the branching of a raceme, or the irregular branching of a corymb; 150 .

Panicled, Paniculate (-atus). In a panicled manner or borne in a panicle.

Pannosus, Panniformis. Having the appearance or texture of felt or woollen cloth.

Papery, Papyraceous. Having the texture of paper.

Papilionaceous (-eus). Butterfly-like; applied to a peculiar polypetalous corolla; 184, 246.

Papillar (-aris), Papillose (-osus), Papillate (-atus). Bearing or resembling papilloe, minnte nipple-shaped projections.

Pappiferous (-us), Pappose (-osus). Bearing a pappus.

Pappus. Thistle-down; thence applied to various hairy tufts on akenes or fruits; and thence to any production or structure which takes the place of the limb of the calyx on the akenes of Compositæ; 192, 295.

Papuliferous (-us), Papulose (-osus). Covered with Pápula, or small pim. ples. 
Paracarpium. Unused name given to an abortive pistil or carpel.

Paracorolla. A crown or internal appendage or deduplication of a corolla.

Parallel-nerved, veined, \&c. Same as Nerved; 91.

Parapetalous ( $-u s)$. Said of stamens, \&ce, which stand at each side of a petal ; 178, 201.

Paráphysis, pl. Paraphyses. Jointed thread-like bodies, of no known function, accompanying the archegonia of Mosses.

Parasitic (-icus). Growing on or in and living upon another plant or even animal; 36.

Parastémon. Name rarely applied to an abortive stamen or body in place of or accessory to a stamen; same as Staminodium.

Parastichies. Secondary spirals in phyllotaxy; 127.

Parénchyma. Common or soft cellular tissue.

Parenchymatous. Of the nature of or composed of parenchyma.

Paries, pl. parietes. The wall of any organ.

Parietal (Parietalis). Borne on or related to the wall; 265.

Paripinnate (-atus). Even-pinnate; same as abruptly pinnate; 101 .

Parted, Partite (-itus). Cleft nearly but not quite to base; 98 .

Parthenogénesis, Parthenógeny. Production of seed without the intervention of pollen; 285.

Partial (Partialis). Secondary, as Partial involucre (142), peduncle (143), petiole (105), umbel (150), \&c.

Partible (Partibilis). At length separating or easily to be separated.

Partition. In one sense a separated portion or segment; in another and the more usual, a wall or dissepiment.

Patelliform (-ormis). Disk-shaped, circular with a rim, of the form of the patella or kneepan.

Patent (Patens). Spreading; either widely open or diverging widely from an axis.

Patentissimus. Snperlative of Patens; extremely spreading.

Pátulous (-us) Slightly or moderately spreading.

Parciflorous (-us). Few-flowered.

Paucifolius. Few-leaved.

Pear-shaped. Obovoid or obconical with more tapering base.
Péctinate (-atus). Pinnatifid with narrow and closely set segments, like comb-teeth.

Pedális. A foot long or high.

Pedate (-atus). Palmately divided or parted with the lateral divisions twocleft; resembling a bird's foot.

Pedatipartitus, -lobatus, -sectus, \&c. Pedately parted, lobed, divided, \&c.

Pedicel (-ellus). An ultimate flowerstalk or its division; the support of a single flower; 143.

Pedicellate (-atus). Pedicelled, borne on a pedicel.

Pediculus. Name sometimes used for Pedicel.

Peduncle (Pedúnculus). A general flower-stalk, supporting either a clus. ter or a solitary flower; in the latter case, the cluster may be regarded as reduced to a single blossom; 143 .

Pedúnculate (-atus). Peduncled, borne on a foot-stalk.

Peloria. An irregular flower become regular by a monstrous development of complementary irregularities; 186.

Peltate (-atus), Peltiform (-ormis). Shield-form; target-shaped; a plane body attached by its lower surface (instead of margin or base) to a stalk; 96, 107.

Peltinerved (-ius). Radiately-nerved or ribbed all round the circle.

Pelviform (-ormis). Basin-shaped; shallow cup-shaped.

Pendent (-ens). Hanging on its stalk or support.

Pendulus (-us), Pendulinus. Hanging more or less, as if from weakness of the support.

Penicillate (-atus), Penicilliform (-ormis). Pencil-shaped, the pencil (penicillum) being a brush or tuft of hairs.

Pennate (-atus). Same as Pinnate.

Penniform (-ormis). In the form of a feather or its plume.

Penninerved (-ervius). Same as pinnately nerved or veined; 93.

Penta. Greek for five; gives compounds such as

Pentacárpellary. Composed of five carpels; 261.

Pentachanium. Name of a pentacarpellary fruit otherwise like a cremocarp.

Pentadelphous (-us). With stamens in five clusters; 250.

Pentagýnia. Linnæan artificial order characterized by Pentagynous, i. e. five-styled flowers; 337 . 
Pentámerous (-us). Composed of five members in a circle; 176.

Pentandria. The Linnæan class with Pentandrous, i. e. five-stamened flowers; $249,334$.

Pentapétalous (-us). Five-petalled; 244.

Pentaphýllous (-us). Five-leaved; 243.

Pentápterous (-us). Five-winged.

Pentasépalous (-us). Of five sepals; 244.

Pentástichous (-us). In five vertical ranks; 123.

Pepo, Peponida, Peponium. A gourdfruit; 298.

Perennial (Perennis, Perennans). Lasting year after year; 32.

Perfect (Perfectus). Said of a flower which is hermaphrodite.

Perfoliate (-atus). Where a stem seemingly passes through a leaf; 167 .

Perforate (-atus). Pierced, or having translucent dots which look like holes.

Pergameneus, Pergamentaceus. Parchment-like in texture.

Peri. Greek for around; hence such compounds as

Perianth (Perianthium). The floral envelopes or leaves of the flower, consisting of calyx, corolla, or both; 164, 243.

Pericarp (-arpium). The fructified ovary; 286.

Pericárpic (-icus). Relating to the pericarp.

Perichatial (-ialis). Relating to the Perichotium, a set of bracts around the fruit-stalk in Mosses.

Pericládium. The sheathing base of a leaf when it expands and surrounds the supporting branch.

Periclinium. Involucre of the capitulum of Compositæ; 148.

Périderm (-erma or -ermis). Outer bark or Epiphloum.

Périgone, Perigónium. Synonym of Perianth; 164.

Perigynium. Name of hypogynous bristles, scales, or a sac, which surrounds the pistil (also the stamens when present) of many Cyperaceæ.

Perigynous (-us). Literally around the ovary; said of organs which are adnate to the perianth, or to this as connate with the low $r$ part of the pistil; 182.

Peripétalous ( $-u s)$. Around the petals.

Peripheric (-icus). Of or belonging to the circumference; as of an embryo coiled round the outside of the albumen.

Periphoranthium. Synonym of the involucre of Compositæ; 148.
Peripterus. Surrounded by a wing or thin border.

Perisperm (-ermium). The albumen of the seed, at least the exterior and ordinary albumen; 14, 310.

Péristome (Peristoma or Peristómium). The fringe or other structure surrounding the orifice (stoma) of a Moss.

Peritropous (-us) or Peritropal. Said of a seed which is horizontal in the pericarp; or of a radicle pointed toward the sides of the pericarp.

Persistent (-ens). Remaining even on the fruit, or over winter ; 243.

Pérsonate (-atus). Masked, as when a bilabiate corolla has a prominent palate; 248 .

Pervious (-ius). With an open passageway.

Pertuse (-usus). Having slits or holes.

Pérula, pl. Perulce. Scales of leaf-buds and the like; 40.

Perulate (-atus). Furnished with pervloe or scales.

Pes, gen. pedis. A foot. Hence in Latin compounds Longipes, longstalked, Brevipes, short-stalked, \&c.

Petal (Petalum). A corolla-leaf; 165.

Petaline (-inus), Petaloid (-oideus). Petal-like, or relating to petals; 118 .

Pétalody. Name for the metamorphosis of other organs (such as stamens) into petals; 174.

Petiolar (-aris). Borne on or relating to a petiole.

Pétiolate (-atus), Pétioled. Having a petiole.

Pétiole (Petiolus). The footstalk of a leaf; 85, 104.

Petiolulate (-atus), Petiolular (-aris). Having a

Pétiolule (Petiólulus). A footstalk of a leaflet; 105.

Petrceus. Growing among rocks.

Petrosus. Growing in stony places.

Phonogams, Phonogamia, Phønogamous plants. Plants sexually propagating by flowers, of which the essential organs are stamens and pistil; 3 , $334,840,344$.

Phalanges, sing. Phalanx. The bundles of stamens in diadelphous or polyadelphous flowers.

Phanerogams, Phanerogamia, \&c. See Phænogams, \&c.

Phloum. Greek name for bark.

Phoeniceus. Deep red with some scarlet.

Phoranthium. A name for the recep 
tacle of the capitulum in Compositæ; 148.

Phycology. The botany of Algæ.

Phylla. Leaves in Greek; combined with Greek numerals, forming such terms as Diphyllous, Triphyllous, \&c., to Polyphyllous.

Phyllocladium. A branch assuming the function of foliage; 65 .

Phyllodineous (-eus). Relating to a

Phyllodium. A petiole usurping the form and function of a leaf-blade; 110.

Phyllody, Phyllomorphy. Names for the transformation or metamorphosis of floral organs into leaves; 174.

Phyllotáxis, Phýllotaxy. Leaf-arrangement; 119.

Phyllomania. The unusual or abnormal production of leaves.

Phyllophore (-orum). The budding summit of a stem on which leaves are developing.

Phyllum. Greek for leaf; 6, 85. See Phylla.

Phyllome, Phylloma. An assemblage of leaves, or of incipient leaves in a bud. Also recently used by German botanists for leaf generically or potentially, that which answers to a leaf; 6 .

Phytography. Botany as relates to the description and illustration of plants ; 345 .

Phy'ology. Synonym of Botany.

Phýtomer, pl. Phytómera. Plant-elements in morphology ; same as

Phyton. Greek name for plant; has been used in the sense of plant-element, or plant-unit; 7 .

Phytótomy. Same as Vegetable Anatomy or Histology ; 2.

Piceus. Pitch-black or brownish-black.

Pictus. Painted, or rather as if painted.

Pileate (-atus), Pileiformis. Having the form of a cap or Pileus.

Pileorhiza. The root-cap.

Piliferous (-us). Bearing or tipped with hairs (pili).

Pilosciusculus. Slightly hairy.

Pilose (-osus). Hairy, in general with any sort of pilosity; in particular with soft and distinct hairs.

Pinna. One of the primary divisions of a pinnate leaf, either simply pinnate, when it is a leaflet, or a partial petiole or rhachis with the leaflets when the leaf is bipinnate; 104 .

Pinnate (-atus). When leaflets are arranged along each side of a common petiole; 100 .
Pinnately cleft, lobed, parted, \&c.; 99.

Pinnately veined. Feather-veined; 93. Pinnátifid (-idus). Pinnately cleft. $p .99$ Pinnatilobatus, Pinnatilobus. Pinnstdy lobed.

Pinnatipartitus. Pinnately parted.

Pinnatiséctus. Pinnately divided quite down to the rbachis.

Pinnule (Pinnula). One of the pinnately disposed divisions of a pinna; a secondary pinna; 104.

Pisiform (-ormis). Pea-shaped; resembling a pea.

Pistil (Pistillum). The female organ of a flower, consisting of ovary, style. and stigma, or at least of ovary and stigma ; 302, 259.

Pistillate (-atus), Pistilliferous. Said of a plant or a blossom provided with pistil, most properly for one having pistil only ; 191.

Pistillidium. One of the names of the analogue of pistil in Mosses, \&c.

Pistillody. Name for the metamorphosis of other organs into carpels; 174.

Pitcher. See Ascidium. A tubular or cup-shaped leaf, which usually holds some liquid; 111.

Pith. A central cellular part of a stem, especially of an exogenous stem; 75 .

Pitted. Marked with small depressions or pits.

Placenta. That in the ovary which bears the ovules, sometimes the mere united margins of the carpel-leaves, sometimes a thickening or enlargement of them, or even of some other part of the ovary; 261.

Placentation $(-i o)$. The disposition of the placentæ.

Placentiform (-ormis). Quoit-shaped, or in form like a flat cake.

Plaited. See Plicate.

Plane (Planus). With flat surface or surfaces.

Platys. Greek for wide, in such compounds as Platyphyllus, broad-leaved, \&c.

Pleios. Greek for full, used in compounds for several or many; as Pleiophýllous, several-leaved, \&c. Similarly Pleistos for a great many.

Pleiochásium. A several-rayed cyme, 152, 155.

Plenus. Full. Flos plenus is what gardeners call a "double flower," that is one in which the petals or other flowerleaves are abnormally multiplied.

Pleurénchyma. Same as woody tissue. 
Plewrorhizal (-us). Embryo with radicle against one edge of the cotyledons; $i$. e. the latter accumbent.

Plicate (-atus), Plicativus. Folded into plaits (plicos), usually lengthwise; 133 , 139.

Plímbeus. Lead-colored; dull gray with some metallic lustre.

Plumose (-osus). Feathered; when bristles, \&c., have fine hairs on each side like the plume of a feather, as the pappus of Thistles.

Plumule (Plimula). The bud or growing point of the embryo above the cotyledons; 17.

Plures. Many or several; used as a prefix in Latin words, such as Pluriflorous (-us), several-flowered; Plurilocular (-aris), several-celled; Plurifoliolate, with several leaflets, \&c., Plurijugate, in several pairs, \&c.

Póculiform (-ormis). In the shape of a drinking-cup or goblet.

Pod. A dry and several-seeded dehiscent fruit; strictly a Legume or a Silique; 288, 292.

Podium, Podus. A footstalk, stipe, or other such support; used only in Greek compounds, as Podocephalus, head pedunculate; Podocarpus, fruit stipitate; or as a suffix, in such words as Leptopodus, slender-stalked; Brachypodus, short-stalked, \&c.

Podétium. Any stalk-like elevation.

Podogýnium. Same as Gynophore.

Podosperm (-irmium). The stalk of a seed; 276, 305 .

Pogon. Greek for a beard; enters into various compound words.

Polémbryony. See Polyémbryony.

Politus. Polished; applied to a smooth and shining surface.

Pointless. Same as Muticons.

Pointletted. Minutely pointed; same as apiculate or as minutely acuminate.

Pollen, Pollen-grains. The fecundating grains or cells contained in the anther; $165,256$.

Pollen-tube. The slender tube which begins as a protrusion of the inner coat of a pollen-grain, and elongates by growth, at least when in contact with the stigma; 258.

Pollicaris. An inch long; the length of the terminal joint of the thumb, pollex.

Poliniferous (-us). Pollen-bearing.

Pollinium. A mass of pollen-grains more or less coherent; 257, 230.
Pollinated (-atus). Said of a stigma when supplied with pollen. .

Poly. In Greek compounds, denotes numerous; as in

Polyadélphia. Name of a Linnæan artificial order with stamens Polyadel phous, or in several phalanges or brotherhoods; 250, 335 .

Polyandria. Name of a Linnæan class with flowers Polyandrous, or having, an indefinite number of stamens; 249 , 334.

Polyainthous (-us). Many-flowered; in the Latin form same as multiflorous.

Polycárpellary. Of many carpels; 261.

Polycárpic (-icus). Fruiting many times or indefinitely; DeCandolle's name for a perennial herb; 33 .

Polycéphalous (-alus). Consisting of or bearing many heads, capitula.

Polycóccus. Of several cocci.

Polycotylédonous (-eus or es). Having several cotyledons; 22, 314 .

Polygámia. Name of a Linnæan class having Polýgamous flowers, i. e. some hermaphrodite, some unisexual; 191, 335. Also of Linnzan orders of Syn. genesia; 337.

Polygýnia. Name of a Linnæan artiflcial order with flowers Polýgynous, i. e. containing numerous carpels; 261, 337.

Polýmerous (-us). Of numerous members to each series or circle.

Polymorphous (-us). Of several or various forms.

Polypetalous (-us). Having separate petals ; 244.

Pólyphore (-brium). A torus which bears many pistils, as that of a strawberry or raspberry.

Polyphýllous (-us). Many-leaved; 244.

Polysépalous (-us). Of separate sepals; 244.

Polyspérmous (-us). Many-seeded.

Polystémonous (-us). With many stamens.

Polystáchyus. Bearing many spikes.

Polýstylous (-us). Bearing many styles.

Polysymmetrical. That which can be divided into similar halves in several or more than one plane; 175.

Polýtocous (-us). Bearing progeny (fruiting) many times, i. e. Jear after year; 33.

Pome (Pomum). Kind of fruit of which the apple is the type; 298.

Pomeridianus. In the afternoon.

Pomiferous (-us). Pome-bearing. 
Pomology. A treatise on or the subject of fruits considered as esculent.

Porose (-osus), Porous. Pierced with small holes or pores.

Posterior. In an axillary flower is the side next the axis of inflorescence; 160.

Posticous (-us). On the posterior side, which in a flower is that next the axis of inflorescence: an adnate anther is posticous when on the outer side of the filament, i. e. when it faces the petals; 253.

Pouch. See Silicle.

Pracox. Appearing or developing early.

Profloration. Same as Estivation; 132.

Prafoliation. Same as Vernation; 132.

Promorse (-orsus). With end as it were bitten off.

Prasinus. Grass green.

Pratensis. Growing in meadows.

Prickly. Armed with Prickles (56), which are outgrowths of the bark or rind.

Primine. Outer coat of the orule; 277.

Primordial (-ialis). The first in order of appearance. Primordial leaves are these of the plumule.

Prismatic (-icus). Prism-shaped, with flat faces separated by angles.

Prócerus. Very tall.

Process (Procéssus). Any projecting appendage.

Procumbent (-ens). Lying along the ground; 53.

Productus. Produced, i. e. extended or prolenged into.

Pro-embryo, 284.

Proles. Progeny; sometimes used for race; 320 .

Proỉiferous (Prólifer, Proliferus). Bearing progeny, in the way of offshoots.

Proliferation or

Prolification is usually taken as the production by one organ of something different, such as the development of buds and plantlets on leaves, of leafy shoots in place of flowers, \&c.; 73.

Proligerous (-us). Same as Proliferous.

Prone (Pronus). Lying flat, especially face downward.

Prupaculum, Propagulum. Name of a shoot, such as a runner or sucker which may serve for propagation.

Propágines. Same as Bulblets.

Prophýlla. Primary leaves, as the first leaves of a branch or axis.

Prosénchyma. Plant-tissue consisting of lengthened, tubular, or fusiform cells.
Prostrate (-atus). Lying quite flat on the ground; 53.

Protos. Greek for first; used in various compounds, such as

Protandrous, Protandry. See Proterandrous.

Proterándrous, also Protandrous, Proterandry. When the anthers of a flower are in anthesis earlier than the stigma; 219, 220.

Proteranthous (-us). Where flowering precedes leafing.

Proterógynous, Proterógyny, or Protogynous, Protogyny. When the stigma is ready for its functions earlier than the anthers of the same blossom; 219.

Protóphytes, Protophyta. Alga, \&c., the supposed first plants.

Prótoplasm, Protoplásma. The formative organic material of plants and animals, in its living state.

Pruinate (-atus), Pruinose (-osus). As if frosted over with a bloom or powder.

Pseudos. Greek for false, a prefix in various compounds, as Pseudo-monocotyledonous; 26.

Pseudo-bulb. A thickened and bulblike internode in epiphytal orchids; a corm.

Pseudocarp (-arpium). The principal or accessery part of an anthocarpous fruit; 300 .

Pseudo-costate. False-ribbed, as where a marginal or intramarginal vein or rib is formed by the confluence of the true veins.

Pseudospermium. Name given to any kind of one-seeded fruit which is indehiscent and resembles a seed, such as an akene, \&c.

Psilos. Greek for naked or bare; as in Psilostachyus, with naked spike.

Pteridium, Pterodium. Names for the Key-fruit or Samara.

Pteris. Used for wing in Greek compounds, also for a Fern.

Pteridographia. The botany of Ferns.

Pterocarpous (-us). Wing-fruited.

Pteropodus. Wing-footed, i. e. petiole wing-margined, \&c.

Ptyxis. Greek name for folding, as of leaves in a bud: 132,133 .

Pubens, Pubes. Used for Pubescent.

Pubérulus. Minutely pubescent.

Pubes. Pubescence, hairiness.

Pubescent (-ens). Clothed or furnished with hairs or down, especially with soft or downy and short hairs. 
Pugioniform (-ormis). Dagger-shaped.

Pullus. Dark-colored; dusky-brown or blackish.

Pulvereus, Pulverulentus. Powdered; as if dusted with powdery matter or minute grains.

Púlvinate (-atus), Pulviniform (-ormis). Cushion-shaped.

Pulvinus. A cushion; name given to an enlargement or swelling close under the insertion of a leaf, or sometimes to the swollen base of a petiole.

Púmilus. Low or little.

Punctate (-atus). Dotted, either with depressions like punctures, or translucent internal glands, or with colored dots.

Puncticulate (-atus). Minutely punctate.

Pungent (-ens). Terminating in a rigid and sharp point or acumination, like a prickle.

Puniceous (-eus). Bright carmine-red.

Purpureus. Originally the red of arterial blood; but our purple is somewhat dull red with a dash of blue or violet.

Purpuráscens. Purplish.

Pusillus. Very small, or weak and slender.

Pustular, Pustulate (-atus), Pustulose (-osus). Having low elevations, like blisters.

Putamen. The shell of a nut; the endocarp of a stone-fruit; 288.

$P y c n o s$, Greek for thick; whence Pycnocephalus, thick-beaded, \&c.

Pygmous. Dwarf, pygmy.

Pyramidal (-alis). Pyramid-shaped.

Pyréne (Pyréna). Same as Nucule or Nutlet; one of the small stones of a drupaceous fruit; 298.

Pyrenarium, Pyridium. A pear or pearlike fruit, same as Pomum.

Pyrenarius. Name of a drupaceous pome, as of Medlar and Cratægus.

Pyridion. Synonym of Pome.

Pyrenocarp (-arpium). A general name for any drupaceous fruit; 292.

Pyriform (-ormis). See Pear-shaped.

Pyxidate (-atus). Furnished with a lid.

Pyxidium, Pyxis. A capsule with transverse dehiscence, making a lid of the upper portion; 293.

Quadri-. In Latin compounds, denotes four; as Quadrangular, Quadrifarious (in four vertical ranks), Quadrijugate (in four pairs), \&c.
Quatérnary, Quaternate. In fours or composed of four; 176.

Quini, Quinary (-ius), Quinate (-atus). In fives; 176.

Quinque. Five. In Latin compounds, giving rise to such terms as

Quincuncial, in a Quincunx; also fiveranked; 123, 136.

Quinquefarious (-ius). In five vertical ranks.

Quinquefoliate (-atus). Five-leaved. Quinquefoliolate, with five leaflets.

Quintuple. 'Dividing into five parts, or five-fold.

Quintuplinerved or -veined. With midrib of leaf dividing into five (i.e. two lateral pairs) above the base; 93 .

Race. A variety of such fixity that it is reproduced by seed; also used in a looser and more extended sense for a series of related individuals without particular regard to rank; 320 .

Raceme (Racémus). An indeterminate or centripetal form of inflorescence with lengthened axis and equal-pedicelled flowers; 146.

Racemiferous. Bearing racemes.

Racemiform (-ormis). In the form of a raceme.

Racemose (-osus). Having the character or appearance of a raceme, or in racemes. nuto, is on

Rachis. See Rhachis.

Radial. Belonging to the ray.

Radiate (-atus). Spreading from or arranged around a common centre, or around the circumference of a circle; bearing rays or ray-flowers.

Radiately veined. Same as Palmately veined; 93.

Radiatiform (-ormis). Said of a capitnlum of flowers which is radiate by enlargement of some of the outer flowers, which however are not truly ligulate, as in species of Centaurea.

Radical (-alis). Belonging to or proceeding from the root, or from a rootlike portion of stem at or below the surface of the soil.

Radicant (Radicans). Rooting.

Radicel. A minute root or a rootlet.

Radiciflorous (-us). Flowering (apparently) from the root.

Radiciform (-ormis), Radicinus. Of the nature or appearance of a root.

Radicle (-icula). Eiterally a diminutive root; but the "radicle" of the embryo, 
so called in descriptive botany, is the hypocotyledonary and primal internode. (See Caulicle); 10.

Radiculose (-osus). Bearing rootlets.

Radix. The root.

Rameal (-alis), Rameus. Belonging to (Ramus) a branch.

Raménta. Thin chaffy scales belonging to the surface or epidermis, such as the chaff on the stalks of many Ferns.

Ramification. Branching; 47.

Ramiflorous $(-u s)$. Flowering on the branches.

Ramose (-osus). Branching or branchy.

Ramulose (-osus). Bearing many branchlets, $i$. e. Ramuli or

Raphe. See Rhaphe.

Ráphides or Rhaphides. Crystals in the cells of plants, especially needleshaped crystals.

Ray (Radius). One of the radiating branches of an umbel (147); also the marginal as opposed to the central part (or disk) of a head, umbel, or other flower-cluster, when there is a difference of structure. Also used as an abbreviated expression for

Ray-flowers. Those which belong to the margin of a circular flower-cluster, and differ from (being usually larger than) those of the disk.

Recaulescence. The adhesion of leaves or their stalks to a stem; 158.

Receptacle (Receptáculum). A portion of axis forming a common support or bed on which a clnster of organs is borne. The receptacle of the flower, or the torus, is the axile portion of a blossom, that which bears sepals, petals, stamens, and pistils; $167,211$. The receptacle of inflorescence is the axis or rhachis of the head, spike, or other dense cluster; 143.

Reclinate (-atus), Reclined, Reclining. Falling or turned toward downward, so that its upper part rests on the ground or other object; 53, 133.

Rectinervius. Straight-veined or straightnerved; 92.

Rectiserial(-ialis). In rectilinear ranks; 124.

Recurved (-us), Recurvatus. Curved backward or downward.

Reduplicate (-atus) or Reduplicativus. Folded and projecting outward.

Reflexed (-us). Abruptly bent or turned downward or backward.

Refracted (-us). Same as reflexed, but abruptly bent from the base.
Regma. A two-several-lobed twoseveral-celled fruit (2-pluricoscous), which separates at maturity into as many 2-valved carpels, as in Euphorbia ; one form of Schizocarp.

Regmacarp (-arpium). A general name of a dry and dehiscent fruit, 292.

Regular (-aris). Uniform in shape or structure; symmetrical as respects shape; 175.

Reniform (-ormis). Kidney-shaped; having the outline of the longitudinal section of a kidney; 96 .

Repand (Repandus). With slightly uneven margin, which, if more pronounced, would be sinuate; 98 .

Repent (Repens). Creeping, i. e. prostrate or horizonal and rooting; 53.

Réplicate (-atus), Replicativus. Folded backward.

Replum. A frame-like placenta (like a door-case), from which the valves of a capsule or other dehiscent fruit fall away in dehiscence, as in Cruciferæ, certain Papaveraceæ, Mimosa, \&c.; 293.

Reptant (Reptans). Same as Repent.

Resupinate. Upside down, or having that appearance.

Rete. Network.

Reticulated (-atus), Retiformis. In the form of network; netted.

Reticulate-veined, 92.

Retináculum. Name sometimes applied to the gland to which one or more pollinia are attached in Orchids, \&c. The persistent and indurated hooklike funiculus of the seeds in most Acanthaceæ.

Retinerved (-ius). Same as Reticulateveined.

Retrocurved (-us). Same as Recurved.

Retroflexed (-us). Same as Reflexed.

Retrorse (-orsus). Directed backward or downward.

Retroverted (Retroversus). Inverted.

Retuse (Retusus). With a shallow or obscure notch at a rounded apex; 97 .

Reversion. A changing back, or in the reverse direction; 171 .

Revolute (-utus). Rolled backward from the margins or apex; 133.

Rhachis. The axis (backbone) of a spike or of a compound leaf; 101, 143.

Rhaphe. The adnate cord or ridge which in an anatropous ovule connects the hilum with the chalaza; $279,307$.

Rhipidium. A fan-shaped cyme; 156. 
Rhizanthous ( $-u s)$. Root-flowered ; flowering from the root or seeming root.

Rhizina. The peculiar roots or roothairs of Mosses, Lichenes, \&c.

Rhizocarpous (-us). Rhizocarpic (-icus). Literally root-fruited; used by DeCandolle for a perennial herb.

Rhizome, Rhizóma. A rootstock; a stem of root-like appearance prostrate on or underground, from which rootlets are sent off; the apex progressively sending up herbaceous stems or flowering stalks and often leaves; 56.

Rhizomorphous (-us). Root-like in appearance.

Rhombic (-icus). Rhomb-shaped.

Rhomboidal (-alis). Approaching a rhombic outline; quadrangular, with the lateral angles obtuse.

Rib. A primary and strong vein or conspicuous portion of the framework of a leaf; 92.

Ribbed. Furnished with prominent ribs.

Rictus. The mouth or gorge of a bilabiate corolla.

Rima. A chink or cleft.

Rimose (-osus). With chinks or cracks, like those of old bark.

Ring. In Ferns, \&c. See Annulus.

Ringent (-ens). Grinning or gaping; as is the mouth of an open bilabiate corolla; 248.

Riparius. Growing along the banks of rivers, \&c.

Rivális. Growing along brooks.

Rivularis. Growing in watercourses or rivulets.

Root. The descending axis. Roots are axes which grow in the opposite direction from the stem, are not composed of nodes and internodes, are mostly developed underground, and absorb moisture, \&c., from the soil ; 27.

Root-cap, 13, 28.

Root-hairs. Attennated unicellular outgrowths or hairs from the newly formed parts of a root, for absorption; 13, 29.

Rootlet. A very slender root or branch of a root.

Rootstock. See Rhizoma; 56.

Roridus. Dewy; covered with particles resembling drops of dew.

Rosaceous (-eus). Arranged like the five petals of a normal rose; 246. Sometimes used for rose-color.
Roseus. Rose-colored; pale red.

Róstellate (-atus). Diminutive of Rostrate.

Rostéllum. A diminutive beak. Also the name applied by Linnæus to the Caulicle or Radicle.

Rostrate (-atus). With a Rostrum, a beak or spur; narrowed into a slender tip or process.

Rosular, Rosulate (-atus). Collected in a rosette.

Rotate (-atus). Wheel-shaped; circular and horizontally spreading very flat; 248.

Rotund (Rotundus, Rotundatus). Rounded in outline; 95.

Rough, Roughish. See Scabrous.

Rubéllus, Rubescent (-ens), Rubens. Reddish. Rubescent also is turning red.

Ruber. Red in general.

Rubicundus. Blushing, turning rosyred.

Rubiginose (osus). Brownish rusty-red.

Ruderal (-alis). Growing in waste places or among rubbish.

Rudiment. An imperfectly developed and functionally useless organ; a Vestige.

Rufous (-us), Rufescent (-ens). Pale red mixed with brown.

$R$ ugose (-osus). Covered or thrown into wrinkles, Ruga.

Ruminated (-atus). As if chewed; said of the albumen of a nutmeg, \&c.; 311.

Runcinate (-atus). Saw-toothed, or sharply incised, the teeth or incisions retrorse.

Runner. A prostrate filiform branch which is disposed to root at the end or elsewhere ; 53.

Running. Same as Repent.

Rupestris, Rupicola. Growing on rocks or in rocky places.

Rúptilis. Bursting irregularly.

Rusty. Same as Rubiginose, Rufescent, and Ferruginous.

Rutilans. Deep red with a metallic lustre.

Sabuloers. Growing in sandy places.

Saccate (-atus), Sacciform. Sac-shaped; baggy.

Sagittate (-atus), Sagittiform (-ormis). Arrow-head-shaped.

Salsuginosus. Growing within reach of salt water.

Salver-shaped. See Hypocraterimorphous; 248. 
Sámara. An indehiscent winged fruit; 294.

Samaroid. Resembling a samara.

Sap-wood. New wood of an exogenous stem; 80.

Sarcocarp (-arpium). The succulent or fleshy portion of a drupe; 285. Has been proposed also as a general name for a baccate fruit; 292.

Sarmentose (-osus). Producing long and lithe branches or runners, viz. Sarments (Sarmenta).

Sativus. That which is sown or planted.

Saw-toothed. See Serrate.

Saxátilis, Saxosus, Saxicolus. Living on or among rocks.

Scabridus, Scabriusculus. Roughish; diminutive of

Scabrous (Scaber). Rough to the touch.

Scalariform (-ormis). Ladder-shaped; with transverse markings like the rounds of a ladder.

Scales. Any thin scarions bodies, usually degenerate leaves, sometimes of epidermal origin.

Scalloped. Same as Crenate; 98.

Scaly. See Scarious, Squamose.

Scaly Buds, 40.

Scandent (-ens). Climbing, in whatever mode; 51.

Scape (Scapus). A peduncle rising from the ground; 51, 143.

Scapiform (-ormis), Scapose (-osus). Resembling a scape.

Scapigerous (-us). Scape-bearing.

Scar. The mark left on the stem by the separation of a leaf, or on a seed, \&c., by its detachment.

Scarious or Scariose (-osus). Thin, dry, membranaceous, and not green.

Schizocarp (-arpium). A pericarp which splits into one-seeded pieces; 296.

Scion. A young shoot; a twig used for grafting.

Sciuroideus. Like a squirrel's tail.

Scleranthium. Name of the fruit of Mirabilis, and the like; an akene enclosed in an indurated portion of calyx-tube.

Scleroideus. Having a hard texture: from Scleros, hard.

Scobiform (-ormis). Having the appearance of sawdust.

Scorpioid. A form of unilateral inflorescence which is circinately coiled in the bud: in the stricter sense, a form with the flowers two-ranked, these being thrown alternately to the right and left; 155, 157.
Scrobiculate (-atus). Marked by minutt or shallow depressions.

Scrotiform (-ormis). Pouch-shaped.

Scurf. Small and bran-like scales on the epidermis.

Scutate (-atus), Scutiform (-ormis). Buckler-shaped.

Scutelliform (-ormis). Platter-shaped.

Scymetar-shaped. See Acinaciform.

Sectile (-ilis). As if cut up into portions.

Section (Sectio). In classification, is applied in a general way to a division in the arrangement of genera, species, or other groups; 327.

Sectus. Completely divided; 99.

Secund (Secundus). When parts or organs are all directed to one side.

Secundiflorus. With flowers of a cluster all secund.

Secundine. The second (inner) coat of an ovule; 277.

Seed. The fertilized and matured ovule; the result of sexual reproduction in a phænogamous plant; 305 .

Seed-leaves. Cotyledons, 11.

Seed-stalk. See Funiculus and Podosperm.

Seed-vessel. See Pericarp.

Segetális. Growing in grain-fields.

Segment (Segmentum). One of the divisions into which a plane organ, such as a leaf, may be cleft.

Segregate (-atus). Separated; kept apart.

Semen. Seed.

Semi. Half, in Latin compour is ; such as

Semi-adherent. The lower half adherent, \&c. ; Semi-amplexicrul (-aulis), half clasping the stem; Semiovate, ovate halved lengthwise, \&ce.

Semianátropous. Same as Amphitropous ; 279.

Semilunar, Semilunate (-atua). A synonym of Lunate, being like a halfmoon.

Seminal (-alis). Relating to the seed.

Seminiferous (-us). Seed-bearing.

Sempervirent (Sempérvirem). Evergreen.

Senary (-arius). In sixes; 176.

Sepal (Sépalum). A calyx-leaf; 165.

Sepaline (-inus), Sepalous. Relating to sepals.

Sepaloid (-oideus). Resembling a sepal.

Sepalody. Name for the metamerphosis of petals, \&c., into sepals or semaloid organs; 174 .

Separated flowers. Those of distinct sexes; same as Diclinous; 191. 
Beptate (-atus). Separated by a partition or septum.

Septicide, Septicidal (-cidus). When a capsule dehisces through the dissepiments or lines of junction; 289.

Septiferous $(-2 u s)$. Bearing the partition or dissepiment.

Septifragal $(-u s)$. Where the valves in dehiscence break away from the dissepiments; 290.

Septum. Any kind of partition, whether a proper dissepiment or not.

Septulate (-atus). Divided by spurious or transverse septa.

Serial (Serialis) or Seriate (Seriatus). Disposed in series or rows, whether transverse or longitudinal.

Sericeous (-eus). Silky; clothed with close-pressed soft and straight pubescence.

Serótinous (-us). Produced comparatively late in the season.

Serrate (-atus). Beset with antrorse teeth; 97.

Serrulate (-atus). Serrate with very small or fine teeth; 97.

Sesqui. A Latin prefix denoting one and a half; as, Sesquipedalis, a foot and a half.

Sessile (-ilis). Sitting close, withont a stalk; destitute of peduncle, pedicel, or petiole, as the case may be.

Seta. A bristle, or bristle-shaped body.

Setaceous (-eus). Bristle-like.

Setiform (-ormis). In the form of a bristle.

Setigerous (-us). Bristle-bearing.

Setose (-osus). Beset with or abounding in bristles; bristly.

Sétula. Diminutive of Seta.

Setulose (-osus). Bearing or consisting of minute bristles.

Sex. Latin for six; as in Sexangular, Sexfarious, Sexpartite, \&c.

Shaggy. Pubescent with long and soft hairs; same as Villous.

Sheath. A tubular or enrolled part or organ, such as the lower portion of the leaf in Grasses. See Vagina.

Sheathing. Enclosing as by a sheath.

Shield-shaped. In the form of a buckler; plane and round or oval, with stalk attached to some part of the under surface; 96. See Clypeate, Scutate, Peltate.

Shrub. A woody perennial of less size than a tree; 50.

Shrubby. Having the character of a shrub. Sieve-cells, 77.
Sigillate (-atus). As if marked with the impression of a seal, as the rootstock of Polygonatum.

Sigmoid (-oideus). Doubly curved like the Greek s or the capital S.

Silicle (Silicula). A short silique, not very much longer than wide; 294.

Siliculosa. Name of the Linnæan artificial order of the class Tetradynamia, having Siliculose pods; 337.

Silique (Siliqua). The peculiar pod of Cruciferæ, especially when much longer than wide; 293.

Siliquosa. Name of the other order of Tetradynamia, with Siliquose fruit, i.e. a Silique; 337.

Silky. See Sericeous.

Silver-grain. The glittering plates in exogenous wood belonging to the medullary rays; 74 .

Simple (Simplex). Of one piece, series, \&c. A simple pistil is of one carpel; a simple leaf, of one blade, \&c.

Simple Fruits, 291.

Simplicissimus. Most simple; completely simple.

Sinistrorse. Turned or directed to the left ; $51,140$.

Sinuate (-atus). With a strongly wavy or recessed margin; 98.

Sinus. A recess or re-entering angle.

Slashed. Same as Laciniate.

Smooth. Either opposed to scabrous, i. e. not rough, or to glabrous, i. a not pubescent; the former is the mose correct application.

Sóboles. Shoots, especially those from the ground.

Soboliferous (-us). Bearing vigorous lithe shoots.

Solid Bulb. A corm; 61.

Solitary (-arius). Single, only one from the same place.

Solubilis. Separating into portions or pieces.

Solutus. Loosed; becoming separate.

Sordidus. Of a dull or dirty hue.

Sorediate (-atus). Bearing small patches on the surface.

Soréma. A heap of carpels belonging to one flower; 263.

Sori, sing. sorus. Heaps, such as the clustered fruit-dots of Ferns.

Sorose. Heaped or bearing Sori.

Sorósis. A fleshy multiple fruit, such as a mulberry, bread-fruit, and pineapple.

Spadiceus. A bright and clear brown, or chestnut color. 
Spadiceous. Having the nature of or bearing a

Spadix. A spike with a fleshy axis; 149.

Span. The length of the space between the tip of the thumb and that of the little finger, when outstretched; about nine inches.

Sparsus. Sparse or scattered; whence Sparsiflorus, with scattered flowers; Sparsifolius, with scattered leaves, \&c.

Spathaceous (-us). Spathe-bearing, or of the nature of a

Spathe (Spatha). A large bract, or a pair of bracts, enclosing a flower-cluster; 142.

Spathella. An unused name for the glumes of Grasses.

Spathilla. A secondary or diminutive spathe.

Spatulate (Spathulatus). Oblong with the lower end attenuated, shaped like a druggist's spatula; 95.

Species. The particular kind, the unit in natural history classification; 317 .

Specific Character, Name, \&c., 349, 363.

Spérmaphore or Spermophore (-orum). A name for the Placenta.

Spérmoderm (-ermis). The outer seedcoat; 305.

Spermodóphorum or Spermóphorum. An unused name for the gynophore in Umbelliferæ. The latter also an unused name for the Placenta; 261.

Spermothéca. An unused name for pericarp.

Spermum. Latin form of the Greek word for seed. Lat. Semen.

Sphalerocarpium. Name proposed for an accessory fruit, such as that of Shepherdia, in which an akene is enclosed in a baccate calyx-tube.

Spica. See Spike.

Spicate (-atus). In the form of or resembling a spike, or disposed in spikes.

Spiciform (-ormis). Spike-like.

Spicula. A diminutive or secondary spike; a Spikelet.

Spike (Spica). A form of indeterminate inflorescence, with flowers sessile on an elongated common axis; 149.

Spikelet (Spicula). A secondary spike; the name given to the Locusta or cluster of one or more flowers of Grasses subtended by a common pair of glumes.

Spindle-shaped. See Fusiform.

Spine (Spina). A sharp-pointed woody or indurated body, commonly a branch, sometimes a petiole, stipule or other part of a leaf; $55,117$.

Spinescent (-ens). Ending in a spine or sharp point; 55.

Spinose (-osus). Furnished with spines, or of a spiny character; 55.

Spinuliferous or Spinulose (-osus). Furnished with diminutive spines or Spinulos.

Spiral (Spirális). As if wound round an axis. Spiral Ducts, 68. Spiral Phyllotaxy, 119, 121.

Spiricles. The delicate coiled threads in the hairs on the surface of certain seeds and akenes, which nncoil when wet; 307.

Spithamaers. A span long; the length spanned between the tip of thumb and forefinger when extended.

Splendens. Resplendent or glittering.

Spongelet, Spongiole (-iola). Name given to young root-tips; once supposed to be a peculiar organ; 28.

Sporadic (-icus). Widely dispersed or scattered.

Sporangium. A spore-case or theca containing the analogues of seeds (spores) in the higher Cryptogams.

Spore (Spora, Greek for seed). The analogue of seed in Cryptogams.

Spore-case. See Sporangium.

Sporidium. Synonym or diminutive of Spore.

Sporiferous. Spore-bearing.

Spórocarp (-arpirum). Name given to certain spore-cases, as of Lycopodiaceæ.

Sporophore (-orum). One of the synonyms of Placenta.

Sporule (Spórula). Diminutive spore or a sort of spore.

Sporuliferous (-us). Bearing or containing spores.

Sport. A bud-variation or seed-variation; 319.

Spumescent (-ens), Spumose. Froth-like in appearance.

Spur. A hollow and slender extension of some portion of the blossom, usually nectariferous, as of the calyx of Larkspur and the corolla of Violet: rarely applied also to a solid spur-like process.

Spurred. Producing a spur. See Calcarate.

Squama. A scale of any sort, nsually the homologue of a leaf.

Squamate (-atus), Squamiferous, Squa mosus. Furnished with scales. 
Squamella, Squámula, Diminutive squama; scales of secondary order or reduced size.

Squamiform (-ormis). Scale-like.

Squamulose (-osus). - Covered or beset with minute scales.

Squarrose (-osus). Literally roughscurfy; applied to bodies rough with spreading and projecting processes, such as tips of bracts, \&c.

Squarrulose (-osus). Diminutively squarrose.

Stachys. Greek for spike.

Stalk. Any kind of lengthened support on which an organ is elevated.

Stamen. One of the elements or phylla of the androeium; 165.

Stamineal, Stamineous (-eus). Relating to the stamens; 191.

Staminiferous (-us). Stamen-bearing.

Staminodium. A sterile stamen, or what answers to a stamen, whatever its form, without anther.

Staminody. Name for the metamorphosis of other floral organs into stamens; 174 .

Standard. The posterior petal of a papilionaceous corolla; 184.

Stans. Supporting itself in an erect position.

Station. Particular place as to soil, exposure, \&c., which a plant affects; 366.

Stellate (-atus). Star-shaped, arranged like the rays or points of a star.

Stellulate (-atus) or Stellular. Diminntive of Stellate.

Stem. The main ascending axis of a plant; 45.

Stemless. See Acaulescent; with no leafbearing stem above ground; 45 .

Stemlet. Diminutive stem; as that of the plumule.

Stenos. Greek for narrow; hence

Stenophyllus. Narrow-leaved, \&c.

Sterigma. Any foliaceous prolongation of the blade of a leaf down on the stem by decurrence.

Stérigmum. Name of Desvaux for the Dieresilis of Mirbel.

Sterile (-ilis). Barren, as a blossom destitute of pistil, 191; a stamen without anther, or an anther without pollen; an ovary, without good ovules, seeds without embryo, \&c. In common English use, a male or staminate flower is said to be a sterile flower.

Stichus. Greek for row or rank, usually meaning vertical rank; hence such compounds as Distichous, two-ranked; Tristichous, three-ranked, \&c.

Stigma, pl. stigmata. That part or surface of a pistil (usually on or a part of the style, or in place of it) which receives the pollen for the fecundation of the ovules; 166.

Stigmatic (-icus), Stigmatose (-orus). Relating to stigma.

Stigmatiferous. Stigma-bearing.

Stings. Stinging hairs, seated on a gland which secretes an acrid liquid, as in Nettles.

Stipe (Stipes). A stalk of various sorts; the support of the cap of a mushroom; the leafstalk of a Fern; any stalk-like support of a gynceium or a carpel; 212.

Stipel (Stipellum), An appendage to a leaflet analogous to the stipule of a leaf; 106.

Stipellate (-atus). Provided with stipels; 106.

Stipitate (-atus). Having a stipe or special stalk.

Stipitiform (-ormis). Shaped like a stipe, stalk-like.

Stipulaceous (-ess), Stipular (-aris). Belonging to stipules.

Stipulate. Possessing stipules.

Stipules. Appendages or adjuncts of a leaf one on each side of the insertion; 85, 105.

Stirps, pl. stirpes. A race.

Stock. Synonym of Race; also the portion of a stem to which a graft is applied; a caudex, rhizoma, or rootlike base of a stem from which roots proceed; 51.

Stole, Stolon (Stolo). A sucker, runner, or any basal branch which is disposed to root; 53.

Stoloniferous (-us). Sending of or propagating by stolons, runners, \&c.

Stoma, pl. stómata, Stomate. One of the apertures in the epidermis of foliaceous parts, through which cavities within communicate with the external air; 89.

Stomatiferous ( $-u s)$. Bearing stomata or "breathing pores."

Stone. The hard endocarp of a drupe.

Stone-fruit. A Drupe, such as a peach or plum; 297.

Stool. The plant from which layers are propagated, by bending down to the ground to be rooted.

Stramineous (-eus). Strsw-like or strswcolored. 
Strap-ahaped. See Ligulate (247) and Lorate.

Striate (-atus). Marked with fine longitudinal lines, streaks, or diminutive grooves or ridges (Stria).

Strict (Strictus). Close or narrow and upright; very straight.

Strigillose (-osus). Minutely strigose.

Strigose (-osus). Beset with striga, or sharp-pointed and appressed straight and stiff hairs or bristles.

Strobilaceous (-eus), Strobiliform (-ormis). Relating to or resembling a Strobile.

Strobile (Stróbilus). An inflorescence formed largely of imbricated scales, as that of Hop and a Fir-cone; 303.

Strombuliformis, Strombuliferus. Twisted spirally into a screw shape, as the legumes of the Screw-bean (Prosopis, sect. Strombocarpa) and of some species of Medicago.

Stróphiole (-iola). An appendage at the hilum of certain seeds; 308.

Structural Botany, 2.

Struma. A wen or any cushion-like swelling on an organ.

Strumose (-osus), Strumiferous (-us). Furnished with a struma or goitre-like swelling.

Stupose (-asus). Tow-like; with tufts or mats of long hairs.

Style (Stylus). The usually attenuated portion of a pistil or carpel between the ovary and stigma; 166.

Styliform (-ormis). Style-shaped.

Styliferous. Style-bearing.

Stylinus. Belonging to the style.

Stylosus. With styles of remarkable length or number, \&c.

Stylopodium. An enlargement or a disklike expansion at the base of a style, as in Umbelliferæ.

Sub. In composition of Latin words in terminology, denotes somewhat or slightly; as, Subacute, Subcordate, that is acutish, somewhat cordate, \&c.

Subclass, 327.

Subconvolute and Subimbricate in æstivation, 137.

Suberose (-osus). Of a corky texture.

Subgenus, 327.

Submerged, Submersed (-us). Growing under water.

Suborder (Subordo), 327.

Subpetiolar (-aris). Under the petiole, as the leaf-buds of Platanus; 42.

subsection, 327.
Subspecies. A group which is ambiguous in rank between variety and species; 320.

Subtribe (Subtribus), 327.

Subulate (-atus), Subuliform (-ormis). Awl-shaped.

Subvariety, 327.

Succise (-isus). As if cut or broken off at the lower end.

Súccubous (- -48$)$. When in leaves crowded on a stem the apex of each leaf is covered by the base of the next above.

Succulent (Succosus). Juicy.

Sucker. A shoot of subterranean origin; 53.

Suffrutescent (-ens). Slightly or obscurely shrubby; 50 .

Suffrutex. An undershrub.

Suffruticose (-osus). Low and shrubby at base; 50 .

Suffultus. Underpropped or supported. Sulcate (-atus). Grooved or furrowed.

Super. Above. See Supra.

Superior, Superus. Growing or placed above; also in a lateral flower on the side next the axis; thus the posterior or upper lip of a corolla is the superior; 160, 183.

Superposed (Superpositus). Vertically over some other part.

Superposition, 179, 195.

Supérvolute (-us), Supervolutive (-ivus). Same as Convolute when applied to plaits; 139.

Supine (-inus). Lying flat with face tupward.

Suppression. Complete abortion; 179, 190.

Supra. Above; hence in Latin compounds, Supra-axillary, above the axil; Suprafoliaceous, above a leaf, \&c.

Supradedecompound. Several times compound.

Surculose (-osus). Producing suckers.

Súrculus. A sucker; a shoot rising from a subterranean base; 53.

Sursum. Upward; directed upward or forward.

Suspended (Suspensus). Hanging directly downward; hanging from the apex of a cell.

Suspensor of the embryo, 284.

Sutural (-alis). Relating to \& suture.

Suture (-ura). A junction or seam of union; used commonly as a line of opening; 260.

Sword-shaped. A blade with two sharp and nearly parallel edges, as in Iris. 
Syconium or Syconus. A multiple fruit like that of the Fig; 148, 303 .

Sylvestris. Growing in woods.

Symmetrical. Regular as to number of parts or as to shape. In the blossom it denotes the former; 175.

Symmetry. In the flower relates to symmetrical disposition of organs on the axis; 174.

Sympetalous (-us). With united petals; same as Gamopetalous; 244.

Symphiantherous (-us). Same as Sy. nantherous and Syngenesious.

Symphysis. Same as Coalescence.

Symphystemonous. With stamens united. Sympode, Sympodium. A stem mado up of a series of superposed branches in a way to imitate a simple axis; a Sympodial stem; 55, 154.

Synacmy. Same as Synanthesis.

Synantherous (-us). Stamens coalescent by their anthers.

Synanthesis. The simultaneous anthesis or readiness of the anthers and stigmas of a blossom; 219.

Syncarp, Syncarpium. A multiple fruit such as a mulberry, or a fleshy aggregate fruit, like that of Magnolia; 299.

Syncarpous (-us). Composed of two or more united carpels; 261, 263.

Syncotyledonous. With cotyledons soldered together.

Synedral. Growing on the angles.

Synéma. The column of monadelphous filaments, as in Mallow.

Syngenesia. Linnæan class (335) characterized by having the anthers united or

Syngenesious. With anthers cohering in a ring; 250.

Synonym. A superseded or unused name ; 354, 365.

Synonymy. All that relates to synonyms; 365.

Synsepalous (-us). Of coalescent sepals; same as Gamosepalous; 244.

Systematic Botany, 2.

Systylus. The coalescence of styles into one body.

Tabescent (-ens). Wasting or shrivelling.

Tail. Any long and slender terminal prolongation.

Taper-pointed. See Acuminate.

Tap-root. A primary descending root forming a direct continuation from the radicle: 31.

Tawny. Same as Fulvous; dull brownish-yellow.
Taxology, Taxonomy. Rolating to classification and its rules; 3,315 .

Teeth. Any small marginal lobes.

Tegmen. The inner coat of a seed; 306.

Tela. Latin name for tissue, cellular tissue, \&c.

Teleianthus. Same as perfect, or hermaphrodite-flowered.

Tendril. A filiform production (either axile or foliar) by which a plant may climb ; 54.

Tepal (Tepalum). A division of perianth, whether sepal or petal (hardly ever used).

Teratological. Relating to malformation or monstrous conditions.

Teratology. The science of monsters and malformations; 170.

Terete (Teres). Round in the sense of having a circular transverse section.

Tergeminate (-atus). Thrice twin.

Terminal (-alis). Proceeding from or belonging to the end or apex; 7 .

Terminology. Same as Glossology; 8, 359.

Ternary (-arius). Same as Trimerous ; consisting of three; 176.

Ternate (Ternus, Ternatus). In threes; as three in a whorl or cluster.

Tessellated (-atus). In chequer-work.

Testa. The outer seed-coat, which is commonly hard and brittle, whence the name, which answers to seed-shell; 305.

Testaceous (-eus). Of the color of unglazed common (brownish-yellow) pottery.

Tetra. In Greek compounds, four; bence

Tetracárpellary (-aris). Of four carpels; 261.

Tetracámarous (-us), Tetracoccus. Of four closed carpels.

Tetradynámia. Linnæan class (335) which has the stamens.

Tetradyinamous (us). With four long and two shorter stamens; 250.

Tetrágonal or Tetragonous (-us). Fourangled.

Tetragýmia. Linnæean artificial order (337), characterized by having the gynœcium.

Tetrágynous. Of four carpels or styles.

Tetrámerous ( $-u s)$. Composed of four members in a circle; 176.

Tetrandria. Linnsean class having the flowers perfect and

Tetrandrous. With four stamens; 249, 334. 
Tetrapetalous (-us). With four petals; 244.

Tetraphýllous (-us). Four-leaved; 243.

Tetraquétrous (-us). With four sharp or salient angles.

Tetrasepalous (-थs). With four sepals; 244.

Tetrástichous ( $-u s)$. In four vertical ranks.

Thalamiflorous $(-u s), 340$. With parts of the flower hypogynous, or on the

Thálamus. The receptacle of a flower; 167. See Torus.

Thallophytes (Thallophyta), 341.

Thallus. A stratum, in place of stem and foliage.

Theca. A case; an anther-cell (251); a spore-case, \&c. (An early name for the anther, 166.)

Thécaphore (-orum). The stipe of a carpel (homologous with petiole); 212.

Thorn. Same as spine; 55.

Throat. The orifice of a gamopetalous corolla or calyx, including any portion between this and the proper tube; 246. See Faux.

Thyrse, Thyrsus. A contracted or ovate panicle; a mixed inflorescence, with main axis indeterminate, but the secondary or ultimate clusters cymose; 159.

Tigelle, Tigellula. A miniature or initial stem; sometimes applied to Caulicle (Radicle), sometimes to Plumule; 10.

Tinctorius. Dyed; used for dyeing; imparting color.

Tissue. The anatomical fabric.

Toméntose (-osus). Densely pubescent with matted wool, or Tomentum.

Tongue-shaped. Long and nearly flat, somewhat fleshy, and rounded at the apex.

Tooth. See Teeth.

Toothed. See Dentate.

Top-shaped. Inversely conical.

Torose (-osus). Cylindrical, with contractions or bulges at intervals.

Tortuous (-osus). Bent or twisted in different directions.

Torulose (-osus). Diminutively or slightly torose.

Tortus. Twisted.

Tortilis. Susceptible of twisting.

Torus. The receptacle of a flower; 167 , 211.

Trabeculate (-atus). Cross-barred.

Trachea. A spiral vessel or duct, named from resemblance to the traches of insects.

Trachycarpous (-us) Rough-fruited.

Trachyspermous. Rough-seeded, \&c.

Transverse (-ersus). Across; right and left as to bract and axis; collateral; 160.

Trapeziform (-ormis), Trapezoid. Unsymmetrically four-sided, like a trapezium.

Tree. A woody plant with an elevated trunk.

Tri-. In compound words, both Latin and Greek, denotes three or triple.

Triachanium. A fruit like a cremocarp but of three carpels.

Triadelphous, Triadelphia. With filaments in three sets; 250.

Triandria. Linnæan class (334) with the flowers.

Triaindrous. With three stamens; 249.

Triangular (-aris), Triangulatus. Threeangled.

Triánthous (-us). Three-flowered.

Tribe. Group superior to genus, inferior to order; 326.

Tricarpellary (-aris). Of three carpels; 261.

Tricarpous (-us). Consisting of three fruits or carpels.

Tricephalous (-us). Bearing three heads.

Trichocarpous (-us). Hairy-fruited.

Trichodes. Resembling hair.

Trichbtomous (- $u s)$. Three-forked; branched into three divisions.

Trichome (Trichóma). Any outgrowth of the epidermis, such as a hair or bristle; 209.

Tricóccous (-us). Consisting of three cocci.

Tricolor. Three-colored.

Tricuspidate (-atus). Tipped with three cusps or pointed tips.

Tridéntate (-atus). Three-toothed.

Tridigitate. Thrice digitate.

Triduius. Lasting for three days.

Triennial (Triennis). Lasting for three years.

Trifarious (-ius). Facing three ways, in three vertical ranks.

Trifid (Trifidus). Three-cleft.

Trifoliate (-ius, Trifoliatus). Threeleaved.

Trifoliolate (-atus). Of three leaflets.

Trifurcate (-atus). Divided into three forks or branches.

Trigamous (-us). Bearing three kinds of flowers.

Trigonows (-us), Trigonal. Three-engled. 
Trigynia. Linnæan artificial order with Trigynous, i.e. three-styled flowers; 337.

Trihilatus. Having three apertures, as in some grains of pollen.

Trijugate (Trijugus). With three pairs of leaflets or pinnæ.

Trilobate (Trilobus). Three-lobed.

Trilocular (-aris). Three-celled.

Trimerous (-us). Three-membered parts in threes; 176.

Trimestris. Lasting for or maturing in three months.

Trimorphous, Trimorpism. Occurring under three forms; 236.

Trinervate (Trinervius). Three-nerved.

Trinodal. Of three nodes or joints.

Triacia. Linnæean artificial order with the flowers.

Tricecious or Trioicons (-us). Having staminate, pistillate and perfect flowers (or three kinds of flowers as to sex), 334 ; on three distinct plants.

Trióvulate (-atus). Having three ovules.

Tripartible (-ibilis). Tending to split into three portions.

Tripartite (-itus). Three-parted.

Tripetaloid (-oideus). As if three-petalled.

Tripetalous(-us). Having three petals.

Triphýllous (-us). Three-leaved; 243.

Tripinnate(-atus). Thrice pinnate; 104.

Tripinnatifid (-idus). Thrice pinnatifid.

Triple-ribbed or nerved. With midrib dividing into three, or sending off on each side a strong branch, above the base of the blade; 93 .

Triplinerved (Triplinervius). Same as Triple-nerved, Triple-ribbed; 93.

Tripterous (-us). Three-winged.

Triquétrous (Triqueter). Three-edged; with three salient angles.

Triquinate (-atus). Divided first into three then into five.

Trisected (-us). Divided into three portions; 99.

Trisepalous (-us). Of three sepals.

Triserial (-alis), Triseriate (-atus). In three horizontal ranks or series.

Tristáchyus. Three-spiked.

Tristichous (-us). In three vertical ranks; 122.

Tristigmatic. With three stigmas.

Tristis. Dull colored.

Tristylous (-us). Having three styles.

Trisulcate (-atus). Three-grooved.

Tritérnate (atus). Thrice ternate; 104.

Trivial names, Nomina trivialia. Common or vulgar names; used by Lin- næus for specific names of a single word; $346,362$.

Trochlear (-earis). Pulley-shaped.

Trophosperm (Trophospermium). Name for the Placenta; 261.

Trumpet-shaped. Tubular, with a dilated orifice.

Truncate (-atus). As if cut off at the end; 97.

Trunk (Truncus). A main stem.

Tryma. A drupaceous nut, with exocarp at length dehiscent or otherwise separating, such as walnut and hickory nut.

Tubaformis. Trumpet-shaped.

Tube (Tubus). Any hollow elongated body or part of an organ; 245 .

Tuber. A thickened and short subterranean branch, beset with buds or eyes; 59.

Tubercle (Tuberculum). A small tuber or an excrescence: or something between a tuber and a root; 60 .

Tuberculate (-atus). Beset with knobby projections or excrescences.

Tuberiferous. Bearing tubers.

Tubular, Tubulosus (-ase). Having a tube; tube-shaped; 248.

Tubuliflorus $(-u s)$. When the flowers of a head have only tubular corollas.

Tunicate (-us). Having coats (tunics).

Turbinate (-atus). Top-shaped.

Turion, (Turio). A scaly sucker or shoot from the ground; 41.

Turnip-shaped. See Napiform.

Twin. In pairs. See Geminate, Didymous.

Twining. Winding spirally and so climbing (Twiners); 51.

Twisted. Contorted.

Two-lipped. See Bilabiate.

Type. The ideal plan or pattern.

Typical. Representing the plan or type.

Uliginose (-osus). Growing in swamps. Ulnaris. Of the length of the ulna or fore-arm.

Umbel (Umbellla). An inflorescence (properly of the Indeterminate type) in which a cluster of pedicels spring all from the same point, like rays of an umbrella; 146.

Úmbellate (-atus), Umbelliform (-ormis). In or like umbels.

Umbellet. A partial or secondary umbel; 150.

Umbelliferous (-us). Bearing umbels. 
Umbellula. A partial or secondary umbel, or umbellet; 150 .

Umbilicate (-atus). Depressed in the centre, navel like.

Umbilicus. The hilum of a seed.

Umbonate (-atus). Bearing an Umbo or loss in the centre.

Umbráculiform (-ormis). Having the general form of an umbrella.

Umbrosus. Growing in shady places.

Unarmed. Destitute of prickles, spines, or other armature.

Uncate (-atus), Uncinate, (-atus), Unciform (-ormis). Hooked; bent or curved at tip in the form of a hook.

Uncialis. An inch (uncia) in length.

Undate (-atus) or Undulate (-atus). Wavy; 98.

Undershrub. A very low shrub; 50.

Unequally pinnate. See Impari-pinnate.

Unguiculate (-atus). Contracted at base into an

Unguis. A claw, or stalk-like base of a petal, \&c.; 245.

Uni-. In Latin compound, one; as

Unicellular. Of one cell; Unicolor, of one color, \&c.

Únicus. Singly or single, solitary.

Uniflorous (-us). One-flowered.

Unifóliate (-atus). One-leaved.

Unifoliolate, of one leaflet; 102.

Unijugate (Unijugus). Of one pair; 102.

Unilabiate (-atus). One-lipped, like the corolla of Acanthus, in which the upper lip is obsolete.

Unilateral (-alis). One-sided; either originating on or more commonly turned all to one side of an axis.

Unilocular (-aris). One-celled.

Uninervate (Uninervis, Uninervius). One-nerved.

Uniovulate (-atus). Having only a solitary ovule.

Uniparous. Bearing one; as a cyme of one axis or branch; $152,155$.

Uniserial (-ialis), Uniseriate (-atus). In one horizontal row or series.

Unisexual (-alis, Unisexus). Of one sex; having stamens only or pistils only; 191.

Únivalved (Univalvis). Of one piece or valve.

Urcélate (-atus). Hollow and contracted at or below the mouth, like an urn or pitcher (Urceolus).

Urens. Stinging, in the manner of nettles.
Utricle (Utriculus). A small bladdery pericarp; 295. Or any small bladdershaped body or appendage; also a synonym of a cell of parenchyma.

Utricular (-aris), Utriculate (-atus), Utriculiform (-ormis), Utriculose (-osus). Having or consisting of utricles, or bladder-like in appearance.

Vacillans. Swinging free, as the anthers of Grasses on their filaments.

$V$ icuus. Void or empty of the proper contents.

Vagina. A sheath, as of a leaf, \&c.

Vaginate. Sheathed.

Vallecule. The intervals or grooves between the ridges or ribs of the fruit Umbelliferæ.

Valvate (-atus), Valvular (-aris). Opening as if by doors or valves, as do most dehiscent fruits (capsules), and some anthers; also the parts of a flower-bud when they exactly meet without overlapping; 135.

Valve ( Valva). One of the pieces into which a capsule splits, 288.

Valved. Same as valvate: hence 3 -valved, 5-valved, many valved, \&c.

Váloula. A diminutive valve. Also used (after Linnæus) for the inner or flower-glumes of Grasses.

$V$ ariegated (-atus). Irregularly colored; in patches of color.

Variety (Varietas). A sort or modification subordinate to species; 318.

Váriolate, Varioláris. Marked as if by the pustules or pittings of smallpox.

Vascular (-aris). Relating to or furnished with vessels (Vasa) or ducts.

Vascular Plants (Vasculares), 340.

Vásculum. Same as Ascidium. Also the botanists' collecting box; 372 .

Vasiform (-ormis). In the form of a vessel, duct, \&c.

Veined. Furnished or traversed with fibro-vascular bundles or threads, especially with those which divide and are reticulated.

Veins (Vena). In general any ramifications or threads of fibro-vascular tissue in a leaf or any flat organ; especially (as distinguished from nerves) those which divide or branch; 92.

Veinless. Destitute of veins.

Veinlet (Vénula). One of the ultimste 
or smaller ramifications of a vein or rib; 93.

Velate (-atus). Veiled.

Velitinous (Velutinus). Velvety: the surface covered with a soft coating of fine and close silky pubescence, or velumen.

$V$ enation (Venatio). The mode of veining; 90.

Venenatus, Venenosus. Poisonous.

Venose (-asus) Veiny; abounding in veins or network.

$V$ entral (-alis). Belonging to the anterior or inner face of a carpel, \&cc.; the opposite of dorsal.

$V$ entricose (-osus). Swelling unequally or inflated on one side.

Ventriculose (-osus). Minntely ventricose.

$V$ enulose (-orus). Abounding with veinlets or venulz.

Vermicular (-aris). Worm-shaped.

Vernal (Vernalis). A ppearing in spring.

Vernation (-atio). The disposition of parts in a leaf-bud; 132.

Vernicose (-osus). As if varnished.

Virrucose (-osus). Covered with warts (verruces) or wart-like elevations.

Versatile (Versátilis). Swinging to and fro; turning freely on its support; 253.

Versicolor. Changing color, or of more than one tint or color.

Vertex. The apex of an organ.

Vertical (-alis). Perpendicular to the horizon; longitudinal.

Verticil (-illus). A whorl; 6.

Verticillaster. A false whorl, composed of a pair of opposite cymes; 159.

Verticillastrate. Bearing or arranged in Verticillasters.

Verticillate (-atus, -aris). Disposed in a whorl; 6, 119, 120.

Vescicle (-icula). A small bladder or air-cavity.

Vesicular (-aris), Vesiculose (-osus). As if composed of little bladders.

Vespertine (Vespertinus). Appearing or expanding in early evening.

Vessels (Vasa). See Ducts.

Véxillary (-aris), Vexillar, 137. Pertaining to the

Vexillum. The standard or large posterior petal of a papilionaceous corolla ; 184.

Villose (orus) or Villous. Bearing shaggy or long and soft (not interwoven) hairs or Villi.

Vimineous (-eus). Bearing long and flex- ible twigs, like those used for wicker work.

Vine. Any trailing or climbing stem: originally that of the Grape from which wine is made.

Vineális. Growing in vineyards.

Violaceous (-eus). Violet-colored.

Virens. Green, or erergreen.

$V$ irescens. Greenish or turning green.

Virgate (-atus). Wand-shaped, or like

a rod; slender, straight, and erect.

Virgultum. A vigorous twig or shoot.

Viridescent (-ens). Same as Virescens.

Viridis. Green.

Viridulus. Greenish.

Virosus. Venomous.

Viscid (-idus), Viscous (-osus). Sticky from a tenacious coating or secretion.

Vitellinus. The yellow hue of the yolk of egg.

Vitellus. Name formerly given to the peculiar albumen which is in some cases deposited within the embryo-sac.

Viticulose (-orus). Sarmentaceous; producing vine-like twigs or suckers, viticula.

Vittce. The fillets or stripes (oil-tubes) of the pericarp of most Umbellifers, which contain an aromatic or peculiar secretion.

Vittate (-atus). Bearing vittce; or with any longitudinal stripes.

Viviparous (-us). Germinating or sprouting from seed or bud while on the parent plant.

Voluble (Volubilis). Twining round a support; 51.

Volutus. Rolled up in any way.

Volva. A wrapper or external covering, especially that of many Fungi.

Wavy. See Undulate.

Waxy. Resembling beeswax in consistence or appearance.

Wedge-shaped or Wedge-form. See Cuneate; 95.

Wheelshaped. See Rotate.

Whorl. Arranged in a circle round an axis; a Verticil; 6.

Whorled. Disposed in whorls.

Wild. Growing without cultivation; spontaneous.

Wing. See Ala. Any Membraneous or thin expansion by which an organ is bordered, surrounded, or otherwise augmented. Also the two lateral petals of a papilionaceous corolla are termed wings; 185. 
Winged. See Alate: bearing a wing or wings.

Withering. See Marcescent.

Wood. The hard part of a stem, \&cc., mainly composed of

Wood-cells, Woody fibre or tissue, 68.

Woolly. See Lanate and Tomentose: clothed with long and tortuous or matted hairs.

Xanthos. Greek for yellow in compounds, such as Xanthophyll, the yellow coloring matter in leaves.
Xenogamy. Fecundation of the ovules of a flower by pollen from some other plant of the same species; cross-fertilization; 216.

Xylinus. Woody, pertaining to wood.

Zoospore. One of the free-moving spores of the lower Cryptogams.

$Z$ ygomorphous (-us). That which can be bisected in only one plane into similar halves; 175.

\section{ADDENDA.}

Antidromous, Antidromy. When the course of a spiral is reversed, 157.

Infertile (-ilis). Said of a pistil or flower which fails to set fruit.

Polyembryony. The production of two or more embryos in a seed, 284.

Saprophytes (-yta). Plants feeding npon decaying vegetable or animal mattar 








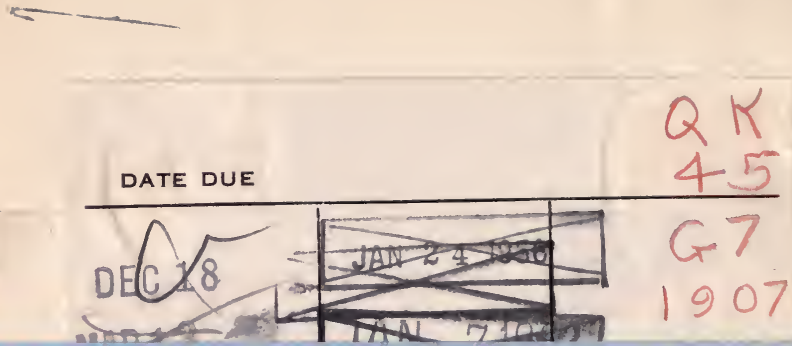

THE LIBRARY

UNIVERSITY OF CALIFORNIA

Santa Barbara

\section{THIS BOOK IS DUE ON THE LAST DATE} STAMPED BELOW.

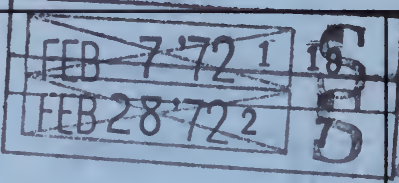




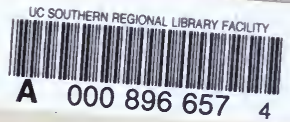

C

1... a bet
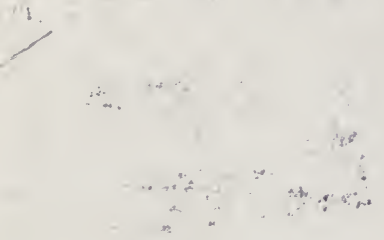

$\because$

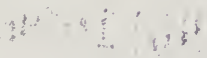


18

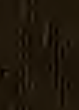

